\title{
Biofilms: Extracellular Bastions of Bacteria
}

\author{
Edited by \\ Alan W. Decho
}

Printed Edition of the Special Issue Published in IJMS

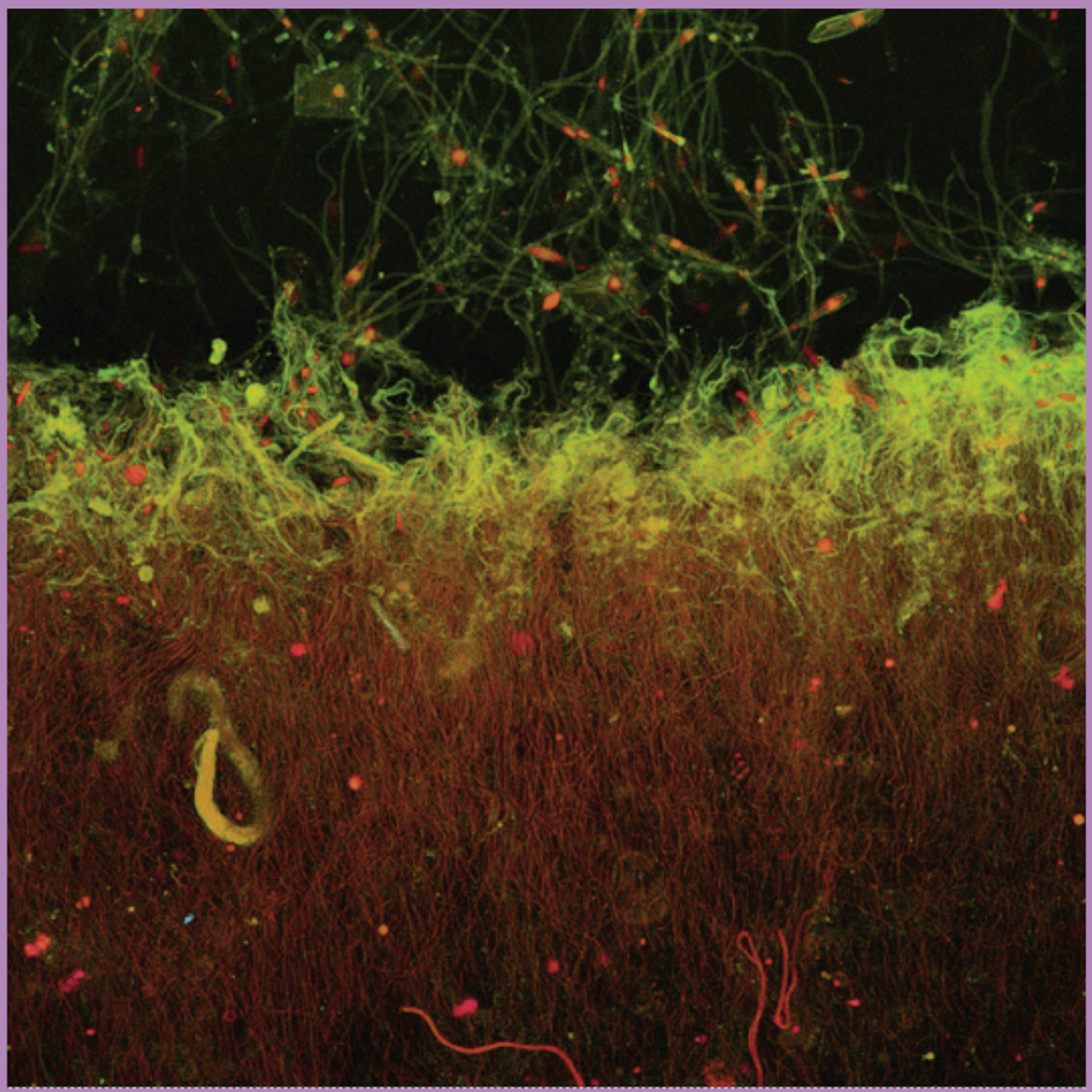

MDPI

www.mdpi.com/journal/ijms 
Alan W. Decho (Ed.)

\section{Biofilms: Extracellular Bastions of Bacteria}


This book is a reprint of the Special Issue that appeared in the online, open access journal, International Journal of Molecular Sciences (ISSN 1422-0067) from 2013-2014 (available at: http://www.mdpi.com/journal/ijms/special_issues/extracellular-bastions-of-bacteria).

\section{Guest Editor}

Alan W. Decho

Department of Environmental Health Sciences

Arnold School of Public Health, University of South Carolina

Columbia, SC. 29208

USA

Editorial Office

MDPI AG

Klybeckstrasse 64

Basel, Switzerland

Publisher

Shu-Kun Lin

Managing Editor

Rui Liu

\section{Edition 2014}

MDPI • Basel • Beijing • Wuhan • Barcelona

ISBN 978-3-906980-94-2 (Hbk)

ISBN 978-3-906980-95-9 (PDF)

Articles in this volume are Open Access and distributed under the Creative Commons Attribution license (CC BY), which allows users to download, copy and build upon published articles even for commercial purposes, as long as the author and publisher are properly credited, which ensures maximum dissemination and a wider impact of our publications. The book taken as a whole is (c) 2014 MDPI, Basel, Switzerland, distributed under the terms and conditions of the Creative Commons by Attribution (CC BY-NC-ND) license (http://creativecommons.org/licenses/by-nc-nd/4.0/). 


\title{
Table of Contents
}

List of Contributors. VI

\author{
Alan W. Decho \\ Preface \\ The EPS Matrix as an Adaptive Bastion for Biofilms: Introduction to Special Issue \\ Reprinted from: Int. J. Mol. Sci. 2013, 14(12), 23297-23300
}

http://www.mdpi.com/1422-0067/14/12/23297

\section{Chapter 1: Spatial Patterns and the Biofilm Matrix}

Robert Almstrand, Frank Persson, Holger Daims, Maria Ekenberg, Magnus Christensson, Britt-Marie Wilén, Fred Sörensson and Malte Hermansson Three-Dimensional Stratification of Bacterial Biofilm Populations in a Moving Bed Biofilm Reactor for Nitritation-Anammox

Reprinted from: Int. J. Mol. Sci. 2014, 15(2), 2191-2206

http://www.mdpi.com/1422-0067/15/2/2191 5

Alexandru I. Petrisor, Sandra Szyjka, Tomohiro Kawaguchi, Pieter T. Visscher, Robert Sean Norman and Alan W. Decho

Changing Microspatial Patterns of Sulfate-Reducing Microorganisms (SRM) during Cycling of Marine Stromatolite Mats

Reprinted from: Int. J. Mol. Sci. 2014, 15(1), 850-877

http://www.mdpi.com/1422-0067/15/1/850

Pablo C. Bogino, María de las Mercedes Oliva, Fernando G. Sorroche and Walter Giordano

The Role of Bacterial Biofilms and Surface Components in Plant-Bacterial Associations Reprinted from: Int. J. Mol. Sci. 2013, 14(8), 15838-15859

http://www.mdpi.com/1422-0067/14/8/15838

Vesna Svetličić, Vera Žutić, Galja Pletikapić and Tea Mišić Radić

Marine Polysaccharide Networks and Diatoms at the Nanometric Scale

Reprinted from: Int. J. Mol. Sci. 2013, 14(10), 20064-20078

http://www.mdpi.com/1422-0067/14/10/20064 77

Elanna Bester, Gideon M. Wolfaardt, Nahid B. Aznaveh and Jesse Greener

Biofilms' Role in Planktonic Cell Proliferation

Reprinted from: Int. J. Mol. Sci. 2013, 14(11), 21965-21982

http://www.mdpi.com/1422-0067/14/11/21965 


\section{Chapter 2: Pathogenic Biofilms}

Mena Abdel-Nour, Carla Duncan, Donald E. Low and Cyril Guyard

Biofilms: The Stronghold of Legionella pneumophila

Reprinted from: Int. J. Mol. Sci. 2013, 14(11), 21660-21675

http://www.mdpi.com/1422-0067/14/11/21660

Qing Wei and Luyan Z. Ma

Biofilm Matrix and Its Regulation in Pseudomonas aeruginosa

Reprinted from: Int. J. Mol. Sci. 2013, 14(10), 20983-21005

http://www.mdpi.com/1422-0067/14/10/20983

Suvi Manner, Malena Skogman, Darla Goeres, Pia Vuorela and Adyary Fallarero

Systematic Exploration of Natural and Synthetic Flavonoids for the Inhibition

of Staphylococcus aureus Biofilms

Reprinted from: Int. J. Mol. Sci. 2013, 14(10), 19434-19451

http://www.mdpi.com/1422-0067/14/10/19434

Meng Chen, Qingsong Yu and Hongmin Sun

Novel Strategies for the Prevention and Treatment of Biofilm Related Infections

Reprinted from: Int. J. Mol. Sci. 2013, 14(9), 18488-18501

http://www.mdpi.com/1422-0067/14/9/18488

Marja T. Pöllänen, Annamari Paino and Riikka Ihalin

Environmental Stimuli Shape Biofilm Formation and the Virulence of

Periodontal Pathogens

Reprinted from: Int. J. Mol. Sci. 2013, 14(8), 17221-17237

http://www.mdpi.com/1422-0067/14/8/17221

António Machado, Kimberly Kay Jefferson and Nuno Cerca

Interactions between Lactobacillus crispatus and Bacterial Vaginosis (BV)-Associated

Bacterial Species in Initial Attachment and Biofilm Formation

Reprinted from: Int. J. Mol. Sci. 2013, 14(6), 12004-12012

http://www.mdpi.com/1422-0067/14/6/12004

\section{Chapter 3: Biotechnological Aspects}

Juan Carlos Camacho-Chab, Jean Guézennec, Manuel Jesús Chan-Bacab, Elvira RíosLeal, Corinne Sinquin, Raquel Muñiz-Salazar, Susana del C. De la Rosa-García, Manuela Reyes-Estebanez and Benjamín Otto Ortega-Morales

Emulsifying Activity and Stability of a Non-Toxic Bioemulsifier Synthesized by Microbacterium sp. MC3B-10

Reprinted from: Int. J. Mol. Sci. 2013, 14(9), 18959-18972

http://www.mdpi.com/1422-0067/14/9/18959 
Kadiya Calderón, Alejandro González-Martínez, Cinta Gómez-Silván, Francisco

Osorio, Belén Rodelas and Jesús González-López

Archaeal Diversity in Biofilm Technologies Applied to Treat Urban and Industrial

Wastewater: Recent Advances and Future Prospects

Reprinted from: Int. J. Mol. Sci. 2013, 14(9), 18572-18598

http://www.mdpi.com/1422-0067/14/9/18572

Huirong Lin, Guangcun Chen, Shenhai Zhu, Yingxu Chen, Dongliang Chen, Wei Xu, Xiaohan Yu and Jiyan Shi

The Interaction of CuS and Halothiobacillus HT1 Biofilm in Microscale Using

Synchrotron Radiation-Based Techniques

Reprinted from: Int. J. Mol. Sci. 2013, 14(6), 11113-11124

http://www.mdpi.com/1422-0067/14/6/11113

Robert J. C. McLean and Kavita S. Kakirde

Enhancing Metagenomics Investigations of Microbial Interactions with

Biofilm Technology

Reprinted from: Int. J. Mol. Sci. 2013, 14(11), 22246-22257

http://www.mdpi.com/1422-0067/14/11/22246.... 


\section{List of Contributors}

Mena Abdel-Nour: Ontario Agency for Health Protection and Promotion (OAHPP), Toronto, ON M9P 3T1, Canada; Department of Laboratory Medicine and Pathobiology, University of Toronto, Toronto, ON M5S 1A8, Canada, Mount Sinai Hospital, Toronto, ON M5G 1X5, Canada.

Robert Almstrand: Department of Chemistry \& Molecular Biology, Microbiology, University of Gothenburg, Box 462, Göteborg SE-405 30, Sweden.

Nahid B. Aznaveh: Chimie, 1045 Avenue de la Médicine, Université Laval, Quebec, QC G1V 0A6, Canada.

Elanna Bester: Department of Chemistry and Biology, 350 Victoria Street, Ryerson University, Toronto, ON M5B 2K3, Canada.

Pablo C. Bogino: Department of Molecular Biology, National University of Río Cuarto, Ruta 36 Km 601, Río Cuarto, Córdoba X5804BYA, Argentina.

Kadiya Calderón: Environmental Microbiology Group, Department of Microbiology, Faculty of Pharmacy, and Institute of Water Research, University of Granada, Campus de Cartuja s/n, Granada 18071, Spain.

Juan Carlos Camacho-Chab: Center of Environmental Microbiology and Biotechnology, Autonomous University of Campeche, Colonia Buenavista, San Francisco de Campeche 24039, Campeche, Mexico.

Nuno Cerca: Centre of Biological Engineering, IBB-Institute for Biotechnology and Bioengineering, University of Minho, Campus de Gualtar 4710-057, Braga, Portugal.

Manuel Jesús Chan-Bacab: Center of Environmental Microbiology and Biotechnology, Autonomous University of Campeche, Colonia Buenavista, San Francisco de Campeche 24039, Campeche, Mexico.

Dongliang Chen: Institute of High Energy Physics, Chinese Academy of Science, Beijing Synchrotron Radiation Facility, Beijing 100049, China.

Guangcun Chen: Department of Environmental Engineering, Zhejiang University, Hangzhou 310058, China.

Meng Chen: Nanova, Inc. Columbia, MO 65211, USA

Yingxu Chen: Department of Environmental Engineering, Zhejiang University, Hangzhou 310058, China.

Magnus Christensson: AnoxKaldnes AB, Klosterängsvägen 11A, Lund SE-226 47, Sweden.

Holger Daims: Division of Microbial Ecology, Department of Microbiology and Ecosystem Science, University of Vienna, Vienna 1090, Austria.

María de las Mercedes Oliva: Department of Microbiology and Immunology, National University of Río Cuarto, Ruta 36 Km 601, Córdoba X5804BYA, Argentina. 
Alan W. Decho: Department of Environmental Health Sciences, Arnold School of Public Health, University of South Carolina, Columbia, SC 29208, USA.

Susana del C. De la Rosa-García: Center of Environmental Microbiology and Biotechnology, Autonomous University of Campeche, Colonia Buenavista, San Francisco de Campeche 24039, Campeche, Mexico.

Carla Duncan: Ontario Agency for Health Protection and Promotion (OAHPP), Toronto, ON M9P 3T1, Canada.

Maria Ekenberg: AnoxKaldnes AB, Klosterängsvägen 11A, Lund SE-226 47, Sweden.

Adyary Fallarero: Pharmaceutical Sciences, Department of Biosciences, Abo Akademi University, Artillerigatan 6A, 3rd Floor, Biocity, Turku FI-20520, Finland.

Walter Giordano: Department of Molecular Biology, National University of Río Cuarto, Ruta 36 Km 601, Río Cuarto, Córdoba X5804BYA, Argentina.

Darla Goeres: Center for Biofilm Engineering, Montana State University, Bozeman, MT 59717, USA.

Cinta Gómez-Silván: Environmental Microbiology Group, Department of Microbiology, Faculty of Pharmacy, and Institute of Water Research, University of Granada, Campus de Cartuja s/n, Granada 18071, Spain.

Jesús González-López: Environmental Microbiology Group, Department of Microbiology, Faculty of Pharmacy, and Institute of Water Research, University of Granada, Campus de Cartuja s/n, Granada 18071, Spain.

Alejandro González-Martínez: Environmental Microbiology Group, Department of Civil Engineering, and Institute of Water Research, University of Granada; Campus de Cartuja s/n, Granada 18071, Spain.

Jesse Greener: Chimie, 1045 Avenue de la Médicine, Université Laval, Quebec, QC G1V 0A6, Canada.

Jean Guézennec: Ifremer Laboratoire Biotechnologies et Molécules Marines, Nantes B. P. 21105, France.

Cyril Guyard: Ontario Agency for Health Protection and Promotion (OAHPP), Toronto, ON M9P 3T1, Canada; Department of Laboratory Medicine and Pathobiology, University of Toronto, Toronto, ON M5S 1A8, Canada; Mount Sinai Hospital, Toronto, ON M5G 1X5, Canada.

Malte Hermansson: Department of Chemistry \& Molecular Biology, Microbiology, University of Gothenburg, Box 462, Göteborg SE-405 30, Sweden.

Riikka Ihalin: Department of Biochemistry and Food Chemistry, University of Turku, FI-20014 Turku, Finland.

Kimberly Kay Jefferson: Department of Microbiology and Immunology, Virginia Commonwealth University, Richmond, VA 23298-0678, USA.

Kavita S. Kakirde: Department of Biology, Texas State University, 601 University Drive, San Marcos, TX 78666, USA. 
Tomohiro Kawaguchi: Department of Environmental Health Sciences, Arnold School of Public Health, University of South Carolina, Columbia, SC 29208, USA.

Huirong Lin: Department of Environmental Engineering, Zhejiang University, Hangzhou 310058, China; Institute of Urban Environment, Chinese Academy of Science, Xiamen 361021, China.

Donald E. Low: Department of Laboratory Medicine and Pathobiology, University of Toronto, Toronto, ON M5S 1A8, Canada; Mount Sinai Hospital, Toronto, ON M5G 1X5, Canada.

Luyan Z. Ma: State Key Laboratory of Microbial Resources, Institute of Microbiology, Chinese Academy of Sciences, No.3, 1st Beichen West Road, Chaoyang District, Beijing 100101, China.

António Machado: Centre of Biological Engineering, IBB-Institute for Biotechnology and Bioengineering, University of Minho, Campus de Gualtar 4710-057, Braga, Portugal; Department of Microbiology and Immunology, Virginia Commonwealth University, Richmond, VA 23298-0678, USA.

Suvi Manner: Pharmaceutical Sciences, Department of Biosciences, Abo Akademi University, Artillerigatan 6A, 3rd Floor, Biocity, Turku FI-20520, Finland.

Robert J. C. McLean: Department of Biology, Texas State University, 601 University Drive, San Marcos, TX 78666, USA.

Tea Mišić Radić: Division for Marine and Environmental Research, Ruđer Bošković Institute, Bijenička 54, 10000 Zagreb, Croatia.

Raquel Muñiz-Salazar: Laboratory of Molecular Ecology and Epidemiology, School of Health Sciences, Autonomous University of Baja California, Tijuana 22390, Baja California, Mexico.

Robert Sean Norman: Department of Environmental Health Sciences, Arnold School of Public Health, University of South Carolina, Columbia, SC 29208, USA.

Benjamín Otto Ortega-Morales: Center of Environmental Microbiology and Biotechnology, Autonomous University of Campeche, Colonia Buenavista, San Francisco de Campeche 24039, Campeche, Mexico.

Francisco Osorio: Environmental Microbiology Group, Department of Civil Engineering, and Institute of Water Research, University of Granada; Campus de Cartuja s/n, Granada 18071, Spain.

Annamari Paino: Department of Biochemistry and Food Chemistry, University of Turku, FI-20014 Turku, Finland.

Frank Persson: Water Environment Technology, Department of Civil and Environmental Engineering, Chalmers University of Technology, Göteborg SE-412 96, Sweden. 
Alexandru I. Petrisor: Department of Urban and Landscape Planning, School of Urban Planning, "Ion Mincu" University of Architecture and Urban Planning, str. Academiei nr. 18-20, sector 1, Bucharest 010014, Romania; National Institute for Research and Development in Constructions, Urbanism and Sustainable Spatial Development URBAN-INCERC, sos. Pantelimon, nr. 266, sector 2, Bucharest 021652, Romania.

Galja Pletikapić: Division for Marine and Environmental Research, Ruđer Bošković Institute, Bijenička 54, 10000 Zagreb, Croatia.

Marja T. Pöllänen: Institute of Dentistry, University of Turku, FI-20014 Turku, Finland.

Manuela Reyes-Estebanez: Center of Environmental Microbiology and Biotechnology, Autonomous University of Campeche, Colonia Buenavista, San Francisco de Campeche 24039, Campeche, Mexico.

Elvira Ríos-Leal: Department of Biotechnology and Bioengineering, Center for Research and Advanced Studies of the National Polytechnic Institute (CINVESTAV), Mexico City 07360, Federal District, Mexico.

Belén Rodelas: Environmental Microbiology Group, Department of Microbiology, Faculty of Pharmacy, and Institute of Water Research, University of Granada, Campus de Cartuja s/n, Granada 18071, Spain.

Jiyan Shi: Department of Environmental Engineering, Zhejiang University, Hangzhou 310058, China.

Corinne Sinquin: Ifremer Laboratoire Biotechnologies et Molécules Marines, Nantes B. P. 21105, France.

Malena Skogman: Pharmaceutical Sciences, Department of Biosciences, Abo Akademi University, Artillerigatan 6A, 3rd Floor, Biocity, Turku FI-20520, Finland.

Fred Sörensson: Department of Chemistry \& Molecular Biology, Microbiology, University of Gothenburg, Box 462, Göteborg SE-405 30, Sweden.

Fernando G. Sorroche: Department of Molecular Biology, National University of Río Cuarto, Ruta 36 Km 601, Río Cuarto, Córdoba X5804BYA, Argentina.

Hongmin Sun: Division of Cardiovascular Medicine, Department of Internal Medicine, University of Missouri, Columbia, MO 65212, USA.

Vesna Svetličić: Division for Marine and Environmental Research, Ruđer Bošković Institute, Bijenička 54, 10000 Zagreb, Croatia.

Sandra Szyjka: Department of Environmental Health Sciences, Arnold School of Public Health, University of South Carolina, Columbia, SC 29208, USA.

Pieter T. Visscher: Center for Integrative GeoSciences, University of Connecticut, 345 Mansfield Rd., U-2045 Storrs, CT 06269, USA.

Pia Vuorela: Pharmaceutical Sciences, Department of Biosciences, Abo Akademi University, Artillerigatan 6A, 3rd Floor, Biocity, Turku FI-20520, Finland; Division of Pharmaceutical Biology, Faculty of Pharmacy, University of Helsinki, Viikinkaari 5E, P.O. Box 56, Helsinki FI-00014, Finland. 
Qing Wei: State Key Laboratory of Microbial Resources, Institute of Microbiology, Chinese Academy of Sciences, No.3, 1st Beichen West Road, Chaoyang District, Beijing 100101, China.

Britt-Marie Wilén: Water Environment Technology, Department of Civil and Environmental Engineering, Chalmers University of Technology, Göteborg SE-412 96, Sweden.

Gideon M. Wolfaardt: Department of Chemistry and Biology, 350 Victoria Street, Ryerson University, Toronto, ON M5B 2K3, Canada; Stellenbosch Institute for Advanced Study, Wallenberg Research Centre at Stellenbosch University, Stellenbosch 7600, South Africa.

Wei Xu: Institute of High Energy Physics, Chinese Academy of Science, Beijing Synchrotron Radiation Facility, Beijing 100049, China.

Qingsong Yu: Department of Mechanical and Aerospace Engineering, University of Missouri, Columbia, MO 65211, USA.

Xiaohan Yu: Institute of Applied Physics, Chinese Academy of Science, Shanghai Synchrotron Radiation Facility, Shanghai 201800, China.

Shenhai Zhu: Department of Environmental Engineering, Zhejiang University, Hangzhou 310058, China.

Vera Žutić: Division for Marine and Environmental Research, Ruđer Bošković Institute, Bijenička 54, 10000 Zagreb, Croatia. 




\title{
Preface
}

\section{The EPS Matrix as an Adaptive Bastion for Biofilms: Introduction to Special Issue}

\author{
Alan W. Decho \\ Reprinted from Int. J. Mol. Sci. Cite as: Decho, A.W. The EPS Matrix as an Adaptive Bastion for \\ Biofilms: Introduction to Special Issue. Int. J. Mol. Sci. 2013, 14, 23297-23300.
}

The process of biofilm formation has knowingly, and even unsuspectingly, baffled scientists for almost as long as the field of microbiology itself has existed. This Special Issue of the International Journal of Molecular Sciences (IJMS) specifically addresses an important component of the biofilm, the extracellular matrix. This matrix forms the protective secretions that surround biofilm cells and afford a "built environment" to contain biofilm processes. During the earlier days of microbiology, it was intriguing to Claude ZoBell that attached bacteria sometimes were able to proliferate when their planktonic counterparts were unable to grow [1]. During the 1970s, this attached state was beginning to be explored [2], and it was realized to be anchored in a matrix of slime-like molecules. The slime-like matrix together with cells was to be called the "biofilm", a term developed by the late Bill Costerton, Bill Characklis and colleagues. The scientific revelation that attached bacteria were different from free (i.e., planktonic) cells in their physiological behavior and adaptability, launched an era of focused exploration in this area of microbiology. It was initially surprising, though not unexpected in retrospect, that interest in biofilms has grown and now infiltrates virtually all aspects of our scientific study. Since that time there has been a near-exponential growth in the numbers of scientific publications addressing biofilms owing to their immediate relevance to ecology, biotechnology, health and industry.

During this exciting time, it was shown that the same strains of bacteria, when grown as free-cells (i.e., plankton) vs. attached cells (i.e., biofilm), exhibited differences in gene expression, cell-cell chemical communication, microspatial distributions, enzyme activities, antibiotic production, physical resistance to dispersion under flow, and other interactions between cells within biofilms $[3,4]$. However, one conspicuous gap emerged in understanding the biofilm. While there was much focus on biofilm cells, there was a relative paucity of studies addressing the extracellular matrix just outside the microbial cell boundaries, even though the extracellular matrix was recognized to be an integral part of the biofilm. It is the extracellular matrix that provides the physical architecture for interactions and facilitates feedback (sensing and signaling) among cells; two essential properties, which allow attached cells to operate differently from their planktonic counterparts.

During the 1990s, the acronym "EPS" was developed by Thomas Neu, Hans-Curt Flemming and colleagues, to encompass the extracellular polymeric substances or secretions. EPS was coined to 
emphasize the wide range of molecules such as proteins, polysaccharides, nucleic acids, and lipids, which comprise these secretions. It is a primary emergent property of the biofilm. Many in-depth reviews and overviews have addressed the specific topic of EPS, and have begun to reveal its complexity, and the difficulty in determining how this extracellular biome influences cells [5-9]. These reviews serve as a foundation for understanding the current knowledge and significant gaps in EPS-related research.

The biofilm, and specifically its EPS-related architecture, are now recognized as an important contributor to the areas of health and disease [10,11], industrial biofouling, biotechnology, and more-general ecosystem health. In the area of microbial ecology, EPS provides the physical architecture to support the incredible diversities observed in microbial mats and natural surface microbial communities, though its roles in this support are poorly understood. Complex communities such as those of microbial mats consist of tens of thousands of microbial species, as determined by 16S rDNA sequencing. The complex communities are tightly enclosed within largely-uncharacterized forms of environmentally-modified EPS, which have evolved and successfully adapted mat systems for literally billions of years. EPS is closely-linked to biogeomineral precipitation [12], and is used to interpret the microbial fossil record and remnants of the earliest life on Earth [13]. It is also being studied in the development of "microbial cement" used to repair cracks in building, statues and engineered structures. Periodontal disease, and its microbial cells anchored in EPS, is now realized to be a complex interplay between hundreds of commensal bacterial species that coexist within distinctly different environments of the oral cavity, and invasive forms reaching beyond those boundaries into the body [14,15]. The human gut microbiome is a recent emerging area of focus in health, and is now realized to be largely biofilm-based [16].

EPS has been difficult to characterize and to define beyond their bulk properties. This is largely because EPS molecules, their interactions, and their multi-functional roles to cells are diverse, and do not lend themselves to standard predictability, nor analyses by standard molecular tools. However, new tools are emerging, or rather, becoming more user-friendly, for the microbiologist and can be used to investigate such small-scale interactions within biofilms, and specifically the diverse EPS components. It is now realized that the study of EPS needs to be addressed (ideally) with minimal disturbance to the matrix during analyses. New approaches can now achieve nanometer-, even angstrom-level spatial resolution of molecules, which are necessary to begin understanding the complexity of EPS. It is especially important to probe the matrix in situ, wherever possible, in order to understand the "functional units" of EPS. That is, how do groups of molecules interact and result in a "function(s)" to cells. Understanding these interactions will reduce to deciphering the basic physical chemistry, while ascertaining their biological role(s). The many interactions occurring among the microbial flora of the gut, such as chemical communication and sensing, are related to EPS-localized processes. Biofilm microorganisms and the unique properties of their EPS are now being explored and exploited in biotechnology for food additives, as well as in pharmaceuticals, for drug delivery. 
This Special Issue is not intended to be all-encompassing in its coverage of EPS, but rather to present a series of EPS studies, and reviews, from different areas of investigation ranging from the environment to health.

\section{Acknowledgments}

This work was supported by a grant from the US National Science Foundation (BME-1032579).

\section{Conflicts of Interest}

The author declares no conflict of interest.

\section{References}

1. ZoBell, C.E. The effect of solid surfaces on bacterial activity. J. Bacteriol. 1943, 46, 75-82.

2. Costerton, J.W.; Geesey, G.G.; Chang, K.-J. How bacteria stick. Sci. Am. 1978, 238, 86-95.

3. Davies, D.G.; Parsek, M.R.; Pearson, J.P.; Iglewski, B.H.; Costerton, J.W.; Greenberg, E.P. The involvement of cell-to-cell signals in the development of a bacterial biofilm. Science 1998, 280, 295-298.

4. Stoodley, P.; Cargo, R.; Rupp, C.J.; Wilson, S.; Klapper, I. Biofilm material properties as related to shear-induced deformation and detachment phenomena. J. Ind. Microbiol. Biotechnol. 2003, 29, 361-367.

5. Neu, T.R.; Lawrence, J.R. In situ Characterization of Extracellular Polymeric Substances (EPS) in Biofilm Systems. In Microbial Extracellular Polymeric Substances; Wingender, J., Neu, T.R., Flemming, H.-C., Eds.; Springer-Verlag: Berlin, Germany, 1999; pp. 21-48.

6. Flemming, H.C.; Neu, T.R.; Wozniak, D. The EPS matrix: The house of biofilm cells. J. Bacteriol. 2007, 189, 7945-7947.

7. Böckelmann, U.; Janke, A.; Kuhn, R.; Neu, T.R.; Wecke, J.; Lawrence, J.R.; Szewzyk, U. Bacterial extracellular DNA forming a defined network-like structure. FEMS Microbiol. Lett. 2006, 262, 31-38.

8. Flemming, H.-C.; Wingender, J. The biofilm matrix. Nat. Revs. Microbiol. 2010, 8, 623-633.

9. Decho, A.W. Microbial exopolymer secretions in ocean environments: Their roles in food webs and marine processes. Oceanogr. Mar. Biol. Ann. Rev. 1990, 28, 73-153.

10. Costerton, J.W.; Stewart, P.S.; Greenberg, E.P. Bacterial biofilms: A common cause of persistent infections. Science 1999, 284, 1318-1322.

11. Hall-Stoodley, L.; Stoodley, P. Bacterial biofilms: From the natural environment to infectious diseases. Nat. Rev. Microbiol. 2005, 2, 95-108.

12. Dupraz, C.; Reid, R.P.; Braissant, O.; Decho, A.W.; Norman, R.S.; Visscher, P.T. Processes of carbonate precipitation in modern microbial mats. Earth Sci. Rev. 2010, 96, 141-162. 
13. Nofke, N.; Decho, A.W.; Stoodley, P. Slime through time: The fossil record of prokaryote evolution. Palaios 2013, 28, 1-5.

14. Jenkinson, H.F.; Lamont, R.J. Oral microbial communities in sickness and in health. Trends Microbiol. 2005, 13, 589-595.

15. Kuramitsu, H.K.; He, X.; Lux, R.; Anderson, M.H.; Shi, W. Interspecies interactions within oral microbial biofilms. Microbiol. Mol. Biol. Rev. 2007, 71, 653-670.

16. Bäckhed, F.; Ley, R.E.; Sonneburg, J.L.; Peterson, D.A.; Gordon, J.I. Host-bacterial mutualism in the human intestine. Science 2005, 307, 1915-1920. 


\title{
1. Spatial Patterns and the Biofilm Matrix
}

\section{Three-Dimensional Stratification of Bacterial Biofilm Populations in a Moving Bed Biofilm Reactor for Nitritation-Anammox}

\author{
Robert Almstrand, Frank Persson, Holger Daims, Maria Ekenberg, Magnus Christensson, \\ Britt-Marie Wilén, Fred Sörensson and Malte Hermansson
}

\begin{abstract}
Moving bed biofilm reactors (MBBRs) are increasingly used for nitrogen removal with nitritation-anaerobic ammonium oxidation (anammox) processes in wastewater treatment. Carriers provide protected surfaces where ammonia oxidizing bacteria (AOB) and anammox bacteria form complex biofilms. However, the knowledge about the organization of microbial communities in MBBR biofilms is sparse. We used new cryosectioning and imaging methods for fluorescence in situ hybridization (FISH) to study the structure of biofilms retrieved from carriers in a nitritation-anammox MBBR. The dimensions of the carrier compartments and the biofilm cryosections after FISH showed good correlation, indicating little disturbance of biofilm samples by the treatment. FISH showed that Nitrosomonas europaea/eutropha-related cells dominated the AOB and Candidatus Brocadia fulgida-related cells dominated the anammox guild. New carriers were initially colonized by AOB, followed by anammox bacteria proliferating in the deeper biofilm layers, probably in anaerobic microhabitats created by AOB activity. Mature biofilms showed a pronounced three-dimensional stratification where AOB dominated closer to the biofilm-water interface, whereas anammox were dominant deeper into the carrier space and towards the walls. Our results suggest that current mathematical models may be oversimplifying these three-dimensional systems and unless the multidimensionality of these systems is considered, models may result in suboptimal design of MBBR carriers.
\end{abstract}

Reprinted from Int. J. Mol. Sci. Cite as: Almstrand, R.; Persson, F.; Daims, H.; Ekenberg, M.; Christensson, M.; Wilén, B.-M.; Sörensson, F.; Hermansson, M. Three-Dimensional Stratification of Bacterial Biofilm Populations in a Moving Bed Biofilm Reactor for Nitritation-Anammox. Int. J. Mol. Sci. 2014, 15, 2191-2206.

\section{Introduction}

Nitrogen removal with anaerobic ammonium oxidizing (anammox) bacteria is an emerging technology for treatment of high strength wastewater. In the process, aerobic ammonia oxidizing bacteria (AOB) oxidize half of the ammonia to nitrite, which is used by anammox bacteria as electron acceptor for oxidizing the remaining ammonia to dinitrogen gas. In the more common full-scale configurations, the processes of nitritation and anammox occur in the same reactor [1]. The AOB and anammox bacteria can reside in suspended microbial assemblages as sludge and/or granules [2], or in biofilms attached to substrata [3]. One prerequisite for nitritation-anammox is the presence of 
both oxic and anoxic environments for AOB and anammox bacteria, respectively. This can be attained by alternating the environmental conditions in time, such as in a sequencing batch reactor [2]. In continuous reactors on the other hand, the microbial groups need to be separated in space, with anammox bacteria residing in anoxic zones of the microbial aggregates, provided by the oxygen demanding activities of AOB. In microbial granules, distinct patterns of stratification have been predicted by modelling and observed with microbiological methods, with AOB being located in the outer aerobic zone near the water interface and with anammox bacteria in the inner anoxic parts [4-8]. For nitritation-anammox biofilms on fixed substrata, the observed localization of microorganisms has been less straightforward. In several reactors, a seemingly scattered distribution of AOB and anammox bacteria has been observed [3,9-11], while in other reactors the distribution of microorganisms has been more orderly structured [12-14], indicating that the factors determining biofilm architecture are complex. Furthermore, there is a need for quantitative image analysis to reveal the actual distribution patterns of the biofilm microorganisms. For moving bed biofilm reactors (MBBRs), which are used today in full-scale nitritation-anammox [15,16], a recent investigation has indicated a more orderly biofilm structure [17], but detailed analysis of biofilm establishment and stratification is still lacking for these systems. One probable reason for this is the challenge to retreive and analyze undisrupted biofilms from the protected carrier compartments. Furthermore, biofilm modeling is a useful tool $[18,19]$ to improve the efficiency of nitritation-anammox MBBRs. For these models a detailed knowledge about the distribution of microorganisms is fundamental.

In this study, we have utilized a cryosectioning approach for the retrieval and study of intact biofilm of different age from protected compartments of carriers residing in a nitritation-anammox MBBR. Fluorescence in situ hybridization (FISH) and confocal laser scanning microscopy (CLSM) was used to identify the AOB and anammox populations. By combining FISH-CLSM with a newly developed digital image analysis method [20], the three-dimensional stratification of AOB and anammox bacteria in intact biofilms was determined and quantified. Differences between young and mature biofilms in terms of established $\mathrm{AOB}$ and anammox populations and biofilm structure were investigated. Finally, image analysis of total carrier compartment i.e., "wall-to-wall" biofilms, allowed an assessment of problems with biofilm retrieval and shrinkage from dehydration and cryo-embedding, which has often been suggested as a serious draw-back of these biofilm research methods.

\section{Results and Discussion}

\subsection{Reactor Conditions}

The nitritation-anammox MBBR was operated for three years. Our study covers 167 days at the end of the reactor runtime, from addition of new carriers to the final sampling. Reactor conditions during this period are summarized in Table 1. Since only trace amounts of organic carbon was added to the synthetic wastewater, and even though AOB in the biofilm could be a source for organic carbon per se [21,22], it is unlikely that denitrification would account for any significant nitrogen removal. 
The ratio of nitrate production to ammonia removal was $12 \%$, which is close to the stoichiometric value for anammox bacteria of $11 \%$, indicating that aerobic nitrite oxidation was not important [23].

Table 1. Reactor conditions and effluent concentrations during the experimental period. Average values and standard deviation (SD). The influent (synthetic wastewater) contained $314 \mathrm{mg} \mathrm{N} \mathrm{L}^{-1}$ as ammonium. HRT = hydraulic retention time; DO = dissolved oxygen.

\begin{tabular}{|c|c|c|c|c|c|c|c|c|c|}
\hline & $\begin{array}{c}\text { Flow } \\
\left(\mathrm{L} \mathrm{h}^{-1}\right)\end{array}$ & $\begin{array}{l}\text { HRT } \\
\text { (h) }\end{array}$ & $\begin{array}{l}\text { Temp } \\
\left({ }^{\circ} \mathrm{C}\right)\end{array}$ & pH & $\begin{array}{c}\text { DO } \\
\left(\mathrm{mg} \mathrm{L}^{-1}\right)\end{array}$ & $\begin{array}{c}\mathrm{NH}_{4}^{+} \\
\left(\mathrm{mg} \mathrm{N} \mathrm{L}^{-1}\right)\end{array}$ & $\begin{array}{c}\mathrm{NO}_{2}^{-} \\
\left(\mathrm{mg} \mathrm{N} \mathrm{L}^{-1}\right)\end{array}$ & $\begin{array}{c}\mathrm{NO}_{3}^{-} \\
\left(\mathrm{mg} \mathrm{N} \mathrm{L}^{-1}\right)\end{array}$ & $\begin{array}{c}\mathrm{N} \\
\text { removal }\end{array}$ \\
\hline Average & 1.2 & 6.3 & 28.3 & 7.8 & 3.6 & 71 & 14 & 25 & $66 \%$ \\
\hline S.D. & 0.2 & 0.7 & 2.9 & 0.3 & 0.5 & 40 & 13 & 12 & $14 \%$ \\
\hline
\end{tabular}

\subsection{Biofilm Retrieval and Sectioning}

Cryo-embedding, followed by freezing and removal of the carrier plastic material enabled the retrieval of biofilm from within individual carrier compartments (for carrier details see Table S1). As shown in Figure S1, the cryosectioned biofilm maintained the square shape in the $x, y$ dimensions. The deepest analyzed cryosections (i.e., in the $z$ dimension, going into the carrier compartment) originated from at least $800 \mu \mathrm{m}$ (Figure 1b). This corresponds to $80 \%$ and $53 \%$ of the maximum depth of the 2 and $3 \mathrm{~mm}$ carriers, respectively. Deeper layers can be analyzed, but long (in the $z$ dimension) frozen biofilm structures can easily break. Previous studies [24,25] have observed that cryo-embedding and dehydration introduce severe distortion, such as shrinkage, to biofilm structure. Since the assembled micrograph squares represent a "wall-to-wall" $x, y$ section of the biofilm (Figure 1a), and the fact that these were of the same dimension as the actual carrier compartment (Figure S1), we suggest that for these and similar types of biofilms, significant shrinkage is not introduced by the applied cryosectioning and hybridization protocols. 
Figure 1. Overview of sample retrieval and analysis. Biofilm carriers containing either young (A1) or mature biofilm $(\mathbf{A 2}, \mathbf{3})$ were cryo-embedded and frozen; After removal of the carrier, biofilm from carrier compartments was frozen solid and associated with the O.C.T. compound (A4); Cryosectioning of the biofilm was followed by FISH and CLSM analysis of biofilm stratification in the $x, y$ and $z$ dimensions (A5); and vertical $(z)$ distribution from one of the compartments is exemplified in (B), anammox (open circles), AOB (closed circles).
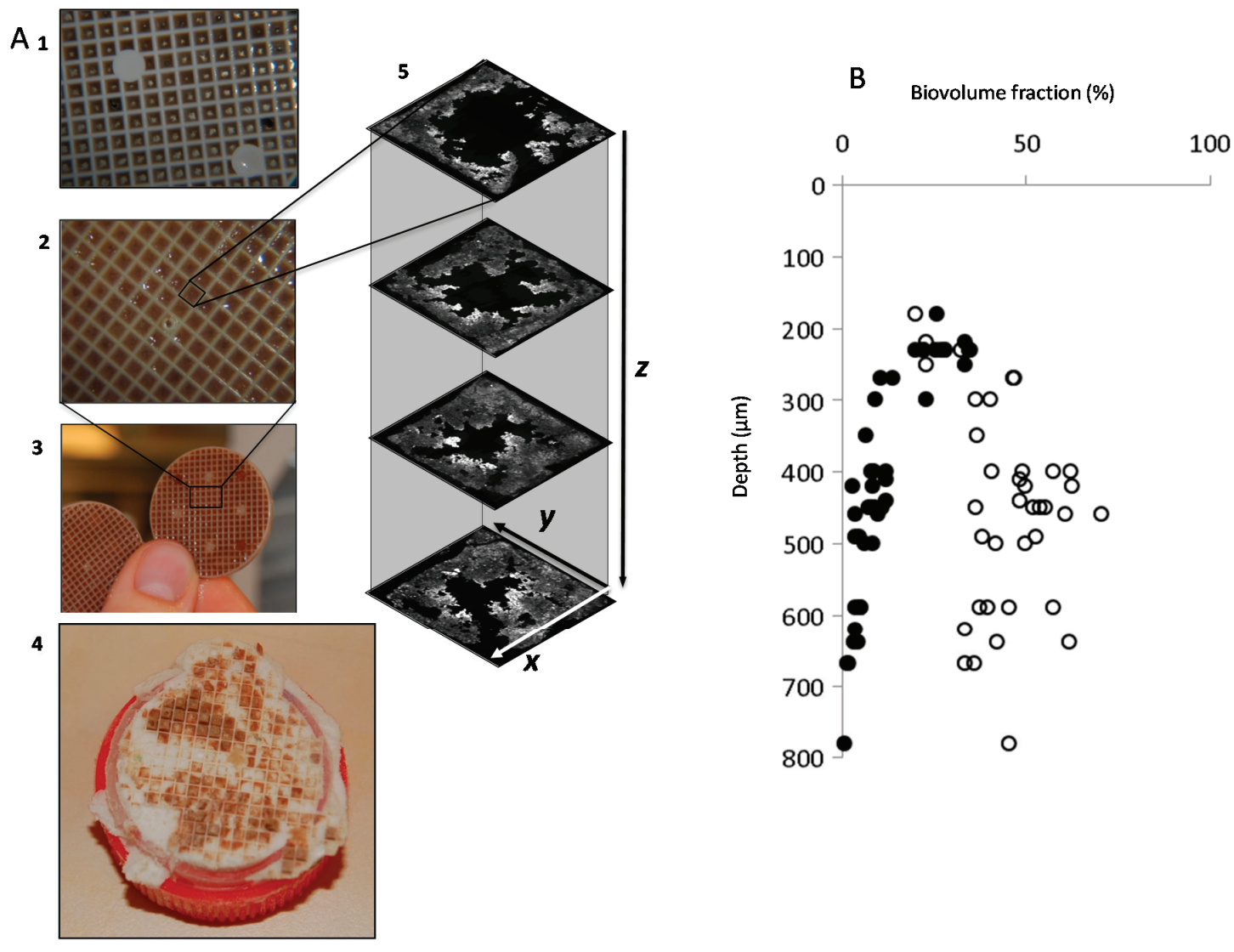

\subsection{Bacterial Community Composition}

A large FISH screening (Table S2) showed that the reactor community was made up of AOB in microcolonies and dense clusters of cells related to the Nitrosomonas europaea/eutropha lineage (cluster 7), hybridizing with the probe Nse1472. This was not unexpected considering the comparatively high ammonium concentrations in the reactor (average $314 \mathrm{mg} \mathrm{N} \mathrm{L}^{-1}$ ). N. europaea/eutropha-related cells are generally encountered in systems with elevated ammonium concentrations [26] and may be regarded as AOB r-strategists with a comparatively high growth rate [27,28]. Simultaneous probe hybridization with Pla46 (targeting the order Planctomycetales), AMX820 (targeting the genera $\mathrm{Ca}$. Brocadia and Ca. Kuenenia) and Bfu613 (targeting Ca. Brocadia fulgida) indicated that the anammox cells were related to Ca. Brocadia fulgida. Ca. Brocadia-like cells were also dominating the anammox 
population on biofilm carriers in a laboratory scale CANON reactor fed with concentrated anaerobic digestion reject water [29] and are possibly r-strategists among anammox bacteria [30]. Furthermore, filamentous cells targeted by probe CF319a (phylum Bacteroidetes among others), were rather evenly distributed, possibly providing structural support for the biofilm, as suggested earlier [31]. Very few NOB cells were present, as targeted by the probes for Nitrobacter, Nitrospira and Nitrotoga (Table S2), which was in accordance with the low aerobic nitrite oxidation (see above).

\subsection{Biofilm Establishment on New Carriers}

Anammox cells were almost completely absent from the relatively thin biofilms on the carriers incubated for five and a half months (Figure 2c,d). A few anammox microcolonies were found, usually in the compartment corners beneath biofilm dominated by approximately $80 \%$ of $N$. europaea/eutropha . Considering the DO concentration in the reactor (on average $3.6 \mathrm{mg} \mathrm{L}^{-1}$, Table 1), the results suggest a sequential colonization with initial formation of an $\mathrm{AOB}$ biofilm that with time created anaerobic microenvironments suitable for anammox bacteria in the deepest parts of the biofilm. It is likely that these environments first arose in the carrier corners, since the mature biofilms were thicker in the corners $(336 \pm 22 \mu \mathrm{m}$, average $\pm \mathrm{SD})$ than on the compartment sides $(235 \pm 19 \mu \mathrm{m})$. Thus, migration of intact $\mathrm{AOB}$ and anammox biofilm clusters alone cannot explain establishment of anammox on new carriers since AOB first needed to provide the anaerobic microenvironment. It has previously been shown that the desired stratification of $\mathrm{AOB}$ and anammox bacteria occurred only if anammox bacteria were established prior to AOB [13]. However, such orderly development was not necessary for stratification to develop here. The discovery of very few anammox bacteria after five and a half months suggests that the development took considerable time. Much faster establishment of anammox bacteria has been detected in anoxic reactors where AOB are not necessary to create anoxic microenvironments [32].

\subsection{Biofilm Structure}

As mentioned above, the biofilm was in general thicker in the corners than on the sides of the compartments. Biomass density, defined as the signal area of the Eub338 probe mix as a fraction of total compartment area (Figure S2), increased significantly with depth down to $400 \mu \mathrm{m}\left(R^{2}=0.4219\right.$, $n=17, \alpha=0.05)$. Thicker biofilms generally have a higher nitrogen removal, but modeling suggests improvements above a thickness of $750 \mu \mathrm{m}$ to be small [33]. At more shallow depths (in the $z$ dimension) erosion and detachment due to the shear forces, rather than electron donor or acceptor concentrations, may have controlled biofilm biomass. It was concluded that nitrifying biofilms on carriers fixed in a flow chamber generally showed enhanced erosion rather than growth when the flow rate increased, despite being supplied with more oxygen and substrate [19]. However, the relationship between carrier movement and the effect of flow velocity on biofilms in MBBRs is still uncertain [34].

The overall vertical distribution in the mature biofilms showed a significant decrease of AOB with carrier compartment depth ( $z$ dimension) $\left(R^{2}=0.80, n=41, \alpha=0.01\right.$; Figure 1b). Similar to AOB, 
anammox cells grew in characteristic clusters or microcolonies of varying size and shape (Figure 2a,b), but instead increased significantly in relative abundance with depth from $180 \mu \mathrm{m}$ down to $400 \mu \mathrm{m}$ $\left(R^{2}=0.66, n=17, \alpha=0.01\right.$; Figure $\left.1 b\right)$. In the horizontal $(x, y)$ dimension AOB dominated in the center parts and anammox in the peripheral part, close to the carrier walls (Figure 3). The least variation in relative population abundance was closer to the walls, such as for anammox in the 0-100 $\mu \mathrm{m}$ section (Figure 3c). Here erosion effects would be less severe compared with the center section where the variation of $\mathrm{AOB}$ was quite large between different compartments (Figure $3 \mathrm{~g}$ ). The combination of FISH, CLSM and new image analysis approaches enabled, for the first time, a detailed investigation of the three-dimensional distribution of AOB and anammox bacteria in MBBR biofilms. A uniquely detailed picture emerged, where the distinct stratification of AOB and anammox bacteria agrees well with the general pattern observed in granular biomass [4-6]. The decrease in relative abundance of $\mathrm{AOB}$ with carrier depth (the $z$ dimension) is possibly caused by oxygen limitation in the deeper parts, whereas anammox bacteria increased down to $400 \mu \mathrm{m}$ depth, below which the abundance leveled out or even decreased. This distribution pattern suggests different functional properties of the microbial communities at different depths of the biofilm in the carrier, where the outer regions contain mainly aerobic nitrite producers whereas the inner regions contain mainly anaerobic nitrite consumers. This kind of information is particularly valuable for understanding the function of MBBRs, since the continuous movement of the carriers in the reactors cause uncertainties about the flux of substrate and electron acceptors to the biofilm [34] and impede microelectrode in situ analysis of the gradients of substrate and electron acceptors near and in the biofilms [19].

Figure 2. Assembled FISH "wall-to-wall" micrographs of biofilm from the biofilm carrier compartments. (A) Mature biofilm from $230 \mu \mathrm{m}$ depth; (B) Mature biofilm from $500 \mu \mathrm{m}$ depth; (C) Young biofilm from $250 \mu \mathrm{m}$ depth; and (D) Young biofilm from $490 \mu \mathrm{m}$ depth. In yellow, AOB cells hybridized with probe Nse1472. In cyan, anammox cells hybridized with probe Bfu613. In green, cells hybridized with the Eub338 (I-IV) probe mix only. Scale bar $=200 \mu \mathrm{m}$.

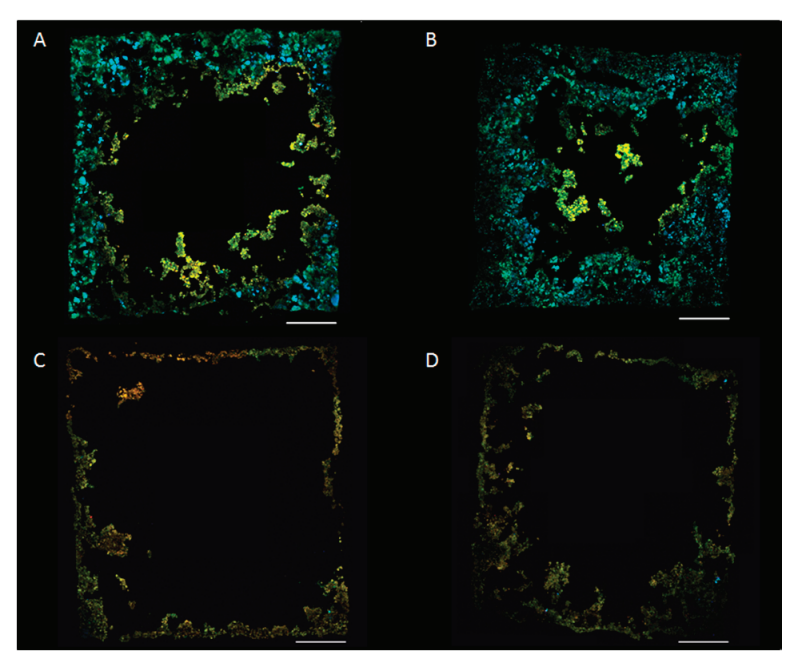


Figure 3. Assembled FISH "wall-to-wall" micrographs of biofilm from the biofilm carrier compartments in the $x, y$ dimension. (A) Example of the multidirectional slicing procedure, where each colored area represents a $100 \mu \mathrm{m}$ thick region of the biofilm from a particular distance from the compartment wall; (B) Schematic representation of the $100 \mu \mathrm{m}$ thick slices, showing average biovolume fractions throughout all depths $(z)$ of AOB and anammox bacteria in the carrier compartments. Average $\pm 95 \%$ confidence intervals, $n=41(n=37$ for slice $400-500 \mu \mathrm{m})$; and $(\mathbf{C}-\mathbf{G})$ Biovolume fractions of anammox bacteria (open circles) and AOB (solid circles) in the concentric areas (colored "slices") at different depths $(z)$ in the carrier compartments. The designations $(\mathbf{C}-\mathbf{G})$ refer to the concentric areas at different distance from the compartment wall, as depicted in (B).

A

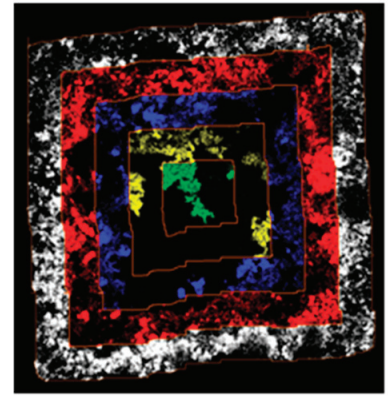

B

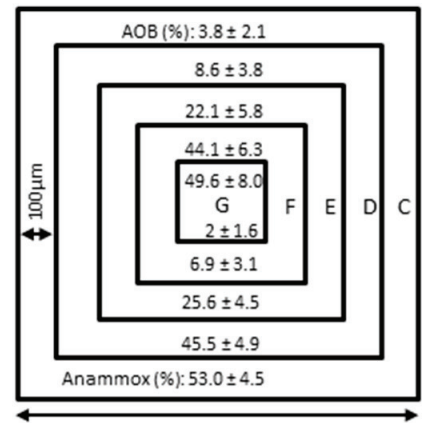

$\sim 1000 \mu \mathrm{m}$
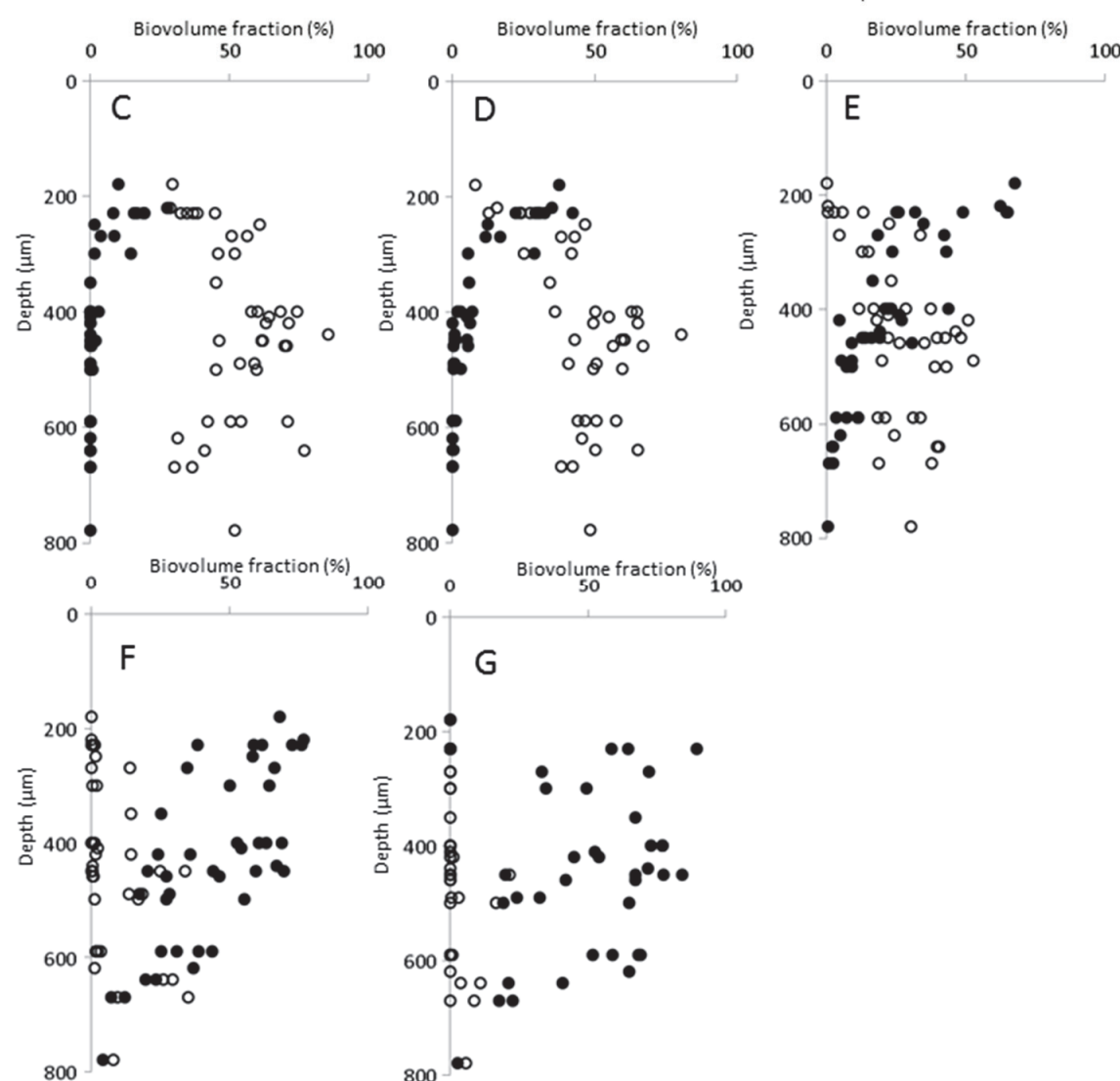

G
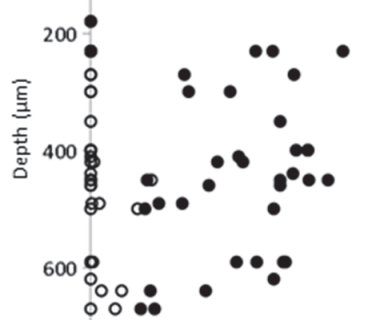

$800-\infty$ 


\section{Experimental Procedures}

\subsection{Reactor Conditions}

A laboratory scale (7.5 liter) MBBR reactor with biofilm carriers (Minichip, AnoxKaldnes, Lund, Sweden) fed with synthetic wastewater (see Supplementary Information) was operated for three years. The reactor conditions and process performance are shown in Table 1.

\subsection{Biofilm Sampling and Preparation}

Characteristics of the biofilm carriers are listed in Table S1. New carriers were added to the reactor on December 17th 2008. Carriers were sampled for initial biofilm screening on May 4th, 2009. On June 2nd 2009, carriers containing young (5.5 months old) or mature ( $>18$ months old) biofilms were sampled from the reactor. The carriers were immediately fixed in $4 \%$ ice-cold paraformaldehyde (PFA; $\mathrm{pH}$ 7.2) on ice for at least $8 \mathrm{~h}$. After fixation, the carriers were submerged in phosphate buffered saline (PBS, pH 7.2) for at least $20 \mathrm{~min}$ and thereafter cut in halves and stored in 1:1 (PBS:EtOH) at $-20{ }^{\circ} \mathrm{C}$ until further use.

For screening of biofilm community composition the biofilm was brushed off from fixed halves of biofilm carriers, fixed again and homogenized [35].

For intact biofilm analyses fixed halves of biofilm carriers were embedded in Tissue-Tek ${ }^{\circledR}$ O.C.T. ${ }^{\text {тм }}$ Compound (Sakura Finetek Europe B.V., Alphen aan den Rijn, The Netherlands), placed in a closed and parafilm-sealed Petri dish (Sarstedt, Helsingborg, Sweden) and incubated overnight at +4 ${ }^{\circ} \mathrm{C}$. Centrifuge tubes $(15 \mathrm{~mL})$ were cut, placed upside down and filled to the brim with OCT compound. Incubated biofilm carriers were placed on top and covered with OCT and put in a liquid nitrogen fume chamber for approximately $60 \mathrm{~min}$, until frozen solid. Tubes were fixed firmly in a vice and the carriers were removed, thereby exposing solid biofilm squares on top of the tubes (Figure 1a) which were sealed with a covering layer of OCT, frozen and stored in $-70{ }^{\circ} \mathrm{C}$. Sectioning of the biofilm from 15 compartments into $10 \mu \mathrm{m}$ thick slices was performed in a cryotome operating at $-20{ }^{\circ} \mathrm{C}$. The produced sections were collected on SuperFrost ${ }^{\circledR}$ Plus Gold microscope slides (Menzel GmbH \& KG, Braunschweig, Germany) and stored in $-20^{\circ} \mathrm{C}$.

\subsection{Fluorescence in Situ Hybridization}

Screening for AOB, NOB and anammox populations was performed on homogenized biofilms, sampled on 14 May 2009, using FISH [35].

On cryosectioned samples for intact biofilm analyses, OCT was removed by a 10 min submersion in $50 \% \mathrm{EtOH}$. Additional fixation, to ensure that all cells in the biofilm would be accessible to the fluorescent probes and FISH, was performed as described earlier [36,37]. The fluorescent probes and unlabeled competitors were obtained from Thermo Electron (Interactiva Division, Ulm, Germany) or MWG Biotech (Ebersberg, Germany). The probes were 5' labeled with Cy3, Cy5, fluorescein or 
Alexa488. Hybridization was carried out at $46{ }^{\circ} \mathrm{C}$ for 2 (homogenized biofilm) or $4 \mathrm{~h}$ (cryosectioned biofilm), followed by washing at $48{ }^{\circ} \mathrm{C}$ for $10 \mathrm{~min}$. Finally, the slides were rinsed in milli-Q water, air dried and mounted in Citifluor AF1 (Citifluor, London, UK). Each of the specific probes (Table S2) was hybridized together with the Eub338 probe mix for quantification of the relative probe signal.

\subsection{Confocal Laser Scanning Microscopy}

Confocal micrographs were acquired using a Bio-Rad Radiance 2000 MP microscope (Bio-Rad, Hemel Hempstead, UK) with a Nikon Plan Fluor 40×/1.40 oil objective, a Red diode laser $(638 \mathrm{~nm})$, a He/Ne laser $(543 \mathrm{~nm})$, and an Argon laser (488 nm). Images for analysis of biofilm structure were collected with the bundled software LaserSharp 2000 as 8-bit images of $1024 \times 1024$ pixels (resolution: 3.30 pixels $/ \mu \mathrm{m}$ ), and Kalman filtration $(n=3)$. For quantification of biofilm populations in homogenized samples, 8 -bit images of $512 \times 512$ pixels (resolution: 1.65 pixels $/ \mu \mathrm{m}$ ), Kalman filtration $(n=2)$ were acquired. The biovolume fractions were measured in 21 microscope fields from each replicate by acquiring three images from different planes in the $z$ dimension for each randomly selected $\mathrm{x}$ and y position, as previously described [38].

\subsection{Digital Image Analysis}

For biofilm structure analysis, the acquired images from each section were assembled manually using Photoshop CS4 extended (Adobe Systems, San Jose, CA, USA) to obtain complete coverage of the carrier compartment biofilm in each image (i.e., "wall-to-wall" images). Here biofilm dimensions were measured to estimate shrinkage of the biofilm during cryosectioning, and biofilm thickness was measured (for details, see Supplementary Information). The biofilm images were then exported to the daime software version 2.0 [39] for measurements of the biovolume fractions of probe targeted bacteria in both homogenized and cryosectioned biofilm samples, and for measurements of the stratification in cryosectioned biofilms using the recently developed "Slicer" tool [20].

\section{Conclusions}

The applied cryosectioning and FISH protocols permitted retrieval and microscopy of intact biofilm from the MBBR carrier compartments with little biofilm distortion.

FISH data showed that $N$. europaea/eutropha-related organisms were the dominant AOB and that Ca. Brocadia fulgida-related organisms were the predominant anammox bacteria, suggesting a sequential colonization pattern of newly introduced carriers. Initial dominance of AOB was followed after about five and a half months by the establishment of anammox cells, probably as a result of formation of local anoxic micro-habitats by AOB.

By the use of novel digital image analysis tools and statistical analyses, substantial three-dimensional stratification of the mature biofilm was observed. In the $z$-dimension, the relative abundance of AOB decreased rapidly with depth, possibly due to oxygen limitation in the deeper parts of the carrier. 
In contrast, anammox bacteria increased in relative abundance down to a depth of $400 \mu \mathrm{m}$. A distinct horizontal $(x, y)$, non-random distribution pattern was also observed, with AOB generally being most abundant in the center and anammox bacteria closer to the walls of the carrier compartments. We conclude that a true three-dimensional biofilm stratification can be expected in MBBR carrier systems, which should be taken into account when modeling and optimizing reactor performance and in the design of new MBBR carriers.

\section{Supplementary Information}

\section{Reactor Medium}

The synthetic reactor media consisted of the following per $100 \mathrm{~L}: 240 \mathrm{~g} \mathrm{NaHCO}, 120 \mathrm{~g} \mathrm{NH} 4 \mathrm{Cl}$, 0.3 g pepton, $0.56 \mathrm{~g} \mathrm{KH}_{2} \mathrm{PO}_{4}, 70 \mathrm{~mL} \mathrm{2M} \mathrm{NaOH}, 40 \mathrm{~mL}$ micro-nutrient solution consisting of (in $\mathrm{g} / \mathrm{L}$ ): $4.8 \mathrm{MgSO}_{4} \cdot 7 \mathrm{H}_{2} \mathrm{O} ; 1.6 \mathrm{MnCl}_{2} \cdot 2 \mathrm{H}_{2} \mathrm{O} ; 5.8 \mathrm{CaCl}_{2} \cdot 2 \mathrm{H}_{2} \mathrm{O} ; 0.48 \mathrm{CoCl}_{2} \cdot 6 \mathrm{H}_{2} \mathrm{O} ; 0.24 \mathrm{NiCl}_{2} \cdot 6 \mathrm{H}_{2} \mathrm{O} ; 0.26 \mathrm{ZnCl}_{2}$; $0.10 \mathrm{CuSO}_{4} \cdot 5 \mathrm{H}_{2} \mathrm{O} ; 1.44 \mathrm{FeCl}_{2} \cdot 4 \mathrm{H}_{2} \mathrm{O} ; 0.0005 \mathrm{BH}_{3} \mathrm{O}_{3} ; 0.0022 \mathrm{Na}_{2} \mathrm{MoO}_{4} \cdot 2 \mathrm{H}_{2} \mathrm{O} ; 0.00114 \mathrm{Na}_{2} \mathrm{SeO}_{3} \cdot 5 \mathrm{H}_{2} \mathrm{O}$; $0.0014 \mathrm{Na}_{3} \mathrm{WO}_{3} \cdot 2 \mathrm{H}_{2} \mathrm{O}$.

\section{Measurement of Biofilm Carrier Compartment Size}

The biofilm carrier compartment dimensions were measured using brightfield microscopy and an eyepiece grid. The area was measured at the surface, halfway to the center and at the center, i.e., the point farthest from the carrier surface. Note that due to the production method the carrier area decreases with depth down to the mid-point of the carrier. That is, the total carrier compartment, from one carrier surface to the other, has a slight "waist" at the center.

\section{Digital Image Analysis of Biofilms}

\subsection{Estimation of Biofilm Shrinkage}

For estimation of biofilm shrinkage due to the cryosectioning and FISH protocols, the sides and diagonals of each assembled biofilm square were measured on the Eub338mix images, using the ruler tool in Photoshop (CS4 extended; Adobe Systems, San Jose, CA, USA). The dimensions were plotted and compared to the dimensions of the carrier compartments as determined by microscopy (see Section 2 above).

\subsection{Estimation of Mature Biofilm Thickness}

For estimation of the mature biofilm thickness, 8 measurements, one from each side and corner of each Eub338mix image were recorded in Photoshop CS4. Obvious biofilm channels were ignored in the measurements. 


\subsection{Estimation of Biovolume Fraction of Populations}

For estimation of the biovolume fraction of each population, an intensity threshold was set manually for each image, using the threshold function in Photoshop CS4. The resulting binary (black and white) images of probe-labeled biomass were exported as 16 megapixel TIFs to the digital image analysis software daime [39], where a noise reduction step was performed ("Noise reduction" function, number of non-zero neighbor pixels: 1). Due to the large size of the images, image resolution was reduced to 1 megapixel before measuring biovolume fractions. Following 2D segmentation of the binary images autofluorescent objects present in both the Nse1472 and Bfu613 images were removed. The biovolume fraction was calculated for each image after an additional step of artefact elimination [with the daime artifact rejection tool using a 50\% congruency threshold and final congruency requirement between the specific probes and the biofilm reference (EUB338mix) of at least 90\%]. Images of homogenized biofilm were analyzed through initial intensity thresholding (cutoff: 30), followed by RATS-L segmentation, followed by artifact elimination and calculation of the biovolume fraction of each specific probe-target population as part of the Eub388 probe mix with a $>90 \%$ requirement for total congruency. The horizontal "wall-to-wall" population distribution was analyzed using the multidirectional Slicer tool in daime 2.0 [20], creating $100 \mu \mathrm{m}$ thick virtual slices and applying a baseline smoothing of $20 \%$. Relative population abundances were estimated for each virtual slice as described above.

Table S1. Characteristics of biofilm carriers. *

\begin{tabular}{ccc}
\hline Carrier specifics & Type 1 ${ }^{\mathbf{1}}$ & Type 2 $^{\mathbf{1}}$ \\
\hline $\begin{array}{c}\text { Depth of carrier compartments } \\
\text { (i.e., } z \text { dimension in figures) }\end{array}$ & $2 \mathrm{~mm}$ & $3 \mathrm{~mm}$ \\
Diameter of the carrier & $30 \mathrm{~mm}$ & $30 \mathrm{~mm}$ \\
Protected surface area per carrier & $2.73 \times 10^{-3} \mathrm{~m}^{2}$ & $4.10 \times 10^{-3} \mathrm{~m}^{2}$ \\
Number of square compartments & 325 & 325 \\
\hline
\end{tabular}

* Minichip, AnoxKaldnes, Lund, Sweden. ${ }^{1}$ Two different carrier variants were used. 
Table S2. Oligonucleotide probes used for fluorescence in situ hybridization (FISH) in this study.

\begin{tabular}{|c|c|c|c|}
\hline Probe name $^{1}$ & Target & Sequence (5'-3') & $\mathbf{F A}^{2}[\%]$ \\
\hline Eub338 3 & Most Bacteria & GCT GCC TCC CGT AGG AGT & $0-50$ \\
\hline Amx 820 & $\begin{array}{l}\text { Anaerobic ammonium-oxidizing bacteria, } \\
\text { Candidatus "Brocadia anammoxidans" and } \\
\text { Candidatus "Kuenenia stuttgartiensis" }\end{array}$ & AAA ACC CCT CTA CTT AGT GCC C & 40 \\
\hline Apr820 & Candidatus Anammoxoglobus propionicus & AAA CCC CTC TAC CGA GTG CCC & 40 \\
\hline Ban162 & Candidatus Brocadia anammoxidans & CGG TAG CCC CAA TTG CTT & 40 \\
\hline BS 820 & $\begin{array}{l}\text { Candidatus Scalindua wagneri, } \\
\text { Candidatus Scalindua sorokinii }\end{array}$ & TAA TTC CCT CTA CTT AGT GCC C & 20 \\
\hline Bfu613 & Candidatus Brocadia fulgida & GGA TGC CGT TCT TCC GTT AAG CGG & 30 \\
\hline Sca1309 & Genus Candidatus Scalindua & TGG AGG CGA ATT TCA GCC TCC & 5 \\
\hline Scabr1114 & Candidatus Scalindua brodae & CCC GCT GGT AAC TAA AAA CAA G & 20 \\
\hline Pla46 & Planctomycetales & GAC TTG CAT GCC TAA TCC & 30 \\
\hline Nso1225 & Most beta-proteobacterial AOB & CGC CAT TGT ATT ACG TGT GA & 35 \\
\hline Nse1472 & $\begin{array}{l}\text { Nitrosomonas europea, } N \text {. halophila, } \\
\text { N. eutropha, Kraftisried-Isolat Nm103 }\end{array}$ & ACC CCA GTC ATG ACC CCC & 50 \\
\hline Ntspa662 4 & Genus Nitrospira & GGA ATT CCG CGC TCC TCT & 35 \\
\hline Ntspa1151 & Sublineage II of the genus Nitrospira & TTC TCC TGG GCA GTC TCT CC & $35-40$ \\
\hline Ntspa1431 & Sublineage I of the genus Nitrospira & TTG GCT TGG GCG ACT TCA & 35 \\
\hline Ntg840 & Nitrotoga arctica & CTA AGG AAG TCT CCT CCC & $10-20$ \\
\hline Nit3 ${ }^{4}$ & Genus Nitrobacter & CCT GTG CTC CAT GCT CCG & 40 \\
\hline $\mathrm{NmII}$ & Nitrosomonas communis lineage & TTA AGA CAC GTT CCG ATG TA & 35 \\
\hline Alf968 & Alphaproteobacteria, except of Rickettsiales & GGT AAG GTT CTG CGC GTT & 20 \\
\hline CF319a & $\begin{array}{c}\text { Most Flavobacteria, some Bacteroidetes, } \\
\text { some Sphingobacteria }\end{array}$ & TGG TCC GTG TCT CAG TAC & 35 \\
\hline $\operatorname{Gam} 42 \mathrm{a}^{4}$ & Gammaproteobacteria & GCC TTC CCA CAT CGT TT & 35 \\
\hline
\end{tabular}

${ }^{1}$ For probe specifications, see ProbeBase (http://www.microbial-ecology.net/probebase/) [40]; ${ }^{2}$ FA = Formamide;

${ }^{3}$ Used in a mix together with Eub338 II, III and IV; and ${ }^{4}$ Used together with an unlabeled oligonucleotide competitor as indicated in the reference. 
Figure S1. Scatter plot of area versus depth (z) for the assembled confocal micrographs (open circles) and Microchip compartment area as determined by light microscopy (closed circles). N.B. due to the production method the carrier area decreases with depth down to the mid-point of the carrier. That is, the total carrier compartment, from one carrier surface to the other, has a slight "waist" at the center. The area of the confocal micrographs was measured in the biofilm reference (Eub338) channel. Error bars $=95 \%$ confidence interval.

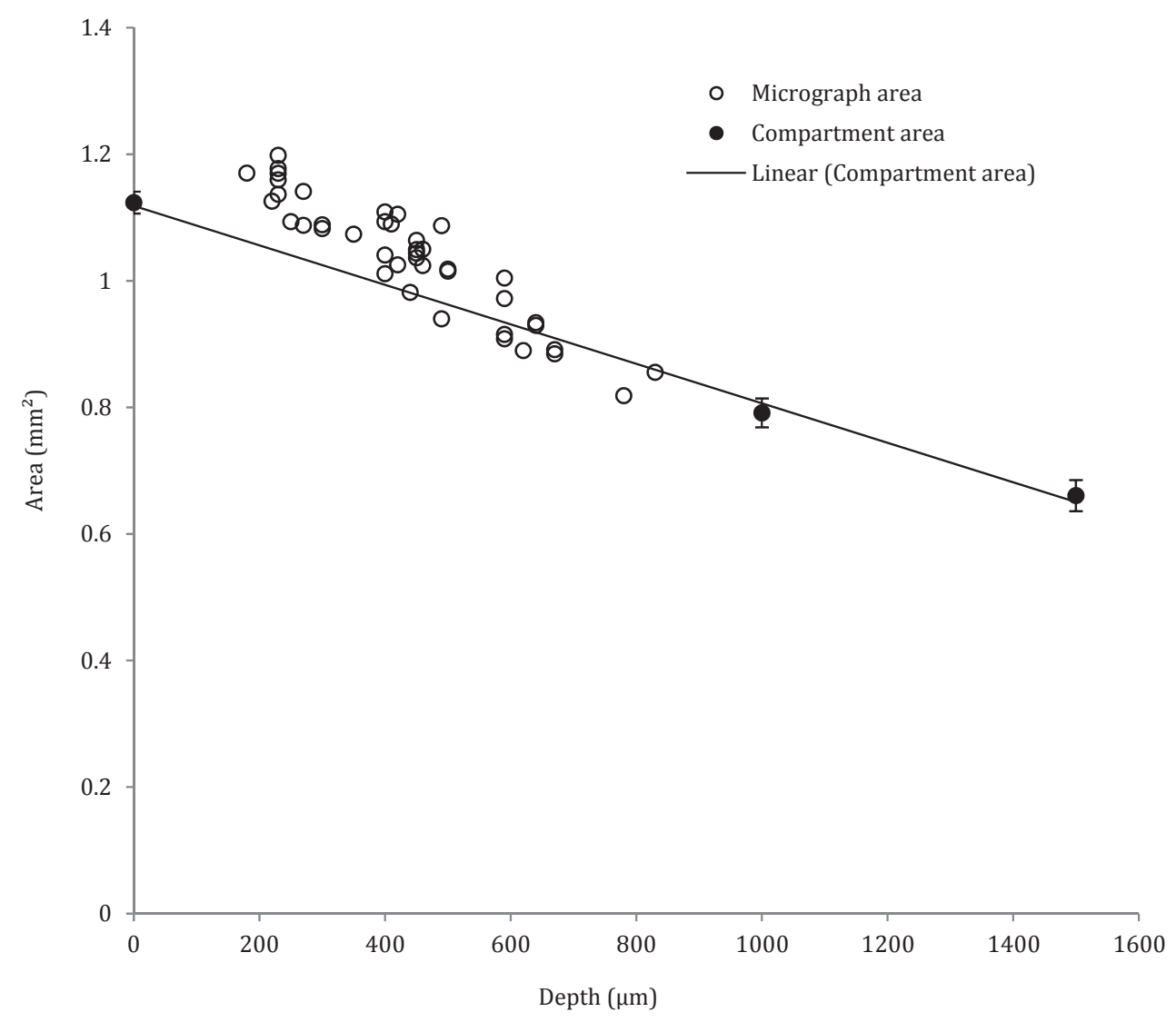


Figure S2. Scatter plot of total biomass areal density fraction $v s$. depth into the carrier. Each data point corresponds to the percentage coverage of the Eub338 probe mix, as determined by FISH, of the community in an assembled "wall-to-wall" micrograph from the indicated depth in the mature biofilm.

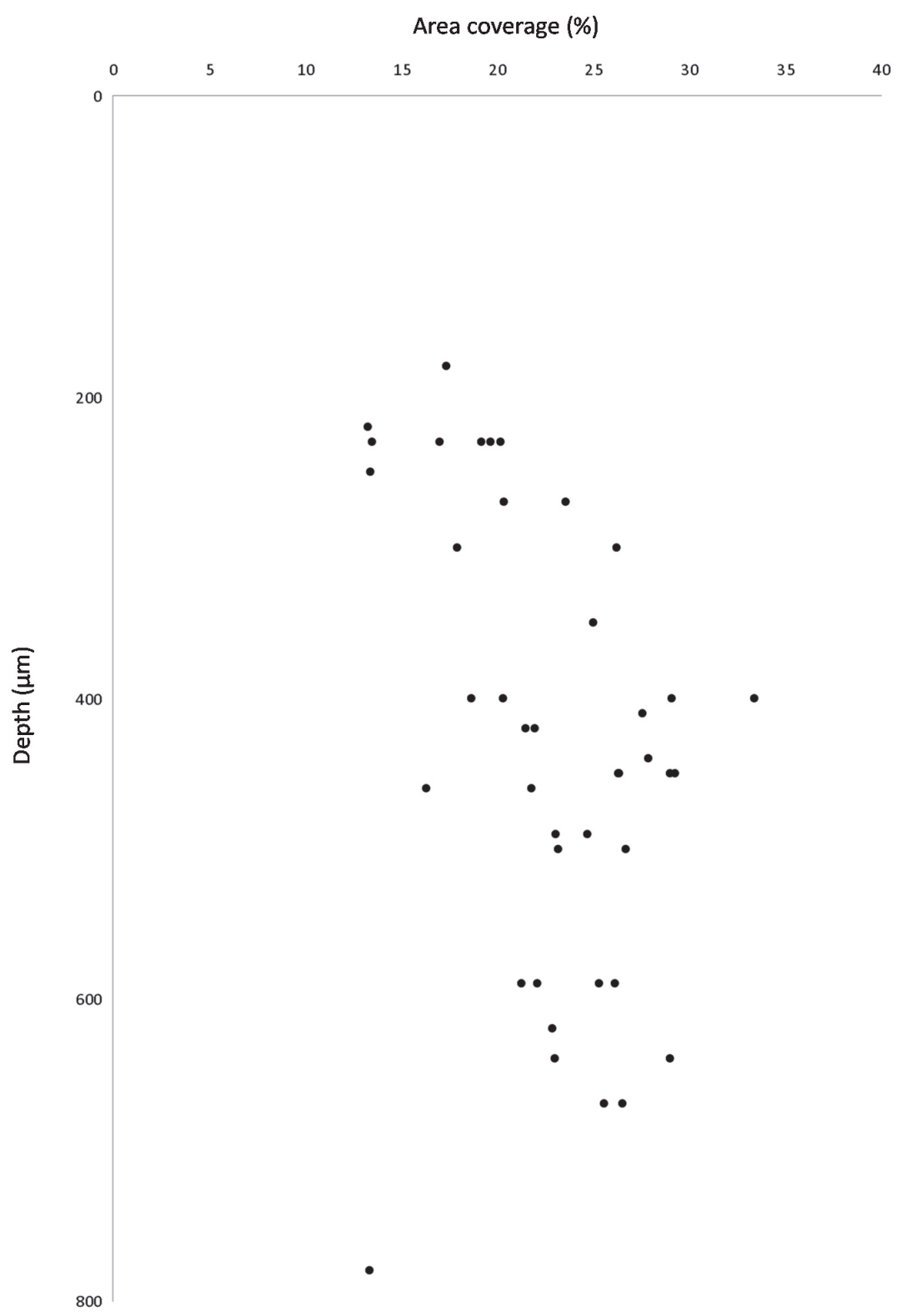

\section{Acknowledgments}

We acknowledge financial support from The Swedish Research Council for Environment, Agricultural Sciences and Spatial Planning (Formas, contract no. 214-2004-1678, 243-2008-131 and 2010-2259, 211-2010-140); The Royal Society of Sciences and Letters in Gothenburg 
(Kungliga Vetenskaps- och Vitterhetssamhället i Göteborg); Göteborgs universitets donationsfonder (contract B432 28/06); and Adlerbertska forskningsfonden (contract B432 835/07). We would like to thank the technical staff at AnoxKaldnes for sampling assistance and pilot plant maintenance. We also thank Alma Masić for valuable suggestions and discussions.

\section{Author Contributions}

M.H., M.C., R.A., F.S. initiated the project. M.H., R.A., F.S. designed the experiment and R.A., M.E., M.C. carried out the laboratory work. RA did biofilm retrieval and preparation, microscopy and image analyses, R.A., H.D., M.H., F.P., F.S. analyzed data and R.A., F.P., M.H., H.D,. B.M.W. wrote the manuscript.

\section{Conflicts of Interest}

The authors declare no conflict of interest.

\section{References}

1. Vlaeminck, S.E.; de Clippeleir, H.; Verstraete, W. Microbial resource management of one-stage partial nitritation/anammox. Microb. Biotechnol. 2012, 5, 433-448.

2. Sliekers, A.O.; Derwort, N.; Gomez, J.L.C.; Strous, M.; Kuenen, J.G.; Jetten, M.S.M. Completely autotrophic nitrogen removal over nitrite in one single reactor. Water Res. 2002, 36, 2475-2482.

3. Pynaert, K.; Smets, B.F.; Wyffels, S.; Beheydt, D.; Siciliano, S.D.; Verstraete, W. Characterization of an autotrophic nitrogen-removing biofilm from a highly loaded lab-scale rotating biological contactor. Appl. Environ. Microbiol. 2003, 69, 3626-3635.

4. Vlaeminck, S.E.; Terada, A.; Smets, B.F.; de Clippeleir, H.; Schaubroeck, T.; Bolca, S.; Demeestere, L.; Mast, J.; Boon, N.; Carballa, M.; Verstraete, W. Aggregate size and architecture determine microbial activity balance for one-stage partial nitritation and anammox. Appl. Environ. Microbiol. 2010, 76, 900-909.

5. Vazquez-Padin, J.; Mosquera-Corral, A.; Campos, J.L.; Mendez, R.; Revsbech, N.P. Microbial community distribution and activity dynamics of granular biomass in a canon reactor. Water. Res. 2010, 44, 4359-4370.

6. Winkler, M.K.H.; Kleerebezem, R.; Kuenen, J.G.; Yang, J.J.; van Loosdrecht, M.C.M. Segregation of biomass in cyclic anaerobic/aerobic granular sludge allows the enrichment of anaerobic ammonium oxidizing bacteria at low temperatures. Environ. Sci. Technol. 2011, 45, 7330-7337.

7. Ni, B.J.; Chen, Y.P.; Liu, S.Y.; Fang, F.; Xie, W.M.; Yu, H.Q. Modeling a granule-based anaerobic ammonium oxidizing (anammox) process. Biotechnol. Bioeng. 2009, 103, 490-499. 
8. Volcke, E.I.P.; Picioreanu, C.; de Baets, B.; van Loosdrecht, M.C.M. The granule size distribution in an anammox-based granular sludge reactor affects the conversion-implications for modeling. Biotechnol. Bioeng. 2012, 109, 1629-1636.

9. Vlaeminck, S.E.; Terada, A.; Smets, B.F.; van der Linden, D.; Boon, N.; Verstraete, W.; Carballa, M. Nitrogen removal from digested black water by one-stage partial nitritation and anammox. Environ. Sci. Technol. 2009, 43, 5035-5041.

10. Qiao, S.; Nishiyama, T.; Fujii, T.; Bhatti, Z.; Furukawa, K. Rapid startup and high rate nitrogen removal from anaerobic sludge digester liquor using a snap process. Biodegradation 2012, 23, 157-164.

11. Liu, T.; Li, D.; Zeng, H.; Li, X.; Liang, Y.; Chang, X.; Zhang, J. Distribution and genetic diversity of functional microorganisms in different canon reactors. Bioresour. Technol. 2012, 123, 574-580.

12. Chen, H.; Liu, S.; Yang, F.; Xue, Y.; Wang, T. The development of simultaneous partial nitrification, anammox and denitrification (snad) process in a single reactor for nitrogen removal. Bioresour. Technol. 2009, 100, 1548-1554.

13. Cho, S.; Fujii, N.; Lee, T.; Okabe, S. Development of a simultaneous partial nitrification and anaerobic ammonia oxidation process in a single reactor. Bioresour. Technol. 2011, 102, 652-659.

14. Tsushima, I.; Ogasawara, Y.; Kindaichi, T.; Satoh, H.; Okabe, S. Development of high-rate anaerobic ammonium-oxidizing (anammox) biofilm reactors. Water Res. 2007, 41, 1623-1634.

15. Plaza, E.; Stridh, S.; Örnmark, J.; Kanders, L.; Trela, J. Swedish experiences of the deammonification process in a biofilm system. In Proceedings of WEF-IWA Conference on Nutrient Recovery and Management, Miami, FL, USA, 9-12 January 2011.

16. Christensson, M.; Ekström, S.; Andersson Chan, A.; Le Vaillant, E.; Lemaire, R. Experience from start-ups of the first anita mox plants. Water Sci. Technol. 2013, 67, 2677-2684.

17. Persson, F.; Sultana, R.; Suarez, M.; Hermansson, M.; Plaza, E.; Wilén, B.-M. Structure and composition of biofilm communities in a moving bed biofilm reactor for nitritation-anammox at low temperatures. Bioresour. Technol. 2014, 154, 267-273.

18. Alpkvist, E.; Bengtsson, J.; Overgaard, N.C.; Christensson, M.; Heyden, A. Simulation of nitrification of municipal wastewater in a Moving Bed ${ }^{\mathrm{TM}}$ biofilm process: A bottom-up approach based on a 2D-continuum model for growth and detachment. Water Sci. Technol. 2007, 55, 247-255.

19. Masic, A.; Bengtsson, J.; Christensson, M. Measuring and modeling the oxygen profile in a nitrifying moving bed biofilm reactor. Math. Biosci. 2010, 227, 1-11.

20. Almstrand, R.; Daims, H.; Persson, F.; Sorensson, F.; Hermansson, M. New methods for analysis of spatial distribution and coaggregation of microbial populations in complex biofilms. Appl. Environ. Microbiol. 2013, 79, 5978-5987.

21. Kindaichi, T.; Ito, T.; Okabe, S. Ecophysiological interaction between nitrifying bacteria and heterotrophic bacteria in autotrophic nitrifying biofilms as determined by microautoradiographyfluorescence in situ hybridization. Appl. Environ. Microbiol. 2004, 70, 1641-1650. 
22. Okabe, H.; Kindaichi, T.; Nakamura, K.; Ito, T. Eco-physiology of autotrophic nitrifying biofilms. Water Sci. Technol. 2005, 52, 225-232.

23. Strous, M.; Heijnen, J.J.; Kuenen, J.G.; Jetten, M.S.M. The sequencing batch reactor as a powerful tool for the study of slowly growing anaerobic ammonium-oxidizing microorganisms. Appl. Microbiol. Biotechnol. 1998, 50, 589-596.

24. De Beer, D.; Stoodley, P.; Roe, F.; Lewandowski, Z. Effects of biofilm structures on oxygen distribution and mass transport. Biotechnol. Bioeng. 1994, 43, 1131-1138.

25. Daims, H.; Wagner, M. In situ techniques and digital image analysis methods for quantifying spatial localization patterns of nitrifiers and other microorganisms in biofilm and flocs. Method Enzymol. 2011, 496, 185-215.

26. Juretschko, S.; Timmermann, G.; Schmid, M.; Schleifer, K.H.; Pommerening-Roser, A.; Koops, H.P.; Wagner, M. Combined molecular and conventional analyses of nitrifying bacterium diversity in activated sludge: Nitrosococcus mobilis and nitrospira-like bacteria as dominant populations. Appl. Environ. Microbiol. 1998, 64, 3042-3051.

27. Koops, H.P.; Pommerening-Roser, A. Distribution and ecophysiology of the nitrifying bacteria emphasizing cultured species. FEMS Microbiol. Ecol. 2001, 37, 1-9.

28. Bollmann, A.; Bar-Gilissen, M.J.; Laanbroek, H.J. Growth at low ammonium concentrations and starvation response as potential factors involved in niche differentiation among ammonia-oxidizing bacteria. Appl. Environ. Microbiol. 2002, 68, 4751-4757.

29. Park, H.; Rosenthal, A.; Jezek, R.; Ramalingam, K.; Fillos, J.; Chandran, K. Impact of inocula and growth mode on the molecular microbial ecology of anaerobic ammonia oxidation (anammox) bioreactor communities. Water Res. 2010, 44, 5005-5013.

30. Van der Star, W.R.; Miclea, A.I.; van Dongen, U.G.; Muyzer, G.; Picioreanu, C.; van Loosdrecht, M.C. The membrane bioreactor: A novel tool to grow anammox bacteria as free cells. Biotechnol. Bioeng. 2008, 101, 286-294.

31. Egli, K.; Bosshard, F.; Werlen, C.; Lais, P.; Siegrist, H.; Zehnder, A.J.B.; van der Meer, J.R. Microbial composition and structure of a rotating biological contactor biofilm treating ammonium-rich wastewater without organic carbon. Microb. Ecol. 2003, 45, 419-432.

32. Isaka, K.; Date, Y.; Sumino, T.; Yoshie, S.; Tsuneda, S. Growth characteristic of anaerobic ammonium-oxidizing bacteria in an anaerobic biological filtrated reactor. Appl. Microbiol. Biotechnol. 2006, 70, 47-52.

33. Terada, A.; Lackner, S.; Tsuneda, S.; Smets, B.F. Redox-stratification controlled biofilm (rescobi) for completely autotrophic nitrogen removal: The effect of co-versus counter-diffusion on reactor performance. Biotechnol. Bioeng. 2007, 97, 40-51.

34. McQuarrie, J.P.; Boltz, J.P. Moving bed biofilm reactor technology: Process applications, design, and performance. Water Environ. Res. 2011, 83, 560-575. 
35. Almstrand, R.; Lydmark, P.; Sorensson, F.; Hermansson, M. Nitrification potential and population dynamics of nitrifying bacterial biofilms in response to controlled shifts of ammonium concentrations in wastewater trickling filters. Bioresour. Technol. 2011, 102, 7685-7691.

36. Lydmark, P.; Lind, M.; Sorensson, F.; Hermansson, M. Vertical distribution of nitrifying populations in bacterial biofilms from a full-scale nitrifying trickling filter. Environ. Microbiol. 2006, 8, 2036-2049.

37. Manz, W.; Amann, R.; Ludwig, W.; Wagner, M.; Schleifer, K.H. Phylogenetic oligodeoxynucleotide probes for the major subclasses of proteobacteria: Problems and solutions. Syst. Appl. Microbiol. 1992, 15, 593-600.

38. Almstrand, R.; Lydmark, P.; Lindgren, P.E.; Sorensson, F.; Hermansson, M. Dynamics of specific ammonia-oxidizing bacterial populations and nitrification in response to controlled shifts of ammonium concentrations in wastewater. Appl. Microbiol. Biotechnol. 2013, 97, 2183-2191.

39. Daims, H.; Lucker, S.; Wagner, M. Daime, a novel image analysis program for microbial ecology and biofilm research. Environ. Microbiol. 2006, 8, 200-213.

40. Loy, A.; Horn, M.; Wagner, M. Probebase: An online resource for rRNA-targeted oligonucleotide probes. Nucl. Acids Res. 2003, 31, 514-516. 


\title{
Changing Microspatial Patterns of Sulfate-Reducing Microorganisms (SRM) during Cycling of Marine Stromatolite Mats
}

\author{
Alexandru I. Petrisor, Sandra Szyjka, Tomohiro Kawaguchi, Pieter T. Visscher, \\ Robert Sean Norman and Alan W. Decho
}

\begin{abstract}
Microspatial arrangements of sulfate-reducing microorganisms (SRM) in surface microbial mats $(\sim 1.5 \mathrm{~mm})$ forming open marine stromatolites were investigated. Previous research revealed three different mat types associated with these stromatolites, each with a unique petrographic signature. Here we focused on comparing "non-lithifying" (Type-1) and "lithifying" (Type-2) mats. Our results revealed three major trends: (1) Molecular typing using the $d s r A$ probe revealed a shift in the SRM community composition between Type- 1 and Type- 2 mats. Fluorescence in-situ hybridization (FISH) coupled to confocal scanning-laser microscopy (CSLM)-based image analyses, and ${ }^{35} \mathrm{SO}_{4}{ }^{2-}$-silver foil patterns showed that SRM were present in surfaces of both mat types, but in significantly $(p<0.05)$ higher abundances in Type- 2 mats. Over $85 \%$ of SRM cells in the top $0.5 \mathrm{~mm}$ of Type- 2 mats were contained in a dense $130 \mu \mathrm{m}$ thick horizontal layer comprised of clusters of varying sizes; (2) Microspatial mapping revealed that locations of SRM and $\mathrm{CaCO}_{3}$ precipitation were significantly correlated $(p<0.05)$; (3) Extracts from Type-2 mats contained acylhomoserine-lactones (C4- ,C6- ,oxo-C6,C7,C8- ,C10- ,C12-, C14-AHLs) involved in cell-cell communication. Similar AHLs were produced by SRM mat-isolates. These trends suggest that development of a microspatially-organized SRM community is closely-associated with the hallmark transition of stromatolite surface mats from a non-lithifying to a lithifying state.
\end{abstract}

Reprinted from Int. J. Mol. Sci. Cite as: Petrisor, A.I.; Szyjka, S.; Kawaguchi, T.; Visscher, P.T.; Norman, R.S.; Decho, A.W. Changing Microspatial Patterns of Sulfate-Reducing Microorganisms (SRM) during Cycling of Marine Stromatolite Mats. Int. J. Mol. Sci. 2014, 15, 850-877.

Abbreviations: SRM, sulfate-reducing microorganisms; EPS, extracellular polymeric secretions; AHL, acylhomoserine lactones; QS, quorum sensing; $\mathrm{CaCO}_{3}$, calcium carbonate; FISH, fluorescence in-situ hybridization; GIS, geographical information systems; CSLM, confocal scanning laser microscopy; daime, digital-image analysis in microbial ecology.

\section{Introduction}

Microbial mats exhibit dense horizontal arrays of different functional groups of bacteria and archaea living in microspatial proximity. The surface mats of open-water marine stromatolites (Highborne Cay, Bahamas) contain cyanobacteria and other common microbial functional groups such as aerobic heterotrophs, fermenters, anaerobic heterotrophs, notably sulfate reducing microbes and 
chemolithotrophs like sulfur oxidizing microbes $[1,2]$. This community cycles through three different mat types and collectively constructs organized, repeating horizontal layers of $\mathrm{CaCO}_{3}$ (i.e., micritic laminae and crusts), with different mineralogical features depending on community types $[3,4]$.

Marine stromatolites represent dynamic biogeochemical systems having a long geological history. As the oldest known macrofossils on earth [5], extant marine stromatolites are still forming in isolated regions of shallow, open-water marine environments and are now known to result from microbially-mediated processes [4]. Stromatolites are ideal systems for studying microbial interactions and for examining mechanisms of organized biogeochemical precipitation of horizontal micritic crusts [4]. Interactions within and between key functional groups will be influenced, in part, by their microspatial proximities.

The surface microbial mats of Bahamian stromatolites are fueled by cyanobacterial autotrophy [6,7]. The surface communities of the mats repeatedly cycle through several distinct stages that have been termed Type-1, Type-2 and Type-3, and are categorized by characteristic changes in precipitation products, as outlined by Reid et al. [4]. Type-1 (binding and trapping) mats represent a non-lithifying, accretion/growth stage that possesses an abundant (and sticky) matrix of extracellular polymeric secretions (EPS) largely produced by cyanobacteria [8]. The EPS trap concentric $\mathrm{CaCO}_{3}$ sediment grains called ooids, and promote an upward growth of the mats. Small microprecipitates are intermittently dispersed within the EPS [9]. This accreting community typically persists for weeks-to-months then transforms into a community that exhibits a distinct bright-green layer of cyanobacteria near the mat surface. Concurrently the surface EPS becomes a "non-sticky" gel and begins to precipitate small patches of $\mathrm{CaCO}_{3}$. This morphs into the Type-2 (biofilm) community, which is visibly different from a Type- 1 community in having a non-sticky mat surface and a thin, continuous (e.g., 20-50 $\mu \mathrm{m}$ ) horizontal lithified layer of $\mathrm{CaCO}_{3}$ (i.e., micritic crust). Type-2 mats are thought to possess a more-structured microbial biofilm community of sulfate-reducing microorganisms (SRM), aerobes, sulfur-oxidizing bacteria, as well as cyanobacteria, and archaea [2]. Studies have suggested that SRM may be major heterotrophic consumers in Type-2 mats, and closely linked to the precipitation of thin laminae $[1,10]$. The lithifying stage sometimes further progresses into a Type-3 (endolithic) mat, which is characterized by abundant populations of endolithic coccoid cyanobacteria Solentia sp. that microbore, and fuse ooids through dissolution and re-precipitation of $\mathrm{CaCO}_{3}$ into a thick contiguous micritized layer $[4,10]$. Intermittent invasions by eukaryotes can alter the development of these mat systems [11].

Over past decades a growing number of studies have shown that SRMs can exist and metabolize under oxic conditions [12-18]. Studies have shown that in marine stromatolites, the carbon products of photosynthesis are rapidly utilized by heterotrophic bacteria, including SRM $[1,4,8,19]$. During daylight, photosynthesis mat surface layers generate very high concentrations of molecular oxygen, mostly via cyanobacteria. Despite high $\mathrm{O}_{2}$ levels during this time, SRM metabolic activities continue [13,16], accounting for as much as ten percent of total SRM daily carbon requirements. During darkness HS- oxidation under denitrifying conditions may lead to $\mathrm{CaCO}_{3}$ precipitation $[1,20]$. Studies showed that concentrations of $\mathrm{CaCO}_{3}$ precipitates were significantly higher in Type-2 (than in Type-1) mats [21]. 
Using ${ }^{35} \mathrm{SO}_{4}$ radioisotope approaches, Visscher and colleagues showed that sulfate reduction activities in Type-2 mats could be spatially aligned with precipitated lamina [10]. This has posited an important role of the SRM in the precipitation of laminae in Type-2 stromatolite mats. A similar role for SRM in precipitation of carbonate laminae has been described in lithifying hypersaline mats [22-24].

The development of a diverse, spatially-organized microbial community is often dependent upon interactions among its resident organisms and their physiochemical environment. Laboratory culture studies show that when bacteria are abundant and in spatial proximity they produce chemical signals, which are used to sense nearby cell densities and to coordinate gene expression among groups of cells in a process called quorum sensing [25]. More recently, a diverse array of chemical signals called acylhomoserine lactones (AHLs) were identified in the surface layers of stromatolite mats [26]. While quorum sensing is now a well-established process in laboratory cultures of bacteria, it is largely unexplored among the SRM [27] and its roles in natural communities are poorly understood [28,29].

Summarizing, SRM are likely to be an important regulatory component in the development and evolution of stromatolite mats [10], and in their precipitation of micritic crusts and laminae [1,22,23,30]. However, analyzing microspatial distributions of bacteria within intact microbial mats has been problematic. Here, we hypothesized that the SRM spatially organize in surface mats, communicate and coordinate activities using chemical signaling, and may be microspatially-associated with the precipitation of horizontal micritic crusts in Type- 2 mats. Our study was designed to examine changes in the community, and in situ microspatial arrangements of SRM in non-lithifying (i.e., Type-1) and lithifying (Type 2) stromatolite mats using fluorescence in-situ hybridization (FISH) probing coupled with confocal scanning laser microscopy (CSLM). Image-analyses, specifically using Geographical Information Systems (GIS) [31] and Digital image Analysis in Microbial Ecology (Daime; [32]) programs were employed to detect and compare changing microspatial arrangements of bacteria.

\section{Results and Discussion}

\subsection{Overall Summary}

Changes in the relative abundances and activities of specific functional groups of bacteria can be an important determinant for influencing elemental cycling and even the broader ecology of microbial mat systems [33]. In the open-water stromatolite mats of the Bahamas, the present study showed that the alternating stages of non-lithifying (Type-1) and lithifying (Type-2) surface mats possessed very different spatial distributions of bacteria, especially within the sulfate-reducing microorganism (SRM) clade. The classic Type-1 mats showed dispersions of cyanobacteria and heterotrophic bacteria, including the SRM, that were relatively random. As Type-1 mats transitioned into Type-2 mats the heterotrophic community, especially the SRM, became more abundant. Using GIS analyses, the area occupied by SRM cells in Type 2 mats was found to be double that of their Type-1 counterparts. Cells also became more microspatially-organized in Type- 2 mats. This was accompanied by an increased frequency of cell clustering. Further, the relative sizes of clusters increased in Type- 2 mats, eventually 
forming an almost contiguous thin $(130 \mu \mathrm{m})$ horizontal layer of SRM at the uppermost mat surface. This suggested an increasing community organization. Development of this dense heterotrophic layer was concurrently associated with precipitation of $\mathrm{CaCO}_{3}$, the production of cell-cell chemical signals, and a dramatic shift in the phenotypic properties of the mats.

\subsection{Properties of Type-1 and Type-2 Mats}

Light microscopy examinations of mat surfaces showed that Type-1 mats of stromatolites were characterized by an irregular and adherent surface (i.e., Type-1 mat; Figure 1A), which collects sediment grains (i.e., carbonate ooids) within a matrix of extracellular polymers (EPS). The EPS matrix is known to enhance light penetration into the mat [34]; a process that is associated with the physical stabilization of the mat since EPS often increases the cohesive properties of sediments [35]. Oxygen profiles show a diffuse zone of photosynthesis and ${ }^{35} \mathrm{SO}_{4}{ }^{2-}$-labeled silver (Ag) foils indicated few SRM were present in the upper mm of the mat (Figure 1A, lower panel). This was followed by the appearance of a thin (30-50 $\mu \mathrm{m}$ thick) crust of $\mathrm{CaCO}_{3}$ precipitate (i.e., Type-2 mat; Figure 1B). The macroscopic appearance of the two types of mat surfaces was easily distinguishable under low magnification (i.e., 70-150×) using a dissecting microscope.

Figure 1. Light micrographs of cross-sections showing surfaces of Type-1 and Type-2 stromatolite mats. Light micrographs of a Type-1 mat (A) show an irregular "sticky" EPS-laden surface that accretes ooid grains, while the Type-2 mat $(\mathbf{B})$ is characterized by a "non-sticky, white precipitate" crust on the surface. Three ooids have been artificially placed on the Type-2 surface crust to further illustrate the precipitate. Scale bars $=500 \mu \mathrm{m}$. Lower panels show 2D images $1 \times 1 \mathrm{~mm}$ in size of the surface of both mats (light grey line indicates the mat surface). Images were generated from ${ }^{35} \mathrm{SO}_{4}{ }^{2-}$ silver (Ag) foil experiments. Mat cross-sections were incubated on silver foil impregnated with the sulfate radioisotope. SRM reduce the ${ }^{35} \mathrm{SO}_{4}{ }^{2-}$ to ${ }^{35} \mathrm{~S}^{2-}$, which precipitates as $\mathrm{Ag}^{35} \mathrm{~S}$ is was visualized with radiography. Black pixels indicated areas of intense sulfate reducing activity.
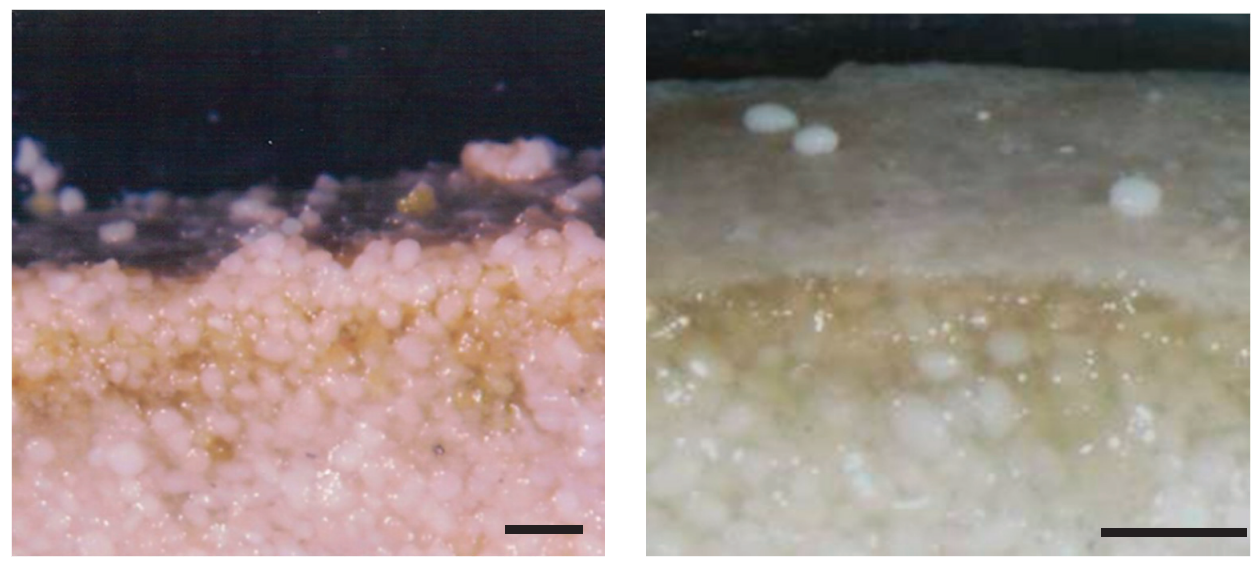
Figure 1. Cont.

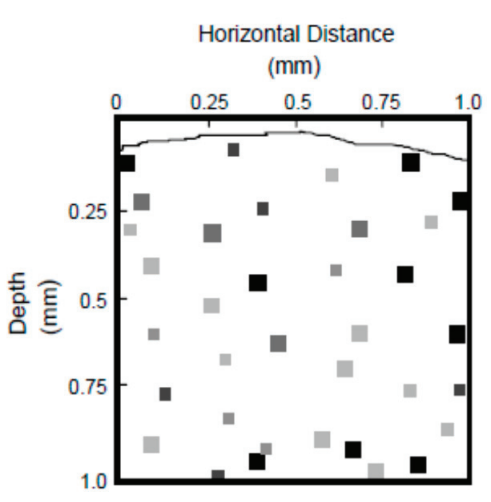

(A) Type-1

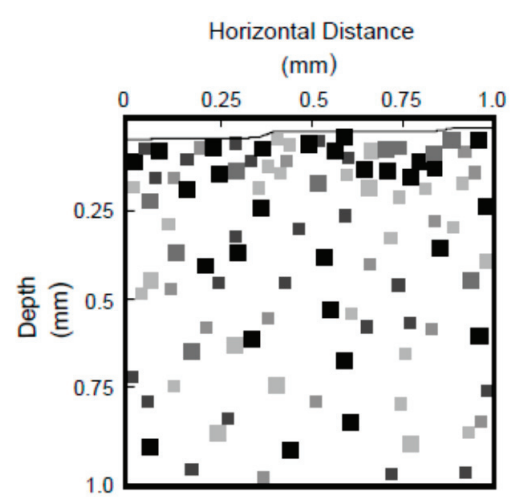

(B) Type-2

\section{3. dsrA Oligoprobing}

Our study utilized the $d s r A$ oligoprobe to conservatively target SRM, including the sulfate-reducing bacteria. Sulfate reduction is known to occur in a wide range of bacteria, and some Archaea [36,37]. Through examinations of intact mat sections, and the coupling of fluorescence in situ hybridization (FISH) with confocal scanning laser microscopy (CSLM), and geographical information systems (GIS) analyses, it was possible to examine the in situ organization of SRM cells over microspatial scales and how the organization of this microbial functional group changed in different mat types within the stromatolite system. We showed that SRM were present in the upper-most surface layers of both Type-1 and Type-2 mats. However, within Type-1 mats, SRM cell abundances were comparatively lower, and SRM cells were relatively randomly dispersed within the EPS matrix. This was confirmed by the ${ }^{35} \mathrm{SO}_{4}{ }^{2-}-\mathrm{Ag}$ foil observations (Figure 1B, lower panel). In contrast, distributions of cells within Type-2 mats showed that SRM became increasingly more abundant and more-clustered in their distribution, especially within the uppermost mat surface. The $d s r A$ probe and ${ }^{35} \mathrm{SO}_{4}{ }^{2-}$-Ag patterns are both in agreement for Type-2 mats as well.

The use of fluorescently-labeled rDNA oligo-probes for determinations of specific microbial cells in complex media presents several inherent obstacles [38,39]. The first relates to non-specific binding of probes in the complex media. Second, the signal intensity of a given cell is directly linked to ribosomal content and hence physiological activities of cells at the time of fixation. However, oligoprobes can be very useful for evaluation of changing spatial patterns of microorganisms $[39,40]$. To further examine the specificity of our $d s r A$ oligoprobe, sections of Type-1 and Type- 2 mats were imaged at higher magnifications (e.g., $600 \times$ to $1000 \times$ ). Co-localized fluorescence of the oligoprobes (indicative of SRM cells) and also DAPI (4',6-diamidino-2-phenylindole, dihydrochloride) or PI (propidium iodide) were used to determine cell-specific binding of oligoprobes and to remove non-specific fluorescence signatures. Hence, cell areas containing both fluorescence signatures were counted as SRM cells. 
This allowed us to reduce the effects of non-specific binding of oligoprobes, and to digitally remove most of the non-specific binding effects in estimations of cell abundances.

\subsection{Relative Abundances of SRM}

Significantly ( $p<0.05$; Student's $t$-test) higher abundances of SRM cells were observed in the surfaces of Type-2 mats when compared with Type-1 mats. Using geographical information systems (GIS) analyses, abundances of cells were determined as a function of "fluorescence area" occupied by SRM cells relative to other fractions of the microbial community. Statistical analyses (Student's $t$-test) compared the portion of the total microbial community that was SRMs located within the top $130 \mu \mathrm{m}$ of the two mat types. Appropriate transformations were made, where necessary, to normalize data for parametric tests. Relative abundances of SRMs in surfaces of Type-1 and Type-2 mats were expressed as a mean $( \pm \mathrm{SE})$ percent $(\%)$ of total cell areas attributable to SRM within the uppermost $130 \mu \mathrm{m}$ of the mats. Results of a student $t$-test showed the surfaces of Type- 2 mats $(88.0 \% \pm 14.2 \% ; n=31$ images analyzed) contained a significantly $(p<0.0001)$ higher abundance of cells (based on cell area) than Type- 1 mats $(39.7 \% \pm 27.5 \% ; n=21)$. The results indicated that as the Type- 1 community transitions into a Type- 2 community, a significantly larger proportion of the total bacteria community (in Type-2 mats) were SRM.

\subsubsection{SRM as Portion of Total Microbial Cells}

Using direct counts of DAPI-stained cells we further confirmed that higher abundances of all microbial cells (i.e., SRM, other bacteria, archaea) occurred in surfaces of Type-2 mats, when compared with Type-1 mats. The SRM comprised greater than half of the total microbial cells extractable from surface Type-2 mats. When cells were extracted from Type-2 mats and direct counts were estimated using either DAPI-staining or propidium-iodide-staining and compared to SRM cell counts using $d s r A$-staining, the SRMs represented $55.9 \% \pm 20.0 \%$ and $56.1 \% \pm 16.2 \%$ (mean \pm SE), respectively, of the total bacteria cells detected. In contrast, SRM cells in Type-1 mats (as estimated using $d s r A$ ) comprised only $20.7 \% \pm 9.3 \%$ of the total microbial cells. These observations were confirmed by the ${ }^{35} \mathrm{SO}_{4}{ }^{2-}-\mathrm{Ag}$ foil observations that documented a 2D distribution of sulfate reducing activity (Figure $1 ;[10]$ ).

Image analyses revealed interesting spatial patterns of bacteria. Images were collected from cross-sections of surface mats and focused analyses from the immediate mat surface to approximately $0.75 \mathrm{~mm}$ depth. Additionally, we analyzed spatial variability of the surface over a full horizontal distance of $850 \mu \mathrm{m}$. This allowed us to examine two-dimensional spatial patterns (e.g., horizontal layering, clustering, and dispersion) over relatively large regions of the uppermost surface of Type-1 and Type-2 mats (Figure 2A1,B1). Higher magnifications $(1000 \times)$ were then used to examine smaller scale (e.g., 1 to $50 \mu \mathrm{m}$ ) patterns and clustering of cells (Figure 2A2,B2). 
Figure 2. Confocal scanning laser micrographs (CSLM) illustrating relative changes microspatial distributions of SRM cells near the surface of (A1,A2) Type-1 (i.e., relatively-scattered) and (B1,B2) Type-2 (i.e., highly-clustered) mats. Images are cross-sections of surface mats showing SRM cells (green fluorescence; $d s r A$ FISH probe), heterotrophic bacteria (red fluorescence stained with propidium-iodide (PI)) and cyanobacteria (red autofluorescence), and ooid sediment grains (artificial blue-color). Yellow circles illustrate typical clustering of SRM cells. Scale bars in $\mathbf{A 1}$ and $\mathbf{B} 1=100 \mu \mathrm{m}$; in $\mathbf{A} \mathbf{2}$ and $\mathbf{B} 2=10 \mu \mathrm{m}$.

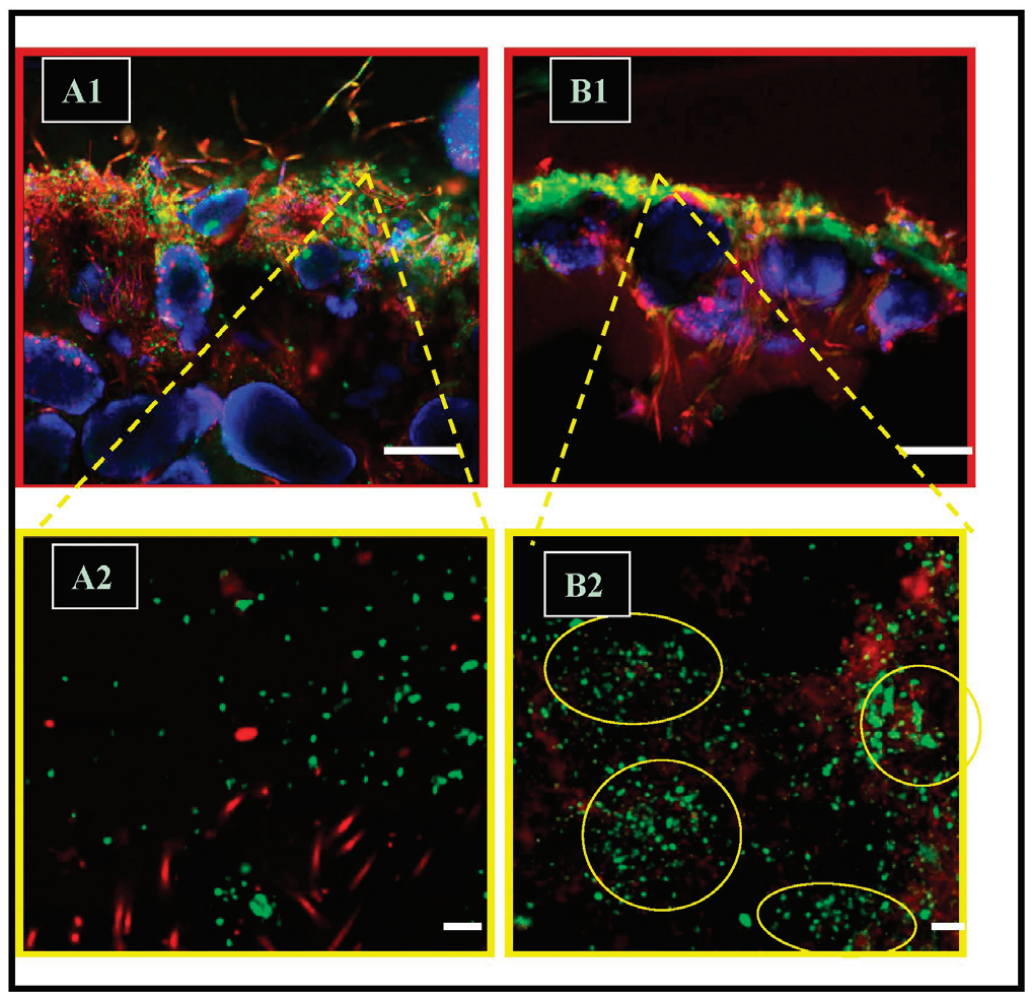

\subsection{Precipitation Patterns: Microspatial Associations of SRMs and Precipitates}

A highly-significant $(p<0.05$; Student's $t$-test) statistical difference was detected in the areas occupied by precipitates. Results showed that precipitates were less abundant, in terms of area, in Type-1 mats when compared with Type-2 mats.

Based on the assumption that precipitation of $\mathrm{CaCO}_{3}$ was related to SRM activities, we examined the microspatial locations of SRM cells and $\mathrm{CaCO}_{3}$ precipitates within images from both Type- 1 and Type-2 mats. A significant $(p<0.05)$ correlation $(r=0.757)$ was found linking SRM and $\mathrm{CaCO}_{3}$ precipitates within the same image $(n=34)$. In both Type- 1 and Type- 2 mats, there was a close microspatial association of SRM cells and $\mathrm{CaCO}_{3}$ precipitates with SRMs constituting over $80 \%$ of microbial cells that were located within a $4.4 \mu \mathrm{m}$ distance of precipitates (Figure 3). Most of these cells occurred within a $1.1 \mu \mathrm{m}$ distance (Table 1). This is noteworthy because although precipitates occur to 
a limited extent in Type-1 mats, SRM were still closely-associated with the precipitates that were present. This suggested a close relationship of SRMs and the precipitation process in both mat types.

Figure 3. Box-plot showing the percent of area occupied by all microbial cells, which were SRM. Results show that in Type- 2 mats, over $80 \%$ of microbial cells (based on area occupied) were SRM. Note: Type-1 mats $(n=21)$ and Type-2 mats $(n=31)$; tails represent 95\% confidence intervals $(\mathrm{CI})$.

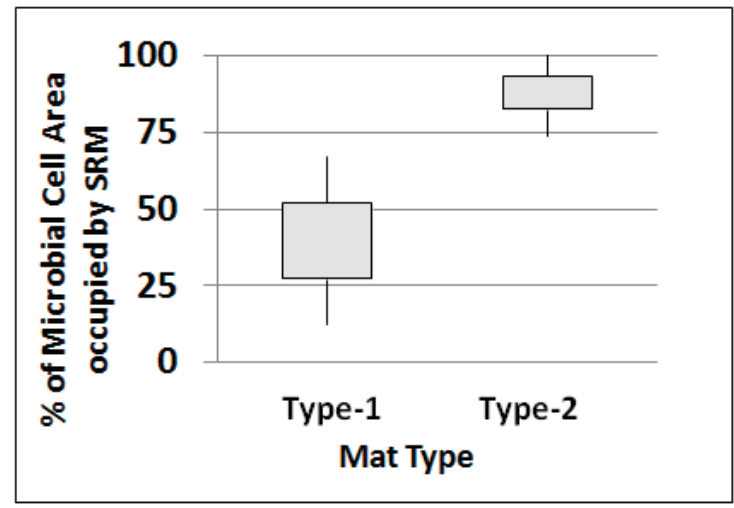

Table 1. Microspatial proximity between $\mathrm{SRMs}$ and $\mathrm{CaCO}_{3}$ precipitates in Type-1 and Type- 2 mats. Table shows percentages of total bacteria, located within 1.1, 2.2, or $4.4 \mu \mathrm{m}$ distances from precipitates, which were SRM. Note that wherever precipitates occurred, greater than $82 \%$ of bacteria in proximity to precipitates were SRM. ( $n=$ number of samples analyzed; $p$-value represents results of ANOVA $F$-test). Type- 1 mats were found to be significantly different from Type-2 $(p<0.05)$. ${ }^{*}=$ designates statistical significance at $p \leq 0.05$.

\begin{tabular}{|c|c|c|c|c|c|c|}
\hline \multirow{3}{*}{$\begin{array}{l}\% \text { Bacteria near } \\
\text { precipitates that } \\
\text { were SRMs }\end{array}$} & \multicolumn{6}{|c|}{ Distance of SRM cells from $\mathrm{CaCO}_{3}$ Precipitates } \\
\hline & \multicolumn{2}{|c|}{$\leq 1.10 \mu \mathrm{m}$} & \multicolumn{2}{|c|}{$\leq 2.20 \mu \mathrm{m}$} & \multicolumn{2}{|c|}{$\leq 4.40 \mu \mathrm{m}$} \\
\hline & $\begin{array}{c}\text { Type- } 1 \\
(n=12)\end{array}$ & $\begin{array}{c}\text { Type-2 } \\
(n=29)\end{array}$ & $\begin{array}{c}\text { Type- } 1 \\
(n=12)\end{array}$ & $\begin{array}{c}\text { Type- } 2 \\
(n=29)\end{array}$ & $\begin{array}{c}\text { Type-1 } \\
(n=12)\end{array}$ & $\begin{array}{c}\text { Type- } 2 \\
(n=29)\end{array}$ \\
\hline Mean & $82.29 *$ & 95.51 & $82.71 *$ & 95.78 & $85.36 *$ & 96.16 \\
\hline$( \pm \mathrm{SE})$ & \pm 29.92 & \pm 7.60 & \pm 29.98 & \pm 7.37 & \pm 25.23 & \pm 7.11 \\
\hline
\end{tabular}

It is important to note that in observing both Type- 1 and Type- 2 natural mats, variability existed over small spatial scales in the patterns of cells and precipitation products. This is likely a result of the localized interactions between bacteria and their environment. While this variability may be adaptive, in an ecological sense, it resulted in having to examine a large number of images to acquire sufficient statistical power for examination of potential differences (if present). Examination of the vertical distribution of SRMs situated within the top $500 \mu \mathrm{m}$ indicated that the majority (over 85\%) of SRM cells were located in the top $130 \mu \mathrm{m}$ of the surface of Type-2 mats. These results suggest that SRM distributions may be used as an instrument of discrimination for categorization between Type-1 and Type-2 mats, with higher surface abundances of SRM occurring in Type-2 mats. 


\subsection{Phylogenetic Analysis of the dsrA Sequences}

Phylogenetic relationships of $d s r A$ gene sequences retrieved from Type-1 and Type-1-2 stromatolite mats revealed an overall low diversity (Figure 4). Type-1 $d s r A$ clone sequences formed 9 different phylogenetic groups with nearly $72 \%$ of clone sequences located in a single clade most similar to $d s r A$ genes of the Gram-negative delta-proteobacteria Desulfovibrio. Type-2 dsrA clones formed 6 different phylogenetic groups with nearly $83 \%$ of all clone sequences located in a single clade most similar to the delta-proteobacteria Desulfomonile tiedjei and other uncultured SRM capable of autotrophic growth. Most of the few remaining $d s r A$ clone sequences formed monophyletic lineages that were distinct for either Type-1 or Type- 2 stromatolite mats and included sequences similar to the deeply branching Thermodesulfovibrio yellowstonii and other uncultured sulfate-reducing bacteria. Preliminary 16S rDNA investigations of SRM diversity in a hypersaline lake with lithifying and non-lithifying mats [22], showed a dominance of delta-proteobacteria ( $91 \%$ and $64 \%$ of total diversity in lithifying and non-lithifying mats, respectively [2]. In this study, a wider diversity of delta-proteobacteria was observed in the lithifying mats when compared to non-lithifying mats and SRM activity was associated with the upper layer of the mats that were forming a $\mathrm{CaCO}_{3}$ crust. This suggests that patterns observed in this study could apply to other lithifying systems as well.

\subsection{Microspatial Clustering Analyses}

Clustering, defined here as the aggregation of cells in spatial proximity, is likely an important parameter for assessing the microbial communities of stromatolites. When microbial cells are clustering together in proximity it increases their ability to interact in both positive and negative manners. Such clusters may provide a suitable proxy indicative of chemical communications, such as quorum sensing (QS) [25] and/or efficiency sensing [41]; processes that bacteria and other microorganisms likely utilize under natural conditions, especially within biofilms (e.g., microbial mats). SRM are physiologically challenged by the exposure to high $\mathrm{O}_{2}$ levels at the surface of the mats where their activity peaks (see [2] for review). It is thought that this high activity is supported by abundant organic carbon, especially low-molecular weight compounds $[8,19]$. Recently QS signals have been extracted from marine stromatolite mats [26]. QS signals could be correlated with SRM and were postulated to play an important role in enabling these anaerobes to cope with $\mathrm{O}_{2}$ concentrations that are deleterious to their physiology [42]. QS contributes to the coordination of gene expression and metabolic activities by neighboring cells, and may play important roles in the development of microbial consortia under natural conditions [42]. In other systems, QS signaling has been shown to be detectable by cells at distances extending up to 73 $\mu \mathrm{m}$ [43]. A second benefit of chemical communication resides in efficiency sensing, often considered an extended form of quorum sensing. Efficiency sensing, however, provides cells with the ability to assess the diffusional properties of their proximal extracellular environment [41]. Finally, clustering invokes a new (and smaller) spatial scale perspective for understanding the formation of sharp geochemical gradients and the efficiency of elemental cycling that are characteristic of mats. 
Figure 4. Phylogenetic tree based on translated amino acid sequences of PCR-amplified dissimilatory sulfite reductase $d s r A$ genes retrieved from type I and type II stromatolites. Tree shows distributions of clones related to known sulfur-reducing bacteria and closely related sequences obtained from the GenBank database. GenBank accession numbers are shown in parentheses for non-collapsed branches and are as follows for collapsed branches: a AFA43406, EU127914, BAB55577, AFA43404, BAB55579, AB061543; ${ }^{\mathrm{b}}$ ACI31420, ABK90679; ' ABK90745, AF334595, ABK90741, ABK90691, AAO61116, ABK90759; ' AF271769, AF273029; ' AF271771, AF334598; ${ }^{\mathrm{f}}$ AF418193, CAY20641, CAY20696; ${ }^{\mathrm{g}}$ YP003806924, AAK83215, AF334600; h AEX31202, CAJ84858, CAQ77308; i ACJ11472, CAJ84838, ACJ11485, ABK90809. The tree was constructed using the maximum likelihood method in MEGA 5 with values at nodes representing bootstrap confidence values with 1000 resamplings. Bootstrap values are shown for branches with more than $50 \%$ bootstrap support. Scale bar represents 0.1 substitutions per site.

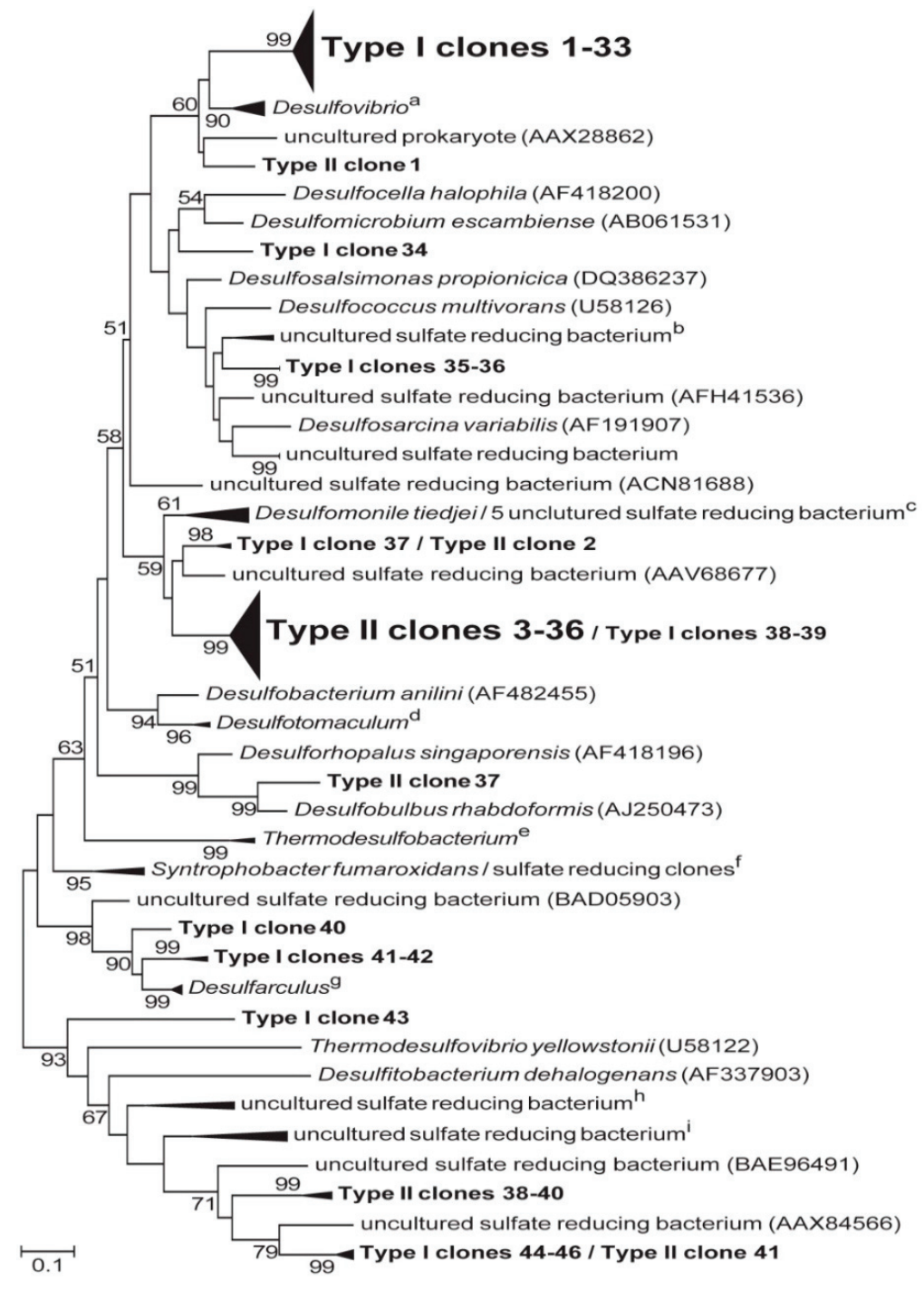


We were able to show that SRM showed little- or no-clustering in Type-1 mats but that very well-developed clustering occurred in Type-2 mats. The rapid upward growth (accreting) nature of Type-1 mats may not allow for such spatial organization to develop. The microspatial organization of cells into clusters (i.e., groups of cells in proximity) was discernible at several spatial scales. Imaging using CSLM was coupled to the general labeling of cells using DAPI and PI, and more specific labeling using FISH targeting the SRM group. Using this approach, two different spatial scales of clustering became detectable. At relatively low magnifications (e.g., 200×) the distinctly higher abundances of SRMs were easily visualized near the surface of Type-2 mats (Figure 2). The non-lithifying Type-1 mats exhibited lower abundances and a relatively "random" distribution of SRM, and other bacteria, when compared with the non-random organization of bacteria in Type-2 mats. Overall differences determined by ANOVA were significant $(F=33.55, p \leq 0.05)$. All aposteriori specific tests (Bonferroni, and Scheffé) placed Type-1 different from the Type-2 mats, the latter of which exhibited significantly greater abundances of SRMs. At higher magnifications it became apparent that the Type2 mat community exhibited an increase in clustering and microspatial organization, especially with regard to the SRM functional group (Figure 2). The frequency of SRM cell clusters increased, when compared with Type-1. Finally, the mean size (and variance) of clusters also increased as mats develop from a Type- 1 to a Type- 2 state, implying that some clusters became quite large. This occurred in the uppermost $50 \mu \mathrm{m}$ of the surface biofilm.

These patterns were supported by image analyses using GIS [44] and Daime [32,45] programs and resulted in statistically $(p<0.001)$ higher abundances of SRM in the surfaces of Type-2 mats (when compared with Type-1). Two different, but complementary, methodological approaches (i.e., Daime and GIS) were used in this study to detect microspatial clustering of cells.

\subsubsection{The Daime Approach}

The first approach, the Daime program [32], allowed us to examine all cell-cell distances within an image and graph the distances. Analyses of SRM spatial arrangements showed that in Type-1 mats (Figure 5A), the pair cross-correlation index $g(r)$ was close to 1 for cell-to-cell distances ranging from 0.1 to $6.44 \mu \mathrm{m}$, which is indicative of a relatively random distribution. A flat line $(r=1)$ was indicative of a relatively random distribution, where all cell-cell distances were equally probable. In Type- 2 mats (Figure 5B), by contrast, the pair cross-correlation index was above 3 at a distance 0.36 $\mu \mathrm{m}$, and rose to 52 at cell-cell distances of $0.03 \mu \mathrm{m}$. These data indicated that the SRM had a high degree of clustering, especially where cell-cell distances were very short. It can be inferred from these data that clusters were abundant in Type-2 mats and that the cells within SRM clusters were in very close proximity (i.e., from 0.03 to $0.36 \mu \mathrm{m}$ ). Overall, when comparing cell distributions in Type-1 and Type- 2 surface mats, there was increased clustering observed in Type- 2 mats. 


\subsubsection{The GIS Approach}

A second approach utilized GIS examined clustering of SRM cells within the surfaces of Type-1, and Type- 2 mats. For each image a buffer area was created that extended from the surface of the mat to approximately $130 \mu \mathrm{m}$ depth. Detection of SRM cells within the buffer area was based on color (as described above) using image classification of FISH-probed cells. A concentric region having a $10 \mu \mathrm{m}$ diameter was generated around each cell. A cluster represented a group of cells having overlapping concentric regions. Subsequent statistical selection of clusters was subjectively based on cluster areas representing greater than five cells having overlapping concentric regions. The size (i.e., area) of each detected cell cluster was measured. While the two methods utilize different approaches to detect clustering, both revealed a similar inference-increased clustering present in Type-2 mats.

Figure 5. Microspatial clustering arrangements of SRM cells located in the surfaces of stromatolite mats using Daime analyses. The graphs exhibit the pair cross-correlation function $g(r)$ for SRM cells. (A) In Type-1 mats, the relatively horizontal line where $g(r)$ approximates 1 indicates relatively random SRM distributions over cell-cell distances ranging from 0.1 to $6.44 \mu \mathrm{m}$; (B) In Type- 2 mats, values of $g(r)$ above 1 indicate a high degree of clustering of SRM cells, especially over short (e.g., 0.03 to $0.36 \mu \mathrm{m}$ ) cell-to-cell distances. This indicates that cells in Type- 2 mats are clustered closely together.
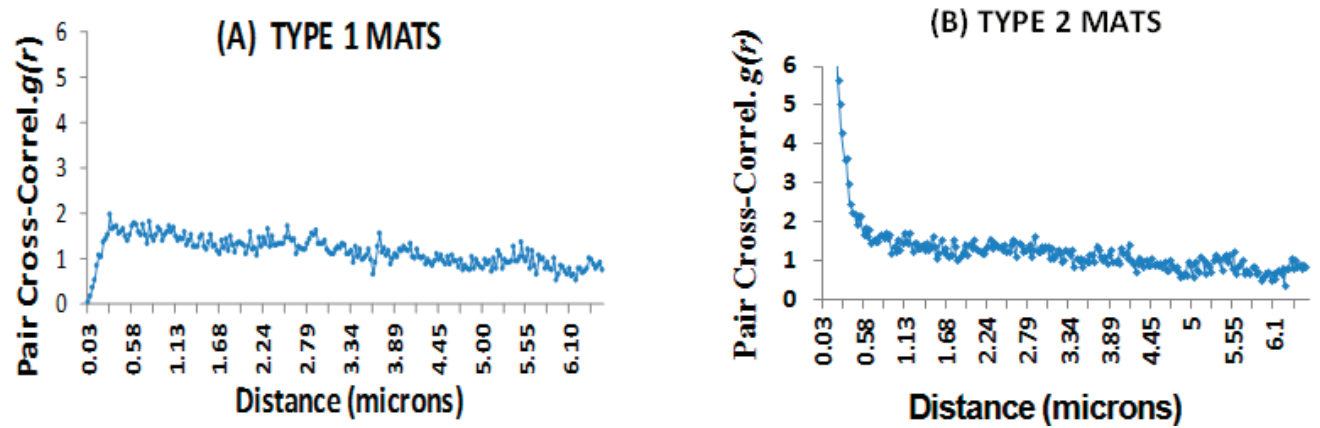

Finally, the size distribution of SRM clusters (including individual cells) was statistically analyzed using samples of 20 images that were randomly selected from microspatial regions within images from each mat type (Type-1, Type-2, and incipient Type-2) labeled with the $d s r A$ oligoprobe. Type-2 exhibits the largest clusters (Figure 6). The mean cluster size was comparatively small in Type-1 mats and large in Type- 2 mats. Variability followed the same pattern, increasing from Type- 1 to Type- 2 .

\subsubsection{Image Analyses}

Proper image interpretation was needed to examine microscopic spatial patterns of cells within the mats. We employed GIS as a tool to decipher and interpret CSLM images collected after FISH probing, due to its power for examining spatial relationships between specific image features [46]. In order to conduct GIS interpolation of spatial relationships between different image features 
(e.g., groups of bacteria), it was necessary to "ground-truth" image features. This allowed for more accurate and precise quantification, and statistical comparisons of observed image features. In GIS, this is typically accomplished through "on-the-ground" sampling of the actual environment being imaged. However, in order to "ground-truth" the microscopic features of our samples (and their images) we employed separate "calibration" studies (i.e., using fluorescent microspheres) designed to "ground-truth" our microscopy-based image data.

Quantitative microspatial analyses of in-situ microbial cells present certain logistical constraints that are not present in the analysis of dispersed cells. In the stromatolite mats, bacterial cells often occurred in aggregated groups or "clusters". Clustering of cells needed evaluation at several spatial scales in order to detect patterns of heterogeneity. Specifically, we wanted to determine if the relatively contiguous horizontal layer of dense SRM that was visible at larger spatial scales was composed of groups of smaller clusters. We employed the analysis of cell area (fluorescence) to examine in-situ microbial spatial patterns within stromatolites. Experimental additions of bacteria-sized $(1.0 \mu \mathrm{m})$ fluorescent microspheres to mats (and no-mat controls) were used to assess the ability of GIS to "count cells" using cell area (based on pixels). The GIS approach (i.e., cell area-derived counts) was compared with the direct counts method, and product moment correlation coefficients $(r)$ were computed for the associations. Under these circumstances the GIS approach proved highly useful.

In the absence of mat, the correlation coefficient $(r)$ between areas and the known concentration was 0.8054 , and the correlation coefficient between direct counts and the known concentration was 0.8136. Areas and counts were also highly correlated $(r=0.9269)$. Additions of microspheres to natural Type-1 mats yielded a high correlation $(r=0.767)$ between area counts and direct counts. It is realized that extension of microsphere-based estimates to natural systems must be viewed conservatively since all microbial cells are neither spherical nor exactly $1 \mu \mathrm{m}$ in diameter (i.e., as the microspheres). Second, extraction efficiencies of microbial cells (e.g., for direct counts) from any natural matrix are uncertain, at best. Hence, the empirical estimates generated here are considered to be conservative ones. This further supports previous assertions that only relative abundances, but not absolute (i.e., accurate) abundances, of cells should be estimated from complex matrices [39] such as microbial mats.

Results of microbial cell estimations derived from both direct counts and area computations, by inherent design, were subject to certain limitations. The first limitation is inherent to the process of image acquisition: many images contain only portions of items (e.g., cells or beads). In terms of counting, fragments or "small" items were summed up approximately to obtain an integer. Therefore, the solution used was the "counting rule". The problem disappears when total areas are computed. A second limitation involves image overlap [47]. This problem affects the computation of areas in the absence of a mathematical model that would account for overlapping objects. The human eye, for example, can readily distinguish between overlapping beads, and as a result traditional counting was less affected. While area computations were slightly influenced by this, the solution was approached in the same fashion as above (i.e., through direct count comparisons) and the results were comparable. A third limitation relates to the three-dimensional nature of samples. Items situated 
slightly below the plane of focus sometimes produce residual fluorescence and appear as smaller items of the same kind or fragments. While those items might have been counted during direct counts, it was difficult to generate an objective means (i.e., a systematic counting rule) to account for such items. A simple solution, however, was obtained when areas were computed during image analysis. The solution resided in the image classification process. Items situated below the plane of focus fluoresced at a lower intensity. Based on the threshold value some of them were classified as background and eliminated from computations, while others were registered as items of interest. As a result, area

Figure 6. Scheme illustrating detection of SRM clusters using GIS. (1) CSLM micrograph showing SRM cells labeled with $d s r A$ probe with background digitally-removed, and identification of individual SRM cells (i.e., black dots); (2) generation of artificial concentric regions with same width $(10 \mu \mathrm{m})$ around each cell or group of cells; (3) identification of overlapping concentric regions; (4) statistical selection of clusters based on area (e.g., overlapping areas of > five cells); (5) Graph showing cluster sizes of SRM cells in Type-1 and Type-2 mats. Means and 95\% confidence intervals are expressed as areas for SRM clusters. Note the significantly larger sizes and variability in cluster-sizes detected in Type- 2 mats.
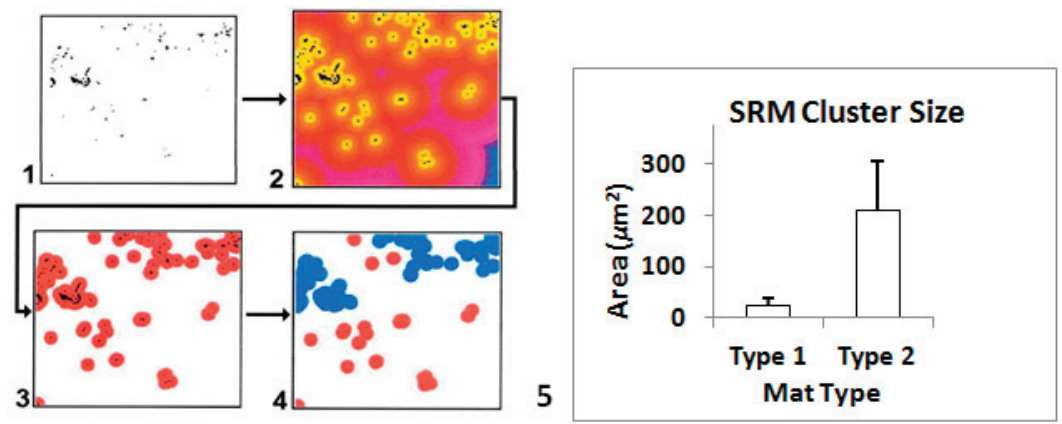

Computation incorporated a systematic approach to overcome this difficulty. Finally, the GIS-based approach was proposed as an alternative to the direct-counts method or other methods, and not as a replacement. Statistical analyses indicated that there were no significant differences between the direct counts and GIS methods when used to estimate the concentrations of microspheres, and area computations using GIS represented a successful alternative for estimating relative abundances of microbial cells in this mat system, especially at high cell abundances.

\subsection{Ground-Truthing GIS at Microbial Spatial Scales}

\subsubsection{Fluorescent Microsphere Additions to Type 1 Mats}

Results from analyses between areas of microspheres computed (via GIS) for each image individually and the total number of microspheres counted within the same image using, showed a highly-significant $(p<0.0001)$ product moment correlation coefficient $(r=0.767)$. 


\subsection{AHL Chemical Signals within Type-2 Mats}

The high abundances of SRM cells underscore the potential impact of this clade on the mat system. The process of cell-cell chemical communication, called quorum sensing, facilitates coordination of group activities, and is now realized to play important roles in natural microbial communities [25-29]. Given the importance of sulfate reduction across many environments, it is therefore surprising that few reports exist for quorum sensing within the sulfate reducing clade, either within the delta proteobacteria [27] or the archaea. This earlier study [27] noted production of several AHLs by a stromatolite mat isolate of Desulfovibrio sp. (strain $\mathrm{H} 2.3 \mathrm{jlac}$ ), one of the same strains examined in this study. We examined two additional strains of SRB isolated from a Type-2 stromatolite mat: Desulfovibrio strain H2.3jman (isolated on mannose as the electron donor) and Desulfovibrio strain

H12.1lac (isolated on lactate as electron donor). Both strains also produced a wide range of AHLs (e.g., C6, C7, C8, C10) under standard culture conditions (Table 2, Figure 7). These are the same molecular congeners of AHL signals that were extracted from our natural mats, where high abundances of SRM were found.

Table 2. Summary table showing acylhomoserine lactones (AHL) extracted from the Type-2 surface mats of marine stromatolites, and from two stromatolite isolates of sulfate-reducing bacteria (SRB). AHLs were identified using mass-spectrometry, and are designated as C4-, C6-, C8-, etc., based on the number of carbons in the acyl chain. An oxo-C6-AHL indicates a C6-AHL having an oxo-group at the C3-position. (* same strain used in [27]).

\begin{tabular}{|c|c|c|c|c|c|c|c|c|c|}
\hline \multirow{2}{*}{$\begin{array}{r}\text { Sample } \\
\text { Type-2 mat extract }\end{array}$} & \multirow{2}{*}{$\begin{array}{c}\text { Strain } \\
\text { designation } \\
-\end{array}$} & \multicolumn{8}{|c|}{ AHLs detected } \\
\hline & & C4- & C6- & C7- & C8- & C10- & C12- & C14- & $\begin{array}{l}\text { oxo- } \\
\text { C6 }\end{array}$ \\
\hline \multicolumn{10}{|l|}{ Desulfovibrio vulgaris } \\
\hline (SRB) subsp. oxamicus & ATCC 33405D & C4- & - & - & C8- & - & - & - & - \\
\hline \multicolumn{10}{|l|}{ SRB isolates from } \\
\hline \multicolumn{10}{|l|}{ Type-2 mats: } \\
\hline Desulfovibro strain 12.1Lac & $\begin{array}{l}\text { GeneBank No. } \\
\text { DQ822785 }\end{array}$ & - & C6- & C7- & C8- & - & - & - & - \\
\hline Desulfovibrio strain $\mathrm{H} 2.3 \mathrm{jLac}$ & $\begin{array}{l}\text { GeneBank No. } \\
\text { DQ822786 }\end{array}$ & - & C6- & C7- & C8- & C10- & C12- & - & $\begin{array}{c}\text { oxo- } \\
\text { C6 }\end{array}$ \\
\hline Desulfovibrio strain H2.3jman & - & - & C6- & C7- & C8- & C10- & - & - & - \\
\hline
\end{tabular}

The observed high abundances and clustering of microbial cells, coupled to the three-dimensional EPS matrix present within mats provide an ideal landscape to foster chemical communication among microbial cells, especially within Type-2 mats. The abundant SRM cell clusters, which were observed 
in the uppermost surfaces of the Type-2 mats using CSLM, present an ideal location for quorum sensing to occur in the mat. Under the natural conditions within microbial mats and the diffusional constraints related to EPS, quorum sensing among cells is likely to efficiently occur over relatively small spatial scales (e.g., 10's of $\mu \mathrm{m}$ ). Interestingly the sizes of SRM clusters, which we measured in Type-2 mats, also occurred within this size range. It must be emphasized, however, that a single mat sample (sample core area $=5.07 \mathrm{~cm}^{2}$ ) used for signal analyses contains a multitude of microbial clusters. Thus the microspatial variability of AHL signals could not be addressed here.

Figure 7. Spectra showing AHLs extracted from Type 2 mats, and AHL standards. Samples are separated using LC/MS. Peaks are shown as a relative percent ( $y$-axis), while $x$-axis shows retention time (RT), expressed in minutes.

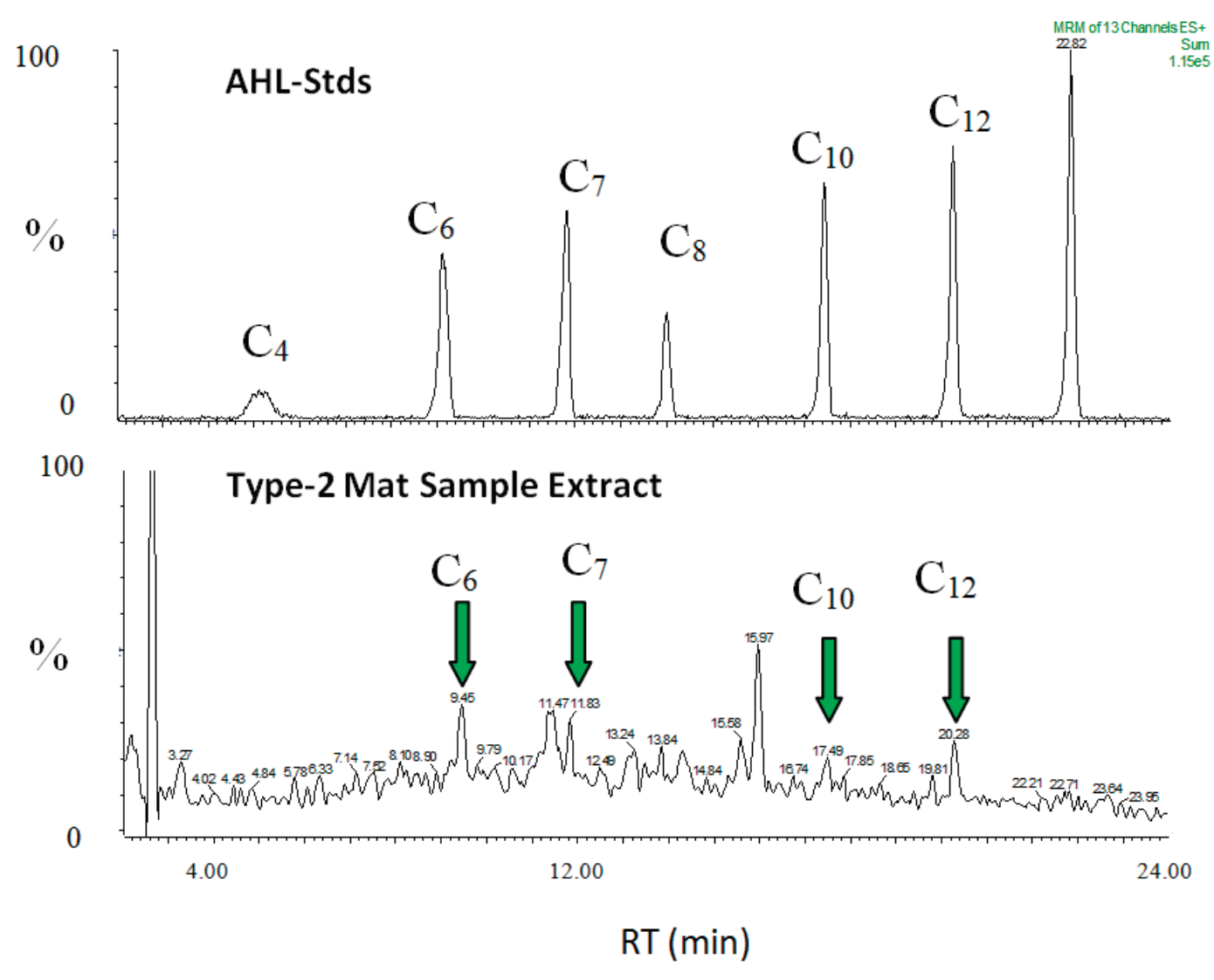

\subsubsection{SRM in Oxic Environments and $\mathrm{CaCO}_{3}$ Precipitation (Relevance)}

Previous microelectrode studies have shown that the surfaces of both Type- 1 and Type- 2 mats were highly-oxygenated during daylight $[10,48]$, with $\mathrm{O}_{2}$ concentrations in stromatolites reaching over $600 \mu \mathrm{M}$ during peak photosynthesis [26]. While $\mathrm{O}_{2}$ has been classically considered to be stressful to most SRM [18], abundant populations of different SRM are now known to occur in oxygenated environments that display maximum metabolic rates under these conditions [12,14,49,50]. 
High abundances of SRM and sulfide-oxidizing microbes (SOM) were reported for the Highborne Cay stromatolites, and associated with this were high rates of sulfate reduction and sulfide oxidation [1]. Interestingly, this study found higher abundances and metabolic rates associated with lithifying layers (i.e., Type-2 mats) than with non-lithifying layers (i.e., Type-1 mats). A similar scenario was described for non-lithifying and lithifying mats in a hypersaline pond in the Bahamas, where higher cell densities and metabolic rates of sulfur-cycling organisms were associated with the mats that precipitated $\mathrm{CaCO}_{3}$ [2,22]. While the SRM in the current study occurred in the uppermost surface (i.e., top $130 \mu \mathrm{m}$ ) of Type- 1 mats, they were significantly denser and more clustered in Type-2 mats. These data suggest that significant sulfur cycling may be occurring within the upper $\mathrm{mm}$ of stromatolite mats. A fundamental question guiding a theoretical understanding of stromatolite formation is: Why do SRMs tend to aggregate at the surface of Type-2 mats? Several possibilities exist to explain the occurrence of SRM at the mat surface: (1) The surface of a Type-2 mat is underlain by a dense layer of cyanobacteria, and hence, is highly-oxic during approximately half the day of each diel cycle. The SRM may receive photosynthetic excretion products from cyanobacteria on a diel basis [8]. It is postulated here that they precipitate a $\mathrm{CaCO}_{3}$ cap to reduce DOC loss to the overlying water (which is oligotrophic), or to enhance efficient recycling of nutrients (e.g., $\mathrm{N}, \mathrm{P}, \mathrm{Fe}$, etc.) within the mat. (2) A second possibility is that the SRM are physiologically adapted to metabolize under oxic conditions part of the time. Studies by Cyprionka [18] and others [2,51] have shown that some SRM may be physiologically adapted to cope with high $\mathrm{O}_{2}$ levels. In this case, $\mathrm{CaCO}_{3}$ precipitation could be advantageous as it produces a cement layer that increases the structural integrity of the stromatolite.

\subsubsection{A Broader Role of Cell Clustering in Microbial Landscapes}

Biofilms have been described as microbial landscapes owing to their physical, metabolic and functional diversity [52]. Our results emphasize that the microspatial patterns of cells within the surface biofilms of marine stromatolites may exist at several different spatial scales: (1) Micro-scale $(\mu \mathrm{m})$ clustering, which may occur as a few (e.g., 2-5) to hundreds of cells within a single cluster. Such clustering may facilitate regulation of group activities, such as quorum sensing; (2) Aggregation of clusters: Clusters themselves may aggregate (i.e., merge with adjacent cell clusters) to form a horizontal layer, within a vertical geochemical gradient region of the mat; (3) Larger mm-scale layering: The visible (to the eye) horizontal zonations, which are indicative of major functional clades within microbial mats, contribute to the exchange of autotrophically-generated DOC to heterotrophs and efficient recycling to reduce loss of DOC to overlying water. QS may be used for coordination of inter- and intra-species metabolic activities, as suggested by Decho and colleagues [42]. In the specific case of SRM, which rely on cyanobacteria for DOC but are negatively affected by the $\mathrm{O}_{2}$ these phototrophs produce, it is of utmost importance to coordinate physiologies (including metabolisms) with other microorganisms that remove $\mathrm{O}_{2}$ during their metabolism. This role could be fulfilled by aerobic heterotrophs and $\mathrm{SOM}$, the latter benefitting from optimal SR activity to provide the substrate for sulfide oxidation. Especially noteworthy is that sulfide removal by SOM also benefits cyanobacteria, for which high 
concentrations of sulfide are toxic. Coordination of metabolisms may be facilitated by QS in this case. Inter-specific QS may ultimately be a key process in shaping the biofilm architecture. This is currently under investigation.

\section{Experimental Section}

\subsection{Sampling of Intact Mats}

All stromatolite sampling was conducted at a subtidal marine environment site at Highborne Cay, Exumas, Bahamas $\left(76^{\circ} 51^{\prime} \mathrm{W} ; 24^{\circ} 42^{\prime} \mathrm{N}\right)$. The site has been under long-term investigation through the Research Initiative on Bahamian Stromatolites (RIBS) project [4]. Freshly-collected intact stromatolites were dissected into working samples (approx. $2 \times 2 \mathrm{~cm}$ ), then immediately fixed (overnight, $4{ }^{\circ} \mathrm{C}$ ) in a $4 \%$ paraformaldehyde (35 ppt seawater; $0.2 \mu \mathrm{m}$-filtered) solution. Portions of mat samples were initially trimmed into thick (approx. 2-4 mm) cross-sections using a rock saw, gently washed, and placed on glass microscope slides. Samples were then prepared for FISH. Surface mats were tentatively identified, based on light-microscopy examination of precipitation products, as either "Type-1" (i.e., no visible surface precipitation), or "Type-2" (i.e., crusty surface precipitation of $\mathrm{CaCO}_{3}$ present) mats (Figure 1). Samples within each mat type were pooled. The samples were used to examine in situ distributions of cells within mats. Samples that were in-transition between full Type-1 or Type-2 were not considered further.

\subsection{Fluorescence in-Situ Hybridization (FISH)}

The oligodeoxynucleotide probe $d s r A B$ was custom-synthesized by GeneDetect (Aukland, New Zealand) using sequences from the 16S rDNA oligonucleotide ProbeBase [53,54]. The probe dsrAB (GD1001-CS with GreenStar *TM FITC fluorescent labeling, Molecular Probes, Eugene, OR, USA) was used to target the dissimilatory sulfite reductase genes $(\operatorname{sr} A B)$ of all recognized lineages of sulfate-reducing bacteria and archaea $[36,38,55]$. The probe was composed of a cocktail of the DSRIF (sequence: ACS CAC TGG AAG CACG) and the DSR $4 R$ (sequence: GTG TAG CAG TTA CCG CA) primers $[38,56,57]$. Concentrations of $d s r A B$ were $5 \mathrm{ng}$ per $\mu \mathrm{L}$, and appropriate nonsense controls were used. Hybridization mixtures were removed and slides were washed for $15 \mathrm{~min}$, in buffer containing $20 \mathrm{mM}$ Tris- $\mathrm{HCl}$ ( $\mathrm{pH} 7.4$ ), $0.225 \mathrm{M} \mathrm{NaCl}$, and $0.01 \%$ SDS. Fluorescence signals were amplified using the Alexa Fluor 488 Signal-Amplification Kit (Molecular Probes, Eugene, OR, USA) for Oregon Green Dye-Conjugated Probes (Molecular Probes, Eugene, OR, USA). DAPI (4'6'-diamidino-2-phenylindole) and PI (Molecular Probes, Eugene, OR, USA) were also used for general bacteria (DNA) staining [58,59]. FISH-probing was conducted according general methods modified from [60-62]. After fixation, intact mat samples were gently washed in phosphate-buffered saline (PBS) and stored in ethanol:PBS $(1: 1)$ at $-20{ }^{\circ} \mathrm{C}$. Samples, sliced into $2-4 \mathrm{~mm}$ sections on glass slides, were immersed in an ethanol series $(50 \%, 80 \%$, and $96 \%$ ) for 3 min each. In situ hybridizations 
were performed at $50{ }^{\circ} \mathrm{C}$ overnight in a hybridization buffer containing $0.9 \mathrm{M} \mathrm{NaCl}, 20 \%$ formamide, $20 \mathrm{mM}$ Tris- $\mathrm{HCl}$ ( $\mathrm{pH} 7.4$ ), and $0.01 \%$ sodium dodecyl sulfate (SDS).

\subsection{Extraction of Bacterial Cells from Mat Slurries}

Cells were extracted from the mat matrix using additional samples. This approach was conducted to determine the portion of total (extractable) cells (i.e., DAPI-stained or PI-stained cells) that hybridized using the FISH probes (i.e., SRM cells). Samples from the uppermost surface mats were fixed in $4 \%$ buffered paraformaldehyde overnight at $4{ }^{\circ} \mathrm{C}$. The mat was gently homogenized into sediment slurries, then suspended in pre-filtered $(0.2 \mu \mathrm{m})$ seawater. Cells were initially separated from sediment particulates using gentle centrifugation $(1500 \times \mathrm{g} ; 2 \mathrm{~min})$. Following, the cells and other organics (e.g., EPS) contained in the supernatant, were removed and subjected to repeated centrifugations $(16,000 \times g ; 10 \mathrm{~min}$ each) to pellet cells, and shear off EPS and other organics. The fixed, extracted cells were washed three times with $1 \times$ PBS (phosphate buffered saline), and stored in PBS/ethanol $(1: 1)$ at $-20{ }^{\circ} \mathrm{C}$ until further processing. Cells, contained in wells on slides, were incubated at $46{ }^{\circ} \mathrm{C}$ for $90 \mathrm{~min}$. in a hybridization buffer containing $0.9 \mathrm{M} \mathrm{NaCl}, 20 \%$ formamide, $20 \mathrm{mM}$ Tris- $\mathrm{HCl}(\mathrm{pH} 7.4$ ), and $0.01 \%$ sodium dodecyl sulfate (SDS). The $d s r A B$ probe concentration for slurry cell incubations was $1.0 \mathrm{ng}$ per $\mu \mathrm{L}$. Hybridization mixtures were removed and the slides were washed for $15 \mathrm{~min}$, in buffer containing $20 \mathrm{mM}$ Tris- $\mathrm{HCl}(\mathrm{pH} 7.4), 225 \mathrm{mM} \mathrm{NaCl}$ and $0.01 \%$ SDS. Washing buffer was removed and washed with distilled water, and slides were air dried. Then, $50 \mu \mathrm{L}$ of DAPI (or PI) was added on slides and incubated for 3 min. After washing with $80 \%$ ethanol, to remove unspecific staining, cells were rinsed in distilled $\mathrm{H}_{2} \mathrm{O}$ and air-dried. The slides were mounted with Citifluor (Citifluor Ltd., Canterbury, UK) and the oligo-probed cells were quantitatively imaged.

\subsection{Confocal Scanning Laser Microscopy (CSLM)}

Images were obtained using a CSLM system (Leica TCS SP5, Leica Microsystems, Germany) equipped with a $\mathrm{Kr}$-Ar laser. For CSLM imaging, three internal detectors were used, each with a 6-position emission filter wheel and a variable confocal aperture. Sample slides were viewed using $20 \times, 40 \times, 60 \times$, or $100 \times$ objectives. The $60 \times$ and $100 \times$ objectives were used with immersion oil (Stephens Scientific Co., \# M4004; Riverdale, NJ, USA; refractive index 1.515) to image individual cells. Final output was represented by colored composite images exported in a tagged image file format (TIFF). Direct counting of DAPI-stained cells and the oligoprobe-hybridized cells were performed on images of 30 independent fields using the automated image analysis software, Cell-C program [63]. In this manner, the relative proportions of SRM: total bacteria cells could be determined for each mat type using the two oligoprobes. 


\subsection{Image Analysis: Geographical Information Systems (GIS) Analyses}

Geographical Information System (GIS) approaches [64,65] were used to analyze CSLM-generated images for spatial patterns of microbial cells and $\mathrm{CaCO}_{3}$ precipitates within sections of intact surface mats. Sets of 25-30 images were sampled each from Type-1 and Type-2 mats. Briefly, images were classified using the Feature Analyst extension of ArcView GIS 3.2 [66,67]. Supervised classification was based on selecting representative pixels for each feature (e.g., SRM, cyanobacteria and bacteria). Based on these selections, the program identified all other pixels belonging to the same class. Since the fluorescence signature of cyanobacteria and bacteria was very similar, the two groups could not be separated spectrally. However, since Feature Analyst allows for the identification of linear features even when they are not continuous, all fluorescent filamentous shapes (i.e., cyanobacteria) were identified. Filamentous shapes were subtracted from the image containing both cyanobacteria and other bacteria using a change-detection protocol. Following this classification, areas within images that were occupied by each feature of interest, such as SRM and other bacteria, were computed. Quantification of a given fraction of a feature that was localized within a certain delimited region was then used to examine clustering of SRM close to the mat surface, and later clustering of SRM in proximity to $\mathrm{CaCO}_{3}$ precipitates.

For purposes of biological relevance, all images collected using CSLM were $512 \times 512$ pixels, and pixel values were converted to micrometers (i.e., $\mu \mathrm{m}$ ). Thus, following conversion into maps, a $512.00 \times 512.00$ pixel image represented an area of $682.67 \times 682.67 \mu \mathrm{m}$. The value of 100 map pixels (approx. $130 \mu \mathrm{m}$ ) that was used to delineate abundance patterns was not arbitrary, but rather the result of analyzing sample images in search of an optimal cutoff value (rounded up to an integer expressed in pixels) for initially visualizing clustering of bacteria at the mat surface. The choice of the values used to describe the microspatial proximity of $\mathrm{SRM}$ to $\mathrm{CaCO}_{3}$ precipitates (i.e., $0.75,1.5$, and 3 pixels) was largely exploratory. Since the mechanistic relevance of these associations (e.g., diffusion distances) were not known, results were presented for three different distances in a series where each distance was double the value of the previous one. Pearson's correlation coefficients were then calculated for each putative association (see below).

\subsubsection{Ground-Truthing GIS}

GIS was used examine spatial relationships between specific image features such as SRM cells. In order to verify the results of GIS analyses, it was necessary to "ground-truth" image features (i.e., bacteria). Therefore, separate "calibration" studies were conducted to "ground-truth" our GIS-based image data at microbial spatial scales.

\subsubsection{Calibrations Using Fluorescent Microspheres}

An experiment was designed to examine the correlation of "direct counts" of added spherical polymer microspheres (1.0 $\mu \mathrm{m}$ dia.) with those estimated using GIS/Image analysis approaches, which 
examined the total "fluorescent area" of the microspheres. The fluorescent microspheres used for these calibrations were trans-fluosphere carboxylate-modified microspheres (Molecular Probes, Molecular Probes, Eugene, OR, USA; T-8883; $1.0 \mu \mathrm{m}$; excit./emiss. 488/645 nm; refractive index =1.6), and have been previously used for similar fluorescence-size calibrations [31]. Direct counts of microspheres (and later, bacteria cells) were determined [68]. Replicate serial dilutions of microspheres: $c, c / 2, c / 4$, $c / 8$, and $c / 16$, (where $c$ is concentration) were homogeneously mixed in distilled water. For each dilution, five replicate slides were prepared and examined using CSLM. From each slide, five images were randomly selected. Output, in the form of bi-color images, was classified using Erdas Imagine 8.5 (Leica Geosystems AG, Heerbrugg, Switzerland). Classification was based on generating two classes ("microspheres" and background) after a maximum number of 20 iterations per pixel, and a convergence threshold of 0.95 and converted into maps. For the resulting surfaces, areas were computed in ArcView GIS 3.2. In parallel, independent direct counts of microspheres were made for each image. Statistical correlations of direct counts (of microspheres) and fluorescent image area were determined.

\subsubsection{Calibrations within Intact Mats}

Finally, fluorescent microspheres were added to the surface of Type-1 mats, as an external standard. Experimental additions of microspheres to Type- 2 mats could not be accomplished because of the non-sticky nature of the mat surfaces. The mats were then imaged by CSLM and analyzed using the previously-described GIS-based approaches. Following image classification, the areas of microspheres were computed for each image, and correlated with the total number of microspheres counted (via direct counts approach) within the same images. This was designed to examine the ability of the image analysis approach to detect individual bacteria-sized objects (i.e., $1 \mu \mathrm{m}$ particles) within the complex matrix of natural stromatolite mats.

\subsubsection{Microspatial Analyses of SRM and Microprecipitates}

SRM activities have been previously implicated in the precipitation of $\mathrm{CaCO}_{3}$ within the Type-2 mats of marine stromatolites [10]. Correlative microspatial associations of $\mathrm{SRMs}$ and $\mathrm{CaCO}_{3}$ precipitates, therefore, were examined over several microspatial scales (approx. 1-5 $\mu \mathrm{m}$ distances) within Type- 1 and Type- 2 mats. For analyses, paired images were used of the same microspatial regions that were obtained at wavelengths specific to the FISH-probes of SRMs and $\mathrm{CaCO}_{3}$ precipitates $(488 / 550 \mathrm{~nm}=$ excit/emiss $\lambda)$.

\subsection{5. ${ }^{35} \mathrm{SO}_{4}{ }^{2-}-$ Silver Foils: 2D-Mapping of Sulfate Reducing Activity}

Sulfate reducing activity was visualized using ${ }^{35} \mathrm{SO}_{4}{ }^{2-}$-labeled $\mathrm{Ag}$ foil [10]. Ag foil (0.1 mm thickness, 99.99\% pure; Sigma-Aldrich, St. Louis, MO, USA) was cleaned using subsequent steps of $30 \% \mathrm{w} / \mathrm{w}$ hydrogen peroxide and acetone. The foils were allowed to air dry in a class 1000 laminar flow hood. The foils were submersed in a radiolabeled sulfate $\left(\mathrm{Na}_{2}{ }^{35} \mathrm{SO}_{4}\right.$; Perkin-Elmer, Waltham, 
MA, USA) solution (ca. $0.1 \mathrm{mCi} / \mathrm{mL}$ ) overnight and allowed to air dry. This treatment was repeated 3-4 times. ${ }^{35} \mathrm{SO}_{4}{ }^{2-}-\mathrm{Ag}$ foils were tested for uniform distribution of the label using a BioRad Molecular Imager System GS-525 (Hercules, CA, USA). Freshly collected stromatolite samples were cut vertically and placed on the foil. After 6-9 h of incubation in the dark at $23{ }^{\circ} \mathrm{C}$, the stromatolite mat samples were removed and the ${ }^{35} \mathrm{SO}_{4}{ }^{2-}$ washed off the foil using distilled water. The foils (containing ${ }^{35} \mathrm{SO}_{4}{ }^{2-}$ produced during SR) were kept in the dark and scanned using the BioRad Molecular Imager System GS-525 to visualize a 2-D $\mathrm{Ag}^{35} \mathrm{SO}_{4}{ }^{2-}$ distribution. The individual pixels represent an area of ca. $50 \times 50 \mu \mathrm{m}$, and darker pixels indicate a higher rate of sulfate reduction.

\subsubsection{Clustering Analyses of SRMs}

The microspatial arrangements of cells relative to each other (i.e., clustering), and changes in relative abundances were examined by examining CSLM images of mat cross-sections. Thirty independent field images from Type-1 and Type-2 mats were examined for each mat type.

\subsubsection{GIS}

Clustering of SRM cells within the surfaces of Type- 1 and Type- 2 mats was analyzed using GIS by creating a buffer area extending from the surface of the mat to approximately $133 \mu \mathrm{m}$ in depth. This surface region was chosen because preliminary examinations showed that most of cells appeared here. Hence our clustering analyses would examine changes in cell distributions within this surface region of the mat. Detection of SRM cells within the buffer area was based on color (as described above) using image classification of FISH-probed cells. A concentric region having a $10 \mu \mathrm{m}$ dia. was generated around each cell. A cluster of cells represented a group of cells having overlapping concentric regions. Subsequent statistical selection of clusters was subjectively based on cluster areas representing greater than five cells. The size (i.e., area) of each detected cell cluster was measured.

\subsubsection{DAIME}

Images collected from CSLM were also analyzed for changes in the spatial patterning of SRM cells in both Type-1 and Type-2 mats using the DAIME program [32]. Clustering within images was analysed using the Spatial:Stereology:Spatial arrangement subprogram with Daime. This calculates distances between all objects (i.e., cells) within an image. Analyzed distances (i.e., $\mu \mathrm{m})$ were expressed as a pair correlation graph. Mean values of pair correlation values $>1$ indicated clustering at a given distance. Values approximating 1 indicated a random distribution of cells, and values $<1$ indicated avoidance.

\subsubsection{Statistical Analyses}

Following spatial analyses, the areas occupied by specific groups of bacteria (e.g., SRM, cyanobacteria) within proximity to the surface, and/or precipitates, cyanobacteria, other bacteria, and cyanobacteria) were tabulated in ArcView GIS (Environmental Systems Research Institute, Redlands, CA, USA). 
Data were examined using statistical analysis systems (SAS Institute Inc., Cary, NC, USA) software programs, for homogeneity of variances, then a range of statistical tests were used to examine potential differences in microspatial arrangements and associations [69,70]. Appropriate transformations were made, where necessary, to normalize data. Differences in precipitate concentrations between Type-1 and Type-2 mats were examined using a student's $t$-test. Overall differences in abundances of SRM among Type-1 and Type-2 mats were compared using analysis of variance (ANOVA). Differences in significant treatment effects were distinguished using Bonferroni and Scheffé aposteriori tests. Logistic regression analyses were used to examine clustering changes during transitions from a Type-1 to Type-2 mat. If no significant differences were detectable, mat data was pooled and analyzed as a single category. Pearson's correlation coefficient analysis was used to determine the specific correlations within given images, of areas occupied by $\mathrm{SRM}$ and $\mathrm{CaCO}_{3}$ precipitates.

\subsection{Molecular Phylogenetic Analysis of dsrA Genes}

For molecular analysis of dissimilatory sulfite reductase $d s r A$ genes, $170 \mathrm{~mm}^{3}$ cores were removed from the surface of type I and II stromatolites. DNA was extracted from these samples using the Power Biofilm DNA Isolation Kit (MoBio Laboratories, Carlsberg, CA, USA) according to the manufacturer's protocol and used as template to generate $d s r$ gene amplicons. Each PCR reaction consisted of $1.5 \mathrm{mM}$ $\mathrm{MgCl}_{2}, 0.2 \mathrm{mM}$ nucleotides, $0.4 \mathrm{uM}$ of primers DSR1F (5'ACS(C/G)CACTGGAAGCACG-3') and DSR4R (5'GTGTAGCAGTTACCGCA3') [38], $1.25 \mathrm{U}$ of Hot start polymerase (Promega), $10 \mathrm{ng}$ of template DNA, and water in a $25 \mu \mathrm{L}$ volume. PCR conditions were conducted as follows: $95{ }^{\circ} \mathrm{C}$ for $5 \mathrm{~min}$, followed by 35 cycles of $95{ }^{\circ} \mathrm{C}$ for $45 \mathrm{~s}, 54{ }^{\circ} \mathrm{C}$ for $40 \mathrm{~s}, 72{ }^{\circ} \mathrm{C}$ for $2 \mathrm{~min}$ and a final extension at $72{ }^{\circ} \mathrm{C}$ for $10 \mathrm{~min}$. PCR amplicons were purified with a QIAQuick PCR Purification Kit (Qiagen Sciences, Maryland, MD, USA) according to the manufacturer's instructions. These purified amplicons were ligated into pCR2.1-TOPO cloning vectors (Invitrogen, Carlsbad, CA, USA), and transformed into One Shot E. coli $\mathrm{DH} 5 \alpha-\mathrm{T} 1^{\mathrm{R}}$ competent cells following the manufacturer's protocol. Transformants were picked and grown overnight at $37{ }^{\circ} \mathrm{C}$ in $\mathrm{LB}$ broth containing $50 \mu \mathrm{g} \mathrm{mL} \mathrm{m}^{-1}$ kanamycin. Plasmids were extracted and purified using QIAprep Spin Miniprep kit (Qiagen Sciences Inc., Alameda, CA, USA), and quantified with a NanoDrop spectrophotometer (NanoDrop Technologies, Inc., Wilmington, DE, USA). Plasmid inserts were sequenced using the M13F (5'GTAAAACGACGGCCAGT3') and M13R (5'CAGGAAACAGCTATGAC3') plasmid vector primers at EnGenCore, LLC (Columbia, SC, USA) using BigDye Terminator version 3.1 cycle sequencing kit (Applied Biosystems, Warrington, UK). Resultant sequences were then searched against the GenBank database using BLASTX with default settings. Translated $d s r A$ gene sequences from type I and II stromatolites were then aligned with amino acid sequences for the top BLAST hit and other characterized $d s r A$ sequences using MUSCLE [71]. Next, a non-rooted phylogenetic tree was constructed using the Maximum Likelihood method based on the Whelan and Goldman model within the MEGA5 [72]. Initial tree(s) for the heuristic search were obtained by applying the Neighbor-Joining method to a matrix of pairwise distances estimated using a JTT model. A discrete Gamma distribution was used to model evolutionary rate differences 
among sites $(5$ categories $(+\mathrm{G}$, parameter $=1.2797))$. Tree robustness was tested using bootstrap analysis with 1000 replicates.

\subsubsection{Extraction and Identification of Quorum Sensing Signals by LC/MS}

Culture supernatants of SRM mat isolates were triple extracted in dichloromethane (DCM), dried under $\mathrm{N}_{2}$ gas, and reconstituted with $50 \%$ acetonitrile, and analyzed by liquid chromatography/mass spectrometry (LC/MS) as previously described [26]. HPLC (150 mm Aquasep $\mathrm{C}_{18}$ column, Somerset, NJ, USA) was used to separate AHLs in samples. Detection and identification of AHLs was conducted using a Waters Premier XE triple quadrupole mass spectrometer (Milford, MA, USA) having positive-ion electrospray ionization. The MS was operated in multiple reaction monitoring mode utilizing two characteristic fragment transitions per analyte (i.e., AHL). Natural mat samples, after gentle homogenization, were extracted in a similar manner to culture samples.

\section{Conclusions}

Abundances of SRM and their specific microspatial distributions, derived from image analyses, were used to create possible instruments of discrimination between non-lithifying Type- 1 and lithifying Type-2 stromatolite mat communities. In general, Type-1 mats can be characterized as having comparatively lower abundances of SRM cells, and relatively dispersed cell distribution patterns (i.e., limited-clustering of SRM cells). In contrast, Type-2 mats exhibit higher abundances and significant clustering of SRM cells within the uppermost $130 \mu \mathrm{m}$ of the surface mat. The GIS approach may be most useful for determination of microbial cell patterns and microspatial organization (i.e., areas occupied by cells) over spatial scales of tens to hundreds of microns. Once proper controls were employed, spatial relationships could be rapidly accessed.

Precipitation of micritic crusts are a characteristic feature of both fossil and present-day marine stromatolites. SRM within surface mats may play a defining role in $\mathrm{C}$ and $\mathrm{S}$ cycling processes that lead to micritic laminae formation in extant marine stromatolites. Our data suggest that development of an abundant and spatially-organized SRM community within the uppermost (oxic region) surface of stromatolite mats was closely aligned with the transition from a non-lithifying (Type-1) to a lithifying (Type-2) state. The progressive development of spatial organization (and high abundances) of SRM in

surface mat layers further presents the likely possibility that quorum sensing may be involved in this transition.

\section{Acknowledgments}

This work was supported by grants from the National Sciences Foundation's BioComplexity Program (EAR - BE 0221796); Earth Sciences Program (EAR-1052974 and Environmental Genomics Program (EF-0723707). We thank the crew of the Research Vessel Walton Smith, and the staff of the Highborne Cay Marina, for their hospitality and efficiency during field research. We thank members 
of the RIBS (Research Initiative for Bahamian Stromatolites) team for stimulating discussion in developing these ideas.

\section{Conflicts of Interest}

The authors declare no conflict of interest.

\section{References}

1. Visscher, P.T.; Reid, R.P.; Bebout, B.M.; Hoeft, S.E.; Macintyre, I.G.; Thompson, J.A., Jr. Formation of lithified micritic laminae in modern marine stromatolites (Bahamas): The role of sulfur cycling. Am. Miner. 1998, 83, 1482-1494.

2. Baumgartner, L.K.; Reid, R.P.; Dupraz, C.; Decho, A.W.; Buckley, D.H.; Spear, J.R.; Przekop, K.M.; Visscher, P.T. Sulfate reducing bacteria in microbial mats: Changing paradigms, new discoveries. Sediment. Geol. 2006, 185, 131-145.

3. Stolz, J.F.; Reid, R.P.; Visscher, P.T.; Decho, A.W.; Norman, R.S.; Aspden, R.J.; Bowlin, E.M.; Franks, J.; Foster, J.S.; Paterson, D.M.; et al. The microbial communities of modern marine stromatolites at Highborne Cay, Bahamas. Atoll Res. Bull. 2010, 567, 1-29.

4. Reid, R.P.; Visscher, P.T.; Decho, A.W.; Stolz, J.F.; Bebout, B.M.; Dupraz, C.; Macintyre, I.G.; Paerl, H.W.; Pinckney, J.L.; Prufert-Bebout, L.; et al. The role of microbes in accretion, lamination, and early lithification of modern marine stromatolites. Nature 2000, 406, 989-992.

5. Grotzinger, J.P.; Knoll, A.H. Stromatolites in PreCambrian carbonates: Evolutionary mileposts or environmental dipsticks? Ann. Rev. Earth Planet Sci. 1999, 27, 313-358.

6. Pinckney, J.L.; Reid, R.P. Productivity and community composition of stromatolitic microbial mats in the Exuma Cays, Bahamas. Facies 1997, 36, 204-207.

7. Paerl, H.W.; Steppe, T.F.; Reid, R.P. Bacterial-mediated precipitation in marine stromatolites. Environ. Microbiol. 2001, 3, 123-130.

8. Decho, A.W.; Visscher, P.T.; Reid, R.P. Production and cycling of natural microbial exopolymers (EPS) within a marine stromatolite. Palaios 2005, 219, 71-86.

9. Andres, M.S.; Sumner, D.Y.; Reid, R.P.; Swart, P.K. Isotopic fingerprints of microbial respiration in aragonite from Bahamian stromatolites. Geology 2006, 34, 973-976.

10. Visscher, P.T.; Reid, R.P.; Bebout, B.M. Microscale observations of sulfate reduction: Evidence of microbial activity forming lithified micritic laminae in modern marine stromatolites. Geology 2000, 28, 919-922.

11. Bowlin, E.M.; Klaus, J.S.; Foster, J.S.; Andres, M.S.; Custals, L.; Reid, R.P. Environmental controls on microbial community cycling in modern marine stromatolites. Sediment. Geol. 2012, 263-264, $45-55$

12. Canfield, D.E.; Des Marais, D.J. Aerobic sulfate reduction in microbial mats. Science 1991, 251, 1471-1473. 
13. Visscher, P.T.; Quist, P.; van Gemerden, H. Methylated sulfur compounds in microbial mats: In situ concentrations and metabolism by a colorless sulfur bacterium. Appl. Environ. Microbiol. 1991, 57, 1758-1763.

14. Fründ, C.; Cohen, Y. Diurnal cycles of sulfate reduction under oxic conditions in microbial mats. Appl. Environ. Microbiol. 1992, 58, 70-77.

15. Krekeler, D.; Signalevich, P.; Teske, A.; Cypionka, H.; Cohen, Y. A sulfate-reducing bacterium from the oxic layer of a microbial mat from Solar Lake (Sinai), Desulfovibrio oxyclinae sp. nov. Archiv. Microbiol. 1997, 176, 69-375.

16. Visscher, P.T.; Gritzer, R.F.; Leadbetter, E.R. Low-molecular weight sulfonates, a major substrate for sulfate reducers in marine microbial mats. Appl. Environ. Microbiol. 1999, 65, 3272-3278.

17. Brune, A.; Frenzel, P.; Cypionka, H. Life at the oxic-anoxic interface: Microbial activities and adaptations. FEMS Microbiol. Rev. 2000, 24, 691-710.

18. Cypionka, H. Oxygen respiration by Desulfovibrio species. Ann. Rev. Microbiol. 2000, 54, 827-848.

19. Gallagher, K.L.; Kading, T.J.; Braissant, O.; Dupraz, C.; Visscher, P.T. Inside the alkalinity engine: The role of electron donors in the organomineralization potential of sulfate-reducing bacteria. Geobiology 2012, 10, 518-530.

20. Visscher, P.T.; Stolz, J.F. Microbial mats as bioreactors: Populations, processes, and products. Palaios 2005, 219, 87-100.

21. Petrisor, A.I.; Decho, A.W. Using geographical information techniques to quantify the spatial structure of endolithic boring processes within sediment grains of marine stromatolites. J. Microbiol. Methods 2004, 56, 173-180.

22. Dupraz, C.; Visscher, P.T.; Baumgartner, L.K.; Reid, R.P. Microbe-mineral interactions: Early carbonate precipitation in a hypersaline lake (Eleuthera Island, Bahamas). Sedimentology 2004, 51, 745-765.

23. Glunk, C.; Dupraz, C.; Braissant, O.; Gallagher, K.L.; Verrecchia, E.P.; Visscher, P.T. Microbially mediated carbonate precipitation in a hypersaline lake, Big Pond (Eleuthera, Bahamas). Sedimentology 2011, 58, 720-738.

24. Dupraz, C.D.; Fowler, A.; Tobias, C.; Visscher, P.T. Stromatolitic knobs in Storr's Lake (San Salvador, Bahamas): A model for formation and alteration of laminae. Geobiology 2013, 11, 527-548.

25. Fuqua, W.C.; Greenberg, E.P. Listening in on bacteria: Acylhomoserine lactone signaling. Nat. Rev. Mol. Cell Biol. 2002, 3, 685-695.

26. Decho, A.W.; Visscher, P.T.; Ferry, J.; Kawaguchi, T.; He, L.; Przekop, K.M.; Norman, R.S.; Reid, R.P. Autoinducers extracted from microbial mats reveal a surprising diversity of $\mathrm{N}$-acylhomoserine lactones (AHLs) and abundance changes that may relate to diel $\mathrm{pH}$. Environ. Microbiol. 2009, 11, 409-420. 
27. Kawaguchi, T.; Chen, Y.P.; Norman, R.S.; Decho, A.W. An in vitro rapid detection/quantification assay for $\mathrm{N}$-acyl homoserine lactones in environmental samples. Appl. Environ. Microbiol. 2008, 74, 3667-3671.

28. Decho, A.W.; Frey, R.L.; Ferry, J.L. Chemical challenges to bacterial AHL signaling in the environment. Chem. Rev. 2011, 11, 86-99.

29. Montgomery, K.; Charlesworth, J.C.; Lebard, R.; Visscher, P.T.; Burns, B.P. Quorum Sensing in Extreme Environments. Life 2013, 3, 131-148.

30. Petrash, D.A.; Gingras, M.K.; Lalonde, S.V.; Orange, F.; Pecoits, E.; Konhauser, K.O. Dynamic controls on accretion and lithification of modern gypsum-dominated thrombolites, Los Roques, Venezuela. Sediment. Geol. 2012, doi:10.1016/j.sedgeo.2011.12.006.

31. Petrisor, A.I.; Kawaguchi, T.; Decho, A.W. Quantifying $\mathrm{CaCO}_{3}$ microprecipitates within developing surface mats of marine stromatolites using GIS and digital image analysis. Geomicrobiol. J. 2004, 21, 491-496.

32. Daims, H.; Lücker, S.; Wagner, M. daime, a novel image analysis program for microbial ecology and biofilm research. Environ. Microbiol. 2006, 8, 200-213.

33. Des Marais, D.J. Long-Term Evolution of the Biogeochemical Carbon Cycle. In Geomicrobiology: Interactions between Microbes and Minerals; Banfield, J.E., Nealson, K.H., Eds.; Mineralogical Society of America Press: Washington, DC, USA, 1997; pp. 427-448.

34. Decho, A.W.; Kawaguchi, T.; Allison, M.A.; Louchard, E.M.; Reid, R.P.; Stephens, F.C.; Voss, K.J.; Wheatcroft, R.A.; Taylor, B.B. Sediment properties influencing upwelling spectral reflectance signatures: The "biofilm gel effect". Limnol. Oceanogr. 2003, 48, 431-443.

35. Paterson, D.M.; Aspden, R.J.; Visscher, P.T.; Consalvey, M.; Andres, M.S.; Decho, A.W.; Stolz, J.; Reid, R.P. Light-dependent biostabilisation of sediments by stromatolite assemblages. PLoS One 2008, 3, e3176.

36. Meyer, B.; Kuever, J. Molecular analysis of the diversity of sulfate-reducing and sulfur-oxidizing prokaryotes in the environment, using aprA as functional marker gene. Appl. Environ. Microbiol. 2007, 73, 7554-7679.

37. Zverlov, V.; Klein, M.; Lucker, S.; Friedrich, M.W.; Kellermann, J.; Stahl, D.A.; Loy, A.; Wagner, M. Lateral gene transfer of dissimilatory (bi)sulfite reductase revisited. J. Bacteriol. 2005, 187, 2203-2208.

38. Wagner, M.; Roger, A.J.; Flax, J.L.; Brusseau, G.A.; Stahl, D.A. Phylogeny of dissimilatory sulfite reductases supports an early origin of sulfate respiration. J. Bacteriol. 1998, 180, 2975-2982.

39. Pernthaler, J.; Glöckner, F.O.; Schönhuber, W.; Amann, R. Fluorescence in situ hybridization (FISH) with rRNA-targeted oligonucleotide probes. Methods Microbiol. 2001, 30, 207-226.

40. Poulsen, L.K.; Ballard, G.; Stahl, D.A. Use of rRNA fluorescence in situ hybridization for measuring the activity of single cells in young and established biofilms. Appl. Environ. Microbiol. 1993, 59, 1354-1360. 
41. Hense, B.A.; Kuttler, C.; Müller, J.; Rothballer, M.; Hartmann, A.; Kreft, J.-U. Does efficiency sensing unify diffusion and quorum sensing. Nat. Rev. Microbiol. 2007, 5, 230-239.

42. Decho, A.W.; Norman, R.S.; Visscher, P.T. Quorum sensing in natural environments: Emerging views from microbial mats. Trends Microbiol. 2010, 18, 73-80.

43. Gantner, S.; Schmid, M.; Dürr, C.; Schuheggar, R.; Steidle, A.; Hutzler, P. In situ quantitation of the spatial scale of calling distances and population density-independent $N$-acylhomoserine lactone-mediated communication by rhizobacteria colonized on plant roots. FEMS Microbiol. Ecol. 2006, 56, 188-194.

44. Petrisor, A.I.; Cuc, A.; Decho, A.W. Reconstruction and computation of microscale biovolumes using geographic information systems: Potential difficulties. Res. Microbiol. 2004, 155, 447-454.

45. Daims, H.; Wagner, M. Quantification of uncultured microorganisms by fluorescence microscopy and digital image analysis. Appl. Microbiol. Biotechnol. 2007, 75, 237-248.

46. Murgante, B.; Las Casas, G. GIS and Fuzzy Sets for the Land Suitability Analysis. In Computational Science and Its Applications, Lecture Notes in Computer Science; Gavrilova, M.L., Kumar, V., Mun, Y., Eds.; Springer: Berlin/Heidelberg, Germany, 2004; Volume 3044, pp. 1036-1045.

47. Walker, R.F.; Ishikawa, K.; Kumagai, M. Fluorescence-assisted image analysis of freshwater microalgae. J. Microbiol. Methods 2002, 51, 149-162.

48. Visscher, P.T.; Surgeon, T.M.; Hoeft, S.E.; Bebout, B.M.; Thompson, J., Jr.; Reid, R.P. Microelectrode Studies in Modern Marine Stromatolites: Unraveling the Earth's Past? In Electrochemical Methods for Environmental Analysis of Trace Metal Biogeochemistry; ACS Symposium Series 881; Taillefert, M., Rozan, T., Eds.; Oxford University Press: New York, NY, USA, 2002; pp. 265-282.

49. Visscher, P.T.; van Ende, F.P.; Schaub, B.E.M.; van Gemerden, H. Competition between anoxygenic phototrophic bacteria and colorless sulfur bacteria in a microbial mat. FEMS Microbiol. Ecol. 1992, 101, 51-58.

50. Jørgensen, B.B. Sulfate reduction and thiosulfate transformations in a cyanobacterial mat during a diel oxygen cycle. FEMS Microbiol. Ecol. 1994, 13, 303-312.

51. Fournier, M.; Zhang, Y.; Wildschut, J.D.; Dolla, A.; Voordouw, J.K.; Schriemer, D.C.; Voordouw, G. Function of oxygen resistance proteins in the anaerobic, sulfate-reducing bacterium Desulfovibrio vulgaris Hildenborough. J. Bacteriol. 2003, 185, 71-79.

52. Battin, T.J.; Sloan, W.T.; Kjelleberg, S.; Daims, H.; Head, I.M.; Curtis, T.P.; Eberl, L. Microbial landscapes: New paths to biofilm research. Nat. Rev. Microbiol. 2007, 5, 76-81.

53. Loy, A.; Maixner, F.; Wagner, M.; Horn, H. ProbeBase-An online resource for rRNA-targeted oligonucleotide probes: New features 2007. Nucl. Acids Res. 2007, 31, 514-516.

54. Loy, A.; Küsel, K.; Lehner, A.; Drake, H.L.; Wagner, M. Microarray and functional gene analyses of sulfate-reducing prokaryotes in low sulfate, acidic fens reveal co-occurrence of recognized genera and novel lineages. Appl. Environ. Microbiol. 2004, 70, 6998-7009. 
55. Klein, M.; Friedrich, M.; Roger, A.J.; Hugenholtz, P.; Fishbain, S.; Abicht, H.; Blackall, L.L.; Stahl, D.A.; Wagner, M. Multiple lateral transfers of dissimilatory sulfite reductase genes between major lineages of sulfate-reducing prokaryotes. J. Bacteriol. 2001, 183, 6028-6035.

56. Minz, D.; Fishbain, S.; Green, S.J.; Muyzer, G.; Cohen, Y.; Rittman, B.E.; Stahl, D.A. Unexpected population distribution in a microbial mat community: Sulfate-reducing bacterial localized to the highly oxic chemocline in contrast to a eukaryotic preference for anoxia. Appl. Environ. Microbiol. 1999, 65, 4659-4665.

57. Minz, D.; Flax, J.I.; Green, S.J.; Muyzer, G.; Cohen, Y.; Wagner, M.; Rittman, B.E.; Stahl, D.E. Diversity of sulfate-reducing bacteria in Oxic and Anoxic regions of a microbial mat characterized by comparative analysis of dissimilatory sulfite reductase genes. Appl. Environ. Microbiol. 1999, 65, 4666-4671.

58. Wagner, M.; Erhart, R.; Manz, W.; Amann, R.; Lemmer, H.; Wedi, D.; Schleifer, K.-H. Development of an rRNA-targeted oligonucleotide probe specific for the genus Acinetobacter and its application for in situ monitoring in activated sludge. Appl. Environ. Microbiol. 1994, 60, 792-800.

59. Wagner, M.; Amann, R.; Kämpfer, P.; Assmus, B.; Hartmann, A.; Hutzler, P.; Springer, N.; Schleifer, K.-H. Identification and in-situ detection of Gram-negative filamentous bacteria in activated sludge. Syst. Appl. Microbiol. 1994, 17, 405-417.

60. Snaidr, J.; Amann, R.; Huber, I.; Ludwig, W.; Schleifer, K.-H. Phylogenetic analysis and in situ identification of bacteria in activated sludge. Appl. Environ. Microbiol. 1997, 63, 2884-2896.

61. Llobet-Brossa, E.; Rossello-Mora, R.; Amann, R. Microbial community composition of Wadden Sea sediments as revealed by fluorescence in situ hybridization. Appl. Environ. Microbiol. 1998, 64, 2691-2696.

62. Amann, R.I, Schleifer, K.-H. Nucleic Acid Probes and Their Application in Environmental Microbiology. In Bergey's Manual of Systematic Bacteriology; Garrity, G.M., Ed.; Springer: New York, NY, USA, 2001; pp. 67-82.

63. Selinummi, J.; Seppälä, J.; Yli-Harja, O.; Puhakka, J.A. Software for quantification of labeled bacteria from digital microscope images by automated image analysis. Biotechniques 2005, 39, 859-863.

64. Fedra, K.; Feoli, E. GIS technology and spatial analysis in coastal zone management. EEZ Technol. 1998, 3, 171-179.

65. Jensen, J.R. Remote Sensing of the Environment. An Earth Resource Perspective; Prentice Hall: Upper Saddle River, NJ, USA, 2000.

66. ERDA Imagine Support (2003). Available online: http://support.erdas.com (accessed on 24 November 2003).

67. Feature Analyst. 2003. Available online: http://www.featureanalyst.com/index.html/support/ support/Support.html (accessed on 25 November 2003). 
68. Kirchman, D.L. Statistical Analysis of Direct Counts of Microbial Abundance. In Handbook of Methods in Aquatic Microbial Ecology; Kemp, P.F., Sherr, B.F., Sherr, E.B., Cole, J.J., Eds.; Lewis Publishers: Boca Raton, FL, USA, 1993; pp. 117-120.

69. Cody, R.P.; Smith, J.K. Applied Statistics and the SAS ${ }^{\circledR}$ Programming Language; Prentice Hall: Upper Saddle River, NJ, USA, 1997; pp. 138-141.

70. SAS. Statistical Analysis Systems; SAS Inst. Inc.: Cary, NC, USA, 2007.

71. Edgar, R.C. MUSCLE: A multiple sequence alignment method with reduced time and space complexity. BMC Bioinforma. 2004, 5, 113.

72. Tamura, K.; Peterson, D.; Peterson, N.; Stecher, G.; Nei, M.; Kumar, S. MEGA5: Molecular evolutionary genetics analysis using maximum likelihood, evolutionary distance, and maximum parsimony methods. Mol. Biol. Evol. 2011, 28, 2731-2739. 


\title{
The Role of Bacterial Biofilms and Surface Components in Plant-Bacterial Associations
}

\author{
Pablo C. Bogino, María de las Mercedes Oliva, Fernando G. Sorroche and \\ Walter Giordano
}

\begin{abstract}
The role of bacterial surface components in combination with bacterial functional signals in the process of biofilm formation has been increasingly studied in recent years. Plants support a diverse array of bacteria on or in their roots, transport vessels, stems, and leaves. These plant-associated bacteria have important effects on plant health and productivity. Biofilm formation on plants is associated with symbiotic and pathogenic responses, but how plants regulate such associations is unclear. Certain bacteria in biofilm matrices have been found to induce plant growth and to protect plants from phytopathogens (a process termed biocontrol), whereas others are involved in pathogenesis. In this review, we systematically describe the various components and mechanisms involved in bacterial biofilm formation and attachment to plant surfaces and the relationships of these mechanisms to bacterial activity and survival.
\end{abstract}

Reprinted from Int. J. Mol. Sci. Cite as: Bogino, P.C.; de las Mercedes Oliva, M.; Sorroche, F.G.;

Giordano, W. The Role of Bacterial Biofilms and Surface Components in Plant-Bacterial Associations. Int. J. Mol. Sci. 2013, 14, 15838-15859.

\section{Introduction}

Biofilms are bacterial communities in which cells are embedded in a matrix of extracellular polymeric compounds attached to a surface [1]. Living in biofilms helps protect bacteria from deleterious conditions [2] and the formation of biofilms appears to be an important factor in the disease cycle of bacterial pathogens in both animals and plants.

Bacterial surface components and extracellular compounds [primarily flagella, lipopolysaccharides (LPSs), and exopolysaccharides (EPSs)], in combination with environmental and quorum-sensing signals, are crucial for autoaggregation and biofilm development in most bacterial species studied to date $[3,4]$. In the generally accepted model of biofilm formation, environmental signals trigger the process, and flagella are required for the biofilm community to approach and move across the surface. The initial steps of attachment are mediated by outer membrane proteins (e.g., calcium-binding proteins), pili, or LPSs. After the formation of microcolonies, the production of quorum-sensing signals is required for the formation of a mature biofilm [5]. EPSs provide the architectural form of biofilms and stabilize their 3-dimensional structure. Biofilms are often permeated by channels that act as a circulatory system, allowing the bacteria to exchange water, nutrients, enzymes, and signals, dispose of potentially toxic metabolites, and display enhanced metabolic cooperativity $[4,6]$. The dispersal of biofilms allows bacteria to colonize other surfaces or substrates, thus completing a sequential developmental process. 
The composition of biofilms varies depending on the system. The major components are typically water and the bacterial cells, followed by the EPSs of the matrix [7], which provides (i) a physical barrier against the diffusion of antibiotics, defense substances, or other important compounds from the host; and (ii) protection against environmental stress factors, such as UV radiation, $\mathrm{pH}$ changes, osmotic stress, and desiccation [8,9]. In Agrobacterium tumefaciens, a plant pathogen that persists as surface-associated populations on plants or soil particles, cellulose overproduction resulted in increased biofilm formation on roots [10]. Minor biofilm components include macromolecules such as proteins, DNA, and various lysis products [1], which affect the overall properties of the biofilm.

Bacterial biofilms are widely distributed and play important roles in many environments. The environments occupied by soil bacteria range from rhizospheres rich in nutrients and root exudates to bulk soil deficient in nitrogen, phosphates, water, and other nutrients. The size of bacterial aggregates varies from small to large as a function of the nutrient availability at a given site [11]. A hypothetical model of various 3-dimensional shapes of root-biofilm structures determined by nutrient availability has been presented [12].

Many species of beneficial soil bacteria, including rhizobia, form microcolonies or biofilms when they colonize roots. We recently summarized data on surface attachment and/or biofilm formation by rhizobacteria [5]. Biofilm development also contributes to the virulence of phytopathogenic bacteria through various mechanisms, including blockage of xylem vessels, increased resistance to plant antimicrobial compounds, and/or enhanced colonization of specific habitats [13]. The processes of autoaggregation and biofilm development are relevant to both bacterial survival and host plant colonization (Figure 1). A variety of environmental, genetic, and structural factors affect bacterial adhesion, cell-cell interactions, and plant colonization, and ultimately plant-bacterial interactions in general. In this article, we review recent findings on the mechanisms involved in attachment, cell aggregation, and biofilm formation on plant surfaces by bacteria.

Figure 1. Bacterial autoaggregation and biofilm development, and their relationship with plant colonization. Cell aggregation and biofilm formation in plant-bacterial associations are regulated by environmental signals, nutrient limitation of growth, quorum sensing, EPSs, flagella, LPSs, and other factors.

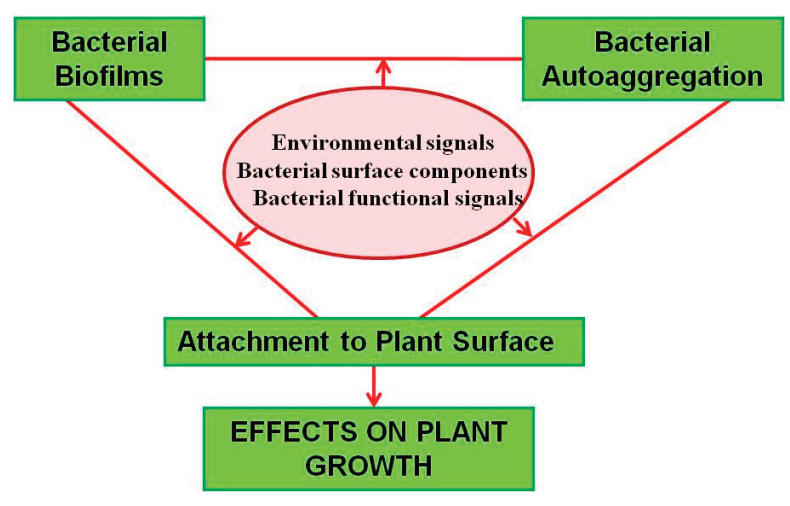




\section{Cell-Cell Adhesive Interactions: Bacterial Autoaggregation}

Bacteria were studied for many years as isolated cell entities. However, like many microorganisms, they have a strong tendency to congregate or aggregate. A common phenotypic manifestation of this behavior is autoaggregation, which is based on adhesive interactions among bacteria. Autoaggregation can be visualized macroscopically by the typical clumping or "fluffing" of cells in liquid cultures, followed by sedimentation of the clumps under static conditions [3,14,15].

Unfavorable growth conditions or low metabolic activity have been found to induce aggregative behavior in bacteria that normally grow in a dispersed, non-aggregated manner. In this context, autoaggregation may reflect a survival strategy that is triggered under hostile environmental conditions [16-19].

The autoaggregative characteristic of bacteria has important implications for the production of bacteria-based inoculants for agriculture. Bacterial aggregates can be produced on a large scale and then separated more easily from the culture medium as compared with dispersed bacteria. The biomass of aggregated bacterial cells in bioreactors remains more constant, and the survival of such bacteria during the inoculant storage period is enhanced, in comparison with non-aggregated cells [17,18,20,21].

\subsection{Surface Factors Involved in Bacterial Autoaggregation}

Because of their strategic location on the cell surface, LPSs, outer membrane proteins, and proteinaceous structures such as pili have been reported to affect adhesion among bacteria and consequently the autoaggregation phenotype.

LPS is an important surface structural component of Gram-negative bacteria and covers $\sim 75 \%$ of the surface area of the outer membrane. It is a tripartite molecule consisting of lipid A, core oligosaccharides, and $O$-antigen, structurally formed by amphiphilic glycoconjugates whose composition varies within and between species. LPS molecules are positioned among the proteins and phospholipids of the outer bacterial membrane and contribute to the structural properties of the membrane; e.g., they act as a permeability barrier against various types of molecules. The structural heterogeneity of the $O$ antigen, the most external portion of the LPS molecule, confers versatility and adaptability to bacteria that are exposed to variable environmental conditions [22]. Changes of LPS structure usually affect adhesive forces among bacteria, possibly through alteration of cell surface hydrophobicity. For example, in rhizobacteria such as Rhizobium leguminosarum and $R$. etli, LPS modifications typically alter the autoaggregation phenotype [23-25]. Ensifer lpsB mutants, which have a truncated LPS core, display a more strongly autoaggregative phenotype as compared with wild-type parental strains (Sorroche et al., unpubl. data). The rhamnose-rich $O$-antigen in the outermost part of the LPS of the xylem-limited phytopathogen Xylella fastidiosa is involved in cell-cell aggregation [26]. The autoaggregative ability of $X$. fastidiosa appears to be an important virulence mechanism because the bacterial clusters block the passage of water and nutrients from the roots to the leaves of the host plant [27-29]. 
Bioassay studies of the impact of biological factors on Azospirillum brasilense autoaggregation indicated that outer membrane proteins promote bacterial flocculation [30]. A 67-kDa outer membrane lectin on the bacterial surface specifically recognized an EPS synthesized by the aggregated cells. The interaction between the lectin and the EPS may be responsible in part for cell-cell interactions leading to autoaggregation of this species [31].

Pili, fimbriae, and flagella are proteinaceous polymeric appendages acting as bacterial surface organelles. Their numerous functions include mediation of motility, interbacterial interactions, bacterial-host interactions, and surface colonization [32]. Pili are associated with autoaggregation in $X$. fastidiosa. This process depends on the presence of polarly located type I and type IV pili, each of which plays a specific role in the structural dynamics of the bacterial aggregates [33].

\subsection{Extracellular Factors Involved in Bacterial Autoaggregation}

Some bacteria secrete molecules that promote autoaggregation. Extracellular polymeric materials have been shown to act as "molecular glue" that initiates and maintains contact between cells, causing flocculation. The main extracellular compounds are EPSs, which are linear or branched molecules formed by one repeated sugar (homopolysaccharides) or by a mixture of different sugars (heteropolysaccharides). An example is galactoglucan (EPS II) from the symbiotic rhizobacterium Ensifer meliloti. This extracellular EPS is secreted in two major fractions, low molecular weight (LMW) and high molecular weight (HMW), according to the degree of polymerization [34]. Mutant strains that are unable to synthesize EPS II fail to autoaggregate under static conditions. A mucR mutant secreting almost exclusively the HMW fraction of EPS II showed a weak aggregative phenotype, suggesting that the LMW fraction plays the active role in autoaggregation. Aggregation of the non-EPS-producing strains and the mucR strain was restored by resuspending the cells in culture medium containing EPS II [14].

Cellulose is an exopolymer with agglutinating activity in $R$. leguminosarum. Upon contact with the host plant, this rhizobacterium aggregates on the root surface using cellulose microfibrils [35-37].

Hostile environmental conditions or low metabolic activity can induce an autoaggregative phenotype via the synthesis of EPSs that have agglutinating activity. For example, the aggregative phenotype of the rhizobacterium $A$. brasilense depends on the production of an arabinose-rich extracellular polysaccharide that is synthesized in cultures in stationary and programmed cell death phases. Aggregative behavior in Pseudomonas aeruginosa is triggered by the presence of the toxic detergent SDS. This behavior depends on production of the EPS PsI. Inactivation of either the psi gene or the c-di-GMP-mediated signaling system that activates the gene results in reduced autoaggregation $[19,38,39]$. 


\section{Cell-Cell and Cell-Surface Interactions: Bacterial Biofilm Formation}

Surface and extracellular bacterial components have been extensively studied because they involve molecules that play crucial roles during the process of infection of the host plant, independently of the development of a beneficial or pathogenic relationship. Such bacterial components are also key molecules in the establishment, maturation, and dispersal of biofilms. We will summarize in this section the structure and function of bacterial compounds that play a role in the development of biofilms by beneficial or pathogenic bacteria associated with the surface or interior of plant tissues.

\subsection{Structural and Functional Components Involved in Biofilm Formation}

All bacteria live as a multicellular conglomerate encased in a protective matrix of polymeric substances produced by the bacteria themselves. The highly organized and dynamic social structure of bacteria requires intercellular communication via quorum sensing [40]. Bacterial aggregates frequently adhere at a solid-liquid interface prior to adsorption on a thin film of organic molecules that constitutes the adhesion site. The transport of cells to this interface may be mediated by passive mechanisms or by the intrinsic motility of planktonic bacteria. The accumulation of bacterial cells at the interface is biphasic, consisting of (i) a non-specific reversible stage mediated by hydrophobic and electrostatic interactions between cells and adjacent surfaces; and (ii) an irreversible stage in which the adhesion process is completed and a bacterial microcolony is established [41]. Surface bacterial components such as flagella, pili, fimbriae, and LPSs play a crucial role in physical processes during the initial stages of biofilm formation on surfaces. The growth, maturation, and disassembly phases of biofilms depend primarily on the biosynthesis of extracellular biopolymers such as EPSs, proteins, and extracellular DNA (eDNA). These polymers promote or provide immobilization of bacterial cells into the matrix, mechanical stability of the biofilm structure, cohesive interaction with the interface, and the architecture and functionality of the encased microbial community [42].

\subsubsection{Surface Bacterial Factors}

Because of their exposure to the external environment and their chemical properties, LPSs on the outer membrane of Gram-negative bacteria are capable of undergoing adhesive interactions with both biotic and abiotic surfaces.

Structural changes of LPSs have been shown to alter biofilm formation or structure in beneficial plant-associated bacteria, including Pseudomonas fluorescens [43]. Mutant strains of various beneficial rhizobacteria with altered LPS structure display changes in the biofilm formation process. For example, a Bradyrhizobium japonicum $O$-antigen mutant showed enhanced adhesion to plastic supports [44]. A R. leguminosarum lipid a mutant showed increased lateral interactions with an abiotic surface; this effect had no effect on the ability of the bacteria to form a biofilm on the surface [45]. A mutant of the alfalfa symbiont $E$. meliloti that synthesized a structurally modified LPS because of mutations of the $\operatorname{lps} B$ and $b a c A$ genes showed reduced biofilm formation ability [46,47]. E. meliloti lps $B$ mutants 
showed reduced nodulation abilities because of delays in the invasion steps; however, their nitrogen-fixing capacity was similar to that of wild-type $[48,49]$, and the modified LPS molecule increased bacterial adsorption to alfalfa roots [50].

In phytopathogenic bacteria, as in beneficial bacteria, LPSs play crucial roles during the early stages of interaction with the host and development of virulence. These phenomena coincide with the normal stages of biofilm formation. Various mutations related to LPS synthesis in phytopathogenic bacteria such as P. aeruginosa [51], Pseudomonas syringae [52], Xanthomonas axonopodis [53], and Xanthomonas citri [54] caused reductions in both biofilm formation ability and virulence.

Because of their surface cell location and physico-chemical properties, LPSs play a key role during the initial steps of biofilm formation (e.g., adherence to surfaces) and the development of mature biofilm through interactions of cells with other cells and with matrix components.

Proteinaceous appendages (pili and flagella) are bacterial virulence factors that lead to pathogenesis in plant, animal, and human hosts and play a key role during colonization steps [55]. The initial stages of biofilm formation are dependent on bacterial motility mediated by the polar flagellum and multiple type IV pili (TfP), which enable the free-swimming phenotype to reach a suitable surface and the surface-motile phenotype to adhere to and move on the surface [56]. These appendages thus have a dual role as motile machines and adhesins that move and fix bacteria to surfaces and among surfaces [57]. Various types of movement (e.g., crawling, pulling, walking) have been associated with TfP [56]. The coordinated TfP pulling associated with release and with flagellar rotation-translation has been presented as a model whereby bacteria are able to travel through the biofilm matrix [58]. Motility-defective mutants of $P$. aeruginosa and $E$. coli were unable to attach to surfaces or to develop a normal biofilm $[59,60]$.

Pili structure is crucial for adhesion and biofilm formation in certain phytopathogenic bacteria, including Acidovorax citrulli, the causal agent of bacterial fruit blotch in cucurbits [61], and $X$. fastidiosa, the causal agent of Pierce's disease in grapes [62]. A. citrulli uses TfP and X. fastidiosa uses type I pili to colonize and move upstream against sap flow in xylem vessels while oriented parallel to the surface, prior to the complete development of biofilm and plant disease. TfP is also important for the pathogenesis of Ralstonia solanacearum and Xanthomonas oryzae pv. oryzicola $[63,64]$. Pili are well-established virulence factors for phytopathogenic bacteria because of their important roles in adherence and plant colonization.

Motility mediated by flagella is manifested as either "swimming" of free cells in aqueous environments and coordinated "swarming" of bacterial populations on solid moist surfaces [65]. Both swimming and swarming are essential for various stages of biofilm development, e.g., the search for a favorable habitat, attachment to a surface, architectural assembly, structural disassembly, and release from the biofilm matrix [66]. The complex association between motility and biofilm formation involves the use of a particular structure for different functions at different stages and requires the precise integration of environmental and cellular signals [67]. 
Flagella-mediated motility in rhizobacteria is essential for biofilm establishment and therefore for plant colonization. E. meliloti, a paradigm of beneficial symbiotic interaction between rhizobacteria and legume plants, showed reduced biofilm formation ability on abiotic surfaces as a result of mutations on genes related to flagella synthesis [68]. An association between flagella-mediated motility and biofilm formation and an effect of quorum-sensing signals on both of these processes were demonstrated in peanut-nodulating Bradyrhizobium sp. strains [69]. Both aflagellate and flagellated but nonmotile mutants of the well-studied pathogen A. tumefaciens, the causal agent of crown gall, showed reduced biofilm formation ability under static conditions because of defects in surface attachment. However, the aflagellate mutants were able to quickly develop an unusually dense and tall biofilm under flow conditions [70]. In contrast to results of other studies that suggest a role of flagella as an adhesin in Aeromonas spp. [71], these results for A. tumefaciens are consistent with those for other bacterial species [72], which suggest that flagella do not function as an adhesin and that other surface structures can be involved in attachment and subsequent biofilm formation [70].

$X$. axonopodis pv. citri, a phytopathogenic bacterium that establishes itself on the leaves (phyllosphere) of citrus species and produces citrus canker disease [73], has the ability to form biofilms on abiotic and biotic surfaces, including the cankers of diseased plants [74]. Flagella-mediated motility plays a key role in several stages of biofilm formation, including surface adherence, maturation, and dispersal [75]. Sliding motility (not mediated by flagella) and the regulation of both swimming and sliding motility through diffusible signal factor (DSF) were reported for $X$. axonopodis [75]. Similar findings were reported for Xanthomonas campestris pv. campestris, although flagellin mutants did not show altered virulence [76]. Swimming motility was found to be essential for biofilm formation and colonization of plant tissues in vascular pathogens such as $R$. solanacearum, Pantoea stewartii, and Dickeya dadantii [77-79].

In contrast to findings in Gram-negative bacteria, it appears that motility is not essential for biofilm development in various non-motile Gram-positive bacteria. Surface proteins (e.g., Bap, Esp) have been reported to be involved in initial adherence to surfaces in these non-motile species [80,81].

Several surface structures that function as adhesins have been found to play important roles during surface attachment. Rhicadhesins and Raps (Rhizobium-adhering proteins) are important for root attachment in various Rhizobiaceae species [82,83]. Glucomannan, a surface polysaccharide of R. leguminosarum bv. trifolli, binds to pea and vetch lectins [84]. Two surface-associated proteins were found to be involved in biofilm formation in Pseudomonas putida. LapA plays a key role in the early stages of biofilm formation by mediating bacterial adherence to various surfaces (including seeds and roots), while LapF is crucial in later stages by mediating cell-cell interactions during sessile growth $[85,86]$.

\subsubsection{Extracellular Factors}

The highly developed level of bacterial organization reflected by biofilm formation ability and multicellularity requires dynamic and functional microorganisms that are embedded into a complex 
mixture of extracellular polymeric components collectively termed the "biofilm matrix" [1]. These components form bridges, channels, avenues, and pores and support an impressively elaborate 3-dimensional architectural structure within which cellular arrangements are transiently constructed. In addition to its structural protective function, the biofilm matrix plays a key role in bacterial physiology and ecology, including cellular interactions, nutrient utilization, horizontal gene transfer, and environmental fitness of the bacterial population [42]. The composition of the biofilm matrix is highly variable, depending on the type of bacteria and biofilm interface. Water is the main component of a mature biofilm. In terms of dry mass, bacteria account for $<10 \%$ of a biofilm, and the matrix accounts for $>90 \%$. The biofilm matrix consists primarily of EPSs and contains smaller proportions of other biopolymers such as proteins, nucleic acids, and lipids [7]. We will summarize here the roles of the major components of the biofilm matrix; i.e., extracellular factors.

A biofilm has been defined as a multicellular bacterial conglomerate adhered to a surface and immersed into a polymeric matrix formed primarily by EPSs [4]. It is therefore not surprising that various bacterial strains, even of the same species, have the ability to synthesize, export, and modify their own characteristic EPS. The function and chemical composition of each EPS is different, depending on the bacterial species or strain. A particular strain may even have the ability to produce different EPSs depending on the environmental conditions, as demonstrated for P. aeruginosa [87] and Streptococcus thermophilus [88]. Most EPSs are polyanionic molecules because of the presence of uronic acids and sugar having substituents such as pyruvate, sulfate, or phosphate. Polycationic EPSs have also been described [89]. The presence of $\beta-1,4$ (or $\beta-1,3)$ and $\alpha-1,2$ (or $\alpha-1,6)$ linkages confers greater rigidity or flexibility, respectively, to the matrix structure. The stability of the biofilm structure is thus dependent on the physico-chemical and biological properties of EPSs and on their interactions with ions, low molecular weight solutes, and other macromolecules such as proteins and eDNA [7]. EPSs are generally required not for initial adhesion but for later architectural development of the biofilm matrix [90]. The EPS network confers mechanical stability, allows for temporary immobilization of cells, and plays a crucial role in most matrix functions, including water retention, protection from environmental stresses, adsorption of compounds, and nutrient availability [42].

The production of EPSs on plant surfaces or tissues allows bacterial colonization and biofilm formation. The biological roles (beneficial or pathogenic) of bacteria on plants are related to these abilities. The compositions and biological roles of selected EPSs produced by well-known plant-associated bacteria are summarized in Table 1. 
Table 1. Production, composition, and functional roles of exopolysaccharides (EPSs) in beneficial and pathogenic plant-associated bacteria.

\begin{tabular}{|c|c|c|c|}
\hline $\begin{array}{l}\text { Bacteria/plant } \\
\text { association }\end{array}$ & Exopolysaccharide & Chemical composition & Function \\
\hline \multirow{2}{*}{$\begin{array}{l}\text { E. meliloti } \\
\text { symbiosis with } \\
\text { Medicago sativa }\end{array}$} & $\begin{array}{l}\text { Succinoglycan (EPS } \\
\text { I), LMW-HMW [91] }\end{array}$ & $\begin{array}{l}\text { Octasaccharide units } \\
\text { (glucose:galactose } 7: 1, \\
\text { bearing succinyl, acetyl, } \\
\text { and pyruvyl substituents) }\end{array}$ & $\begin{array}{l}\text { Required for biofilm formation } \\
\text { [68] } \\
\text { EPS I LMW symbiotically active } \\
\text { [92] }\end{array}$ \\
\hline & $\begin{array}{l}\text { Galactoglucan (EPS } \\
\text { II), LMW-HMW [93] }\end{array}$ & $\begin{array}{l}\text { Disaccharide units } \\
\text { (acetylated glucose- } \\
\text { pyruvylated galactose) }\end{array}$ & $\begin{array}{l}\text { EPS II LMW symbiotically active } \\
\text { [34] } \\
\text { EPS II LMW controls biofilm } \\
\text { formation [94] }\end{array}$ \\
\hline $\begin{array}{l}R . \\
\text { leguminosarum } \\
\text { symbiosis with } \\
\text { Trifolium, Pisum, } \\
\text { Vicia and } \\
\text { Phaseolus } \text { spp. } \\
\end{array}$ & Acidic EPS $[95,96]$ & $\begin{array}{l}\text { Octasaccharide units } \\
\text { (glucose:glucuronic } \\
\text { acid:galactose 5:2:1, } \\
\text { modified by acetyl, } \\
\text { pyruvyl and 3- } \\
\text { hydroxybutanoyl groups) }\end{array}$ & $\begin{array}{l}\text { Development of a structured } \\
\text { biofilm }[83,97] \\
\text { Required for infection and } \\
\text { nodulation }[98,99]\end{array}$ \\
\hline $\begin{array}{l}\text { B. japonicum } \\
\text { symbiosis with } \\
\text { Glycine max }\end{array}$ & EPS $[100,101]$ & $\begin{array}{l}\text { Pentasaccharide units } \\
\text { (mannose:galacturonic } \\
\text { acid:glucose:galactose } \\
\text { 1:1:2:1) }\end{array}$ & $\begin{array}{l}\text { Biofilm formation on both inert } \\
\text { and biotic surfaces. Roles during } \\
\text { the early stages of interaction with } \\
\text { the host plant (initial attachment of } \\
\text { rhizobia to root epidermal cells) } \\
{[102]}\end{array}$ \\
\hline $\begin{array}{l}\text { M. tianshanense } \\
\text { symbiosis with } \\
\text { Glycyrrhiza } \\
\text { uralensis }\end{array}$ & EPS & ND & $\begin{array}{l}\text { Involved in biofilm formation } \\
\text { and successful establishment of } \\
\text { symbiosis [103] }\end{array}$ \\
\hline $\begin{array}{l}\text { A. tumefaciens } \\
\text { ubiquitous } \\
\text { plant pathogen }\end{array}$ & Succinoglycan [104] & See above & $\begin{array}{l}\text { Increased production of } \\
\text { succinoglycan results in reduced } \\
\text { attachment and biofilm } \\
\text { formation [105] }\end{array}$ \\
\hline $\begin{array}{l}X \text {. fastidiosa } \\
\text { plant pathogen }\end{array}$ & $\begin{array}{l}\text { Putative Fastidian } \\
\text { gum [106] }\end{array}$ & $\begin{array}{l}\text { Putative tetrasaccharide } \\
\text { units (glucose-1- } \\
\text { phosphate, glucose, } \\
\text { mannose, and glucuronic } \\
\text { acid) }\end{array}$ & $\begin{array}{l}\text { Possibly involved in bacterial } \\
\text { pathogenicity [106] } \\
\text { Cell attachment and overall } \\
\text { biofilm formation [107] }\end{array}$ \\
\hline $\begin{array}{l}X . \text { campestris } \\
X . \text { axonopodis } \\
\text { plant pathogens }\end{array}$ & Xanthan gum [108] & $\begin{array}{l}\text { Pentasaccharide units } \\
\text { (glucose:mannose:glucuro } \\
\text { nic acid 2:2:1 derivatized } \\
\text { with acetyl and pyruvyl } \\
\text { moieties) }\end{array}$ & $\begin{array}{l}\text { Essential for microcolony } \\
\text { formation }[74] \\
\text { Formation of structured biofilms } \\
\text { on abiotic surfaces and in infected } \\
\text { plants }[109,110]\end{array}$ \\
\hline
\end{tabular}


Table 1. Cont.

\begin{tabular}{|c|c|c|c|}
\hline $\begin{array}{l}\text { Bacteria/plant } \\
\text { association }\end{array}$ & Exopolysaccharide & Chemical composition & Function \\
\hline $\begin{array}{l}\text { P. stewartii } \\
\text { plant pathogen }\end{array}$ & Stewartan [111] & $\begin{array}{l}\text { Heptasaccharide units } \\
\text { (glucose:galactose:glucuro } \\
\text { nic acid 3:3:1) }\end{array}$ & $\begin{array}{l}\text { Essential for appropriate } \\
\text { adhesion and for maturation of } \\
\text { biofilm structure. Also a } \\
\text { virulence factor required for } \\
\text { effective host colonization and } \\
\text { efficient dissemination through } \\
\text { xylem vessels [112] }\end{array}$ \\
\hline \multirow{2}{*}{$\begin{array}{l}\text { E. amylovora } \\
\text { plant pathogen }\end{array}$} & Amylovoran [113] & $\begin{array}{l}\text { Pentasaccharide units } \\
\text { (galactose:glucose } 4: 1, \\
\text { and pyruvate residues) }\end{array}$ & $\begin{array}{l}\text { Pathogenicity factor required for } \\
\text { biofilm formation [114] }\end{array}$ \\
\hline & Levan [115] & Homopolymer of fructose & $\begin{array}{l}\text { Virulence factor. Also } \\
\text { contributes to biofilm formation } \\
{[114]}\end{array}$ \\
\hline $\begin{array}{l}\text { R. solanacearum } \\
\text { plant pathogen }\end{array}$ & Acidic EPS I [116] & $\begin{array}{l}\text { Putative structure } \\
\text { composed by } N \text { - } \\
\text { acetylgalactosamine and } \\
\text { amino sugars } \\
\text { (bacillosamine, } \\
\text { galactosaminuronic acid) }\end{array}$ & Major virulence factor [117] \\
\hline
\end{tabular}

LMW: low molecular weight; HMW: high molecular weight; ND: not determined.

The importance of cellulose (a neutral homopolysaccharide) as a key component of the polysaccharidic matrix has been demonstrated in several Enterobacteriaceae species [118], the plant-associated bacterium A. tumefaciens [119], and Rhizobium species [36,120]. Cellulose plays a key role in adherence to plant tissues, biofilm formation, and the support of matrix architecture.

Polysaccharides from Arabidopsis roots were recently found to serve as both signals for biofilm formation and a source of sugars for the synthesis of matrix EPSs in the beneficial Gram-positive bacterium Bacillus subtilis [121]. Future studies on the triggering of bacterial biofilm formation by plant root exudates will be useful.

Extracellular proteins are major constituents of the biofilm matrix, but have received relatively little study in comparison with other components such as EPSs. Proteins in the biofilm matrix have both structural and physiological functions. Some matrix proteins function as extracellular enzymes and are associated with activities such as the degradation and recycling of biopolymers for nutrient availability and the modification of other exopolymers for shaping or releasing of cells from the biofilm structure. Enzymes that play such roles in the biofilm matrix include lipases, hydrolases, lyases, and glycanases $[83,122,123]$. Certain enzymes released by pathogenic bacteria may act as 
virulence factors $[124,125]$, but such a function has not been evaluated in the context of biofilms on plant surfaces.

Some proteins in the biofilm matrix have structural functions, e.g., as lectins that bind bacterial cells to the polymeric matrix. Examples of such extracellular carbohydrate-binding proteins include a glucan-binding protein in Streptococcus mutans [126], LecA and LecB in P. aeruginosa [127,128], TasA in Bacillus subtilis [129], and lectins in A. brasilense [31]. In P. aeruginosa, a large quantity of matrix proteins was found in outer membrane vesicles, a typical matrix biofilm component in this species [130]. Amyloids are another common type of matrix protein with extracellular adhesin function [131].

Biofilms provide an ideal location for the exchange of genetic material. Higher levels of conjugation have been demonstrated for bacterial populations in biofilms as compared with planktonic bacteria [132]. eDNA is an important constituent of the biofilm matrix [133] and plays a role in biofilm formation in various bacterial species, including P. aeruginosa [134] and Bacillus cereus [135]. The quantity, localization, and origin of eDNA vary depending on the bacterial species. Some studies found that eDNA is arranged in certain patterns [136] and that its release is based on the lysis of certain types of bacteria [137], suggesting the occurrence of programmed cell death in biofilms [138]. In Gram-positive bacteria, eDNA is involved in adhesion to hydrophobic surfaces and in bacterial autoaggregation [139].

Lipids are also components of the biofilm matrix [140], although they have received little study in the context of plant-bacterial associations. Lipids in biofilms generally act as biosurfactants with functions such as surface activity, dispersal and bioavailability of hydrophobic substances, antibacterial or antifungal properties, and bacterial attachment and detachment [141]. Such properties have been well characterized for the rhamnolipids of $P$. aeruginosa, which play important roles at several stages of biofilm development, including surface interaction, microcolony formation, structural maintenance, and biofilm dispersal [142].

Our knowledge of the identification and functions of extracellular proteins, eDNA, and lipids in the biofilm matrix of plant-associated bacteria remains limited and fragmentary. Further studies along this line will greatly enhance our understanding of the process of biofilm formation.

\section{Relationship between Biofilm Formation and Bacterial Autoaggregation}

Bacteria have the unique ability to form complex cellular assemblies on biotic surfaces (animal tissues, plant tissues, detritus) and abiotic surfaces (sediments, soil particles, medical or laboratory instruments). Depending on the quantities of cells and extracellular components, such assemblies range from random cell aggregations observed on surfaces or in liquid suspension to complex, highly developed assemblies of cells encased in a exopolymeric matrix and attached to a surface (i.e., biofilms) [143]. There are several bacterial models that are useful for studying the relationships between cell aggregations and biofilms. The adhesin AIDA, a surface glycoprotein of E. coli, has been shown to promote strong bacterial autoaggregation, biofilm formation, and in vitro 
adhesion to human and mammalian cells [144]. Strains of the opportunistic bacterium Myroides odoratus that showed strong adhesion to inert supports also showed enhanced autoaggregative ability [145]. Changes in the cell surface of Porphyromonas gingivalis (a pathogenic bacterium involved in periodontal disease) led to increased cell-cell interactions and consequent increases in autoaggregation and biofilm formation [146].

Variants of the phytopathogen $X$. fastidiosa with mutation of a gene involved in signal transduction showed a modified transcriptional profile of genes related to biofilm formation and bacterial aggregation traits such as surface attachment, EPS synthesis, and virulence [147].

Autoaggregative behavior has also been correlated with biofilm formation ability in beneficial plant-associated bacteria. Strongly autoaggregative mutants of the rhizobacterium A brasilense showed a high tendency to form biofilms on inert supports [148]. In the rhizobacterium E. meliloti, autoaggregation [14] and biofilm formation [5] depend on a combination of bacterial signals, surface components, and EPSs. The development of cell interactions in both sessile populations and planktonic aggregations of various native strains of E. meliloti showed a positive correlation with the above processes and a requirement for EPS II, indicating the involvement of the same physical adhesive forces in autoaggregation and biofilm formation [15].

Surface and extracellular factors are involved in both cell aggregation and biofilm formation, processes that depend in part on physical interactions among bacteria. It is therefore reasonable to presume that alterations in one of these processes lead to changes in the other. Cell aggregation on surfaces most likely represents a transitional state that precedes the development of a structured biofilm. We postulate that the linkage of or transition from bacterial aggregation to biofilm formation is crucial for the establishment of beneficial or pathogenic relationships between bacteria and plants. Such relationships are developed through (i) interactions among bacteria in or near the plant microenvironment (e.g., rhizosphere or phyllosphere); (ii) interactions between bacteria and plant surfaces (e.g., leaf or root epidermis, root hairs, transport vessels); and (iii) biofilm formation and their biological effects.

\section{Intergeneric Adhesive Interactions: Coaggregation}

The coaggregation process has been defined as adhesion among genetically different microorganisms [149]. The phenomenon of coaggregation was initially described for bacteria that inhabit the human oral cavity and subsequently extended to bacteria found in other habitats, including aquatic environments and sludge [150]. Coaggregation processes and factors that affect them have been described for plant growth-promoting rhizobacteria (PGPR) [151]. These findings are relevant to our understanding of plant-bacterial interactions and the development of commercial inoculants.

Coaggregation is an integral process in the formation of mixed biofilms and is therefore ecologically important. Two models have been proposed to explain how a mixed biofilm can support different types of planktonic phase-derived bacteria. According to the first model, planktonic free cells in suspension specifically recognize and adhere to genetically different bacteria in a biofilm. The second model involves initial coaggregation of planktonic bacteria and subsequent adhesion and 
integration of the coaggregate during biofilm formation [149]. Regardless of these models, the coaggregation phenomenon was found to be dependent on cell surface hydrophobicity and the partner strains that participated in the interaction [152].

On a molecular level, coaggregation of human intestinal or oral bacteria and of aquatic bacteria depends on the interaction of a lectin of one participant with a complementary glycosidic receptor of the other participant [153]. Similar mechanisms are expected in bacteria that establish associations with plants, particularly in certain habitats in which bacterial populations are highly diverse, e.g., rhizospheric soil. Cell-free culture supernatants of E. meliloti containing EPS II induced the autoaggregation of several rhizospheric bacteria, including strains of Pseudomonas, Azospirillum, and Burkholderia. These findings suggest that interactions between EPS II and rhizobacteria play an important ecological role. EPS II itself may be capable of connecting different bacterial cells. According to this hypothetical model, EPS II-producing E. meliloti cells may act as "bridges" during the process of coaggregation with other rhizospheric bacteria [50].

\section{Concluding Remarks}

The bacterial cell surface plays a key role in bacterial aggregation, which in turn promotes bacterial dispersal, survival, and the ability to adhere to plant surfaces. It has been well documented that bacterial autoaggregation and biofilm development, and the relationship of these processes with plant colonization, are dependent on both surface bacterial factors and extracellular factors.

Bacteria gain several advantages from living in biofilms, including protection from predation, desiccation, and exposure to antibacterial substances, and improved acquisition of nutrients released in the plant environment. Biofilms provide survival sites for both beneficial and opportunistic pathogenic bacteria, by providing protection as above and increasing the potential of the bacteria to survive and evolve in the plant environment. Biofilms have been shown to enhance (i) the fitness of individual bacteria and (ii) more generalized plant health and productivity as a result of the cumulative selective advantage of the individual bacteria.

Detailed elucidation of the mechanisms involved in the various stages of biofilm formation will improve our understanding of microbial adaptations to this mode of life in a wide range of environments and of the interactions of bacteria with their eukaryotic hosts. Multidisciplinary studies using new approaches will clarify the ways in which bacteria move and interact in a variety of surface microenvironments during biofilm development. Such knowledge will enhance our understanding of biofilm formation on plant surfaces and of the sophisticated processes of interaction between prokaryotes and eukaryotes.

\section{Acknowledgments}

This review and our studies described herein were supported by grants from the Secretaría de Ciencia y Técnica (UNRC), Agencia Nacional de Promoción Científica y Tecnológica (ANPCyT), and 
Consejo Nacional de Investigaciones Científicas y Técnicas of the República Argentina (CONICET). FGS was supported by a fellowship from the CONICET. PCB, MMO and WG are Career Members of CONICET. The authors thank S. Anderson for English editing of the manuscript.

\section{Conflict of Interest}

The authors declare no conflict of interest.

\section{References}

1. Branda, S.S.; Vik, S.; Friedman, L.; Kolter, R. Biofilms: The matrix revisited. Trends Microbiol. 2005, 13, 20-26.

2. Davey, M.E.; O'Toole, G.A. Microbial biofilms: From ecology to molecular genetics. Microbiol. Mol. Biol. Rev. 2000, 64, 847-867.

3. Schembri, M.A.; Christianesen, G.; Klemm, P. FimH-mediated autoaggregation of E. coli. Mol. Microbiol. 2001, 41, 1419-1430.

4. Costerton, J.W.; Lewandowski, Z.; Caldwell, D.E.; Korber, D.R.; Lappin-Scott, H.M. Microbial biofilms. Annu. Rev. Microbiol. 1995, 49, 711-745.

5. Rinaudi, L.V.; Giordano, W. An integrated view of biofilm formation in rhizobia. FEMS Microbiol. Lett. 2010, 304, 1-11.

6. Stanley, N.R.; Lazazzera, B.A. Environmental signals and regulatory pathways that influence biofilm formation. Mol. Microbiol. 2004, 52, 917-924.

7. Sutherland, I.W. Biofilm exopolysaccharides: A strong and sticky framework. Microbiology 2001, 147, 3-9.

8. Flemming, H.C. Biofilms and environmental protection. Water Sci. Technol. 1993, 27, 1-10.

9. Gilbert, P.; Das, J.; Foley, I. Biofilms susceptibility to antimicrobials. Adv. Dent. Res. 1997, 11, $160-167$.

10. Matthysse, A.G.; Marry, M.; Krall, L.; Kaye, M.; Ramey, B.E.; Fuqua, C.; White, A.R. The effect of cellulose overproduction on binding and biofilm formation on roots by Agrobacterium tumefaciens. Mol. Plant Microbe Interact. 2005, 18, 1002-1010.

11. Van de Mortel, M.; Halverson, L.J. Cell envelope components contributing to biofilm growth and survival of Pseudomonas putida in low-water-content habitats. Mol. Microbiol. 2004, 52, 735-750.

12. Rudrappa, T.; Biedrzycki, M.L.; Bais, H.P. Causes and consequences of plant-associated biofilms. FEMS Microbiol. Ecol. 2008, 64, 153-166.

13. Mansfield, J.; Genin, S.; Magori, S.; Citovsky, V.; Sriariyanum, M.; Ronald, P.; Dow, M.; Verdier, V.; Beer, S.V.; Machado, M.A.; et al. Top 10 plant pathogenic bacteria in molecular plant pathology. Mol. Plant Pathol. 2012, 13, 614-629. 
14. Sorroche, F.G.; Rinaudi, L.V.; Zorreguieta, A.; Giordano, W. EPS II-dependent autoaggregation of Sinorhizobium meliloti planktonic cells. Curr. Microbiol. 2010, 61, 465-470.

15. Sorroche, F.G.; Spesia, M.B.; Zorreguieta, A.; Giordano, W. A positive correlation between bacterial autoaggregation and biofilm formation in native Sinorhizobium meliloti isolates from Argentina. Appl. Environ. Microbiol. 2012, 78, 4092-4101.

16. Neyra, C.; Sadasivan, L. Flocculation in Azospirillum brasilense and Azospirillum lipoferum: Exopolysacharides and cyst formation. J. Bacteriol. 1985, 163, 716-723.

17. Nikitina, V.E.; Ponomareva, E.G.; Alen'kina, S.A.; Konnova, S.A. The role of cell-surface lectins in the aggregation of Azospirilla. Microbiology 2001, 70, 471-476.

18. Bahat-Samet, E.; Castro-Sowinski, S.; Okon, Y. Arabinose content of extracellular polysaccharide plays a role in cell aggregation of Azospirillum brasilense. FEMS Microbiol. Lett. 2004, 237, 195-203.

19. Klebensberger, J.; Birkenmaier, A.; Geffers, R.; Kjelleberg, S.; Philipp, B. SiaA and SiaD are essential for inducing autoaggregation as a specific response to detergent stress in Pseudomonas aeruginosa. Environ. Microbiol. 2009, 11, 3073-3086.

20. Malik, A.; Sakamoto, M.; Hanazaki, S.; Osawa, M.; Susuki, T.; Tochigi, M.; Kakii, K. Coaggregation among nonfloculating bacteria isolated from activated sludge. Appl. Environ. Microbiol. 2003, 69, 6056-6064.

21. Burdman, S.; Jurkevitch, E.; Soria-Díaz, M.E.; Serrano, A.M.; Okon, Y. Extracellular polysaccharide composition of Azospirillum brasilense and its relation with cell aggregation. FEMS. Microbiol. Lett. 2000, 189, 259-264.

22. Lerouge, I.; Vanderlayden, J. $O$-antigen structural variation: Mechanisms and possible roles in animal/plant-microbe interactions. FEMS Microbiol. Rev. 2001, 26, 17-47.

23. Priefer, U.B. Genes involved in lipopolysaccharide production and symbiosis are clustered on the chromosome of Rhizobium leguminosarum biovar viciae VF39. J. Bacteriol. 1989, 171, 6161-6168.

24. Cava, J.R.; Elias, P.M.; Turowski, D.A.; Noel, K.D. Rhizobium leguminosarum CFN42 genetic region encoding lipopolysaccharide structures essential for complete nodule development on bean plants. J. Bacteriol. 1989, 171, 8-15.

25. García de los Santos, A.; Brom, S. Characterization of two plasmid-borne lps beta loci of Rhizobium etli required for lipopolysaccharide synthesis and for optimal interaction with plants. Mol. Plant Microbe Interact. 1997, 10, 891-902.

26. Clifford, J.C.; Rapicavoli, J.N.; Roper, M.C. A rhamnose-rich $O$-antigen mediates adhesion, virulence and host colonization for the xylem-limited phytopathogen, Xylella fastidiosa. Mol. Plant. Microbe Interact. 2013, 26, 676-685.

27. Hopkins, D.L. Seasonal concentration of the Pierce's disease bacterium in grapevine stems, petioles, and leaf veins. Phytopathology 1981, 71, 415-418. 
28. Tyson, G.E.; Stojanovic, B.J.; Kuklinski, R.F.; Divittorio, T.J.; Sullivan, M.L. Scanning electron microscopy of Pierce's disease bacterium in petiolar xylem of grape leaves. Phytopathology 1985, 75, 264-269.

29. Newman, K.L.; Almeida, R.P.P.; Purcell, A.H.; Lindow, S.E. Use of a green fluorescent strain for analysis of Xylella fastidiosa colonization of Vitis vinifera. Appl. Environ. Microbiol. 2003, 69, 7319-7327.

30. Burdman, S.; Jurkevitch, E.; Schwartsburd, B.; Okon, Y. Involvement of outer membrane proteins in the aggregation of Azospirillum brasilense. Microbiology 1999, 145, 1145-1152.

31. Mora, P.; Rosconi, F.; Franco Fraguas, L.; Castro-Sowinski, S. Azospirillum brasilense Sp7 produces an outer-membrane lectin that specifically binds to surface-exposed extracellular polysaccharide produced by the bacterium. Arch. Microbiol. 2008, 189, 519-524.

32. Craig, L.; Pique, M.E.; Tainer, J.A. Type IV pilus structure and bacterial pathogenicity. Nature 2004, 2, 363-378.

33. De La Fuente, L.; Burr, T.J.; Hoch, H.C. Autoaggregation of Xilella fastidiosa cells is influenced by type I and type IV pili. Appl. Environ. Microbiol. 2008, 74, 5579-5581.

34. González, J.E.; Reuhs, B.L.; Walker, G.C. Low molecular weight EPS II of Rhizobium meliloti allows nodule invasion in Medicago sativa. Proc. Natl. Acad. Sci. USA 1996, 93, 8636-8641.

35. Ausmees, N.; Jonsson, H.; Höglund, S.; Ljunggren, H.; Lindberg, M. Structural and putative regulatory genes involved in cellulose synthesis in Rhizobium leguminosarum bv. trifolii. Microbiology 1999, 145, 1253-1262.

36. Laus, M.C.; van Brussel, A.A.; Kijne, J.W. Role of cellulose fibrils and exopolysaccharides of Rhizobium leguminosarum in attachment to and infection of Vicia sativa root hairs. Mol. Plant Microbe Interact. 2005, 18, 533-538.

37. Williams, A.; Wilkinson, A.; Krehenbrink, M.; Russo, D.M.; Zorreguieta, A.; Downie, J.A. Glucomannan-mediated attachment of Rhizobium leguminosarum to pea root hairs is required for competitive nodule infection. J. Bacteriol. 2008, 190, 4706-4715.

38. Klebensberger, J.; Rui, O.; Fritz, E.; Schink, B.; Philipp, B. Cell aggregation of Pseudomonas aeruginosa strain PAO1 as an energy-dependent stress response during growth with sodium dodecyl sulfate. Arch. Microbiol. 2006, 185, 417-427.

39. Klebensberger, J.; Lautenschlager, K.; Bressler, D.; Wingender, J.; Philipp, B. Detergent-induced cell aggregation in subpopulations of Pseudomonas aeruginosa as a preadaptive survival strategy. Environ. Microbiol. 2007, 9, 2247-2259.

40. Hooshangi, S.; Bentley, W.E. From unicellular properties to multicellular behavior: Bacteria quorum sensing circuitry and applications. Curr. Opin. Biotech. 2008, 19, 550-555.

41. Klausen, M.; Gjermansen, M.; Kreft, J.U.; Tolker-Nielsen, T. Dynamics of development and dispersal in sessile microbial communities: Examples from Pseudomonas aeruginosa and Pseudomonas putida model biofilms. FEMS Microbiol. Lett. 2006, 261, 1-11.

42. Flemming, H.C.; Wingender, J. The biofilm matrix. Nature Rev. Microbiol. 2010, 8, 623-633. 
43. Spiers, A.J.; Rainey, P.B. The Pseudomonas fluorescens SBW25 wrinkly spreader biofilm requires attachment factor, cellulose fibre and LPS interactions to maintain strength and integrity. Microbiology 2005, 151, 2829-2839.

44. Lee, Y.W.; Jeong, S.Y.; In, Y.H.; Kim, K.Y.; So, J.S.; Chang, W.S. Lack of $O$-polysaccharide enhances biofilm formation by Bradyrhizobium japonicum. Lett. Appl. Microbiol. 2010, 50, 452-456.

45. Vanderlinde, E.M.; Muszynski, A.; Harrison, J.J.; Koval, S.F.; Foreman, D.L.; Ceri, H.; Kannenberg, E.L.; Carlson, R.W.; Yost, C.K. Rhizobium leguminosarum biovar viciae 3841, deficient in 27-hydroxyoctacosanoate-modified lipopolysaccharide, is impaired in desiccation tolerance, biofilm formation and motility. Microbiology 2009, 155, 3055-3069.

46. Ferguson, G.P.; Roop R.M., II; Walker, G.C. Deficiency of a Sinorhizobium meliloti bacA mutant in alfalfa symbiosis correlates with alteration of the cell envelope. J. Bacteriol. 2002, $184,5625-5632$.

47. Hirsch, A.M.; Lum, M.R.; Fujishige, N.A. Microbial Encounters of a Symbiotic Kind-Attaching to Roots and Other Surfaces. In Root Hairs: Plant Cell Monographs; Emons, A.M.C., Ketelaar, T., Eds.; Springer-Verlag: Berlin, Germany, 2009; Volume 12, pp. 295-314.

48. Lagares, A.; Caetano-Anolles, G.; Niehaus, K.; Lorenzen, J.; Ljunggren, H.D.; Pühler, A.; Favelukes, G. A Rhizobium meliloti lipopolysaccharide mutant altered in competitiveness for nodulation of alfalfa. J. Bacteriol. 1992, 174, 5941-5952.

49. Campbell, G.R.O.; Reuhs, B.L.; Walker, G.C. Chronic intracelular infection of alfalfa nodules by Sinorhizobium meliloti requires correct lipopolysaccharide core. Proc. Natl. Acad. Sci. USA 2002, 99, 3938-3943.

50. Sorroche, F.G. National University of Río Cuarto, Córdoba, Argentina. Unpublished work, 2011.

51. Lau, P.C.Y.; Lindhout, T.; Beveridge, T.J.; Dutcher, J.R.; Lam, J.S. Differential lipopolysaccharide core capping leads to quantitative and correlated modifications of mechanical and structural properties in Pseudomonas aeruginosa biofilms. J. Bacteriol. 2009, 191, 6618-6631.

52. Deng, W.L.; Lin, Y.C.; Lin, R.H.; Wei, C.F.; Huang, Y.C.; Peng, H.L.; Huang, H.C. Effects of galU mutation on Pseudomonas syringae-Plant interactions. Mol. Plant Microbe Interact. 2010, 23, 1184-1196.

53. Li, J.; Wang, N. The wxacO gene of Xanthomonas citri ssp. citri encodes a protein with a role in lipopolysaccharide biosynthesis, biofilm formation, stress tolerance and virulence. Mol. Plant Pathol. 2011, 12, 381-396.

54. Li, J.; Wang, N. Genome-wide mutagenesis of Xanthomonas axonopodis pv. citri reveals novel genetic determinants and regulation mechanisms of biofilm formation. PLoS One 2011, 6, e21804.

55. Dhakal, B.K.; Bower, J.M.; Mulvey, M.A. Pili, Fimbriae. In Encyclopedia of Microbiology; Moselio, S., Ed.; Academy Press: Oxford, UK, 2009; p. 470.

56. Conrad, J.C. Physics of bacterial near-surface motility using flagella and type IV pili: Implications for biofilm formation. Res. Microbiol. 2012, 163, 619-629. 
57. Petrova, O.E.; Sauer, K. Sticky situations: Key components that control bacterial surface attachment. J. Bacteriol. 2012, 194, 2413-2425.

58. Jin, F.; Conrad, J.C.; Gibiansky, M.L.; Wong, G.C.L. Bacteria use type-IV pili to slingshot on surfaces. Proc. Natl. Acad. Sci. USA 2011, 108, 12617-12622.

59. Wood, T.K.; González Barrios, A.F.; Herzberg, M.; Lee, J. Motility influences biofilm architecture in Escherichia coli. Appl. Microbiol. Biotechnol. 2006, 72, 361-367.

60. Barken, K.B.; Pamp, S.J.; Yang, L.; Gjermansen, M.; Bertrand, J.J.; Klausen, M.; Givskov, M.; Whitchurch, C.B.; Engel, J.B.; Tolker-Nielsen, T. Roles of type IV pili, flagellum-mediated motility and extracellular DNA in the formation of mature multicellular structures in Pseudomonas aeruginosa biofilms. Environ. Microbiol. 2008, 10, 2331-2343.

61. Bahar, O.; de la Fuente, L.; Burdman, S. Assessing adhesion, biofilm formation and motility of Acidovorax citrulli using microfluidic flow chambers. FEMS Microbiol. Lett. 2010, 312, 33-39.

62. De la Fuente, L.; Montanes, E.; Meng, Y.; Li, Y.; Burr, T.J.; Hoch, H.C.; Wu, M. Assessing adhesion forces of type I and type IV pili of Xylella fastidiosa bacteria by use of a microfluidic flow chamber. Appl. Environ. Microbiol. 2007, 73, 2690-2696.

63. Kang, Y.; Liu, H.; Genin, S.; Schell, M.A.; Denny, T.P. Ralstonia solanacearum requires type 4 pili to adhere to multiple surfaces and for natural transformation and virulence. Mol. Microbiol. 2002, 2, 427-437.

64. Wang, L.; Makino, S.; Subedee, A.; Bogdanove, A.J. Novel candidate virulence factors in rice pathogen Xanthomonas oryzae pv. oryzicola as revealed by mutational analysis. Appl. Environ. Microbiol. 2007, 73, 8023-8027.

65. Jarrell, K.F.; McBride, M.J. The surprisingly diverse ways that prokaryotes move. Nat. Rev. Microbiol. 2008, 6, 466-476.

66. Klausen, M.; Heydorn, A.; Ragas, P.; Lambertsen, L.; Aaes-Jørgensen, A.; Molin, S.; Tolker-Nielsen, T. Biofilm formation by Pseudomonas aeruginosa wild type, flagella and type IV pili mutants. Mol. Microbiol. 2003, 48, 1511-1524.

67. Verstraeten, N.; Braeken, K.; Debkumari, B.; Fauvart, M.; Fransaer, J.; Vermant, J.; Michiels, J. Living on a surface: Swarming and biofilm formation. Trends Microbiol. 2008, 16, 496-506.

68. Fujishige, N.A.; Kapadia, N.N.; de Hoff, P.L.; Hirsch, A.M. Investigations of Rhizobium biofilm formation. FEMS Microbiol. Ecol. 2006, 56, 195-206.

69. Nievas, F.; Bogino, P.; Sorroche, F.; Giordano, W. Detection, characterization, and biological effect of quorum-sensing signaling molecules in peanut-nodulating bradyrhizobia. Sensors 2012, $12,2851-2873$.

70. Merritt, P.M.; Danhorn, T.; Fuqua, C. Motility and chemotaxis in Agrobacterium tumefaciens surface attachment and biofilm formation. J. Bacteriol. 2007, 189, 8005-8014.

71. Kirov, S.M.; Castrisios, M.; Shaw, J.G. Aeromonas flagella (polar and lateral) are enterocyte adhesins that contribute to biofilm formation on surfaces. Infect. Immun. 2004, 72, 1939-1945. 
72. Lemon, K.P.; Higgins, D.E.; Kolter, R. Flagellar motility is critical for Listeria monocytogenes biofilm formation. J. Bacteriol. 2007, 189, 4418-4424.

73. Brunings, A.M.; Gabriel, D.W. Xanthomonas citri: Breaking the surface. Mol. Plant Pathol. 2003, 4, 141-157.

74. Rigano, L.A.; Siciliano, F.; Enrique, R.; Sendín, L.; Filippone, P.; Torres, P.S.; Qüesta, J.; Dow, J.M.; Castagnaro, A.P.; Vojnov, A.A.; et al. Biofilm formation, epiphytic fitness, and canker development in Xanthomonas axonopodis pv. citri. Mol. Plant Microbe Interact. 2007, 20, 1222-1230.

75. Malamud, F.; Torres, P.S.; Roeschlin, R.; Rigano, L.A.; Enrique, R.; Bonomi, H.R.; Castagnaro A.P.; Marano, M.R.; Vojnov, A.A. The Xanthomonas axonopodis pv. citri flagellum is required for mature biofilm and canker development. Microbiology 2011, 157, 819-829.

76. Lee, M.C.; Weng, S.F.; Tseng, Y.H. Flagellin gene fliC of Xanthomonas campestris is upregulated by transcription factor Clp. Biochem. Biophys. Res. Commun. 2003, 307, 647-652.

77. Tans-Kersten, J.; Huang, H.; Allen, C. Ralstonia solanacearum needs motility for invasive virulence on tomato. J. Bacteriol. 2001, 183, 3597-3605.

78. Herrera, C.M.; Koutsoudis, M.D.; Wang, X.; von Bodman, S.B. Pantoea stewartii subsp. stewartii exhibits surface motility, which is a critical aspect of Stewart's wilt disease development on maize. Mol. Plant Microbe Interact. 2008, 21, 1359-1370.

79. Jahn, C.E.; Willis, D.K.; Charkowski, A.O. The flagellar sigma factor fliA is required for Dickeya dadantii virulence. Mol. Plant Microbe Interact. 2008, 21, 1431-1442.

80. Cucarella, J.; Solano, C.; Valle, J.; Amorena, B.; Lasa, I.; Penadés, J.R. Bap, a Staphylococcus aureus surface protein involved in biofilm formation. J. Bacteriol. 2001, 183, 2888-2896.

81. Toledo-Arana, A.; Valle, J.; Solano, C.; Arrizubieta, M.J.; Cucarella, J.; Lamata, M. The enterococcal surface protein, Esp, is involved in Enterococcus faecalis biofilm formation. Appl. Environ. Microbiol. 2001, 67, 4538-4545.

82. Ausmees, N.; Jacobsson, K.; Lindberg, M. A unipolarly located, cell-surface-associated agglutinin, RapA, belongs to a family of Rhizobium-adhering proteins (Rap) in Rhizobium leguminosarum bv. trifolii. Microbiology 2001, 147, 549-559.

83. Russo, D.M.; Williams, A.; Edwards, A.; Posadas, D.M.; Finnie, C.; Dankert, M.; Downie, J.A.; Zorreguieta, A. Proteins exported via the PrsD-PrsE type I secretion system and the acidic exopolysaccharide are involved in biofilm formation by Rhizobium leguminosarum. J. Bacteriol. 2006, 188, 4474-4486.

84. Laus, M.C.; Logman, T.J.; Lamers, G.E.; van Brussel, A.A.; Carlson, R.W.; Kijne, J.W. A novel polar surface polysaccharide from Rhizobium leguminosarum binds host plant lectin. Mol. Microbiol. 2006, 59, 1704-1713.

85. Hinsa, S.M.; Espinosa-Urgel, M.; Ramos, J.L.; O’Toole, G.A. Transition from reversible to irreversible attachment during biofilm formation by Pseudomonas fluorescens WCS365 requires an $\mathrm{ABC}$ transporter and a large secreted protein. Mol. Microbiol. 2003, 49, 905-918. 
86. Martínez-Gil, M.; Yousef-Coronado, F.; Espinosa-Urgel, M. LapF, the second largest Pseudomonas putida protein, contributes to plant root colonization and determines biofilm architecture. Mol. Microbiol. 2010, 77, 549-561.

87. Ryder, C.; Byrd, M.; Wozniak, D.J. Role of exopolysaccharides in Pseudomonas aeruginosa biofilm development. Curr. Opin. Microbiol. 2007, 10, 644-648.

88. Vaningelgem, F.; Zamfir, M.; Mozzi, F.; Adriany, T.; Vancanneyt, M.; Swings, J.; de Vuyst, L. Biodiversity of exopolysaccharides produced by Streptococcus thermophilus strains is reflected in their production and their molecular and functional characteristics. Appl. Environ. Microbiol. 2004, 70, 900-912.

89. Jefferson, K.K. Bacterial Polysaccharides. Current Innovations and Future Trends; Ullrich, M., Ed.; Caister Academic: Norfolk, UK, 2009; pp. 175-186.

90. Sutherland, I.W. Biofilm Exopolysaccharides. In Microbial Extracellular Polymeric Substances; Wingender, J., Neu, T.R., Flemming, H.C., Eds.; Springer: Berlin, Germany, 1999; pp. 73-92.

91. Reuber, T.L.; Walker, G.C. Biosynthesis of succinoglycan, a symbiotically important exopolysaccharide of Rhizobium meliloti. Cell 1993, 74, 269-280.

92. Cheng, H.P.; Walker G.C. Succinoglycan is required for initiation and elongation of infection threads during nodulation of alfalfa by Rhizobium meliloti. J. Bacteriol. 1998, 180, 5183-5191.

93. Her, G.R.; Glazebroock, J.; Walker, G.C.; Reinhold, V.N. Structural studies of a novel exopolysaccharide produced by a mutant of Rhizobium meliloti strain Rm1021. Carbohyd. Res. 1990, 198, 305-312.

94. Rinaudi, L.V.; González, J.E. The low-molecular-weight fraction of exopolysaccharide II from Sinorhizobium meliloti is a crucial determinant of biofilm formation. J. Bacteriol. 2009, 191, 7216-7224.

95. Robertson, B.K.; Aman, P.; Darvill, A.G.; McNeil, M.; Albersheim, P. Host-symbiont interactions. The structure of acidic extracellular polysaccharides secreted by Rhizobium leguminosarum and Rhizobium trifolii. Plant Physiol. 1981, 67, 389-400.

96. Philip-Hollingsworth, S.; Hollingsworth, R.I.; Dazzo, F.B. Host-range related structural features of the acidic extracellular polysaccharides of Rhizobium trifolii and Rhizobium leguminosarum. J. Biol. Chem. 1989, 264, 1461-1466.

97. Janczarek, M.; Kutkowska, J.; Piersiak, T.; Skorupska, A. Rhizobium leguminosarum bv. trifolii rosR is required for interaction with clover, biofilm formation and adaptation to the environment. BMC Microbiol. 2010, 10, doi:10.1186/1471-2180-10-284.

98. Rolfe, B.G.; Carlson, R.W.; Ridge, R.W.; Dazzo, R.W.; Mateos, F.B.; Pankhurst, C.E. Defective infection and nodulation of clovers by exopolysaccharide mutants of Rhizobium leguminosarum bv. trifolii. Aust. J. Plant Physiol. 1996, 23, 285-303. 
99. Van Workum, W.A.T.; van Slageren, S.; van Brussel, A.A.N.; Kijne, J.W. Role of exopolysaccharides of Rhizobium leguminosarum bv. viciae as host plant specific molecules required for infection thread formation during nodulation of Vicia sativa. Mol. Plant Microbe Interact. 1998, 11, 1233-1241.

100. Minamisawa, K. Comparison of extracellular polysaccharide composition, rhizobiotoxine production, and hydrogenase phenotype among various strains of Bradyrhizobium japonicum. Plant Cell Physiol. 1989, 30, 877-884.

101. Poveda, A.; Santamaria, M.; Bernabe, M.; Prieto, A.; Briux, M.; Corzo, J.; Jimenez-Barbero, J. Studies on the structure and the solution conformation of an acidic extracellular polysaccharide isolated from Bradyrhizobium. Carbohyd. Res. 1997, 304, 209-217.

102. Pérez-Giménez, J.; Mongiardini, E.J.; Althabegoiti, M.J.; Covelli, J.; Quelas, J.I.; López-García, S.L.; Lodeiro, A.R. Soybean lectin enhances biofilm formation by Bradyrhizobium japonicum in the absence of plants. Int. J. Microbiol. 2009, 2009, doi:10.1155/2009/719367.

103. Wang, P.; Zhong, Z.; Zhou, J.; Cai, T.; Zhu, J. Exopolysaccharide biosynthesis is important for Mesorhizobium tianshanense: Plant host interaction. Arch. Microbiol. 2008, 189, 525-530.

104. Cangelosi, G.A.; Hung, L.; Puvanesarajah, V.; Stacey, G.; Ozga, D.A.; Leigh, J.A.; Nester, E.W. Common loci for Agrobacterium tumefaciens and Rhizobium meliloti exopolysaccharide synthesis and their roles in plant interactions. J. Bacteriol. 1987, 169, 2086-2091.

105. Tomlinson, A.D.; Ramey-Hartung, B.; Day, T.W.; Merritt, P.M.; Fuqua, C. Agrobacterium tumefaciens ExoR represses succinoglycan biosynthesis and is required for biofilm formation and motility. Microbiology 2010, 156, 2670-2681.

106. Da Silva, F.R.; Vettore, A.L.; Kemper, E.L.; Leite, A.; Arruda, P. Fastidian gum: The Xylella fastidiosa exopolysaccharide possibly involved in bacterial pathogenicity. FEMS Microbiol. Lett. 2001, 203, 165-171.

107. Roper, M.C.; Greve, L.C.; Labavitch, J.M.; Kirkpatrick, B.C. Detection and visualization of an exopolysaccharide produced by Xylella fastidiosa in vitro and in planta. Appl. Environ. Microbiol. 2007, 73, 7252-7258.

108. Jansson, P.E.; Kenne, L.; Lindberg, B. Structure of the extracellular polysaccharide from Xanthomonas campestris. Carbohyd. Res. 1975, 45, 274-282.

109. Rigano, L.A.; Payette, C.; Brouillard, G.; Marano, M.R.; Abramowicz, L.; Torres, P.S.; Yun, M.; Castagnaro, A.P.; Oirdi, M.E.; Dufour, V.; et al. Bacterial cyclic beta-(1,2)-glucan acts in systemic suppression of plant immune responses. Plant Cell 2007, 19, 2077-2089.

110. Torres, P.S.; Malamud, F.; Rigano, L.A.; Russo, D.M.; Marano, M.R.; Castagnaro, A.P.; Zorreguieta, A.; Bouarab, K.; Dow, J.M.; Vojnov, A.A. Controlled synthesis of the DSF cell-cell signal is required for biofilm formation and virulence in Xanthomonas campestris. Environ. Microbiol. 2007, 9, 2101-2109. 
111. Nimtz, M.; Mort, A.; Wray, V.; Domke, T.; Zhang, Y.; Coplin, D.L.; Geider, K. Structure of stewartan, the capsular exopolysaccharide from the corn pathogen Erwinia stewartii. Carbohyd. Res. 1996, 288, 189-201.

112. Koutsoudis, M.D.; Tsaltas, D.; Minogue, T.D.; von Bodman, S.B. Quorum-sensing regulation governs bacterial adhesion, biofilm development, and host colonization in Pantoea stewartii subspecies stewartii. Proc. Natl. Acad. Sci. USA 2006, 103, 5983-5988.

113. Nimtz, M.; Mort, A.; Domke, T.; Wray, V.; Zhang, Y.; Qiu, F.; Coplin, D.; Geider, K. Structure of amylovoran, the capsular exopolysaccharide from the fire blight pathogen Erwinia amylovora. Carbohyd. Res. 1996, 287, 59-76.

114. Koczan, J.M.; McGrath, M.J.; Zhao, Y.; Sundin, G.W. Contribution of Erwinia amylovora exopolysaccharides amylovoran and levan to biofilm formation: Implications in pathogenicity. Phytopathology 2009, 99, 1237-1244.

115. Geier, G.; Geider, K. Characterization and influence on virulence of the levansucrase gene from the fireblight pathogen Erwinia amylovora. Physiol. Mol. Plant Pathol. 1993, 42, 387-404.

116. Cook, D.; Sequeira, L. Genetic and biochemical characterization of a gene cluster from Pseudomonas solanacearum required for extracellular polysaccharide production and for virulence. J. Bacteriol. 1991, 173, 1654-1662.

117. Chapman, M.R.; Kao, C.C. EpsR modulates production of extracellular polysaccharides in the bacterial wilt pathogen Ralstonia (Pseudomonas) solanacearum. J. Bacteriol. 1998, 180, 27-34.

118. Zogaj, X.; Nimtz, M.; Rohde, M.; Bokranz, W.; Römling, U. The multicellular morphotypes of Salmonella typhimurium and Escherichia coli produce cellulose as the second component of the extracellular matrix. Mol. Microbiol. 2001, 39, 1452-1463.

119. Matthysse, A.G.; White, S.; Lightfoot, R. Genes required for cellulose synthesis in Agrobacterium tumefaciens. J. Bacteriol. 1995, 177, 1069-1075.

120. Robledo, M.; Rivera, L.; Jiménez-Zurdo, J.I.; Rivas, R.; Dazzo, F.; Velázquez, E.; Martínez-Molina, E.; Hirsch, A.M.; Mateos, P.F. Role of Rhizobium endoglucanase CelC2 in cellulose biosynthesis and biofilm formation on plant roots and abiotic surfaces. Microb. Cell Fact. 2012, 11, 125.

121. Beauregard, P.B.; Chai, Y.; Vlamakis, H.; Losick, R.; Kolter, R. Bacillus subtilis biofilm induction by plant polysaccharides. Proc. Natl. Acad. Sci. USA 2013, 110, 1621-1630.

122. Zhang, X.; Bishop, P. Biodegradability of biofilm extracellular polymeric substances. Chemosphere 2003, 50, 63-69.

123. Laue, H.; Schenk, A.; Li, H.; Lambertsen, L.; Neu, T.R.; Molin, S.; Ullrich, M.S. Contribution of alginate and levan production to biofilm formation by Pseudomonas syringae. Microbiology 2006, 152, 2909-2918.

124. Dafna, T.A.; Rosenberg, T.; Navon, N.; Burdman, S. A secreted lipolytic enzyme from Xanthomonas campestris pv. vesicatoria is expressed in planta and contributes to its virulence. Mol. Plant Pathol. 2012, 13, 556-567. 
125. Hu, J.; Qian, W.; He, C. The Xanthomonas oryzae pv. oryzae eglXoB endoglucanase gene is required for virulence to rice. FEMS Microbiol. Lett. 2007, 269, 273-279.

126. Lynch, D.J.; Fountain, T.L.; Mazurkiewicz, J.E.; Banas, J.A. Glucan-binding proteins are essential for shaping Streptococcus mutans biofilm architecture. FEMS Microbiol. Lett. 2007, 268, 158-165.

127. Tielker, D.; Hacker, S.; Loris, R.; Strathmann, M.; Wingender, J.; Wilhelm, S.; Rosenau, F.; Jaeger, K.E. Pseudomonas aeruginosa lectin LecB is located in the outer membrane and is involved in biofilm formation. Microbiology 2005, 151, 1313-1323.

128. Diggle, S.P.; Stacey, R.E.; Dodd, C.; Cámara, M.; Williams, P.; Winzer, K. The galactophilic lectin, LecA, contributes to biofilm development in Pseudomonas aeruginosa. Environ. Microbiol. 2010, 8, 1095-1104.

129. Branda, S.S.; Chu, F.; Kearns, D.B.; Losick, R.; Kolter, R. A major protein component of the Bacillus subtilis biofilm matrix. Mol. Microbiol. 2006, 59, 1229-1238.

130. Toyofuku, M.; Roschitzki, B.; Riedel, K.; Eberl, L. Identification of proteins associated with the Pseudomonas aeruginosa biofilm extracellular matrix. J. Proteome Res. 2012, 11, 4906-4915.

131. Larsen, P.; Nielsen, J.L.; Dueholm, M.S.; Wetzel, R.; Otzen, D.; Nielsen, P.H. Amyloid adhesins are abundant in natural biofilms. Environ. Microbiol. 2007, 9, 3077-3090.

132. Molin, S.; Tolker-Nielsen, T. Gene transfer occurs with enhanced efficiency in biofilms and induces enhanced stabilisation of the biofilm structure. Curr. Opin. Biotechnol. 2003, 14, 255-261.

133. Dominiak, D.M.; Nielsen, J.L.; Nielsen, P.H. Extracellular DNA is abundant and important for microcolony strength in mixed microbial biofilms. Environ. Microbiol. 2011, 13, 710-721.

134. Yang, L.; Barken, K.B.; Skindersoe, M.E.; Christensen, A.B.; Givskov, M.; Tolker-Nielsen, T. Effects of iron on DNA release and biofilm development by Pseudomonas aeruginosa. Microbiology 2007, 153, 1318-1328.

135. Vilain, S.; Pretorius, J.M.; Theron, J.; Broezel, V.S. DNA as an adhesion: Bacillus cereus requires extracellular DNA to form biofilms. Appl. Environ. Microbiol. 2009, 75, 2861-2868.

136. Böckelmann, U.; Janke, A.; Kuhn, R.; Neu, T.R.; Wecke, J.; Lawrence, J.R.; Szewzyk, U. Bacterial extracellular DNA forming a defined network-like structure. FEMS Microbiol. Lett. 2006, 262, 31-38.

137. Allesen-Holm, M.; Barken, K.B.; Yang, L.; Klausen, M.; Webb, J.S.; Kjelleberg, S.; Molin, S.; Givskov, M.; Tolker-Nielsen, T. A characterization of DNA release in Pseudomonas aeruginosa cultures and biofilms. Mol. Microbiol. 2006, 59, 1114-1128.

138. Wang, J.; Bayles, K.W. Programmed cell death in plants: Lessons from bacteria? Trends Plant Sci. 2013, 18, 133-139.

139. Das, T.; Prashant, S.K.; Busscher, H.J.; van der Mei, H.C.; Krom, B.P. Role of extracellular DNA in initial bacterial adhesion and surface aggregation. Appl. Environ. Microbiol. 2010, 76, 3405-3408. 
140. Conrad, A.; Suutari, M.K.; Keinänen, M.M.; Cadoret, A.; Faure, P.; Mansuy-Huault, L.; Block, J.C. Fatty acid lipid fractions in extracellular polymeric substances of activated sludge flocs. Lipids 2003, 38, 1093-1105.

141. Ron, E.Z.; Rosenberg, E. Natural role of biosurfactants. Environ. Microbiol. 2001, 3, 229-236.

142. Pamp, S.J.; Tolker-Nielsen, T. Multiple roles of biosurfactants in structural biofilm development by Pseudomonas aeruginosa. J. Bacteriol. 2007, 189, 2531-2539.

143. Stoodley, P.; Sauer, K.; Davies, D.G.; Costerton, J.W. Biofilms as complex differentiated communities. Annu. Rev. Microbiol. 2002, 56, 187-209.

144. Sherlock, O.; Schembri, M.A.; Reisner, A.; Klemm, P. Novel roles for the AIDA adhesin from diarrheagenic Escherichia coli: Cell aggregation and biofilm formation. J. Bacteriol. 2004, 186, 8058-8065.

145. Jacobs, A.; Chenia, H.Y. Biofilm-forming capacity, surface hydrophobicity and aggregation characteristics of Myroides odoratus isolated from South African Oreochromis mossambicus fish. J. Appl. Microbiol. 2009, 107, 1957-1966.

146. Yamaguchi, M.; Sato, K.; Yukitake, H.; Noiri, Y.; Ebisu, S.; Nakayama, K. Porphyromonas gingivalis mutant defective in a putative glycosyltransferase exhibits defect in biosynthesis of polysaccharide portions of lipopolysaccharide, decreased gingipain activities, strong autoaggregation and increased biofilm formation. Infec. Immun. 2010, 78, 3801-3812.

147. Voegel, T.M.; Doddapaneni, H.; Cheng, D.W.; Lin, H.; Stenger, D.C.; Kirkpatrick, B.C.; Roper, M.C. Identification of a response regulator involved in surface attachment, cell-cell aggregation, exopolysaccharide production and virulence in the plant pathogen Xylella fastidiosa. Mol. Plant Pathol. 2013, 14, 256-264.

148. Nievas, F. National University of Río Cuarto, Córdoba, Argentina. Unpublished work, 2012.

149. Rickard, A.H.; Gilbert, P.; High, N.J.; Kolenbrander, P.E.; Handley, P.S. Bacterial Coaggregation: An integral process in the development of multi-species biofilms. Trends Microbiol. 2003, 11, 94-100.

150. Phuong, K.; Kakii, K.; Nikata, T. Intergeneric coaggregation of non-flocculating Acinetobacter spp. isolates with other sludge-constituting bacteria. J. Biosci. Bioeng. 2009, 107, 394-400.

151. Joe, M.M.; Jaleel, C.A.; Sivakumar, P.K.; Zhao, C.X.; Karthikeyan, B. Co-aggregation in Azospirillum brasilensense MTCC-125 with other PGPR strains: Effect of physical and chemical factors and stress endurance ability. J. Taiwan Inst. Chem. E 2009, 40, 491-499.

152. Malik, A.; Kakii, K. Pair dependent co-aggregation behavior of nonflocculating sludge bacteria, Biotechnol. Lett. 2003, 25, 981-986.

153. Ledder, R.G.; Timperley, A.S.; Friswell, M.K.; MacFarlane, S.; McBain, A.J. Coaggregation between and among human intestinal and oral bacteria. FEMS Microbiol. Ecol. 2008, 66, 630-636. 


\title{
Marine Polysaccharide Networks and Diatoms at the Nanometric Scale
}

\section{Vesna Svetličić, Vera Žutić, Galja Pletikapić and Tea Mišić Radić}

\begin{abstract}
Despite many advances in research on photosynthetic carbon fixation in marine diatoms, the biophysical and biochemical mechanisms of extracellular polysaccharide production remain significant challenges to be resolved at the molecular scale in order to proceed toward an understanding of their functions at the cellular level, as well as their interactions and fate in the ocean. This review covers studies of diatom extracellular polysaccharides using atomic force microscopy (AFM) imaging and the quantification of physical forces. Following a brief summary of the basic principle of the AFM experiment and the first AFM studies of diatom extracellular polymeric substance (EPS), we focus on the detection of supramolecular structures in polysaccharide systems produced by marine diatoms. Extracellular polysaccharide fibrils, attached to the diatom cell wall or released into the surrounding seawater, form distinct supramolecular assemblies best described as gel networks. AFM makes characterization of the diatom polysaccharide networks at the micro and nanometric scales and a clear distinction between the self-assembly and self-organization of these complex systems in marine environments possible.
\end{abstract}

Reprinted from Int. J. Mol. Sci. Cite as: Svetličić, M.; Žutić, V.; Pletikapić, G.; Radić, T.M. Marine Polysaccharide Networks and Diatoms at the Nanometric Scale. Int. J. Mol. Sci. 2013, 14, 20064-20078.

\section{Introduction}

Diatoms, important marine photoautotrophic protists that account for up to $25 \%$ of the primary production on Earth [1], produce large quantities of extracellular polymeric substances (EPS), consisting predominantly of polysaccharides [2]. Diatom extracellular polymers participate in various processes, both at the cellular level and in the environment. At the cellular level, extracellular polymers have several important functions, of which some of the most frequently recognized are sessile adhesion, gliding, protection against drying, stabilization of habitats through prevention of sediment erosion, and the formation of biofilms and colonies [2,3]. The total amount of exopolysaccharides produced by diatoms is far in excess of that required for movement or adhesion [3-5] and is referred to as the photosynthetic overflow. In the marine environment, extracellular polysaccharide production by diatoms is a significant route by which photosynthetically produced organic carbon enters the trophic web and may influence the physical environment in the sea. Specifically, species of diatoms in the northern Adriatic Sea can produce large amounts, up to $50 \mathrm{~g} / \mathrm{m}^{3}$ of extracellular polysaccharides in a month [6], resulting in the episodic formation of a macroscopic gel phase $[7,8]$. 
Marine polysaccharide gels represent a form of molecular organization in which biopolymer molecules form solvated three-dimensional networks imbedded in seawater. Intense metabolic activities of microorganisms within gel aggregates (e.g., [9]) result in the formation of sharp microbiogeochemical gradients. The diffusion-slowing properties of the gel phase aid in maintaining these gradients over a very small $(\mu \mathrm{m})$ spatial scale. The continued presence of sharp microbiogeochemical gradients results in the formation of microbial consortia, structured arrangements of microorganisms exhibiting different but highly specific physiological activities over small spatial scales.

Unlike chemical gels that are formed by chemical reaction using a cross-linking agent, it is characteristic of anionic polysaccharide macromolecules to form gels by physical bonds through the intermolecular forces among polymer chains [10,11]. Among the new methodologies (experimental and theoretical) developed for and applied to polysaccharide conformation and dynamics, solution properties, chain aggregation and gelation [12] using atomic force microscopy (AFM) have yielded the most striking results [13].

AFM has been extensively used in nanoscale studies of EPS intimately associated with frustules as coating and adhesive structures (strands, tethers, pads and stalks), as recently reviewed by Higgins and Wetherbee, 2012 [14]. Here, we intend to review recent AFM studies of diatom EPS focusing on the detection of the supramolecular structures of polysaccharide fibrils produced by marine diatoms, either attached to the diatom cell wall or released into the surrounding seawater.

\section{Basic Principles of AFM and Its Application to Polysaccharides}

AFM connects the nanometer- and micrometer-length scales, utilizing a sharp probe that senses interatomic forces acting between the surface of a sample and the atoms at the apex of the tip. The physical basis behind AFM and its ability to "feel" the surface make AFM a versatile tool in biophysics, allowing high resolution imaging, nanomechanical characterization and measurements of inter- and intramolecular forces in living and non-living structures [15-19]. Thanks to the simple principle on which it is based, the AFM is a surprisingly small and compact instrument. Its use includes an electronic control unit, computer and usually two monitors for the simultaneous checking of the image and imaging parameters. The probe, which scans the sample surface, consists of a cantilever and a tip located at its free end. The deflection of the cantilever is measured by an optical detection system. Registered values of cantilever deflection are electronically converted into a pseudo 3D image of a sample. As a result AFM produces real 3D images of a sample with a vertical resolution of $0.1 \mathrm{~nm}$ and lateral resolution of $1 \mathrm{~nm}$. The measured forces range from $10^{-6} \mathrm{~N}$ to $10^{-11} \mathrm{~N}$. In AFM force spectroscopy, a single molecule or fiber is stretched between the AFM flexible cantilever tip and a flat substrate. A polysaccharide molecule, protein or other biopolymer is either adsorbed to the substrate or linked to it through the formation of covalent bonds. When the tip and substrate are brought together and then withdrawn, one or more molecules can attach to the tip. The deflection of the cantilever measures the force on the polymer with an accuracy of $\sim 5 \mathrm{pN}$, while the piezoelectric positioner records the changes in the end-to-end length of the molecule with an accuracy of $0.1 \mathrm{~nm}$. AFM force 
spectroscopy is a widely used method in polymer biophysics, allowing the measurement of the mechanical properties of single molecules with the possibility of quantifying the forces involved directly in both intra- and inter-molecular polymer interactions [18,20-23]. It has also been adopted in advancing diatom research into the nanotechnology [14].

In the AFM imaging mode that makes visualization at the molecular scale of polysaccharide samples possible [24-32], the molecules are usually spread on freshly cleaved mica (a hydrophilic aluminosilicate mineral). The imaging of hydrated samples is preferably conducted in air to inhibit the unfavorable motion of polysaccharides in liquid medium. Protocols for marine sample AFM imaging have been recently developed for single diatom cells and released polymers, isolated polysaccharides from diatom cultures and polymer networks of the marine gel phase [33-39].

\section{AFM Studies of Diatom EPS}

Higgins and coworkers [40] were the first to use AFM for the characterization of diatom extracellular polymers. Intra- and intermolecular forces were measured between polymers on the cell wall and between those extruded from the diatom raphe on diatom species Craspedostauros australis E.J. Cox and Pinnularia viridis (Nitzsch) Ehrenberg [41,42]. The resulting force curves obtained from the pores of cell walls were attributed to the soft and compressible material. However, due to their complexity, it was difficult to assign specific interactions between biopolymers to patterns on the force curves. AFM force spectroscopy was also applied to study extracellular adhesive pads released by the diatom Toxarium undulatum Bailey [43-45]. These pads are very sticky and cells use them to form colonies or attach themselves to the surface. The resulting force profiles with numerous sawtooth patterns (e.g., [46]) were attributed to the extensible modular proteins that are associated into the nanofibers. In a differently designed experiment, Arce and coworkers [47] compared the adhesion of whole diatom Navicula spp. cells on different surfaces. In that study, individual cells were glued to tipless cantilevers. With such "diatom probes," standard force curves were recorded on surfaces such as Intersleek (a hydrophobic agent inhibiting biofilm formation) and mica. The resulting force curves showed comparable adhesion forces, and it was concluded that the extracellular polymeric material on the surface of Navicula spp. has both hydrophobic and hydrophilic properties. Direct imaging of EPS molecules was, however, hampered by the weak interaction of strands and tethers with the substrates used in the liquid [41]. These difficulties were overcome by using mica as a substrate and by imaging in air under ambient conditions (experimental details in [35]).

\subsection{EPS of Cylindrotheca Species}

The ubiquitous marine diatoms of the Cylindrotheca spp. were used in AFM studies of exopolysaccharide production [35-38]. The Cylindrotheca closterium (Ceratonea Closterium Ehrenberg) strain CCNA1 [35] was isolated from northern Adriatic seawater, while the CCMP1544 and 
Cylindrotheca fusiformis Reimann \& J.C. Lewin, CCMP343 strains were obtained from the Bigelow Laboratory for Ocean Sciences.

The molecular organization of the EPS biopolymers released by C. closterium was approached at different levels: (i) EPS released by a single cell; (ii) EPS released in the culture medium and (iii) as biofilms grown on mica slides inserted in the culture [35]. The release of extracellular polymers by single cells was investigated by AFM in exponential and stationary growth phases. While the release of extracellular polymers in the exponential phase of growth was negligible, in the stationary phase extracellular polymers were visualized on more than $25 \%$ of the cells. The AFM data are in line with literature data on increased production of extracellular polymers in the stationary growth phase [48-52]. Parallel experiments with Alcian Blue staining and light microscopy performed in the cell culture have shown that the fibrils extending from the cell rostrum were mainly polysaccharides that existed in the liquid phase before the cell deposition to the mica surface [53].

Figure 1. Extracellular polymers released by C. closterium (CCNA1) obtained by AFM imaging in contact mode after deposition on mica surface. (a) AFM image of the whole cell presented as deflection data. The arrow indicates the position of the polymer excretion site; (b) The released polymers still attached to the apex of the cell rostrum, deflection data, scan size $5 \mu \mathrm{m} \times 5 \mu \mathrm{m}$; (c) Released polymers presented as height data, scan size $4 \mu \mathrm{m} \times 4 \mu \mathrm{m}$ and vertical scale shown as the color bar (reproduced from [33]).
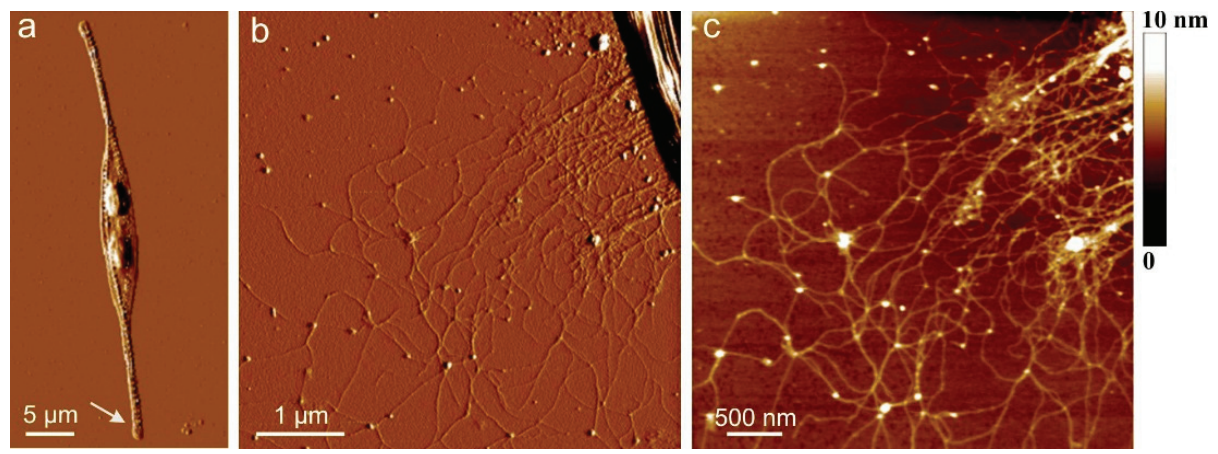

AFM images of extracellular polymers released by $C$. closterium are shown in Figure 1. The image of the whole cell (Figure 1a) presents the general features of the C. closterium cell with two chloroplasts and its drawn-out flexible rostra. The arrow indicates the position of polymer release shown in $\mathrm{b}$ and $\mathrm{c}$ of Figure 1. Bundles of polymer fibrils appear at the position close to the site of excretion. Their heights were 5-7 $\mathrm{nm}$. These bundles unfold into a fibrillar network with gradually decreasing fibril heights reaching a distance of up to $10 \mu \mathrm{m}$ from the cell wall. At the distance of $1 \mu \mathrm{m}$, a dense network is observed with fibril heights of 2-3 nm. At larger distances, C. closterium EPS appeared as a relaxed network of fibrils with incorporated spherical nanoparticles/globules. The fibrils appeared flexible, usually with a curved shape, some of them even forming loops. The globules were found to interconnect two or more fibrils but were also imbedded along a single fibril. The fibril 
heights were in the range of 0.6 to $1.2 \mathrm{~nm}$, while the average height of the incorporated globules was $5 \mathrm{~nm}$. It was hypothesized that the globules are positively charged proteins whose function is the intracellular packing of negatively charged polysaccharide fibrils [35].

\subsection{Biofilm of Cylindrotheca Closterium}

Although several AFM studies exist that explored the nature of diatom biofilms and adhesives [40,45,47,54], visualization of a biofilm has only been achieved by AFM imaging in air [35]. The mica slides were withdrawn from the flasks when the cultures of diatom C. closterium entered the stationary growth phase (after 18 days), washed with ultrapure water and imaged in air after drying.

The observed biofilm appeared as a continuous fibrillar network between predominantly individual cells (Figure 2). Some cells were associated (Figure 2a) and 2-6 cells were captured on a $35 \mu \mathrm{m} \times 35 \mu \mathrm{m}$ scanned biofilm surface. At a higher resolution, the biofilm was visualized as a dense fibrillar network with pore sizes ranging from $50 \mathrm{~nm}$ to $300 \mathrm{~nm}$ (Figure 2b,c). A gradual increase in pore sizes was detected going from the cell wall to the distance of $10 \mu \mathrm{m}$ (Figure 2b). The globules (3-12 nm high) found exclusively on the fibrillar network appear as silica nanoparticles nucleated from the culture medium. Shchipunov and coworkers applied AFM to demonstrate that gel-forming polysaccharides (e.g., carrageenans) promote silica precipitation, serving as a template [55,56]. Comparison of the fibril and globule height analyses in the EPS of the two C. closterium strains and the biofilm grown in a C. closterium (CCNA1) culture is given in Table 1.

Figure 2. AFM image of biofilm grown in a CCNA1 culture formed on a mica slide. (a) Association of cells in the biofilm (height data, vertical scale $1.5 \mu \mathrm{m}$ ); (b) Cell rostrum surrounded by the biofilm network (deflection data); (c) The biofilm network (height data, vertical scale $10 \mathrm{~nm}$ ). Images were acquired in contact mode (reproduced from [35]).
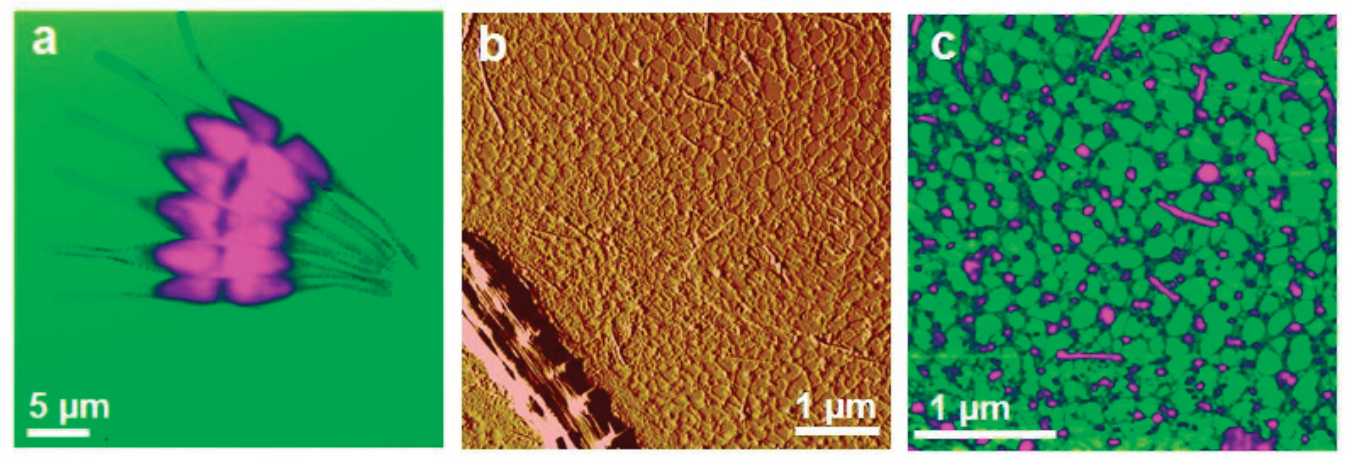
Table 1. Height ranges of the fibrils and globules in the EPS and biofilm of C. closterium strains CCNA1 and CCMP1544 (data from [35]).

\begin{tabular}{cccccccc}
\hline \multirow{2}{*}{ Cell culture } & \multicolumn{3}{c}{ Fibril height/nm } & \multicolumn{3}{c}{ Globule height/nm } \\
& EPS bound to cell & EPS in bulk culture & Biofilm & EPS bound to cell & EPS in bulk culture & Biofilm \\
\hline CCNA1 & $0.4-1.9$ & $0.4-2.2$ & $1.7-4.0$ & $3-12$ & $2-12$ & $3-12$ \\
CCMP1544 & $0.6-1.6$ & $0.7-2.6$ & - & $3-9$ & $2-13$ & - \\
\hline
\end{tabular}

\subsection{Polysaccharide Network in Diatom Colony Formation}

Diatoms have evolved a variety of colonial life forms in which cells are connected by organic threads, mucilage pads or silicate structures. In general, these connecting structures are clearly visible by light or electron microscopy. The colonial planktonic diatom Bacteriastrum jadranum Godrijan, Marić \& Phannkuchen [57] was found to be unusual, since the chain formation does not involve fusion of the setae of adjacent cells [39], unlike all other known colonial Bacteriastrum species [58]. Moreover, no thread or any other organic or inorganic substance clearly visible by light or electron microscopy connects the cells.

Figure 3. Structural details of the cell jacket network obtained by AFM. (A) branching fibril with height analysis along the indicated line; (B) 2D network of interconnect patches; (C) Spatial arrangement of interconnected patches in the 3D collapsed network (3D view). Images were acquired in tapping mode (reproduced from [39]).

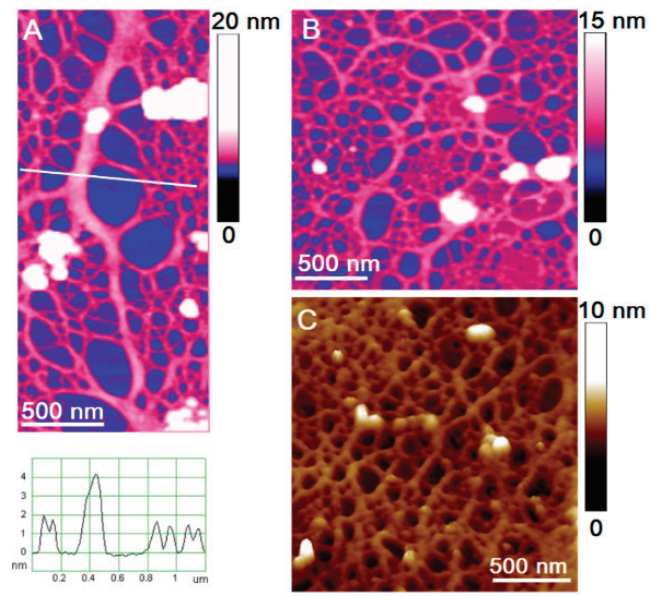

AFM imaging [39] provided the first evidence that B. jadranum cells in colonies are enclosed in a fibrillar polysaccharide network, termed a cell jacket. At nanoscale resolution, the cell jacket appeared as a cross-linked fibrillar network organized into recognizable patterns (Figure 3). Circular high-density domains (patches, Figure 3B), were surrounded and interconnected by thicker fibrils in a continuous network and appear as the basic structural motive. Pores inside a patch were of the same hexagonal shape, 8-100 $\mathrm{nm}$ in size. Their size was continuously smaller from the patch edge toward the center. 
The branching fibrils (Figure 3A) can be considered as the backbone of the network, critical for assuring its integrity. The pore-forming fibrils within the patches were only $0.6-1.6 \mathrm{~nm}$ high, the surrounding fibrils connecting the patches were $2.0-2.8 \mathrm{~nm}$ high, while the branching fibrils were considerably wider but not higher than $4.0 \mathrm{~nm}$. Quantitative analysis of the cell jacket network is given in Table 2 .

Table 2. Cell jacket network: pores and pore-forming fibrils analyzed over a surface area of $4 \times 4 \mu \mathrm{m}^{2}$ (data from [39]).

\begin{tabular}{ccc}
\hline \multicolumn{2}{c}{ Pores } & Pore-forming fibrils \\
\hline size $/ \mathrm{nm}$ & number & height $/ \mathrm{nm}$ \\
\hline $8-100$ & 900 & $0.6-1.6$ \\
$100-160$ & 200 & $2.0-2.8$ \\
$500-1000$ & 10 & $2.5-4.0$ \\
\hline
\end{tabular}

It was concluded that the Bacteriastrum polysaccharide jacket represents an essential part of the cell, as the conjunction of the polymer network with the frustule appears to be extremely tight and such specific and unique patterns were not found in the polysaccharide networks of marine gel imaged by AFM.

\section{AFM of Marine Gel}

The broad polydispersity of marine gels ranges from microscopic to macroscopic dimensions [59]. Santschi and coworkers [60] were the first to use AFM to image individual fibrillar polysaccharides in marine macromolecular organic matter. The massive appearance of gelatinous macroaggregates known as mucilage events $[7,8,61]$ offered a possibility for systematic studies of the marine gel phase using AFM [53,62]. The macromolecular characterization of the isolated polysaccharide fraction using physico-chemical techniques [63] showed that they are polydisperse high-molecular weight heteropolysaccharides, in which at least some of the hydroxyl groups of sugar residues are substituted by ester sulfate groups and to a minor extent by carboxylic groups-uronic acid.

These features, conferring a marked polyelectrolytic behavior of the polysaccharides in salt solutions, were also found for the polysaccharide fraction from C. closterium EPS [36]. The fact that the EPS isolated polysaccharide fraction has the capacity to self-assemble into a gel network (Figure 4) is an important finding, with implications on the mechanism of gel phase formation in marine systems [36]. 
Figure 4. AFM images of polysaccharides isolated from the CCNA1 culture and dissolved in ultrapure water: (a) Single fibrils (concentration $5 \mathrm{mg} / \mathrm{L}$ ) vertical scale $2.5 \mathrm{~nm}$; $(\mathbf{b}, \mathbf{c})$ Fibril networks (concentration $10 \mathrm{mg} / \mathrm{L}$ ), vertical scales: $5 \mathrm{~nm}(\mathbf{b})$ and $10 \mathrm{~nm}(\mathbf{c})$. The height analyses are shown along the indicated lines. The images were acquired in tapping mode and are presented as height data (reproduced from [35]).
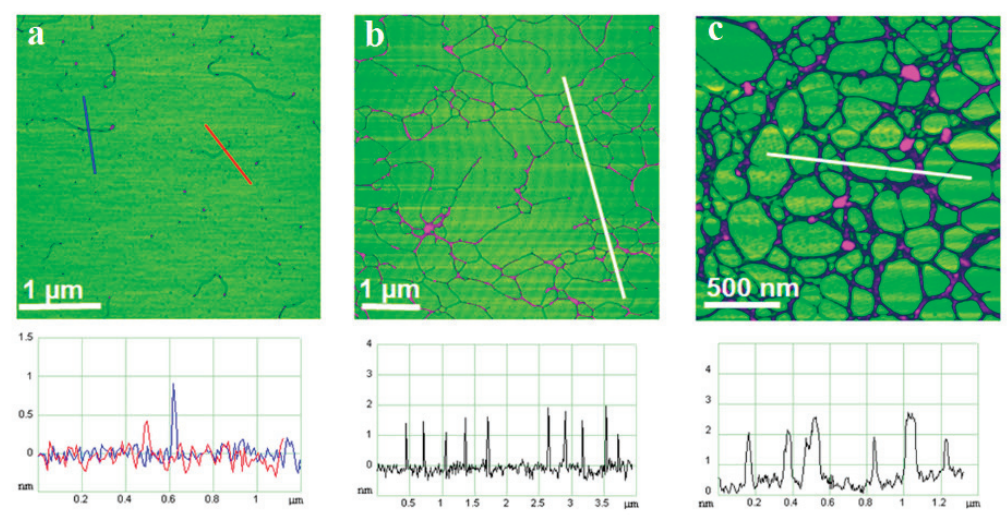

\subsection{Imaging a Polysaccharide Network of Marine Gel}

Development of the protocol for the AFM imaging of the marine gel phase was a critical step. The sampling procedure and specimen preparation protocol for AFM imaging is described in detail by Mišić, Radić et al. [34]. The main organizational features of the polymer gel network were preserved during the transfer of marine gel from seawater to a mica substrate in air. The appearance of a marine gel network at micro and nanometric scales is shown in Figure 5. The gel network imaged by AFM is to a certain extent distorted from the $3 \mathrm{D}$ structure in the aqueous phase due to attachment and stretching on the mica surface. Nevertheless, such constraints make studies of fibril associations at the molecular level that would not be accessible by other techniques possible. AFM imaging of marine gel provided insight into the molecular organization of the gel network and associations between polysaccharide fibrils forming the network. Among the complex network structures, associations of fibrils forming junction zones were identified. Modes of fibril associations into junction zones are exemplified in Figure 6. 
Figure 5. Marine gel fibrils at micro and nanometric scales: (a) A polysaccharide network of marine gel aggregate imaged in seawater by confocal microscopy after FITC-Concavalin A staining; (b,c) High resolution AFM images of marine gel fibrils with different degrees of cross-linking. AFM images were acquired in tapping mode in air using mica as a substrate (reproduced from [53]).
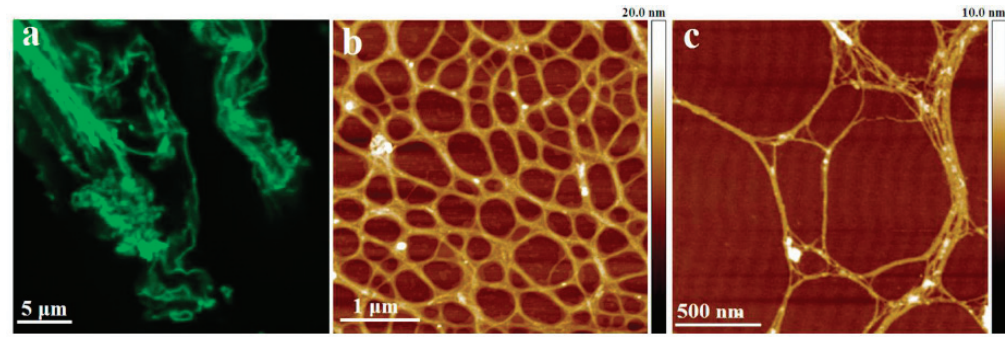

Figure 6. Mode of fibril associations into junction zones obtained by high resolution AFM imaging: (a) Two $0.7 \mathrm{~nm}$ high fibrils forming a $260 \mathrm{~nm}$ long junction zone; (b) Two $1.3 \mathrm{~nm}$ high fibrils forming 70 and $120 \mathrm{~nm}$ long junction zones; (c) Side-by-side association of two $1.6 \mathrm{~nm}$ high fibrils. The images were acquired in contact mode (adapted from [34]).

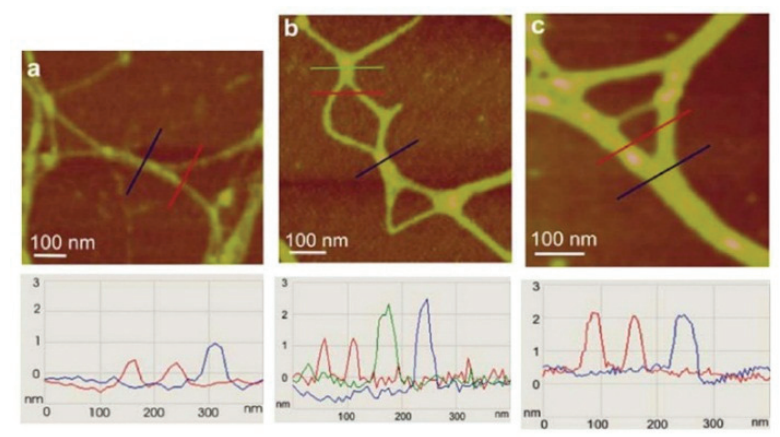

The evolution of polysaccharide fibrils into marine gel during the mucilage event in the northern Adriatic Sea was captured by AFM [36]. The samples were prepared from macroaggregates collected after different residence times in the water column, from the early stage of gel phase formation to the condensed (mature) gel network of an older macroaggregate. The long polymer strands with small patches of initial fibril associations (Figure 7a) coexisted with the continuous gel network shown in Figure $7 \mathrm{~b}$. With a prolonged residence time (one month), a more condensed network was formed, as presented in Figure 7c. 
Figure 7. Evolution of polymer networks in the macroscopic gel phase from the early stage of gel phase formation $(\mathbf{a}, \mathbf{b})$ to the condensed gel network of an older macroaggregate (c). The AFM images were acquired in contact mode and presented as height data, scan size $4 \mu \mathrm{m} \times 4 \mu \mathrm{m}$ (reproduced from [36]).
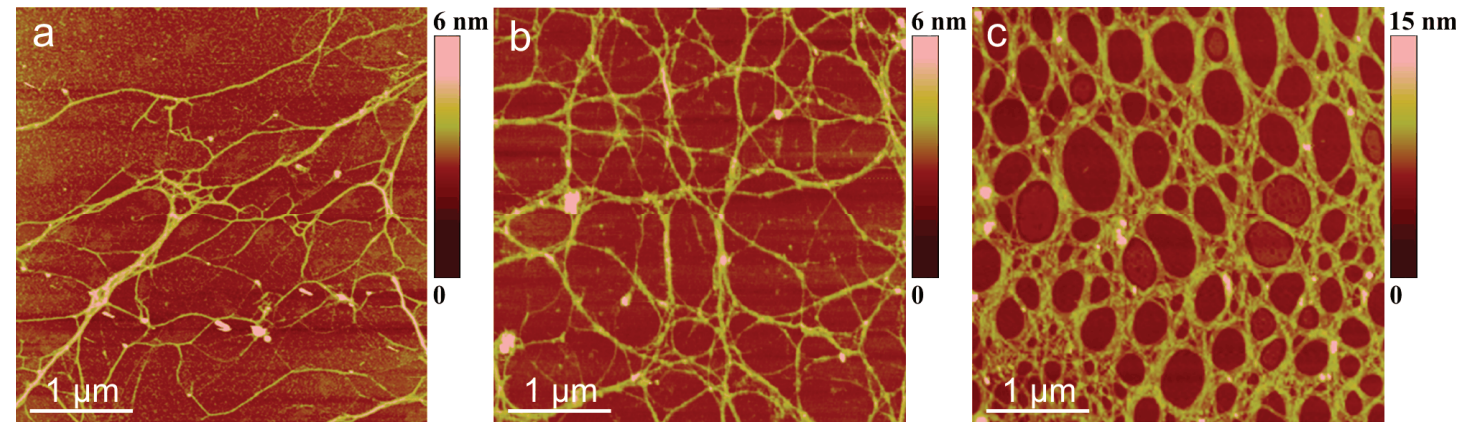

\subsection{Force Spectroscopy of a Marine Gel Network}

The knowledge of the mechanical strength of individual molecular assemblies within a marine gel network contributes to the understanding of the gel phase formation and its persistence in the marine environment. Due to the inherent complexity and heterogeneity of the marine gel phase, it is difficult to isolate the physical forces in the biopolymer network assemblies. However, based on AFM imaging and differential scanning calorimetry, the marine gel was characterized as a thermoreversible physical gel and the dominant mode of gelation was proposed to be the crosslinking of polysaccharide fibrils by hydrogen bonding, which results in helical structures and their associations [34].

Force spectroscopy and high resolution AFM imaging were applied to quantify the intramolecular, interdomain and intermolecular forces within the marine gel network [63,64]. The ability to control the degree of gel network entanglements by dilution and stirring was used to probe marine polysaccharides at different levels of association. The typical events that lead to specific patterns upon stretching include the entropic behavior of individual fibrils (Figure 8) and more complex events, such as the unfolding of polysaccharide entanglements (Figure 9).

Figure 8. Force curves of a single polysaccharide fibril from a disentangled gel network (AFM image shown as the insert) acquired in filtered seawater: approach curve in red and extension curve in blue (adapted from [63]).
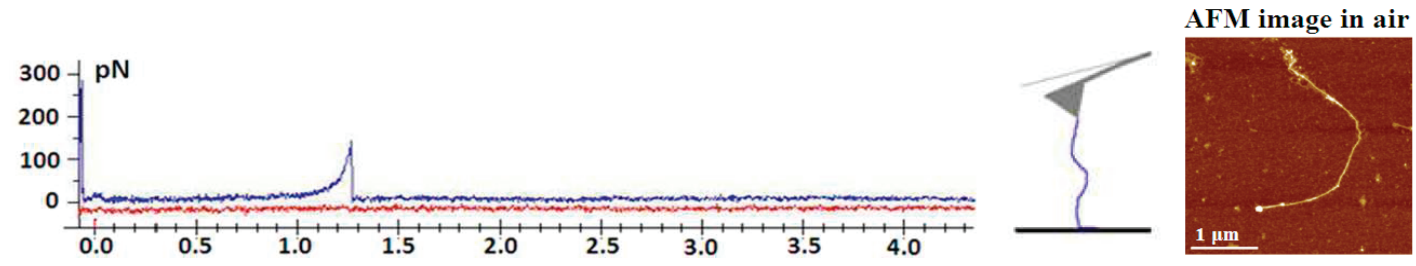
Figure 9. Force curves of polysaccharide fibrils in a marine gel network (AFM image shown as the insert) acquired in filtered seawater: approach curve in red and extension curve in blue (adapted from [63]).

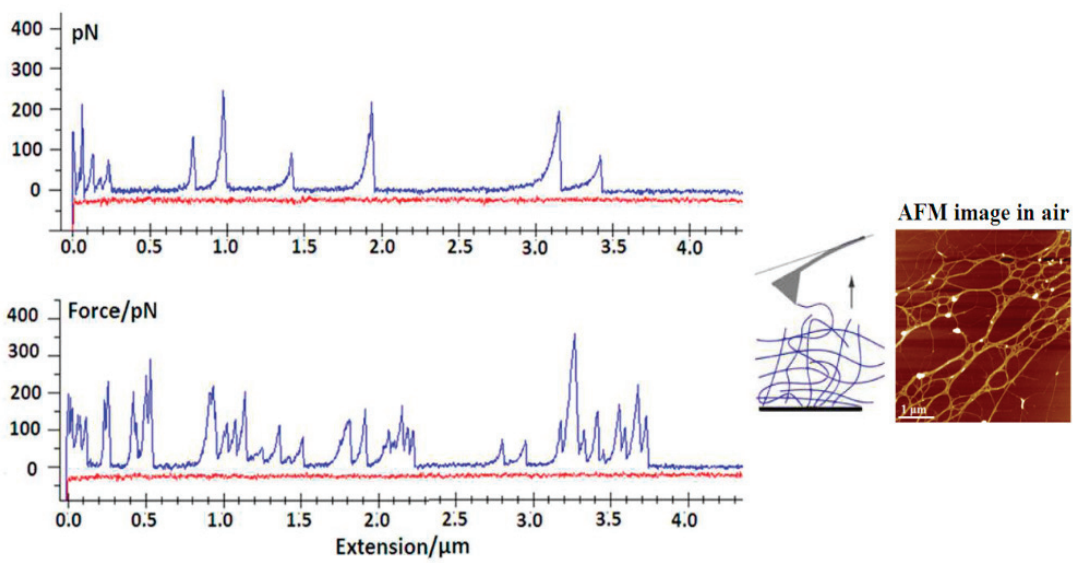

Marine gels are highly extensible, as they may be stretched with very little force to distances of up to several micrometers. Fairly large forces are required to unzip the fibrils, suggesting that lateral stability may be important in maintaining the structural integrity of the marine gel.

\section{Conclusions}

AFM made characterization of diatom polysaccharide networks at the nanometric scale and a clear distinction between the self-assembly and self-organization of these complex systems possible. Marine polysaccharides produced by diatoms are shown to form distinct supramolecular assemblies that are best described as gel networks. These photosynthetically produced macromolecules may stay attached to the cell wall or be released into the environment.

This review encompasses three specific examples of polysaccharide polymer networks attached to the diatom cell wall: (i) Cylindrotheca closterium polymers at the moment of their release; (ii) a C. closterium biofilm grown on an atomically smooth substrate and (iii) a 3D polysaccharide network enclosing a cell colony of planktonic diatom Bacteriastrum jadranum.

Extracellular polymers produced by $C$. closterium exhibit a certain level of self-organization, while the highest level of self-organization was found in a 3D polysaccharide network produced by $B$. jadranum. The polysaccharide fibrillar network of $B$. jadranum represents an essential part of the cell and not a random extracellular polysaccharide structure. With a more generalized use of AFM, it would probably be discovered that there are many similar types of coverings among planktonic diatoms, as well as diatoms adapted to other habitats (e.g., benthos, tychoplankton etc.). This may be additionally extended to a wider range of microalgae and protists. 
In contrast to the networks attached to the diatom cells, free-floating marine gel aggregates are formed by a self-assembly of diatom-released polymers. Structural details of the gel network visualized down to the molecular level revealed monomolecular, helical and superhelical associations.

The physical forces in marine gel network assemblies have been quantified using force spectroscopy together with high resolution AFM imaging. The marine gels appeared highly extensible, as they could be stretched with very little force to distances of up to several micrometers. Such self-assembled networks with randomly distributed microscopic features and high extensibility are capable of responding to environmental conditions, such as change in salinity, temperature, $\mathrm{pH}$ and shear stress, maintaining favorable physiological conditions for microbial communities.

\section{Acknowledgments}

The research was supported by the Croatian Ministry of Science, Education and Sport, the project Surface Forces on an Atomic Scale Applied in Marine Science and Nanotechnology (No. 0982934-2744).

\section{Conflicts of Interest}

The authors declare no conflict of interest.

\section{References}

1. Falkowski, P.; Raven, J.A. Aquatic Photosynthesis; Blackwell: Malden, MA, USA, 1997.

2. Hoagland, K.D.; Rosovski, J.R.; Gretz, M.R.; Roemer, S.C. Diatom extracellular polymeric substances: Function, fine structure, chemistry and physiology. J. Phycol. 1993, 29, 537-566.

3. Underwood, G.J.C.; Paterson, D.M. The importance of extracellular carbohydrate production by marine epipelic diatoms. Adv. Bot. Res. 2003, 40, 184-240.

4. Decho, A.W. Microbial exopolymer secretions in ocean environments: Their role(s) in food webs and marine processes. Oceanogr. Mar. Biol. Annu. Rev. 1990, 28, 73-153.

5. Staats, N.; Stal, L.I.; de Winder, B.; Mur, L.R. Oxygenic photosynthesis as driving process in exopolysaccharide production of benthic diatoms. Mar. Ecol. Prog. Ser. 2000, 193, 261-269.

6. Myklestad, S.M. Release of extracellular products by phytoplankton with special emphasis on polysaccharides. Sci. Total Environ. 1995, 165, 155-164.

7. Vollenweider, R.; Rinaldi, A. Marine mucilages. Sci. Total Environ. 1995, 165, 1-235.

8. Giani, M.; Degobbis, D.; Rinaldi, A. Mucilages in the Adriatic and Tyrrhenian Seas. Sci. Total Environ. 2005, 353, 1-379.

9. Müller-Niklas, G.; Schuster, S.; Kaltenbök, E.; Herndl, G.J. Organic content and bacterial metabolism in amorphous aggregations of the northern Adriatic Sea. Limnol. Oceanogr. 1994, 39, 58-68.

10. Rinaudo, M. Advances in Characterization of Polysaccharides in Aqueous Solution and Gel State. In Polysaccharides-Structural Diversity and Functional Versatiliy, Dumitriu, S., Ed.; Marcel Dekker: New York, NY, USA, 2005; pp. 237-252. 
11. Israelachvili, J.N. Intermolecular and Surface Forces, 3rd ed.; Academic Press: London, UK, 2010.

12. Dimitriu, S. Polysaccharides: Structural Diversity and Functional Versatility, 2nd ed.; Marcel Dekker: New York, NY, USA, 2005.

13. Cesàro, A.; Bellich, B.; Borgogna, M. Biophysical functionality in polysaccharides: From Lego-blocks to nano-particles. Eur. Biophys. J. 2012, 41, 379-395.

14. Higgins, M.J.; Wetherbee, R. The Role of Atomic Force Microscopy in Advancing Diatom Research into the Nanotechnology Era. In Life at the Nanoscale: Atomic Force Microscopy of Live Cells, Dufrene, Y., Ed.; Pan Stanford Publishing: Singapore, 2011; pp. 405-420.

15. Eaton, P.; West, P. Atomic Force Microscopy; Oxford University Press: New York, NY, USA, 2010.

16. Jena, B.P.; Hörber, J.K.H. Force Microscopy: Applications in Biology and Medicine; John Wiley \& Sons: New York, NY, USA, 2006.

17. Dufrene, Y. Life at the Nanoscale: Atomic Force Microscopy of Live Cells; Pan Stanford Publishing: Singapore, 2011.

18. Zhang, W.; Zhang, X. Single molecule mechanochemistry of macromolecules. Prog. Polym. Sci. 2003, 28, 1271-1295.

19. Akai, A. Review on: Atomic force microscopy applied to nano-mechanics of the cell. Adv. Biochem. Eng. Biotechnol. 2010, 119, 47-61.

20. Bustamante, C.; Macosko, J.C.; Wuite, G.J. Grabbing the cat by the tail: Manipulating molecules one by one. Nat. Rev. Mol. Cell Biol. 2000, 1, 130-136.

21. Noy, A. Handbook of Molecular Force Spectroscopy; Springer: Livermore, CA, USA, 2007.

22. Giannotti, M.I.; Vancso, G.J. Interrogation of single synthetic polymer chains and polysaccharides by AFM-based force spectroscopy. Chem. Phys. Chem. 2007, 8, 2290-2307.

23. Zhang, X.; Liu, C.; Wang, Z. Force spectroscopy of polymers: Studying on intramolecular and intermolecular interactions in single molecular level. Polymer 2008, 49, 3353-3361.

24. Kirby, A.R.; Gunning, A.P.; Morris, V.J. Imaging polysaccharides by atomic force microscopy. Biopolymers 1996, 38, 355-366.

25. Morris, V.J.; Kirby, A.R.; Gunning, A.P. Atomic Force Microscopy for Biologists; Imperial College Press: London, UK, 1999.

26. Abu-Lail, N.I.; Camesano, T.A. Polysaccharide properties probed with atomic force microscopy. J. Microsc. 2003, 212, 217-238.

27. Abu-Lail, N.I.; Camesano, T.A. Atomic Force Microscope and Single-Molecule Force Microscopy Studies of Biopolymers. In Dekker Encyclopedia of Nanoscience and Nanotechnology, Schwarz, J., Contescu, C., Putyera, K., Eds.; Taylor \& Francis: London, UK, 2004; pp. 119-131.

28. McIntire, T.M.; Brant, D.A. Imaging of individual biopolymers and supramolecular assemblies using noncontact atomic force microscopy. Biopolymers 1997, 42, 133-146.

29. Ikeda, S.; Morris, V.J.; Nishinari, K. Microstructure of aggregated and nonaggregated kappa-carrageenan helices visualized by atomic force microscopy. Biomacromolecules 2001, 2, 1331-1337. 
30. Keresztes, Z.; Rigó, T.; Telegdi, J.; Kálmán, E. Investigation of biopolymer networks by means of AFM. Appl. Phys. A 2001, 72, 113-116.

31. Funami, T.; Hiroe, M.; Noda, S.; Asai, I.; Ikeda, S.; Nishimari, K. Influence of molecular structure imaged with atomic force microscopy on the rheological behavior of carrageenan aqueous systems in the presence or absence of cations. Food Hydrocolloids 2007, 21, 617-629.

32. Noda, S.; Funami, T.; Nakauma, M.; Asai, I.; Takahashi, R.; Al-Assaf, S.; Ikeda S. Molecular structures of gellan gum imaged with atomic force microscopy in relation to the rheological behavior in aqueous systems. 1. Gellan gum with various acyl contents in the presence and absence of potassium. Food Hydrocolloids 2008, 22, 1148-1159.

33. Svetličić, V.; Balnois, E.; Žutić, V.; Chevalet, J.; Hozić Zimmermann, A.; Kovač, S.; Vdović, N. Electrochemical detection of gel microparticles in seawater. Croat. Chem. Acta 2006, 79, 107-113.

34. Mišić Radić, T.; Svetličić, V.; Žutić, V.; Boulgaropoulos, B. Seawater at the nanoscale: Marine gel imaged by atomic force microscopy. J. Mol. Recognit. 2011, 24, 397-405.

35. Pletikapić, G.; Mišić Radić, T.; Hozić Zimmermann, A.; Svetličić, V.; Pfannkuchen, M.; Marić, D.; Godrijan, J.; Žutić, V. Extracellular polymer release AFM imaging of extracellular polymer release by marine diatom Cylindrotheca closterium (Ehrenberg) Reiman \& J.C. Lewin. J. Mol. Recognit. 2011, 24, 436-445.

36. Svetličić, V.; Žutić, V.; Mišić Radić, T.; Pletikapić, G.; Hozić Zimmerman, A.; Urbani, R. Polymer networks produced by marine diatoms in the northern Adriatic Sea. Mar. Drugs 2011, 9 , 666-679.

37. Pletikapić, G.; Berquand, A.; Mišić Radić, T.; Svetličić, V. Quantitative nanomechanical mapping of marine diatom. J. Phycol. 2012, 48, 174-185.

38. Pletikapić, G.; Vinković Vrček, I.; Žutić, V.; Svetličić, V. Atomic force microscopy characterization of silver nanoparticles interactions with marine diatom cells and extracellular polymeric substance. J. Mol. Recognit. 2012, 25, 309-317.

39. Bosak, S.; Pletikapić, G.; Hozić, A.; Svetličić, V.; Sarno, D.; Viličić, D. A novel type of colony formation in marine planktonic diatoms revealed by atomic force microscopy. PLoS One 2012, 7, e44851.

40. Higgins, M.J.; Crawford, S.A.; Mulvaney, P.; Wetherbee, R. Characterization of the adhesive mucilages secreted by live diatom cells using atomic force microscopy. Protist 2002, 153, 25-38.

41. Higgins, M.J.; Molino, P.; Mulvaney, P.; Wetherbee, R. The structure and nanomechanical properties of the adhesive mucilage that mediates diatom-substratum adhesion and motility. J. Phycol. 2003, 39, 1181-1193.

42. Higgins, M.J.; Sader, J.E.; Mulvaney, P.; Wetherbee, R. Probing the surface of living diatoms with atomic force microscopy: The nanostructure and nanomechanical properties of the mucilage layer. J. Phycol. 2003, 39, 722-734. 
43. Dugdale, T.M.; Dagastine, R.; Chiovitti, A.; Mulvaney, P.; Wetherbee, R. Single adhesive nanofibres from a live diatom have the signature fingerprint of modular proteins. Biophys. $J$. 2005, 89, 4252-4260.

44. Dugdale, T.M.; Dagastine, R.; Chiovitti, A.; Wetherbee, R. Diatom adhesive mucilage contains distinct supramolecular assemblies of a single modular protein. Biophys. J. 2006, 90, 2987-2993.

45. Dugdale, T.M.; Willis, A.; Wetherbee, R. Adhesive modular proteins occur in the extracellular mucilage of the motile, pennate diatom phaeodactylum tricornutum. Biophys. J. 2006, 90, L58-L60.

46. Rief, M.; Gautel, M.; Oesterhelt, F.; Fernandez, J.M.; Gaub, H.E. Reversible unfolding of individual titin immunoglobulin domains by AFM. Science 1997, 16, 1109-1112.

47. Arce, F.T.; Avci, R.; Beech, I.B.; Cooksey, K.E.; Wigglesworth-Cooksey, B. A live bioprobe for studying diatom-surface interactions. Biophys. J. 2004, 87, 4284-4297.

48. Staats, N.; de Winder, B.; Stal, L.J.; Mur, L.R. Isolation and characterization of extracellular polysaccharides from the epipelic diatoms Cylindrotheca closterium and Navicula salinarum. Eur. J. Phycol. 1999, 34, 161-169.

49. Staats, N.; Stal, L.J.; Mur, L.R. Exopolysaccharide production by the epipelic diatom Cylindrotheca closterium: Effects of nutrient conditions. J. Exp. Mar. Biol. Ecol. 2000, 249, 13-27.

50. Alcoverro, T.; Conte, E.; Mazzella, L. Production of mucilage by the Adriatic epipelic diatom Cylindrotheca closterium (Bacillariophyceae) under nutrient limitation. J. Phycol. 2000, 36, 1087-1095.

51. Smith, D.J.; Underwood, G.J.C. Production of extracellular carbohydrates by estuarine benthic diatoms: The effects of growth phase and light and dark treatment. J. Phycol. 2000, 36, 321-333.

52. De Brouwer, J.F.C.; Stal, L.J. Daily fluctuations of exopolymers in cultures of the benthic diatoms Cylindrotheca closterium and Nitzschia sp. (Bacillariophyceae). J. Phycol. 2002, 38, 464-472.

53. Pletikapić, G. Nanomechanical Properties of Diatom Cell Surfaces and Extracellular Polymers. Ph.D. Thesis, University of Zagreb, Zagreb, Croatia, March 2013.

54. Stal, L.J.; de Brouwer, J.F.C. Biofilm formation by benthic diatoms and their influence on the stabilization of intertidal mudflats. Berichte-Forschungszentrum Terramare 2003, 12, 109-111.

55. Shchipunov, Y.A. Sol-gel-derived biomaterials of silica and carrageenans. J. Colloid Interface Sci. 2003, 268, 68-76.

56. Shchipunov, Y.A.; Kojima, A.; Imae, T. Polysaccharides as a template for silicate generated by sol-gel processes. J. Colloid Interface Sci. 2005, 285, 574-580.

57. Godrijan, J.; Marić, D.; Imešek, M.; Janeković, I.; Schweikert, M.; Pfannkuchen , M. Diversity, occurrence, and habitats of the diatom genus Bacteriastrum (Bacillariophyta) in the northern Adriatic Sea, with the description of B. jadranum sp. nov. Bot. Mar. 2012, 55, 1-12.

58. Sarno, D.; Zingone, A.; Marino, D. Bacteriastrum parallelum sp. nov., a new diatom from the Gulf of Naples, and new observations on B. furcatum (Chaetocerotaceae, Bacillariophyta). Phycologia 1997, 36, 257-266. 
59. Verdugo, P.; Alldredge, A.L.; Azam, F.; Kirchman, D.L.; Passow, U.; Santschi, P.H. The oceanic gel phase: A bridge in the DOM-POM continuum. Mar. Chem. 2004, 92, 67-85.

60. Santschi, P.H.; Balnois, E.; Wilkinson, K.J.; Zhang. J.; Buffle, J. Fibrillar polysaccharides in marine macromolecular organic matter as imaged by atomic force microscopy and transmission electron microscopy. Limnol. Oceanogr. 1998, 43, 896-908.

61. Svetličić, V.; Žutić, V.; Hozić Zimmermann, A. Biophysical scenario of giant gel formation in the northern Adriatic Sea. Ann. N. Y. Acad. 2005, 1048, 524-527.

62. Mišić Radić, T. Supramolecular organization of marine gel biopolymers studied by atomic force microscopy. Ph.D. Thesis, University of Zagreb, Zagreb, Croatia, October 2010.

63. Urbani, R.; Sist, P.; Pletikapić, G.; Mišić Radić, T.; Svetličić, V.; Žutić, V. Diatom Polysaccharides: Extracellular Production, Isolation and Molecular Characterization. In The Complex World of Polysaccharide, Karunaratn, D.N., Ed.; Intech: Rijeka, Croatia, 2012; pp. 346-356.

64. Svetličić, V.; Pletikapić, G.; Mišić Radić, T.; Kellermayer, M.S.Z.; Brujić, J. Force spectroscopy of marine polysaccharides: From gel networks to individual fibrils. Technical Report for AFMBiomed Conference: Shanghai, China, May 2013. 


\title{
Biofilms' Role in Planktonic Cell Proliferation
}

\section{Elanna Bester, Gideon M. Wolfaardt, Nahid B. Aznaveh and Jesse Greener}

\begin{abstract}
The detachment of single cells from biofilms is an intrinsic part of this surface-associated mode of bacterial existence. Pseudomonas sp. strain CT07gfp biofilms, cultivated in microfluidic channels under continuous flow conditions, were subjected to a range of liquid shear stresses $(9.42 \mathrm{mPa}$ to $320 \mathrm{mPa}$ ). The number of detached planktonic cells was quantified from the effluent at 24-h intervals, while average biofilm thickness and biofilm surface area were determined by confocal laser scanning microscopy and image analysis. Biofilm accumulation proceeded at the highest applied shear stress, while similar rates of planktonic cell detachment was maintained for biofilms of the same age subjected to the range of average shear rates. The conventional view of liquid-mediated shear leading to the passive erosion of single cells from the biofilm surface, disregards the active contribution of attached cell metabolism and growth to the observed detachment rates. As a complement to the conventional conceptual biofilm models, the existence of a biofilm surface-associated zone of planktonic cell proliferation is proposed to highlight the need to expand the traditional perception of biofilms as promoting microbial survival, to include the potential of biofilms to contribute to microbial proliferation.
\end{abstract}

Reprinted from Int. J. Mol. Sci. Cite as: Bester, E.; Wolfaardt, G.M.; Aznaveh, N.B.; Greener, J. Biofilms' Role in Planktonic Cell Proliferation. Int. J. Mol. Sci. 2013, 14, 21965-21982.

\section{Introduction}

The detachment of single cells or aggregates of cells from biofilms is increasingly recognized as an intrinsic part of this surface-associated mode of bacterial existence. The detachment or dispersal of cells from the biofilm is typically viewed as the "final" step in biofilm development, as reviewed by [1], which enables a fraction of the biofilm-associated cells to escape unfavorable conditions within the biofilm and initiate the establishment of a new biofilm elsewhere. While this conceptual view of biofilm development as a linear process, consisting of five consecutive phases [2], can be beneficial in elucidating the various biotic and abiotic factors that influence biofilm formation, it can also obscure the fact that detachment does occur during earlier stages of the biofilm life-cycle and is not restricted to "mature" biofilm microcolonies only. For example it was estimated that up to $44 \%$ of Pseudomonas aeruginosa PA01 cells emigrated within the first $35 \mathrm{~h}$ of attachment [3].

Different detachment mechanisms have been identified and are generally classified as either passive or active based on whether the removal of attached biomass is due to factors such as human intervention (i.e., antimicrobial treatment), the result of abiotic forces (i.e., increase shear or particle abrasion), or an active microbial response to environmental cues that requires genetic regulation.

The rapid dissolution of biofilms of various Pseudomonad species in response to changes in carbon and nitrogen availability has been reported [4-6]. Large numbers of planktonic cells were observed to 
be swimming away from a previously stable $P$. putida biofilm within minutes of the removal of carbon from the growth medium, or a cessation in the liquid flow [5]. A decrease in the amount of intracellular secondary signaling molecule cyclic-di-GMP was found to induce biofilm dispersal through the induction of the LapG cysteine proteinase, which in turn modified the adhesion protein LapA, thereby dissolving the biofilm [7]. This observation indicates that individual cells have the ability to dissociate themselves from their neighbors and/or the biofilm matrix.

"Seeding dispersal", describes a process where large $(>80 \mu \mathrm{m}$ diameter $) P$. aeruginosa PAO1 microcolonies break open to release a subpopulation of planktonic cells into the bulk-liquid [8]. It is as yet unclear how widespread this phenomenon is among different bacterial species or whether the above-mentioned global dispersion-response to changes in the environment occurs by the same mechanism(s).

From a mass balance point of view, biofilm development is the net result of biomass accumulation and biomass detachment or decay. Indeed, biofilm biomass does not accumulate indefinitely, but instead a pseudo steady state is reached, where further growth is balanced by detachment or decay. Passive biofilm detachment mechanisms have been defined, somewhat arbitrarily, as erosion or sloughing, based on the detachment frequency and size of the detached particle, in addition to biomass removal due to abrasion, predator grazing or human intervention strategies [9]. The term "erosion" is frequently used to describe one of the most common, and likely underestimated, biofilm detachment processes. While erosion is defined in the Merriam-Webster Learner's Dictionary as "the gradual destruction of something by natural forces", or "the process by which something is worn away", in biofilm-related literature the term "erosion" has been defined as the "continuous removal of small particles of biofilm" and is "presumed to be the result of shear forces exerted by moving fluid in contact with the biofilm surface" [10]. In order to sustain a continuous detachment rate while maintaining a pseudo steady state biofilm structure, continuous growth by the attached biomass is required. In fact, from a theoretical examination of a biofilm mass balance, it is evident that the maximum sustainable detachment rate is governed by the biomass growth rate [10].

Previous work by Rittman in 1982 [11] proposed a model wherein the rate of biofilm erosion due to liquid shear stress was dependent on the amount of attached biofilm, based on the analysis of a subset of empirical data produced by Trulear and Characklis (1982) [12] for aerobic, multispecies biofilms cultivated in an annular reactor and subjected to different shear forces. Subsequent experimentation by Peyton and Characklis (1993) [10] investigated the response of multispecies and pure culture Pseudomonas aeruginosa biofilms to variations in shear stress $(1.44,2.20$, or $2.97 \mathrm{~Pa})$ and substrate availability $\left(0.8,4.0\right.$, or 7.2 grams glucose carbon $\left.\mathrm{m}^{-3}\right)$. Biofilm substrate utilization rates and erosion rates were shown to increase with an increase in biofilm biomass, as proposed by the previous model [11]. However, contrary to this model, the erosion rates were not directly related to the applied liquid shear stress, but instead to the substrate loading rates; where an increase in carbon availability led to an increase in the detachment rate. The authors furthermore re-analyzed the full data set 
previously published [12] and found no indication of a linear relationship between biofilm erosion rates and the applied shear stress $\left(r^{2}=0.00038\right)$.

Stewart (1993) [13] further reinforced the link between a metabolically active biofilm region, responsible for carbon utilization, and biofilm detachment. Several mathematical expressions were derived to explain biofilm detachment, one of which explicitly accounted for spatial variation of growth rates within the biofilm. This expression provided a good qualitative prediction of detachment rates for the empirical steady state data from Trulear and Characklis (1982) [12].

Despite the existence of these publications, the presence of single cells in the effluent of continuous-flow biofilm cultivation systems is still often ascribed to the erosion of the biofilm surface solely due to liquid shear stress [14-16].

Previous work by our group has detailed the extent to which single and multi-species biofilms cultivated under continuous flow conditions in glass tubes produced and released planktonic cells to the bulk-liquid. Contrary to the accepted 5-stage model of biofilm development where dispersion of single cells from the biofilm only takes place upon maturation of a microcolony, an increase in planktonic cell numbers was evident as early as 6 hours after reactor inoculation [17,18]. The planktonic cell numbers in the effluent continued to increase during biofilm development and generally reached a plateau after 3 to 4 days, likely once the biofilm biomass reached a pseudo steady state. Variation in the bulk-liquid flow rates, leading to average shear rates ranging from $19.1 \times 10^{-3} \mathrm{mPa}$ to $93.9 \mathrm{mPa}$, did not result in a linear response in the magnitude of planktonic cells enumerated from the effluent, as would be expected if shear erosion was the dominant determinant of detachment (use of the term "average" to describe shear rates is due to the variation in shear rates along the cross section of a channel; lower shear rates will be present near the walls, with high shear rates in the center). Instead, the impact of reduced flow rates on the availability of nutrients and/or oxygen on biofilm development was found to be a greater determinant of planktonic cell numbers [18]. The removal of the sole carbon source, while maintaining a constant average shear stress, was shown to not only reduce the metabolic activity of a biofilm to below detection limits, but was accompanied by a 1 to 2 order of magnitude reduction in the number of viable planktonic cells produced by the biofilm [19]. Upon the re-introduction of carbon after eight days of starvation, the pre-disturbance levels of planktonic cell yield and $\mathrm{CO}_{2}$ respiration rates were re-established within $24 \mathrm{~h}$.

To distinguish these observations from the widely held erosion-mediated cell removal and to emphasize the role played by microbial physiology, we proposed the use of the term "biofilm-derived planktonic cell yield" to describe this process.

The use of square glass tubes with a comparatively large cross sectional area $\left(0.04 \mathrm{~cm}^{2}\right)$, restricted the period of time during which biofilms could be subjected to high shear rates due to the large volumes of sterile growth media required. For example, a continuous flow rate of $450 \mathrm{~mL} \mathrm{~h}^{-1}$, which results in an average shear stress of $93.9 \mathrm{mPa}$ in an uncolonized glass tube, could only be maintained for $12 \mathrm{~h}$ in a typical laboratory continuous flow system [18]. Using microfluidic flowcells, we quantify various biofilm parameters as well as biofilm-derived planktonic cell yield under higher average shear 
stresses than those applied previously to determine whether Pseudomonas sp. strain CT07gfp biofilms can maintain their physical structure (biomass) as well as the continuous yield of planktonic cells if subjected to significant removal forces.

\section{Results and Discussion}

\subsection{Biofilm-Associated Planktonic Cell Production}

The bulk-liquid flow rates at which the growth medium was supplied to the microfluidic channels resulted in dilution rates that greatly exceeded the maximum rate at which Pseudomonas sp. strain CT07gfp can replicate when growing in suspension. Consequently, it is assumed that an independently replicating planktonic population of bacteria would be incapable of persisting in the bulk-liquid phase of the channels. The culturable cell numbers enumerated from the effluent samples were thus presumed to originate from surface-associated growth. The majority of the detached biomass particles in the effluent consisted of single or dividing cells, whereas the presence of large sloughed aggregates of cells were rarely observed (data not shown).

Comparatively small differences in the rate of planktonic cell production by biofilms subjected to a large range of shear stresses is evident from Figure 1, apart from the lowest shear rate $(9.42 \mathrm{mPa})$ where the numbers of cells present in the effluent were consistently lower. Statistical analysis indicated a significant difference between the cell yield from biofilms subjected to the lowest shear stress $(9.42 \mathrm{mPa})$ and those at higher shear stresses $\left(P_{0.05}=1.36 \times 10^{-5}\right)$. The reduced flux of nutrients to the biofilm was probably a major cause for the lower cell yield, which is in agreement with the earlier observations [13] regarding the link between carbon utilization and biofilm detachment. The rate of planktonic cell production generally increased slightly over the course of incubation and peaked at the production of $\sim 10^{7}$ cells per $\mathrm{cm}^{2}$ of internal channel surface area per hour, for biofilms subjected to the higher shear rates $(95.9 \mathrm{mPa}, 160 \mathrm{mPa}$ and $320 \mathrm{mPa})$. Two-factor ANOVA and subsequent Post Hoc analysis indicated a statistically significant higher yield from 96 hour-old biofilms subjected to $320 \mathrm{mPa}$ than younger biofilms exposed to the same shear stress $\left(P_{0.05}=1.14 \times 10^{-5}\right)$. This observation is somewhat unexpected, since the cell yield generally exhibits only minor fluctuation once biofilm development reaches a steady state after 3 to 4 days of cultivation. 
Figure 1. The viable cell numbers (colony forming units (CFU) per $\mathrm{mL}$ of effluent) released from biofilms, normalized with respect to the bulk-liquid flow rate $\left(\mathrm{mL} \mathrm{h}^{-1}\right)$ and total substratum area $\left(\mathrm{cm}^{2}\right)$ available for cell attachment and biofilm development. Biofilms were allowed to develop in replicate microfluidic channels for up to $96 \mathrm{~h}$ under different bulk-liquid flow velocities; thereby subjecting the biofilms to a wide range of average fluid shear rates $(\mathrm{mPa})$. Error bars indicate the standard deviation of samples taken from replicate biofilms (two experimental rounds, with each round consisting of biofilms growing in two microfluidic channels).

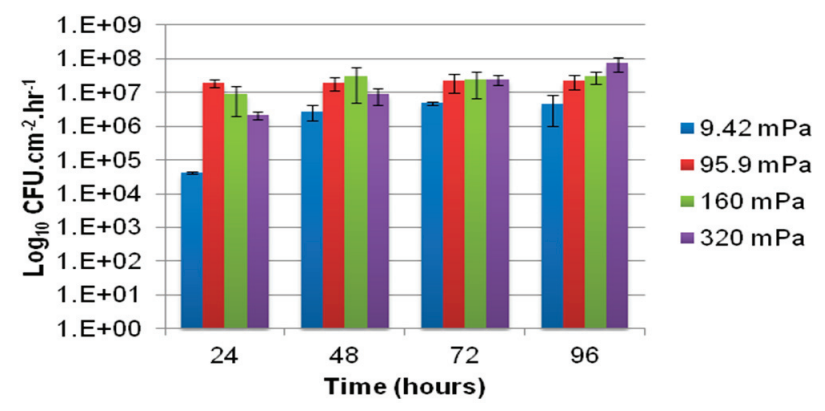

\subsection{Biofilm Morphology}

The extent of biofilm development was quantified by confocal scanning laser microscopy (CLSM) and subsequent analysis of average biofilm thickness with COMSTAT (Figure 2). Biofilm development under the lowest average shear rate $(9.42 \mathrm{mPa})$ was significantly lower, with a decline in the amount of attached biomass over the course of $96 \mathrm{~h}$ (Figure 3), likely due to a lack of nutrients and/or oxygen. In contrast, the average thickness of the biofilms exposed to higher shear rates (and thus higher substrate loading rates) generally increased due to attached cell growth.

Figure 2. The average thickness of microfluidic channel biofilms as determined by COMSTAT analysis of replicate confocal scanning laser microscopy (CLSM) Z-stacks. The biofilms were subjected to four different bulk-liquid flow velocities to exert a wide range of bulk shear stresses on the biofilms during development. Error bars indicate the standard deviation of the average thickness of duplicate biofilms, cultivated in separate microfluidic channels. Ten microscope fields, each with an area of $101,761 \mu^{2}$ $(318 \mu \mathrm{m} \times 318 \mu \mathrm{m})$, were chosen at random along a central transect starting from the channel inlet, and a Z-stack of images was captured in the $z$-direction at $0.60 \mu \mathrm{m}$ intervals.

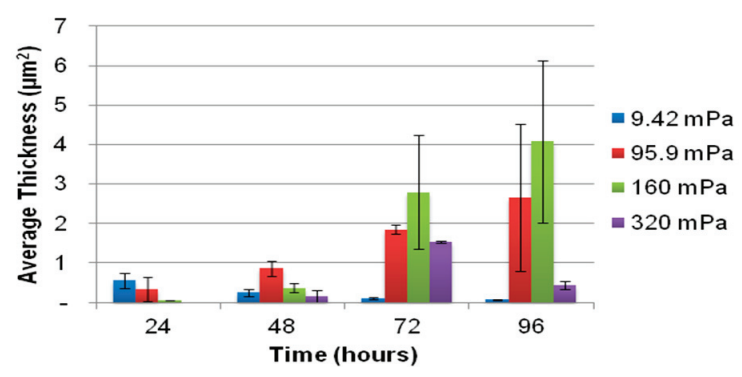


Figure 3. Representative CLSM orthogonal projections of stacks of images taken of the various biofilms at $0.6 \mu \mathrm{m}$ depth intervals. The main part of each image consists of a single $2 \mathrm{D}$ slice of the biofilm ( $x y$-direction) whereas the smaller side panels below ( $x z$-direction) and to the right ( $y z$-direction) indicate a digital projection of the depth of biofilm biomass from the attachment surface to the bulk-liquid interface. A scale bar indicating $50 \mu \mathrm{m}$ is included in the bottom left image.

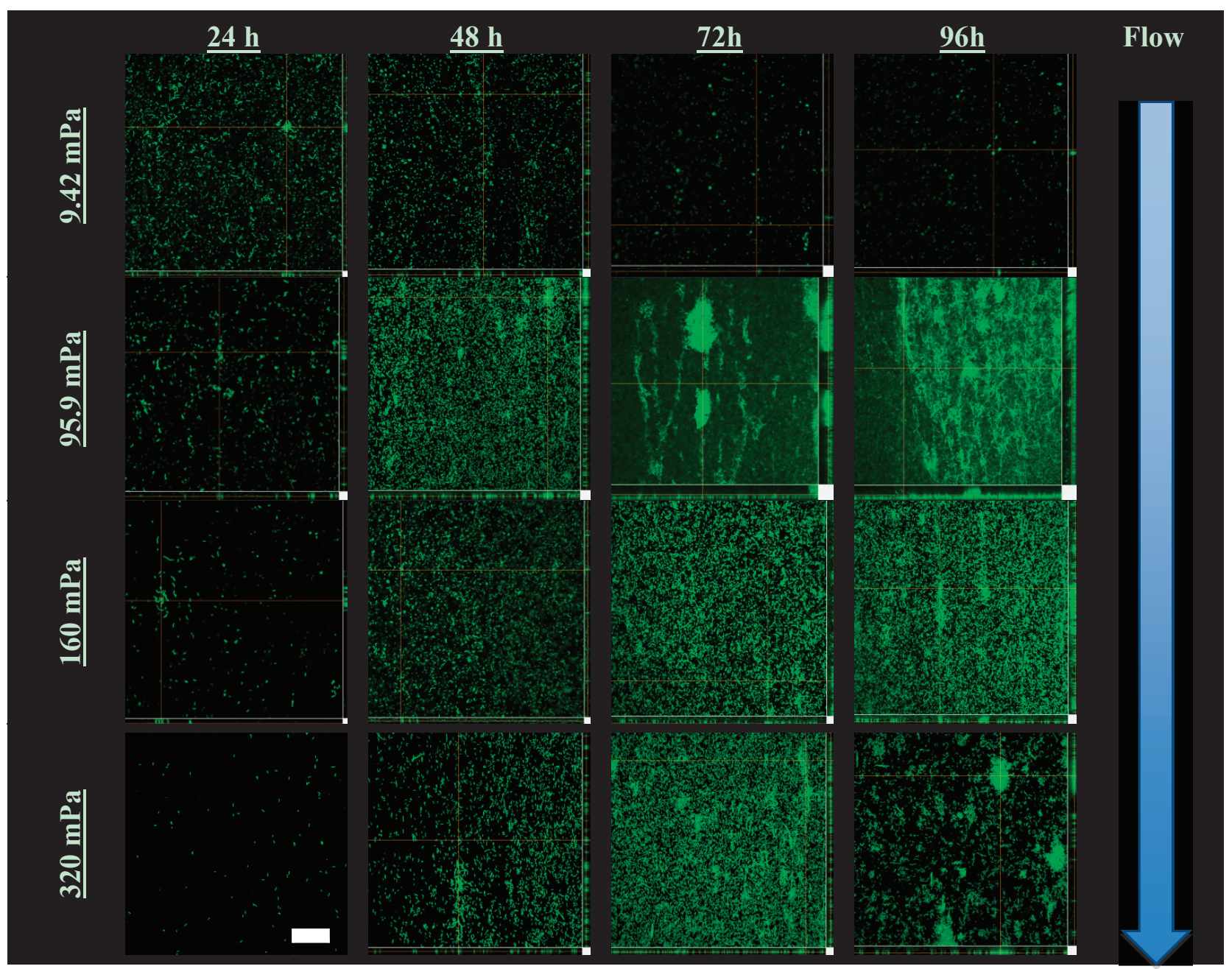

Higher flow velocities increase substrate supply and thus availability, which supports the accumulation of greater amounts of attached biomass. However, higher flow velocities also exert more significant shear stresses on the biomass, leading to a greater probability of biomass detachment. The highest shear rates applied in this study were not sufficient to prevent biofilms from developing at the glass surface, although a decrease in the average biofilm thickness at $96 \mathrm{~h}$ (Figure 2) may suggest that the narrowing of the channel's cross section due to biofilm development on the channel walls increased the bulk average shear rate to such an extent that a portion of the attached biomass was unable to resist shear mediated detachment. Despite the reduction in average biofilm thickness, the yield of planktonic 
cells to the bulk-liquid was observed to increase, (Figure 1), which suggests that biofilms maintain their proliferation function under a wide range of flow conditions and biofilm form.

The development of chains of cells and the formation of large ridges of matrix-embedded cells interconnecting individual microcolonies were also observed. As could be expected, these ridges or filaments were oriented parallel to the direction of flow, as could be noted for 72 and 96 hour-old biofilms subjected to a shear stress of $95.9 \mathrm{mPa}$ and 96 hour-old biofilms subjected to $160 \mathrm{mPa}$ (Figure 3).

CLSM projections (Figure 3) illustrate the morphology of biofilms developing under the different shear stresses. The use of the $40 \times$ objective during microscopy facilitated the capture of the variation in biofilm morphology along the majority of the entire cross section of each channel. The reduction in local shear rates in the vicinity of the corners of the channels (where the glass substratum meets the walls of the microfluidic channels), compared to the higher shear removal forces operating along the center of the channel, allowed more biofilm biomass to accumulate near the wall. This is evident from the large amounts of green fluorescent biomass present towards the right hand of some of the projections (95.9 $\mathrm{mPa}$ at 72 and $96 \mathrm{~h}$, Figure 3). The heterogeneity in the amount of biomass developing along the cross section (perpendicular to flow), as well as the length of each channel (in line with the flow from in- to outlet), is reflected in the large standard deviations in the average biofilm thickness (Figure 2).

\subsection{Relationship between Average Shear Rates and Planktonic Cell Production Rates}

Previously published data [18] on the influence of shear rates on Pseudomonas sp. strain CT07 biofilms cultivated in macroscopic square glass tubes using the same growth medium, is combined with the data from Figure 1 and presented in Figure 4 for comparative purposes. Apart from the reduced planktonic cell production rates from biofilms subjected to the lowest average shear rates $\left(19.1 \times 10^{-3} \mathrm{mPa}\right.$ in the Glass tubes, and $9.42 \mathrm{mPa}$ in the Microfluidic channels), likely due to restricted nutrient and oxygen availability, the general rates at which planktonic cells were produced and released did not vary substantially for a range of average shear stresses spanning 2 orders of magnitude. These data do not support the prevailing assumption that the magnitude of the shear stresses applied to biofilms determines the extent of single cell detachment due to erosive action.

A recent report [16] described the effect of successive step increases in wall shear stress on multispecies biofilm detachment rates; the area of the detached particles were used to empirically distinguish between eroded particles $\left(0.04 \mu \mathrm{m}^{2}\right.$ to $\left.5 \mu \mathrm{m}^{2}\right)$ and sloughed aggregates $\left(>5 \mu \mathrm{m}^{2}\right)$. The first increase from $5.1 \mathrm{mPa}$ to $21.8 \mathrm{mPa}$ (4-fold increase) did not result in a significant increase in the frequency of erosion or sloughing, whereas a further doubling of shear stress to $43.6 \mathrm{mPa}$ significantly increased the occurrence of sloughing as well as erosion. This led the authors to suggest that "a critical shear stress exists, below which the erosion rate is independent of shear stress". If this statement is applicable, the highest shear stress applied in this study $(320 \mathrm{mPa})$ still remains below the "critical shear stress' required to erode the biofilm. 
Figure 4. A comparison of biofilm-associated planktonic cell production rates from biofilms grown in microfluidic channels (MF, this study) and square glass tubes (GT, reference [18]) subjected to a wide range of average shear rates by varying the bulk-liquid flow rates. The inner dimensions of the square glass tubes were $2 \mathrm{~mm} \times 2 \mathrm{~mm} \times 152.4 \mathrm{~mm}$ (Friedrich \& Dimmock, Inc., Millville, NJ, USA).

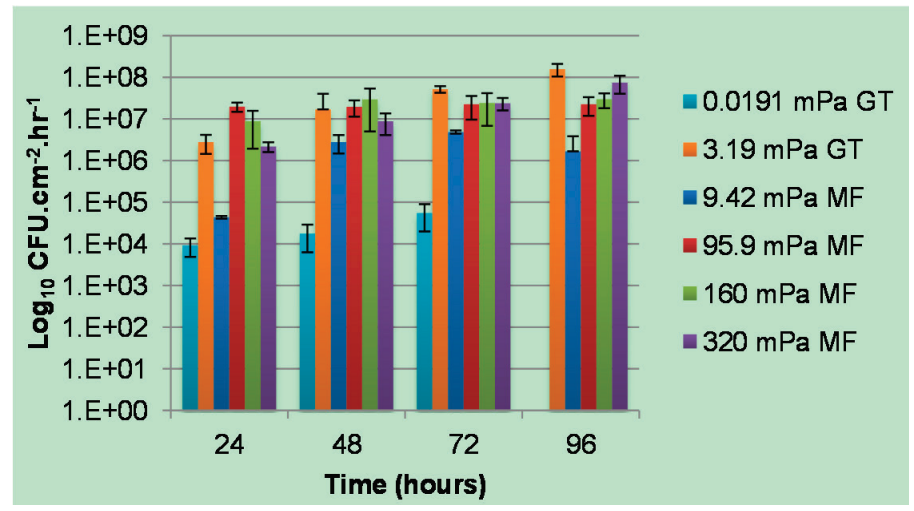

When shear mediated detachment from biofilms is modeled mathematically, the mathematical expression for the detachment rate is often defined to be dependent on biofilm thickness and/or biofilm biomass, since thicker biofilms extending into the bulk-liquid would be subjected to higher shear forces [11,20,21]. However, upon analysis of an extensive set of data [13], it was concluded that expressions of a first- or second-order dependence of the detachment rate on biofilm biomass alone did not fit the empirical data. Instead, an expression also incorporating microbial growth rates, which are dependent on substrate availability, was found to provide a better description [13].

A positive correlation between an increase in the surface area of the biofilm and the number of planktonic cells present in the bulk-liquid phase associated with biofilm reactors could support a role for both active and passive detachment mechanisms. It can be hypothesized that an increase in the biofilm surface area (due to a more varied topography) would expose a greater number of attached cells to optimal nutrient and/oxygen supply from the bulk-liquid as well as the removal of toxic metabolites. These favorable conditions would lead to higher overall growth and cell division rates and together with the increase in biofilm surface area, would increase the potential for active release of newly formed daughter cells to the bulk-liquid after cell division. Similarly, it can be argued that liquid-mediated shear erosion may also lead to the removal of more cells by passive erosive detachment from the biofilm surface upon an increase in the area of the biofilm exposed to liquid shear.

The biofilm surface area $\left(\mu \mathrm{m}^{2}\right)$ exposed to the bulk-liquid was accordingly calculated (Figure 5a) using the results of COMSTAT analysis, as detailed in the Experimental section. To our knowledge this has not been attempted before, however, the values obtained correlated well with the degree of biofilm development, as evident from the average biofilm thickness (Figure 2) and the extent of substratum coverage (Figure 3). The values were utilized to investigate whether a correlation between the extent of planktonic cell yield and biofilm surface area could be identified for biofilms subjected to 
different shear forces (Figure $5 b$ ). The data from Figure $5 b$ does not seem to support a linear relationship between the biofilm surface area and the number of cells yielded or eroded from the biofilm, for any of the different average shear rates.

This result demonstrates the self-regulating ability of biofilms to maintain function under various conditions; in this case the proliferation function, expressed as biofilm-to-planktonic cell yield, remained relatively stable when the variable was shear rate. The great variety of biofilm composition (cells and EPS matrix) and structure described in the literature suggests that a notable degree of plasticity enables such self-regulation and the ability to maintain biofilm function under varying conditions of shear stress or substrate/nutrient type and availability, reactor configuration, etc. It is evident from the results presented here that shear stress (i.e., "erosion") alone cannot account for the numbers of biofilm-derived planktonic cells present in the effluent.

Figure 5. (a) The area of the biofilm $\left(\mu \mathrm{m}^{2}\right)$ exposed to the bulk-liquid environment was calculated for each Z-stack from data obtained after COMSTAT analysis of the CLSM images. The grey bar indicates the area of the glass substratum; note that the incomplete coverage of the glass surface, and the patchy nature of biofilms as evident in Figure 3, explains why the area of the glass surface often exceeds that of the biofilms; (b) The relationship between the average cell production rate $\left(\log _{10} \mathrm{CFU} . \mathrm{cm}^{-2} \mathrm{~h}^{-1}\right)$ and the surface area of the biofilm $\left(\log _{10} \mu \mathrm{m}^{2}\right)$ exposed to the bulk-liquid, for biofilms developed at 4 different average shear rates.

(a)

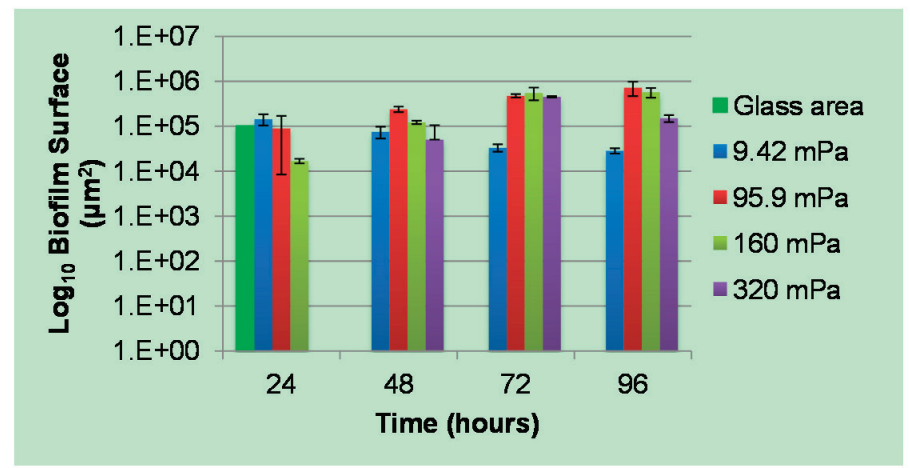

(b)

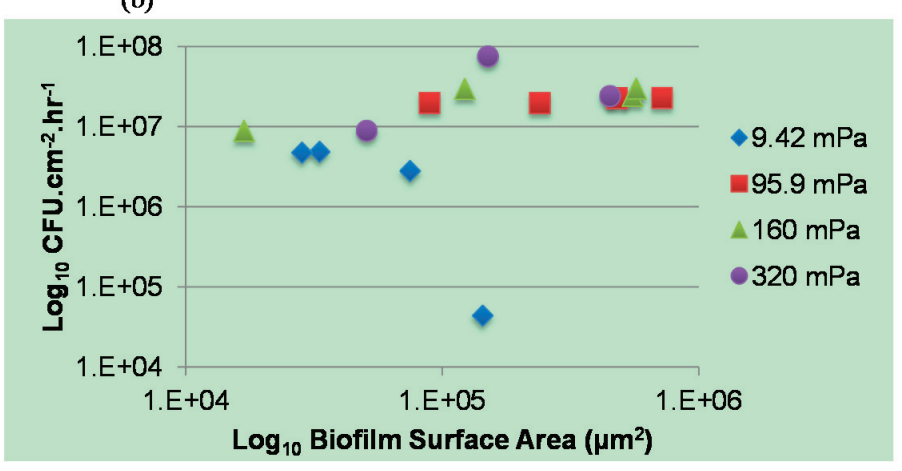


The detachment of cells from biofilms is often ascribed to the need for cells to escape unfavorable environmental conditions and to facilitate the colonization of new habitats. The potential role of biofilms, or perhaps biofilm surface-associated zones, as niches for planktonic cell production has often been overlooked. The observation that planktonic cells are able to remain associated with the biofilm [22] for extended periods indicates that their reactor residence time could be prolonged to such an extent that an independently replicating planktonic population can become established in the reactor. An illustration of such biofilm or surface-associated 'zone of planktonic cell replication' is given in Figure 6.

Figure 6. An illustration of the development of the proposed biofilm surface-associated zone of planktonic cell replication. (a) In the early stages of biofilm development, after individual cells colonize the surface and initiate microcolony formation, planktonic cells are produced and released; (b) As the biofilm continues to develop planktonic cell yield increases, despite EPS accumulation, as well as the potential for the sloughing of larger aggregates of cells embedded within EPS; (c) A Comsol simulation of the wall shear stress resulting from flow rates $\left(\mathrm{mL} \mathrm{h}^{-1}\right)$ of (i) $97.0 \times 10^{-2}$; (ii) $48.5 \times 10^{-2}$; (iii) $29.1 \times 10^{-2}$; and (iv) $28.6 \times 10^{-3}$ flowing through a microchannel with dimensions of $h=130 \mu \mathrm{m}$ and $w=300 \mu \mathrm{m}$. Shear stress values approached 0 in the corners where the glass substratum meets the channel wall (at $x=0 \mu \mathrm{m}$ and $x=300 \mu \mathrm{m}$ ) for all flow rates; (d) Cell movement in surface-associated zone. Single cell translocation (shown at the right of the illustration), both with respect to distance and direction, was determined by time-lapse microscopy at various distances (z-direction) from the solid substratum. From these observations it is evident that the outer regions of the biofilm EPS have different viscosity than that of the biofilm core. Images are not drawn to scale.

(a)

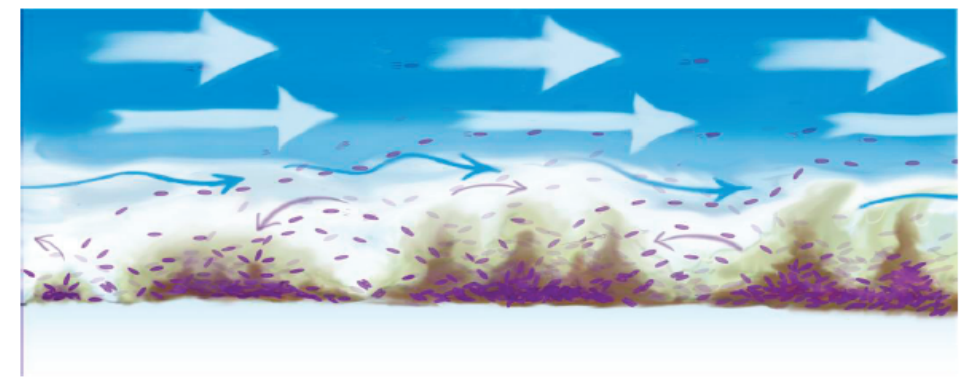

(b)

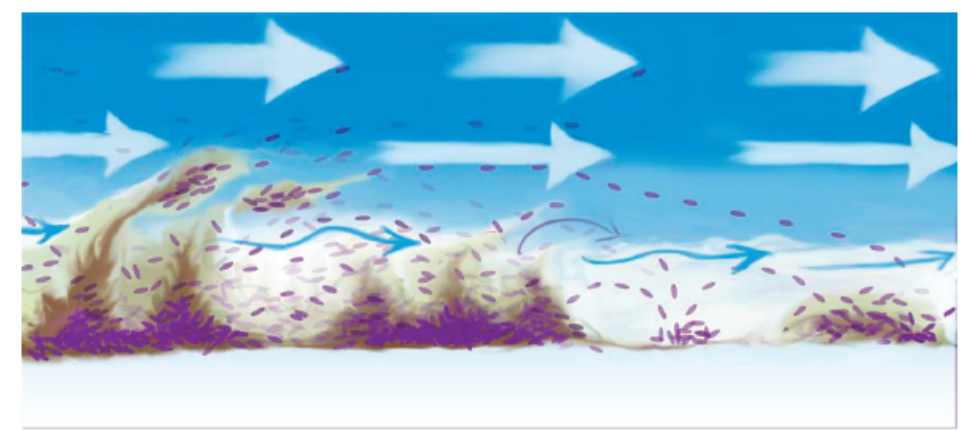


Figure 6. Cont.

(c)

(d)

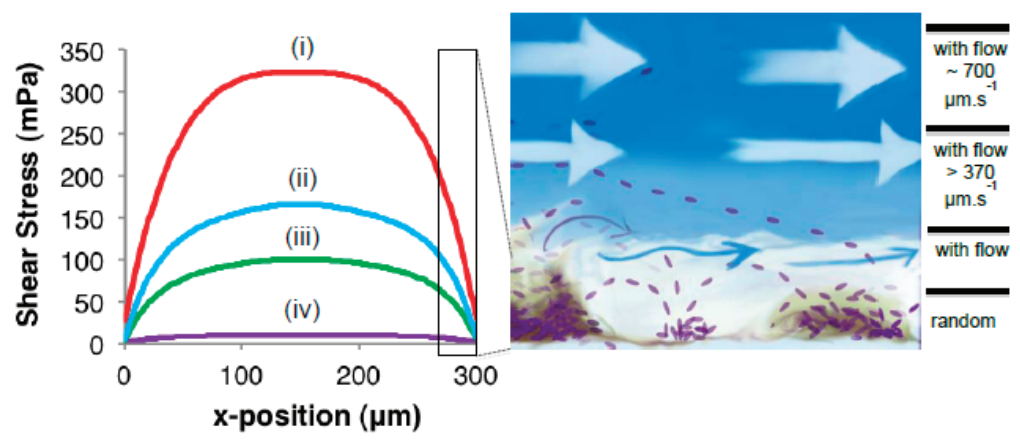

Biofilms are mostly studied using cell-specific stains, or cells tagged with fluorescent proteins, as in the current study. This, together with the highly diffused nature of EPS, complicates efforts to determine the extent of the extracellular matrix of biofilms. Coverage of biofilm microcolonies by a strongly cohesive matrix material at the biofilm bulk-liquid interface will hinder the release of cells from the biofilm (i.e., the concept of irreversible attachment). Considering the high yield of cells from biofilms as reported here, it is clear that such a zone of planktonic cell replication exists. In fact, the presence and close association of motile single cells with immobile, matrix-embedded biofilm cells can be shown with relative ease during microscopic investigation of biofilms under continuous flow conditions. These typically reveal that in the immediate vicinity of the biofilm, motile planktonic cells can propel themselves in any direction to interact with other microcolonies, or re-attach in an uncolonized area to initiate biofilm formation, but if they stray too close to the edge of the region of reduced flow velocity, the cells become entrained by the bulk-liquid flow (Figure 6a,b).

To illustrate the differences in flow rate, we used Comsol simulations to show the wall shear stress resulting from the four different flow rates $\left(\mathrm{mL} \mathrm{h}^{-1}\right)$ of (i) $97.0 \times 10^{-2}$; (ii) $48.5 \times 10^{-2}$; (iii) $29.1 \times 10^{-2}$; and (iv) $28.6 \times 10^{-3}$ flowing through a microchannel with dimensions of $h=130 \mu \mathrm{m}$ and $w=300 \mu \mathrm{m}$. As shown in Figure 6c, shear stress values approach 0 in the corners where the glass substratum meets the channel wall (at $x=0 \mu \mathrm{m}$ and $x=300 \mu \mathrm{m}$ ) for all flow rates. The maximum and average wall shear stress values (mPa) for flow rates (i-iv) were: (i) $415 \mathrm{mPa}$ and $321 \mathrm{mPa}$; (ii) $209 \mathrm{mPa}$ and $162 \mathrm{mPa}$; (iii) $125 \mathrm{mPa}$ and $97.4 \mathrm{mPa}$; and (iv) $12.4 \mathrm{mPa}$ and $9.62 \mathrm{mPa}$.

To compare microbial behavior with these flow conditions, time-lapse microscopy was used to track the movement of single cells at various vertical distances (z-direction) from a biofilm-colonized glass substratum. Single, planktonic cells were able to move at angles diagonal to the prevailing flow direction only while they remained within a depth similar to the average thickness of the biofilm (3.5 $\mu \mathrm{m}$ in this case) where the bulk-liquid flow velocities were sufficiently reduced. Measurements taken at greater distances from the glass substratum (up to $12 \mu \mathrm{m}$ ) indicated that while the trajectory of single cells was exclusively parallel to the direction of bulk-liquid flow, the cells travelled at reduced velocities (maximum measured $370 \pm 100 \mu \mathrm{m} \mathrm{s}^{-1}$ ) compared to the bulk-liquid velocity of $700 \mu \mathrm{m} \mathrm{s}^{-1}$ 
$\left(0.1 \mathrm{~mL} \mathrm{~h}^{-1}\right)$ (Figure 6d). Particles could not be tracked at greater distances from the surface due to the high velocities, but large numbers of single cells were routinely swept past the field of view in the bulk-liquid phase. While these cells were unable to overcome the prevailing flow velocity, it can reasonably be assumed that a reduction in flow velocity or change in flow patterns (i.e., eddies) may carry the cells to regions of slower flow where flagellar-driven motility could propel the cells towards a surface.

The association and persistence of planktonic cells in this region of reduced flow could lead to the establishment of an independent planktonic cell population in a reactor, where nutrient availability, the accumulation of waste products and/or signaling molecules within this region of reduced flow have the potential to govern the degree of planktonic cell replication. A previous report suggested that the co-existence of motile single cells with attached cells could afford the biofilm greater flexibility to respond to environmental cues [22]. The phenotype of biofilm-derived planktonic cells has been shown to be different from planktonic cells cultivated in batch suspension. Planktonic cells yielded from Staphylococcus aureus biofilms exhibited reduced production of a collagen adhesin and thus a lower subsequent rate of adhesion and biofilm formation [23]. A shortened lag in Pseudomonas sp. strain CT07 biofilm development has been reported by employing biofilm-derived cells as inocula, as compared to cells cultivated in batch suspensions [24]. Together with the enhanced antimicrobial susceptibility previously reported [17], the existence of a third phenotype for biofilm-derived planktonic cells has been postulated [25].

The role of biofilms in planktonic cell proliferation has not been adequately recognized to date. The metabolic capabilities of self-immobilized microbial communities are exploited in wastewater treatment facilities and in the production of high value metabolites, whereas the recalcitrance of undesirable and antimicrobial resistant fouling biofilms is often lamented. However, the results presented here and elsewhere $[17,18,26]$ indicate that these are not the only properties of biofilms with the potential to impact society. The incorporation of pathogens into environmental biofilms associated with plumbing material or medical equipment and subsequent dissemination to susceptible individuals has been documented to contribute to healthcare-associated infections and subsequent mortality [27-30]. The detachment of single cells from biofilms that develop on implanted medical devices could also lead to secondary infections at other sites, or septicemia [23].

\section{Experimental Section}

\subsection{Strain and Culture Conditions}

An environmental pseudomonad, isolated from a cooling tower and designated as Pseudomonas sp. strain CT07 (GenBank Accession number DQ 777633) was used for all of the experimentation [17]. A gene sequence encoding for the constitutive expression of a green fluorescent protein (GFP) was inserted into the bacterial chromosome using a mini-Tn7 system as previously described [18]. 
Cultivation took place at room temperature $\left(24 \pm 2{ }^{\circ} \mathrm{C}\right)$ in modified $\mathrm{AB}$ defined medium (final concentration of $1.51 \mathrm{mmol} / \mathrm{L}\left(\mathrm{NH}_{4}\right)_{2} \mathrm{SO}_{4}, 3.37 \mathrm{mmol} / \mathrm{L} \mathrm{Na}_{2} \mathrm{HPO}_{4}, 2.20 \mathrm{mmol} / \mathrm{L} \mathrm{KH}_{2} \mathrm{PO}_{4}, 179 \mathrm{mmol} / \mathrm{L}$ $\mathrm{NaCl}, 0.1 \mathrm{mmol} / \mathrm{L} \mathrm{MgCl} 2 \cdot 6 \mathrm{H}_{2} \mathrm{O}, 0.01 \mathrm{mmol} / \mathrm{L} \mathrm{CaCl}_{2} \cdot 2 \mathrm{H}_{2} \mathrm{O}$ and $0.001 \mathrm{mmol} / \mathrm{L} \mathrm{FeCl}_{3}$ ) [31] with $1 \mathrm{mmol} / \mathrm{L} \mathrm{Na}$-Citrate $6 \mathrm{H}_{2} \mathrm{O}$ as the sole carbon source. Pre-cultures were incubated in batch with aeration for $16-18 \mathrm{~h}$ prior to the inoculation of microfluidic channels.

\subsection{Microfluidic Device Fabrication}

A silicon template containing microfeatures from a photoresist (SU-8 50, Microchem Inc., Newton, MA, USA) was prepared via photolithography, based on a photo mask that was produced using computer aided design software (AutoCAD). The height of all features on the silicon template was $130 \mu \mathrm{m}$ as defined by the spin coating process. After photolithography, the silicon template contained the inverse features required for the microfluidic device. These consisted of two sets of channels in triplicate, for statistical purposes. The first set of channels had a width (w) of $2 \mathrm{~mm}$ and the second had a width of $300 \mu \mathrm{m}$. All 6 channels had a length $(l)$ of $40 \mathrm{~mm}$. In this study, only the $300 \mu \mathrm{m}$-wide channels were used in order to achieve the desired range of average shear rates. Figure 7a shows a schematic of one $w=300 \mu \mathrm{m}$ channel. The microfluidic devices were prepared by casting uncured poly dimethyl siloxane (PDMS) (Ellsworth Adhesives Canada, Syligard 184) against the silicon template and heating to $70{ }^{\circ} \mathrm{C}$ overnight [32]. After the cured PDMS was demoulded from the silicon template the micro fabrication contained the features of the microfluidic channel and inlet and outlet access holes were punched at each end of the channel. Finally, a glass cover slip (VWR, catalogue number CA48404-143) was bonded to the PDMS after exposure to air plasma (HARRICK PLASMA -PCD-001) for $90 \mathrm{~s}$, thereby sealing the device. The coverslip thickness was $170 \mu \mathrm{m}$, which matched working distance requirements for the confocal microscope objectives. Liquid delivery tubing was connected to the device inlets and outlets via metal elbow capillaries and glued in place using multi-purpose silicone sealant. The entire device was placed in a custom polycarbonate holder, which positioned the device with the glass side up for inspection by the upright confocal imaging system (Figure 7). 
Figure 7. (a) Two-dimensional schematic for a single channel used in this study consisting of a channel width $(w)$ of $300 \mu \mathrm{m}$ and length $(l)$ of $40 \mathrm{~mm}$. The height (not shown) is $130 \mu \mathrm{m}$. The two circular sections at the end of the channel mark the inlet and outlet; (b) A photograph of the microfluidic device in a polycarbonate holder. The holder positions the device with the glass side up for inspection by the confocal system and provides space on the bottom (PDMS) side for liquid delivery tubing access to the inlet and outlet holes. The $w=2 \mathrm{~mm}$ channels are connected to liquid delivery tubing and filled with a blue dye for visualization.

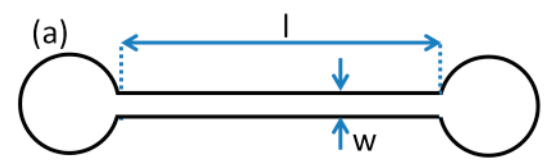

(b)

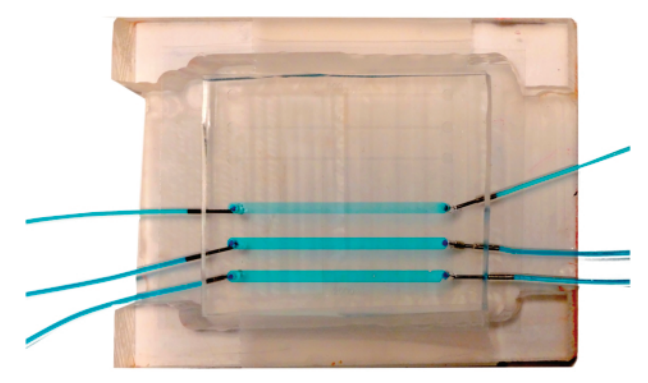

\subsection{Continuous-Flow Cultivation of Biofilms}

Biofilms were cultivated in microfluidic channels for up to 4 days. Thick-walled silicone tubing (Cole Parmer, $0.89 \mathrm{~mm}$ inner diameter, catalogue number 07 625-26) connected the inlet of each microfluidic channel to a multi-channel syringe pump (Model NE-1600, New Era Pump Systems Inc., Wantagh, NY, USA), while Tygon tubing transferred the effluent to a waste container.

The connective tubing and channels were disinfected with a once-through flow of ethanol for $1.5 \mathrm{~h}$, followed by sterile distilled water for a minimum of $24 \mathrm{~h}$. The rinsing water was replaced with sterile growth medium and any air bubbles were flushed out prior to stopping the flow for inoculation. A sterile needle and syringe were used to inject $0.05 \mathrm{~mL}$ of the pre-culture containing on average $10^{7} \mathrm{CFU} \mathrm{mL} \mathrm{m}^{-1}$ into each channel, by puncturing a hole through the upstream silicone tubing. The hole was sealed immediately afterwards with all-purpose silicone sealant, and liquid flow was initiated after 10 min at different flow velocities with the syringe pump. The sterile distilled water and growth medium were placed in an ultrasonic cleaner and sonicated at $40 \mathrm{kHz}$ for $20-40 \mathrm{~min}$ to remove excess dissolved gases prior to aspirating the liquid into sterile syringes and connecting the syringes to the inlet tubing. 
Biofilm development and the associated planktonic cell yield were determined at four different growth medium flow velocities $\left(28.6 \times 10^{-3}, 29.1 \times 10^{-2}, 48.5 \times 10^{-2}, 97.0 \times 10^{-2} \mathrm{~mL} \mathrm{~h}^{-1}\right)$ resulting in laminar flow in the channels. The corresponding average shear stresses were calculated by Equation (1) below, and are noted in Table 1 together with Reynolds number for each of the four flow rates.

$$
\text { shear stress }\left(P_{a}\right)=6 \times u \times Q_{/} \times h^{2}
$$

where $u$ is the dynamic viscosity (taken as $0.001002 \mathrm{~Pa}$.s for water at $20^{\circ} \mathrm{C}$ ), $Q$ is the volumetric flow rate $\left(\mathrm{m}^{3} \mathrm{~s}^{-1}\right), w$ is the width of the channel $(\mathrm{m})$ and $h$ is the height of the channel $(\mathrm{m})$.

Table 1. Laminar flow velocities in the microfluidic channels with corresponding Reynolds numbers and average shear rates applied to biofilms.

\begin{tabular}{ccccc}
\hline Regime & (i) & (ii) & (iii) & (iv) \\
\hline Flow velocity $\left(\mathrm{mL} \mathrm{h}^{-1}\right)$ & $28.6 \times 10^{-3}$ & $29.1 \times 10^{-2}$ & $48.5 \times 10^{-2}$ & $97.0 \times 10^{-2}$ \\
Average shear stress $(\mathrm{mPa})$ & 9.42 & 95.9 & 160 & 320 \\
Reynolds number & $3.68 \times 10^{-2}$ & $3.75 \times 10^{-1}$ & $6.24 \times 10^{-1}$ & 1.25 \\
\hline
\end{tabular}

\subsection{Biofilm-Derived Planktonic Cell Yield}

\subsubsection{Viable Cell Counts}

The number of viable cells that were released from the biofilm and became entrained in the bulk-liquid phase was determined using serial dilution in sterile saline $(0.9 \% \mathrm{NaCl})$ and drop plating onto agar-solidified-modified $\mathrm{AB}$ medium, containing $10 \mathrm{mmol} \mathrm{L}^{-1}$ citrate. Connectors were emplaced near the outlet side of each channel from which effluent was collected at 24-h intervals after inoculation. The number of colony forming units per milliliter $\left(\mathrm{CFU} \mathrm{mL}{ }^{-1}\right)$ of effluent was enumerated after 4 to 6 days of incubation at room temperature and normalized with respect to the growth medium flow velocity $\left(\mathrm{mL} \mathrm{h}^{-1}\right)$ and the total internal surface area of the channel consisting of both PDMS and glass $\left(\mathrm{cm}^{2}\right)$ to compare the rate of cell yield $\left(\mathrm{CFU} \mathrm{cm} \mathrm{cm}^{-2} \mathrm{~h}^{-1}\right)$ among biofilms subjected different shear rates.

\subsubsection{Qualitative Assessment of Biomass Size Distribution}

In addition to daily sampling the effluent for viable cell counts, additional effluent was collected periodically. These samples were incubated with formaldehyde (final concentration 3.8\% v/v) to preserve cell integrity and prevent growth and cell division, at $4{ }^{\circ} \mathrm{C}$ prior to dilution of a subsample (if necessary) and incubation with the fluorescent nucleic acid stain 4',6-diamidino-2-phenylindole (DAPI) at a final concentration of $20 \mu \mathrm{g} \mathrm{mL}^{-1}$ for $20 \mathrm{~min}$ in the absence of light. Each sample was filtered onto a black polycarbonate filter ( $0.2 \mu \mathrm{m}$ pore-size, $25 \mathrm{~mm}$ diameter, Nucleopore, Whatman), followed by placing the filter on a microscope slide with drop of Citifluor antifade mounting medium (AF2, Electron Microscopy Sciences, Hatfield, PA, USA) and a coverslip. Several microscope fields were investigated 
at random from each filter $(60 \times$ oil immersion objective, Nikon $90 \mathrm{i}$ epifluorescent microscope, Mississauga, ON, Canada) to qualitatively evaluate the size distribution of detached biomass (single cells $v s$. large biomass aggregates).

\subsection{Confocal Scanning Laser Microscopy and COMSTAT Image Analysis}

The extent of biofilm development in duplicate microfluidic channels was examined at 24 hour-intervals with confocal scanning laser microscopy (CLSM, Nikon Eclipse 90i, Mississauga, ON, Canada), using a 40×/0.75 Plan-Fluor objective with excitation of the green fluorescent protein at $488 \mathrm{~nm}$ and detection of emission with a band pass 515/30 filter. Ten microscope fields, each with an area of $101,761 \mu \mathrm{m}^{2}(318 \mu \mathrm{m} \times 318 \mu \mathrm{m})$, were chosen at random along a central transect starting from the channel inlet, and a stack of images was captured in the $z$-direction at $0.60 \mu \mathrm{m}$ intervals and stored for subsequent analysis with COMSTAT [33].

A selected number of the COMSTAT functions were used for the analysis of the biofilm: the biovolume of each image stack $\left(\mu \mathrm{m}^{3} \mu \mathrm{m}^{-2}\right)$, the mean thickness of the biofilm $(\mu \mathrm{m})$ and the biofilm surface area-to-volume ratio $\left(\mu \mathrm{m}^{2} \mu \mathrm{m}^{-3}\right)$. The biofilm surface area $\left(\mathrm{um}^{2}\right)$ (i.e., the area of the biofilm exposed to the bulk-liquid) was calculated using the results of COMSTAT analysis, by multiplying the biofilm biovolume $\left(\mu \mathrm{m}^{2} \mu \mathrm{m}^{-3}\right)$ by the $x y$ attachment area $\left(101,761 \mu \mathrm{m}^{2}\right)$, and the surface area-to-biovolume ratio $\left(\mu \mathrm{m}^{2} \mu \mathrm{m}^{-3}\right)$ for each Z-stack of images. The corresponding values obtained correlated well with the degree of biofilm development, as seen in the extent of substratum coverage and average biofilm thickness. The values were primarily utilized for qualitative purposes to identify potential relationships between the planktonic cell yield from biofilms and the different shear forces that they are subjected to.

\subsection{Statistical Analysis}

The extent of biofilm-derived planktonic cell yield for each of the four growth medium flow velocities was evaluated in 2 independent experimental rounds. Each round consisted of biofilm development in duplicate microfluidic channels. The planktonic cell yield data was analyzed using two-factor Analysis of variance (ANOVA, with replication) at a significance level of 0.05 , followed by pair-wise comparisons with Tukey's Post Hoc test.

\subsection{Comsol Simulations}

Shear stress simulations were conducted using Comsol MultiPhysics (version 3.5) on a PC system featuring an Intel Core i5-2400 (3.10 GHz) processor running Windows 7 with 64-bit precision. Course, physics-controlled mesh was verified to produce rapid results without sacrificing accuracy. A segment of the channel was created with dimensions $300 \mu \mathrm{m} \times 130 \mu \mathrm{m}$ with channel length between the inlet and measurement point being chosen as $1 \mathrm{~mm}$. Flow was directed along the axis connecting the inlet and outlet with the inlet velocity calculated based on the flow rate and the channel dimensions. 
The wall shear stress was measured along the long edge of the channel cross-section $(300 \mu \mathrm{m})$ for each flow rate and a smoothing algorithm was used to remove small digitization effects related from the course mesh.

\section{Conclusions}

The role of biofilms as a microbial survival strategy is often recognized, such as the continued survival of EPS-encased microbes despite multiple antimicrobial challenges. This study demonstrates that in addition to the prevention of cell washout at high liquid shear rates, biofilms also fulfill a proliferation function with continuous cell release into the bulk-liquid, and that shear rates have relatively little impact on such biofilm-to-planktonic cell yield. Instead, biofilms utilize shear to maintain optimum thickness and metabolic activity, which differs from the traditional view that biofilms primarily consist of slow-growing cells.

As a complement to the conventional conceptual biofilm models, we propose the existence of a biofilm surface-associated zone of planktonic cell proliferation. The results suggest the existence of a zone at the biofilm-liquid interface with high metabolic activity where cells are neither irreversibly attached nor imbedded in the EPS matrix, and where shear rates are too low to cause erosion. Such a surface-associated zone with non-attached cells greatly extends biofilm function and probably consists mostly of cells that do not have a typical biofilm phenotype. This phenomenon emphasizes the need to develop improved techniques to better define the EPS boundaries within which cells are immobilized. It appears possible that the EPS in this region is highly responsive to the prevailing environmental conditions, with microbes having the ability to modify EPS rigidity in order to restrict cell movement and thereby maintaining biofilm biomass under conditions that do not support active metabolism and cell replication, or under conditions conducive to microbial activity to allow cells to move away in order to maintain optimum gradients of nutrients and metabolites.

The production and release of significant numbers of planktonic cells by biofilms has long been disregarded. However, results indicate that the traditional perception of biofilms as promoting microbial survival should be expanded to include the potential to contribute to microbial proliferation.

\section{Acknowledgments}

Karen Quinto is gratefully acknowledged for the illustration in Figure 6. The research was funded by grants (to G.M.W.) from the Canada Research Chair Program and the Natural Sciences and Engineering Research Council of Canada.

\section{Conflicts of Interest}

The authors declare no conflict of interest. 


\section{References}

1. McDougald, D.; Rice, S.A.; Barraud, N.; Steinberg, P.D.; Kjelleberg, S. Should we stay or should we go: Mechanisms and ecological consequences for biofilm dispersal. Nat. Rev. Microbiol. 2012, 10, 39-50.

2. Sauer, K.; Camper, A.; Ehrlich, G.; Costerton, J.; Davies, D. Pseudomonas aeruginosa displays multiple phenotypes during development as a biofilm. J. Bacteriol. 2002, 184, 1140-1154.

3. Rice, A.R.; Hamilton, M.A.; Camper, A.K. Movement, replication, and emigration rates of individual bacteria in a biofilm. Microb. Ecol. 2003, 45, 163-172.

4. Delaquis, P.; Caldwell, D.; Lawrence, J.; McCurdy, A. Detachment of Pseudomonas fluorescens from biofilms on glass surfaces in response to nutrient stress. Microb. Ecol. 1989, 18, 199-210.

5. Gjermansen, M.; Ragas, P.; Sternberg, C.; Molin, S.; Tolker-Nielsen, T. Characterization of starvation-induced dispersion in Pseudomonas putida biofilms. Environ. Microbiol. 2005, 7, 894-906.

6. Sauer, K.; Cullen, M.; Rickard, A.; Zeef, L.; Davies, D.; Gilbert, P. Characterization of nutrient-induced dispersion in Pseudomonas aeruginosa PAO1 biofilm. J. Bacteriol. 2004, 186, $7312-7326$.

7. Gjermansen, M.; Nilsson, M.; Yang, L.; Tolker-Nielsen, T. Characterization of starvation-induced dispersion in Pseudomonas putida biofilms: Genetic elements and molecular mechanisms. Mol. Microbiol. 2010, 75, 815-826.

8. Purevdorj-Gage, B.; Costerton, W.J.; Stoodley, P. Phenotypic differentiation and seeding dispersal in non-mucoid and mucoid Pseudomonas aeruginosa biofilms. Microbiology 2005, 151, $1569-1576$.

9. Bryers, J.D. Biologically active surfaces: Processes governing the formation and persistence of biofilms. Biotechnol. Prog. 1987, 3, 57.

10. Peyton, B.M.; Characklis, W.G. A statistical-analysis of the effect of substrate utilization and shear-stress on the kinetics of biofilm detachment. Biotechnol. Bioeng. 1993, 41, 728-735.

11. Rittmann, B.E. The effect of shear-stress on biofilm loss rate. Biotechnol. Bioeng. 1982, 24, 501-506

12. Trulear, M.G.; Characklis, W.G. Dynamics of biofilm processes. J. Water Pollut. Control Fed. 1982, 54, 1288-1301.

13. Stewart, P.S. A model of biofilm detachment. Biotechnol. Bioeng. 1993, 41, 111-117.

14. Choi, Y.C.; Morgenroth, E. Monitoring biofilm detachment under dynamic changes in shear Stress using laser-based particle size analysis and mass fractionation. Water Sci. Technol. 2003, 47, 69-76.

15. Derlon, N.; Coufort-Saudejaud, C.; Queinnec, I.; Paul, E. Growth limiting conditions and denitrification govern extent and frequency of volume detachment of biofilms. Chem. Eng. J. 2013, 218, 368-375. 
16. Walter, M.; Safari, A.; Ivankovic, A.; Casey, E. Detachment characteristics of a mixed culture biofilm using particle size analysis. Chem. Eng. J. 2013, 228, 1140.

17. Bester, E.; Kroukamp, O.; Hausner, M.; Edwards, E.A.; Wolfaardt, G.M. Biofilm form and function: Carbon availability affects biofilm architecture, metabolic activity and planktonic cell yield. J. Appl. Microbiol. 2011, 110, 387-398.

18. Bester, E.; Kroukamp, O.; Wolfaardt, G.M.; Boonzaaier, L.; Liss, S.N. Metabolic differentiation in biofilms as indicated by carbon dioxide production rates. Appl. Environ. Microbiol. 2010, 76, 1189-1197.

19. Bester, E.; Wolfaardt, G.; Joubert, L.; Garny, K.; Saftic, S. Planktonic-cell yield of a Pseudomonad biofilm. Appl. Environ. Microbiol. 2005, 71, 7792-7798.

20. Chambless, J.D.; Stewart, P.S. A three-dimensional computer model analysis of three hypothetical biofilm detachment mechanisms. Biotechnol. Bioeng. 2007, 97, 1573-1584.

21. Xavier, J.D.B.; Picioreanu, C.; van Loosdrecht, M.C.M. A general description of detachment for multidimensional modelling of biofilms. Biotechnol. Bioeng. 2005, 91, 651-669.

22. Tolker-Nielsen, T.; Brinch, U.C.; Ragas, P.C.; Andersen, J.B.; Jacobsen, C.S.; Molin, S. Development and dynamics of Pseudomonas sp biofilms. J. Bacteriol. 2000, 182, 6482-6489.

23. Ymele-Leki, P.; Ross, J.M. Erosion from Staphylococcus aureus biofilms grown under physiologically relevant fluid shear forces yields bacterial cells with reduced avidity to collagen. Appl. Environ. Microbiol. 2007, 73, 1834-1841.

24. Kroukamp, O.; Dumitrache, R.G.; Wolfaardt, G.M. Pronounced effect of the nature of the inoculum on biofilm development in flow systems. Appl. Environ. Microbiol. 2010, 76, 6025-6031.

25. Rollet, C.; Gal, L.; Guzzo, J. Biofilm-detached cells, a transition from a sessile to a planktonic phenotype: A comparative study of adhesion and physiological characteristics in Pseudomonas aeruginosa. FEMS Microbiol. Lett. 2009, 290, 135-142.

26. Bester, E.; Edwards, E.A.; Wolfaardt, G.M. Planktonic cell yield is linked to biofilm development. Can. J. Microbiol. 2009, 55, 1195-1206.

27. Anaissie, E.J.; Penzak, S.R.; Dignani, M.C. The hospital water supply as a source of nosocomial infections. Arch. Intern. Med. 2002, 162, 1483-1492.

28. Hota, S.; Hirji, Z.; Stockton, K.; Lemieux, C.; Dedier, H.; Wolfaardt, G.; Gardam, M.A. Outbreak of multidrug-resistant Pseudomonas aeruginosa colonization and infection secondary to imperfect intensive care unit room design. Infect. Control Hosp. Epidemiol. 2009, 30, 25-33.

29. Nishiuchi, Y.; Tamaru, A.; Kitada, S.; Taguri, T.; Matsumoto, S.; Tateishi, Y.; Yoshimura, M.; Ozeki, Y.; Matsumura, N.; Ogura, H.; et al. Mycobacterium avium complex organisms predominantly colonize in the bathtub inlets of patients' bathrooms. Jpn. J. Infect. Dis. 2009, 62, 182-186.

30. Pajkos, A.; Vickery, K.; Cossart, Y. Is biofilm accumulation on endoscope tubing a contributor to the failure of cleaning and decontamination? J. Hosp. Infect. 2004, 58, 224-229. 
31. Clark, D.J.; Maaloe, O. DNA replication and division cycle in Escherichia coli. J. Mol. Biol. 1967, 23, 99-112.

32. Xia, Y.N.; Whitesides, G.M. Soft lithography. Angew. Chem. Int. Ed. 1998, 37, 551-575.

33. Heydorn, A.; Nielsen, A.T.; Hentzer, M.; Sternberg, C.; Givskov, M.; Ersboll, B.K.; Molin, S. Quantification of biofilm structures by the novel computer program COMSTAT. Microbiology 2000, 146, 2395-2407. 


\title{
2. Pathogenic Biofilms
}

\section{Biofilms: The Stronghold of Legionella pneumophila}

\section{Mena Abdel-Nour, Carla Duncan, Donald E. Low and Cyril Guyard}

\begin{abstract}
Legionellosis is mostly caused by Legionella pneumophila and is defined as a severe respiratory illness with a case fatality rate ranging from $5 \%$ to $80 \%$. L. pneumophila is ubiquitous in natural and anthropogenic water systems. L. pneumophila is transmitted by inhalation of contaminated aerosols produced by a variety of devices. While L. pneumophila replicates within environmental protozoa, colonization and persistence in its natural environment are also mediated by biofilm formation and colonization within multispecies microbial communities. There is now evidence that some legionellosis outbreaks are correlated with the presence of biofilms. Thus, preventing biofilm formation appears as one of the strategies to reduce water system contamination. However, we lack information about the chemical and biophysical conditions, as well as the molecular mechanisms that allow the production of biofilms by L. pneumophila. Here, we discuss the molecular basis of biofilm formation by L. pneumophila and the roles of other microbial species in L. pneumophila biofilm colonization. In addition, we discuss the protective roles of biofilms against current L. pneumophila sanitation strategies along with the initial data available on the regulation of L. pneumophila biofilm formation.
\end{abstract}

Reprinted from Int. J. Mol. Sci. Cite as: Abdel-Nour, M.; Duncan, C.; Low, D.E.; Guyard, C. Biofilms: The Stronghold of Legionella pneumophila. Int. J. Mol. Sci. 2013, 14, 21660-21675.

\section{Introduction}

The Gram-negative bacterium Legionella pneumophila is responsible for the majority of legionellosis cases and is a significant contributor of community acquired, and hospital acquired pneumonia with a case fatality rate ranging from $5 \%$ to $80 \%[1,2]$. L. pneumophila is an aquatic pathogen that is ubiquitously found in nature, in both anthropogenic structures and in environmental waters [3-7]. In vitro, L. pneumophila is able to produce monospecies biofilms (Figure 1) that is believed to contain an extracellular matrix [8,9]. In the environment, L. pneumophila can be found in several different habitats, including multispecies biofilms. In naturally occurring multispecies biofilms, the colonization with L. pneumophila can be influenced by several other species of microorganisms [10,11]. Of these microorganisms, protozoa are arguably one of the most important in determining L. pneumophila persistence, as the pathogen uses protozoa to replicate intracellularly [12]. Co-evolution with multiple species of protozoa has resulted in the development of mechanisms that allow L. pneumophila to occupy a very broad host range, and to infect human cells [13-15]. 
Figure 1. Monospecies biofilm of L. pneumophila labelled with the DNA stain Syto62. Scale bar represents $100 \mu \mathrm{m}$.

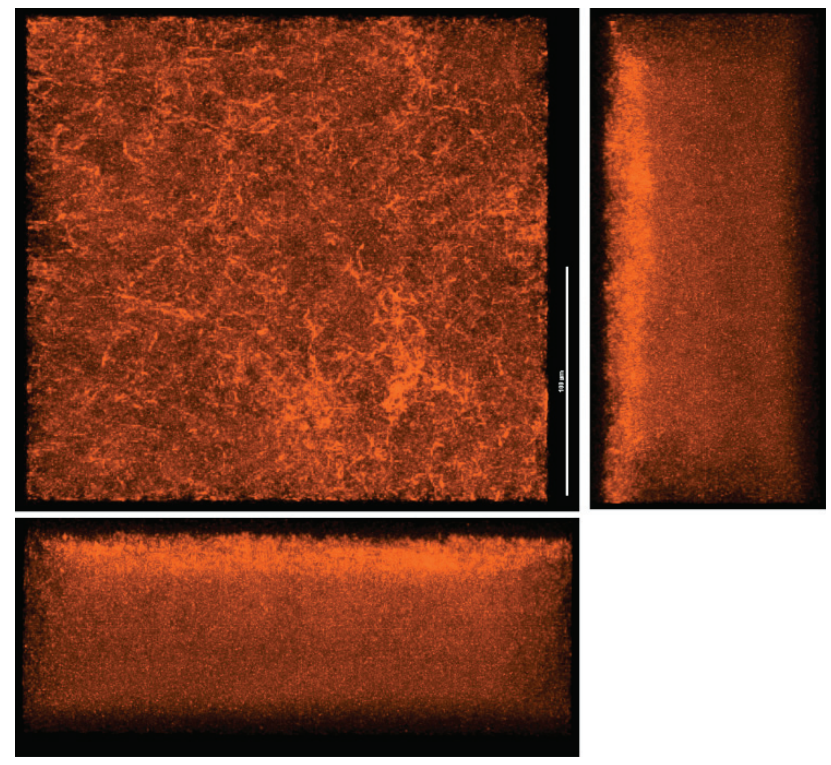

Recent reports suggest that the growth of Legionella in biofilms may lead to enhanced virulence. L. pneumophila isolates from serogroups 1,10 , and 12 that were collected from biofilms were more cytotoxic towards amoeba than reference outbreak and worldwide epidemic strains [16]. Moreover, initial data suggest that biofilm-derived Legionella pneumophila evades the innate immune response in macrophages [17]. As legionellosis is not transmitted from person to person, insights into the ecology of L. pneumophila may yield information that can be used to prevent the colonization of anthropogenic systems by L. pneumophila. In light of recent discoveries, this review intends to provide an overview of the findings on biofilm production and colonization by L. pneumophila.

\section{Protozoa and L. pneumophila Biofilm Formation}

Protozoa play a crucial role in the lifecycle of Legionella species as they provide a habitat for their environmental survival and replication [12,18-21]. In biofilm communities, several amoeba species have been found associated with L. pneumophila [22]. To feed, protozoan species often graze on bacteria present in multispecies biofilms, a phenomenon that L. pneumophila exploits in order to replicate (Figure 2) [23,24]. As a consequence, the presence of protozoa in anthropogenic water sources has been deemed a risk factor for L. pneumophila outbreaks [23]. In fact, the amount of L. pneumophila in biofilms is directly correlated with the biomass of protozoa [25]. This is in accordance with in vitro models showing that the presence of amoeba species promotes the biofilm formation of L. pneumophila on pins of "inverse" microtiter plates [26]. L. pneumophila is also capable of growing off the debris from dead amoebae, thus, amoeba may also encourage the replication of L. pneumophila indirectly [27]. Floating biofilms, also contain protozoa in association 
with L. pneumophila suggesting that L. pneumophila may attach to protozoa in floating biofilms in the absence of available abiotic surfaces [28,29]. In addition to the role of protozoa as a means of replication, the intracellular stage of L. pneumophila provides protection from environmental stressors [30,31] including biocides used to disinfect water systems [32,33]. Indeed, biofilms produced with L. pneumophila in the presence of thermotolerant amoebae allow L. pneumophila to persist after heat treatment [34], demonstrating that amoebae can provide a protective niche for L. pneumophila [30].

Figure 2. A. castellanii infected with L. pneumophila expressing green fluorescent protein. Scale bar represents $10 \mu \mathrm{m}$.

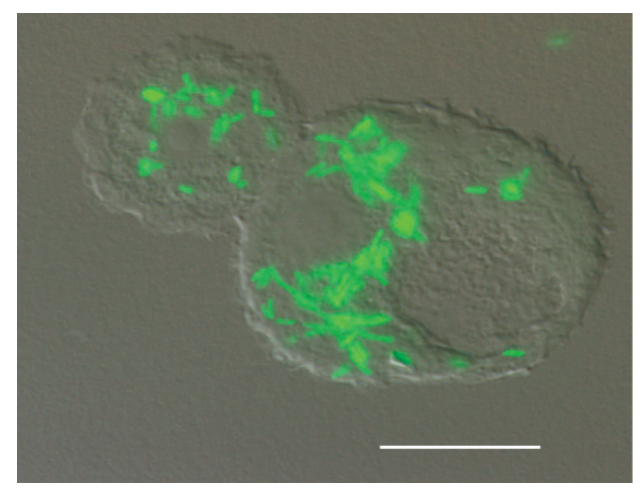

\section{Physiochemical Determinants in L. pneumophila Biofilm Formation and Colonization}

Attachment is the process of one object adhering to another, and when producing surface associated biofilms, attachment of L. pneumophila serves as an initial crucial step, whether it is on biotic or abiotic surfaces. Once bacteria are attached to a substratum and a biofilm is formed, the process of spreading and persisting within a new area is defined as colonization. Although L. pneumophila can often be found attached to various surfaces in the environment, colonization of existing biofilms in addition to attachment to abiotic substrates is determined by a wide variety of parameters (Figure 3) [35]. One important factor that governs the adherence of L. pneumophila in anthropogenic water systems is the composition of the surface material to which the bacteria are adhering [36]. L. pneumophila can adhere well to several different plastics that are commonly used in plumbing, whereas copper inhibits its attachment [36-38]. It remains unclear however whether this is due to differences in surface and L. pneumophila interactions or because different plumbing materials select for different pioneering species, which establishes the initial biofilm and L. pneumophila colonizes afterwards. 
Figure 3. L. pneumophila (denoted by Lpn and shown in orange) replicate within environmental protozoa. Uptake within protozoan hosts is promoted by the presence of other amoebae and bacterial species such as $P$. aeruginosa (top left) and by environmental cues such as quorum sensing (green hexagons, top right). Environmental cues can also influence changes in L. pneumophila cell metabolism that favour biofilm production and colonization, which may occur following replication within protozoa or independently of protozoa infection (middle). Other microbial species such as $P$. aeruginosa (Lpn antagonistic microbial species, brown) can inhibit L. pneumophila colonization (bottom left). The presence of other microorganisms such as $K$. pneumoniae alleviates the inhibitory effect of $P$. aeruginosa (Lpn permissive microbial species, blue) and allows L. pneumophila to be incorporated within biofilms. L. pneumophila produces a surfactant (brown circles), which is toxic to other Legionella species (red), and may therefore prevent incorporation of these bacteria within biofilms. Physio-chemical parameters such as divalent cations (grey circles) can favour L. pneumophila biofilm colonization while other factors such as the presence of nanoparticles and copper (blue circles) can hinder L. pneumophila colonization.

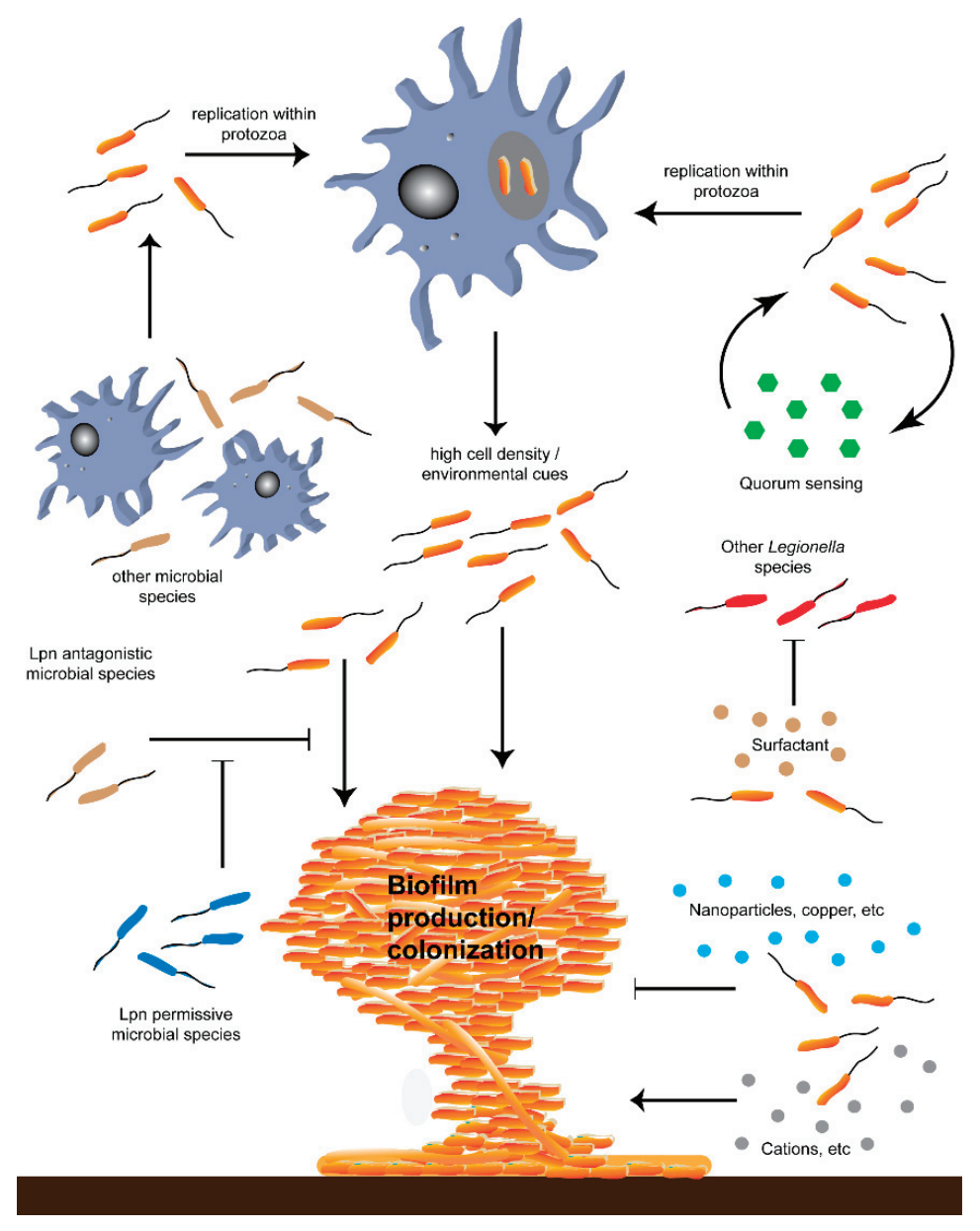


Cations are implicated in the attachment of bacteria to different substrata, and can contribute to biofouling [39]. Similarly, both calcium and magnesium were demonstrated to facilitate the attachment of L. pneumophila to abiotic surfaces [40]. Elevated zinc, magnesium, and manganese levels are correlated with increased L. pneumophila contamination and zinc increases the ability of L. pneumophila to bind to host cells such as human lung epithelial cells, suggesting that cations may increase the attachment of $L$. pneumophila to biotic surfaces in addition to abiotic substrata [41-43]. Interestingly as it pertains to the cation dependent attachment of $L$. pneumophila, an orthologue of the Pseudomonas fluorescens calcium-dependent cyclic-diGMP regulated protease LapG was identified in L. pneumophila. LapG regulates biofilm formation of Pseudomonas fluorescens by cleaving the surface adhesin LapA required for biofilm formation [44,45].

In addition to the presence of cations, the availability of carbon favours the colonization of biofilms with L. pneumophila, presumably because it provides nutrients for the bacteria to replicate [46]. Notably, the increase in biofilm production due to organic-carbon has only been reported at $20{ }^{\circ} \mathrm{C}$, suggesting that carbon may only influence biofilm production at certain temperatures [47]. Temperature is also an important determinant for L. pneumophila biofilm colonization. Studies have shown that heating water above $55^{\circ} \mathrm{C}$ can reduce the detectable amount of L. pneumophila in water systems, even in the presence of organic carbon sources, however this may be due to a decrease in other biofilm species which may serve as a platform for L. pneumophila colonization $[48,49]$.

Static and flow conditions of water play important roles in the biofilm formation and biofilm colonization with L. pneumophila in water systems. Stagnation of water in distribution systems seems to favour colonization with L. pneumophila [50]. Moreover, Legionnaires' disease cases have been linked to stagnant water in hospital settings [51]. In accordance with these data, a constant flow in anthropogenic water can decrease the presence of $L$. pneumophila through the use of Venturi systems by preventing the attachment of the bacteria to surfaces [52]. However, biofilms in aquatic environments can persist under turbulent flow conditions [53,54] and maintain a population of L. pneumophila [55]. To explain the persistence of L. pneumophila under turbulent flow, it was proposed that the bacteria can localize to the sediment where it is less affected by turbulence [56,57]. The settling of L. pneumophila in environmental sediments, which was recently linked to quorum sensing, will be discussed below [58,59].

Although the majority of L. pneumophila biofilm formation/colonization research has been focused on determining the physiochemical parameters that allow L. pneumophila to colonize and form biofilms, little is known regarding the L. pneumophila molecular factors that contribute directly to this process. The Legionella collagen-like protein ( $\mathrm{Lcl}$ ) was initially identified as an adhesin required for infection of protozoa and macrophages [60]. Subsequently, Lcl was found to be an important mediator of L. pneumophila biofilm formation [61]. Lcl facilitates biofilm production by promoting attachment to abiotic substrates as well as cell-cell/cell-matrix interactions [62]. Type IV pili was also implicated in L. pneumophila biofilm colonization based in its role in adherence to protozoan cells [63]. However, a site directed type IV pili mutant was shown to colonize biofilms of other organisms as well as 
wild-type bacteria [64]. In addition to surface exposed adhesins, the twin arginine transport (Tat) secretion system has also been implicated in biofilm formation. Deletion of the $t a t B$ and tatC genes resulted in a significant reduction in biofilm formation, however the specific role that this secretion system plays is unknown [65].

\section{Regulation of L. pneumophila Endogenous Factors that May Influence Biofilm Colonization}

For L. pneumophila, as well as for other microorganisms, biofilm formation is an environmental response that can promote survival. L. pneumophila, like many other microorganisms, responds to environmental cues, which can greatly influence biofilm formation and or colonization (Figure 3). One important environmental prompt is iron, which has important roles in the growth of many organisms, and can influence L. pneumophila replication [66]. The addition of lactoferrin, an iron chelator, can directly kill L. pneumophila demonstrating the importance of iron in L. pneumophila viability [67]. Furthermore, bacterial ferrous iron transport promotes the intracellular replication of L. pneumophila in protozoa, which may influence multispecies biofilm colonization [68]. Iron is also required for the production of melanin and it is believed that deletion of the $l b t A$ and $l b t B$ genes, which encode iron siderophores prevent growth within aquatic biofilms [66]. Interestingly, although iron is essential for biofilm formation, high iron concentrations can inhibit biofilm formation, yet to date the reasons for this are unknown [8].

The ability of bacteria to monitor and respond to cell density is known as quorum sensing and it is a crucial process during biofilm production. Among quorum sensing molecules, $\alpha$-hydroxy ketones (AHKs) have been identified in L. pneumophila, and are similar to the AHKs produced by Vibrio cholera [69,70]. Although there is currently no evidence that AHKs regulate L. pneumophila biofilm production directly, these molecules regulate a wide variety of traits that may influence L. pneumophila biofilm production/colonization indirectly, including virulence (infection of protozoan hosts in multispecies biofilms), extracellular filament production, and sedimentation through the lqs gene cluster, which encodes for the AHK synthase LqsA, the AHK sensor LqsS and the response regulator LqsR $[58,71,72]$. In addition to the products of this gene cluster, an orphan sensor kinase named LqsT regulates competence, a process that is correlated to biofilm formation in other species [59].

The second-messenger molecule cyclic di-GMP (c-di-GMP) is also an important signaling system that allows bacteria to respond to environmental changes [73] L. pneumophila has 22 predicted genes related to c-di-GMP production, degradation and/or recognition [74]. One of these genes, $\operatorname{lpg} 1057$, was found to encode an enzyme responsible for the production of cyclic di-GMP which promotes biofilm formation, and is the only c-di-GMP related gene to date found to directly influence monospecies biofilm production of L. pneumophila [75]. In response to amino acid starvation, the alarmone guanosine tetraphosphate (ppGpp) can also regulate L. pneumophila gene expression [76]. Although the ppGpp system is mainly linked to the regulation of virulence related traits, this system may indirectly affect environmental biofilm colonization by influencing L. pneumophila-amoeba interactions. In addition, sensitivity to ppGpp signaling requires the sigma factor RpoS [77]. RpoS in 
turn influences LqsR expression, suggesting that virulence related traits regulated by AHKs require multiple environmental signals [78]. In parallel with the ppGpp-RpoS regulation of virulence, downstream is the two-component system LetA/LetS [79]. The LetA/LetS system relieves the repression of virulence related genes by the RNA binding protein CsrA [80]. Despite the initially suspected roles of these transcriptional regulators in surface attachment and biofilm formation, none of the mutants lacking rpoS, letA or csrA were affected in biofilm formation in the L. pneumophila strain JR32 [26]. Of the known L. pneumophila sigma factors, to date only the flagellar sigma factor FliA has been implicated in the regulation of biofilm production and deletion of fliA results in a decrease in biofilm formation in JR32, however it is unclear what downstream or upstream factors are involved in this process [26].

Temperature was mentioned above as being an important determinant for biofilm colonization $[48,49]$. In addition, temperature can regulate the properties of the biofilms produced by L. pneumophila [81]. In vitro, at $37-42{ }^{\circ} \mathrm{C}$, monospecies biofilms are mycelial mat-like and are composed of filamentous bacteria whereas biofilms produced at $25^{\circ} \mathrm{C}$ are thinner and made up of rod shaped cells [81]. These findings coincide with other studies demonstrating that the filamentation of L. pneumophila is regulated by temperature [82]. Filamentous growth occurs in other bacterial species to increase fitness against adverse environmental conditions [83]. In turn, intracellular filamentatous L. pneumophila can produce progeny more efficiently than short rod forms [84]. Furthermore, the length of L. pneumophila cells has been linked to ppGpp signalling [80]. In vitro, biofilms produced at $37{ }^{\circ} \mathrm{C}$ are much more robust than at $25^{\circ} \mathrm{C}$ [26], and interestingly biofilms produced at $25{ }^{\circ} \mathrm{C}$ are more adherent [81]. In addition, the production of the L. pneumophila type II secretion system, and type IV pili are temperature regulated, and may influence attachment at different temperatures [85].

\section{The Role of Non-Protozoa Microbial Species in L. pneumophila Biofilm Colonization}

Environmental biofilms often contain several different bacterial species [86]. These bacterial species may promote the persistence of $L$. pneumophila in biofilms, while other species inhibit $L$. pneumophila's colonization (Figure 3). For example, Flavobacterum breve and cyanobacterial species can promote L. pneumophila growth and colonization in biofilms by providing a source of nutrients $[87,88]$. In vitro, the growth of L. pneumophila is necrotrophic when heat killed Pseudomonas putida bacteria are given as a nutrient source, however heat killed Gram-positive organisms such Bacillus subtilis and Lactobacillus plantarum did not alter the growth of L. pneumophila, suggesting that L. pneumophila is capable of replicating without the presence of protozoan species, and that necrotrophic growth of L. pneumophila is restricted to certain microbial species [27].

Summer seasons, which coincide with legionellosis outbreaks, favour the proliferation of L. pneumophila in cooling tower microbial populations while other Legionella species decrease in number [89]. Based on this shift in abundance it has been hypothesized that L. pneumophila may inhibit the growth of other Legionella species. In fact, L. pneumophila produces a surfactant secreted by the protein TolC, which is toxic to other Legionella species, but has no effect on Pseudomonas aeruginosa, 
Klebsiella pneumoniae and Listeria monocytogenes [90]. Therefore it is tempting to speculate that L. pneumophila may influence the growth of other Legionella species in their natural environment.

One of the most studied bacteria that can influence L. pneumophila's biofilm colonization ability is $P$. aeruginosa. Although there is a body of evidence suggesting that L. pneumophila can coexist in biofilms with $P$. aeruginosa, these studies were performed with inoculums from natural environmental sources, which may contain several different bacterial species [11,38]. In contrast to these studies, monospecies biofilms with $P$. aeruginosa were shown to prevent $L$. pneumophila colonization [26,91]. This phenomenon may be mediated by acylhomoserine lactones (AHLs) produced by P. aeruginosa as these AHLs not only inhibit the growth of L. pneumophila but also its biofilm production [92]. Furthermore, specific AHLs produced by P. aeruginosa can downregulate Lcl production, which is essential for biofilm formation in L. pneumophila [62]. Interestingly, the in vitro inhibition of $L$. pneumophila colonization by $P$. aeruginosa is alleviated if $K$. pneumoniae is present in the produced biofilm [91]. In fact complex multispecies biofilms that contain both $P$. aeruginosa and $K$. pneumoniae are permissive for L. pneumophila colonization [28]. The presence of amoeba seems to also effect whether $P$. aeruginosa is antagonistic to $L$. pneumophila colonization, as biofilms which contain both Acanthamoeba castellanii and P. aeruginosa, increase the uptake of L. pneumophila within A. castellanii, and the colonization of L. pneumophila in biofilms [93].

\section{The Resistance of $L$. pneumophila Containing Biofilms to Biocides}

There is a great interest in improving methods for disinfecting L. pneumophila containing biofilms because of the ongoing threat to human health posed by these organisms in anthropogenic water sources. Due to the intracellular lifestyle of L. pneumophila within protozoa, however, it is difficult to tease out whether the resistance of L. pneumophila in environmental biofilms is due to the biofilm structure, its association with amoeba or both. It is however evident that environmental L. pneumophila found in biofilms are extremely resilient to treatment with biocides [94]. L. pneumophila exposed to environmental stresses and/or found within biofilms can enter a viable but non-culturable (VBNC) state, and treatment of water systems with biocides can make L. pneumophila enter the VBNC state [95]. This property makes the accurate assessment of the contamination levels with L. pneumophila cumbersome since it requires the co-culturing of L. pneumophila with amoeba to lift the VBNC state [96].

Recently, nanoparticles have been suggested to be powerful tools to prevent L. pneumophila biofilm formation, as nanoparticles are able to disrupt L. pneumophila-amoebae interactions and biofilm structure [97,98]. Nanoparticles can also effectively clear L. pneumophila from mixed species biofilms and appear to be an attractive treatment option for disinfecting anthropogenic water sources [99]. The most common biocides used to control water-borne pathogens are generally chlorine derivatives, and chlorine derivatives are more efficacious than UV for disinfecting L. pneumophila [100-102]. Yet chloramine, one of the most potent chlorine derivative biocides, does not completely eradicate L. pneumophila from aquatic biofilms [103,104]. 
The location of the biofilm can also play a role in resistance to disinfection strategies. This is particularly the case for biofilms formed in sediments, which provide protection to L. pneumophila from UV radiation [105]. Furthermore, L. pneumophila bacteria grown on a solid surface are more resistant to killing by iodine than bacteria grown in broth, suggesting that there are metabolic differences between surface associated and planktonic phase bacteria [106]. This is consistent with data suggesting that sessile and planktonic L. pneumophila in biofilms have different gene expression profiles [8].

\section{Conclusions}

L. pneumophila is an environmental pathogen, and understanding the ecology of this pathogen can help to determine methods for preventing its environmental dissemination and the transmission of legionellosis. There are a multitude of factors that can influence whether L. pneumophila produces biofilms, and likely many more that remain to be uncovered. Although there have been significant advances in the understanding L. pneumophila biofilm formation and colonization in the last several years, there is much that remains unknown. The presence of other microbial species, physiochemical parameters, and L. pneumophila gene regulation are all factors that could potentially be exploited to prevent colonization of L. pneumophila in anthropogenic systems. The physiochemical parameters, which favour biofilm, formation is a topic of great interest. Research has yielded insight into factors, which could potentially limit L. pneumophila growth and may be useful for the prevention of legionellosis. One area of increasing interest is the role of other bacterial species in L. pneumophila biofilm production, and the mechanism with which certain species promote L. pneumophila growth while other species inhibit it. Another question that remains to be answered is to what extent the intracellular lifestyle contributes to L. pneumophila biofilm resistance to disinfection in situ. Finally, there is still much unknown about the endogenous factors that L. pneumophila utilizes to facilitate biofilm formation, such as what L. pneumophila quorum sensing systems regulate biofilm formation and what other factors are involved, (for example an extracellular matrix has been found in L. pneumophila monospecies biofilms but has yet to be characterized [8]). Ultimately, this research can yield valuable information that can lead to translational research for prevention and protection against L. pneumophila infections.

\section{Acknowledgments}

This work was supported by the Ontario Agency for Health protection and Promotion, and the Canadian Institutes of Health Research (MOP-102514).

\section{Conflicts of Interest}

The authors declare no conflict of interest. 


\section{References}

1. Carratala, J.; Fernandez-Sabe, N.; Ortega, L.; Castellsague, X.; Roson, B.; Dorca, J.; Fernandez-Aguera, A.; Verdaguer, R.; Martinez, J.; Manresa, F.; et al. Outpatient care compared with hospitalization for community-acquired pneumonia: A randomized trial in low-risk patients. Ann. Intern. Med. 2005, 142, 165-172.

2. Yu, V.L.; Plouffe, J.F.; Pastoris, M.C.; Stout, J.E.; Schousboe, M.; Widmer, A.; Summersgill, J.; File, T.; Heath, C.M.; Paterson, D.L.; et al. Distribution of Legionella species and serogroups isolated by culture in patients with sporadic community-acquired Legionellosis: An international collaborative survey. J. Infect. Dis. 2002, 186, 127-128.

3. Bentham, R.H.; Broadbent, C.R. A model for autumn outbreaks of Legionnaires' disease associated with cooling towers, linked to system operation and size. Epidemiol. Infect. 1993, 111, 287-295.

4. Fields, B.S.; Benson, R.F.; Besser, R.E. Legionella and Legionnaires' disease: 25 years of investigation. Clin. Microbiol. Rev. 2002, 15, 506-526.

5. Feazel, L.M.; Baumgartner, L.K.; Peterson, K.L.; Frank, D.N.; Kirk Harris, J.; Pace, N.R. Opportunistic pathogens enriched in showerhead biofilms. Proc. Natl. Acad. Sci. USA 2009, 106, 16393-16398.

6. McEvoy, M.; Batchelor, N.; Hamilton, G.; MacDonald, A.; Faiers, M.; Sills, A.; Lee, J.; Harrison, T. A cluster of cases of Legionnaires' disease associated with exposure to a spa pool on display. Commun. Dis. Public Health 2000, 3, 43-45.

7. Wadowsky, R.M.; Yee, R.B.; Mezmar, L.; Wing, E.J.; Dowling, J.N. Hot water systems as sources of Legionella pneumophila in hospital and nonhospital plumbing fixtures. Appl. Environ. Microbiol. 1982, 43, 1104-1110.

8. Hindre, T.; Bruggemann, H.; Buchrieser, C.; Hechard, Y. Transcriptional profiling of Legionella Pneumophila biofilm cells and the influence of iron on biofilm formation. Microbiology 2008, 154, 30-41.

9. $\quad$ Pecastaings, S.; Berge, M.; Dubourg, K.M.; Roques, C. Sessile Legionella pneumophila is able to grow on surfaces and generate structured monospecies biofilms. Biofouling 2010, 26, 809-819.

10. Kwon, S.; Moon, E.; Kim, T.; Hong, S.; Park, H. Pyrosequencing demonstrated complex microbial communities in a membrane filtration system for a drinking water treatment plant. Microbes Environ. 2011, 26, 149-155.

11. Murga, R.; Forster, T.S.; Brown, E.; Pruckler, J.M.; Fields, B.S.; Donlan, R.M. Role of biofilms in the survival of Legionella pneumophila in a model potable-water system. Microbiology 2001, 147, 3121-3126.

12. Rowbotham, T.J. Pontiac fever, ameobae and Legionllae. Lancet 1981, 317, 40-41.

13. Molmeret, M.; Horn, M.; Wagner, M.; Santic, M.; Abu Kwaik, Y. Amoebae as training grounds for intracellular bacterial pathogens. Appl. Environ. Microbiol. 2005, 71, 20-28. 
14. Steinert, M.; Hentschel, U.; Hacker, J. Legionella pneumophila: An aquatic microbe goes astray. FEMS Microbiol. Rev. 2002, 26, 149-162.

15. Yan, L.; Cerny, R.L.; Cirillo, J.D. Evidence that hsp90 is involved in the altered interactions of Acanthamoeba castellanii variants with bacteria. Eukaryotic Cell 2004, 3, 567-578.

16. Chaabna, Z.; Forey, F.; Reyrolle, M.; Jarraud, S.; Atlan, D.; Fontvieille, D.; Gilbert, C. Molecular diversity and high virulence of Legionella pneumophila strains isolated from biofilms developed within a warm spring of a thermal spa. BMC Microbiol. 2013, 13, 17.

17. Abu Khweek, A.; Fernandez Davila, N.S.; Caution, K.; Akhter, A.; Abdulrahman, B.A.; Tazi, M.; Hassan, H.; Novotny, L.A.; Bakaletz, L.O.; Amer, A.O. Biofilm-derived Legionella pneumophila evades the innate immune response in macrophages. Front. Cell Infect. Microbiol. 2013, 3, 18.

18. Barker, J.; Lambert, P.A.; Brown, M.R. Influence of intra-amoebic and other growth conditions on the surface properties of Legionella pneumophila. Infect. Immun. 1993, 61, 3503-3510.

19. Newsome, A.L.; Farone, M.B.; Berk, S.G.; Gunderson, J.H. Free living amoebae as opportunistic hosts for intracellular bacterial parasites. J. Eukaryot. Microbiol. 2001, 48, 13S-14S.

20. Rowbotham, T.J. Isolation of Legionella pneumophila from clinical specimens via amoebae, and the interaction of those and other isolates with amoebae. J. Clin. Pathol. 1983, 36, 978-986.

21. Skinner, A.R.; Anand, C.M.; Malic, A.; Kurtz, J.B. Acanthamoebae and environmental spread of Legionella pneumophila. Lancet 1983, 2, 289-290.

22. Taylor, M.; Ross, K.; Bentham, R. Legionella, protozoa, and biofilms: Interactions within complex microbial systems. Microb. Ecol. 2009, 58, 538-547.

23. Valster, R.M.; Wullings, B.A.; van der Kooij, D. Detection of protozoan hosts for Legionella pneumophila in engineered water systems by using a biofilm batch test. Appl. Environ. Microbiol. 2010, 76, 7144-7153.

24. Valster, R.M.; Wullings, B.A.; van den Berg, R.; van der Kooij, D. Relationships between free-living protozoa, cultivable Legionella spp., and water quality characteristics in three drinking water supplies in the caribbean. Appl. Environ. Microbiol. 2011, 77, 7321-7328.

25. Liu, R.; Yu, Z.; Guo, H.; Liu, M.; Zhang, H.; Yang, M. Pyrosequencing analysis of eukaryotic and bacterial communities in faucet biofilms. Sci. Total Environ. 2012, 435-436, 124-131.

26. Mampel, J.; Spirig, T.; Weber, S.S.; Haagensen, J.A.; Molin, S.; Hilbi, H. Planktonic replication is essential for biofilm formation by Legionella pneumophila in a complex medium under static and dynamic flow conditions. Appl. Environ. Microbiol. 2006, 72, 2885-2895.

27. Temmerman, R.; Vervaeren, H.; Noseda, B.; Boon, N.; Verstraete, W. Necrotrophic growth of Legionella pneumophila. Appl. Environ. Microbiol. 2006, 72, 4323-4328.

28. Declerck, P.; Behets, J.; van Hoef, V.; Ollevier, F. Replication of Legionella pneumophila in floating biofilms. Curr. Microbiol. 2007, 55, 435-440.

29. Hsu, B.; Huang, C.; Chen, J.; Chen, N.; Huang, J. Comparison of potentially pathogenic free-living amoeba hosts by Legionella spp. in substrate-associated biofilms and floating biofilms from spring environments. Water Res. 2011, 45, 5171-5183. 
30. Atlas, R.M. Legionella: From environmental habitats to disease pathology, detection and control. Environ. Microbiol. 1999, 1, 283-293.

31. Hoffman, P.S. Invasion of eukaryotic cells by Legionella pneumophila: A common strategy for all hosts? Can. J. Infect. Dis. 1997, 8, 139-146.

32. Donlan, R.M.; Forster, T.; Murga, R.; Brown, E.; Lucas, C.; Carpenter, J.; Fields, B. Legionella pneumophila associated with the protozoan Hartmannella vermiformis in a model multi-species biofilm has reduced susceptibility to disinfectants. Biofouling 2005, 21, 1-7.

33. Thomas, V.; Bouchez, T.; Nicolas, V.; Robert, S.; Loret, J.F.; Levi, Y. Amoebae in domestic water systems: Resistance to disinfection treatments and implication in Legionella persistence. J. Appl. Microbiol. 2004, 97, 950-963.

34. Storey, M.V.; Winiecka-Krusnell, J.; Ashbolt, N.J.; Stenstrom, T. The efficacy of heat and chlorine treatment against thermotolerant Acanthamoebae and Legionellae. Scand. J. Infect. Dis. 2004, 36, 656-662.

35. Wright, J.B.; Ruseska, I.; Athar, M.A.; Corbett, S.; Costerton, J.W. Legionella pneumophila grows adherent to surfaces in vitro and in situ. Infect. Control Hosp. Epidemiol. 1989, 10, 408-415.

36. Rogers, J.; Dowsett, A.B.; Dennis, P.J.; Lee, J.V.; Keevil, C.W. Influence of plumbing materials on biofilm formation and growth of Legionella pneumophila in potable water systems. Appl. Environ. Microbiol. 1994, 60, 1842-1851.

37. Rogers, J.; Dowsett, A.B.; Dennis, P.J.; Lee, J.V.; Keevil, C.W. Influence of temperature and plumbing material selection on biofilm formation and growth of Legionella pneumophila in a model potable water system containing complex microbial flora. Appl. Environ. Microbiol. 1994, 60, 1585-1592.

38. Moritz, M.M.; Flemming, H.; Wingender, J. Integration of Pseudomonas aeruginosa and Legionella pneumophila in drinking water biofilms grown on domestic plumbing materials. Int. J. Hyg. Environ. Health 2010, 213, 190-197.

39. Geesey, G.G.; Wigglesworth-Cooksey, B.; Cooksey, K.E. Influence of calcium and other cations on surface adhesion of bacteria and diatoms: A review. Biofouling 2000, 15, 195-205.

40. Koubar, M.; Rodier, M.H.; Frere, J. Involvement of minerals in adherence of Legionella pneumophila to surfaces. Curr. Microbiol. 2013, 66, 437-442.

41. Yaradou, D.F.; Raze, D.; Ginevra, C.; Ader, F.; Doleans-Jordheim, A.; Vandenesch, F.; Menozzi, F.D.; Etienne, J.; Jarraud, S. Zinc-dependent cytoadherence of Legionella pneumophila to human alveolar epithelial cells in vitro. Microb. Pathog. 2007, 43, 234-242.

42. Bargellini, A.; Marchesi, I.; Righi, E.; Ferrari, A.; Cencetti, S.; Borella, P.; Rovesti, S. Parameters predictive of Legionella contamination in hot water systems: Association with trace elements and heterotrophic plate counts. Water Res. 2011, 45, 2315-2321. 
43. Borella, P.; Montagna, M.T.; Romano-Spica, V.; Stampi, S.; Stancanelli, G.; Triassi, M.; Marchesi, I.; Bargellini, A.; Neglia, R.; Paglionico, N.; et al. Relationship between mineral content of domestic hot water and microbial contamination. J. Trace Elem. Med. Biol. 2003, 17, $37-43$.

44. Boyd, C.D.; Chatterjee, D.; Sondermann, H.; O'Toole, G.A. LapG, required for modulating biofilm formation by Pseudomonas fluorescens $\mathrm{Pf0}-1$, is a calcium-dependent protease. J. Bacteriol. 2012, 194, 4406-4414.

45. Chatterjee, D.; Boyd, C.D.; O’Toole, G.A.; Sondermann, H. Structural characterization of a conserved, calcium-dependent periplasmic protease from Legionella pneumophila. J. Bacteriol. 2012, 194, 4415-4425.

46. Giao, M.S.; Wilks, S.A.; Azevedo, N.F.; Vieira, M.J.; Keevil, C.W. Comparison between standard culture and peptide nucleic acid 16S rRNA hybridization quantification to study the influence of physico-chemical parameters on Legionella pneumophila survival in drinking water biofilms. Biofouling 2009, 25, 343-351.

47. Pang, C.M.; Liu, W. Biological filtration limits carbon availability and affects downstream biofilm formation and community structure. Appl. Environ. Microbiol. 2006, 72, 5702-5712.

48. Van der Kooij, D.K.; Veenendaal, H.R.; Scheffer, W.J.H. Biofilm formation and multiplication of Legionella in a model warm water system with pipes of copper, stainless steel and cross-linked polyethylene. Water Res. 2005, 39, 2789-2798.

49. Martinelli, F.; Caruso, A.; Moschini, L.; Turano, A.; Scarcella, C.; Speziani, F. A comparison of Legionella pneumophila occurrence in hot water tanks and instantaneous devices in domestic, nosocomial, and community environments. Curr. Microbiol. 2000, 41, 374-376.

50. Ciesielski, C.A.; Blaser, M.J.; Wang, W.L. Role of stagnation and obstruction of water flow in isolation of Legionella pneumophila from hospital plumbing. Appl. Environ. Microbiol. 1984, 48, 984-987.

51. Fisher-Hoch, S.; Bartlett, C.L.; Tobin, J.O.; Gillett, M.B.; Nelson, A.M.; Pritchard, J.E.; Smith, M.G.; Swann, R.A.; Talbot, J.M.; Thomas, J.A. Investigation and control of an outbreaks of Legionnaires' disease in a district general hospital. Lancet 1981, 1, 932-936.

52. Makin, T.; Pride, M. Venturi system could be major breakthrough. Health Estate 2010, 64, $27-33$.

53. Storey, M.V.; Langmark, J.; Ashbolt, N.J.; Stenstrom, T.A. The fate of Legionellae within distribution pipe biofilms: Measurement of their persistence, inactivation and detachment. Water Sci. Technol. 2004, 49, 269-275.

54. Lehtola, M.J.; Torvinen, E.; Kusnetsov, J.; Pitkanen, T.; Maunula, L.; von Bonsdorff, C.; Martikainen, P.J.; Wilks, S.A.; Keevil, C.W.; Miettinen, I.T. Survival of Mycobacterium avium, Legionella pneumophila, Escherichia coli, and caliciviruses in drinking water-associated biofilms grown under high-shear turbulent flow. Appl. Environ. Microbiol. 2007, 73, 2854-2859. 
55. Liu, Z.; Lin, Y.E.; Stout, J.E.; Hwang, C.C.; Vidic, R.D.; Yu, V.L. Effect of flow regimes on the presence of Legionella within the biofilm of a model plumbing system. J. Appl. Microbiol. 2006, 101, 437-442.

56. Fliermans, C.B.; Cherry, W.B.; Orrison, L.H.; Smith, S.J.; Tison, D.L.; Pope, D.H. Ecological distribution of Legionella pneumophila. Appl. Environ. Microbiol. 1981, 41, 9-16.

57. Stout, J.E.; Yu, V.L.; Best, M.G. Ecology of Legionella pneumophila within water distribution systems. Appl. Environ. Microbiol. 1985, 49, 221-228.

58. Tiaden, A.; Spirig, T.; Sahr, T.; Walti, M.A.; Boucke, K.; Buchrieser, C.; Hilbi, H. The autoinducer synthase LqsA and putative sensor kinase lqss regulate phagocyte interactions, extracellular filaments and a genomic island of Legionella pneumophila. Environ. Microbiol. 2010, 12, 1243-1259.

59. Kessler, A.; Schell, U.; Sahr, T.; Tiaden, A.; Harrison, C.; Buchrieser, C.; Hilbi, H. The Legionella pneumophila orphan sensor kinase LqsT regulates competence and pathogenhost interactions as a component of the LAI-1 circuit. Environ. Microbiol. 2013, 15, 646-662.

60. Vandersmissen, L.; de Buck, E.; Saels, V.; Coil, D.A.; Anne, J. A Legionella pneumophila collagen-like protein encoded by a gene with a variable number of tandem repeats is involved in the adherence and invasion of host cells. FEMS Microbiol. Lett. 2010, 306, 168-176.

61. Duncan, C.; Prashar, A.; So, J.; Tang, P.; Low, D.E.; Terebiznik, M.; Guyard, C. Lcl of Legionella pneumophila is an immunogenic GAG binding adhesin that promotes interactions with lung epithelial cells and plays a crucial role in biofilm formation. Infect. Immun. 2011, 6, 2168-2181.

62. Mallegol, J.; Duncan, C.; Prashar, A.; So, J.; Low, D.E.; Terebeznik, M.; Guyard, C. Essential roles and regulation of the Legionella pneumophila collagen-like adhesin during biofilm formation. PLoS One 2012, 7, e46462.

63. Stone, B.J.; Kwaik, Y.A. Expression of multiple pili by Legionella pneumophila: Identification and characterization of a type IV pilin gene and its role in adherence to mammalian and protozoan cells. Infect. Immun. 1998, 66, 1768-1775.

64. Lucas, C.E.; Brown, E.; Fields, B.S. Type IV Pili and Type II secretion play a limited role in Legionella pneumophila biofilm colonization and retention. Microbiology 2006, 152, 3569-3573.

65. De Buck, E.; Maes, L.; Meyen, E.; van Mellaert, L.; Geukens, N.; Anne, J.; Lammertyn, E. Legionella pneumophila Philadelphia-1 tatB and tatC affect intracellular replication and biofilm formation. Biochem. Biophys. Res. Commun. 2005, 331, 1413-1420.

66. Cianciotto, N.P. Iron acquisition by Legionella pneumophila. Biometals 2007, 20, 323-331.

67. Orsi, N. The antimicrobial activity of lactoferrin: Current status and perspectives. Biometals 2004, 17, 189-196.

68. Robey, M.; Cianciotto, N.P. Legionella pneumophila feoAB promotes ferrous iron uptake and intracellular infection. Infect. Immun. 2002, 70, 5659-5669. 
69. Tiaden, A.; Hilbi, H. A-hydroxyketone synthesis and sensing by Legionella and Vibrio. Sensors 2012, 12, 2899-2919.

70. Spirig, T.; Tiaden, A.; Kiefer, P.; Buchrieser, C.; Vorholt, J.A.; Hilbi, H. The Legionella autoinducer synthase LqsA produces an $\alpha$-hydroxyketone signaling molecule. J. Biol. Chem. 2008, 283, 18113-18123.

71. Tiaden, A.; Spirig, T.; Hilbi, H. Bacterial gene regulation by $\alpha$-hydroxyketone signaling. Trends Microbiol. 2010, 18, 288-297.

72. Tiaden, A.; Spirig, T.; Carranza, P.; Bruggemann, H.; Riedel, K.; Eberl, L.; Buchrieser, C.; Hilbi, H. Synergistic contribution of the Legionella pneumophila Lqs genes to pathogen-host interactions. J. Bacteriol. 2008, 190, 7532-7547.

73. McDonough, K.A.; Rodriguez, A. The myriad roles of cyclic AMP in microbial pathogens: From signal to sword. Nat. Rev. Microbiol. 2011, 10, 27-38.

74. Levi, A.; Folcher, M.; Jenal, U.; Shuman, H.A. Cyclic diguanylate signaling proteins control intracellular growth of Legionella pneumophila. mBio 2011, 2, e00316-10.

75. Carlson, H.K.; Vance, R.E.; Marletta, M.A. H-NOX regulation of c-di-GMP metabolism and biofilm formation in Legionella pneumophila. Mol. Microbiol. 2010, 77, 930-942.

76. Hammer, B.K.; Swanson, M.S. Co-ordination of Legionella pneumophila virulence with entry into stationary phase by ppGpp. Mol. Microbiol. 1999, 33, 721-731.

77. Bachman, M.A.; Swanson, M.S. RpoS co-operates with other factors to induce Legionella pneumophila virulence in the stationary phase. Mol. Microbiol. 2001, 40, 1201-1214.

78. Tiaden, A.; Spirig, T.; Weber, S.S.; Bruggemann, H.; Bosshard, R.; Buchrieser, C.; Hilbi, H. The Legionella pneumophila response regulator LqsR promotes host cell interactions as an element of the virulence regulatory network controlled by RpoS and LetA. Cell. Microbiol. 2007, 9, 2903-2920.

79. Hammer, B.K.; Tateda, E.S.; Swanson, M.S. A two-component regulator induces the transmission phenotype of stationary-phase Legionella pneumophila. Mol. Microbiol. 2002, 44, $107-118$.

80. Molofsky, A.B.; Swanson, M.S. Legionella pneumophila CsrA is a pivotal repressor of transmission traits and activator of replication. Mol. Microbiol. 2003, 50, 445-461.

81. Piao, Z.; Sze, C.C.; Barysheva, O.; Iida, K.; Yoshida, S. Temperature-regulated formation of mycelial mat-like biofilms by Legionella pneumophila. Appl. Environ. Microbiol. 2006, 72, $1613-1622$

82. Konishi, T.; Yamashiro, T.; Koide, M.; Nishizono, A. Influence of temperature on growth of Legionella pneumophila biofilm determined by precise temperature gradient incubator. J. Biosci. Bioeng. 2006, 101, 478-484.

83. Justice, S.S.; Hunstad, D.A.; Cegelski, L.; Hultgren, S.J. Morphological plasticity as a bacterial survival strategy. Nat. Rev. Microbiol. 2008, 6, 162-168. 
84. Prashar, A.; Bhatia, S.; Tabatabaeiyazdi, Z.; Duncan, C.; Garduno, R.A.; Tang, P.; Low, D.E.; Guyard, C.; Terebiznik, M.R. Mechanism of invasion of lung epithelial cells by filamentous Legionella pneumophila. Cell. Microbiol. 2012, 14, 1632-1655.

85. Liles, M.R.; Viswanathan, V.K.; Cianciotto, N.P. Identification and temperature regulation of Legionella pneumophila genes involved in type IV pilus biogenesis and type II protein secretion. Infect. Immun. 1998, 66, 1776-1782.

86. Messi, P.; Anacarso, I.; Bargellini, A.; Bondi, M.; Marchesi, I.; de Niederhausern, S.; Borella, P. Ecological behaviour of three serogroups of Legionella pneumophila within a model plumbing system. Biofouling 2011, 27, 165.

87. Tison, D.L.; Pope, D.H.; Cherry, W.B.; Fliermans, C.B. Growth of Legionella pneumophila in association with blue-green algae (Cyanobacteria). Appl. Environ. Microbiol. 1980, 39, 456-459.

88. Wadowsky, R.M.; Yee, R.B. Satellite growth of Legionella pneumophila with an environmental isolate of Flavobacterium breve. Appl. Environ. Microbiol. 1983, 46, 1447-1449.

89. Wery, N.; Bru-Adan, V.; Minervini, C.; Delgenes, J.; Garrelly, L.; Godon, J. Dynamics of Legionella spp. and bacterial populations during the proliferation of L. pneumophila in a cooling tower facility. Appl. Environ. Microbiol. 2008, 74, 3030-3037.

90. Stewart, C.R.; Burnside, D.M.; Cianciotto, N.P. The surfactant of Legionella pneumophila is secreted in a TolC-dependent manner and is antagonistic toward other Legionella species. J. Bacteriol. 2011, 193, 5971-5984.

91. Stewart, C.R.; Muthye, V.; Cianciotto, N.P. Legionella pneumophila persists within biofilms formed by Klebsiella pneumoniae, Flavobacterium sp., and Pseudomonas fluorescens under dynamic flow conditions. PLoS One 2012, 7, e50560.

92. Kimura, S.; Tateda, K.; Ishii, Y.; Horikawa, M.; Miyairi, S.; Gotoh, N.; Ishiguro, M.; Yamaguchi, K. Pseudomonas aeruginosa las quorum sensing autoinducer suppresses growth and biofilm production in Legionella species. Microbiology 2009, 155, 1934-1939.

93. Declerck, P.; Behets, J.; Delaedt, Y.; Margineanu, A.; Lammertyn, E.; Ollevier, F. Impact of non-Legionella bacteria on the uptake and intracellular replication of Legionella pneumophila in Acanthamoeba castellanii and Naegleria lovaniensis. Microb. Ecol. 2005, 50, 536-549.

94. Emtiazi, F.; Schwartz, T.; Marten, S.M.; Krolla-Sidenstein, P.; Obst, U. Investigation of natural biofilms formed during the production of drinking water from surface water embankment filtration. Water Res. 2004, 38, 1197-1206.

95. Giao, M.S.; Wilks, S.; Azevedo, N.F.; Vieira, M.J.; Keevil, C.W. Incorporation of natural uncultivable Legionella pneumophila into potable water biofilms provides a protective niche against chlorination stress. Biofouling 2009, 25, 335-341.

96. Alleron, L.; Merlet, N.; Lacombe, C.; Frere, J. Long-term survival of Legionella pneumophila in the viable but nonculturable state after monochloramine treatment. Curr. Microbiol. 2008, 57, 497-502. 
97. Raftery, T.D.; Lindler, H.; McNealy, T.L. Altered host cell-bacteria interaction due to nanoparticle interaction with a bacterial biofilm. Microb. Ecol. 2013, 65, 496-503.

98. Stojak, A.R.; Raftery, T.; Klaine, S.J.; McNealy, T.L. Morphological responses of Legionella pneumophila biofilm to nanoparticle exposure. Nanotoxicology 2011, 5, 730-742.

99. Rogers, J.; Dowsett, A.B.; Keevil, C.W. A paint incorporating silver to control mixed biofilms containing Legionella pneumophila. J. Ind. Microbiol. 1995, 15, 377-383.

100. Liu, Z.; Stout, J.E.; Boldin, M.; Rugh, J.; Diven, W.F.; Yu, V.L. Intermittent use of copper-silver ionization for Legionella control in water distribution systems: A potential option in buildings housing individuals at low risk of infection. Clin. Infect Dis. 1998, 26, 138-140.

101. Schwartz, T.; Hoffmann, S.; Obst, U. Formation of natural biofilms during chlorine dioxide and u.v. disinfection in a public drinking water distribution system. J. Appl. Microbiol. 2003, 95, 591-601.

102. Walker, J.T.; Mackerness, C.W.; Mallon, D.; Makin, T.; Williets, T.; Keevil, C.W. Control of Legionella pneumophila in a hospital water system by chlorine dioxide. J. Ind. Microbiol. 1995, 15, 384-390.

103. Pryor, M.; Springthorpe, S.; Riffard, S.; Brooks, T.; Huo, Y.; Davis, G.; Sattar, S.A. Investigation of opportunistic pathogens in municipal drinking water under different supply and treatment regimes. Water Sci. Technol. 2004, 50, 83-90.

104. Williams, M.M.; Braun-Howland, E. Growth of Escherichia coli in model distribution system biofilms exposed to hypochlorous acid or monochloramine. Appl. Environ. Microbiol. 2003, 69, $5463-5471$.

105. Kusnetsov, J.M.; Keskitalo, P.J.; Ahonen, H.E.; Tulkki, A.I.; Miettinen, I.T.; Martikainen, P.J. Growth of Legionella and other heterotrophic bacteria in a circulating cooling water system exposed to ultraviolet irradiation. J. Appl. Microbiol. 1994, 77, 461-466.

106. Cargill, K.L.; Pyle, B.H.; Sauer, R.L.; McFeters, G.A. Effects of culture conditions and biofilm formation on the iodine susceptibility of Legionella pneumophila. Can. J. Microbiol. 1992, 38, 423-429. 


\title{
Biofilm Matrix and Its Regulation in Pseudomonas aeruginosa
}

\author{
Qing Wei and Luyan Z. Ma
}

\begin{abstract}
Biofilms are communities of microorganisms embedded in extracellular polymeric substances (EPS) matrix. Bacteria in biofilms demonstrate distinct features from their free-living planktonic counterparts, such as different physiology and high resistance to immune system and antibiotics that render biofilm a source of chronic and persistent infections. A deeper understanding of biofilms will ultimately provide insights into the development of alternative treatment for biofilm infections. The opportunistic pathogen Pseudomonas aeruginosa, a model bacterium for biofilm research, is notorious for its ability to cause chronic infections by its high level of drug resistance involving the formation of biofilms. In this review, we summarize recent advances in biofilm formation, focusing on the biofilm matrix and its regulation in $P$. aeruginosa, aiming to provide resources for the understanding and control of bacterial biofilms.
\end{abstract}

Reprinted from Int. J. Mol. Sci. Cite as: Wei, Q.; Ma, L.Z. Biofilm Matrix and Its Regulation in Pseudomonas aeruginosa. Int. J. Mol. Sci. 2013, 14, 20983-21005.

\section{Introduction}

Biofilms are microbial communities encased in extracellular polymeric substances (EPS) [1]. Biofilm formation represents a protective mode of growth that allows microorganisms to survive in hostile environments and disperse seeding cells to colonize new niches under desirable conditions. Biofilms can form on a variety of surfaces and are prevalent in natural, industrial, and hospital niches. These sessile microbial communities are physiologically distinct from free-living planktonic counterparts [2,3]. Clinically, biofilms are responsible for many persistent and chronic infections due to their inherent resistance to antimicrobial agents and the selection for phenotypic variants. A better understanding of the genetic and molecular mechanisms of biofilm formation may provide strategies for the control of chronic infections and problems related to biofilm formation.

The EPS of biofilm is a mixture of polysaccharides, extracellular DNA (eDNA), and proteins, which function as matrix, or glue, holding microbial cells together. The biofilm matrix contributes to the overall architecture and the resistance phenotype of biofilms [4,5]. Uncovering roles played by EPS matrices in biofilm formation will be beneficial for the design of targeted molecules to control biofilm formation. In this review, advances in biofilm formation and regulation are presented with a focus on the biofilm matrix in $P$. aeruginosa, a model organism for biofilm research.

\section{Matrices of $P$. aeruginosa Biofilms}

Colonization of the lungs of cystic fibrosis $(\mathrm{CF})$ patients by $P$. aeruginosa is the major cause of morbidity and mortality in CF populations. These infections generally persist despite the use of long 
term aggressive antimicrobial therapy and have been associated with the formation of antibioticresistant biofilms, whereby bacterial communities form microcolonies embedded in a hydrated EPS matrix [6,7]. The relative importance of the EPS matrix is dependent on the genetic background of strains, nutritional conditions and developmental phases of biofilms [8]. It is generally acknowledged that the EPS of biofilms functions as both a structural scaffold and/or a protective barrier to harsh environments $[9,10]$. At least three polysaccharides (Psl, Pel and alginate) have been identified in $P$. aeruginosa that play important roles in structure maintenance and antibiotic resistance of biofilm [9,11-15]. The respective nature and functions in biofilm formation and development of biofilm matrix components including exopolysaccharides (Psl, Pel, and alginate), eDNA, proteins, and proteinaceous surface appendages such as fimbriae, type IV pili (T4P), and flagellum will be discussed below.

\subsection{Psl Polysaccharide}

Polysaccharide synthesis locus of $P$. aeruginosa PAO1 was identified in 2004 by three different groups $[11,13,16]$. The Psl cluster consists of 15 co-transcribed genes (pslA to pslO, PA2231-2245) encoding proteins to synthesize Psl, which is important to initiate and maintain biofilm structure by providing cell-cell and cell-surface interactions [15,17-19]. It was further demonstrated that only 11 of the $15 \mathrm{psl}$ genes are required for the synthesis of Psl-dependent biofilm [20]. A deletion from pslA to pslD in P. aeruginosa strain PA14 leads to the incapability of producing Psl polysaccharide [21]. It was previously shown that Psl is a galactose-rich and mannose-rich exopolysaccharide with relatively lower amounts of glucose and xylose [17]. Recently, Psl was found to contain a repeating pentasaccharide consisting of D-mannose, D-glucose, and L-rhamnose [20]. Additionally, functions of individual $p s l$ genes such as $p s l A, p s l B$ and $p s l D$ have been studied at genetic and biochemical levels, revealing that those genes are crucial for the biofilm formation and Psl synthesis [22-24].

The roles of Psl in biofilm formation have been thoroughly investigated due to its major contribution to the biofilm formation in P. aeruginosa [19]. Firstly, overproduction of the Psl polysaccharide led to enhanced cell-surface and intercellular adhesion of $P$. aeruginosa, suggesting its importance in adhesion, which is critical for initiation and maintenance of the biofilm structure $[18,20]$. Afterwards, using fluorescently labeled lectins, Ma and colleagues could directly visualize Psl exopolysaccharide formation at different stages of biofilm development (Figure 1). They found that Psl polysaccharide anchors on bacterial cell surface in a helical shape, which promotes strong bacterial cell-cell interactions. This results in the assembly of a biofilm and its matrix at the early stage of biofilm development. Later on, Psl polysaccharide accumulated on the periphery of three dimensionstructured macrocolonies during biofilm maturation. This localization pattern provided the structure support and allowed for later biofilm dispersion [15]. In addition, Psl staining demonstrated that Psl can form a fiber-like matrix that enmeshes bacteria within biofilms. Recently, it was found that Psl fiber matrix was formed via a T4P-dependent migration strategy, a way similar to spider web formation [25]. Independently, Zhao and colleagues also showed that $P$. aeruginosa can deposit Psl 
trails during migration on a surface, which influences the surface motility of subsequent cells, leading to the biofilm initiation [26]. These recent discoveries further expand our understanding on the biology of Psl polysaccharide.

Figure 1. Scheme of biofilm development in P. aeruginosa. Selected images showed how the matrix of Psl polysaccharide (red fluorescence) enmeshes bacterial cells (green fluorescence) within bacterial communities during biofilm development (I: initial attachment; II: irreversible attachment; III: microcolony formation; IV: biofilm maturation; V: biofilm dispersion). The figure was used with the permission of the authors $[15,27]$ and modified herein.

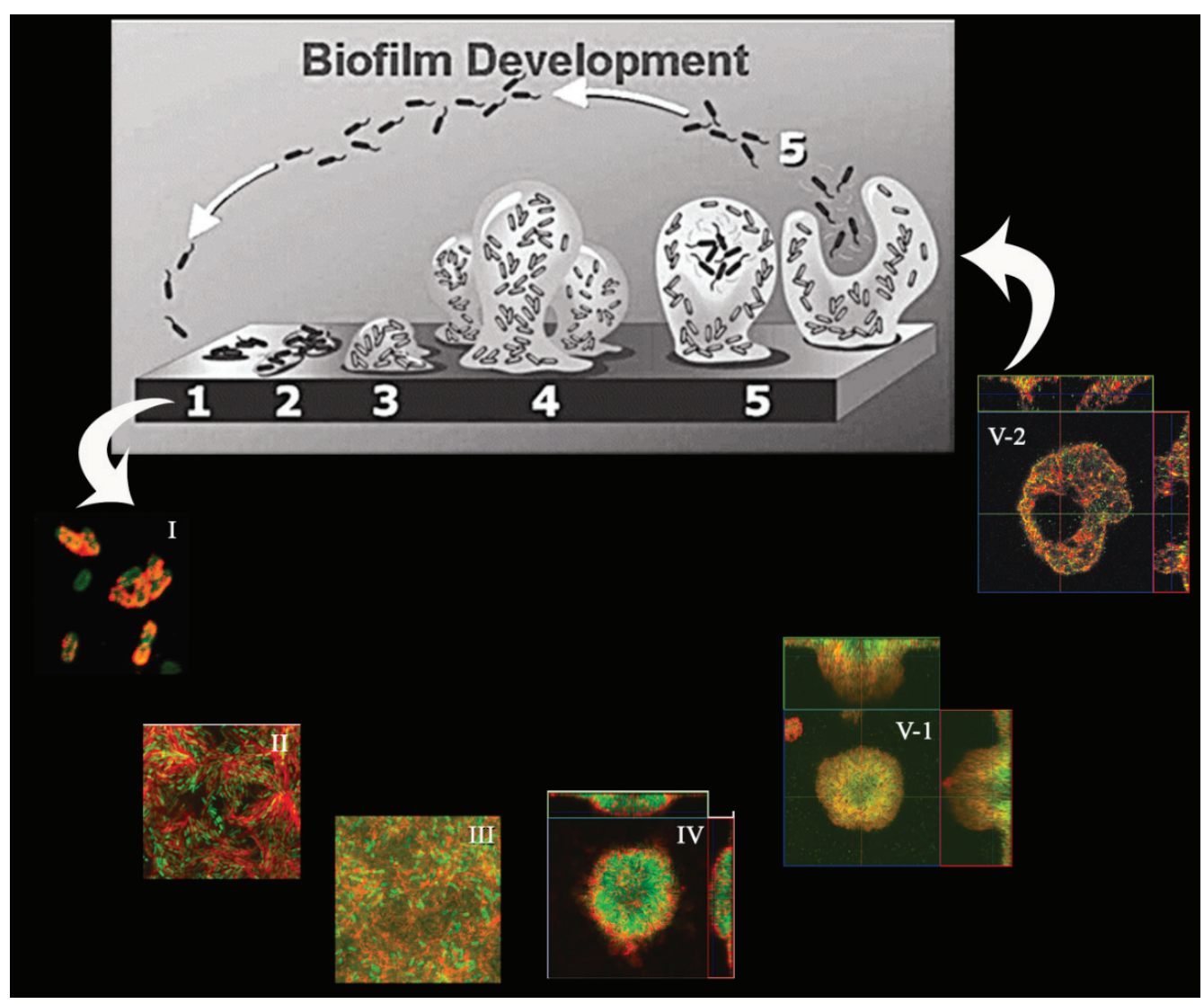

Strikingly, the function of Psl was further characterized to have a signaling role in stimulating two diguanylate cyclase, SiaD and SadC, to produce more of the intracellular second messenger molecule c-di-GMP, thus ultimately increasing the production of Psl itself and forming a unique positive feedback regulatory circuit [28].

In addition, Psl was found to have roles in pathogenesis and protection against the immune system. It was shown that by increasing contact between bacterial cells and epithelial cells, Psl polysaccharide indirectly stimulates NF- $\mathrm{BB}$ activity and facilitates flagellin-mediated proinflammatory signaling [29]. Furthermore, Mishra et al. found that $P$. aeruginosa Psl polysaccharide could reduce neutrophil phagocytosis and the oxidative response via limiting complement-mediated opsonization [30]. This 
study clearly presented Psl as a survival advantage in vivo and provided evidence for the clearance of persistent infections using Psl as a target.

Reports showed that Psl also had roles in antibiotics resistance. It was recently revealed that Psl can promote resistance to the biofilm inhibitor Polysorbate 80 [31]. Yang and colleagues reported that the formation of tight microcolony structure, mainly by Psl, in $P$. aeruginosa contributed to the resistance to antibiotic treatment [19]. By using fluorescent labeling of antibiotics, the extracellular matrix was also found to protect $P$. aeruginosa biofilms from killing by limiting the penetration of tobramycin; this sequestration happened at the periphery of biofilms [32]. However, no clear evidence was identified in which biofilm matrix is critical for this protection and interaction. Furthermore, another group showed that Psl provided a generic first line of defense against both cationic and anionic antibiotics during the initial stages of biofilm development and the Psl-mediated protection was extendable to Escherichia coli and Staphylococcus aureus in co-culture biofilms [33].

In summary, Psl not only functions as a scaffold for biofilm development, but also serves as a signaling molecule or track for the subsequent events leading to the formation of biofilms. This positive feedback circuit presents an evolutionary survival advantage for $P$. aeruginosa to colonize different niches. Besides, Psl also functions as a barrier for immune and antibiotic attacks.

\subsection{Pel Polysaccharide}

Pel polysaccharide, which is synthesized by the products of the pel gene cluster (pelA-F, PA3058PA3064), is a glucose-rich and cellulase-sensitive extracellular matrix [12]. This gene cluster is conserved in other Gram-negative bacteria [34]. A pel mutant appeared to be deficient in the formation of pellicles at the air-liquid interface in standing cultures. Pel is also required for the formation of solid surface-associated biofilms [11]. Interestingly, in a non-piliated P. aeruginosa PAK strain, the pel mutation was discovered to have severe defects in the initial attachment process on solid surfaces, suggesting that Pel polysaccahride can compensate as an attachment factor in the absence of other adhesins such as type IV pili [34]. However, the precise role of Pel polysaccharide in attachment in other $P$. aeruginosa strains needs further investigation. In addition, Pel polysaccharide can serve as a primary structure scaffold for the community of cells by maintaining the cell-to-cell interactions in PA14 biofilms and play a protective role by enhancing resistance to aminoglycoside antibiotics in biofilms [14]. The role of Pel in biofilm formation was further investigated and it was revealed that Pel could function together with other types of EPS throughout biofilm development in $P$. aeruginosa PAO1, although in a less important role as compared to Psl. [19].

One remaining question about Pel is its biochemical composition. Although the original study identified Pel as a glucose-rich matrix material [12], its defined structure and feature have not been completely understood. Recently, the main glucose-containing carbohydrate of the extracellular matrix of $P$. aeruginosa PA14 was characterized to be glycerophosphorylated cyclic $\beta$ - $(1,3)$-glucans, which was synthesized by $n d v B$ locus but not the pel operon [35]. A systematic analysis of the extracellular carbohydrates produced by $P$. aeruginosa PA14 elucidated the structure of a LPS $O$-antigen polysaccharide, 
which suggested that the pel locus might be involved in the production of the LPS [36]. Recently, biochemical studies identified PelF as a cytosolic glycosyltransferase that utilizes UDP-glucose as substrate for Pel synthesis [37]. In addition, Colvin and his coworkers examined the deacetylase activity of PelA and found that this function is important for the production of the Pel polysaccharide [38]. Both studies contributed to the understanding of the synthesis of Pel in P. aeruginosa.

\subsection{Alginate}

Alginate is the exopolysaccharide that is often and mainly produced by $P$. aeruginosa clinical isolates from the lungs of CF patients [39]. The typical mucoid phenotype is due to the overproduction of this polysaccharide, which protects $P$. aeruginosa from harsh environments in CF lungs by providing an extracellular matrix in biofilms. However, it is not absolutely required during the formation of nonmucoid biofilms in vitro [40]. Alginate plays important roles in structural stability and protection of biofilms. It is necessary for water and nutrient retention in biofilms [41]. Interestingly, it was recently found that mucoid $P$. aeruginosa strains also relied on Psl to form biofilms $[42,43]$. Alginate has been identified to have functions in persistence and immune evasion [44]. Overproduction of alginate could provide resistance to antibiotics as well as opsonophagocytosis [45,46]. Alginate also has the ability to scavenge free radicals released from neutrophils and activate macrophages in vitro that are commonly used to kill pathogens [47]. Bragonzi and colleagues reported that overproduction of alginate did not provide increased persistence in a murine lung infection model, perhaps likely due to the reversion of mucoid phenotype to non-mucoid phenotype during infections [48].

\subsection{Extracellular DNA}

Extracellular DNA (eDNA) constitutes another important component of the $P$. aeruginosa biofilm matrix $[16,49,50]$. The eDNA appears to be generated from random chromosomal DNA that serves as a cell-to-cell interconnecting component in the biofilm. Biofilm eDNA staining suggests that the eDNA is located primarily in high concentrations within the stalks of mushroom-shaped microcolonies [49]. In addition, bacterial cells also undergo autolysis in biofilm microcolonies, but it is unclear whether autolysis contributes to eDNA or biofilm development [51]. Several hypotheses have been proposed such as direct secretion, lysis of sub-population by prophage and release of small membrane vesicles [52].

Similar to other types of biofilm matrices, eDNA also has multifaceted roles in biofilm formation, such as contribution to cation gradients, genomic DNA release and antibiotic resistance [53]. eDNA also acts as a nutrient source for bacteria during starvation [54]. Interestingly, it was recently shown that $P$. aeruginosa produces an extracellular deoxyribonuclease (PA3909) that is required for utilization of eDNA as a nutrient source, further amplifying the role of eDNA during $P$. aeruginosa biofilm formation [55]. In addition, eDNA was shown to form bundles with F-actin liberated from necrotic neutrophils and the presence of those bundles could stimulate the initial development of P. aeruginosa biofilms [56]. eDNA can also activate neutrophils through a CpG- and TLR9-independent 
mechanism and serve as a major proinflammatory component of $P$. aeruginosa biofilms [57]. eDNA was further found to facilitate the twitching motility-mediated biofilm expansion by maintaining coherent cell alignments to coordinate the movement of cells in the leading edge vanguard rafts [58].

\subsection{Proteins and Proteinaceous Bacterial Surface Appendages}

Aside from exopolysaccharides and eDNA, extracellular proteins and several proteinaceous components are also considered to be matrix components, including type IV pili, flagella, and fimbriae. These components were found to mainly play auxiliary functions as adhesion factors and structural support in the biofilm formation of $P$. aeruginosa [59].

Flagella mediate swimming and swarming motility of $P$. aeruginosa. It can also act as an adhesin and play critical roles in the initial cell-to-surface interactions [60]. T4P is a linear actuator critical for twitching motility that involves an extension-grip-retraction mechanism [61]. T4P plays important roles in microcolony formation of $P$. aeruginosa biofilms by forming typical mushroom caps [60]. As mentioned above, T4P-driven bacterial motilities can help to form Psl fiber matrix [25]. Another group, however, drew the conclusion that flagella and pili are not required for the initial attachment or biofilm formation [62], indicating that flagella- and pili-mediated biofilm formation could be conditional and nutritional. Recently, another newly identified adhesin named CdrA was demonstrated to be a key protein functioning as a structural component of $P$. aeruginosa EPS matrix [63]. This adhesin could directly interact with Psl polysaccharide to mediate bacterial auto-aggregation and increase biofilm stability.

The $P$. aeruginosa Cup fimbriae constitute one class of appendages that facilitate the biofilm formation and assemble through chaperone/usher pathway [64]. In P. aeruginosa PAO1, at least four Cup systems (CupA, B, C, and E) have been identified and vary in organizations and functions [65]. It was demonstrated that Cup fimbriae are critical for the initial stage of biofilm development, particularly in cell-to-cell interaction and microcolony formation [66,67].

Numerous investigations on biofilm formation, especially the biofilm matrices of $P$. aeruignosa have provided insights into the importance and nature of each matrix component and laid foundations for the efficient treatment of biofilm-related $P$. aeruginosa infections. The roles of matrix components in $P$. aeruginosa biofilms are summarized in Table 1. 
Table 1. Roles of different exopolysaccharides (EPS) in Pseudomonas aeruginosa

\begin{tabular}{|c|c|c|c|}
\hline EPS & Locus * & Roles & References \\
\hline \multirow{8}{*}{ Psl } & \multirow{8}{*}{$\begin{array}{l}\text { PA2231- } \\
\text { PA2245 }\end{array}$} & Initial attachment and adhesion & {$[15,17-19]$} \\
\hline & & Primary biofilm scaffold & {$[15,19]$} \\
\hline & & Proinflammatory signaling & {$[20]$} \\
\hline & & Antibiotics resistance & {$[19]$} \\
\hline & & Avoidance of host defence mechanisms & {$[30]$} \\
\hline & & Signaling molecule to stimulate biofilm formation & {$[28]$} \\
\hline & & Resistance to biofilm inhibitor Polysorbate 80 & {$[31]$} \\
\hline & & Guide of exploration and microcolony formation & {$[26]$} \\
\hline \multirow{4}{*}{ Pel } & \multirow{4}{*}{$\begin{array}{l}\text { PA3058- } \\
\text { PA3064 }\end{array}$} & Pellicle formation and solid surface-associated biofilm formation & {$[11]$} \\
\hline & & Aggregating of bacterial cells & {$[14]$} \\
\hline & & Aminoglycosides antibiotic resistance & {$[14]$} \\
\hline & & Initial attachment in the absence of type IV pili & {$[34]$} \\
\hline \multirow{5}{*}{ Alginate } & \multirow{5}{*}{$\begin{array}{c}\text { PA3540- } \\
\text { PA3548 }\end{array}$} & Persistence and immune evasion & {$[44]$} \\
\hline & & Resistance to antibiotics as well as opsonophagocytosis & {$[45,46]$} \\
\hline & & ROS scavenge & {$[47]$} \\
\hline & & Leading to mucoid & {$[39]$} \\
\hline & & Water and nutrient retention & {$[41]$} \\
\hline \multirow{5}{*}{ eDNA } & & Nutrient & {$[54,55]$} \\
\hline & & Scaffold & {$[49]$} \\
\hline & & Antibiotics resistance & {$[53]$} \\
\hline & & Major proinflammatory component & {$[57]$} \\
\hline & & Promoting self-organization of bacterial biofilms & {$[58]$} \\
\hline \multirow{4}{*}{$\begin{array}{c}\text { Proteinaceous } \\
\text { component }\end{array}$} & Flagella & Initial cell-to-surface interactions & {$[60]$} \\
\hline & Pili & The formation of mushroom-like microcolony & {$[60]$} \\
\hline & $\mathrm{CdrA}$ & Mediate aggregation and increase biofilm stability & {$[63]$} \\
\hline & Cup fimbriae & Cell-to-cell interaction and microcolony formation & {$[66,67]$} \\
\hline
\end{tabular}

* All loci were extracted from Pseudomonas Genome Database (www.pseudomonas.com) [21]. ROS, reactive oxygen species.

\section{Regulation of Biofilm Matrix in P. aeruginosa}

Gene regulation is important for our understanding of biofilm formation. Generally, organisms form a biofilm in response to several factors including nutritional cues, secondary messengers, host-derived signals or, in some cases, to sub-inhibitory concentrations of antibiotics $[1,68]$. When a cell switches to the biofilm mode of growth, it undergoes a phenotypic shift in behavior whereby a large array of genes is differentially regulated [69].

Biofilm formation is a multicellular process involving environmental signals and a concerted regulation combining both environmental signals and regulatory networks. Due to the major roles of EPS matrix in biofilm formation, its regulation is discussed. 


\section{1. c-di-GMP}

Bis-(3'-5')-cyclic dimeric guanosine monophosphate (c-di-GMP), a ubiquitous intracellular second messenger widely distributed in bacteria, was discovered in 1987 as an allosteric activator of the cellulose synthase complex in Gluconacetobacter xylinus [70]. In general, c-di-GMP stimulates the biosynthesis of adhesins and exopolysaccharide mediated biofilm formation and inhibits bacterial motilities, which controls the switch between the motile planktonic and sessile biofilm-associated lifestyle of bacteria (Figure 2). Moreover, c-di-GMP controls the virulence of animal and plant pathogens, progression through the cell cycle, antibiotic production and other cellular functions [71-73].

Figure 2. Schematic presentation of physiological functions of c-di-GMP. In bacterial cells, c-di-GMP is generated by diguanylate cyclases (DGC) and broken down by specific phosphodiesterases (PDE). As a second messenger, low levels of c-di-GMP can promote motility by upregulating flagellar expression, assembly or interfering with flagellar motor function and are required for the expression of acute virulence genes. High levels of c-di-GMP however favor sessility and stimulate the synthesis of various matrix exopolysaccharides, such as Pel (mediated by PelD) and alginate (mediated by Alg44) [71,74,75].

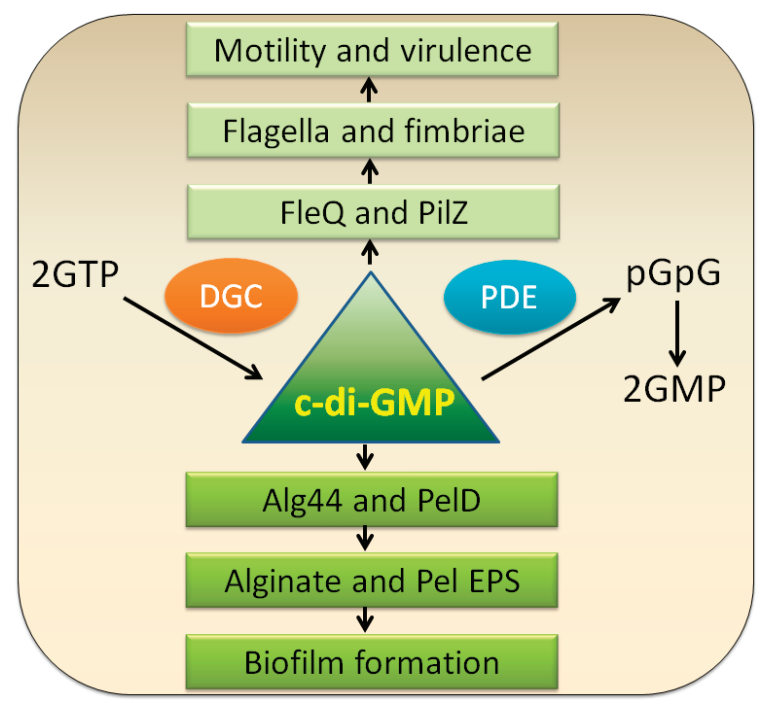

C-di-GMP is synthesized from two molecules of GTP by diguanylate cyclases (DGC) containing GGDEF domains and is broken down into 5'-phosphoguanylyl-(3'-5')-guanosine (pGpG) by specific phosphodiesterases (PDE) containing EAL or HD-GYP domains; $\mathrm{pGpG}$ is subsequently split into two GMP molecules (Figure 2). These conserved domains are essential for their corresponding enzymatic activities [71,73]. Whole genome sequencing analysis has revealed that E. coli has 19 GGDEF and 17 EAL domain proteins while Vibrio vulnificus encodes up to 100 of those proteins [73]. In P. aeruginosa, there are 41 of such proteins, including 3 HD-GYP, 17 GGDEF, and 5 EAL domain proteins, as well as 16 proteins with both GGDEF and EAL domains [76,77]. Most proteins that contain these domains 
show a multi-modular arrangement. In addition to GGDEF, EAL, or HD-GYP domains, there are a variety of sensory domains such as signal receiver or transmission domains and response regulator domains that are likely to receive signals from the environment [73]. These signals are proposed to be translated as an alteration of the enzymatic activity that would result in local or global fluctuations in c-di-GMP levels, which in turn would lead to behavioral adjustments [1].

The mechanism of c-di-GMP signal transduction generally involves the first recognition of c-di-GMP signal and the subsequent phenotypic regulation. To exert its function, c-di-GMP binds to effectors (c-di-GMP receptors), and by allostery, alters their structure and output function [71]. Those c-di-GMP effectors are highly diverse, among which the PilZ family of proteins are the best-studied. In P. aeruginosa, at least four c-di-GMP effectors are present including FleQ, PelD, Alg44, and PilZ. FleQ is a c-di-GMP-binding transcription factor, which generally functions as an activator in flagella biosynthesis. Yet it can also act as a repressor for the transcription of the pel gene cluster in the absence of c-di-GMP and an activator upon c-di-GMP binding [78]. PelD is part of pel operon of $P$. aeruginosa activated by direct binding c-di-GMP through a site that resembles the I site motif in GGDEF domain proteins [79]. Alg44 is another PilZ family protein involved in alginate synthesis [80]. PilZ is a type IV fimbrial biogenesis protein involved in twitching [81]. However, it is still a mystery if there is any receptor protein of c-di-GMP accounting for Psl polysaccharide production.

Intriguingly, c-di-GMP signaling has been shown to be involved in mediating the formation of small colony variants (SCV) in P. aeruginosa [82-85]. A phenotypic variant regulator (PvrR), containing a conserved EAL domain, involved in the hydrolysis of c-di-GMP, has been identified to control the wild type-like, antibiotics susceptible revertants [7]. Importantly, the link between antibiotic resistance and biofilm formation was firstly evidenced by the study of such RSCV (rugose small colony variant) phenotypes. The wspF mutant, also displays a SCV phenotype and the underlying mechanism was attributed to the activation of a GGDEF domain containing protein WspR $[82,83]$. Another interesting characteristic of $P$. aeruginosa SCVs with regard to c-di-GMP is the overexpression of Pel and Psl polysaccharides, leading to the auto-aggregation and hyper adherence phenotypes [86-88]. This feature seems to be a common theme for SCV of $P$. aeruginosa.

As we mentioned above, $P$. aeruginosa PAO1 contains 41 DGCs and PDEs that cooperatively mediate the overall concentration of c-di-GMP and finally modulate the EPS production. Original studies have led to extensive functional characterization of c-di-GMP-modulating enzymes and their roles in biofilm formation [7,68,76,77,83,84,88-94]. Based on these results, an emerging model holds that distinct or localized c-di-GMP pools may exist to reciprocally regulate motility and biofilm formation. Different lines of evidences have added bonus points to this hypothesis. One example is arr (aminoglycoside response regulator) which is predicted to encode an inner-membrane $\mathrm{PDE}$ and seems to be essential for the induction of biofilm formation while contributing to biofilm-specific aminoglycoside resistance [68]. The other example is RoeA, a DGC that plays different roles in regulating motility and biofilm formation as compared to another DGC SadC [94]. Specifically, RoeA contributes to biofilm formation by mainly controlling polysaccharide production, 
whereas SadC strongly impacts on flagella motility. The studies of these proteins suggested that there were subcellular pools of c-di-GMP in the cell and such pools could be produced from several ways such as specific localization and/or activation of DGCs, limitation of c-di-GMP diffusion through its effectors and/or degraders and the availability of c-di-GMP effectors [71,94].

\subsection{GacA/GacS Two-Component Systems}

Expression of the pel and psl genes for exopolysaccharide production in P. aeruginosa can be regulated by GacA/GacS two-component system. One of the mechanisms involves two histidine kinases, RetS and LadS that act in opposing ways on the GacA/GacS two-component system (Figure 3). The GacA/GacS system subsequently controls the transcription of two small regulatory RNAs (sRNAs), $r s m Y$ and $r s m Z$, leading to the decrease or increase in the translation of the pel or psl operon $[95,96]$. Transcriptomic analysis showed that GacS directly controls the transcription of $r \operatorname{sm} Y$ and rsmZ, thereby antagonizing the activities of RNA-binding translational regulator, RsmA, to control the expression of over 500 genes [97,98]. It was further proved that upon binding of RsmA with the promoter of the $p s l$ operon, the region spanning the ribosome binding site of $p s l \mathrm{mRNA}$ forms a secondary stem-loop structure that prevents ribosome access and the subsequent translation, without affecting transcription [99]. This translational control of Psl expression constitutes a novel example of translational repression by RsmA.

Furthermore, analyses of the mRNA levels using microarray analysis have shown that RetS is required for the expression of genes involved in virulence such as the type III secretion system (T3SS), yet acts as a repressor for the type VI secretion system (T6SS) and genes involved in exopolysaccharide synthesis, leading to the inhibition of biofilm formation [96]. This defines RetS as a pleiotropic regulator of multiple virulence phenotypes that mediates the activation of genes involved in acute infections and the repression of genes associated with chronic persistence [96]. A recent report showed that RetS could directly interact with GacS to modulate its phosphorylation state. [100]. During the acute infection phase, RetS interacts with GacS to form heterodimers, blocking GacS autophosphorylation and leading to reduction in $r s m Z$ expression. Finally, RsmA lacking RsmZ will promote the translation of genes required for acute virulence factors. While sensing unknown environmental signals, GacS and RetS each form homodimers, allowing GacS autophosphorylation and subsequent phosphorylation of GacA, finally resulting in the expression of genes involved in chronic infections (Figure 3) [100]. Very recently, a novel RetS interacting protein, PA1611 was identified and characterized as able to both promote biofilm formation and repress T3SS and swarming motility [101], adding complexity to the classical GacS/GacA regulatory cascade. On the other hand, LadS was found to antagonize the effect of RetS, contributing to the repression of T3SS and the activation of genes necessary for exopolysaccharide production promoting biofilm formation [95] (Figure 3). However, there is a paucity of information detailing whether LadS affects the GacS or RetS. Interestingly, one $P$. aeruginosa reference strain PA14 was found to have a natural ladS mutation, explaining why PA14 exhibits increased virulence and displays attenuated biofilm formation as compared to PAO1 [102]. 
In addition, the histidine phosphotransfer $(\mathrm{Hpt})$ protein $\mathrm{HptB}$ signaling pathway was found to control biofilm formation and T3SS, and fine-tunes $P$. aeruginosa pathogenesis [103]. Typically, Hpt protein acts as a phosphorylation relay that transits the activation signal from a sensor kinase to the cognate response regulator. Bordi and co-workers found that in contrast to the double control of $r s m Y Z$ expression by RetS, HptB exclusively regulates $\operatorname{rsm} Y$ expression. Importantly, in this study, they demonstrated a redundant effect of the two sRNAs on T3SS gene expression, while the influence on pel gene expression is additive, further underpinning the novel mechanism of fine-tuned regulation of gene expression [103].

Figure 3. Schematic diagram of the two-component system regulation of biofilm formation and virulence in $P$. aeruginosa $[95,96,100,104]$. Unknown environmental cues received by the input domains of the three membrane-associated sensor kinases (GacS, LadS and RetS) activate or repress the expression of genes necessary for acute or chronic infection. Free regulatory protein RsmA can bind to the promoter regions of multiple genes, thus repressing expression of biofilm associated genes such as psl locus and enhancing bacterial motility and the production of several acute virulence factors (Red lines). When the response regulator GacA is phosphorylated by the upstream sensor kinase GacS, the production of small regulatory RNAs RsmZ and RsmY are stimulated, followed by the titrating to RsmA protein, which ultimately de-represses the expression of biofilm-related genes and represses the production of virulence-related factors (Green lines). The signaling cascade going through RetS, operating in an opposite manner to that of GacS and LadS, generates more free RsmA, resulting in T3SS activation and biofilm repression (Red lines). T3SS, type 3 secretion system. EPS, exopolysacchrides. P means phosphorylated state of GacA. Dark red circle indicates RsmA protein, which binds to the genomic DNA without environmental stimulation and binds to RsmY or RsmZ when the upstream pathways are activated.

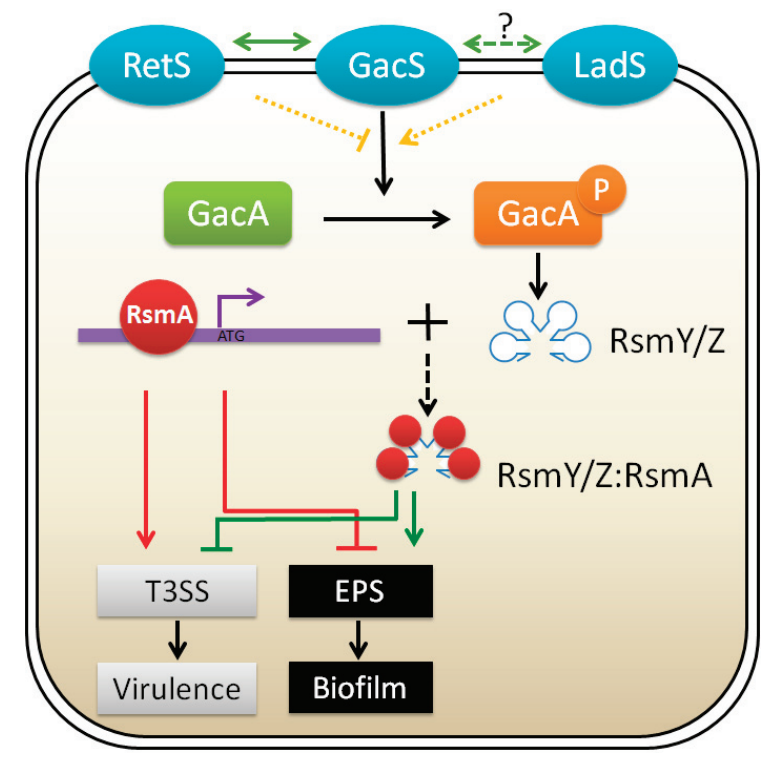




\subsection{Quorum Sensing}

Quorum sensing (QS), known as bacterial cell-cell communication system, represents another multicellular activity which involves the production, secretion, and detection of molecules called autoinducers (AIs) to modulate behaviors of the bacterial population [105]. QS provides a strategy for bacteria to detect each other's presence and to regulate gene expression in response to changes of bacterial population density. Up to now, many biological processes have been found to be controlled by QS, such as bioluminescence, biofilm formation, virulence factor expression, antibiotics production, sporulation, and competence for DNA uptake [106,107].

P. aeruginosa employs three quorum sensing signaling systems (LasR/LasI, RhlR/RhlI and PQS) to control cellular processes involved in the production of extracellular virulence factors and to control biofilm formation $[108,109]$. A large number of genes (as many as 200 300, about $6 \%$ of the genome size), including virulence factor genes and genes involved in biofilm development, are activated by two typical, interconnected and homologous acyl-homoserine lactone (AHL) quorum sensing systems, namely the LasR/LasI and RhlR/RhlI systems .

It has been shown that signal molecule 3-oxo-C12-HSL (synthesized by LasI) is necessary for the establishment of a differentiated $P$. aeruginosa biofilm since a lasI mutant forms flat, undifferentiated biofilms unlike wild-type biofilms [2] and lasI is expressed in a large number of cells during the initial stage of biofilm formation [110]. In contrast, the RhlR/RhlI system was found to be activated during the maturation stage of $P$. aeruginosa biofilm development [111], and might be important for the survival of bacterial cells growing in anaerobic conditions in biofilms [112,113].

In $P$. aeruginosa, quorum sensing regulation of exopolysaccharide was revealed to be mediated by a tyrosine phosphatase named TpbA (PA3885) that is controlled by LasR/I system and negatively regulates Pel polysaccharide production through dephosphorylation of a GGDEF-motif protein, TpbB (PA1120) [114]. This study has generated a common theme that QS seems to be a negative regulator of c-di-GMP signaling. Recently, it was shown that Psl itself could also function as a signaling molecule to stimulate its own expression via two diguanylate cyclases [28], generating a positive feedback circuit that allows efficient biofilm formation. In addition, Gilbert and colleagues found that the QS regulator LasR could bind to the promoter region of the psl operon, suggesting that QS can regulate psl expression [115]. Furthermore, the release of eDNA was demonstrated to be controlled via AHL- and Pseudomonas quinolone signal (PQS)-mediated quorum sensing systems [49].

\subsection{Other Types of Regulation}

In addition to the typical regulation of biofilm development, the biofilm matrix is also under control by other types of regulation. One example is the metabolic regulation mediated by $\mathrm{AlgC}$, a checkpoint enzyme that coordinates the total amount of exopolysaccharides in P. aeruginosa by control of sugar precursors pool for exopolysaccharides synthesis [116] (Figure 4). It was demonstrated that overexpression of one exoplysaccharide could reduce the production of the other. For example, 
overproduction of Psl led to reduced level of alginate, Pel overexpression resulted in less Psl production, and overproduction of alginate and Psl caused decreased levels of B-band LPS. The enzymatic regulation of exopolysaccharide provided us a very interesting clue about the survival strategy used by $P$. aeruginosa in diverse conditions. It is easily speculated that $P$. aeruginosa produces one major type of exopolysaccharide in certain phases whereas it generates another major type of exopolysaccharide upon changing environments.

As a key polysaccharide for biofilm formation, Psl expression is regulated at multiple levels. In addition to the aforementioned mechanisms, Psl was found to be regulated by RpoS transcriptionally, and post-transcriptionally by RsmA, an RNA binding protein [99]. The transcriptional regulator AmrZ, previously shown to positively regulate twitching motility and alginate synthesis [117], was also shown to directly bind to the promoter region of the psl operon to repress its transcription [118]. The AmrZ-mediated switch from Psl production to alginate production provides another example of acute-to-chronic transition strategy used by $P$. aeruginosa.

Figure 4. Diagram of AlgC-dependent enzymatic regulation of the production of exopolysaccharides in $P$. aeruginosa PAO1 [116]. The product of $\operatorname{algC}$ gene (AlgC) is a bifunctional enzyme with phosphomannomutase (PMM) and phosphoglucomutase (PMG) activities that can catalyze the conversion of mannose-6-phosphate (mannose-6-P) and glucose-6-phosphate (glucose-6-P) into mannose-1-phosphate (mannos-1-P) and glucose-1-phosphate (glucose-1-P), respectively. The PMM/PMG activity of $\mathrm{AlgC}$ is required for the biosynthesis pathways of four exopolysaccharides (Psl, alginate, LPS and Pel) in P. aeruginosa. Experimental data showed that overproduction of individual exopolysaccharides reduces synthesis of the other exopolysaccharides, indicating that $\mathrm{AlgC}$ is the checkpoint enzyme that limits the production of $P$. aeruginosa exopolysaccharides, influencing the biofilm formation.

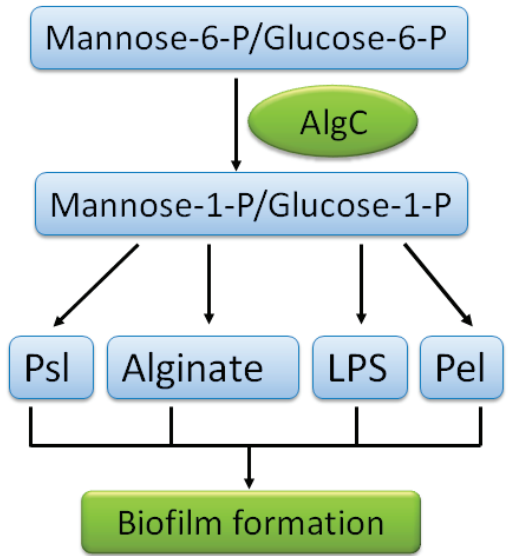




\section{Matrix-Driven Strategies against Biofilms}

Once biofilms develop into a mature stage, they become extremely difficult to eradicate from infections sites with traditional antimicrobial agents [6]. Agents that inhibit biofilm formation or transform bacteria from biofilm life style to free-living individuals are ideal to eradicate biofilm. The strategies used for anti-biofilm mainly stem from two basic ways: matrix synthesis and its regulatory mechanisms.

For example, disruption of the initial attachment that is dependent on a large array of adhesins would contribute to inhibition of the establishment of biofilms, while the digestion of the EPS matrix may be another method to interfere with biofilm formation. As we mentioned before, DNase I treatment has already shown efficacy in the inhibition of the early development of biofilm [50]. It was also reported that alginate lyase could enhance antibiotic killing of mucoid $P$. aeruginosa in biofilms [119]. In addition, the macrolide antibiotic azithromycin was shown to block alginate formation and quorum sensing signaling [120] and was further reported to improve lung function of CF patients, especially in the subgroup chronically colonized by Pseudomonas [121].

Antagonizing the intracellular signaling molecules to control biofilm formation has also been investigated. One example is the identification of furanones, which have shown their ability to inhibit the biofilm formation of $P$. aeruginosa in vitro $[122,123]$. Molecules of this type have been reported to function through inhibiting the AHL-dependent QS systems in P. aeruginosa. Iron has also been employed in distinct aspects to control the formation of biofilms. Singh and his colleagues have identified an innate immunity component, lactoferrin, which prevents $P$. aeruginosa biofilm formation by chelating iron and stimulating the type IV pili-mediated twitching motility [124]. Furthermore, iron salts such as ferric ammonium citrate were found to not only perturb biofilm formation but also disrupt existing biofilms by $P$. aeruginosa [125]. In a screen of co-therapy of antibiotics against $P$. aeruginosa, 14-alpha-lipoyl andrographolide (AL-1), a diterpenoid lactone derivative from the herb Andrographis paniculata appeared to inhibit biofilm formation by decreasing EPS production and to sensitize the bacterium to a variety of antibiotics [126].

Recently, it was found that Gram-positive bacterium Bacillus subtilis produced a factor that prevented biofilm formation and could break down existing biofilms. The factor was identified to be a mixture of D-leucine, D-methionine, D-tyrosine, and D-tryptophan that could disassemble at nanomolar concentrations. D-amino acid treatment subserved the release of amyloid fibers that linked cells together in the biofilm. In addition, D-amino acids also prevented biofilm formation by Staphylococcus aureus and $P$. aeruginosa, indicating it may be a widespread signal for biofilm disassembly [127]. Furthermore, the same group identified another biofilm disassembly compound, norspermidine, which targets directly and specifically with the exopolysaccharide matrix and this biofilm inhibition effect could be enhanced together with D-amino acids and is effective in other bacterial species [128]. 


\section{Perspectives}

Accumulating data presented in the recent literature provides valuable insights into the novel roles of the biofilm matrix and its regulatory mechanism in $P$. aeruginosa biofilm formation. A deep understanding of the mechanisms involved in biofilm formation will ultimately shed light on the generation of alternative treatments for $P$. aeruginosa infections. There is no doubt that future studies will reveal additional biofilm matrix components and identify more elaborate regulatory circuits for biofilm formation. Finally, the interaction of the biofilm matrix and the synergistic effects of different anti-biofilm strategies should also be regarded as major concerns.

\section{Acknowledgments}

We thank Shiwei Wang, Di Wang, Tianhu Zhao and other students from Ma Lab at Institute of Microbiology, Chinese Academy of Sciences for their help in manuscript preparation. We are also grateful to reviewers for their critical and constructive suggestions. This work was supported by Chinese Academy of Science grant KSCXZ-YW-BR-5 (L.M.), National Natural Science Foundation of China grant 31270177, 31140041 (L.M.), and 31300066 (Q.W.).

\section{Conflicts of Interest}

The authors declare no conflict of interest.

\section{References}

1. Karatan, E.; Watnick, P. Signals, regulatory networks, and materials that build and break bacterial biofilms. Microbiol. Mol. Biol Rev. 2009, 73, 310-347.

2. Davies, D.G.; Parsek, M.R.; Pearson, J.P.; Iglewski, B.H.; Costerton, J.W.; Greenberg, E.P. The involvement of cell-to-cell signals in the development of a bacterial biofilm. Science 1998, 280, 295-298.

3. Hall-Stoodley, L.; Costerton, J.W.; Stoodley, P. Bacterial biofilms: From the natural environment to infectious diseases. Nat. Rev. 2004, 2, 95-108.

4. Sutherland, I.W. The biofilm matrix-An immobilized but dynamic microbial environment. Trends Microbiol. 2001, 9, 222-227.

5. Branda, S.S.; Vik, S.; Friedman, L.; Kolter, R. Biofilms: The matrix revisited. Trends Microbiol. 2005, 13, 20-26.

6. Costerton, J.W.; Stewart, P.S.; Greenberg, E.P. Bacterial biofilms: A common cause of persistent infections. Science 1999, 284, 1318-1322.

7. Drenkard, E.; Ausubel, F.M. Pseudomonas biofilm formation and antibiotic resistance are linked to phenotypic variation. Nature 2002, 416, 740-743. 
8. Flemming, H.C.; Neu, T.R.; Wozniak, D.J. The EPS matrix: The "house of biofilm cells". J. Bacteriol. 2007, 189, 7945-7947.

9. $\quad$ Ryder, C.; Byrd, M.; Wozniak, D.J. Role of polysaccharides in Pseudomonas aeruginosa biofilm development. Curr. Opin. Microbiol. 2007, 10, 644-648.

10. Parsek, M.R.; Singh, P.K. Bacterial biofilms: An emerging link to disease pathogenesis. Annu. Rev. Microbiol. 2003, 57, 677-701.

11. Friedman, L.; Kolter, R. Two genetic loci produce distinct carbohydrate-rich structural components of the Pseudomonas aeruginosa biofilm matrix. J. Bacteriol. 2004, 186, 4457-4465.

12. Friedman, L.; Kolter, R. Genes involved in matrix formation in Pseudomonas aeruginosa PA14 biofilms. Mol. Microbiol. 2004, 51, 675-690.

13. Jackson, K.D.; Starkey, M.; Kremer, S.; Parsek, M.R.; Wozniak, D.J. Identification of psl, a locus encoding a potential exopolysaccharide that is essential for Pseudomonas aeruginosa PAO1 biofilm formation. J. Bacteriol. 2004, 186, 4466-4475.

14. Colvin, K.M.; Gordon, V.D.; Murakami, K.; Borlee, B.R.; Wozniak, D.J.; Wong, G.C.; Parsek, M.R. The pel polysaccharide can serve a structural and protective role in the biofilm matrix of Pseudomonas aeruginosa. PLoS Pathog. 2010, 7, e1001264.

15. Ma, L.; Conover, M.; Lu, H.; Parsek, M.R.; Bayles, K.; Wozniak, D.J. Assembly and development of the Pseudomonas aeruginosa biofilm matrix. PLoS Pathog. 2009, 5, e1000354.

16. Matsukawa, M.; Greenberg, E.P. Putative exopolysaccharide synthesis genes influence Pseudomonas aeruginosa biofilm development. J. Bacteriol. 2004, 186, 4449-4456.

17. Ma, L.; Lu, H.; Sprinkle, A.; Parsek, M.R.; Wozniak, D.J. Pseudomonas aeruginosa Psl is a galactose- and mannose-rich exopolysaccharide. J. Bacteriol. 2007, 189, 8353-8356.

18. Ma, L.; Jackson, K.D.; Landry, R.M.; Parsek, M.R.; Wozniak, D.J. Analysis of Pseudomonas aeruginosa conditional psl variants reveals roles for the psl polysaccharide in adhesion and maintaining biofilm structure postattachment. J. Bacteriol. 2006, 188, 8213-8221.

19. Yang, L.; Hu, Y.F.; Liu, Y.; Zhang, J.D.; Ulstrup, J.; Molin, S. Distinct roles of extracellular polymeric substances in Pseudomonas aeruginosa biofilm development. Environ. Microbiol. 2011, 13, 1705-1717.

20. Byrd, M.S.; Sadovskaya, I.; Vinogradov, E.; Lu, H.P.; Sprinkle, A.B.; Richardson, S.H.; Ma, L.Y.; Ralston, B.; Parsek, M.R.; Anderson, E.M.; et al. Genetic and biochemical analyses of the Pseudomonas aeruginosa Psl exopolysaccharide reveal overlapping roles for polysaccharide synthesis enzymes in Psl and LPS production. Mol. Microbiol. 2009, 73, 622-638.

21. Winsor, G.L.; Lam, D.K.; Fleming, L.; Lo, R.; Whiteside, M.D.; Yu, N.Y.; Hancock, R.E.; Brinkman, F.S. Pseudomonas Genome Database: Improved comparative analysis and population genomics capability for Pseudomonas genomes. Nucleic Acids Res. 2011, 39, D596-D600.

22. Campisano, A.; Schroeder, C.; Schemionek, M.; Overhage, J.; Rehm, B.H. PsID is a secreted protein required for biofilm formation by Pseudomonas aeruginosa. Appl. Environ. Microbiol. 2006, 72, 3066-3068. 
23. Overhage, J.; Schemionek, M.; Webb, J.S.; Rehm, B.H. Expression of the psl operon in Pseudomonas aeruginosa PAO1 biofilms: PslA performs an essential function in biofilm formation. Appl. Environ. Microbiol. 2005, 71, 4407-4413.

24. Lee, H.J.; Chang, H.Y.; Venkatesan, N.; Peng, H.L. Identification of amino acid residues important for the phosphomannose isomerase activity of PslB in Pseudomonas aeruginosa PAO1. FEBS Lett. 2008, 582, 3479-3483.

25. Wang, S.; Parsek, M.R.; Wozniak, D.J.; Ma, L.Z. A spider web strategy of type IV pili-mediated migration to build a fibre-like Psl polysaccharide matrix in Pseudomonas aeruginosa biofilms. Environ. Microbiol. 2013, 15, 2238-2253.

26. Zhao, K.; Tseng, B.S.; Beckerman, B.; Jin, F.; Gibiansky, M.L.; Harrison, J.J.; Luijten, E.; Parsek, M.R.; Wong, G.C. Psl trails guide exploration and microcolony formation in Pseudomonas aeruginosa biofilms. Nature 2013, 497, 388-391.

27. Stoodley, P.; Sauer, K.; Davies, D.G.; Costerton, J.W. Biofilms as complex differentiated communities. Annu. Rev. Microbiol. 2002, 56, 187-209.

28. Irie, Y.; Borlee, B.R.; O’Connor, J.R.; Hill, P.J.; Harwood, C.S.; Wozniak, D.J.; Parsek, M.R. Self-produced exopolysaccharide is a signal that stimulates biofilm formation in Pseudomonas aeruginosa. Proc. Natl. Acad. Sci. USA 2012, 109, 20632-20636.

29. Byrd, M.S.; Pang, B.; Mishra, M.; Swords, W.E.; Wozniak, D.J. The Pseudomonas aeruginosa exopolysaccharide Psl facilitates surface adherence and NF-kappaB activation in A549 cells. mBiosphere 2010, 1, doi:10.1128/mBio.00140-10.

30. Mishra, M.; Byrd, M.S.; Sergeant, S.; Azad, A.K.; Parsek, M.R.; McPhail, L.; Schlesinger, L.S.; Wozniak, D.J. Pseudomonas aeruginosa Psl polysaccharide reduces neutrophil phagocytosis and the oxidative response by limiting complement-mediated opsonization. Cell Microbiol. 2012, 14, 95-106.

31. Zegans, M.E.; Wozniak, D.; Griffin, E.; Toutain-Kidd, C.M.; Hammond, J.H.; Garfoot, A.; Lam, J.S. Pseudomonas aeruginosa exopolysaccharide Psl promotes resistance to the biofilm inhibitor polysorbate 80. Antimicrob. Agents Chemother.2012, 56, 4112-4122.

32. Tseng, B.S.; Zhang, W.; Harrison, J.J.; Quach, T.P.; Song, J.L.; Penterman, J.; Singh, P.K.; Chopp, D.L.; Packman, A.I.; Parsek, M.R. The extracellular matrix protects Pseudomonas aeruginosa biofilms by limiting the penetration of tobramycin. Environ. Microbiol. 2013, 15, 2865-2878.

33. Billings, N.; Ramirez Millan, M.; Caldara, M.; Rusconi, R.; Tarasova, Y.; Stocker, R.; Ribbeck, K. The extracellular matrix component Psl provides fast-acting antibiotic defense in Pseudomonas aeruginosa biofilms. PLoS Pathog. 2013, 9, e1003526.

34. Vasseur, P.; Vallet-Gely, I.; Soscia, C.; Genin, S.; Filloux, A. The pel genes of the Pseudomonas aeruginosa PAK strain are involved at early and late stages of biofilm formation. Microbiology 2005, 151, 985-997. 
35. Sadovskaya, I.; Vinogradov, E.; Li, J.J.; Hachani, A.; Kowalska, K.; Filloux, A. High-level antibiotic resistance in Pseudomonas aeruginosa biofilm: The $n d v B$ gene is involved in the production of highly glycerol-phosphorylated beta-(1->3)-glucans, which bind aminoglycosides. Glycobiology 2010, 20, 895-904.

36. Coulon, C.; Vinogradov, E.; Filloux, A.; Sadovskaya, I. Chemical analysis of cellular and extracellular carbohydrates of a biofilm-forming strain Pseudomonas aeruginosa PA14. PLoS One 2010, 5, e14220.

37. Ghafoor, A.; Jordens, Z.; Rehm, B.H. Role of PelF in Pel polysaccharide biosynthesis in Pseudomonas aeruginosa. Appl. Environ. Microbiol. 2013, 79, 2968-2978.

38. Colvin, K.M.; Alnabelseya, N.; Baker, P.; Whitney, J.C.; Howell, P.L.; Parsek, M.R. PelA deacetylase activity is required for Pel polysaccharide synthesis in Pseudomonas aeruginosa. J. Bacteriol. 2013, 195, 2329-2339.

39. Govan, J.R.; Deretic, V. Microbial pathogenesis in cystic fibrosis: Mucoid Pseudomonas aeruginosa and Burkholderia cepacia. Microbiol. Rev. 1996, 60, 539-574.

40. Wozniak, D.J.; Wyckoff, T.J.; Starkey, M.; Keyser, R.; Azadi, P.; O’Toole, G.A.; Parsek, M.R. Alginate is not a significant component of the extracellular polysaccharide matrix of PA14 and PAO1 Pseudomonas aeruginosa biofilms. Proc. Natl. Acad. Sci. USA 2003, 100, 7907-7912.

41. Sutherland, I.W. Biofilm exopolysaccharides: A strong and sticky framework. Microbiology 2001, 147, 3-9.

42. Ma, L.; Wang, S.; Wang, D.; Parsek, M.R.; Wozniak, D.J. The roles of biofilm matrix polysaccharide Psl in mucoid Pseudomonas aeruginosa biofilms. FEMS Immunol. Med. Microbiol. 2012, 65, 377-380.

43. Yang, L.; Hengzhuang, W.; Wu, H.; Damkiaer, S.; Jochumsen, N.; Song, Z.; Givskov, M.; Hoiby, N.; Molin, S. Polysaccharides serve as scaffold of biofilms formed by mucoid Pseudomonas aeruginosa. FEMS Immunol. Med. Microbiol. 2012, 65, 366-376.

44. Leid, J.G.; Willson, C.J.; Shirtliff, M.E.; Hassett, D.J.; Parsek, M.R.; Jeffers, A.K. The exopolysaccharide alginate protects Pseudomonas aeruginosa biofilm bacteria from IFN-gamma-mediated macrophage killing. J. Immunol. 2005, 175, 7512-7518.

45. Simpson, J.A.; Smith, S.E.; Dean, R.T. Alginate inhibition of the uptake of Pseudomonas aeruginosa by macrophages. J. Gen. Microbiol. 1988, 134, $29-36$.

46. Simpson, J.A.; Smith, S.E.; Dean, R.T. Alginate may accumulate in cystic-fibrosis lung because the enzymatic and free-radical capacities of phagocytic-cells are inadequate for its degradation. Biochem. Mol. Biol Int. 1993, 30, 1021-1034.

47. Simpson, J.A.; Smith, S.E.; Dean, R.T. Scavenging by alginate of free-radicals released by macrophages. Free Radic. Bio. Med. 1989, 6, 347-353.

48. Bragonzi, A.; Paroni, M.; Nonis, A.; Cramer, N.; Montanari, S.; Rejman, J.; Di Serio, C.; Doring, G.; Tummler, B. Pseudomonas aeruginosa microevolution during cystic fibrosis lung infection establishes clones with adapted virulence. Am. J. Resp. Crit. Care 2009, 180, 138-145. 
49. Allesen-Holm, M.; Barken, K.B.; Yang, L.; Klausen, M.; Webb, J.S.; Kjelleberg, S.; Molin, S.; Givskov, M.; Tolker-Nielsen, T. A characterization of DNA release in Pseudomonas aeruginosa cultures and biofilms. Mol. Microbiol. 2006, 59, 1114-1128.

50. Whitchurch, C.B.; Tolker-Nielsen, T.; Ragas, P.C.; Mattick, J.S. Extracellular DNA required for bacterial biofilm formation. Science 2002, 295, 1487.

51. Webb, J.S.; Thompson, L.S.; James, S.; Charlton, T.; Tolker-Nielsen, T.; Koch, B.; Givskov, M.; Kjelleberg, S. Cell death in Pseudomonas aeruginosa biofilm development. J. Bacteriol. 2003, $185,4585-4592$.

52. Spoering, A.L.; Gilmore, M.S. Quorum sensing and DNA release in bacterial biofilms. Curr. Opin. Microbiol. 2006, 9, 133-137.

53. Mulcahy, H.; Charron-Mazenod, L.; Lewenza, S. Extracellular DNA chelates cations and induces antibiotic resistance in Pseudomonas aeruginosa biofilms. PLoS Pathog. 2008, 4, e1000213.

54. Finkel, S.E.; Kolter, R. DNA as a nutrient: Novel role for bacterial competence gene homologs. J. Bacteriol. 2001, 183, 6288-6293.

55. Mulcahy, H.; Charron-Mazenod, L.; Lewenza, S. Pseudomonas aeruginosa produces an extracellular deoxyribonuclease that is required for utilization of DNA as a nutrient source. Environ. Microbiol. 2010, 12, 1621-1629.

56. Parks, Q.M.; Young, R.L.; Poch, K.R.; Malcolm, K.C.; Vasil, M.L.; Nick, J.A. Neutrophil enhancement of Pseudomonas aeruginosa biofilm development: Human F-actin and DNA as targets for therapy. J. Med. Microbiol. 2009, 58, 492-502.

57. Fuxman Bass, J.I.; Russo, D.M.; Gabelloni, M.L.; Geffner, J.R.; Giordano, M.; Catalano, M.; Zorreguieta, A.; Trevani, A.S. Extracellular DNA: A major proinflammatory component of Pseudomonas aeruginosa biofilms. J. Immunol. 2010, 184, 6386-6395.

58. Gloag, E.S.; Turnbull, L.; Huang, A.; Vallotton, P.; Wang, H.; Nolan, L.M.; Mililli, L.; Hunt, C.; Lu, J.; Osvath, S.R.; et al. Self-organization of bacterial biofilms is facilitated by extracellular DNA. Proc. Natl. Acad. Sci. USA 2013, 110, 11541-11546.

59. Mann, E.E.; Wozniak, D.J. Pseudomonas biofilm matrix composition and niche biology. Fems. Microbiol. Rev. 2012, 36, 893-916.

60. O'Toole, G.A.; Kolter, R. Flagellar and twitching motility are necessary for Pseudomonas aeruginosa biofilm development. Mol. Microbiol. 1998, 30, $295-304$.

61. Skerker, J.M.; Berg, H.C. Direct observation of extension and retraction of type IV pili. Proc. Natl. Acad. Sci. USA 2001, 98, 6901-6904.

62. Klausen, M.; Heydorn, A.; Ragas, P.; Lambertsen, L.; Aaes-Jorgensen, A.; Molin, S.; Tolker-Nielsen, T. Biofilm formation by Pseudomonas aeruginosa wild type, flagella and type IV pili mutants. Mol. Microbiol. 2003, 48, 1511-1524.

63. Borlee, B.R.; Goldman, A.D.; Murakami, K.; Samudrala, R.; Wozniak, D.J.; Parsek, M.R. Pseudomonas aeruginosa uses a cyclic-di-GMP-regulated adhesin to reinforce the biofilm extracellular matrix. Mol. Microbiol. 2010, 75, 827-842. 
64. Vallet, I.; Olson, J.W.; Lory, S.; Lazdunski, A.; Filloux, A. The chaperone/usher pathways of Pseudomonas aeruginosa: Identification of fimbrial gene clusters (cup) and their involvement in biofilm formation. Proc. Natl. Acad. Sci. USA 2001, 98, 6911-6916.

65. Giraud, C.; Bernard, C.S.; Calderon, V.; Yang, L.; Filloux, A.; Molin, S.; Fichant, G.; Bordi, C.; De Bentzmann, S. The PprA-PprB two-component system activates CupE, the first non-archetypal Pseudomonas aeruginosa chaperone-usher pathway system assembling fimbriae. Environ. Microbiol. 2011, 13, 666-683.

66. Kulasekara, H.D.; Ventre, I.; Kulasekara, B.R.; Lazdunski, A.; Filloux, A.; Lory, S. A novel two-component system controls the expression of Pseudomonas aeruginosa fimbrial cup genes. Mol. Microbiol. 2005, 55, 368-380.

67. Ruer, S.; Stender, S.; Filloux, A.; De Bentzmann, S. Assembly of fimbrial structures in Pseudomonas aeruginosa: Functionality and specificity of chaperone-usher machineries. J. Bacteriol. 2007, 189, 3547-3555.

68. Hoffman, L.R.; D’Argenio, D.A.; MacCoss, M.J.; Zhang, Z.; Jones, R.A.; Miller, S.I. Aminoglycoside antibiotics induce bacterial biofilm formation. Nature 2005, 436, 1171-1175.

69. Whiteley, M.; Bangera, M.G.; Bumgarner, R.E.; Parsek, M.R.; Teitzel, G.M.; Lory, S.; Greenberg, E.P. Gene expression in Pseudomonas aeruginosa biofilms. Nature 2001, 413, 860-864.

70. Ross, P.; Weinhouse, H.; Aloni, Y.; Michaeli, D.; Weinberger-Ohana, P.; Mayer, R.; Braun, S.; De Vroom, E.; Van der Marel, G.A.; Van Boom, J.H.; et al. Regulation of cellulose synthesis in Acetobacter xylinum by cyclic diguanylic acid. Nature 1987, 325, 279-281.

71. Hengge, R. Principles of c-di-GMP signalling in bacteria. Nat. Rev. 2009, 7, 263-273.

72. Cotter, P.A.; Stibitz, S. c-di-GMP-mediated regulation of virulence and biofilm formation. Curr. Opin. Microbiol. 2007, 10, 17-23.

73. Jenal, U.; Malone, J. Mechanisms of cyclic-di-GMP signaling in bacteria. Annu. Rev. Genet. 2006, 40, 385-407.

74. Merighi, M.; Lee, V.T.; Hyodo, M.; Hayakawa, Y.; Lory, S. The second messenger bis-(3'-5')cyclic-GMP and its PilZ domain-containing receptor Alg44 are required for alginate biosynthesis in Pseudomonas aeruginosa. Mol. Microbiol. 2007, 65, 876-895.

75. Romling, U.; Galperin, M.Y.; Gomelsky, M. Cyclic di-GMP: The first 25 years of a universal bacterial second messenger. Microbiol. Mol. Biol Rev. 2013, 77, 1-52.

76. Ryan, R.P.; Lucey, J.; O’Donovan, K.; McCarthy, Y.; Yang, L.; Tolker-Nielsen, T.; Dow, J.M. HD-GYP domain proteins regulate biofilm formation and virulence in Pseudomonas aeruginosa. Environ. Microbiol. 2009, 11, 1126-1136.

77. Kulasakara, H.; Lee, V.; Brencic, A.; Liberati, N.; Urbach, J.; Miyata, S.; Lee, D.G.; Neely, A.N.; Hyodo, M.; Hayakawa, Y.; et al. Analysis of Pseudomonas aeruginosa diguanylate cyclases and phosphodiesterases reveals a role for bis-(3'-5')-cyclic-GMP in virulence. Proc. Natl. Acad. Sci. USA 2006, 103, 2839-2844. 
78. Hickman, J.W.; Harwood, C.S. Identification of FleQ from Pseudomonas aeruginosa as a c-di-GMP-responsive transcription factor. Mol. Microbiol. 2008, 69, 376-389.

79. Lee, V.T.; Matewish, J.M.; Kessler, J.L.; Hyodo, M.; Hayakawa, Y.; Lory, S. A cyclic-di-GMP receptor required for bacterial exopolysaccharide production. Mol. Microbiol. 2007, 65, 1474-1484.

80. Remminghorst, U.; Rehm, B.H. Alg44, a unique protein required for alginate biosynthesis in Pseudomonas aeruginosa. FEBS Lett. 2006, 580, 3883-3888.

81. Alm, R.A.; Bodero, A.J.; Free, P.D.; Mattick, J.S. Identification of a novel gene, pilZ, essential for type 4 fimbrial biogenesis in Pseudomonas aeruginosa. J. Bacteriol. 1996, 178, 46-53.

82. D'Argenio, D.A.; Calfee, M.W.; Rainey, P.B.; Pesci, E.C. Autolysis and autoaggregation in Pseudomonas aeruginosa colony morphology mutants. J. Bacteriol. 2002, 184, 6481-6489.

83. Hickman, J.W.; Tifrea, D.F.; Harwood, C.S. A chemosensory system that regulates biofilm formation through modulation of cyclic diguanylate levels. Proc. Natl. Acad. Sci. USA 2005, 102, 14422-14427.

84. Kuchma, S.L.; Brothers, K.M.; Merritt, J.H.; Liberati, N.T.; Ausubel, F.M.; O’Toole, G.A. BifA, a cyclic-Di-GMP phosphodiesterase, inversely regulates biofilm formation and swarming motility by Pseudomonas aeruginosa PA14. J. Bacteriol. 2007, 189, 8165-8178.

85. Meissner, A.; Wild, V.; Simm, R.; Rohde, M.; Erck, C.; Bredenbruch, F.; Morr, M.; Romling, U.; Haussler, S. Pseudomonas aeruginosa cupA-encoded fimbriae expression is regulated by a GGDEF and EAL domain-dependent modulation of the intracellular level of cyclic diguanylate. Environ. Microbiol. 2007, 9, 2475-2485.

86. Kirisits, M.J.; Prost, L.; Starkey, M.; Parsek, M.R. Characterization of colony morphology variants isolated from Pseudomonas aeruginosa biofilms. Appl. Environ. Microbiol. 2005, 71, 4809-4821.

87. Starkey, M.; Hickman, J.H.; Ma, L.; Zhang, N.; De Long, S.; Hinz, A.; Palacios, S.; Manoil, C.; Kirisits, M.J.; Starner, T.D.; et al. Pseudomonas aeruginosa rugose small-colony variants have adaptations that likely promote persistence in the cystic fibrosis lung. J. Bacteriol. 2009, 191, 3492-3503.

88. Malone, J.G.; Jaeger, T.; Spangler, C.; Ritz, D.; Spang, A.; Arrieumerlou, C.; Kaever, V.; Landmann, R.; Jenal, U. YfiBNR mediates cyclic di-GMP dependent small colony variant formation and persistence in Pseudomonas aeruginosa. PLoS Pathog. 2010, 6, e1000804.

89. Choy, W.K.; Zhou, L.; Syn, C.K.; Zhang, L.H.; Swarup, S. MorA defines a new class of regulators affecting flagellar development and biofilm formation in diverse Pseudomonas species. J. Bacteriol. 2004, 186, 7221-7228.

90. Kazmierczak, B.I.; Lebron, M.B.; Murray, T.S. Analysis of FimX, a phosphodiesterase that governs twitching motility in Pseudomonas aeruginosa. Mol. Microbiol. 2006, 60, 1026-1043.

91. Klebensberger, J.; Birkenmaier, A.; Geffers, R.; Kjelleberg, S.; Philipp, B. SiaA and SiaD are essential for inducing autoaggregation as a specific response to detergent stress in Pseudomonas aeruginosa. Environ. Microbiol. 2009, 11, 3073-3086. 
92. Merritt, J.H.; Brothers, K.M.; Kuchma, S.L.; O’Toole, G.A. SadC reciprocally influences biofilm formation and swarming motility via modulation of exopolysaccharide production and flagellar function. J. Bacteriol. 2007, 189, 8154-8164.

93. Roy, A.B.; Petrova, O.E.; Sauer, K. The phosphodiesterase DipA (PA5017) is essential for Pseudomonas aeruginosa biofilm dispersion. J. Bacteriol. 2012, 194, 2904-2915.

94. Merritt, J.H.; Ha, D.G.; Cowles, K.N.; Lu, W.; Morales, D.K.; Rabinowitz, J.; Gitai, Z.; O'Toole, G.A. Specific control of Pseudomonas aeruginosa surface-associated behaviors by two c-di-GMP diguanylate cyclases. mBiosphere 2010, 1, doi:10.1128/mBio.00183-10.

95. Ventre, I.; Goodman, A.L.; Vallet-Gely, I.; Vasseur, P.; Soscia, C.; Molin, S.; Bleves, S.; Lazdunski, A.; Lory, S.; Filloux, A. Multiple sensors control reciprocal expression of Pseudomonas aeruginosa regulatory RNA and virulence genes. Proc. Natl. Acad. Sci. USA 2006, 103, 171-176.

96. Goodman, A.L.; Kulasekara, B.; Rietsch, A.; Boyd, D.; Smith, R.S.; Lory, S. A signaling network reciprocally regulates genes associated with acute infection and chronic persistence in Pseudomonas aeruginosa. Dev. cell 2004, 7, 745-754.

97. Brencic, A.; McFarland, K.A.; McManus, H.R.; Castang, S.; Mogno, I.; Dove, S.L.; Lory, S. The GacS/GacA signal transduction system of Pseudomonas aeruginosa acts exclusively through its control over the transcription of the RsmY and RsmZ regulatory small RNAs. Mol. Microbiol. 2009, 73, 434-445.

98. Brencic, A.; Lory, S. Determination of the regulon and identification of novel mRNA targets of Pseudomonas aeruginosa RsmA. Mol. Microbiol. 2009, 72, 612-632.

99. Irie, Y.; Starkey, M.; Edwards, A.N.; Wozniak, D.J.; Romeo, T.; Parsek, M.R. Pseudomonas aeruginosa biofilm matrix polysaccharide Psl is regulated transcriptionally by RpoS and post-transcriptionally by RsmA. Mol. Microbiol. 2010, 78, 158-172.

100. Goodman, A.L.; Merighi, M.; Hyodo, M.; Ventre, I.; Filloux, A.; Lory, S. Direct interaction between sensor kinase proteins mediates acute and chronic disease phenotypes in a bacterial pathogen. Genes Dev. 2009, 23, 249-259.

101. Kong, W.; Chen, L.; Zhao, J.; Shen, T.; Surette, M.G.; Shen, L.; Duan, K. Hybrid sensor kinase PA1611 in Pseudomonas aeruginosa regulates transitions between acute and chronic infection through direct interaction with RetS. Mol. Microbiol. 2013, 88, 784-797.

102. Mikkelsen, H.; McMullan, R.; Filloux, A. The Pseudomonas aeruginosa reference strain PA14 displays increased virulence due to a mutation in ladS. PLoS One 2011, 6, e29113.

103. Bordi, C.; Lamy, M.C.; Ventre, I.; Termine, E.; Hachani, A.; Fillet, S.; Roche, B.; Bleves, S.; Mejean, V.; Lazdunski, A.; et al. Regulatory RNAs and the HptB/RetS signalling pathways fine-tune Pseudomonas aeruginosa pathogenesis. Mol. Microbiol. 2010, 76, 1427-1443.

104. Jimenez, P.N.; Koch, G.; Thompson, J.A.; Xavier, K.B.; Cool, R.H.; Quax, W.J. The multiple signaling systems regulating virulence in Pseudomonas aeruginosa. Microbiol. Mol. Biol Rev. 2012, 76, 46-65. 
105. Camilli, A.; Bassler, B.L. Bacterial small-molecule signaling pathways. Science 2006, 311, 1113-1116.

106. Fuqua, C.; Winans, S.C.; Greenberg, E.P. Census and consensus in bacterial ecosystems: The LuxR-LuxI family of quorum-sensing transcriptional regulators. Annu. Rev. Microbiol. 1996, 50, 727-751.

107. Waters, C.M.; Bassler, B.L. Quorum sensing: Cell-to-cell communication in bacteria. Annu. Rev. Cell Dev. Bio. 2005, 21, 319-346.

108. Schuster, M.; Greenberg, E.P. A network of networks: Quorum-sensing gene regulation in Pseudomonas aeruginosa. Int. J. Med. Microbiol. 2006, 296, 73-81.

109. Venturi, V. Regulation of quorum sensing in Pseudomonas. FEMS Microbiol. Rev. 2006, 30, 274-291.

110. De Kievit, T.R.; Gillis, R.; Marx, S.; Brown, C.; Iglewski, B.H. Quorum-sensing genes in Pseudomonas aeruginosa biofilms: Their role and expression patterns. Appl. Environ.Microbiol. 2001, 67, 1865-1873.

111. Sauer, K.; Camper, A.K.; Ehrlich, G.D.; Costerton, J.W.; Davies, D.G. Pseudomonas aeruginosa displays multiple phenotypes during development as a biofilm. J. Bacteriol. 2002, 184, 1140-1154.

112. Yoon, S.S.; Hennigan, R.F.; Hilliard, G.M.; Ochsner, U.A.; Parvatiyar, K.; Kamani, M.C.; Allen, H.L.; DeKievit, T.R.; Gardner, P.R.; Schwab, U.; et al. Pseudomonas aeruginosa anaerobic respiration in biofilms: Relationships to cystic fibrosis pathogenesis. Dev. Cell 2002, 3, 593-603.

113. Singh, P.K.; Schaefer, A.L.; Parsek, M.R.; Moninger, T.O.; Welsh, M.J.; Greenberg, E.P. Quorum-sensing signals indicate that cystic fibrosis lungs are infected with bacterial biofilms. Nature 2000, 407, 762-764.

114. Ueda, A.; Wood, T.K. Connecting quorum sensing, c-di-GMP, pel polysaccharide, and biofilm formation in Pseudomonas aeruginosa through tyrosine phosphatase TpbA (PA3885). PLoS Pathog. 2009, 5, e1000483.

115. Gilbert, K.B.; Kim, T.H.; Gupta, R.; Greenberg, E.P.; Schuster, M. Global position analysis of the Pseudomonas aeruginosa quorum-sensing transcription factor LasR. Mol. Microbiol. 2009, 73, 1072-1085.

116. Ma, L.; Wang, J.; Wang, S.; Anderson, E.M.; Lam, J.S.; Parsek, M.R.; Wozniak, D.J. Synthesis of multiple Pseudomonas aeruginosa biofilm matrix exopolysaccharides is post-transcriptionally regulated. Environ. Microbiol. 2012, 14, 1995-2005.

117. Tart, A.H.; Blanks, M.J.; Wozniak, D.J. The AlgT-dependent transcriptional regulator AmrZ (AlgZ) inhibits flagellum biosynthesis in mucoid, nonmotile Pseudomonas aeruginosa cystic fibrosis isolates. J. Bacteriol. 2006, 188, 6483-6489.

118. Jones, C.J.; Ryder, C.R.; Mann, E.E.; Wozniak, D.J. AmrZ modulates Pseudomonas aeruginosa biofilm architecture by directly repressing transcription of the psl operon. J. Bacteriol. 2013, 195, 1637-1644. 
119. Alkawash, M.A.; Soothill, J.S.; Schiller, N.L. Alginate lyase enhances antibiotic killing of mucoid Pseudomonas aeruginosa in biofilms. Acta Pathol. Microbiol. Immunol. Scand. 2006, 114, 131-138.

120. Hoffmann, N.; Lee, B.; Hentzer, M.; Rasmussen, T.B.; Song, Z.; Johansen, H.K.; Givskov, M.; Hoiby, N. Azithromycin blocks quorum sensing and alginate polymer formation and increases the sensitivity to serum and stationary-growth-phase killing of Pseudomonas aeruginosa and attenuates chronic $P$. aeruginosa lung infection in $\mathrm{Cftr}^{--}$mice. Antimicrobial. Agents Chemother. 2007, 51, 3677-3687.

121. Florescu, D.F.; Murphy, P.J.; Kalil, A.C. Effects of prolonged use of azithromycin in patients with cystic fibrosis: A meta-analysis. Pulm. Pharmaco. Ther. 2009, 22, 467-472.

122. Hentzer, M.; Riedel, K.; Rasmussen, T.B.; Heydorn, A.; Andersen, J.B.; Parsek, M.R.; Rice, S.A.; Eberl, L.; Molin, S.; Hoiby, N.; et al. Inhibition of quorum sensing in Pseudomonas aeruginosa biofilm bacteria by a halogenated furanone compound. Microbiology 2002, 148, 87-102.

123. Givskov, M.; de Nys, R.; Manefield, M.; Gram, L.; Maximilien, R.; Eberl, L.; Molin, S.; Steinberg, P.D.; Kjelleberg, S. Eukaryotic interference with homoserine lactone-mediated prokaryotic signalling. J. Bacteriol. 1996, 178, 6618-6622.

124. Singh, P.K.; Parsek, M.R.; Greenberg, E.P.; Welsh, M.J. A component of innate immunity prevents bacterial biofilm development. Nature 2002, 417, 552-555.

125. Musk, D.J.; Banko, D.A.; Hergenrother, P.J. Iron salts perturb biofilm formation and disrupt existing biofilms of Pseudomonas aeruginosa. Chem. Biol. 2005, 12, 789-796.

126. Zeng, X.; Liu, X.; Bian, J.; Pei, G.; Dai, H.; Polyak, S.W.; Song, F.; Ma, L.; Wang, Y.; Zhang, L. Synergistic effect of 14-alpha-lipoyl andrographolide and various antibiotics on the formation of biofilms and production of exopolysaccharide and pyocyanin by Pseudomonas aeruginosa. Antimicrob. Agents Chemother.2011, 55, 3015-3017.

127. Kolodkin-Gal, I.; Romero, D.; Cao, S.; Clardy, J.; Kolter, R.; Losick, R. D-amino acids trigger biofilm disassembly. Science 2010, 328, 627-629.

128. Kolodkin-Gal, I.; Cao, S.; Chai, L.; Bottcher, T.; Kolter, R.; Clardy, J.; Losick, R. A self-produced trigger for biofilm disassembly that targets exopolysaccharide. Cell 2012, 149, 684-692. 


\title{
Systematic Exploration of Natural and Synthetic Flavonoids for the Inhibition of Staphylococcus aureus Biofilms
}

\author{
Suvi Manner, Malena Skogman, Darla Goeres, Pia Vuorela and Adyary Fallarero
}

\begin{abstract}
When single-cell (or suspended) bacteria switch into the biofilm lifestyle, they become less susceptible to antimicrobials, imposing the need for anti-biofilms research. Flavonoids are among the most extensively studied natural compounds with an unprecedented amount of bioactivity claims. Most studies focus on the antibacterial effects against suspended cells; fewer reports have researched their anti-biofilm properties. Here, a high throughput phenotypic platform was utilized to screen for the inhibitory activity of 500 flavonoids, including natural and synthetic derivatives, against Staphylococcus aureus biofilms. Since discrepancies among results from earlier antibacterial studies on flavonoids had been noted, the current study aimed to minimize sources of variations. After the first screen, flavonoids were classified as inactive (443), moderately active (47) or highly active (10). Further, exclusion criteria combining bioactivity and selectivity identified two synthetic flavans as the most promising. The body of data reported here serves three main purposes. First, it offers an improved methodological workflow for anti-biofilm screens of chemical libraries taking into account the (many times ignored) connections between anti-biofilm and antibacterial properties. This is particularly relevant for the study of flavonoids and other natural products. Second, it provides a large and freely available anti-biofilm bioactivity dataset that expands the knowledge on flavonoids and paves the way for future structure-activity relationship studies and structural optimizations. Finally, it identifies two new flavans that can successfully act on biofilms, as well as on suspended bacteria and represent more feasible antibacterial candidates.
\end{abstract}

Reprinted from Int. J. Mol. Sci. Cite as: Manner, S.; Skogman, M.; Goeres, D.; Vuorela, P.; Fallarero, A. Systematic Exploration of Natural and Synthetic Flavonoids for the Inhibition of Staphylococcus aureus Biofilms. Int. J. Mol. Sci. 2013, 14, 19434-19451.

\section{Introduction}

One of the most ground-breaking advancements of the microbiological research during the past 40 years has been the recognition of bacterial biofilms as the predominant bacterial lifestyle instead of bacterial suspensions [1,2]. Bacterial biofilms is the term used to describe the surface-attached bacterial lifestyle. Cells in biofilms grow as communities, surrounded by a self-produced thick layer of extracellular polymeric substances (EPS, also known as matrix or slime). Biofilms are structurally and also functionally different from single-cell (suspended) bacteria [3]. The presence of the EPS protects cells in biofilms from the detrimental effects of chemical insults and harsh environmental conditions. Moreover, in the complex tri-dimensional architecture of biofilms, subpopulations of cells co-exist in all stages of growth, including a fraction of dormant cells that are not metabolically active. This 
combination of factors helps to explain why biofilms possess much lower susceptibility to antimicrobial therapy or biocides, when compared to suspended cells [4-6]. Biofilms are involved in a wide range of infections, such as chronic wounds [7,8], otitis [9], cystic fibrosis [10] and those associated with medical devices [11], and they are claimed to be responsible for an overwhelming proportion of persistent, antibiotic-resistant infections.

Current challenges faced within the anti-biofilms field are enormous and are present at different stages in the drug discovery process. From a pre-clinical perspective, a limited repertoire of molecules has been reported that can act in vitro on existing biofilms at low concentrations, especially in the case of those formed by Staphylococcus aureus [12]. Then, even if some compounds can successfully enter the drug discovery pipeline, another more serious challenge is the absence of a clearly-defined regulatory pathway for those products to be registered with relevant agencies, such as the European Medicines Agency, the US Food and Drug Administration or the US Environmental Protection Agency. As a result, only one disinfectant (commercially sold by Sterilex, a US company) and no antibiotics have been approved by a regulatory agency to be used specifically against bacterial biofilms. Clearly, expanding the search for anti-biofilms, as well as consistently documenting their benefits with convincing results is deemed as an imperative need of current biomedical research in the hopes of delivering tangible solutions to biofilm infections.

Flavonoids are one of the most widely recognized groups of natural products, even outside the scientific community. They are largely represented in the human diet, as they are present in plants, seeds and various foodstuffs. From a chemical viewpoint, flavonoids are phenolic compounds that consist of two benzene rings (A and B) combined with an oxygen-containing heterocyclic benzopyran ring (C). Flavonoids can be divided into different classes based on their molecular structure. The number of these classes varies according to the classification criteria. For instance, according to the position of the phenyl ring (B) relative to the benzopyran moiety, they can be classified as flavonoids (2-phenyl-benzopyrans), isoflavonoids (3-phenyl-benzopyrans) and neoflavonoids (4-phenyl-benzopyrans) [13]. Oxidation and saturation status in the heterocyclic ring also enables division of flavonoids into flavans, flavanones, dihydroflavonols, flavonols, flavones, flavone-3-ols and flavone-3,4-diols, while, depending upon the type, number and arrangement of substituents, flavonoids can be further divided into other groups, such as anthocyanidins and chalcones [14]. So far, more than 6500 flavonoids have been discovered, and a total of 14 classes have been proposed by Cushnie and Lamb [15]. From a biological perspective, flavonoids are one of the most extensively studied types of natural compounds, with a massive amount of research published supporting an unprecedented amount of bioactivity claims. In the field of anti-infectives, flavonoids have been reported to display antibacterial, antiviral, antiprotozoan and antifungal properties $[16,17]$. Most of the studies performed against bacterial infections have focused on suspended cells, with flavones, chalcones, flavonols, flavan-3-ols, flavanones and flavolans as the most successful flavonoid classes $[15,18,19]$. 
This article focuses on the use of flavonoids as a representative chemical template to perform a large screening in search for compounds that can counteract $S$. aureus biofilms. The screened collection consisted of a commercial set of 500 natural and synthetic flavonoids that covers various structural classes (Figure 1) and includes many well-known dietary flavonoids. To the best of our knowledge, the current contribution represents the largest systematic screening study performed with flavonoids for anti-biofilm effects. Compounds per class present in the library is indicated between parentheses. Flavanones, isoflavonoids, neoflavonoids and dihydroflavonols are also included.

Figure 1. The most important flavonoid classes represented in the flavonoids chemical library. The amount of compounds per class present in the library is indicated between parentheses. Flavanones, isoflavonoids, neoflavonoids and dihydroflavonols are also included.

* The numbering of the chemical structure of the flavonols and flavans is similar to the flavones, and it follows the criteria of [15].

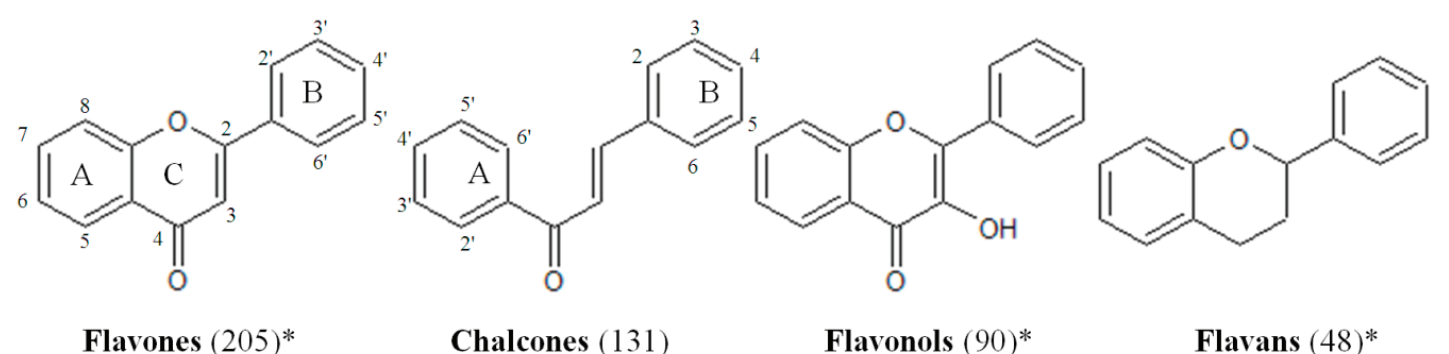

\section{Results and Discussion}

\subsection{Design of the Flavonoid Anti-Biofilm Screening for More Meaningful Data Generation}

Earlier studies dealing with the antibacterial properties of flavonoids performed by different groups have generated conflicting data. However, a seminal contribution by Cushnie and Lamb in 2005 [18] elucidated the major reasons that could explain such contradictions, namely, differences in the types of assays used, a lack of optimization or even a failure to enumerate the starting bacterial concentrations, differences in the solvents used to dissolve the flavonoids, as well as in the origin of the compounds (i.e., if they are obtained from a commercial or a natural source). Taking this into account, one of the aims of this study was to design chemical screening to minimize these sources of variation.

Here, the strategy that was adopted for anti-biofilm screening against Staphylococcus aureus spp. includes a parallel exposure scheme in which bacteria are treated with the compounds before biofilm formation takes place (prior-to-exposure) and once biofilms are formed (post-exposure paradigm). This strategy has been described in the earlier contributions of our group [20-23], and a detailed scheme is presented in [22]. It solely relies on optimized methods to quantify biofilm viability (with resazurin staining) and biomass (with crystal violet staining) under repeatable conditions that have been summarized here and are also detailed in earlier contributions [20-23]. Key conditions, such as 
biofilm formation time, starting bacterial concentrations or available surface for biofilm formation, are comparable to those that have been applied in anti-biofilm studies on 96-microwell plates [24,25], making inter-laboratory comparisons feasible. Special attention was paid to control the initial concentration of added bacteria, as it is one of the most critical factors in antimicrobial assays [25], as well as to maintain it throughout the screening and follow-up studies. Unlike the antibacterial assays against planktonic bacteria for which straightforward guidelines exist from the Clinical and Laboratory Standards Institute, as well as from the European Committee on Antimicrobial Susceptibility Testing (EUROCAST), only one standard for an anti-biofilm screening assay in microwell plates has been accepted so far by the American Society for Testing of Materials (ASTM E2799-12), and it does not apply to Staphylococcus aureus biofilms.

To avoid identifying only strain-specific hits, the initial screening was performed simultaneously against two clinical $S$. aureus strains, and only those flavonoids highly active against both strains and in both exposure paradigms (prior-to and post-biofilm formation) were chosen for further study (selection criteria are discussed in Section 2.2). Moreover, all the tested compounds were obtained from the same company (TimTec, see Section 3.1), to avoid differences due to the source. In Table S1, a list of the flavonoids library is included. Their structures can be retrieved with the company codes using the freely available TimTec database (http://www.echemstore.com/). Trivial names of the natural flavonoids, as well as short names of the natural derivatives were also compiled and included in this Table. All the 500 flavonoids used in this study were prepared in $20 \mathrm{mM}$ in dimethylsulfoxide (DMSO), as this is the most widely used solvent for the solubilization of large chemical libraries. Precipitation upon dilution in DMSO was recorded for 31 flavonoids (Table S1). All the precipitated samples corresponded to being inactive, most likely because precipitation lowers the compound concentration in the solution, resulting in an underestimation of the anti-biofilm activity [26]. However, the population of non-entirely solubilized flavonoids accounted for less than $6.5 \%$ of the total collection and, therefore, has a minimal impact on the usefulness of this study.

\subsection{Anti-Biofilm Screening: Inactive and Moderately Active Flavonoids}

Results of the inhibitory activity of the entire flavonoids collection prior-to (a) and post-(b) biofilm formation based on viability results are shown in Figure 2. The selection process is summarized in Scheme 1, and the raw screening data are presented in Table S1. 
Figure 2. Anti-biofilm effects of the flavonoids collection when added prior-to (a) or post-biofilm formation (b). Strains 1 and 2 are S. aureus ATCC 25923 and Newman clinical strains, respectively. Highly active flavonoids are those present in both shadowed areas. Primary screening results are presented in Table S1.

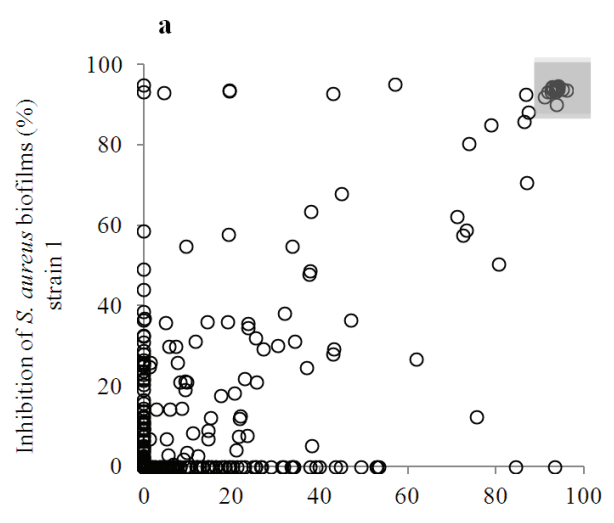

Inhibition of S. aureus biofilms (\%), strain 2

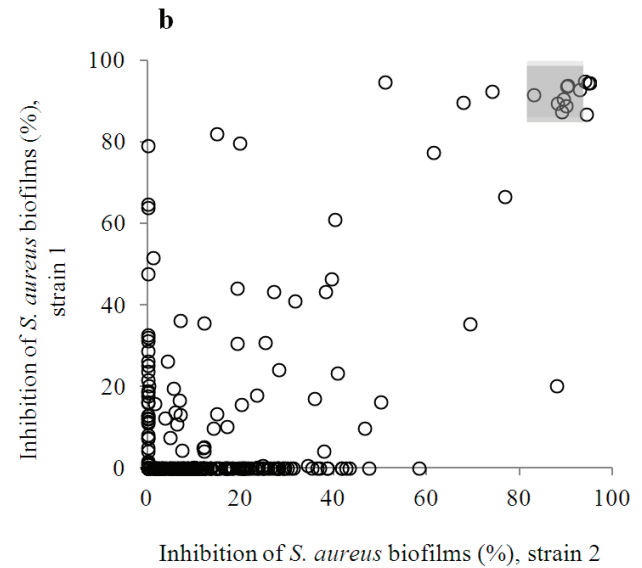

Inhibition of S. aureus biofilms (\%), strain 2

Scheme 1. Summary of the anti-biofilm screening and selection criteria applied to the collection in this study. Highly and moderately active flavonoids are listed in Tables S2 and $\mathrm{S} 3$, respectively.

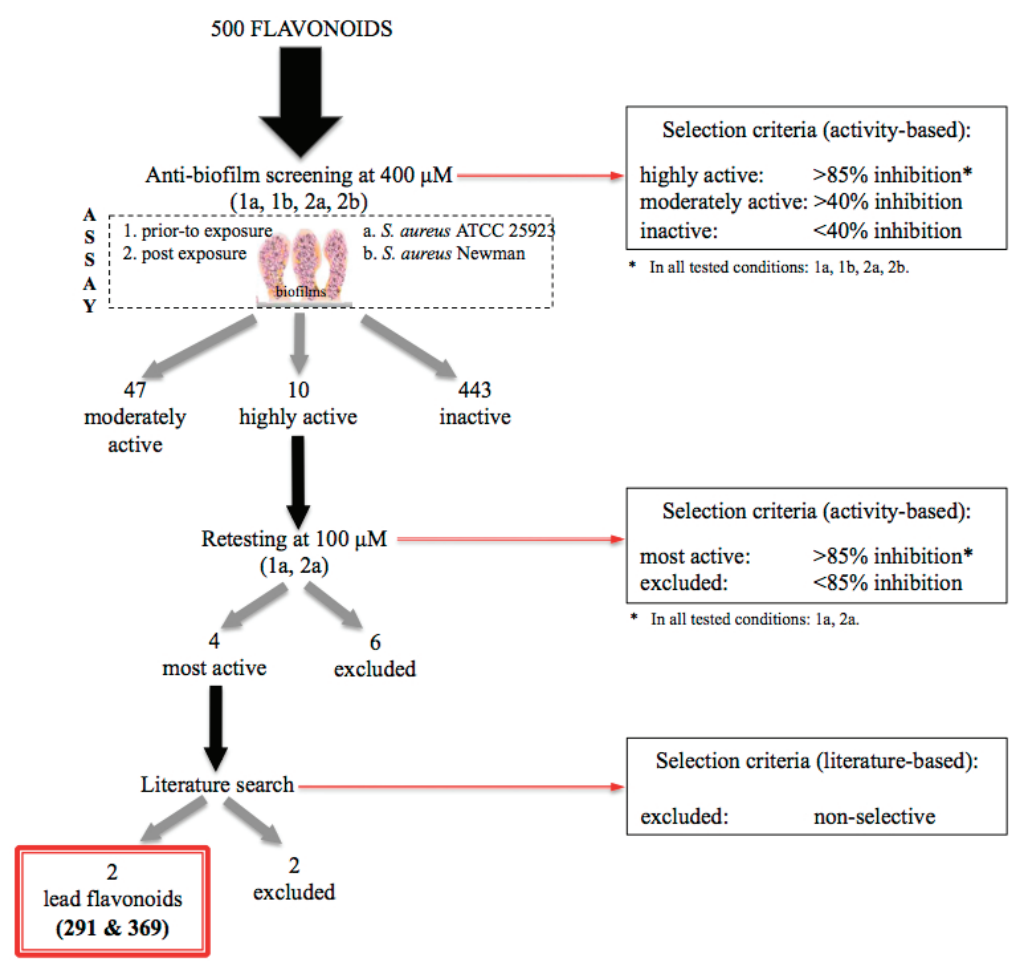

More than $80 \%$ of flavonoids (443) caused less than $40 \%$ inhibition of the biofilm formation by S. aureus (Figure 2) at $400 \mu \mathrm{M}$, and they were declared inactive. In general, many flavonoids had 
strain-specific effects, and their inhibition percentages were lower in the post-exposure paradigm. Upon closer inspection of the screening results (Table S1), ten flavonoids were tentatively identified as highly active, causing more than an $85 \%$ inhibition of biofilm viability (based on resazurin staining), when measured using both exposure assays, as well as both $S$. aureus strains. This corresponds to the compounds that are present in both of the shadowed areas marked in the Figure 2, and they are compiled in Table S2. The calculated overall hit rate, based on the amount of compounds identified as highly active, was $2 \%$.

Between the inactive and highly active flavonoids, 47 were found to inhibit biofilm viability more than $40 \%$, and they were classified as moderately active. Flavonoids that displayed activity in only one assay condition (for instance, compound 231) were intentionally excluded. Thus, all the flavonoids within the moderately active group also displayed varying levels of activity in the other assay conditions. Eight of the moderately active flavonoids were only active in the pre-exposure scheme, and five showed strain-selectivity. A list of the moderately active ones is presented in Table S3.

Observations were first made on the group of inactive flavonoids (Table S1). Dietary flavonoids, present in citrus, such as kaempferol (69) and naringenin (164), have been proven to act as quorum sensing (QS) inhibitors by interfering with the interaction between acyl-homoserine lactones (AHLs, the signal molecules of Gram-negative bacteria) and their receptors, leading to inhibition of biofilm formation by Escherichia coli O157:H7 and Vibrio harveyi BB120 [15,27], but they were classified as inactive in this study. Other QS inhibitors, such as baicalein (159) and catechin (160), were found inactive, as well, when, previously, they had been shown to act on the cytoplasmic membrane-associated receptors, TraR and RhlR, respectively, in this way suppressing biofilm formation by Pseudomonas aeruginosa [28,29]. The lack of activity of all these compounds in $S$. aureus biofilms would thus suggest that they may preferentially act in Gram-negative bacteria.

Several flavonoids present in the moderately active group have been extensively studied and were earlier reported with different bioactivities in a variety of targets, including antimicrobial activity (Table S3). However, a total of 20 flavonoids in this group had not been reported as active in the PubChem Compound (http://www.ncbi.nlm.nih.gov/pccompound), the largest publicly available repository for small molecular weight molecules, which is connected to their bioactivities via the PubChem Bioassay project (http://www.ncbi.nlm.nih.gov/pcassay). Thus, 20 new bioactive flavonoids were identified as a result of this contribution.

Chalcones and flavones are the most highly represented flavonoid classes (Table S2) with 12 and 14 moderately active ones, respectively. This could be a reflection of the fact that these two chemical classes were also the most abundant within the collection (Figure 1). Within the chalcones, isoliquiritigenin (372) has been earlier shown to possess potent antibacterial properties against suspended Ralstonia solanacearum [30] and biofilm-forming Porphyromonas gingivalis [31], both Gram-negative bacteria, but no information had been published concerning the effects against Gram-positive bacteria. Chalcones typically exhibited activity prior to biofilm formation, which was not surprising, as many of them had been reported to exhibit antibacterial properties. Eight of them 
$(189,267,372,466,467,470,474,477)$ are hydroxylated in position 2 ' in the A ring, which has earlier been shown to benefit their antibacterial effects $[32,33]$. Four share a hydroxylation in position 4 ' in the A ring $(189,372,470$ and 477), and this hydroxylation is also present in three other chalcones (251, 425 and 475); thus, within the moderately active chalcones, a total of 11 compounds (out of 12) have hydroxylations in positions $2^{\prime}$ or $4^{\prime}$ in the A ring. In position 4 of the $\mathrm{B}$ ring, hydroxylation (189, 267 and 372) or methoxylation $(251,425$ and 477$)$ seemed to be also a relevant structural feature, but it always occurred in conjunction with the substitutions in the A ring discussed earlier. Thus, this may be important, but not sufficient.

In the case of flavones, substitutions in the A ring in positions 7 (-O-acyl or - $O$-alkylamino) and $5(-\mathrm{OH})$ had been indicated as crucial for antibacterial activity [15,34], and they are indeed present in compounds 52 and 54 (7,-O-acyl) and in 56 and $311(5,-\mathrm{OH})$. However, it was more commonly present in the hydroxylation of position 7 in the A ring, which occurs in 56, 121, 135, 166, 188, 222, 232 and 311 (eight out of 14 flavones). In two (166 and 232), only hydroxylations in the A ring are present (no substituents in the B ring), and one of them (166, 7,8-dihydroxyflavone) was found active in the two exposure conditions and in both $S$. aureus strains, with inhibition percentages ranging from $61.5 \%$ to $93.3 \%$. The impact of substitutions in the B ring of flavones has been much less studied in the literature. Here, it was found that hydroxylation or $O$-acylation in positions $3^{\prime}(\mathbf{5 2}, \mathbf{5 4}, \mathbf{5 6}, \mathbf{2 1 1}, 214$ and 222) or $4^{\prime}(\mathbf{5 2}, \mathbf{5 4}, \mathbf{5 6}, \mathbf{2 1 1}, 214$ and 311) were beneficial. The essentiality of the $\mathrm{B}$ ring substitution is supported by flavone 214 (3',4'-dihydroxyflavone), which displayed high inhibition values of biofilm formation by $S$. aureus 25923 strain (over 64\%) in the absence of any other changes in the A ring. Additionally, four moderately active flavones also share a substituent $\left(-\mathrm{OH}\right.$ or $\left.-\mathrm{OCH}_{3}\right)$ in $6{ }^{\prime}(110,121,129$ and 135). These indicated motifs in the B ring could be valuable guidance for future chemical refinements on the flavones scaffold. The key structural features for chalcones and flavones, which have been discussed above, are summarized in Figure 3.

Figure 3. Key structural features present in the anti-biofilm chalcones and flavones (moderately and highly active ones).

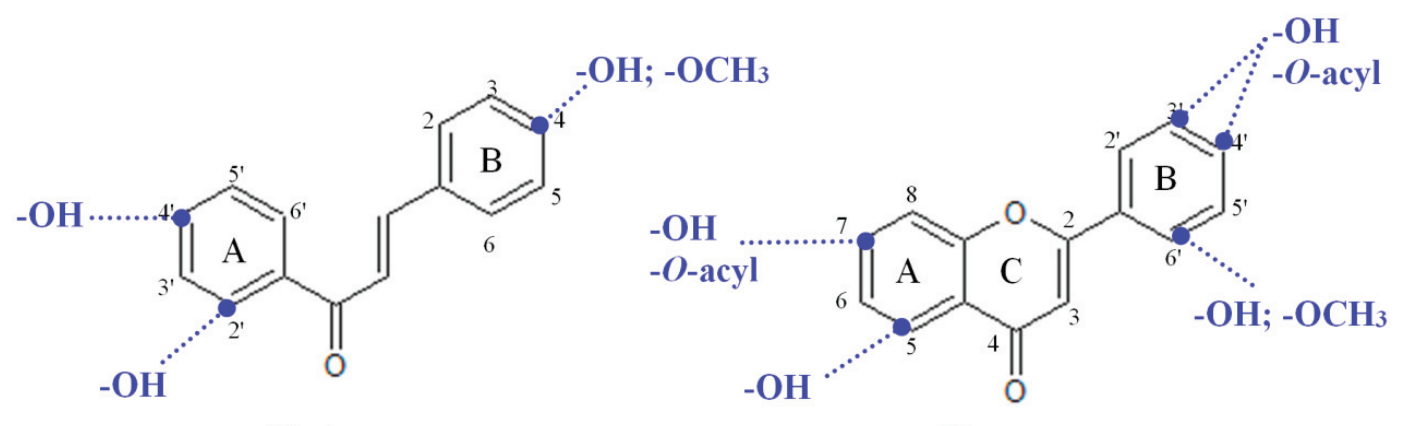

Chalcones

Flavones

Moreover, seven moderately active flavonols (the third most represented flavonoid class after flavones and chalcones) were identified within the moderately active flavonoids. Simultaneous 
hydroxylations of ring $\mathrm{A}$ and $\mathrm{B}$ in various positions occurred in all flavonols, except in one (155), where only $-\mathrm{OH}$ groups were present in the A ring. Among these flavonols, quercetin (58) was identified. Quercetin is one of the most extensively studied dietary flavonoids and natural compounds in general. One interesting aspect is that quercetin was found slightly more effective in pre-existing biofilms. Quercetin has been reported to be antibacterial and anti-biofilm against $S$. aureus. In fact, Lee et al. [35] recently showed that it inhibits biofilm formation (prior-to exposure) by $S$. aureus strains, including ATCC 25923, at concentrations within the range of 17-170 $\mu \mathrm{M}$. Thus, the activity found here is lower than the one reported earlier [35]. Unfortunately, [35] included no information on the solvent used to dissolve the quercetin, and it has been shown that quercetin is highly prone to aggregation, depending upon the vehicle, ionic strength and $\mathrm{pH}$ [36]. Formation of aggregates has been postulated as one possible reason for quercetin's promiscuous activity in a variety of assays [37] and may be one explanation for the discrepancy between the results of [35] and the current study. Similarly, the pentaacetate derivative of quercetin (54) was identified here to be moderately active (Table S1), but it was on the boundary of being classified as highly active, causing more than an $80 \%$ inhibition of biofilm formation in all the assay conditions. Lastly, fisetin (162) was found as a moderately active flavonol and had been earlier reported to specifically inhibit $S$. aureus 8324 biofilms at concentrations within the range of $28-56 \mu \mathrm{M}$ with negligible effects on planktonic bacteria [38].

Novel information was also gathered for other natural flavonoids. The flavonol, galangin (155), and the isoflavone, osajin (288), were also highly effective in the pre-exposure assay and inhibited the viability of existing biofilms. In the first case, galangin (155) has been previously reported as a potent antibacterial against suspended $S$. aureus [26], which could reasonably explain its effectiveness in the pre-exposure assay. No prior reports of the antibacterial properties of osajin (288) have been found, but claims of its antioxidant activity have been supported [39].

\subsection{Highly Active Flavonoids and Further Selection Process}

The ten compounds that were identified as highly active, according to the initial screening results, are listed in Table 1. Their structures and bioactivities, as described in the PubChem Compound database are compiled in Table S2. 
Table 1. Results from the first screening assay and reconfirmation trial for the ten flavonoids originally classified as highly active (summarized in Scheme 1).

\begin{tabular}{|c|c|c|c|c|c|c|c|c|}
\hline \multirow{4}{*}{ Code } & \multirow{4}{*}{ Company ID } & \multirow{4}{*}{ Class } & \multicolumn{6}{|c|}{ Inhibition of biofilm formation (\%) } \\
\hline & & & \multicolumn{4}{|c|}{ Primary screening at $400 \mu \mathrm{M}$} & \multicolumn{2}{|c|}{ Reconfirmation trial at $100 \mu \mathrm{M}$} \\
\hline & & & \multicolumn{2}{|c|}{ Prior-to-exposure } & \multicolumn{2}{|c|}{ Post-exposure } & Prior-to-exposure & Post-exposure \\
\hline & & & strain 1 & strain 2 & strain 1 & strain 2 & \multicolumn{2}{|c|}{ strain 1} \\
\hline 33 & ST014848 & isoflavone & 93.8 & 93.8 & 94.5 & 94.9 & $19.7 \pm 5.6$ & 0 \\
\hline 59 & ST024709 & flavanone & 94.1 & 92.6 & 94.8 & 94.0 & $95.5 \pm 0.1$ & $92.5 \pm 3.2$ \\
\hline 139 & ST056204 & flavanone & 93.8 & 95.1 & 86.9 & 94.3 & $95.0 \pm 0.1$ & $93.6 \pm 1.1$ \\
\hline 291 & ST075672 & flavan & 93.2 & 92.6 & 94.6 & 94.7 & $95.4 \pm 0.1$ & $94.1 \pm 1.2$ \\
\hline 369 & ST081006 & flavan & 93.6 & 96.1 & 93.9 & 90.3 & $95.3 \pm 0.2$ & $93.3 \pm 1.7$ \\
\hline 424 & ST092293 & chalcone & 93.8 & 94.3 & 93.7 & 90.2 & $15.9 \pm 5.1$ & 0 \\
\hline 432 & ST093738 & flavan & 94.1 & 94.0 & 89.4 & 88.1 & 0 & 0 \\
\hline 446 & ST098360 & flavanone & 92.0 & 91.2 & 92.9 & 92.9 & 0 & 0 \\
\hline 464 & ST095411 & chalcone & 93.7 & 93.7 & 90.5 & 89.4 & 0 & 0 \\
\hline 469 & ST095417 & chalcone & 94.8 & 94.1 & 88.8 & 90.0 & 0 & 0 \\
\hline
\end{tabular}

Strains 1 and 2 refer to $S$. aureus ATCC 25923 and Newman clinical strains, respectively.

Six natural flavonoids are present in the highly active group $(59,139,424,446,464$ and 469). The first two $(\mathbf{5 9}, \mathbf{1 3 9})$ are discussed further in this chapter. Compound 446, isosakuranetin, ((2S)-5,7-dihydroxy-2-(4-methoxyphenyl)-2,3-dihydrochromen-4-one)), has been isolated from the flowers of Chromolaena odorata, and it has been reported to possess moderate anti-mycobacterial activity with minimal inhibitory concentrations (MIC) of $174.8 \mu \mathrm{M}$ [40]. On the other hand, compound 464 (2',4'-dihydroxychalcone) has been recently demonstrated as the most active constituent of the plant, Muntingia calabura, against suspended $S$. aureus (the same strain used in the current study) with an estimated MIC value of $50 \mu \mathrm{g} / \mathrm{mL}(208 \mu \mathrm{M})$ [41]. Thus, at $400 \mu \mathrm{M}$, the antibacterial activity of $\mathbf{4 6 4}$ on suspended cells could be one possible mechanism for the prevention of biofilm formation registered in the current study. None of these highly active flavonoids have been previously reported to possess anti-biofilm properties (Table S2). The chalcones in this group (424, 464 and 469) have hydroxylation in positions 2' and 4', as previously noted in the group of moderately active ones. Because these chalcones were also effective in existing biofilms, albeit only at $400 \mu \mathrm{M}$, it could be that these features play a role not only for antibacterial, but also for anti-biofilm activity.

These ten highly active flavonoids were further retested at $100 \mu \mathrm{M}$ (Scheme 1; Table 1), and the high activity was only preserved in four molecules: two flavanones $(59, \mathbf{1 3 9})$ and two flavan derivatives $(\mathbf{2 9 1}, \mathbf{3 6 9})$. Their structures are shown in Figure 4. 
Figure 4. The four most active anti-biofilm flavonoids identified in this contribution.

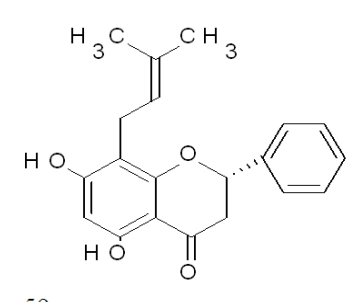

59 phenylchroman-4-one) promptly revealed that it is present in Mexican plants of the Tephrosia genus and is shown to possess inhibitory effects on the dengue virus at relatively low micromolar concentrations $(25 \mu \mathrm{M})$ [42]. On the other hand, flavanone 139 (3,5,7-trihydroxy-2-phenylchromen-4-one), also known as the 8-prenylnaringenin, is typically found in hops and is a well-known and potent phyto-estrogen with documented in vitro and in vivo effects [43]. The side prenylation in position 8 is also present in glabranine, which suggests the importance of this side chain. The 6-prenylated naringenin (absent in this flavonoid library) has been shown to be antibacterial against suspended S. aureus (MIC of $18.3 \mu \mathrm{M}$ ) [44]. It has been speculated that the lipophilicity that is provided by the prenyl side chain could improve the bacterial transmembrane transport of these derivatives [45] and may tentatively facilitate the interaction of both compounds (59 and 139) with the biofilm matrix, in comparison to naringenin (164, inactive here). However, at this point, it was reasoned that compounds with other properties (such as antiviral or estrogenic) would not be selective anti-biofilms, and they may cause undesirable off-target effects. Consequently, flavanones 59 and 139 were excluded from further analysis.

Attention was then focused on the flavan derivatives, 291 (6-chloro-4-(6-chloro-7hydroxy-2,4,4-trimethylchroman-2-yl)benzene-1,3-dioland) and 369 (4-(6-hydroxyspiro[1,2,3,3a,9apentahydrocyclopenta[1,2-b]chromane-9,1'-cyclopentane]-3a-yl)benzene-1,3-diol). Upon a literature search, no bioactivity data were found associated with these molecules. This search included the freely available Antimicrobial Index database (http://antibiotics.toku-e.com/), which is a very complete source of antibacterial molecules, as well as the PubChem database. One factor to keep in mind is that, in general, studies on the bioactivity of flavans appear to be more scarce in comparison to other flavonoid classes [46], and fewer screenings for their antibacterial activity have been published.

\subsection{The Two Most Potent Flavonoids: Potencies, Efficacies and Mechanistic Insights}

The two identified flavans prevented bacterial colonization and decreased the viability of existing biofilms (Table 2). They also caused a reduction in biofilm biomass, and the potency values quantified with the crystal violet assay were similar to the ones presented here (results not shown). The activity order was maintained in both exposure strategies, with 291 being the most active. Interestingly, the ratios between the concentrations needed to reduce $50 \%$ of the viable cells in the existing biofilm, and 
those needed to prevent $50 \%$ of biofilm formation varied between 2.7 and 3.4 ; that is a great advantage if compared with the antibiotic, penicillin $\mathrm{G}$ (Table 2).

Table 2. Anti-biofilm and antibacterial potencies of the top two flavonoids (flavans 291 and 369). MIC, minimal inhibitory concentrations; MBC, minimal bactericidal concentrations.

\begin{tabular}{|c|c|c|c|c|}
\hline \multirow[t]{2}{*}{ Code } & \multicolumn{2}{|c|}{$\begin{array}{c}\text { Effects on biofilms }\left(\mathrm{IC}_{50}, \mu \mathrm{M}\right)(\mu \mathrm{g} / \mathrm{mL}) \\
(95 \% \text { confidence intervals })\end{array}$} & \multicolumn{2}{|c|}{ Effects on suspended bacteria } \\
\hline & Prior-to-exposure & Post-exposure & MIC, $\mu \mathrm{M}$ & $\mathbf{M B C}, \mu \mathrm{M}$ \\
\hline 291 & $\begin{array}{c}10.2(3.77) \\
(8.9-11.6)\end{array}$ & $\begin{array}{l}\mathbf{2 7 . 9}(10.3) \\
(22.9-33.9)\end{array}$ & $20(7.38)$ & $15(5.54)$ \\
\hline 369 & $\begin{array}{l}\mathbf{1 7 . 7}(6.24) \\
(12.7-24.8)\end{array}$ & $\begin{array}{l}\mathbf{6 0 . 5}(21.3) \\
(49.6-73.9)\end{array}$ & $40(14.1)$ & $40(14.1)$ \\
\hline Penicillin G & $\begin{array}{r}\mathbf{0 . 1 3}(0.048) \\
(0.12-0.14)\end{array}$ & $45.2 \% *$ & $\mathbf{0 . 1 2}(0.045)$ & $\mathbf{0 . 1 3}(0.048)$ \\
\hline
\end{tabular}

* Percent inhibition at $5 \mathrm{mM}$. Penicillin fails to cause more than $50 \%$ of biofilm inhibition in the post-exposure assay, as previously shown in [22].

The same viability staining was applied to measure the efficacy these flavonoids had against suspended cells, so the comparison of the antibacterial and anti-biofilm results could be somewhat easier. The two most active flavans were shown to display a potent antibacterial activity, with similar MIC and minimal bactericidal concentrations (MBC) values quantified on the suspended cells (Table 2). MIC values, in particular, corresponding to $7.3 \mu \mathrm{g} / \mathrm{mL}$ and $14.1 \mu \mathrm{g} / \mathrm{mL}$ for compounds 291 and 369, respectively, are indicative of a significant antibacterial activity, judging from previous indications that compounds with MICs $\leq 100 \mu \mathrm{g} / \mathrm{mL}$ are considered noteworthy and those with MICs $\leq 10 \mu \mathrm{g} / \mathrm{mL}$ are regarded to be very interesting [15,47]. Compound 291 caused 50\% inhibition of biofilm formation at $10 \mu \mathrm{M}$, and it reached more than $90 \%$ of biofilm viability inhibition with a minor concentration increase (at $13 \mu \mathrm{M})$, which was very close to the MBC value quantified here $(15 \mu \mathrm{M})$. Similarly, compound 369 had a half maximal inhibitory concentration ( $\left.\mathrm{IC}_{50}\right)$ of $17.7 \mu \mathrm{M}$ and caused $90 \%$ inhibition of biofilm formation at $40 \mu \mathrm{M}$, corresponding to its $\mathrm{MBC}$.

Based on how close the anti-biofilm $\mathrm{IC}_{90}$ and the $\mathrm{MBC}$ values were, it could be suggested that these flavans caused a significant killing upon direct interaction with the suspended cells, resulting in a reduction of the suspended viable cell density initially present to attach to the polystyrene surface of the microtiter well plates to begin the biofilm formation process. However, on the other hand, a former contribution demonstrated a very significant biofilm formation after $18 \mathrm{~h}$, even if only a low concentration of viable bacterial cells $\left(10^{3}\right.$ colony forming units, $\left.\mathrm{CFU} / \mathrm{mL}\right)$ was present at the beginning of the incubation period [20-23]. Thus, reducing the starting population of viable suspended bacteria even by 3-log units would still not be enough to explain the ability of these compounds to significantly inhibit bacterial colonization and biofilm formation. Consequently, it is likely that in the presence of $\mathbf{2 9 1}$ and 369, some cells are still able to attach and form biofilms, but their maturation 
process is significantly hampered, resulting in the presence of less viable cells in the bacterial biofilm core, after $18 \mathrm{~h}$. This possibility is supported by the fact that $\mathbf{2 9 1}$ and $\mathbf{3 6 9}$ were also potent in the post-exposure assay (when they only encounter bacterial biofilms), as previously discussed at the beginning of this section.

Next, the killing efficacy was studied. Formed $S$. aureus biofilms $(18 \mathrm{~h})$ were exposed to various concentrations of the two flavans during $24 \mathrm{~h}$, and the density of biofilm bacteria left on the wells and bacteria in the planktonic phase were measured using agar plate counts (Table 3). The log R parameter was calculated by comparing the log counts from the treated wells to untreated controls, as in [48].

Table 3. Killing efficacy of flavans 291 and 369.

\begin{tabular}{cccc}
\hline Code & Concentration $(\boldsymbol{\mu M})$ & Log Reduction (biofilm phase) & Log Reduction (planktonic phase) \\
\hline \multirow{2}{*}{$\mathbf{2 9 1}$} & 20 & 0.6 & 0.1 \\
& 80 & 1.5 & 0.7 \\
& 200 & 3.5 & 3.5 \\
& 400 & 4.6 & 4.7 \\
$\mathbf{3 6 9}$ & 50 & 1.5 & 1.2 \\
& 100 & 3.9 & 4.1 \\
& 250 & 3.1 & 9.0 \\
penicillin G & 400 & 3.9 & 9.0 \\
\hline
\end{tabular}

This experiment intended to clarify the ability of these compounds to reduce the viable bacterial burden in the biofilm phase using the reference or golden standard method for bacterial quantification (the agar plate counts). Due to the laboriousness and low throughput of this method, it is only applicable for follow-up studies in screening campaigns for chemical libraries, at the point when active ones have been selected and a reasonable amount of samples are to be handled. Compounds causing at least a 3-log reduction are of greater interest, since a 3-log reduction of the biofilm burden is highly desirable to assist the immune system in clearing the remaining pathogens in vivo, in immunotolerant biofilm infections $[49,50]$.

Furthermore, in this experiment, the remaining viable bacteria in the planktonic phase were quantified. Although planktonic cells are removed (and flavonoids are added), once the biofilms have been formed for $18 \mathrm{~h}$, the continuation of the experiment for an additional $24 \mathrm{~h}$ results in space limitations for the existing $S$. aureus biofilms, due to the relatively small size of the wells. A fraction of the biofilm population then gets detached and can switch into the suspended state to maintain the stability of the established biofilms. Accordingly, at the end of the post-exposure time, a high concentration of viable biofilm bacteria is typically recovered from the untreated wells $\left(4 \times 10^{9} \mathrm{CFU} / \mathrm{mL}\right.$, corresponding to $\left.5 \times 10^{8} \mathrm{CFU} / \mathrm{cm}^{2}\right)$, as well as of suspended bacteria from the same wells $\left(6 \times 10^{9} \mathrm{CFU} / \mathrm{mL}\right)$. 
Flavans 291 and 369 caused more than 3-log reduction of the biofilm viable core at concentrations of 200 and $100 \mu \mathrm{M}$, respectively, indicative of 99.9\% killing. Applying flavan 291 resulted in a similar $\log$ reduction of biofilm and planktonic cells throughout the entire concentration range, confirming that this compound has both antibacterial and anti-biofilm activity and that it can be equally effective at targeting both, under the same experimental conditions. Flavan 369, on the other hand, was more effective in reducing the viable suspended bacteria (achieving the maximum $\log \mathrm{R}$ values with no detectable living colonies) than the viable core of bacterial cells residing on the $S$. aureus biofilms. This suggests instead that $\mathbf{3 6 9}$ is a flavan behaving more as an antibacterial than an anti-biofilm compound.

If only the antibacterial activity is to be taken into account, 291 ranks within the top 10 most active flavonoids reported in the literature (reviewed by Cushnie and Lamb [15]). However, it is the fact that 291, as well as $\mathbf{3 6 9}$ are also potent anti-biofilm agents that makes them highly interesting. Bacteria are switching between single-cell and biofilm states in host organisms, and the predominant lifestyle can dynamically change depending on various complex factors. Thus, compounds that can successfully act on both at fairly similar concentrations are the most promising starting point for more feasible candidates for antibacterials.

\section{Experimental Section}

\subsection{Compounds Collection}

The studied collection consisted of 500 synthetic and natural flavonoids that are commercially sold by TimTec (www.timtec.net). Structures of all compounds can be retrieved from the vendor's database (http://www.echemstore.com/). Flavonoids with 9 different basic cores are present in the library (flavanones, flavones, chalcones, flavonols, dihydroflavonols, flavans, anthocyanins, isoflavonoids and neoflavonoids). The list of all tested compounds is presented in Table S1, as well as their trivial and short names, when available. The average molecular weight of the collection is $342.8 \mathrm{~g} / \mathrm{mol}$, and the averages of predicted $\log P$ and $\log S$ are 3.49 and -4.46 , respectively, as provided by the supplier. Compound identities were confirmed by the supplier, using Nuclear Magnetic Resonance spectroscopy (NMR) (300 MHz or higher) and Liquid Chromatography-Mass Spectrometry (LC/MS). Compound purities were measured using High-Performance Liquid Chromatography (HPLC) and ensured to be over 95\%. All compounds were dissolved in dry DMSO to a concentration of $20 \mathrm{mM}$ and were maintained in matrix storage tubes (Thermo Fisher Scientific, Waltham, MA, USA) at $-20{ }^{\circ} \mathrm{C}$. From those stocks, the compounds were added directly into the assay plates containing the culture media or further dilutions in dry DMSO were made for the bioactivity follow-ups with the most active compounds. Additional amounts of flavans 291 (company ID: ST075672) and 369 (company ID: ST081006) were purchased from TimTec for the characterization studies. Structural validation for these two compounds is presented in Table S4. 


\subsection{Biofilm Assay}

S. aureus (ATCC 25923 and Newman, both clinical strains of human origin) were used for the primary screening of the flavonoids collection. Bacteria were cultured in $30 \mathrm{~g} / \mathrm{L}$ tryptic soy broth (TSB, Fluka Biochemika, Buchs, Switzerland) under aerobic conditions at $37{ }^{\circ} \mathrm{C}, 200 \mathrm{rpm}$ for $4 \mathrm{~h}$ to reach exponential growth. Biofilms were formed according to the conditions previously described [23]. Briefly, exponentially grown bacteria $\left(10^{6} \mathrm{CFU} / \mathrm{mL}, 200 \mu \mathrm{L}\right)$ were added to flat-bottomed 96well microplates (Nunclon $\Delta$ surface) (Nunc, Roskilde, Denmark), and biofilms were formed at $37{ }^{\circ} \mathrm{C}$, $200 \mathrm{rpm}$ for $18 \mathrm{~h}$ in $30 \mathrm{~g} / \mathrm{L}$ TSB.

\subsection{Exposure to Flavonoids}

The anti-biofilm effects of the flavonoids were examined prior to biofilm and post-biofilm formation, as recently described in [23]. During the pre-exposure, compounds and bacterial suspension were added, and the effects were examined after incubation at $37{ }^{\circ} \mathrm{C}, 200 \mathrm{rpm}$ for $18 \mathrm{~h}$. In the post-exposure, biofilms were formed first during $18 \mathrm{~h}\left(37^{\circ} \mathrm{C}, 200 \mathrm{rpm}\right.$, as described earlier), flavonoids were added and plates were incubated for $24 \mathrm{~h}$ at $37^{\circ} \mathrm{C}, 200 \mathrm{rpm}$. Penicillin $\mathrm{G}$, used as the control antibiotic in all experiments, was prepared in Mueller-Hinton Broth (MHB) and tested at $400 \mu \mathrm{M}$. Untreated biofilms, cell-free samples with TSB and biofilms exposed to $2 \%$ DMSO were included as controls. Initial screening of the entire collection was conducted at a final compound concentration of $400 \mu \mathrm{M}$ for both bacterial strains. The reconfirmation trial was performed for selected compounds at $100 \mu \mathrm{M}$.

\subsection{Quantification of Biofilms}

Biofilm viability and biomass were measured using resazurin and crystal violet staining assays, as previously described [23]. Biofilms were first stained with resazurin $20 \mu \mathrm{M}$ (Sigma-Aldrich, St. Louis, MO, USA) for $20 \mathrm{~min}$ at room temperature (RT), (darkness, $200 \mathrm{rpm}$ ), followed by the measurement of the fluorescence emitted by the resorufin (the reduced form of the resazurin), at $\lambda_{\mathrm{exc}}=560 \mathrm{~nm}$ and $\lambda_{\mathrm{em}}=590 \mathrm{~nm}$ using a Varioskan reader (Thermo Fisher Scientific, Vantaa, Finland). The resazurin stain was then removed and replaced with crystal violet, which was added in the sample plate using a Multidrop ${ }^{\circledR}$ Combi dispenser (Thermo Fisher Scientific, Vantaa, Finland) and incubated for 5 min (RT, static conditions). After staining, biofilms were washed three times with Milli-Q (MQ) water with the aid of a Biomek $3000^{\circledR}$ liquid handling workstation (Beckman Coulter Inc., Fullerton, CA, USA). The remaining dye was recovered by the addition of $96 \%$ ethanol, and after $1 \mathrm{~h}$, the absorbance was measured at $\lambda=595 \mathrm{~nm}$ using a Varioskan plate reader. 


\subsection{Anti-Biofilm Potency and Efficacy Testing}

Anti-biofilm potencies of selected compounds (coded 291 and 369) were measured using 18 concentration points within a concentration range of $10-400 \mu \mathrm{M}$ in both exposure schemes. Anti-biofilm efficacies were measured using the Log Reduction ( $\log \mathrm{R})$ assay [48], which is based on viable cell counts in tryptic soy agar (TSA) plates. At the end of the $24 \mathrm{~h}$ exposure to these compounds, planktonic cells were transferred to sterile plates, while biofilms were scraped off the wells in $100 \mu \mathrm{L}$ TSB using sterile plastic sticks and rinsed with an additional $100 \mu \mathrm{L}$ of TSB. To disperse the bacterial aggregates, samples were immersed in a high power ultrasonic bath (Bandelin Sonorex Digitec, Zurich, Switzerland) using an in-house built-in device that allowed them to be in full contact with the water. Sonication was performed at RT ( $5 \mathrm{~min}, 35 \mathrm{kHz})$. The disaggregated biofilms, as well as the planktonic cells, were serially diluted, spread onto TSA plates and incubated at $37{ }^{\circ} \mathrm{C}$ overnight. The $\log _{10}$ density of viable cells $(\mathrm{CFU} / \mathrm{mL})$ in treated and control wells were determined, and $\log \mathrm{R}$ was calculated from the difference of the $\log _{10}$ density on the untreated biofilms (or the planktonic phase of the corresponding wells) and the $\log _{10}$ density on the biofilms treated with the flavonoids (or the planktonic phase of the corresponding wells). To confirm that all biofilms have been recovered, the scraped wells were stained with resazurin (as in Section 3.4).

\subsection{Bacteriostatic and Bactericidal Effect on Planktonic Cells}

Minimal inhibitory concentrations (MIC) of 291 and 369 for planktonic bacteria were first measured. After exposing biofilms to the flavonoids (at $37{ }^{\circ} \mathrm{C}$ for $18 \mathrm{~h}$ ), the planktonic phase was transferred to sterile 96-microtiter well plates, and quantitative readouts were obtained (at $\lambda=620 \mathrm{~nm}$ ) using the Varioskan Flash Multimode Plate Reader (2.4.3.37 software, Thermo Fisher Scientific Oy, Vantaa, Finland, 2004), as in [23]. The minimal bactericidal concentrations (MBC) were also measured. For this purpose, after making the MIC determinations, suspensions were mixed with resazurin $400 \mu \mathrm{M}(10 \mu \mathrm{L})$, to reach a final concentration of $20 \mu \mathrm{M}$. Plates were then incubated in the darkness, RT, with $200 \mathrm{rpm}$ shaking for approximately for $4 \mathrm{~min}$, followed by the measurement of fluorescence $\left(\lambda_{\mathrm{exc}}=570 \mathrm{~nm} ; \lambda_{\mathrm{em}}=590 \mathrm{~nm}\right)$ using the Varioskan Flash Multimode Plate Reader (2.4.3.37 software, Thermo Fisher Scientific Oy, Vantaa, Finland, 2004).

\subsection{Statistical Analysis and Data Processing}

At least four replicates per treatment were included in each plate, and two separate experiments (biological replicates) were always run. Anti-biofilm activities were expressed as inhibition percentages of the untreated biofilms (Equation 1). The potencies of the anti-biofilm effects ( $\mathrm{IC}_{50}$ ) of 291 and 369 were calculated from 18 concentration points via a non-linear regression analysis (sigmoidal dose-response with variable slope), and the results are presented with $95 \%$ confidence intervals. Below, $\mu_{\max }$, and $\mu_{\min }$ represent the means (average) of the signals (the fluorescence of the 
reduced resazurin or absorbance of the crystal violet stained biofilms) recorded in untreated biofilms and TSB controls, respectively.

$$
\text { Inhibition } \%=\left[\left(\mu_{\max }-\mu_{\text {treated well })} /\left(\mu_{\max }-\mu_{\min }\right)\right] \times 100 \%\right.
$$

Quality control of the screening process was done via the calculation of the screening window coefficient $(Z)$ and signal-to-background $(S / B)$ and signal-to-noise $(S / N)$ ratios, as defined by [51,52]. Calculated parameters during the first screening behaved as follows: $Z>0.6 ; S / B>16$ and $S / N>7$. All data processing and statistical analysis was done with Microsoft Excel 2010 software and GraphPad Prism version 5.0 for Mac, GraphPad Software (San Diego, CA, USA, 2009), respectively.

\section{Conclusions}

The body of data produced here serves three main purposes. First, it offers an improved methodological workflow for anti-biofilm phenotypic screens of chemical libraries. By using methods optimized for biofilm quantification in the context of chemical screening and by designing the study with two exposure modes and two Staphylococcus spp. Strains, the prior flaws of antibacterial studies of flavonoids have been minimized. Furthermore, to improve data analysis, the probable connections between the anti-biofilm and antibacterial properties of the flavonoids were investigated, which is often times ignored in the scientific literature. This is particularly relevant for the proper interpretation of the bioactivity data obtained from flavonoids, but also from other natural products with reported antibacterial effects, for instance, phenolic acids, catechins and phytosterols, among others.

Second, it provides a large anti-biofilm bioactivity dataset for flavonoids. An effort was made to highlight relevant flavonoids and to compare current results with prior contributions, so that a better understanding of their bioactivity profiles was achieved. The dataset built here will also hopefully pave the way for future structure-activity relationship (SAR) studies and structural optimizations.

Finally, this contribution identifies two new synthetic flavans (compounds 291 and 369) as potent antimicrobials that can successfully act on biofilms and suspended $S$. aureus and represent more feasible antibacterial candidates, to be included in a new generation of pharmaceuticals. This research may also potentially spark interest for more focused studies on this flavonoid class. More data is indeed needed on their in vivo bioavailabilites and safety profiles, which will benefit a better exploitation of flavans as drug leads.

\section{Acknowledgments}

The authors thank the Academy of Finland (WoodyFilm project decision 264064; Bioarmi project decision 128870), the Drug Discovery and Chemical Biology network of Biocenter Finland the Finnish Bioeconomy Cluster, the Borg Foundation and Medicinska Understödsföreningen Liv och Hälsa for financial support. The contribution of Oyvind M. Andersen (University of Bergen, Norway) during the preparation of this manuscript is also greatly appreciated. 


\section{Conflicts of Interest}

The authors declare no conflict of interest.

\section{References}

1. Donlan, R.M. Biofilm formation: A clinically relevant microbiological process. Clin. Infect. Dis. 2001, 33, 1387-1392.

2. Donlan, R.M.; Costerton, J.W. Biofilms: Survival mechanisms of clinically relevant microorganisms. Clin. Microbiol. Rev. 2002, 15, 167-193.

3. Sauer, K.; Camper, A.K. Characterization of phenotypic changes in Pseudomonas putida in response to surface-associated growth. J. Bacteriol. 2001, 183, 6579-6589.

4. Tote, K.; vanden Berghe, D.; Deschacht, M.; de Wit, K.; Maes, L.; Cos, P. Inhibitory efficacy of various antibiotics on matrix and viable mass of Staphylococcus aureus and Pseudomonas aeruginosa biofilms. Int. J. Antimicrob. Agents 2009, 33, 525-531.

5. Landini, P.; Antoniani, D.; Burgess, J.G.; Nijland, R. Molecular mechanisms of compounds affecting bacterial biofilm formation and dispersal. Appl. Microbiol. Biotechnol. 2010, 86, 813-823.

6. Parsek, M.R.; Singh, P.K. Bacterial biofilms: An emerging link to disease pathogenesis. Annu. Rev. Microbiol. 2003, 57, 677-701.

7. Malic, S.; Hill, K.E.; Hayes, A.; Percival, S.L.; Thomas, D.W.; Williams, D.W. Detection and identification of specific bacteria in wound biofilms using peptide nucleic acid fluorescent in situ hybridization (PNA-FISH). Microbiology 2009, 155, 2603-2611.

8. James, G.A.; Swogger, E.; Wolcott, R.; deLancey Pulcini, E.; Secor, P.; Sestrich, J.; Costerton, J.W.; Stewart, P.S. Biofilms in chronic wounds. Wound Repair Regener. 2008, 16, 37-44.

9. Hall-Stoodley, L.; Hu, F.Z.; Gieseke, A.; Nistico, L.; Nguyen, D.; Hayes, J.; Forbes, M.; Greenberg, D.P.; Dice, B.; Burrows, A.; et al. Direct detection of bacterial biofilms on the middle-ear mucosa of children with chronic otitis media. JAMA 2006, 296, 202-211.

10. Singh, P.K.; Schaefer, A.L.; Parsek, M.R.; Moninger, T.O.; Welsh, M.J.; Greenberg, E.P. Quorum-sensing signals indicate that cystic fibrosis lungs are infected with bacterial biofilms. Nature 2000, 407, 762-764.

11. Adair, C.G.; Gorman, S.P.; Feron, B.M.; Byers, L.M.; Jones, D.S.; Goldsmith, C.E.; Moore, J.E.; Kerr, J.R.; Curran, M.D.; Hogg, G.; et al. Implications of endotracheal tube biofilm for ventilator-associated pneumonia. Intensive Care Med. 1999, 25, 1072-1076.

12. Worthington, R.J.; Richards, J.J.; Melander, C. Small molecule control of bacterial biofilms. Org. Biomol. Chem. 2012, 10, 7457-7474.

13. Samanta, A.; Das, G.; Das, S.K. Roles of flavonoids in plants. Int. J. Pharm. Sci. Technol. 2011, 6, 12-35.

14. Kumar, B.; Sandhar, H.K.; Prasher, S.; Tiwari, P.; Salhan, M.; Sharma, P. A review of phytochemistry and pharmacology of flavonoids. Int. Pharm. Sci. 2011, 1, 25-41. 
15. Cushnie, T.P.; Lamb, A.J. Recent advances in understanding the antibacterial properties of flavonoids. Int. J. Antimicrob. Agents 2011, 38, 99-107.

16. Havsteen, B.H. The biochemistry and medical significance of the flavonoids. Pharmacol. Ther. 2002, 96, 67-202.

17. Alvesalo, J.; Vuorela, H.; Tammela, P.; Leinonen, M.; Saikku, P.; Vuorela, P. Inhibitory effect of dietary phenolic compounds on Chlamydia pneumoniae in cell cultures. Biochem. Pharmacol. 2006, 71, 735-741.

18. Cushnie, T.P.; Lamb, A.J. Antimicrobial activity of flavonoids. Int. J. Antimicrob. Agents 2005, 26, 343-356.

19. Rauha, J.P.; Remes, S.; Heinonen, M.; Hopia, A.; Kähkönen, M.; Kujala, T.; Pihlaja, K.; Vuorela, H.; Vuorela, P. Antimicrobial effects of finnish plant extracts containing flavonoids and other phenolic compounds. Int. J. Food Microbiol. 2000, 56, 3-12.

20. Sandberg, M.; Määttänen, A.; Peltonen, J.; Vuorela, P.M.; Fallarero, A. Automating a 96-well microtitre plate model for Staphylococcus aureus biofilms: An approach to screening of natural antimicrobial compounds. Int. J. Antimicrob. Agents 2008, 32, 233-240.

21. Sandberg, M.E.; Schellmann, D.; Brunhofer, G.; Erker, T.; Busygin, I.; Leino, R.; Vuorela, P.M.; Fallarero, A. Pros and cons of using resazurin staining for quantification of viable Staphylococcus aureus biofilms in a screening assay. J. Microbiol. Methods 2009, 78, 104-106.

22. Skogman, M.E.; Vuorela, P.M.; Fallarero, A. Combining biofilm matrix measurements with biomass and viability assays in susceptibility assessments of antimicrobials against Staphylococcus aureus biofilms. J. Antibiot. 2012, 65, 453-459.

23. Fallarero, A.; Skogman, M.; Kujala, J.; Rajaratnam, M.; Moreira, V.M.; Yli-Kauhaluoma, J.; Vuorela, P. (+)-Dehydroabietic acid, an abietane-type diterpene, inhibits Staphylococcus aureus biofilms in vitro. Int. J. Mol. Sci. 2013, 14, 12054-12072.

24. Peeters, E.; Nelis, H.J.; Coenye, T. Comparison of multiple methods for quantification of microbial biofilms grown in microtiter plates. J. Microbiol. Methods 2008, 72, 157-165.

25. Mariscal, A.; Lopez-Gigosos, R.M.; Carnero-Varo, M.; Fernandez-Crehuet, J. Fluorescent assay based on resazurin for detection of activity of disinfectants against bacterial biofilm. Appl. Microbiol. Biotechnol. 2009, 82, 773-783.

26. Cushnie, T.P.; Hamilton, V.E.; Lamb, A.J. Assessment of the antibacterial activity of selected flavonoids and consideration of discrepancies between previous reports. Microbiol. Res. 2003, 158, 281-289.

27. Vikram, A.; Jayaprakasha, G.K.; Jesudhasan, P.R.; Pillai, S.D.; Patil, B.S. Suppression of bacterial cell-cell signalling, biofilm formation and type III secretion system by citrus flavonoids. J. Appl. Microbiol. 2010, 109, 515-527.

28. Zeng, Z.; Qian, L.; Cao, L.; Tan, H.; Huang, Y.; Xue, X.; Shen, Y.; Zhou, S. Virtual screening for novel quorum sensing inhibitors to eradicate biofilm formation of Pseudomonas aeruginosa. Appl. Microbiol. Biotechnol. 2008, 79, 119-126. 
29. Vandeputte, O.M.; Kiendrebeogo, M.; Rajaonson, S.; Diallo, B.; Mol, A.; El Jaziri, M.; Baucher, M. Identification of catechin as one of the flavonoids from Combretum albiflorum bark extract that reduces the production of quorum-sensing-controlled virulence factors in Pseudomonas aeruginosa PAO1. Appl. Environ. Microbiol. 2010, 76, 243-253.

30. Zhao, X.; Mei, W.; Gong, M.; Zuo, W.; Bai, H.; Dai, H. Antibacterial activity of the flavonoids from Dalbergia odorifera on Ralstonia solanacearum. Molecules 2011, 16, 9775-9782.

31. Feldman, M.; Santos, J.; Grenier, D. Comparative evaluation of two structurally related flavonoids, isoliquiritigenin and liquiritigenin, for their oral infection therapeutic potential. J. Nat. Prod. 2011, 74, 1862-1867.

32. Avila, H.P.; Smânia, E.F.A.; Monache, F.D.; Smânia, A. Structure-activity relationship of antibacterial chalcones. Bioorg. Med. Chem. 2008, 16, 9790-9794.

33. Alvarez, M.e.L.; Zarelli, V.E.; Pappano, N.B.; Debattista, N.B. Bacteriostatic action of synthetic polyhydroxylated chalcones against Escherichia coli. Biocell 2004, 28, 31-34.

34. Li, H.Q.; Shi, L.; Li, Q.S.; Liu, P.G.; Luo, Y.; Zhao, J.; Zhu, H.L. Synthesis of C(7) modified chrysin derivatives designing to inhibit beta-ketoacyl-acyl carrier protein synthase III (FABH) as antibiotics. Bioorg. Med. Chem. 2009, 17, 6264-6269.

35. Lee, J.H.; Park, J.H.; Cho, H.S.; Joo, S.W.; Cho, M.H.; Lee, J. Anti-biofilm activities of quercetin and tannic acid against Staphylococcus aureus. Biofouling 2013, 29, 491-499.

36. Pohjala, L.; Tammela, P. Aggregating behavior of phenolic compounds-A source of false bioassay results? Molecules 2012, 17, 10774-10790.

37. McGovern, S.L.; Shoichet, B.K. Kinase inhibitors: Not just for kinases anymore. J. Med. Chem. 2003, 46, 1478-1483.

38. Dürig, A.; Kouskoumvekaki, I.; Vejborg, R.M.; Klemm, P. Chemoinformatics-assisted development of new anti-biofilm compounds. Appl. Microbiol. Biotechnol. 2010, 87, 309-317.

39. Fránová, J.; Pavlík, M. Testing of antidiabetic and antioxidative effect of the flavonoid osajin in an experiment. Ceska Slov. Farm. 2007, 56, 200-204.

40. Suksamrarn, A.; Chotipong, A.; Suavansri, T.; Boongird, S.; Timsuksai, P.; Vimuttipong, S.; Chuaynugul, A. Antimycobacterial activity and cytotoxicity of flavonoids from the flowers of Chromolaena odorata. Arch. Pharm. Res. 2004, 27, 507-511.

41. Sufian, A.S.; Ramasamy, K.; Ahmat, N.; Zakaria, Z.A.; Yusof, M.I. Isolation and identification of antibacterial and cytotoxic compounds from the leaves of Muntingia calabura L. J. Ethnopharmacol. 2013, 146, 198-204.

42. Sánchez, I.; Gómez-Garibay, F.; Taboada, J.; Ruiz, B.H. Antiviral effect of flavonoids on the dengue virus. Phytother. Res. 2000, 14, 89-92.

43. Zanoli, P.; Zavatti, M. Pharmacognostic and pharmacological profile of Humulus lupulus L. J. Ethnopharmacol. 2008, 116, 383-396.

44. Mizobuchi, S.; Sato, Y. Antifungal activities of hop bitter resins and related compounds. Agric. Biol. Chem. 1985, 49, 399-403. 
45. Shen, G.; Huhman, D.; Lei, Z.; Snyder, J.; Sumner, L.W.; Dixon, R.A. Characterization of an isoflavonoid-specific prenyltransferase from Lupinus albus. Plant Physiol. 2012, 159, 70-80.

46. Chang, S.Y.; Cheng, M.J.; Peng, C.F.; Chang, H.S.; Chen, I.S. Antimycobacterial butanolides from the root of Lindera akoensis. Chem. Biodiversity 2008, 5, 2690-2698.

47. Ríos, J.L.; Recio, M.C. Medicinal plants and antimicrobial activity. J. Ethnopharmacol. 2005, 100, 80-84.

48. Pitts, B.; Hamilton, M.A.; Zelver, N.; Stewart, P.S. A microtiter-plate screening method for biofilm disinfection and removal. J. Microbiol. Methods 2003, 54, 269-276.

49. Jensen, P.; Givskov, M.; Bjarnsholt, T.; Moser, C. The immune system vs. Pseudomonas aeruginosa biofilms. FEMS Immunol. Med. Microbiol. 2010, 59, 292-305.

50. Müller, G.; Kramer, A. Biocompatibility index of antiseptic agents by parallel assessment of antimicrobial activity and cellular cytotoxicity. J. Antimicrob. Chemother. 2008, 61, 1281-1287.

51. Zhang, J.H.; Chung, T.D.; Oldenburg, K.R. A simple statistical parameter for use in evaluation and validation of high throughput screening assays. J. Biomol. Screening 1999, 4, 67-73.

52. Bollini, S.; Herbst, J.J.; Gaughan, G.T.; Verdoorn, T.A.; Ditta, J.; Dubowchik, G.M.; Vinitsky, A. High-throughput fluorescence polarization method for identification of fkbp12 ligands. J. Biomol. Screening 2002, 7, 526-530. 


\title{
Novel Strategies for the Prevention and Treatment of Biofilm Related Infections
}

\author{
Meng Chen, Qingsong Yu and Hongmin Sun
}

\begin{abstract}
Biofilm formation by human bacterial pathogens on implanted medical devices causes major morbidity and mortality among patients, and leads to billions of dollars in healthcare cost. Biofilm is a complex bacterial community that is highly resistant to antibiotics and human immunity. As a result, novel therapeutic solutions other than the conventional antibiotic therapies are in urgent need. In this review, we will discuss the recent research in discovery of alternative approaches to prevent or treat biofilms. Current anti-biofilm technologies could be divided into two groups. The first group focuses on targeting the biofilm forming process of bacteria based on our understanding of the molecular mechanism of biofilm formation. Small molecules and enzymes have been developed to inhibit or disrupt biofilm formation. Another group of anti-biofilm technologies focuses on modifying the biomaterials used in medical devices to make them resistant to biofilm formation. While these novel anti-biofilm approaches are still in nascent phases of development, efforts devoted to these technologies could eventually lead to anti-biofilm therapies that are superior to the current antibiotic treatment.
\end{abstract}

Reprinted from Int. J. Mol. Sci. Cite as: Chen, M.; Yu, Q.; Sun, H. Novel Strategies for the Prevention and Treatment of Biofilm Related Infections. Int. J. Mol. Sci. 2013, 14, 18488-18501.

\section{Introduction}

Biofilm is a community of bacteria that are attached to a substratum or surface. Bacteria in biofilm are embedded in extracellular polymeric matrix produced by the bacteria. Bacteria develop biofilm on submerged surfaces such as natural aquatic systems, water pipes, living tissues, tooth surfaces, indwelling medical devices and implants [1]. Biofilm formation on indwelling medical devices and implants such catheters, mechanical heart valves, pacemakers, prosthetic joints, and contact lenses pose a critical medical problem. Both Gram-negative and Gram-positive bacteria can form biofilms on indwelling medical devices. The most common biofilm-forming bacteria include Enterococcus faecalis, Staphylococcus aureus, Staphylococcus epidermidis, Streptococcus viridans, Escherichia coli, Klebsiella pneumoniae, Proteus mirabilis, and Pseudomonas aeruginosa [2].

Among these biofilm-forming bacteria, S. aureus and S. epidermidis are most commonly found on cardiovascular devices [3,4]. It was estimated that $S$. aureus and $S$. epidermidis caused about $40 \%-50 \%$ of prosthetic heart valve infections, and $50 \%-70 \%$ catheter biofilm infections [5]. Each year about 250,000-500,000 primary blood stream infections occur among the 150 million intravascular devices implanted in the US. Health care cost could be increased from $\$ 4000$ to $\$ 56,000$ for each infection [6,7]. Approximately $87 \%$ of blood stream infections were caused by staphylococci [5]. Taken together, the burden on healthcare system by $S$. aureus and $S$. epidermidis in biofilm is enormous. 
Biofilm formation is initiated when bacterial cells attach and adhere to the surfaces of implants or host tissues. S. aureus generates multiple adhesive factors that could bind to host factors [8]. The host factors could mediate bacterial attachment to implant surfaces, which is covered by host plasma and other extracellular components. For example, S. aureus produces fibronectin-binding proteins (FnBPA and $\mathrm{FnBPB}$ ) [9], collagen-binding protein Cna [10] and fibrinogen-binding proteins, clumping factor $\mathrm{A}$ and $\mathrm{B}$ (ClfA and ClfB) $[11,12]$ to bind host plasma and extracellular matrix (ECM) components. Bacteria attached to the surfaces will proliferate, aggregate and recruit cells from the surrounding to form and differentiate into biofilm structures [13]. Bacterial attachment to the surface will change from reversible to irreversible accompanied by profound physiological, gene expression and protein profile changes. The mature biofilm structures consist of complex architecture and channels. Bacterial cells can detach from mature biofilms and spread to other organ systems $[13,14]$. As a result, biofilms become sources of persistent and chronic infections.

Bacteria in biofilm behave differently from planktonic bacteria, especially in terms of their response to antibiotic treatment [2]. Biofilm-associated bacteria are highly resistant to antibiotics. The complicated structure of biofilm with extracellular polymeric matrix could prevent antibiotics from reaching the bacteria. Bacteria in biofilm could also adopt a slow growing or starved state due to the altered microenvironment such as depletion of nutrition and accumulation of waste. The changed physiological state of bacteria could make them more resistant to antibiotics, which target more active cell processes [3,15-17].

In addition to the difficulty of treating biofilm with conventional antibiotic therapy, treating biofilm is further hindered by the rising antibiotic resistance among pathogens. Antibiotics targets are essential for bacterial survival. As a result, antibiotic resistant strains have been favored by selective pressure [18]. Antibiotic resistance in $S$. aureus such as the methicillin resistance is one of the most urgent medical problems [19,20]. It was estimated that 94,360 invasive methicillin-resistant Staphylococcus aureus (MRSA) infections occurred in the US in 2005, and these infections were associated with death in 18,650 cases [21]. Although $S$. epidermidis is part of the normal human epithelial bacterial flora, it can cause infection when skin or mucous membrane is injured. Biofilm formation on implanted indwelling medical devices is the major manifestation of $S$. epidermidis pathogenesis [3]. Antibiotic resistance is also widespread in S. epidermidis. For example, more than $70 \%$ of all hospital isolates of S. epidermidis are resistant to methicillin [22]. In summary, alternative approaches other than conventional antibiotic therapy are in urgent need to treat biofilm related infections. In this review, we will discuss alternative approaches to prevent or treat biofilms focusing on $S$. aureus and $S$. epidermidis, two of the most important biofilm forming pathogens. 


\section{Anti-Biofilm Agents}

\subsection{Small Molecules}

High throughput screening of small molecule libraries has been one of the major approaches to search for drug leads. In recent years, high throughput screening has been increasingly adopted in academics to screen for low molecular weight compounds with desired biological properties. A chemical series of small compounds was identified by our group that inhibited the virulence gene expression of Gram positive pathogens such as Streptococcus pyogenes and S. aureus [23,24].

We performed a high throughput screening of 55,000 chemical compounds to search for inhibitors of gene expression of a key S. pyogenes virulence factor streptokinase [24]. A lead compound and its analogs were identified to be able to inhibit streptokinase gene expression. Detailed analysis of the global effect of the inhibitor on $S$. pyogenes gene expression demonstrated that the inhibitor changed gene expression of many key virulence factors. Furthermore, the lead compound also protected mice against $S$. pyogenes infection [24]. Analogs of the lead compounds were subsequently tested in $S$. aureus. Two analogs from the same chemical series inhibited biofilm formation by $S$. aureus [23]. The anti-biofilm compound also inhibited gene expression of a number of important $S$. aureus virulence factors [23]. Among the inhibited genes are genes known to be involved in biofilm formation. Inhibition of these genes could lead to inhibition of biofilm formation. The broad spectrum anti-virulence effect of the compounds on both $S$. pyogenes and $S$. aureus suggested that this class of compounds could target a conserved gene regulatory mechanism. As a result, this class of compounds could potentially be developed into novel anti-microbial agents against multiple pathogens.

Panmanee et al. screened 42,865 compounds to identify compounds that inhibited formation of or kill $S$. epidermidis biofilms. Sixteen compounds were confirmed to be able to either kill or inhibit S. epidermidis biofilm [25]. The mechanism of action of these anti-biofilm compounds remained to be characterized. Sambanthamoorthy et al. performed high throughput screening on 66,000 compounds and natural products to identify small molecules that inhibited induction of Vibrio cholerae cyclic di-GMP-inducible transcription [26]. Cyclic di-GMP is a second-messenger signal that is a key regulator of switch between planktonic and attached lifestyle of the majority of bacteria [27,28]. A benzimidazole compound demonstrated broad spectrum inhibition of biofilm formation by several Gram-negative and Gram-positive bacterial pathogens, including P. aeruginosa and S. aureus [26]. Opperman et al. screened 87,250 compounds for inhibitors of $S$. epidermidis biofilm [29]. Twenty three aryl rhodanines were identified to inhibit early phase biofilm formation by multiple strains of S. aureus, S. epidermidis, and E. faecalis [29]. However, the mechanism underlying the function of the aryl rhodanines was unclear.

P. aeruginosa produces an organic compound cis-2-decenoic acid capable of dispersing established biofilms and inhibiting biofilm development by a number of bacteria [30]. It was observed that $P$. aeruginosa dispersed from a continuous culture biofilm after medium flow stopped for several hours. The extracellular message that induced the release of cells from biofilm was purified from the 
organic fraction of spent medium and identified as cis-2-decenoic acid which was able to disperse biofilms by E. coli, K. pneumoniae, P. mirabilis, S. pyogenes, B. subtilis, S. aureus, and C. albicans [30]. Similarly, bacteria produce d-amino acids, which inhibited biofilm formation by $S$. aureus and $P$. aeruginosa [31].

$\mathrm{N}$-acetylcysteine is a mucolytic agent that could interfere with exopolysaccharide formation in biofilms and inhibit $S$. epidermidis biofilm formation [32]. Metallic cations such as $\mathrm{Ca}^{2+}$ and $\mathrm{Mg}^{2+}$ play roles in microbial adherence and biofilm formation. As a result, chelators that can remove these cations could also inhibit biofilm formation [33].

The number of small molecules that can interfere with biofilm formation and thus serve as lead for development of anti-biofilm agents is growing rapidly (Table 1). However, mechanisms of action of many of these small molecules are still unclear which hinders the further development. More pharmacokinetic and in vivo studies are needed to optimize these leads to meet the necessary criteria for medical application.

Table 1. Small molecules that can inhibit biofilm formation.

\begin{tabular}{|c|c|c|c|}
\hline Agent & Mechanism & Effect & Reference \\
\hline $\begin{array}{l}\text { Anti-virulence } \\
\text { compounds }\end{array}$ & $\begin{array}{l}\text { Inhibition of gene expression of } \\
\text { virulence factors }\end{array}$ & Inhibition of biofilm formation by $S$. aureus & {$[23]$} \\
\hline $\begin{array}{l}\text { Anti-biofilm } \\
\text { compounds }\end{array}$ & Unknown & $\begin{array}{l}\text { Inhibition of biofilm formation by } \\
\qquad \text { S. epidermidis }\end{array}$ & {$[25]$} \\
\hline $\mathrm{ABC}-1$ & $\begin{array}{l}\text { Inhibition of } \\
\text { c-di-GMP-inducible } \\
\text { transcription } \\
\end{array}$ & $\begin{array}{c}\text { Inhibition of biofilm formation by multiple } \\
\text { Gram-negative and Gram-positive bacterial } \\
\text { pathogens }\end{array}$ & {$[26]$} \\
\hline Aryl rhodanines & Unknown & $\begin{array}{l}\text { Inhibition of biofilm formation by } S \text {. aureus } \\
\text { and } S . \text { epidermidis }\end{array}$ & [29] \\
\hline Cis-2-decenoic acid & Unknown & $\begin{array}{l}\text { Dispersion of biofilms by E. coli, } \\
\text { K. pneumoniae, P. mirabilis, S. pyogenes, } \\
\text { B. subtilis, S. aureus, and C. albicans }\end{array}$ & {$[30]$} \\
\hline D-amino acids & Unknown & $\begin{array}{l}\text { Inhibition of biofilm formation by } S . \text { aureus } \\
\text { and P. aeruginosa }\end{array}$ & {$[31]$} \\
\hline$N$-acetylcysteine & $\begin{array}{l}\text { Interference with } \\
\text { exopolysaccharide formation } \\
\text { in biofilms }\end{array}$ & $\begin{array}{l}\text { Inhibition of biofilm formation by } \\
\text { S. epidermidis }\end{array}$ & {$[32]$} \\
\hline Chelators & $\begin{array}{l}\text { Interference with metal ion's } \\
\text { function in biofilm formation }\end{array}$ & Inhibition of biofilm formation by $S$. aureus & {$[33]$} \\
\hline
\end{tabular}

\subsection{Matrix-Targeting Enzymes}

Disrupting or degrading the extracellular polymeric matrix of biofilms can weaken and disperse biofilms. There have been a number of studies done to degrade matrix components such as polysaccharide, eDNA and proteins [34]. The Gram-negative, oral bacterium Actinobacillus 
actinomycetemcomitans produces dispersin B that could disperse biofilms by other bacteria. Kaplan et al. found that dispersin B could disrupt extracellular matrix of $S$. epidermidis biofilm and disperse the biofilm [35]. Extracellular genomic DNA (eDNA) is released by bacteria as an important component of extracellular matrix of biofilm [36]. As a result, DNase I was shown to be able to disperse $S$. aureus biofilms [37]. Proteinase K and trypsin effectively disrupted $S$. aureus biofilms [38]. There are still a lot of limitations with these approaches. The in vivo efficacy of such approaches isn't well established and treating host with proteins could cause inflammatory and allergic reaction, which could affect the therapeutic potential [38].

\section{Bioengineering Approaches}

\subsection{Bactericidal/Bacteriostatic Coating}

Altering the surface properties of indwelling medical devices is one of the main focuses to prevent or decrease biofilm infections [3,39]. One of the approaches to make biomaterial surfaces resistant to biofilm formation is to coat the surface with bactericidal/bacteriostatic substances. Antibiotics are commonly used. For example, vancomycin was covalently bonded to the surface of titanium metal implant. As a result, $S$. epidermidis biofilm formation was significantly inhibited on a vancomycin coated titanium alloy [40]. Antibiotics have been used to impregnate catheters to prevent biofilm formation in clinics [41-44]. However, using antibiotics could lead to selection of antibiotic resistance and even induce biofilm formation [45].

Heavy metal silver was also used as an anti-biofilm agent by depositing silver on the surfaces of biomaterials using coating technology [46,47]. Silver is one of the strongest bactericidal agents. The mechanism of the bactericidal function of silver is still unclear. It was observed that when silver ion penetrated into cells, DNA was condensed and lost ability to replicate, which led to cell death. Silver ion could also inactivate proteins by reacting with the thiol groups in cysteine residues [48-50]. Silver nanoparticles have been studied for their antimicrobial property. Because silver nanoparticles have extremely large surface area, they can interact with microorganisms better. The nanoparticles could penetrate inside the bacteria and react with proteins and DNA, and interrupt the respiratory chain and cell division, leading to cell death [48].

Coating medical devices with silver ions or metallic silver has disappointing clinic results, probably due to inactivation of metallic silver when the devices contacting blood and coating wearing off [48]. On the other hand, biofilm formation by a number of pathogens such E. coli, Enterococcus, S. aureus, coagulase-negative Staphylococci on silver nanoparticle coated catheters was almost completely prevented [51]. However, silver nanoparticle could have genotoxic and cytotoxic effects on human cells at high dose [49]. Accelerated thrombin formation and platelet activation were also observed on surfaces of catheters coated with the silver nanoparticles, which could increase the thrombosis risk of patients in clinics [52]. As a result, much effort is still needed to improve the silver nanoparticle coating technology to diminish these side-effects. 
Red alga Delisea pulchra produces halogenated furanones that can inhibit fouling of their surface. Furanones have been studied as a new class of anti-microbial agents [53,54]. Furanone was coated on biomaterial surfaces by physical adsorption and biofilm formation by S. epidermidis was significantly inhibited by furanone coating [55]. Furanone was also covalently bonded to Silastic Tenckhoff catheters and rendered inhibitory effect on biofilm formation [56]. Furthermore, in a sheep catheter infection model, furanone coated catheters tended to cause less severe infection than control catheters [56].

Covalently coupled 3-(trimethoxysilyl)-propyldimethyloctadecylammonium chloride (QAS) to silicone rubber will generate quaternary ammonium groups on the surface with antimicrobial activity. Viability of S. aureus adhered to QAS-coated silicone rubber was decreased, both in vitro and in vivo [57]. Quaternary ammonium functionalized silica nanoparticles was used to coat glass surfaces and exhibited inhibition of growth and accumulation of Gram-negative and Gram-positive bacteria on the surface [58].

One of the shortcomings of the bactericidal surfaces is that they could be covered by macromolecules and dead microorganisms, and then lose their antimicrobial function [59].

\subsection{Anti-Adhesion Coating}

The infection-resistant surface of indwelling medical devices could also be achieved by depositing a thin layer of anti-adhesion coating on the surface to reduce attachment of pathogenic bacteria. The number of bacteria that may adhere and their ability to grow and spread on biomaterial surfaces is greatly influenced by not only the bacteria but also the physicochemical properties of the biomaterial. The surface properties of biomaterials or medical devices can be changed by coating application or surface modification to create the desired anti-adhesion characteristics without altering the bulk properties of materials. These surface properties include chemical composition and reactivity, hydrophilicity and hydrophobicity [60], surface roughness [61,62] or texture [63], and surface charge. Following this approach, our research team has developed trimethylsilane (TMS) plasma nanocoatings using low temperature plasma coating technology to coat surfaces of stainless steel and titanium for reduced bacterial adhesion and biofilm formation [64]. Significant inhibition of S. epidermidis biofilm was observed on TMS plasma coated stainless steel and titanium. The biofilm inhibition could be attributed to the coating chemical inertness, low surface free energy, coating smoothness, and surface-bound $\mathrm{CH}_{3}$ groups. The changed surface properties could result in less protein adsorbed to the coated surfaces than that adsorbed to the uncoated stainless steel and titanium controls, leading to significantly decreased bacterial adhesion.

Harris et al. coated titanium surface with Poly(l-lysine)-grafted-poly(ethylene glycol) (PLL-g-PEG) to decrease non-specific adsorption of blood. The PEG coating also decreased S. aureus adhesion [65]. Zwitterionic poly(carboxybetaine methacrylate) (pCBMA) film grafted to glass surface was shown to be highly resistant to fibrinogen adhesion and $S$. epidermidis and $P$. aeruginosa attachment and accumulation [66]. It is believed that the surface hydration layer generated by these hydrophilic coatings could serve as a physical and energetic barrier to protein adsorption and thus bacteria adhesion [67]. 
A superhydrophobic coating on glass surface was synthesized from a mixture of nanostructured silica colloids and a low surface energy fluorinated silane xerogel. The adhesion of $S$. aureus and P. aeruginosa to the silica-colloid-doped fluorinated surfaces was decreased by two orders of magnitude versus the control [68]. It was found that fibrinogen adsorption on the superhydrophobic surface was very low, leading to low attachment of $S$. aureus [69]. Low surface energy chemistry and nano-textured morphology of the superhydrophobic coating could result in reduced protein adsorption and bacterial attachment. A barrier to wetting could be created by trapping pockets of air in the nano-scale morphology, which in effect presents a reduced surface area onto which protein molecules can diffuse from the solution [69].

The surface roughness of biomaterials has been recognized as one of many important factors for surface-bacterium interactions. Many studies have shown that the surface roughness of biomaterials strongly influences the degree of bacterial attachment to surfaces [62,70,71]. For instance, streptococcal adhesion was sensitive to surface roughness and enhanced as the roughness of composite surfaces increased from $20 \mathrm{~nm}$ to 150 and $350 \mathrm{~nm}$ [72]. S. epidermidis adhesion and growth were markedly higher on rough titanium surfaces than on smooth surfaces [73]. In contrast, there was greater attachment of $S$. aureus cells to mechanochemically polished titanium than the as-received titanium, even though the polished surfaces were much smoother. It was thus speculated that mechanochemical polishing generated nanoscale surface features on the titanium surfaces with a characteristic pattern more suitable for anchoring of spherical $S$. aureus cells [62].

$\mathrm{Xu}$ et al. reported that submicron (staphylococcal bacterial dimension) surface textures (400-500 nm) on poly(urethane urea) films reduced the material's surface area accessible to bacteria of $S$. epidermidis and $S$. aureus, resulting in a decreased probability of interaction with the material surface or adhesive plasma proteins (e.g., fibrinogen and fibronectin) adsorbed onto the material. Thus, the flow of fluid over the material surface removes bacteria from a textured surface more efficiently than it would from a smooth surface, and subsequently resists bacterial adhesion and biofilm formation [63].

Organoselenium can catalyze the formation of superoxide radicals to prevent bacterial colonization on biomaterial surfaces [74]. Organoselenium antimicrobial agent selenocyanatodiacetic acid (SCAA) was coated on hemodialysis catheters by covalent bonding and demonstrated both in vitro and in vivo efficacy at preventing S. aureus biofilm formation [75].

Polymer brush coatings are another type of promising anti-adhesion coatings for inhibition of biofilms. Polymer brush coatings are formed when hydrophilic polymer long-chains are attached to a surface and stretch out into the surrounding medium [76,77]. Polymer brush coatings that have been mostly studied for preventing biofilm formation are made from poly(ethylene oxide) (PEO) [78-81]. As the PEO long-chains are highly mobile and attain extremely large exclusion volume, compression of the PEO long-chain brushes upon approach by incoming proteins or bacteria would give rise to an increase in the local concentration of PEO, which would lead to a repulsive osmotic pressure to repel the approaching proteins or bacteria and keep them away at a distance [77]. Excellent in vitro results 
have shown significant reduction in protein adsorption and bacterial adhesion, and thus the high effectiveness of polymer brush coatings in preventing bacterial adhesion $[82,83]$. In contrast, in vivo results $[84,85]$ using PEO brush coatings have been discouraging mainly due to the weak surface attachment of polymer chains and the susceptibility of PEO to oxidation damage that prevent successful applications of such coatings for in vivo conditions [77].

Anti-adhesion coatings prevent biofilm formation at early stages, which should be more desirable in clinical settings. However, in vivo efficacy success is still elusive with many of the coatings. Due to the complexity of interaction between coating surfaces with bacteria and host proteins, the mechanism of anti-adhesion coatings is also difficult to pinpoint. As a result, more effort is needed to further exploit this promising strategy for prevention of biofilm related infections.

In summary, the bioengineering approaches (Table 2) could prevent biofilm formation which is more desirable than treating biofilm related infection. In spite of the shortcomings of many of the approaches, improving biomaterial anti-biofilm properties remains the most effective and promising strategy to prevent the morbidity and mortality associated with biofilm infections.

Table 2. Surface modification approaches that can inhibit biofilm formation.

\begin{tabular}{|c|c|c|c|}
\hline Coating agent & Coating method & Mechanism & Reference \\
\hline Antibiotics & Non-covalent, covalent bonding & Bactericidal/Bacteriostatic & {$[40-44]$} \\
\hline Silver & $\begin{array}{c}\text { Plasma deposition, sol-gel coating, } \\
\text { wet-chemical coating }\end{array}$ & Bactericidal & {$[46,47,51]$} \\
\hline Furanones & Physical adsorption, covalent bonding & Bactericidal/Bacteriostatic & {$[55,56]$} \\
\hline QAS & Covalent bonding & $\begin{array}{l}\text { Inhibition of bacterial } \\
\text { adhesion and viability }\end{array}$ & {$[57]$} \\
\hline $\begin{array}{c}\text { Silica nanoparticles with } \\
\text { QAS }\end{array}$ & Covalent bonding & Bactericidal/Bacteriostatic & {$[58]$} \\
\hline TMS & $\begin{array}{c}\text { Plasma coating deposition with covalent } \\
\text { bonding }\end{array}$ & Anti-adhesion & {$[64]$} \\
\hline PLL-g-PEG & Physical adsorption \& covalent coupling & Anti-adhesion & {$[65]$} \\
\hline pCBMA & $\begin{array}{c}\text { Zwitterionic surfaces grafted via radical } \\
\text { polymerization }\end{array}$ & Anti-adhesion & {$[66]$} \\
\hline $\begin{array}{c}\text { Silica colloids/Silane } \\
\text { xerogel }\end{array}$ & Synthesis of superhydrophobic coating & Anti-adhesion & {$[68]$} \\
\hline Submicron surface textures & Physical surface roughness modification & Anti-adhesion & {$[63]$} \\
\hline Selenocyanatodiacetic acid & Covalent bonding & Anti-adhesion & {$[75]$} \\
\hline Polymer brush coatings & Surface grafting & Anti-adhesion & {$[82,83]$} \\
\hline
\end{tabular}

\section{Conclusions}

The approaches under development to prevent and treat biofilm caused infections include small molecules and matrix-targeting enzymes, bactericidal and anti-adhesion coatings. Small molecules and 
enzymes have been investigated to inhibit or disrupt biofilm formation. Anti-biofilm coatings have been targeting on modifying the surface of medical devices for enhanced inhibition of bacterial adhesion and/or growth leading to high resistance to biofilm formation. These novel anti-biofilm technologies could eventually lead to anti-biofilm therapies that are superior to the current antibiotic treatment.

\section{Acknowledgments}

The works of the authors are supported by NIH Grant P01HL573461 to HS, and NIH Grant 1R44HL097485-01A2 to MC. We would also like to thank all our colleagues on the works discussed in the review. We apologize to all colleagues whose works could not be cited due to space limitations.

\section{Conflicts of Interest}

The authors declare no conflict of interest.

\section{References}

1. Donlan, R.M. Biofilms: Microbial life on surfaces. Emerg. Infect. Dis. 2002, 8, 881-890.

2. Donlan, R.M. Biofilms and device-associated infections. Emerg. Infect. Dis. 2001, 7, 277-281.

3. Otto, M. Staphylococcal biofilms. Curr. Top. Microbiol. Immunol. 2008, 322, 207-228.

4. Otto, M. Staphylococcus epidermidis-The "accidental" pathogen. Nat. Rev. Microbiol. 2009, 7, 555-567.

5. Agarwal, A.; Singh, K.P.; Jain, A. Medical significance and management of staphylococcal biofilm. FEMS Immunol. Med. Microbiol. 2010, 58, 147-160.

6. Maki, D.G.; Kluger, D.M.; Crnich, C.J. The risk of bloodstream infection in adults with different intravascular devices: A systematic review of 200 published prospective studies. Mayo Clin. Proc. 2006, 81, 1159-1171.

7. Uckay, I.; Pittet, D.; Vaudaux, P.; Sax, H.; Lew, D.; Waldvogel, F. Foreign body infections due to Staphylococcus epidermidis. Ann. Med. 2009, 41, 109-119.

8. Gotz, F. Staphylococcus and biofilms. Mol. Microbiol. 2002, 43, 1367-1378.

9. Menzies, B.E. The role of fibronectin binding proteins in the pathogenesis of Staphylococcus aureus infections. Curr. Opin. Infect. Dis. 2003, 16, 225-229.

10. Switalski, L.M.; Patti, J.M.; Butcher, W.; Gristina, A.G.; Speziale, P.; Hook, M. A collagen receptor on Staphylococcus aureus strains isolated from patients with septic arthritis mediates adhesion to cartilage. Mol. Microbiol. 1993, 7, 99-107.

11. Ni Eidhin, D.; Perkins, S.; Francois, P.; Vaudaux, P.; Hook, M.; Foster, T.J. Clumping factor B (ClfB), a new surface-located fibrinogen-binding adhesin of Staphylococcus aureus. Mol. Microbiol. 1998, 30, 245-257. 
12. McDevitt, D.; Nanavaty, T.; House-Pompeo, K.; Bell, E.; Turner, N.; McIntire, L.; Foster, T.; Hook, M. Characterization of the interaction between the Staphylococcus auireus clumping factor (ClfA) and fibrinogen. Eur. J. Biochem. FEBS 1997, 247, 416-424.

13. Stoodley, P.; Sauer, K.; Davies, D.G.; Costerton, J.W. Biofilms as complex differentiated communities. Annu. Rev. Microbiol. 2002, 56, 187-209.

14. Fey, P.D.; Olson, M.E. Current concepts in biofilm formation of Staphylococcus epidermidis. Future Microbiol. 2010, 5, 917-933.

15. Costerton, J.W.; Stewart, P.S.; Greenberg, E.P. Bacterial biofilms: A common cause of persistent infections. Science 1999, 284, 1318-1322.

16. Fux, C.A.; Costerton, J.W.; Stewart, P.S.; Stoodley, P. Survival strategies of infectious biofilms. Trends Microbiol. 2005, 13, 34-40.

17. Stewart, P.S.; Costerton, J.W. Antibiotic resistance of bacteria in biofilms. Lancet 2001, 358, $135-138$.

18. Martinez, J.L.; Baquero, F. Interactions among strategies associated with bacterial infection: Pathogenicity, epidemicity, and antibiotic resistance. Clin. Microbiol. Rev. 2002, 15, 647-679.

19. Chambers, H.F.; DeLeo, F.R. Waves of resistance: Staphylococcus aureus in the antibiotic era. Nat. Rev. Microbiol. 2009, 7, 629-641.

20. Grundmann, H.; ires-de-Sousa, M.; Boyce, J.; Tiemersma, E. Emergence and resurgence of meticillin-resistant Staphylococcus aureus as a public-health threat. Lancet 2006, 368, 874-885.

21. Klevens, R.M.; Morrison, M.A.; Nadle, J.; Petit, S.; Gershman, K.; Ray, S.; Harrison, L.H.; Lynfield, R.; Dumyati, G.; Townes, J.M.; et al. Invasive methicillin-resistant Staphylococcus aureus infections in the United States. JAMA 2007, 298, 1763-1771.

22. Diekema, D.J.; Pfaller, M.A.; Schmitz, F.J.; Smayevsky, J.; Bell, J.; Jones, R.N.; Beach, M.; Group, S.P. Survey of infections due to Staphylococcus species: Frequency of occurrence and antimicrobial susceptibility of isolates collected in the United States, Canada, Latin America, Europe, and the Western Pacific region for the SENTRY Antimicrobial Surveillance Program, 1997-1999. Clin. Infect. Dis. 2001, 32, S114-S132.

23. Ma, Y.; Xu, Y.; Yestrepsky, B.D.; Sorenson, R.J.; Chen, M.; Larsen, S.D.; Sun, H. Novel inhibitors of Staphylococcus aureus virulence gene expression and biofilm formation. PLoS One 2012, 7, e47255.

24. Sun, H.; Xu, Y.; Sitkiewicz, I.; Ma, Y.; Wang, X.; Yestrepsky, B.D.; Huang, Y.; Lapadatescu, M.C.; Larsen, M.J.; Larsen, S.D.; et al. Inhibitor of streptokinase gene expression improves survival after group A streptococcus infection in mice. Proc. Natl. Acad. Sci. USA 2012, 109, 3469-3474.

25. Panmanee, W.; Taylor, D.; Shea, C.J.; Tang, H.; Nelson, S.; Seibel, W.; Papoian, R.; Kramer, R.; Hassett, D.J.; Lamkin, T.J. High-throughput screening for small-molecule inhibitors of Staphylococcus epidermidis RP62a biofilms. J. Biomol. Screening 2013, 18, 820-829. 
26. Sambanthamoorthy, K.; Gokhale, A.A.; Lao, W.; Parashar, V.; Neiditch, M.B.; Semmelhack, M.F.; Lee, I.; Waters, C.M. Identification of a novel benzimidazole that inhibits bacterial biofilm formation in a broad-spectrum manner. Antimicrob. Agents Chemother. 2011, 55, 4369-4378.

27. Jenal, U.; Dorman, C.J. Small molecule signaling. Curr. Opin. Microbiol. 2009, 12, 125-128.

28. Romling, U.; Balsalobre, C. Biofilm infections, their resilience to therapy and innovative treatment strategies. J. Inter.Med. 2012, 272, 541-561.

29. Opperman, T.J.; Kwasny, S.M.; Williams, J.D.; Khan, A.R.; Peet, N.P.; Moir, D.T.; Bowlin, T.L. Aryl rhodanines specifically inhibit staphylococcal and enterococcal biofilm formation. Antimicrob. Agents Chemother. 2009, 53, 4357-4367.

30. Davies, D.G.; Marques, C.N. A fatty acid messenger is responsible for inducing dispersion in microbial biofilms. J. Bacteriol. 2009, 191, 1393-1403.

31. Kolodkin-Gal, I.; Romero, D.; Cao, S.; Clardy, J.; Kolter, R.; Losick, R. D-amino acids trigger biofilm disassembly. Science 2010, 328, 627-629.

32. Perez-Giraldo, C.; Rodriguez-Benito, A.; Moran, F.J.; Hurtado, C.; Blanco, M.T.; Gomez-Garcia, A.C. Influence of $N$-acetylcysteine on the formation of biofilm by Staphylococcus epidermidis. J. Antimicrob. Chemother. 1997, 39, 643-646.

33. Abraham, N.M.; Lamlertthon, S.; Fowler, V.G.; Jefferson, K.K. Chelating agents exert distinct effects on biofilm formation in Staphylococcus aureus depending on strain background: Role for clumping factor B. J. Med. Microbiol. 2012, 61, 1062-1070.

34. Kiedrowski, M.R.; Horswill, A.R. New approaches for treating staphylococcal biofilm infections. Ann. N. Y. Acad. Sci. 2011, 1241, 104-121.

35. Kaplan, J.B.; Ragunath, C.; Velliyagounder, K.; Fine, D.H.; Ramasubbu, N. Enzymatic detachment of Staphylococcus epidermidis biofilms. Antimicrob. Agents Chemother. 2004, 48, 2633-2636.

36. Mann, E.E.; Rice, K.C.; Boles, B.R.; Endres, J.L.; Ranjit, D.; Chandramohan, L.; Tsang, L.H.; Smeltzer, M.S.; Horswill, A.R.; Bayles, K.W. Modulation of eDNA release and degradation affects Staphylococcus aureus biofilm maturation. PLoS One 2009, 4, e5822.

37. Izano, E.A.; Amarante, M.A.; Kher, W.B.; Kaplan, J.B. Differential roles of poly- $N$-acetylglucosamine surface polysaccharide and extracellular DNA in Staphylococcus aureus and Staphylococcus epidermidis biofilms. Appl. Environ. Microbiol. 2008, 74, 470-476.

38. Chaignon, P.; Sadovskaya, I.; Ragunah, C.; Ramasubbu, N.; Kaplan, J.B.; Jabbouri, S. Susceptibility of staphylococcal biofilms to enzymatic treatments depends on their chemical composition. Appl. Microbiol. Biotechnol. 2007, 75, 125-132.

39. Pavithra, D.; Doble, M. Biofilm formation, bacterial adhesion and host response on polymeric implants-Issues and prevention. Biomed. Mater. 2008, 3, 034003.

40. Antoci, V., Jr.; Adams, C.S.; Parvizi, J.; Davidson, H.M.; Composto, R.J.; Freeman, T.A.; Wickstrom, E.; Ducheyne, P.; Jungkind, D.; Shapiro, I.M.; et al. The inhibition of Staphylococcus epidermidis biofilm formation by vancomycin-modified titanium alloy and implications for the treatment of periprosthetic infection. Biomaterials 2008, 29, 4684-4690. 
41. Casey, A.L.; Mermel, L.A.; Nightingale, P.; Elliott, T.S. Antimicrobial central venous catheters in adults: A systematic review and meta-analysis. Lancet Infect. Dis. 2008, 8, 763-776.

42. McConnell, S.A.; Gubbins, P.O.; Anaissie, E.J. Do antimicrobial-impregnated central venous catheters prevent catheter-related bloodstream infection? Clin. Infect. Dis. 2003, 37, 65-72.

43. Hockenhull, J.C.; Dwan, K.M.; Smith, G.W.; Gamble, C.L.; Boland, A.; Walley, T.J.; Dickson, R.C. The clinical effectiveness of central venous catheters treated with anti-infective agents in preventing catheter-related bloodstream infections: A systematic review. Crit. Care Med. 2009, 37, 702-712.

44. Niel-Weise, B.S.; Stijnen, T.; van den Broek, P.J. Anti-infective-treated central venous catheters: A systematic review of randomized controlled trials. Intensive Care Med. 2007, 33, 2058-2068.

45. Hoffman, L.R.; D’Argenio, D.A.; MacCoss, M.J.; Zhang, Z.; Jones, R.A.; Miller, S.I. Aminoglycoside antibiotics induce bacterial biofilm formation. Nature 2005, 436, 1171-1175.

46. Jiang, H.; Manolache, S.; Wong, A.C.L.; Denes, F.S. Plasma-enhanced deposition of silver nanoparticles onto polymer and metal surfaces for the generation of antimicrobial characteristics. J. Appl. Polym. Sci. 2004, 93, 1411-1422.

47. Stobie, N.; Duffy, B.; McCormack, D.E.; Colreavy, J.; Hidalgo, M.; McHale, P.; Hinder, S.J. Prevention of Staphylococcus epidermidis biofilm formation using a low-temperature processed silver-doped phenyltriethoxysilane sol-gel coating. Biomaterials 2008, 29, 963-969.

48. Rai, M.; Yadav, A.; Gade, A. Silver nanoparticles as a new generation of antimicrobials. Biotechnol. Adv. 2009, 27, 76-83.

49. Jena, P.; Mohanty, S.; Mallick, R.; Jacob, B.; Sonawane, A. Toxicity and antibacterial assessment of chitosan-coated silver nanoparticles on human pathogens and macrophage cells. Int. J. Nanomed. 2012, 7, 1805-1818.

50. Feng, Q.L.; Wu, J.; Chen, G.Q.; Cui, F.Z.; Kim, T.N.; Kim, J.O. A mechanistic study of the antibacterial effect of silver ions on Escherichia coli and Staphylococcus aureus. J. Biomed. Mater. Res. 2000, 52, 662-668.

51. Roe, D.; Karandikar, B.; Bonn-Savage, N.; Gibbins, B.; Roullet, J.B. Antimicrobial surface functionalization of plastic catheters by silver nanoparticles. J. Antimicrob. Chemother. 2008, 61, 869-876.

52. Stevens, K.N.; Crespo-Biel, O.; van den Bosch, E.E.; Dias, A.A.; Knetsch, M.L.; Aldenhoff, Y.B.; van der Veen, F.H.; Maessen, J.G.; Stobberingh, E.E.; Koole, L.H. The relationship between the antimicrobial effect of catheter coatings containing silver nanoparticles and the coagulation of contacting blood. Biomaterials 2009, 30, 3682-3690.

53. Khan, M.S.; Husain, A. Syntheses and reactions of some new 2-arylidene-4-(biphenyl-4-yl)-but3-en-4-olides with a study of their biological activity. Pharmazie 2002, 57, 448-452.

54. Kozminykh, V.O.; Igidov, N.M.; Kozminykh, E.N.; Aliev, Z.G. Reactions of 5-aryl-furan-2,3-diones with acylmethylenetriphenylphosphoranes: Synthesis and biological activity of 3(2H)-furanone derivatives. Pharmazie 1993, 48, 99-106. 
55. Baveja, J.K.; Willcox, M.D.; Hume, E.B.; Kumar, N.; Odell, R.; Poole-Warren, L.A. Furanones as potential anti-bacterial coatings on biomaterials. Biomaterials 2004, 25, 5003-5012.

56. Hume, E.B.; Baveja, J.; Muir, B.; Schubert, T.L.; Kumar, N.; Kjelleberg, S.; Griesser, H.J.; Thissen, H.; Read, R.; Poole-Warren, L.A.; et al. The control of Staphylococcus epidermidis biofilm formation and in vivo infection rates by covalently bound furanones. Biomaterials 2004, 25, 5023-5030.

57. Gottenbos, B.; van der Mei, H.C.; Klatter, F.; Nieuwenhuis, P.; Busscher, H.J. In vitro and in vivo antimicrobial activity of covalently coupled quaternary ammonium silane coatings on silicone rubber. Biomaterials 2002, 23, 1417-1423.

58. Song, J.; Kong, H.; Jang, J. Bacterial adhesion inhibition of the quaternary ammonium functionalized silica nanoparticles. Colloids Surf., B 2011, 82, 651-656.

59. Klibanov, A.M. Permanently microbicidal materials coatings. J. Mater. Chem. 2007, 17, 2479-2482.

60. Boks, N.P.; Kaper, H.J.; Norde, W.; van der Mei, H.C.; Busscher, H.J. Mobile and immobile adhesion of staphylococcal strains to hydrophilic and hydrophobic surfaces. J. Colloid Interface Sci. 2009, 331, 60-64.

61. Tang, H.; Cao, T.; Liang, X.; Wang, A.; Salley, S.O.; McAllister, J., II; Ng, K.Y. Influence of silicone surface roughness and hydrophobicity on adhesion and colonization of Staphylococcus epidermidis. J. Biomed. Mater. Res., Part A 2009, 88, 454-463.

62. Truong, V.K.; Lapovok, R.; Estrin, Y.S.; Rundell, S.; Wang, J.Y.; Fluke, C.J.; Crawford, R.J.; Ivanova, E.P. The influence of nano-scale surface roughness on bacterial adhesion to ultrafine-grained titanium. Biomaterials 2010, 31, 3674-3683.

63. Xu, L.C.; Siedlecki, C.A. Submicron-textured biomaterial surface reduces staphylococcal bacterial adhesion and biofilm formation. Acta Biomater. 2012, 8, 72-81.

64. Ma, Y.; Chen, M.; Jones, J.E.; Ritts, A.C.; Yu, Q.; Sun, H. Inhibition of Staphylococcus epidermidis biofilm by trimethylsilane plasma coating. Antimicrob. Agents Chemother. 2012, 56, 5923-5937.

65. Harris, L.G.; Tosatti, S.; Wieland, M.; Textor, M.; Richards, R.G. Staphylococcus aureus adhesion to titanium oxide surfaces coated with non-functionalized and peptide-functionalized poly(L-lysine)-grafted-poly(ethylene glycol) copolymers. Biomaterials 2004, 25, 4135-4148.

66. Cheng, G.; Zhang, Z.; Chen, S.; Bryers, J.D.; Jiang, S. Inhibition of bacterial adhesion and biofilm formation on zwitterionic surfaces. Biomaterials 2007, 28, 4192-4199.

67. Chen, S.F.; Li, L.Y.; Zhao, C.; Zheng, J. Surface hydration: Principles and applications toward low-fouling/nonfouling biomaterials. Polymer 2010, 51, 5283-5293.

68. Privett, B.J.; Youn, J.; Hong, S.A.; Lee, J.; Han, J.; Shin, J.H.; Schoenfisch, M.H. Antibacterial fluorinated silica colloid superhydrophobic surfaces. Langmuir 2011, 27, 9597-9601.

69. Stallard, C.P.; McDonnell, K.A.; Onayemi, O.D.; O’Gara, J.P.; Dowling, D.P. Evaluation of protein adsorption on atmospheric plasma deposited coatings exhibiting superhydrophilic to superhydrophobic properties. Biointerphases 2012, 7, 31. 
70. Ivanova, E.P.; Mitik-Dineva, N.; Wang, J.; Pham, D.K.; Wright, J.P.; Nicolau, D.V.; Mocanasu, R.C.; Crawford, R.J. Staleya guttiformis attachment on poly(tert-butylmethacrylate) polymeric surfaces. Micron 2008, 39, 1197-2104.

71. Mitik-Dineva, N.; Wang, J.; Truong, V.K.; Stoddart, P.; Malherbe, F.; Crawford, R.J.; Ivanova, E.P. Escherichia coli, Pseudomonas aeruginosa, and Staphylococcus aureus attachment patterns on glass surfaces with nanoscale roughness. Curr. Microbiol. 2009, 58, 268-273.

72. Mei, L.; Busscher, H.J.; van der Mei, H.C.; Ren, Y. Influence of surface roughness on streptococcal adhesion forces to composite resins. Dent. Mater. 2011, 27, 770-778.

73. Wu, Y.; Zitelli, J.P.; TenHuisen, K.S.; Yu, X.; Libera, M.R. Differential response of Staphylococci and osteoblasts to varying titanium surface roughness. Biomaterials 2011, 32, 951-960.

74. Mathews, S.M.; Spallholz, J.E.; Grimson, M.J.; Dubielzig, R.R.; Gray, T.; Reid, T.W. Prevention of bacterial colonization of contact lenses with covalently attached selenium and effects on the rabbit cornea. Cornea 2006, 25, 806-814.

75. Tran, P.L.; Lowry, N.; Campbell, T.; Reid, T.W.; Webster, D.R.; Tobin, E.; Aslani, A.; Mosley, T.; Dertien, J.; Colmer-Hamood, J.A.; et al. An organoselenium compound inhibits Staphylococcus aureus biofilms on hemodialysis catheters in vivo. Antimicrob. Agents Chemother. 2012, 56, 972-978.

76. Busscher, H.J.; Rinastiti, M.; Siswomihardjo, W.; van der Mei, H.C. Biofilm formation on dental restorative and implant materials. J. Dent. Res. 2010, 89, 657-665.

77. Roosjen, A.; Norde, W.; van der Mei, H.C.; Busscher, H.J. The use of positively charged or low surface free energy coatings versus polymer brushes in controlling biofilm formation. Prog. Colloid Polym. Sci. 2006, 132, 138-144.

78. Bridgett, M.J.; Davies, M.C.; Denyer, S.P. Control of staphylococcal adhesion to polystyrene surfaces by polymer surface modification with surfactants. Biomaterials 1992, 13, 411-416.

79. Huang, N.P.; Michel, R.; Voros, J.; Textor, M.; Hofer, M.; Rossi, A.; Elbert, D.L.; Hubbell, J.A.; Spencer, N.D. Poly(L-lysine)-g-poly(ethylene glycol) layers on metal oxide surfaces: Surface-analytical characterization and resistance to serum and fibrinogen adsorption. Langmuir 2001, 17, 489-498.

80. Zhu, B.; Eurell, T.; Gunawan, R.; Leckband, D. Chain-length dependence of the protein and cell resistance of oligo(ethylene glycol)-terminated self-assembled monolayers on gold. J. Biom. Mater. Res. 2001, 56, 406-416.

81. Currie, E.P.; Norde, W.; Cohen Stuart, M.A. Tethered polymer chains: surface chemistry and their impact on colloidal and surface properties. Adv. Colloid Interface Sci. 2003, 100-102, 205-265.

82. Roosjen, A.; van der Mei, H.C.; Busscher, H.J.; Norde, W. Microbial adhesion to poly(ethylene oxide) brushes: Influence of polymer chain lenghth and temperature. Langmuir 2004, 20, 10949-10955. 
83. Roosjen, A.; Kaper, H.J.; van der Mei, H.C.; Norde, W.; Busscher, H.J. Inhibition of adhesion of yeasts and bacteria by poly(ethylene oxide)-brushes on glass in a parallel plate flow chamber. Microbiology 2003, 149, 3239-3246.

84. Olsson, J.; van der Heijde, Y.; Holmberg, K. Plaque formation in vivo and bacterial attachment in vitro on permanently hydrophobic and hydrophilic surfaces. Caries Res. 1992, 26, 428-433.

85. Park, K.D.; Kim, S.W. PEO-Modified Surfaces-In Vitro, Ex Vivo, and In Vivo Blood Compatibility. In Poly(ethyleneglycol) Chemistry: Biotechnical and Biomedical Applications, Harris, J.M., Ed.; Plenum Press: New York, NY, USA, 1992; pp. 283-301. 


\title{
Environmental Stimuli Shape Biofilm Formation and the Virulence of Periodontal Pathogens
}

\section{Marja T. Pöllänen, Annamari Paino and Riikka Ihalin}

\begin{abstract}
Periodontitis is a common inflammatory disease affecting the tooth-supporting structures. It is initiated by bacteria growing as a biofilm at the gingival margin, and communication of the biofilms differs in health and disease. The bacterial composition of periodontitis-associated biofilms has been well documented and is under continual investigation. However, the roles of several host response and inflammation driven environmental stimuli on biofilm formation is not well understood. This review article addresses the effects of environmental factors such as $\mathrm{pH}$, temperature, cytokines, hormones, and oxidative stress on periodontal biofilm formation and bacterial virulence.
\end{abstract}

Reprinted from Int. J. Mol. Sci. Cite as: Pöllänen, M.T.; Paino, A.; Ihalin, R. Environmental Stimuli Shape Biofilm Formation and the Virulence of Periodontal Pathogens. Int. J. Mol. Sci. 2013, 14, 17221-17237.

\section{Introduction}

Periodontitis is a common disease affecting the tooth-supporting structures of millions of people worldwide, and it is a multifactorial disease initiated by bacteria growing as a biofilm at the gingival margin. Periodontal biofilms are diverse, and the nature and communication of these biofilms differs in health and disease. The bacterial composition of periodontitis-associated biofilms has been well documented and is under constant analysis. Several key pathogens have been identified: Porphyromonas gingivalis, Treponema denticola, Tannerella forsythia, Aggregatibacter actinomycetemcomitans and more recently also Filifactor alocis, Staphylococcus aureus and the genus Desulfobulbus [1-4]. In addition to bacteria, viruses are commonly detected from periodontal lesions and subgingival plaque samples of patients with aggressive periodontitis [5,6]. Furthermore, the association of the biofilm-forming yeast Candida albicans has been detected in approximately $50 \%$ of severe chronic periodontitis patients and in only $15 \%$ of subgingival samples isolated from healthy patients [7]. Periodontal biofilm formation is a stepwise and continuous process. In the initial phase, the gram-positive and aerobic bacteria dominate. Later, the gram-negative anaerobic periodontopathogens increase in the biofilm. Clinically, the course of periodontitis leads to increased subgingival inflammation and formation of periodontal pockets. The subgingival environment is ideal for the periodontopathogens, being alkaline, hemin and protein rich with various cytokines and hormones. The bacterial cells in biofilm are surrounded by extracellular polymeric substance (EPS), which is composed of polysaccharides, proteins and extracellular DNA, and may account for as much as $90 \%$ of the total mass of the biofilm [8-10]. The EPS protects pathogens from host defence cells, such as macrophages, and humoural immune defence factors, such as antibodies and complement, as well as antibiotics. In addition, the high bacterial cell densities in biofilm enable small molecule mediated inter- and 
intra-species crosstalk, i.e., quorum sensing, which itself may regulate virulence gene expression via pathogens. Moreover, both the host response and the environmental factors in periodontitis can affect the biofilm formation and virulence gene expression of periodontal pathogens (Figure 1). We discuss this crosstalk network of molecular interactions in this review article.

Figure 1. Interactions between periodontal pathogens and host in the subgingival environment.

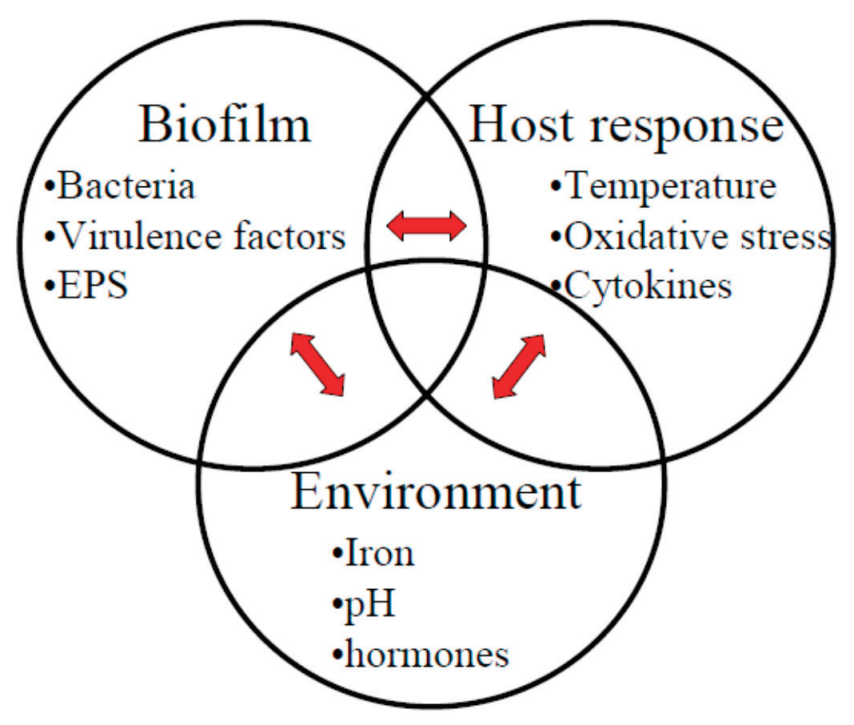

\section{Host Inflammatory Reaction-Related Stimuli}

The oral environment is an ideal, nutrient-rich, warm and growth-promoting place for bacteria to form communities. This first part of the digestive tract offers the bacteria perfect non-shedding surfaces of the teeth to attach and multiply. The bacterial biofilm on the tooth surface activates both the innate and adaptive host responses, which, in turn, have an effect on the biofilm. The first-line host defence is initiated by the polymorphonuclear (PMN) leukocytes that are recruited to the site by chemotactic factors, e.g., the gradient of IL-8 and ICAM-1 in the junctional epithelium [11]. In the subgingival area, the temperature increases, and the inflammatory reaction causes the release of reactive oxygen species (ROS), such as hydrogen peroxide $\left(\mathrm{H}_{2} \mathrm{O}_{2}\right)$ and superoxide $\left(\mathrm{O}_{2}{ }^{-}\right)$, and cytokines from the host cells to destroy the bacteria. However, the bacterial biofilm is a community, and not only the bacteria but also their virulence and the EPS surrounding them may be affected and changed by the changes produced during the inflammation process.

\subsection{Temperature}

Changes in the environmental temperature have an effect on various functions and virulence of diverse microbial species. Bacteria can sense changes in temperature by proteins, e.g., transcriptional regulators, kinases (e.g., histidine kinase in association with a cytoplasmic response regulator) and 
chaperones, and via their membrane lipids (for a review see [12]). In the periodontal pocket, an approximately $2{ }^{\circ} \mathrm{C}$ increase in the local subgingival temperature has been reported in diseased sites compared with healthy sites [13]. The temperature increase is a host defence mechanism that triggers virulence and heat shock gene expression in bacteria in response [12]. However, the temperature increase also affects the attachment of bacteria, coaggregation of bacteria, and protease production [14-17]. P. gingivalis has displayed decreased expression of proteases and down-regulation of the genes coding fimbrial proteins in response to temperature elevation $[15,16]$. Furthermore, the structure of lipid-A in $P$. gingivalis also appears to be affected by temperature. In elevated temperature environments, increasing amounts of monophosphorylated penta-acylated lipid A are expressed [18]. This lipid A form in turn appears to be a more potent activator of the host Toll-like receptor 4 (TLR4) and further renders the bacteria more susceptible to host defensins [18]. However, the net effect of the temperature increase seems to favour the periodontal pathogens in subgingival biofilms because increased proportions of Prevotella intermedia, $P$. gingivalis and A. actinomycetemcomitans have been reported in sites with elevated temperatures [19].

\subsection{Oxidative Stress}

ROS generation, as a part of the host defence mechanism or from the initial Streptococcal colonisers in the biofilm, induces oxidative stress in other biofilm bacteria and especially in the anaerobic species of the community. The anaerobic bacteria sense the levels of ROS by transcriptional regulators such as OxyR, PerR and OhrR. Superoxide dismutases, alkyl hydroperoxide reductase $(\mathrm{AhpC})$ and catalases are produced by the bacteria for the detoxification of the ROS [20,21]. In the periodontal biofilm community, $F$. nucleatum is important as an intermediate coloniser between the early Streptococcal and late anaerobic periodontopathogenic colonisers. F. nucleatum appears to facilitate the survival of other anaerobic bacteria in the biofilm [22]. Although an obligate anaerobe, $F$. nucleatum can adapt to oxidative stress in the biofilm and even increase in number in aerobic conditions for up to 2 days $[23,24]$. The response of $F$. nucleatum to oxidative stress appears to be mediated by the AhpC redox system [25]. Furthermore, the oxidative stress appears to also alter the carbohydrate metabolism of $F$. nucleatum by modifying or increasing the intracellular concentrations of glycolytic enzymes, thereby decreasing ATP production. Increases in the chaperone proteins ClpB and DnaK, the heat shock protein HtpG and the transcription repressor HrcA in F. nucleatum in oxidative stress conditions appear to be aimed at diminishing the harmful effects of ROS [25]. In addition, the periodontopathogens have developed strategies to adapt to oxidative stress. For example, $P$. gingivalis produces superoxide dismutase, AhpC, rubrerythrin (rbr), heat shock proteins ( $\mathrm{HtpG}$ ) and chaperons GroEL and DnaK when challenged with oxidative stress [26]. Similarly, elevated inflammatory temperatures upregulate the expression of superoxide dismutase in $P$. gingivalis [27]. Furthermore, the expression of several genes with unknown functions has been observed to be altered in $P$. gingivalis under oxidative stress [28]. 


\subsection{Inflammatory Cytokines}

In periodontitis, during the active phases of the tissue destruction, the periodontal tissue and gingival fluid typically contain high levels of proinflammatory mediators such as interleukin (IL)- $1 \beta[3,29,30]$. This overexpression of IL- $1 \beta$ results in host tissue damage, which is characteristic for periodontal disease and aimed at eliminating pathogens together with the regulation of the immune response [31-33]. In periodontium, cytokines are released by first-line human defence cells after identification of periodontopathogens and bacterial products. For instance, gingival epithelial cells and fibroblasts can secrete IL-1 $\beta$ after $P$. gingivalis and $A$. actinomycetemcomitans infection or after being cultured in the presence of Treponema denticola lipooligosaccharides [34,35]. Oral bacteria-derived compounds, such as leucotoxins and lipopolysaccharides of $A$. actinomycetemcomitans, induce IL-1 $\beta$ secretion in macrophages $[36,37]$. Macrophages and monocytes are considered the main producers of IL- $1 \beta$ during inflammation [38-40]. As a key conductor of the inflammatory response, IL-1 $\beta$ induces the release of other proinflammatory mediators $[34,41]$. Thus, the release of IL-6 and IL-8 from gingival epithelial cells during periodontal infection can be hindered by blocking induction of IL-1 $\beta$ induction [34]. Tumour necrosis factor-alpha (TNF- $\alpha$ ), IL- 6 and IL- 8 are cytokines commonly released by epithelial cells after bacterial infection [42-45]. Recent studies suggest that the gingival cell response differs when infected with oral biofilm [46] or with multispecies biofilms ([47]; reviewed in [48]) as compared with planktonic bacterial infection.

Human IL-1 $\beta$, crucial for the host battle against pathogens, might also be sensed by host-colonising microbes. The first evidence of bacterial response against cytokines was observed in studies with virulent Escherichia coli strains over 20 years ago. It was shown that $E$. coli cells can bind IL-1 $\beta$ and that the growth of these strains increased after IL- $1 \beta$ exposure, whereas treatment with IL- 4 or TNF- $\alpha$ was ineffective. Moreover, the use of decoy receptor IL-Ra for IL-1 $\beta$ reversed the growth-promoting effect in E. coli. [49] Later, it was demonstrated that other bacterial species such as Staphylococcus aureus, Pseudomonas aeruginosa and Acinetobacter spp. can alter their growth properties as a consequence of exposure to IL-1 $\beta$, IL-6 or TNF- $\alpha$ [50].

Gram-positive $S$. aureus has been a central model species for studies of the role of IL-1 $\beta$ in pathogen-cytokine crosstalk. Surprisingly, $S$. aureus, which is most often associated with nasal passages and skin, was also identified from subgingival plaques in $60 \%$ of aggressive periodontitis patients belonging to a group of non-smokers [4]. According to an in vitro experiment, the growth of S. aureus biofilms increases when cultured in the presence of IL-1 $\beta[51,52]$. The growth enhancement was also observed with two linear peptide fragments $(<5 \mathrm{kDa})$ of human IL-1 $\beta$ [53]. In addition to growth enhancement, the cytokine modulated the gene expression of $S$. aureus biofilms. The cytokine decreased the gene expression of some toxin-encoding genes and increased the expression of host tissue-attachment responsible genes [54].

The hypothesis concerning the capability of the bacteria to specifically bind IL- $1 \beta$ was strengthened by the characterisation of a specific bacterial outer membrane receptor for IL- $1 \beta$ in gram-negative Yersinia pestis. The IL-1 $\beta$-interacting protein is known as a capsule antigen F1 assembly protein 
(Caf1A), which contributes to capsule antigen (Caf1) transportation across the outer membrane [55]. Interestingly, Cafl displays 28\% sequence homology with human IL-Ra [56]. The second bacterial cytokine receptor, the outer membrane protein OprF, which binds only human interferon- $\gamma$, was initially observed in gram-negative $P$. aeruginosa. As a response to cytokine binding, $P$. aeruginosa increased lectin-encoding gene (lecA) expression in a quorum sensing dependent manner [57]. The hydrophobic galactose-binding lectin localised in the EPS of $P$. aeruginosa biofilms contributes to species biofilm formation and endothelial cell adherence [58].

Cytokines, such as IL-1 $\alpha$, IL-1 $\beta$, IL-2, IL-3, IL-4, IL6, IL-7 [59] and TNF [60], use their carbohydrate-binding domains to recognise specific oligosaccharide ligands (reviewed in [61]). The receptor-binding site of IL-1 associates with its cognate receptor, and the second domain, localised opposite to the receptor binding sites, interacts with carbohydrate. For instance, IL-1 $\alpha$ and IL- $\beta$ have different carbohydrate binding activities. Whereas IL-1 $\alpha$ binds $\mathrm{N}$-glycan with two $\alpha$-2-3-linked sialic acid residues, IL-1 $\beta$ recognises the $\alpha 2-3$-sialylated $\beta$-galactosyl-ceramides, which have very long and unusual long-chain bases [62]. Moreover, some lipooligosaccharides of Haemophilus species are sialylated, and they encode sialyltransferases [63,64].

A. actinomycetemcomitans is the only major periodontopathogen to our knowledge that has been shown to both sense and bind IL-1 $\beta$. The clinical strains of the species display a physiological response to cytokines by decreasing their metabolism and by increasing their biofilm mass [65]. A. actinomycetemcomitans biofilms co-cultured with an organotypic gingival mucosa model bind IL-1 $\beta$, but the use of antibiotics during co-culturing inhibits IL-1 $\beta$ binding [66]. Moreover, the species appears to uptake IL-1 $\beta$ as the cytokine has been detected in the intracellular space of the bacterium [66]. Two intracellular proteins, the trimeric form of ATP synthase subunit $\beta$ and bacterial histone-like protein HU, have displayed interaction with human IL- $\beta[65,66]$. The interaction of internalised IL-1 $\beta$ with a key protein in cellular energy production and genomic DNA condensing HU protein might explain the above-described physiological responses of $A$. actinomycetemcomitans. These results suggest that viable $A$. actinomycetemcomitans cells possess a specific uptake mechanism for IL-1 $\beta$. According to our recent results, A. actinomycetemcomitans encodes a Pasteurellaceae-specific outer membrane lipoprotein responsible for IL-1 $\beta$ interaction [67]. In addition to bacterial species, herpesviruses and yeasts found in subgingival biofilms can sense and bind the cytokines produced by the host $[68,69]$.

\section{Periodontitis-Associated Environmental Factors}

Various environmental factors, other than those strictly related to the inflammatory response of the host, may change during the progression of periodontitis. Such factors include, for example, $\mathrm{pH}$, the concentration of iron and hemin, and the presence of various host hormones. All these factors can be sensed by at least some of the periodontal pathogens, although studies at the molecular level are scarce. However, the results obtained thus far suggest that elevated $\mathrm{pH}$ and iron limitation may enhance the biofilm formation of some species and influence virulence gene expression, which, in turn, might alter the host inflammatory response. 


\subsection{Alkaline $\mathrm{pH}$}

The environment of the periodontitis-associated gingival pocket, and especially the gingival crevicular fluid, is characterised by alkaline $\mathrm{pH}$, which may rise above 8.5 [70-72]. Some periodontal pathogens, such as $P$. gingivalis, $P$. intermedia and $F$. nucleatum, are able to elevate the ambient $\mathrm{pH}$ by fermenting amino acids in vitro [73], a feature which may also alkalify the microenvironment in subgingival biofilm locally.

An alkaline $\mathrm{pH}$ of 8.2 has been shown to increase cell surface hydrophobicity as well as induce the co-adhesion and biofilm formation of $F$. nucleatum, which is accompanied by decreased intracellular polyglucose content and elongation of individual cells [74]. When grown at a slightly lower $\mathrm{pH}$ than 8.2 , i.e., at $\mathrm{pH} 7.8, F$. nucleatum cells display upregulated expression of the enzyme formiminotetrahydrofolate cyclodeaminase, which could be involved in raising the surrounding $\mathrm{pH}$ value [75]. In addition, the production of a non-iron redox acceptor flavodoxin, the expression of which is typically upregulated in iron-limited growth conditions [76], was also observed to be upregulated in alkaline $\mathrm{pH}$ conditions [75]. F. nucleatum cells appear to change their metabolism in response to high $\mathrm{pH}$, because some enzymes of the glycolytic pathway, as well as glutamic acid and histidine catabolism, are downregulated in planktonic cells grown at an alkaline $\mathrm{pH}$ of 7.8 [75]. However, when the $\mathrm{pH}$ is further raised to 8.2 , which induces biofilm formation, the amounts of glycolytic enzymes do not increase, whereas glucose storage and lactate production increases [77]. In contrast to increased glucose storage, the production of various proteins involved in protein synthesis decrease at high $\mathrm{pH}$ values in F. nucleatum biofilm [77]. At $\mathrm{pH} \mathrm{8.2,} \mathrm{another} \mathrm{change} \mathrm{in} \mathrm{the} \mathrm{expression} \mathrm{of} \mathrm{metabolic}$ enzymes is the increased production of glutamate dehydrogenase, which might indicate that the bacterium adjusts its metabolism to the increased concentration of glutamate in the gingival crevicular fluid associated with inflamed periodontal tissue [77]. The cellular stress response in bacteria might also be activated at an alkaline $\mathrm{pH}$ because $F$. nucleatum cells upregulate the expression of peptidylprolyl cis-trans isomerase (PPI) and the heat-shock protein GroEL [75,77]. Of these proteins, GroEL might have a role in the host-bacterium crosstalk because GroEL-like proteins may modulate the host immune response, as shown with F. nucleatum [78] and A. actinomycetemcomitans [79]. Moreover, GroEL might be a link between periodontitis and systemic diseases, such as atherosclerosis, as $F$. nucleatum GroEL induces various risk factors of atherosclerosis in mice [80].

Whereas some of the $\mathrm{pH}$-regulated intracellular proteins may alter the virulence of the bacterium, one interesting group of $\mathrm{pH}$-regulated proteins are expressed in the cellular envelope of the bacterial cell. In particular, the proteins that are involved in adhesion to other periodontal pathogens as well as to host cells may play important roles in virulence. When $F$. nucleatum was grown at an alkaline $\mathrm{pH}$ of 8.2, elevated levels of FomA adhesion isoforms were detected [77]. FomA may function as recruiter of other periodontal pathogens, such as $P$. gingivalis, [81], and has been proven to be a possible vaccine target in a mouse study [82]. Some of the downregulated cellular envelope proteins of $F$. nucleatum are involved in ATP synthesis and maintenance of a neutral cyto- or periplasmic $\mathrm{pH}$, indicating 
decreased metabolic activity and adjustment to alkaline conditions, respectively [83]. Some of the downregulated proteins likely have dual roles, as in the case of butyrate-acetoacetate CoA transferase, which is involved both in energy metabolism and, as a virulence factor, butyric acid production [83]. The group of cellular envelope proteins that were upregulated at an alkaline $\mathrm{pH}$ contained at least two putative surface antigens: outer membrane protein (OMP), belonging to the Omp IP family of porins, and a pathogen-specific membrane antigen that was predicted to have high affinity to $\mathrm{Fe}^{2+}$ [83]. In addition to the Omp IP family porins, the expression levels of various transporter proteins was altered when F. nucleatum cells were grown in biofilm at a $\mathrm{pH}$ of 8.2, which could be an indication of a changed need to uptake various solutes from the microenvironment in the biofilm [77]. Most of the studies that have investigated the effects of alkaline environment on periodontal pathogens have been performed in F. nucleatum. However, up to $50 \%$ of the alkaline pH-regulated genes coding F. nucleatum cell envelope proteins could have been acquired through horizontal gene transfer, and similar proteins are also found in other periodontal pathogens, such as $P$. gingivalis and Treponema denticola [83].

\subsection{Iron and Hemin}

Because free iron catalyses the formation of toxic free radicals from $\mathrm{H}_{2} \mathrm{O}_{2}$ and is essential for the function of both the host and the pathogenic bacteria, human organs have developed complex ways to limit the availability of free iron in the environment [84]. Thus, the environment that surrounds potential colonisers when they enter a human host is suboptimal in terms of free iron concentration. Most of the host iron is bound to iron-binding proteins such as transferrin, ferritin, lactoferrin and haemoglobin that contain hemin or haem. However, the situation may change during the progression of periodontitis. It has been hypothesised that the concentration of hemin may increase due to the increasing concentration of haemoglobin leaking from vascular ulcers of the gingival pocket. Some periodontal pathogens, such as $P$. gingivalis, $T$. denticola and A. actinomycetemcomitans, have been demonstrated to express hemin-binding proteins on their surfaces [85-87] that may facilitate iron acquisition in free iron-limited conditions. Moreover, hemin may also directly regulate the virulence characteristics of $P$. gingivalis [88].

Iron chelation has been shown to increase the expression of the EPS-, fimbrial-, and LPS-related genes, $\mathrm{pgaC}$, $\operatorname{tad} \mathrm{V}$, and $\mathrm{rmlB}$, respectively, in A. actinomycetemcomitans, which also leads to increased biofilm formation [89]. The effect of limited concentrations of iron most likely is mediated by small regulatory RNAs (sRNA) in A. actinomycetemcomitans, though the target genes for these sRNAs, have not been yet identified [90]. The most studied periodontal pathogen, regarding the need and effects of iron on the bacterium, is likely $P$. gingivalis. In agreement with being an essential growth factor and important cause of oxidative stress (for review see [9]), iron limitation upregulates the genes involved in iron uptake and downregulates the genes associated with the storage of iron as well as the oxidative stress response of $P$. gingivalis [9]. Moreover, by limiting iron and hemin availability, the host can also increase biofilm formation, the invasion of single bacterial cells to the host cells [9], and increase vesicle secretion and protease production of $P$. gingivalis [91]. Another potential virulence 
factor of $P$. gingivalis that is regulated by hemin is LPS, and more specifically, the lipid A form of it [88]. A form of lipid A, which is a Toll-like receptor (TLR) 4 antagonist, is produced at high hemin concentrations, whereas at low hemin concentrations TLR4-agonist lipid A is the major form, suggesting that $P$. gingivalis can alter the host response with the changing hemin microenvironment [88].

\subsection{Hormones}

Although various bacterial species are known to respond to the stress-related hormones adrenaline and noradrenaline, and the molecular players of their sensory machinery have been clarified in detailed (reviewed in [92]), the periodontal pathogens have been little studied. In the first study that investigated the effects of catecholamines, noradrenaline and adrenaline, on periodontal bacteria, both negative and positive growth effects on planktonic species were reported [93]. However, both catecholamines inhibited the growth of "red complex" [94] periodontal pathogens P. gingivalis and T. forsythia (formerly Bacteroides forsythus) as well as A. actinomycetemcomitans serotypes a and b and F. nucleatum [93]. Thus, the authors stressed the importance of negative growth effects and hypothesised that these species might also use catecholamines to enhance virulence gene expression [93]. A recent study by Saito et al. [95] demonstrated that growth inhibition of $P$. gingivalis by noradrenaline is accompanied with enhanced production of the virulence-associated protease arg-gingipain B and downregulation of the genes coding polysaccharide biosynthesis-related proteins.

The most significant rise in the levels of the female sex hormones, oestrogen and progesterone, occurs during pregnancy [96]. Although pregnancy gingivitis is currently categorised under the class of "dental plaque-induced gingival diseases modified by the endocrine system" [97], the effects of hormone levels on the progression of gingivitis during pregnancy is still under debate [98-100]. It appears that even though gingival inflammation may intensify during pregnancy, the hormones themselves may cause controversial changes in the periodontium, including decreased inflammatory reactions [101-104] and changes in the composition of subgingival biofilm [105-107]. Moreover, some gram-negative periodontal pathogens, such as Prevotella melaninogenica, P. intermedia and $P$. gingivalis are able to take up estradiol and progesterone, which the Prevotella species may use as a growth factor instead of vitamin K [108]. However, whether these hormones affect the biofilm formation and the virulence of periodontal pathogens is not known.

\section{Conclusions}

In periodontitis, the crosstalk between the host and the bacterial biofilm is diverse and bidirectional. The host response and environmental changes induce stress in the biofilm bacteria (Table 1). Elevated temperature of the subgingival environment, though aimed to eliminate the pathogens appears to only decrease virulence factors in pathogens (e.g., proteases in P. gingivalis) and does not sufficiently eliminate the pathogens [19]. The change in the local $\mathrm{pH}$ towards an alkaline environment appears to play an important role in the shift towards periodontopathogenic biofilm composition. 
The biofilm mass is increased in alkaline conditions and, in particular, the intermediate coloniser F. nucleatum displays increased adhesion and coaggregation with other bacteria. Oxidative stress and the inflammatory cytokine IL- $1 \beta$ result in decreased metabolism in periodontal biofilm but still increase various virulence factors as well as biofilm formation. The limited amount of free iron appears to enhance biofilm EPS formation [89]. During periodontal inflammation, the increased amount of hemin might downregulate the expression of bacterial virulence factors and upregulate the expression of immune-suppressing molecules. In summary, the environmental changes generated in inflammation favour biofilm formation and appear to drive the bacteria into the shelter provided by the EPS and the lower metabolic activity. The inflammatory environment with active immune cells and a hostile humoural response is not ideal for planktonic bacteria, which are released by mature biofilm when expanding to new habitats. Biofilm formation might explain the onset of less progressive phases in periodontal inflammation and tissue destruction and allow the periodontal pathogens to persist in subgingival spaces.

Table 1. Environmental stimuli affecting periodontal biofilm and bacterial virulence factors.

\begin{tabular}{llcc}
\hline Stimuli & Effect & Species & References \\
\hline \multirow{2}{*}{$\begin{array}{l}\text { Elevated } \\
\text { temperature }\end{array}$} & Proteases $\downarrow$ & Porphyromonas gingivalis & {$[16]$} \\
& Fimbrial proteins $\downarrow$ & & {$[15]$} \\
& TLR4 activating lipid-A $\uparrow$ & & {$[18]$} \\
\hline \multirow{4}{*}{ Oxidative } & ATP production $\downarrow$ & Fusobacterium nucleatum & {$[25]$} \\
stress & Chaperones ClpB, DnaK $\uparrow$ & & {$[25]$} \\
& Heat shock protein HtpG $\uparrow$ & & {$[25]$} \\
\hline \multirow{2}{*}{ Oxidative } & Transcription repressor HrcA $\uparrow$ & Porphyromonas gingivalis & {$[26]$} \\
stress & Chaperones ClpB, DnaK $\uparrow$ & & {$[26]$} \\
& Heat shock protein HtpG $\uparrow$ & Aggregatibacter & {$[6]$} \\
\hline Inflammatory & Superoxide dismutase $\uparrow$ & actinomycetemcomitans & {$[65]$} \\
cytokine IL-1 $\beta$ & Miofilm formation $\uparrow$ & & {$[74]$} \\
& Cotabolism $\downarrow$ & & {$[74]$} \\
& Biofilm formation $\uparrow$ & & {$[75]$} \\
& Flavodoxin $\uparrow$ & & {$[77]$} \\
& Glucose storage $\uparrow$ & & {$[77]$} \\
& Lactate production $\uparrow$ & & {$[77]$} \\
& Protein synthesis enzymes $\downarrow$ & & {$[77]$} \\
Alkaline pH & Glutamate dehydrogenase $\uparrow$ & {$[75,77]$} \\
& PPI and GroEL $\uparrow$ & {$[77]$} \\
& FomA adhesion isoforms $\uparrow$ & {$[83]$} \\
& ATP synthesis proteins $\downarrow$ & & {$[83]$} \\
& Butyrate-acetoacetate CoA transferase $\downarrow$ & & {$[83]$} \\
\hline & Surface antigens Omp IP $\uparrow$ & &
\end{tabular}


Table 1. Cont.

\begin{tabular}{lllc}
\hline Stimuli & Effect & Species & References \\
\hline \multirow{4}{*}{ Iron-limitation } & EPS $(\mathrm{pgaC}) \uparrow$ & & {$[89]$} \\
& Fimbrial $(\mathrm{tad} V) \uparrow$ & Aggregatibacter & {$[89]$} \\
& LPS $(\mathrm{rmlB}) \uparrow$ & actinomycetemcomitans & {$[89]$} \\
& Biofilm formation $\uparrow$ & & {$[89]$} \\
\hline & Iron uptake $\uparrow$ & & {$[9]$} \\
& Iron storage $\downarrow$ & Porphyromonas gingivalis & {$[9]$} \\
Iron limitation & Oxidative stress response $\downarrow$ & & {$[9]$} \\
& Biofilm formation $\uparrow$ & & {$[9]$} \\
& Host cell invasion $\uparrow$ & Porphyromonas gingivalis & {$[9]$} \\
\hline \multirow{2}{*}{ High hemin } & Proteases $\downarrow$ & & {$[91]$} \\
concentration & Vesicles $\downarrow$ & \multirow{2}{*}{ Porphyromonas gingivalis } & {$[93]$} \\
& TLR4 inactivating lipid A $\uparrow$ & & {$[95]$} \\
\hline \multirow{2}{*}{ Noradrenaline } & Growth $\downarrow$ & Arg-gingipain B $\uparrow$ & \\
\hline
\end{tabular}

\section{Acknowledgments}

Biofilm research in the Ihalin laboratory has been funded by the Academy of Finland, the Paulo Foundation, the Ella and Georg Ehrnrooth Foundation, the Turku University Foundation and the Finnish Dental Society Apollonia.

\section{Conflicts of Interest}

The authors declare no conflict of interest.

\section{References}

1. Bartold, P.M.; van Dyke, T.E. Periodontitis: A host-mediated disruption of microbial homeostasis. Unlearning learned concepts. Periodontol. 2000 2013, 62, 203-217.

2. Griffen, A.L.; Beall, C.J.; Campbell, J.H.; Firestone, N.D.; Kumar, P.S.; Yang, Z.K.; Podar, M.; Leys, E.J. Distinct and complex bacterial profiles in human periodontitis and health revealed by 16S pyrosequencing. ISME J. 2012, 6, 1176-1185.

3. Rescala, B.; Rosalem, W., Jr.; Teles, R.P.; Fischer, R.G.; Haffajee, A.D.; Socransky, S.S.; Gustafsson, A.; Figueredo, C.M. Immunologic and microbiologic profiles of chronic and aggressive periodontitis subjects. J. Periodontol. 2010, 81, 1308-1316.

4. Fritschi, B.Z.; Albert-Kiszely, A.; Persson, G.R. Staphylococcus aureus and other bacteria in untreated periodontitis. J. Dent. Res. 2008, 87, 589-593.

5. Saygun, I.; Kubar, A.; Sahin, S.; Sener, K.; Slots, J. Quantitative analysis of association between herpesviruses and bacterial pathogens in periodontitis. J. Periodontal. Res. 2008, 43, 352-359. 
6. Imbronito, A.V.; Okuda, O.S.; Maria de Freitas, N.; Moreira Lotufo, R.F.; Nunes, F.D. Detection of herpesviruses and periodontal pathogens in subgingival plaque of patients with chronic periodontitis, generalized aggressive periodontitis, or gingivitis. J. Periodontol. 2008, 79, 2313-2321.

7. Canabarro, A.; Valle, C.; Farias, M.R.; Santos, F.B.; Lazera, M.; Wanke, B. Association of subgingival colonization of Candida albicans and other yeasts with severity of chronic periodontitis. J. Periodontal. Res. 2013, 48, 428-432.

8. Flemming, H.C.; Wingender, J. The biofilm matrix. Nat. Rev. Microbiol. 2010, 8, 623-633.

9. Lewis, J.P. Metal Uptake in host-pathogen interactions: Role of iron in Porphyromonas gingivalis interactions with host organisms. Periodontol. 2000 2010, 52, 94-116.

10. McDougald, D.; Rice, S.A.; Barraud, N.; Steinberg, P.D.; Kjelleberg, S. Should we stay or should we go: Mechanisms and ecological consequences for biofilm dispersal. Nat. Rev. Microbiol. 2012, 10, 39-50.

11. Tonetti, M.S.; Imboden, M.A.; Lang, N.P. Neutrophil Migration into the gingival sulcus is associated with transepithelial gradients of interleukin-8 and ICAM-1. J. Periodontol. 1998, 69, 1139-1147.

12. Shapiro, R.S.; Cowen, L.E. Thermal control of microbial development and virulence: Molecular mechanisms of microbial temperature sensing. MBio 2012, 3, doi:10.1128/mBio.00238-12.

13. Fedi, P.F., Jr.; Killoy, W.J. Temperature differences at periodontal sites in health and disease. J. Periodontol. 1992, 63, 24-27.

14. Percival, R.S.; Marsh, P.D.; Devine, D.A.; Rangarajan, M.; Aduse-Opoku, J.; Shepherd, P.; Curtis, M.A. Effect of temperature on growth, hemagglutination, and protease activity of Porphyromonas gingivalis. Infect. Immun. 1999, 67, 1917-1921.

15. Amano, A.; Fujiwara, T.; Nagata, H.; Kuboniwa, M.; Sharma, A.; Sojar, H.T.; Genco, R.J.; Hamada, S.; Shizukuishi, S. Prophyromonas gingivalis fimbriae mediate coaggregation with Streptococcus oralis through specific domains. J. Dent. Res. 1997, 76, 852-857.

16. Murakami, Y.; Nagata, H.; Amano, A.; Takagaki, M.; Shizukuishi, S.; Tsunemitsu, A.; Aimoto, S. Inhibitory effects of human salivary histatins and lysozyme on coaggregation between Porphyromonas gingivalis and Streptococcus mitis. Infect. Immun. 1991, 59, 3284-3286.

17. Sato, T.; Nakazawa, F. Coaggregation between Prevotella oris and Porphyromonas gingivalis. J. Microbiol. Immunol. Infect. 2012, doi:10.1016/j.jmii.2012.09.005.

18. Curtis, M.A.; Percival, R.S.; Devine, D.; Darveau, R.P.; Coats, S.R.; Rangarajan, M.; Tarelli, E.; Marsh, P.D. Temperature-dependent modulation of Porphyromonas gingivalis lipid A structure and interaction with the innate host defenses. Infect. Immun. 2011, 79, 1187-1193.

19. Haffajee, A.D.; Socransky, S.S.; Smith, C.; Dibart, S.; Goodson, J.M. Subgingival temperature (III). Relation to microbial counts. J. Clin. Periodontol. 1992, 19, 417-422.

20. Imlay, J.A. Cellular defenses against superoxide and hydrogen peroxide. Annu. Rev. Biochem. 2008, 77, 755-776. 
21. Cabiscol, E.; Tamarit, J.; Ros, J. Oxidative stress in bacteria and protein damage by reactive oxygen species. Int. Microbiol. 2000, 3, 3-8.

22. Bradshaw, D.J.; Marsh, P.D.; Watson, G.K.; Allison, C. Role of Fusobacterium nucleatum and coaggregation in anaerobe survival in planktonic and biofilm oral microbial communities during aeration. Infect. Immun. 1998, 66, 4729-4732.

23. Silva, V.L.; Diniz, C.G.; Cara, D.C.; Santos, S.G.; Nicoli, J.R.; Carvalho, M.A.; Farias, L.M. Enhanced pathogenicity of Fusobacterium nucleatum adapted to oxidative stress. Microb. Pathog. 2005, 39, 131-138.

24. Gursoy, U.K.; Pöllänen, M.; Könönen, E.; Uitto, V.J. Biofilm formation enhances the oxygen tolerance and invasiveness of Fusobacterium nucleatum in an oral mucosa culture model. J. Periodontol. 2010, 81, 1084-1091.

25. Steeves, C.H.; Potrykus, J.; Barnett, D.A.; Bearne, S.L. Oxidative stress response in the opportunistic oral pathogen Fusobacterium nucleatum. Proteomics 2011, 11, 2027-2037.

26. Okano, S.; Shibata, Y.; Shiroza, T.; Abiko, Y. Proteomics-based analysis of a counter-oxidative stress system in Porphyromonas gingivalis. Proteomics 2006, 6, 251-258.

27. Amano, A.; Sharma, A.; Sojar, H.T.; Kuramitsu, H.K.; Genco, R.J. Effects of temperature stress on expression of fimbriae and superoxide dismutase by Porphyromonas gingivalis. Infect. Immun. 1994, 62, 4682-4685.

28. McKenzie, R.M.; Johnson, N.A.; Aruni, W.; Dou, Y.; Masinde, G.; Fletcher, H.M. Differential response of Porphyromonas gingivalis to varying levels and duration of hydrogen peroxide-induced oxidative stress. Microbiology 2012, 158, 2465-2479.

29. Gamonal, J.; Acevedo, A.; Bascones, A.; Jorge, O.; Silva, A. Levels of interleukin-1 beta, -8, and -10 and RANTES in gingival crevicular fluid and cell populations in adult periodontitis patients and the effect of periodontal treatment. J. Periodontol. 2000, 71, 1535-1545.

30. Silva, N.; Dutzan, N.; Hernandez, M.; Dezerega, A.; Rivera, O.; Aguillon, J.C.; Aravena, O.; Lastres, P.; Pozo, P.; Vernal, R.; et al. Characterization of progressive periodontal lesions in chronic periodontitis patients: Levels of chemokines, cytokines, matrix metalloproteinase-13, periodontal pathogens and inflammatory cells. J. Clin. Periodontol. 2008, 35, 206-214.

31. Graves, D.T.; Cochran, D. The contribution of interleukin-1 and tumor necrosis factor to periodontal tissue destruction. J. Periodontol. 2003, 74, 391-401.

32. Ishihara, Y.; Nishihara, T.; Maki, E.; Noguchi, T.; Koga, T. Role of interleukin-1 and prostaglandin in in vitro bone resorption induced by Actinobacillus actinomycetemcomitans lipopolysaccharide. J. Periodontal. Res. 1991, 26, 155-160.

33. Cochran, D.L. Inflammation and bone loss in periodontal disease. J. Periodontol. 2008, 79, $1569-1576$.

34. Eskan, M.A.; Benakanakere, M.R.; Rose, B.G.; Zhang, P.; Zhao, J.; Stathopoulou, P.; Fujioka, D.; Kinane, D.F. Interleukin-1beta modulates proinflammatory cytokine production in human epithelial cells. Infect. Immun. 2008, 76, 2080-2089. 
35. Tanabe, S.; Bodet, C.; Grenier, D. Treponema denticola lipooligosaccharide activates gingival fibroblasts and upregulates inflammatory mediator production. J. Cell. Physiol. 2008, 216, $727-731$.

36. Kelk, P.; Claesson, R.; Chen, C.; Sjöstedt, A.; Johansson, A. IL-1beta secretion induced by Aggregatibacter (Actinobacillus) actinomycetemcomitans is mainly caused by the leukotoxin. Int. J. Med. Microbiol. 2008, 298, 529-541.

37. Tanabe, S.I.; Grenier, D. Macrophage tolerance response to Aggregatibacter actinomycetemcomitans lipopolysaccharide induces differential regulation of tumor necrosis factor-alpha, interleukin-1 beta and matrix metalloproteinase 9 secretion. J. Periodontal. Res. 2008, 43, 372-377.

38. Matsuki, Y.; Yamamoto, T.; Hara, K. Interleukin-1 mRNA-expressing macrophages in human chronically inflamed gingival tissues. Am. J. Pathol. 1991, 138, 1299-1305.

39. Hsi, E.D.; Remick, D.G. Monocytes are the major producers of interleukin-1 beta in an ex vivo model of local cytokine production. J. Interferon Cytokine Res. 1995, 15, 89-94.

40. Takeichi, O.; Saito, I.; Tsurumachi, T.; Saito, T.; Moro, I. Human polymorphonuclear leukocytes derived from chronically inflamed tissue express inflammatory cytokines in vivo. Cell. Immunol. 1994, 156, 296-309.

41. Vardar-Sengul, S.; Arora, S.; Baylas, H.; Mercola, D. Expression profile of human gingival fibroblasts induced by interleukin-1beta reveals central role of nuclear factor-kappa $b$ in stabilizing human gingival fibroblasts during inflammation. J. Periodontol. 2009, 80, 833-849.

42. Uchida, Y.; Shiba, H.; Komatsuzawa, H.; Takemoto, T.; Sakata, M.; Fujita, T.; Kawaguchi, H.; Sugai, M.; Kurihara, H. Expression of IL-1 beta and IL-8 by human gingival epithelial cells in response to Actinobacillus actinomycetemcomitans. Cytokine 2001, 14, 152-161.

43. Dickinson, B.C.; Moffatt, C.E.; Hagerty, D.; Whitmore, S.E.; Brown, T.A.; Graves, D.T.; Lamont, R.J. Interaction of oral bacteria with gingival epithelial cell multilayers. Mol. Oral Microbiol. 2011, 26, 210-220.

44. Stathopoulou, P.G.; Benakanakere, M.R.; Galicia, J.C.; Kinane, D.F. Epithelial cell pro-inflammatory cytokine response differs across dental plaque bacterial species. J. Clin. Periodontol. 2010, 37, 24-29.

45. Umeda, J.E.; Demuth, D.R.; Ando, E.S.; Faveri, M.; Mayer, M.P. Signaling transduction analysis in gingival epithelial cells after infection with Aggregatibacter actinomycetemcomitans. Mol. Oral Microbiol. 2012, 27, 23-33.

46. Peyyala, R.; Kirakodu, S.S.; Novak, K.F.; Ebersole, J.L. Oral microbial biofilm stimulation of epithelial cell responses. Cytokine 2012, 58, 65-72.

47. Guggenheim, B.; Gmur, R.; Galicia, J.C.; Stathopoulou, P.G.; Benakanakere, M.R.; Meier, A.; Thurnheer, T.; Kinane, D.F. In vitro modeling of host-parasite interactions: The 'subgingival' biofilm challenge of primary human epithelial cells. BMC Microbiol. 2009, 9, doi:10.1186/ 1471-2180-9-280. 
48. Peyyala, R.; Ebersole, J.L. Multispecies biofilms and host responses: "Discriminating the trees from the forest". Cytokine 2013, 61, 15-25.

49. Porat, R.; Clark, B.D.; Wolff, S.M.; Dinarello, C.A. Enhancement of growth of virulent strains of Escherichia coli by interleukin-1. Science 1991, 254, 430-432.

50. Meduri, G.U.; Kanangat, S.; Stefan, J.; Tolley, E.; Schaberg, D. Cytokines IL-1beta, IL-6, and TNF-alpha enhance in vitro growth of bacteria. Am. J. Respir. Crit. Care Med. 1999, 160, 961-967.

51. Stashenko, P.; Fujiyoshi, P.; Obernesser, M.S.; Prostak, L.; Haffajee, A.D.; Socransky, S.S. Levels of interleukin 1 beta in tissue from sites of active periodontal disease. J. Clin. Periodontol. 1991, 18, 548-554.

52. McLaughlin, R.A.; Hoogewerf, A.J. Interleukin-1beta-induced growth enhancement of Staphylococcus aureus occurs in biofilm but not planktonic cultures. Microb. Pathog. 2006, 41, 67-79.

53. Kanangat, S.; Bronze, M.S.; Meduri, G.U.; Postlethwaite, A.; Stentz, F.; Tolley, E.; Schaberg, D. Enhanced extracellular growth of Staphylococcus aureus in the presence of selected linear peptide fragments of human interleukin (IL)-1beta and IL-1 receptor antagonist. J. Infect. Dis. 2001, 183, 65-69.

54. Kanangat, S.; Postlethwaite, A.; Cholera, S.; Williams, L.; Schaberg, D. Modulation of virulence gene expression in Staphylococcus aureus by interleukin-1beta: Novel implications in bacterial pathogenesis. Microbes Infect. 2007, 9, 408-415.

55. Zav'yalov, V.P.; Chernovskaya, T.V.; Navolotskaya, E.V.; Karlyshev, A.V.; MacIntyre, S.; Vasiliev, A.M.; Abramov, V.M. Specific high affinity binding of human interleukin 1 beta by Caf1A usher protein of Yersinia pestis. FEBS Lett. 1995, 371, 65-68.

56. Zav'yalov, V.; Denesyuk, A.; Zav'yalova, G.; Korpela, T. Molecular modeling of the steric structure of the envelope F1 antigen of Yersinia pestis. Immunol. Lett. 1995, 45, 19-22.

57. Wu, L.; Estrada, O.; Zaborina, O.; Bains, M.; Shen, L.; Kohler, J.E.; Patel, N.; Musch, M.W.; Chang, E.B.; Fu, Y.X.; et al. Recognition of host immune activation by Pseudomonas aeruginosa. Science 2005, 309, 774-777.

58. Diggle, S.P.; Stacey, R.E.; Dodd, C.; Camara, M.; Williams, P.; Winzer, K. The galactophilic lectin, LecA, contributes to biofilm development in Pseudomonas aeruginosa. Environ. Microbiol. 2006, 8, 1095-1104.

59. Cebo, C.; Dambrouck, T.; Maes, E.; Laden, C.; Strecker, G.; Michalski, J.C.; Zanetta, J.P. Recombinant human interleukins IL-1alpha, IL-1beta, IL-4, IL-6, and IL-7 show different and specific calcium-independent carbohydrate-binding properties. J. Biol. Chem. 2001, 276, 5685-5691.

60. Sherblom, A.P.; Decker, J.M.; Muchmore, A.V. The lectin-like interaction between recombinant tumor necrosis factor and uromodulin. J. Biol. Chem. 1988, 263, 5418-5424. 
61. Cebo, C.; Vergoten, G.; Zanetta, J.P. Lectin activities of cytokines: Functions and putative carbohydrate-recognition domains. Biochim. Biophys. Acta 2002, 1572, 422-434.

62. Vergoten, G.; Zanetta, J.P. Structural differences between the putative carbohydrate-recognition domains of human IL-1 alpha, IL-1 beta and IL-1 receptor antagonist obtained by in silico modeling. Glycoconj. J. 2007, 24, 183-193.

63. Mandrell, R.E.; McLaughlin, R.; Aba Kwaik, Y.; Lesse, A.; Yamasaki, R.; Gibson, B.; Spinola, S.M.; Apicella, M.A. Lipooligosaccharides (LOS) of some Haemophilus species mimic human glycosphingolipids, and some LOS are sialylated. Infect. Immun. 1992, 60, 1322-1328.

64. Li, Y.; Sun, M.; Huang, S.; Yu, H.; Chokhawala, H.A.; Thon, V.; Chen, X. The hd0053 gene of Haemophilus ducreyi encodes an a2,3-sialyltransferase. Biochem. Biophys. Res. Commun. 2007, 361, 555-560.

65. Paino, A.; Tuominen, H.; Jääskeläinen, M.; Alanko, J.; Nuutila, J.; Asikainen, S.E.; Pelliniemi, L.J.; Pöllänen, M.T.; Chen, C.; Ihalin, R. Trimeric form of intracellular ATP synthase subunit beta of Aggregatibacter actinomycetemcomitans binds human interleukin-1beta. PLoS One 2011, 6, e18929.

66. Paino, A.; Lohermaa, E.; Sormunen, R.; Tuominen, H.; Korhonen, J.; Pöllänen, M.T.; Ihalin, R. Interleukin- $1 \beta$ is internalised by viable Aggregatibacter actinomycetemcomitans biofilm and locates to the outer edges of nucleoids. Cytokine 2012, 60, 565-574.

67. Paino, A.; Ahlstrand, T.; Nuutila, J.; Navickaite, I.; Lahti, M.; Tuominen, H.; Välimaa, H.; Lamminmäki, U.; Pöllänen, M.T.; Ihalin, R. Identification of a novel bacterial outer membrane interleukin-1beta-binding protein from Aggregatibacter actinomycetemcomitans. PLoS One 2013, 8, e70509.

68. Alcami, A. Viral mimicry of cytokines, chemokines and their receptors. Nat. Rev. Immunol. 2003, 3, 36-50.

69. Treseler, C.B.; Maziarz, R.T.; Levitz, S.M. Biological activity of interleukin-2 bound to Candida albicans. Infect. Immun. 1992, 60, 183-188.

70. Bickel, M.; Munoz, J.L.; Giovannini, P. Acid-base properties of human gingival crevicular fluid. J. Dent. Res. 1985, 64, 1218-1220.

71. Bickel, M.; Cimasoni, G. The $\mathrm{pH}$ of human crevicular fluid measured by a new microanalytical technique. J. Periodontal. Res. 1985, 20, 35-40.

72. Eggert, F.M.; Drewell, L.; Bigelow, J.A.; Speck, J.E.; Goldner, M. The pH of gingival crevices and periodontal pockets in children, teenagers and adults. Arch. Oral Biol. 1991, 36, 233-238.

73. Takahashi, N. Acid-neutralizing activity during amino acid fermentation by Porphyromonas gingivalis, Prevotella intermedia and Fusobacterium nucleatum. Oral Microbiol. Immunol. 2003, 18, 109-113.

74. Zilm, P.S.; Rogers, A.H. Co-adhesion and biofilm formation by Fusobacterium nucleatum in response to growth pH. Anaerobe 2007, 13, 146-152. 
75. Zilm, P.S.; Bagley, C.J.; Rogers, A.H.; Milne, I.R.; Gully, N.J. The proteomic profile of Fusobacterium nucleatum is regulated by growth pH. Microbiology 2007, 153, 148-159.

76. Kapatral, V.; Anderson, I.; Ivanova, N.; Reznik, G.; Los, T.; Lykidis, A.; Bhattacharyya, A.; Bartman, A.; Gardner, W.; Grechkin, G.; et al. Genome sequence and analysis of the oral bacterium Fusobacterium nucleatum strain ATCC 25586. J. Bacteriol. 2002, 184, 2005-2018.

77. Chew, J.; Zilm, P.S.; Fuss, J.M.; Gully, N.J. A proteomic investigation of Fusobacterium nucleatum alkaline-induced biofilms. BMC Microbiol. 2012, 12, doi:10.1186/1471-2180-12-189.

78. Skar, C.K.; Kruger, P.G.; Bakken, V. Characterisation and subcellular localisation of the GroEL-like and DnaK-like proteins isolated from Fusobacterium nucleatum ATCC 10953. Anaerobe 2003, 9, 305-312.

79. Oscarsson, J.; Karched, M.; Thay, B.; Chen, C.; Asikainen, S. Proinflammatory effect in whole blood by free soluble bacterial components released from planktonic and biofilm cells. BMC Microbiol. 2008, 8, doi:10.1186/1471-2180-8-206.

80. Lee, H.R.; Jun, H.K.; Kim, H.D.; Lee, S.H.; Choi, B.K. Fusobacterium nucleatum GroEL induces risk factors of atherosclerosis in human microvascular endothelial cells and apoE(-/-) mice. Mol. Oral Microbiol. 2012, 27, 109-123.

81. Shaniztki, B.; Hurwitz, D.; Smorodinsky, N.; Ganeshkumar, N.; Weiss, E.I. Identification of a Fusobacterium nucleatum PK1594 galactose-binding adhesin which mediates coaggregation with periopathogenic bacteria and hemagglutination. Infect. Immun. 1997, 65, 5231-5237.

82. Liu, P.F.; Shi, W.; Zhu, W.; Smith, J.W.; Hsieh, S.L.; Gallo, R.L.; Huang, C.M. Vaccination targeting surface FomA of Fusobacterium nucleatum against bacterial co-aggregation: implication for treatment of periodontal infection and halitosis. Vaccine 2010, 28, 3496-3505.

83. Zilm, P.S.; Mira, A.; Bagley, C.J.; Rogers, A.H. Effect of alkaline growth $\mathrm{pH}$ on the expression of cell envelope proteins in Fusobacterium nucleatum. Microbiology 2010, 156, 1783-1794.

84. Schaible, U.E.; Kaufmann, S.H. Iron and microbial infection. Nat. Rev. Microbiol. 2004, 2, 946-953.

85. Shoji, M.; Shibata, Y.; Shiroza, T.; Yukitake, H.; Peng, B.; Chen, Y.Y.; Sato, K.; Naito, M.; Abiko, Y.; Reynolds, E.C.; et al. Characterization of hemin-binding protein 35 (HBP35) in Porphyromonas gingivalis: Its cellular distribution, thioredoxin activity and role in heme utilization. BMC Microbiol. 2010, 10, doi:10.1186/1471-2180-10-152.

86. $\mathrm{Xu}, \mathrm{X}$.; Kolodrubetz, D. Construction and analysis of hemin binding protein mutants in the oral pathogen Treponema denticola. Res. Microbiol. 2002, 153, 569-577.

87. Rhodes, E.R.; Menke, S.; Shoemaker, C.; Tomaras, A.P.; McGillivary, G.; Actis, L.A. Iron acquisition in the dental pathogen Actinobacillus actinomycetemcomitans: What does it use as a source and how does it get this essential metal? Biometals 2007, 20, 365-377.

88. Al-Qutub, M.N.; Braham, P.H.; Karimi-Naser, L.M.; Liu, X.; Genco, C.A.; Darveau, R.P. Hemin-dependent modulation of the lipid A structure of Porphyromonas gingivalis lipopolysaccharide. Infect. Immun. 2006, 74, 4474-4485. 
89. Amarasinghe, J.J.; Scannapieco, F.A.; Haase, E.M. Transcriptional and translational analysis of biofilm determinants of Aggregatibacter actinomycetemcomitans in response to environmental perturbation. Infect. Immun. 2009, 77, 2896-2907.

90. Amarasinghe, J.J.; Connell, T.D.; Scannapieco, F.A.; Haase, E.M. Novel iron-regulated and Fur-regulated small regulatory RNAs in Aggregatibacter actinomycetemcomitans. Mol. Oral Microbiol. 2012, 27, 327-349.

91. Smalley, J.W.; Birss, A.J.; McKee, A.S.; Marsh, P.D. Haemin-restriction influences haemin-binding, haemagglutination and protease activity of cells and extracellular membrane vesicles of Porphyromonas gingivalis W50. FEMS Microbiol. Lett. 1991, 69, 63-67.

92. Hughes, D.T.; Sperandio, V. Inter-kingdom signalling: Communication between bacteria and their hosts. Nat. Rev. Microbiol. 2008, 6, 111-120.

93. Roberts, A.; Matthews, J.B.; Socransky, S.S.; Freestone, P.P.; Williams, P.H.; Chapple, I.L. Stress and the periodontal diseases: Effects of catecholamines on the growth of periodontal bacteria in vitro. Oral Microbiol. Immunol. 2002, 17, 296-303.

94. Socransky, S.S.; Haffajee, A.D.; Cugini, M.A.; Smith, C.; Kent, R.L., Jr. Microbial complexes in subgingival plaque. J. Clin. Periodontol. 1998, 25, 134-144.

95. Saito, T.; Inagaki, S.; Sakurai, K.; Okuda, K.; Ishihara, K. Exposure of P. gingivalis to noradrenaline reduces bacterial growth and elevates ArgX protease activity. Arch. Oral Biol. 2011, 56, 244-250.

96. Mariotti, A. Sex steroid hormones and cell dynamics in the periodontium. Crit. Rev. Oral Biol. Med. 1994, 5, 27-53.

97. Armitage, G.C. Development of a classification system for periodontal diseases and conditions. Ann. Periodontol. 1999, 4, 1-6.

98. Jonsson, R.; Howland, B.E.; Bowden, G.H. Relationships between periodontal health, salivary steroids, and Bacteroides intermedius in males, pregnant and non-pregnant women. J. Dent. Res. 1988, 67, 1062-1069.

99. Figuero, E.; Carrillo-de-Albornoz, A.; Herrera, D.; Bascones-Martinez, A. Gingival changes during pregnancy: I. Influence of hormonal variations on clinical and immunological parameters. J. Clin. Periodontol. 2010, 37, 220-229.

100. Gursoy, M.; Gursoy, U.K.; Sorsa, T.; Pajukanta, R.; Könönen, E. High salivary estrogen and risk of developing pregnancy gingivitis. J. Periodontol. 2012, doi:10.1902/jop.2012.120512.

101. Lopatin, D.E.; Kornman, K.S.; Loesche, W.J. Modulation of immunoreactivity to periodontal disease-associated microorganisms during pregnancy. Infect. Immun. 1980, 28, 713-718.

102. Lapp, C.A.; Thomas, M.E.; Lewis, J.B. Modulation by progesterone of interleukin- 6 production by gingival fibroblasts. J. Periodontol. 1995, 66, 279-284.

103. Rodriguez, E.; Lopez, R.; Paez, A.; Masso, F.; Montano, L.F. 17Beta-estradiol inhibits the adhesion of leukocytes in TNF-alpha stimulated human endothelial cells by blocking IL-8 and MCP-1 secretion, but not its transcription. Life Sci. 2002, 71, 2181-2193. 
104. Shu, L.; Guan, S.M.; Fu, S.M.; Guo, T.; Cao, M.; Ding, Y. Estrogen modulates cytokine expression in human periodontal ligament cells. J. Dent. Res. 2008, 87, 142-147.

105. Jensen, J.; Liljemark, W.; Bloomquist, C. The effect of female sex hormones on subgingival plaque. J. Periodontol. 1981, 52, 599-602.

106. Raber-Durlacher, J.E.; van Steenbergen, T.J.; van der Velden, U.; de Graaff, J.; Abraham-Inpijn, L. Experimental gingivitis during pregnancy and post-partum: Clinical, endocrinological, and microbiological aspects. J. Clin. Periodontol. 1994, 21, 549-558.

107. Carrillo-de-Albornoz, A.; Figuero, E.; Herrera, D.; Bascones-Martinez, A. Gingival changes during pregnancy: II. Influence of hormonal variations on the subgingival biofilm. J. Clin. Periodontol. 2010, 37, 230-240.

108. Kornman, K.S.; Loesche, W.J. Effects of estradiol and progesterone on Bacteroides melaninogenicus and Bacteroides gingivalis. Infect. Immun. 1982, 35, 256-263. 


\title{
Interactions between Lactobacillus crispatus and Bacterial Vaginosis (BV)-Associated Bacterial Species in Initial Attachment and Biofilm Formation
}

\author{
António Machado, Kimberly Kay Jefferson and Nuno Cerca
}

\begin{abstract}
Certain anaerobic bacterial species tend to predominate the vaginal flora during bacterial vaginosis (BV), with Gardnerella vaginalis being the most common. However, the exact role of $G$. vaginalis in BV has not yet been determined. The main goal of this study was to test the hypothesis that G. vaginalis is an early colonizer, paving the way for intermediate (e.g., Fusobacterium nucleatum) and late colonizers (e.g., Prevotella bivia). Theoretically, in order to function as an early colonizer, species would need to be able to adhere to vaginal epithelium, even in the presence of vaginal lactobacilli. Therefore, we quantified adherence of $G$. vaginalis and other BV-associated bacteria to an inert surface pre-coated with Lactobacillus crispatus using a new Peptide Nucleic Acid (PNA) Fluorescence In Situ Hybridization (FISH) methodology. We found that G. vaginalis had the greatest capacity to adhere in the presence of L. crispatus. Theoretically, an early colonizer would contribute to the adherence and/or growth of additional species, so we next quantified the effect of G. vaginalis biofilms on the adherence and growth of other BV-associated species by quantitative Polymerase Chain Reaction (qPCR) technique. Interestingly, G. vaginalis derived a growth benefit from the addition of a second species, regardless of the species. Conversely, G. vaginalis biofilms enhanced the growth of $P$. bivia, and to a minor extent of $F$. nucleatum. These results contribute to our understanding of BV biofilm formation and the progression of the disorder.
\end{abstract}

Reprinted from Int. J. Mol. Sci. Cite as: Machado, A.; Jefferson, K.K.; Cerca, N. Interactions between Lactobacillus crispatus and Bacterial Vaginosis (BV)-Associated Bacterial Species in Initial

Attachment and Biofilm Formation. Int. J. Mol. Sci. 2013, 14, 12004-12012.

\section{Introduction}

Bacterial vaginosis (BV) is the most common vaginal disorder in women of reproductive age but its etiology is still unclear [1]. However, BV is characterized by a decrease in beneficial vaginal bacteria, such as Lactobacillus cripatus, and by an increase of the number of anaerobic bacteria, such as Gardnerella vaginalis, Mobiluncus mulieris, Atopobium vaginae, Prevotella bivia and Fusobacteria nucleatum [2-4]. BV is typically a polymicrobial condition [5,6]. Recently it has been found that multi-species microbial biofilms are involved in BV [4]; however, the process by which this multi-species biofilm is established remains unknown. In general, single-species biofilm formation involves two main independent steps: initial adhesion to the surface and biofilm accumulation [7]. In contrast, multi-species biofilm formation may be more complex and depend upon interactions between the species involved. The most thoroughly studied clinically relevant polymicrobial biofilm is 
the oral biofilm associated with periodontitis [8]. During the development of these biofilms, early colonizers first adhere to the tooth pellicle and provide a surface to which intermediate colonizers can adhere as well as producing more optimal conditions for growth of successive species $[9,10]$. This community in turn provides an environment conducive to the adherence and growth of secondary colonizers. Similar to oral biofilms, it has been hypothesized that $G$. vaginalis is the initial colonizing species and that $G$. vaginalis biofilms are conducive to growth, adherence and/or biofilm formation by other BV anaerobes, but this has yet to be demonstrated [4].

The main goal of our work was to assess the potential of bacterial species commonly found in BV as early or late colonizers. We first quantified the initial adhesion potential to an inert surface pre-coated with Lactobacillus crispatus and then compared single-species or dual-species biofilms formation in order to assess the potential symbiotic interactions between BV-associated bacterial species.

\section{Results and Discussion}

\subsection{Determination of Early Adhesion Potential to Surface Coated with L. crispatus}

In 1983, Spiegel and colleagues postulated that bacterial vaginosis was a polymicrobial infection, where G. vaginalis was the prevalent species [11]. However, the etiology of BV remains unknown, and it is unclear which, if any of the BV-associated anaerobes are capable of disrupting an established Lactobacillus population and initiate colonization on the vaginal epithelium. Several species of lactobacilli may colonize the healthy vagina, however each species differs in its probiotic activity due to differences in their abilities to endure changes in conditions, such as $\mathrm{pH}$ variations due to menstruation or sexual intercourse, and due to differences in their abilities to produce antimicrobial compounds such as lactic acid, hydrogen peroxide and bacteriocins [12]. L. crispatus is able to produce several antimicrobial compounds and is inversely associated with BV [13]. We therefore chose this species as a representative for use in our study. We attempted to evaluate the early adhesion to an inert surface pre-coated with $L$. crispatus by know BV associated anaerobes at different concentrations $\left(1 \times 10^{3}\right.$ and $\left.3 \times 10^{9} \mathrm{CFU} / \mathrm{mL}\right)$. As shown in Table $1, G$. vaginalis was more adherent at either concentration than the other BV anaerobes (ANOVA Tukey statistical test, $p<0.05$ ), followed by $F$. nucleatum and $P$. bivia, respectively. These results are in agreement with several previous studies [14-16] supporting evidence that $G$. vaginalis has significant initial adhesion potential. This suggests that $G$. vaginalis could be the early colonizer in the progression of BV. Although A. vaginae and M. mulieris are often associated with BV [17-19], their capacity to adhere to glass pre-coated with L. crispatus was the lowest of all tested anaerobes, suggesting that they are not strong candidates as early colonizers in BV. Interestingly, M. mulieris appeared to displace L. crispatus more effectively than any of the other anaerobes tested, including G. vaginalis (ANOVA Tukey statistical test value, $p<0.05$; see Table 2). Since this species did not adhere as well, this suggests that it may secrete some soluble factors that displace the lactobacilli. However, these in vitro experiments are limited in that the bacteria were allowed to adhere to glass rather than vaginal epithelium and adherence to vaginal 
epithelium is likely influenced by a number of host-related and bacteria-specific factors, such as mucus production and the involvement of specific receptors on the epithelial surface $[1,3]$.

Table 1. Blockage of adherence of bacterial vaginosis (BV)-associated anaerobes to glass by adherent $L$. crispatus. The number of each BV-associated anaerobes that adhered per $\mathrm{cm}^{2}$ of glass ( \pm standard deviation) is shown on the left and the percentage of bacteria that adhered when the glass was pre-coated with L. crispatus relative to the control ( \pm standard deviation) is shown on the right.

\begin{tabular}{lcc}
\hline & $\begin{array}{c}\text { Number of BV anaerobe } \\
\text { per } \mathbf{~ c m}^{2}\end{array}$ & $\begin{array}{c}\text { Percentage adherent to } \\
\text { L. crispatus-coated glass }\end{array}$ \\
\hline High inocula & $5.71 \times 10^{7}\left( \pm 2.14 \times 10^{4}\right)$ & $86.86 \%^{\mathrm{c}, \mathrm{d}, \mathrm{e}, \mathrm{f}}( \pm 14.14)$ \\
$\quad$ G. vaginalis 101 & $6.85 \times 10^{6}\left( \pm 3.38 \times 10^{5}\right)$ & $48.74 \%^{\mathrm{a}, \mathrm{b}}( \pm 3.36)$ \\
A. vaginae FA & $5.76 \times 10^{6}\left( \pm 1.21 \times 10^{5}\right)$ & $82.22 \%^{\mathrm{a}, \mathrm{b}}( \pm 0.37)$ \\
M. mulieris ATCC 26-9 & $1.64 \times 10^{7}\left( \pm 6.29 \times 10^{5}\right)$ & $101.67 \%^{\mathrm{b}}( \pm 28.19)$ \\
P. bivia ATCC 29303 & $2.54 \times 10^{7}\left( \pm 9.41 \times 10^{5}\right)$ & $68.83 \%^{\mathrm{a}, \mathrm{b}}( \pm 5.60)$ \\
F. nucleatum 718BVC & & \\
Low inocula & $6.89 \times 10^{6}\left( \pm 1.26 \times 10^{6}\right)$ & $72.33 \%( \pm 4.36)$ \\
G. vaginalis 101 & $1.47 \times 10^{5}\left( \pm 9.65 \times 10^{4}\right)$ & $50.27 \%^{\mathrm{a}}( \pm 3.97)$ \\
A. vaginae FA & $1.33 \times 10^{6}\left( \pm 5.05 \times 10^{4}\right)$ & $70.15 \%( \pm 7.80)$ \\
M. mulieris ATCC 26-9 & $2.99 \times 10^{6}\left( \pm 1.44 \times 10^{5}\right)$ & $84.17 \%( \pm 1.57)$ \\
P. bivia ATCC 29303 & $2.68 \times 10^{6}\left( \pm 5.52 \times 10^{4}\right)$ & $60.15 \%{ }^{\mathrm{a}}( \pm 0.28)$ \\
F. nucleatum 718BVC &
\end{tabular}

High inocula $=1 \times 10^{9} \mathrm{CFU} / \mathrm{mL}$, Low inocula $=1 \times 10^{3} \mathrm{CFU} / \mathrm{mL}$. ${ }^{a} p<0.05$ when using $t$-student statistical analysis (95\% confidence interval) for comparison of control and bacteria tested in the adhesion assay; ${ }^{\mathrm{b}} p<0.05$ analysed using ANOVA Tukey statistical test (95\% confidence interval) for comparison with G. vaginalis strain tested in the adhesion assay; ${ }^{c} p<0.05$ analysed using ANOVA Tukey statistical test (95\% confidence interval) for comparison with $A$. vaginae strain tested in the adhesion assay; ${ }^{\mathrm{d}} p<0.05$ analysed using ANOVA Tukey statistical test (95\% confidence interval) for comparison with M. mulieris strain tested in the adhesion assay; ${ }^{\mathrm{e}} p<0.05$ analysed using ANOVA Tukey statistical test $(95 \%$ confidence interval) for comparison with $P$. bivia strain tested in the adhesion assay; ${ }^{\mathrm{f}} p<0.05$ analysed using ANOVA Tukey statistical test ( $95 \%$ confidence interval) for comparison with $F$. nucleatum strain tested in the adhesion assay. 
Table 2. Displacement of adherent L. crispatus by BV-associated anaerobes. Following the addition of a BV-associated anaerobe, the number of remaining L. crispatus was counted and compared to the L. crispatus control counting $\left(7.36 \times 10^{7} \pm 9.97 \times 10^{4}\right)$. The percentage ( \pm standard deviation) of $L$. crispatus that remained adherent after addition of each BV anaerobe at high or low inocula is shown below.

\begin{tabular}{|c|c|}
\hline & Percentage of $L$. crispatus remaining after addition of $\mathrm{BV}$ anaerobe \\
\hline \multicolumn{2}{|l|}{ High inocula } \\
\hline G. vaginalis 101 & $88.60 \%{ }^{\mathrm{b}, \mathrm{c}}( \pm 5.14)$ \\
\hline A. vaginae $\mathrm{FA}$ & $99.29 \%{ }^{\mathrm{a}}( \pm 7.26)$ \\
\hline M. mulieris ATCC 26-9 & $76.62 \%{ }^{\mathrm{a}}( \pm 11.93)$ \\
\hline P. bivia ATCC 29303 & $94.86 \%( \pm 20.60)$ \\
\hline F. nucleatum $718 \mathrm{BVC}$ & $97.65 \%( \pm 7.41)$ \\
\hline \multicolumn{2}{|l|}{ Low inocula } \\
\hline G. vaginalis 101 & $101.51 \%{ }^{\mathrm{b}, \mathrm{c}}( \pm 28.52)$ \\
\hline A. vaginae $\mathrm{FA}$ & $71.18 \%{ }^{\mathrm{a}}( \pm 12.54)$ \\
\hline M. mulieris ATCC 26-9 & $68.48 \%{ }^{\mathrm{a}}( \pm 12.79)$ \\
\hline P. bivia ATCC 29303 & $97.39 \%( \pm 2.44)$ \\
\hline F. nucleatum 718BVC & $98.34 \%( \pm 9.52)$ \\
\hline \multicolumn{2}{|c|}{$\begin{array}{l}\text { High inocula }=1 \times 10^{9} \mathrm{CFU} / \mathrm{mL} \text {, Low inocula }=1 \times 10^{3} \mathrm{CFU} / \mathrm{mL} .{ }^{\mathrm{a}} p<0.05 \text { analysed using ANOVA Tukey } \\
\text { statistical test }(95 \% \text { confidence interval) for comparison with G. vaginalis strain tested in the adhesion assay; } \\
\text { b } p<0.05 \text { analysed using ANOVA Tukey statistical test (95\% confidence interval) for comparison with } \\
\text { A. vaginae strain tested in the adhesion assay; }{ }^{\mathrm{c}} p<0.05 \text { analysed using ANOVA Tukey statistical test } \\
\text { (95\% confidence interval) for comparison with } M \text {. mulieris strain tested in the adhesion assay. }\end{array}$} \\
\hline
\end{tabular}

\subsection{G. vaginalis Mediated Dual Species Biofilms}

Studies have shown the prevalence of biofilm formation in BV samples, exposing G. vaginalis as a main component of these biofilms, leading to the hypothesis that $G$. vaginalis initiates the biofilm allowing successive species to adhere and proliferate $[4,20]$. However, this has yet to be determined experimentally. We examined whether synergistic or antagonistic interactions would contribute to or prevent growth of BV anaerobes within an early-stage G. vaginalis biofilm. G. vaginalis biofilms were allowed to develop for $24 \mathrm{~h}$, after which a second anaerobe was introduced and co-cultured in the system for an additional $24 \mathrm{~h}$. Quantitative PCR analysis was used to determine the number of $G$. vaginalis and the second species within the biofilm. Notably, G. vaginalis growth was augmented by the incorporation of a second anaerobe after the initial $24 \mathrm{~h}$ biofilm formation (Table 3). $G$. vaginalis growth increased in the presence of every species $(\approx 3$ fold increase) but the greatest increase was found in the presence of $P$. bivia (3.83-fold increase) and M. mulieris (3.78-fold increase) as shown in Table 3. Interestingly, $F$. nucleatum and $P$. bivia reached higher numbers when co-cultured with $G$. vaginalis strains, showing $\approx 2$ and $\approx 4$ fold increases (see Table 3 ), respectively. This is in agreement with a report from Pybus and Onderdonk revealing a symbiotic relationship between 
G. vaginalis and P. bivia [17] and suggesting that symbiotic relationships established between $G$. vaginalis and other anaerobes in BV biofilms could contribute to the progression of BV. The results with $F$. nucleatum were interesting as well. Although $F$. nucleatum has not been extensively studied in $\mathrm{BV}$ infection, it plays a key role in the establishment of oral biofilms as a bridging species [21]. In fact, Foster and Kolenbrander [21] demonstrated that F. nucleatum is capable of co-aggregating with pathogenic bacteria and becoming a dominant member of the oral multispecies biofilm after several days of incubation although it commonly failed to grow by itself in biofilms. Similarly, our results suggest that $F$. nucleatum could be capable of joining an initial biofilm and eventually establishing a symbiotic relationship with $G$. vaginalis. Again, our study is limited in its complexity and lacks host-specific factors, but it does suggest that certain BV-related species can cooperate and this may provide some insight regarding the ability of these bacterial species to become dominant in an environment normally dominated by lactobacilli.

Table 3. Results of the quantitative PCR (qPCR) from mixed biofilm formation assays with Gardnerella vaginalis 101 and a second BV anaerobe. All experiments were done in triplicate.

\begin{tabular}{|c|c|c|c|c|c|}
\hline \multirow[b]{2}{*}{ Biofilm } & \multicolumn{2}{|c|}{ Single specie biofilm } & \multicolumn{2}{|c|}{ Multispecies biofilm } & \multirow{2}{*}{$\begin{array}{c}\% \text { GV in } \\
\text { mixed biofilm }\end{array}$} \\
\hline & $\begin{array}{l}\text { GV control } \\
\text { CT }\end{array}$ & $\begin{array}{l}\text { 2nd anaerobe } \\
\text { control CT }\end{array}$ & $\begin{array}{l}\text { GV fold } \\
\text { increase }\end{array}$ & $\begin{array}{c}\text { 2nd anaerobe } \\
\text { fold increase }\end{array}$ & \\
\hline $\begin{array}{l}\text { G. vaginalis }(48 \mathrm{~h}) \& \\
\text { M. mulieris }(24 \mathrm{~h})\end{array}$ & $14.13( \pm 0.12)$ & $31.99( \pm 1.09)$ & $3.78( \pm 1.10)^{\mathrm{a}}$ & $0.89( \pm 0.17)$ & 99.9997 \\
\hline $\begin{array}{l}\text { G. vaginalis }(48 \mathrm{~h}) \& \\
\text { A. vaginae }(24 \mathrm{~h})\end{array}$ & $14.13( \pm 0.12)$ & $26.38( \pm 0.33)$ & $3.38( \pm 0.79)^{\mathrm{a}}$ & $1.37( \pm 0.17)$ & 99.9844 \\
\hline $\begin{array}{l}\text { G. vaginalis }(48 \mathrm{~h}) \& \\
\text { P. bivia }(24 \mathrm{~h})\end{array}$ & $14.13( \pm 0.12)$ & $24.84( \pm 0.03)$ & $3.82\left( \pm 0.03^{\mathrm{a}}\right.$ & $4.20( \pm 0.92)^{\mathrm{a}}$ & 99.8960 \\
\hline $\begin{array}{l}\text { G. vaginalis }(48 \mathrm{~h}) \& \\
\text { F. nucleatum }(24 \mathrm{~h})\end{array}$ & $14.13( \pm 0.12)$ & $24.24( \pm 2.57)$ & $3.39( \pm 0.28)^{\mathrm{a}}$ & $1.63( \pm 0.44)$ & 99.9236 \\
\hline
\end{tabular}

Legend-GV, G. vaginalis 101; CT, threshold cycle; ( \pm standard deviation), standard deviation from the average values from triplicate assays are in parenthesis after the average value. ${ }^{a} p<0.05$ when using $t$-student statistical analysis (95\% confidence interval) for comparison of control and bacteria tested in the biofilm assay.

\section{Experimental Section}

\subsection{Culture of Bacterial Strains}

L. crispatus EX533959VC06 was grown in Man, Rogosa and Sharpe both (MRS; Sigma-Aldrich; Buchs, Switzerland) at $37{ }^{\circ} \mathrm{C}$ under anaerobic conditions (AnaeroGen Atmosphere Generation system; Oxoid; Cambridge, UK) for 24-48 h prior to adhesion assays. Also, G. vaginalis 101, Atopobium vaginae FA, Mobiluncus mulieris ATCC 26-9, Prevotella bivia ATCC 29303 and Fusobacteria 
nucleatum 718BVC were grown in supplement Brain Heart Infusion (sBHI; Oxoid) and incubated at $37{ }^{\circ} \mathrm{C}$ under anaerobic conditions (AnaeroGen Atmosphere Generation system; Oxoid) for 24-48 h prior to adhesion assays. Prior to displacement/blockage assays, all strains were harvested by centrifugation $(4000 \mathrm{~g}, 12 \mathrm{~min}$, at room temperature), washed twice with sterile PBS. The pellet from each bacteria culture was resuspended in PBS and its concentration was adjusted to $1 \times 10^{9} \mathrm{CFU} / \mathrm{mL}$ by optical density at $600 \mathrm{~nm}$ using a microplate reader (Tecan; Zurich, Switzerland).

\subsection{Early Adhesion Assays}

Aliquots of $40 \mu \mathrm{L}$ of L. crispatus culture media with a concentration of $1 \times 10^{9} \mathrm{CFU} / \mathrm{mL}$ were added to each well from the 8 chamber glass slide intended to the adhesion assay. Then, 8 chamber glass slides were incubated for $4 \mathrm{~h}$ at $37{ }^{\circ} \mathrm{C}$, in anaerobic conditions, and $120 \mathrm{rpm}$. Non-adherent lactobacilli were removed by washing with $400 \mu \mathrm{L}$ of sterile PBS and subsequently a second adhesion step was performed, using one BV-associated anaerobe with two different concentrations $\left(1 \times 10^{3}\right.$ or $1 \times 10^{9} \mathrm{CFU} / \mathrm{mL}$ ), for $30 \mathrm{~min}$ at $37{ }^{\circ} \mathrm{C}$, in anaerobic conditions and $120 \mathrm{rpm}$ at the same range of concentrations. Finally, each well of the incubated 8 chamber slide was carefully washed twice with $40 \mu \mathrm{L}$ of sterile PBS to remove non-adherent bacteria and let to air-dry before FISH hybridization procedure. Adhesion controls were performed simultaneously in each 8 chamber slide adding each bacterium individually and maintaining the same experimental conditions. All these assays were elaborated with duplicates and each assay was repeated three independent times.

\subsection{Fluorescent in Situ Hybridization and Adhered Bacteria Quantification}

The 8 chamber glass slides containing the adhered bacteria were first fixed and hybridized with Lac663 and Gard162 PNA probes, that we previously developed and optimized [22]. Briefly, the adhered bacteria glass slides were fixed with $4 \%$ paraformaldehyde followed by $50 \%$ methanol, for $10 \mathrm{~min}$, at room temperature, on each solution. After the fixation step, the glass slides were covered with $20 \mu \mathrm{L}$ of hybridization solution with PNA probe $(200 \mathrm{nM})$. Hybridization was performed at $60{ }^{\circ} \mathrm{C}$ for $90 \mathrm{~min}$ and for washing $\left(60^{\circ} \mathrm{C}\right.$ for $\left.30 \mathrm{~min}\right)$ and a fresh solution was prepared less than $24 \mathrm{~h}$ before use. Finally, the glass slides were allowed to air dry in the dark. An additional DAPI staining step was done at the end of the hybridization procedure, covering each glass slide with $20 \mu \mathrm{L}$ of DAPI $(2.5 \mu \mathrm{g} / \mathrm{mL}$, Sigma) for $5 \mathrm{~min}$ at room temperature in the dark, followed by five washing steps with $20 \mu \mathrm{L}$ of PBS. Then immediate observation was elaborated in the fluorescence microscope. Microscopic visualization was performed using an EVOS $f l$ fluorescence microscope (AMG; Bothell, WA, USA) equipped with a CCD camera (Sony ICX285AQ color; Fujian, China) and filters capable of detecting the two PNA probes and DAPI staining. All these assays were repeated three times, on separate days, with three fields of view assessed each time. In each experimental assay, a negative control was performed simultaneously with each step previous described, but where no probe or DAPI staining 
were added in the hybridization step. Bacteria adhered cells quantification was realized through the National Institutes of Health image analysis software ImageJ (version 1.451) [23].

\subsection{G. vaginalis Mixed Species Biofilms Assays and Quantitative-PCR Procedure}

The formation of $G$. vaginalis mixed biofilms were performed in a chemically medium (CDM), previously developed by Geshnizgani and Onderdonk [24]. An initial inoculation of $100 \mu \mathrm{L}$ overnight of $G$. vaginalis 101 growth was placed into $10 \mathrm{~mL}$ of CDM. Then, $2 \mathrm{~mL}$ of $G$. vaginalis strain were put in each well of 6-well plate and incubated for $24 \mathrm{~h}$, at $37^{\circ} \mathrm{C}$, in anaerobic conditions. After $24 \mathrm{~h}$, $\mathrm{CDM}$ media was changed in each well plate by a fresh CDM media and an inoculation of $50 \mu \mathrm{L}$ overnight culture from a different second anaerobe was performed. Next, the 6-well plates were incubated for another $24 \mathrm{~h}$, at $37^{\circ} \mathrm{C}$, in anaerobic conditions. Finally, CDM media and planktonic cells were removed from all 6-well plates and then DNA was extracted from biofilm samples by using a Dneasy blood and tissue kit (Qiagen; Hilden, Germany), following manufacturer instructions. All qPCR assays were performed using a Taq $2 \times$ Master Mix (BioLabs; Ipswich, MA, USA) on an iCycler iQ5 real-time detection system (Bio-Rad; Hercules, CA, USA). Each $25 \mu \mathrm{L}$ reaction mixture contained $12.5 \mu \mathrm{L}$ Taq $2 \times$ Master Mix, $1.0 \mu \mathrm{L}$ of $10 \mu \mathrm{M}$ from forward and reverse primers (see Table 4), $2 \mu \mathrm{L}$ template DNA, $8.5 \mu \mathrm{L}$ of nuclease-free water. Temperature cycling for all assays was $95{ }^{\circ} \mathrm{C}$ for $10 \mathrm{~min}$, followed by 40 cycles at $95{ }^{\circ} \mathrm{C}$ for $15 \mathrm{~s}, 54{ }^{\circ} \mathrm{C}$ for $30 \mathrm{~s}$ and $72{ }^{\circ} \mathrm{C}$ for $15 \mathrm{~s}$. Negative controls (no template DNA) were run with every assay to check for contamination. Assay results were expressed as threshold cycle number $\left(C_{\mathrm{t}}\right)$ of the $16 \mathrm{~S}$ rRNA gene copies amplification per template DNA sample. All these assays were elaborated with duplicates and each assay was repeated three independent times.

Table 4. Set of primers used in this study according to the Ribosomal Database Project II (RDPII) for quantitative real-time PCR.

\begin{tabular}{ccccc}
\hline $\begin{array}{c}\text { Bacteria } \\
\text { target }\end{array}$ & qPCR primers & $\begin{array}{c}\text { DNA } \\
\text { target }\end{array}$ & $\begin{array}{c}\text { Accession number } \\
\text { in RDPII }\end{array}$ & $\begin{array}{c}\text { Localization in } \\
\text { RDPII sequence }\end{array}$ \\
\hline $\begin{array}{c}\text { G. vaginalis } \\
\text { G. vaginalis }\end{array}$ & Fw 5'-CACATTGGGACTGAGATACGG-3' & 16S rRNA & S002289761 & $325-345$ \\
$\begin{array}{l}\text { M. } \text { mulieris } \\
\text { M. } \text { mulieris }\end{array}$ & Fw 5'-CGTGTACACTCACCCGAAAGC-3' & 16S rRNA & S002289761 & $470-490$ \\
A. vaginae & Fw 5'-TATATCGCATGATGTATATGGG-3' & 16S rRNA & S000607439 & $184-205$ \\
A. vaginae & Rv 5'-CATTTCACCGCTACACTTGG-3' & 16S rRNA & S000607439 & $658-677$ \\
P. bivia & Fw 5'-CGCACAGTAAACGATGGATG-3' & 16S rRNA & S000414458 & $806-825$ \\
P. bivia & Rv 5'-ATGCAGCACCTTCACAGATG-3' & 16S rRNA & S000414458 & $1032-1051$ \\
F. nucleatum & Fw 5'-ATTTGTAGGAATGCCGATGG-3' & 16S rRNA & S001577261 & $694-713$ \\
F. nucleatum & Rv 5'-TACTTATCGCGTTTGCTTGG-3' & 16S rRNA & S001577261 & $842-861$ \\
\hline
\end{tabular}

Searched through RDPII (last accession, December 2012) with the following data set options: Strain -Both; Source-Both; Size—> 1200bp; Quality—Both. 


\subsection{Statistical Analysis}

The data was analysed using a two-tailed ANOVA or Student's $t$-test with SPSS statistical software (version 17.0) and expressed as mean \pm standard deviation (SD). $p<0.05$ was considered significant.

\section{Conclusions}

Our results suggest that $G$. vaginalis may be more suited as an early colonizer relative to the $\mathrm{BV}$-associated anaerobes tested in the initial adhesion assay, and that it may play a key role in the early establishment of BV biofilms, as previously postulated by Swidsinski et al. [4]. All anaerobes tested enhanced biofilm formation by $G$. vaginalis and also $G$. vaginalis biofilms enhanced the growth of $P$. bivia and to a minor extent of $F$. nucleatum. These observations provide some clarification regarding the ability of each individual $\mathrm{BV}$-associated anaerobe tested to adhere in the presence of a protective layer of lactobacilli and regarding the ability of $G$. vaginalis biofilms to thrive in presence of other anaerobes.

\section{Acknowledgments}

This work was supported by European Union funds (FEDER/COMPETE) and by national funds (FCT) under the project with reference FCOMP-01-0124-FEDER-008991 (PTDC/BIA-MIC/ 098228/2008) and in part by funds from the National Institutes of Health (P60-MD002256). AM acknowledges the FCT individual fellowship SFRH/BD/62375/2009.

\section{Conflict of Interest}

AM and NC have submitted a patent request for the PNA probes used in this study.

\section{References}

1. Turovskiy, Y.; Noll, K.S.; Chikindas, M.L. The etiology of bacterial vaginosis. J. Appl. Microbiol. 2011, 110, 1105-1128.

2. De Backer, E.; Verhelst, R.; Verstraelen, H.; Alqumber, M.A.; Burton, J.P.; Tagg, J.R.; Temmerman, M.; Vaneechoutte, M. Quantitative determination by real-time PCR of four vaginal Lactobacillus species, Gardnerella. vaginalis and Atopobium. vaginae indicates an inverse relationship between L. gasseri and L. iners. BMC Microbiol. 2007, doi:10.1186/1471-2180-7-115.

3. Schwebke, J.R. New concepts in the etiology of bacterial vaginosis. Curr. Infect. Dis. Rep. 2009, 11, 143-147.

4. Swidsinski, A.; Mendling, W.; Loening-Baucke, V.; Ladhoff, A.; Swidsinski, S.; Hale, L.P.; Lochs, H. Adherent biofilms in bacterial vaginosis. Obstet. Gynecol. 2005, 106, 1013-1023.

5. Fredricks, D.N.; Fiedler, T.L.; Marrazzo, J.M. Molecular identification of bacteria associated with bacterial vaginosis. N. Engl. J. Med. 2005, 353, 1899-1911. 
6. Verstraelen, H.; Swidsinski, A. The biofilm in bacterial vaginosis: Implications for epidemiology, diagnosis and treatment. Curr. Opin. Infect. Dis. 2013, 26, 86-89.

7. Cerca, N.; Martins, S.; Pier, G.B.; Oliveira, R.; Azeredo, J. Quantitative analysis of adhesion and biofilm formation on hydrophilic and hydrophobic surfaces of clinical isolates of Staphylococcus epidermidis. Res. Microbiol. 2005, 156, 506-514.

8. Darveau, R.P. Periodontitis: A polymicrobial disruption of host homeostasis. Nat. Rev. Microbiol. 2010, 8, 481-490.

9. Bodet, C.; Chandad, F.; Grenier, D. Pathogenic potential of Porphyromonas gingivalis, Treponema denticola and Tannerella forsythia, the red bacterial complex associated with periodontitis. Pathol. Biol. 2007, 55, 154-162.

10. Holt, S.C.; Ebersole, J.L. Porphyromonas gingivalis, Treponema denticola, and Tannerella forsythia: The "red complex", a prototype polybacterial pathogenic consortium in periodontitis. Periodontol. 2000 2005, 38, 72-122.

11. Spiegel, C.A.; Davick, P.; Totten, P.A.; Chen, K.C.; Eschenbach, D.A.; Amsel, R.; Holmes, K.K. Gardnerella vaginalis and anaerobic bacteria in the etiology of bacterial (nonspecific) vaginosis. Scand. J. Infect. Dis. Suppl. 1983, 40, 41-46.

12. Tamrakar, R.; Yamada, T.; Furuta, I.; Cho, K.; Morikawa, M.; Yamada, H.; Sakuragi, N.; Minakami, H. Association between Lactobacillus species and bacterial vaginosis-related bacteria, and bacterial vaginosis scores in pregnant Japanese women. BMC Infect. Dis. 2007, 7, 1-8.

13. McLean, N.W.; Rosenstein, I.J. Characterisation and selection of a Lactobacillus species to re-colonise the vagina of women with recurrent bacterial vaginosis. J. Med. Microbiol. 2000, 49, 543-552.

14. Patterson, J.L.; Girerd, P.H.; Karjane, N.W.; Jefferson, K.K. Effect of biofilm phenotype on resistance of Gardnerella vaginalis to hydrogen peroxide and lactic acid. Am. J. Obstet. Gynecol. 2007, 197, 170.e1-170.e7.

15. Patterson, J.L.; Stull-Lane, A.; Girerd, P.H.; Jefferson, K.K. Analysis of adherence, biofilm formation and cytotoxicity suggests a greater virulence potential of Gardnerella vaginalis relative to other bacterial-vaginosis-associated anaerobes. Microbiology 2010, 156, 392-399.

16. Harwich, M.D.; Alves, J.M.; Buck, G.A.; Strauss, J.F.; Patterson, J.L.; Oki, A.T.; Girerd, P.H.; Jefferson, K.K. Drawing the line between commensal and pathogenic Gardnerella vaginalis through genome analysis and virulence studies. BMC Genomics 2010, 11, 375-386.

17. Pybus, V.; Onderdonk, A. Evidence for a commensal, symbiotic relationship between gardnerella vaginalis and prevotella bivia involving ammonia: Potential significance for bacterial vaginosis. J. Inf. Dis. 1997, 175, 406-413.

18. Ferris, M.J.; Masztal, A.; Aldridge, K.E.; Fortenberry, J.D.; Fidel, P.L., Jr.; Martin, D.H. Association of Atopobium vaginae, a recently described metronidazole resistant anaerobe, with bacterial vaginosis, BMC Infect. Dis. 2004, doi:10.1186/1471-2334-4-5. 
19. Srinivasan, S.; Liu, C.; Mitchell, C.M.; Fiedler, T.L.; Thomas, K.K.; Agnew, K.J.; Marrazzo, J.M.; Fredricks, D.N. Temporal variability of human vaginal bacteria and relationship with bacterial vaginosis. PLoS One 2010, 5, doi:10.1371/journal.pone.0010197.

20. Swidsinski, A.; Dörffel, Y.; Loening-Baucke, V.; Schilling, J.; Mendling, W. Response of Gardnerella vaginalis biofilm to 5 days of moxifloxacin treatment. FEMS Immunol. Med. Microbiol. 2011, 61, 41-46.

21. Foster, J.S.; Kolenbrander, P.E. Development of a multispecies oral bacterial community in a saliva-conditioned flow cell. Appl. Environ. Microbiol. 2004, 70, 4340-4348.

22. Machado, A.; Almeida, C.; Salgueiro, D.; Henriques, A.; Vaneechoutte, M.; Haesebrouck, F.; Vieira, M.J.; Rodrigues, L.; Azevedo, N.F.; Cerca, N. Fluorescence in Situ hybridization method using peptide nucleic acid probes for rapid detection of Lactobacillus and Gardnerella spp. BMC Microbiol. 2013, 13, 82, doi:10.1186/1471-2180-13-82.

23. Collins, T.J. ImageJ for microscopy. Biotechniques 2007, 43, 25-30.

24. Geshnizgani, A.; Onderdonk, A. Defined medium simulating genital tract secretions for growth of vaginal microflora. J. Clin. Microbiol. 1992, 30, 1323-1326. 


\title{
3. Biotechnological Aspects
}

\section{Emulsifying Activity and Stability of a Non-Toxic Bioemulsifier Synthesized by Microbacterium sp. MC3B-10}

\author{
Juan Carlos Camacho-Chab, Jean Guézennec, Manuel Jesús Chan-Bacab, Elvira Ríos-Leal, \\ Corinne Sinquin, Raquel Muñiz-Salazar, Susana del C. De la Rosa-García, \\ Manuela Reyes-Estebanez and Benjamín Otto Ortega-Morales
}

\begin{abstract}
A previously reported bacterial bioemulsifier, here termed microbactan, was further analyzed to characterize its lipid component, molecular weight, ionic character and toxicity, along with its bioemulsifying potential for hydrophobic substrates at a range of temperatures, salinities and $\mathrm{pH}$ values. Analyses showed that microbactan is a high molecular weight (700 kDa), non-ionic molecule. Gas chromatography of the lipid fraction revealed the presence of palmitic, stearic, and oleic acids; thus microbactan may be considered a glycolipoprotein. Microbactan emulsified aromatic hydrocarbons and oils to various extents; the highest emulsification index was recorded against motor oil (96\%). The stability of the microbactan-motor oil emulsion model reached its highest level (94\%) at $50{ }^{\circ} \mathrm{C}$, $\mathrm{pH} 10$ and 3.5\% $\mathrm{NaCl}$ content. It was not toxic to Artemia salina nauplii. Microbactan is, therefore, a non-toxic and non-ionic bioemulsifier of high molecular weight with affinity for a range of oily substrates. Comparative phylogenetic assessment of the 16S rDNA gene of Microbacterium sp. MC3B-10 with genes derived from other marine Microbacterium species suggested that this genus is well represented in coastal zones. The chemical nature and stability of the bioemulsifier suggest its potential application in bioremediation of marine environments and in cosmetics.
\end{abstract}

Reprinted from Int. J. Mol. Sci. Cite as: Camacho-Chab, J.C.; Guézennec, J.; Chan-Bacab, M.J.; Ríos-Leal, E.; Sinquin, C.; Muñiz-Salazar, R.; del C. De la Rosa-García, S.; Reyes-Estebanez, M.; Ortega-Morales, B.O. Emulsifying Activity and Stability of a Non-Toxic Bioemulsifier Synthesized by Microbacterium sp. MC3B-10. Int. J. Mol. Sci. 2013, 14, 18959-18972.

\section{Introduction}

Microorganisms produce a wide variety of high and low molecular weight biosurfactants. These active molecules include proteins, polysaccharides, lipopeptides, glycolipids, flavolipids, phospholipids and lipopolysaccharides [1]. High molecular weight biosurfactants, usually referred to as bioemulsifiers, can form and stabilize oil-in-water or water-in-oil emulsions, work at low concentrations and exhibit considerable substrate specificity [2]. The chemical diversity and functional properties of these compounds result in a broad spectrum of potential applications in sectors as diverse as agriculture, cosmetics, environmental, food, leather, paper, pharmaceutical and textile industries [2,3]. Biologically derived surface-active molecules have advantages over their synthetic counterparts, 
including biodegradability, lower toxicity, novel structural chemistry and high stability at extreme temperature, salinity and $\mathrm{pH}[2,4]$. Some bioemulsifiers, e.g., emulsan [5], have been extensively characterized and reached commercial applications, chiefly in the bioremediation sector.

Bioprospection of various habitats, in particular marine environments [6,7], has yielded many novel biomolecules produced by microorganisms. An earlier report showed that the extracellular biopolymer produced by Microbacterium sp. MC3B-10 emulsified hexane, decane and hexadecane at higher efficiencies than commercial surfactants $\operatorname{Triton}^{\circledR} \mathrm{X}-100$ and Tween ${ }^{\circledR} 80$ [8]. This extracellular biopolymer will be referred to as microbactan after its bacterial producer. The goal of the present study was to characterize in greater detail this extracellular biopolymer and determine the emulsifying stability as a function of key variables.

\section{Results and Discussion}

\subsection{Characterization of Microbactan}

Microbactan was produced by fermentation in shaker flasks; no attempt was made at this time to optimize its production using a bioreactor, where more strict control of variables can be achieved. The reproducibility of production conditions employed in this study was confirmed by the yield and the primary chemical profile of the biopolymer, which was comparable to the previous report [8]. Our previous work showed that microbactan was dominated by carbohydrates and proteins, and was preliminarily considered a glycoprotein. The present study also revealed the presence of lipids, shown by the peak at $2927 \mathrm{~cm}^{-1}$ in the FT-IR analysis, which represents the asymmetric stretch $(\mathrm{C}-\mathrm{H})$ of $-\mathrm{CH}_{2}$ groups combined with that of $-\mathrm{CH}_{3}$ groups in lipids [9]. Quantitative assessment by absorbance showed that the lipid signature detected by FT-IR corresponded to a lipid content of $8 \% \pm 0.5 \%$. The gas chromatograph analysis of the lipid fraction revealed the presence of palmitic (C-16), stearic (C-18) and oleic (C-18:1) acids. Other fatty acids, found at lower levels, were myristoleic (C-14:1) and linoleic (C-18:2). The lipid content and the previously reported chemical composition of $\sim 90 \%$ carbohydrates and proteins [8] represented almost $100 \%$ of the total mass of the microbactan on a dry weight basis, suggesting that this biopolymer is a class of glycolipoprotein. The fatty acids detected (palmitic, stearic and oleic) have been reported in bioemulsifiers produced by Yarrowia lipolytica [10] and Penicillium sp. [11]. However, the presence of other substituents of extracellular biopolymers such as pyruvil, succinyl and sulfates, which often occur at minor levels [4,9], was not investigated.

High performance size exclusion chromatography showed that microbactan had a molecular weight (MW) approaching $700 \mathrm{kDa}$ and a polydispersity index (Mw/number average molecular weight) of 1.3; a value close to 1 denotes a polymer with homogeneous monomer grouping. These results indicate that microbactan is a homogeneous high molecular weight glycolipoprotein, a finding that is consistent with previous reports showing that, in general, bioemulsifiers are high molecular weight polymers $[1,12]$. The commercial bioemulsifier alasan ${ }^{\circledR}$ has a molecular weight of approximately $1000 \mathrm{kDa}$ [13]. Most bacterial bioemulsifiers are polymers of either carbohydrates or proteins, or even 
glycoproteins [1,6]. Thavasi and colleagues report marine-derived glycolipoprotein emulsifiers from Corynebacterium kutcheri and Bacillus megaterium [14,15]. The putative glycolipoprotein nature of microbactan is, therefore, to some extent unusual among marine bioemulsifiers.

Microbactan was shown by the modified double diffusion test to be a non-ionic emulsifier. The ionic character of polymers is one of the features that contribute strongly to the functional properties of emulsifiers; this property is often reported for synthetic emulsifiers or novel emulsifying formulations used for a range of applications. Despite the importance of this feature, it is rarely reported in newly discovered bioemulsifiers. The non-ionic nature of emulsifiers greatly contributes to emulsion stability, generating a number of short-range repulsive forces, such as steric, hydration, and thermal fluctuation interactions, which prevent the droplets from getting too close together [16].

\subsection{Emulsifying Potential}

Tables 1 and 2 show the emulsifying activity of microbactan and control commercial emulsifiers tested against different substrates at different times. Statistical analysis showed significant differences between microbactan and these controls $(F=84.24 ; p<0.05)$. Synthetic surfactants Triton ${ }^{\circledR} \mathrm{X}-100$ and Tween $^{\circledR} 80$ were more efficient than microbactan and the commercial biopolymers, reaching emulsification efficiencies of $100 \%$ against oils (with the exception of motor oil), irrespective of time of incubation (24 and $96 \mathrm{~h}$ ). Microbactan showed stronger emulsifying activities than gum arabic but was comparable to the emulsifying efficiency of xanthan gum, another bacterially-produced biopolymer. The emulsifying activity of microbactan was dependent on the type of substrate $(F=16.2 ; p<0.05)$; this is consistent with other reports on substrate-specific hydrocarbon metabolism by marine bacteria $[17,18]$. Microbactan emulsions with the tested substrates were rather stable over time (Tables 1 and 2), varying only slightly between 24 and $96 \mathrm{~h}$.

Table 1. Emulsifying activity of microbactan, commercial synthetic surfactants and natural biopolymer emulsifiers on various hydrophobic substrates after $24 \mathrm{~h}$ of evaluation.

\begin{tabular}{|c|c|c|c|c|c|}
\hline \multirow{2}{*}{ Hydrophobic substrate } & \multirow{2}{*}{ Microbactan a } & \multicolumn{2}{|c|}{ Synthetic surfactants a } & \multicolumn{2}{|c|}{ Biopolymers ${ }^{\text {a }}$} \\
\hline & & Tween 80 & Triton-X-100 & Gum arabic & Xanthan gum \\
\hline Benzene & $76.9 \pm 2.4$ & $98.7 \pm 0.6$ & $54.3 \pm 2.0$ & $80.7 \pm 3.0$ & $64.7 \pm 1.3$ \\
\hline Xylene & $81.5 \pm 3.4$ & $94.7 \pm 6.1$ & $98.2 \pm 0.4$ & $72.6 \pm 3.4$ & $76.8 \pm 1.7$ \\
\hline Crude oil & $76.5 \pm 2.1$ & $82.9 \pm 0.6$ & 100 & $54.7 \pm 3.7$ & $95.0 \pm 0.9$ \\
\hline Motor oil & $96.3 \pm 0.1$ & $54.9 \pm 1.4$ & $68.5 \pm 6$ & $95.2 \pm 1.1$ & $89.5 \pm 3.3$ \\
\hline Sunflower oil & $84.4 \pm 5.4$ & 100 & 100 & $77.8 \pm 1.5$ & $62.4 \pm 2.4$ \\
\hline Corn oil & $81.1 \pm 1.6$ & 100 & 100 & 0 & $90.6 \pm 1.9$ \\
\hline Olive oil & $76.1 \pm 0.3$ & 100 & 100 & $96.6 \pm 0.1$ & $76.6 \pm 5.4$ \\
\hline Mineral oil & 0 & $95.9 \pm 5.6$ & 100 & $60.3 \pm 2.8$ & $86.5 \pm 3.8$ \\
\hline
\end{tabular}

${ }^{a}$ Results are expressed as percentages of the total height occupied by the emulsion; values are means of at least three determinations. 
Table 2. Emulsifying activity of microbactan, commercial synthetic surfactants and natural biopolymer emulsifiers on various hydrophobic substrates after $96 \mathrm{~h}$ of evaluation.

\begin{tabular}{|c|c|c|c|c|c|}
\hline \multirow{2}{*}{ Hydrophobic substrate } & \multirow{2}{*}{ Microbactan a } & \multicolumn{2}{|c|}{ Synthetic surfactants ${ }^{a}$} & \multicolumn{2}{|c|}{ Biopolymers $^{\text {a }}$} \\
\hline & & Tween 80 & Triton-X-100 & Gum arabic & Xanthan gum \\
\hline Benzene & $75.3 \pm 3.8$ & $93.2 \pm 5$ & $54.3 \pm 2.1$ & $78.9 \pm 0$ & $61.7 \pm 1.4$ \\
\hline Xylene & $75.4 \pm 0.5$ & $94.1 \pm 5$ & $97.9 \pm 0.5$ & $63.7 \pm 3$ & $75 \pm 1.6$ \\
\hline Crude oil & $72 \pm 4.8$ & $85.5 \pm 5$ & $100 \pm 0$ & $53.2 \pm 2.4$ & $93.8 \pm 2.5$ \\
\hline Motor oil & $96.3 \pm 0.1$ & $53.5 \pm 2.3$ & $59 \pm 4.2$ & $92.8 \pm 1.8$ & $83.7 \pm 3.2$ \\
\hline Sunflower oil & $83.8 \pm 3.4$ & 100 & 100 & $77.8 \pm 2.1$ & $62.4 \pm 2.4$ \\
\hline Corn oil & $81.1 \pm 1.6$ & 100 & 100 & 0 & $91.5 \pm 0.8$ \\
\hline Olive oil & $76.1 \pm 0.5$ & 100 & 100 & $96.6 \pm 0.6$ & $78.2 \pm 2.6$ \\
\hline Mineral oil & 0 & $91.2 \pm 2.3$ & $100 \pm 0$ & $56.8 \pm 2.3$ & $82.9 \pm 2$ \\
\hline
\end{tabular}

a Results are expressed as percentages of the total height occupied by the emulsion; values are means of at least three determinations.

An established criterion for emulsion-stabilizing capacity is the ability of an emulsifier to maintain at least $50 \%$ of the original volume of the emulsion for $24 \mathrm{~h}[4,19]$. Microbactan emulsions remained stable for several months, showing no sign of droplet coalescence after standing at room temperature $\left(28^{\circ} \mathrm{C}\right)$. This extended stability has previously been observed for glycoprotein bioemulsifiers produced by a marine Antarctobacter [20]. Emulsifying and surfactant activities are together responsible for important functional properties of bacterial exopolymers. Our analyses revealed that microbactan has emulsifying but not surfactant activity. Surface-active biomolecules are classified as surfactants when they lower the interfacial or surface tension and emulsifiers when they form stable emulsions [19,21]. Overall, our results indicate that microbactan is a true bioemulsifier.

\subsection{Effect of Temperature, $\mathrm{pH}$ and $\mathrm{NaCl}$ on Emulsifying Activity}

The effect of these three key variables that influence emulsifying activity was assessed at 24, 48, 72 and $96 \mathrm{~h}$. As expected, they influenced the emulsifying activity of microbactan, but their effects occurred at different levels. A time-dependent decrease of emulsifying activity was observed at $100{ }^{\circ} \mathrm{C}$ $(F=38.13 ; p<0.005)$. This was not the case for activities at $50{ }^{\circ} \mathrm{C}$ and $5{ }^{\circ} \mathrm{C}$. The highest level of activity was found at $50{ }^{\circ} \mathrm{C}$ (emulsifying activity of $95.7 \% \pm 2.5 \%$ ) irrespective of time of incubation (Figure 1). The loss of emulsifying activity at $100{ }^{\circ} \mathrm{C}$ can be explained by denaturation of the protein fraction of microbactan during heating [22], as seen with other microbial biosurfactants [23]. Similarly, the activity associated with the upper limit of the range of salinities tested $(3.5 \%, 5 \%$, and $10 \%)$ declined as a function of time to level off at 72 and $96 \mathrm{~h}$. The highest levels of activity were observed at 3.5\% (Figure 2), not dissimilar to the biosurfactant produced by Aeromonas spp., which maintained emulsifying activity up to $5 \% \mathrm{NaCl}$ [24]. On the other hand, no significant effect on activity was observed as a function of time with the $\mathrm{pH}$ values tested (Figure 3). However, slightly higher levels of emulsifying activity were recorded at acid and alkaline $\mathrm{pH}$ values, suggesting the ionization of 
functional groups that resulted in the activation of less surface-active species within the bioemulsifier matrix [25]. In comparison, biodispersan from Acinetobacter calcoaceticus A2 had an optimum functional $\mathrm{pH}$ value in the range of 9 to 12 for limestone-dispersing activity [26]. It has been shown that the emulsifying activity of certain polymers is modified at different extents when temperature and $\mathrm{pH}$ covariate, this is probably due to the synergistic influence of these factors on surface-active proteins, whose conformation and functional groups are influenced as a function of these factors.

Figure 1. Emulsifying activity of microbactan on motor oil at different temperatures up to 96 h. $5^{\circ} \mathrm{C}(\bullet), 50{ }^{\circ} \mathrm{C}(\bullet)$ and $100{ }^{\circ} \mathrm{C}(\boldsymbol{\Delta})$. Values represent means $\pm \mathrm{SD}(n=3)$.

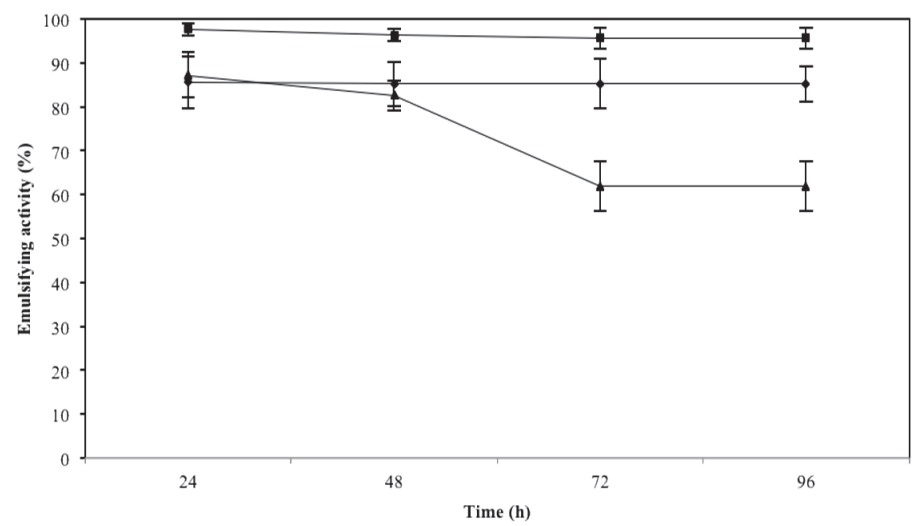

Figure 2. Emulsifying activity of microemulsan on motor oil at various salinities up to $96 \mathrm{~h}$. $3.5 \%(\bullet), 5 \%(\bullet)$ and $10 \%(\Delta) \mathrm{NaCl}$ concentration. Values represent means $\pm \mathrm{SD}(n=3)$.

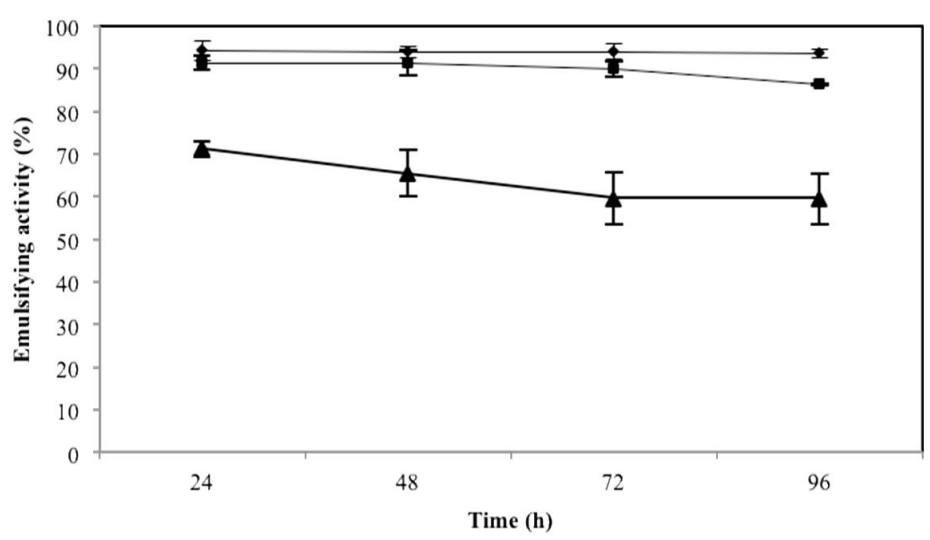


Figure 3. Emulsifying activity of microbactan on motor oil at different $\mathrm{pH}$ values. $\mathrm{pH} 4(\bullet), \mathrm{pH} 7(\boldsymbol{\bullet})$ and $\mathrm{pH} 10(\boldsymbol{\Delta})$.Values represent means $\pm \mathrm{SD}(n=3)$.

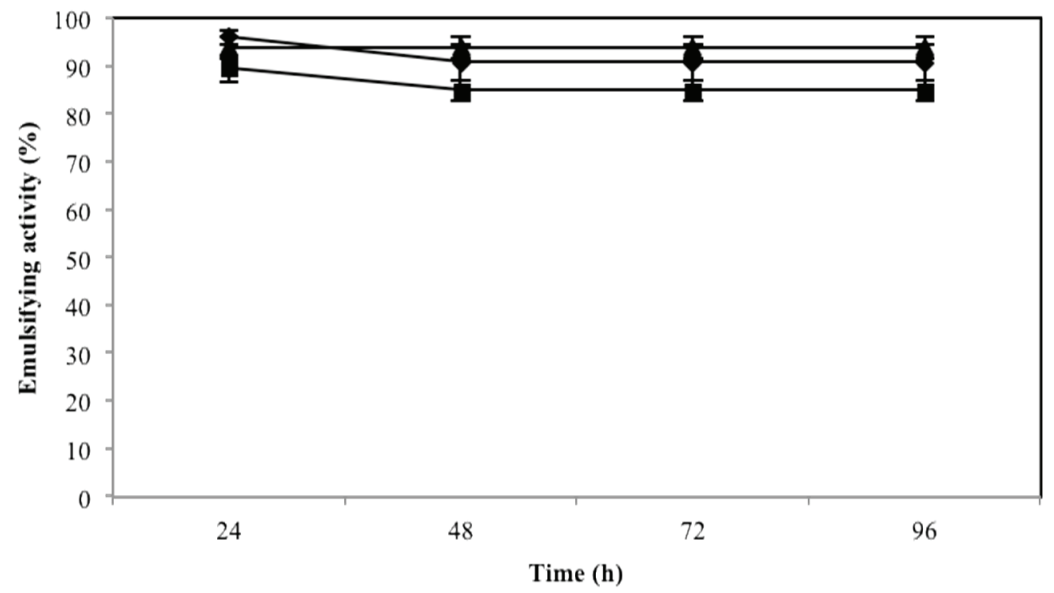

These results suggest that microbactan could find application in environmental marine processes such as enhanced oil recovery, cleaning of oil reservoirs and enhancement of biodegradation rates of spilled oils [2]. Bioemulsifiers have a wide diversity of composition and structure and are characterized by improved functionality and stability. Their potential applications include: the oil and petroleum industries, water and soil bioremediation, metal treatment and processing, detergents and laundry supplies, agriculture, textile manufacturing, pulp and paper processing, paints, cosmetics, pharmaceuticals, personal care products and food processing [4,6]. Microbactan has higher emulsifying activity at $50{ }^{\circ} \mathrm{C}$ and $3.5 \% \mathrm{NaCl}$, conditions typical of intertidal environments [8]. If the molecule remains stable under these conditions for long periods, it may prove specifically useful for bioremediation of polluted intertidal habitats [27]. The stability of the emulsions under diverse conditions, such as temperature, pressure, $\mathrm{pH}$ and ionic strength, makes this biopolymer a versatile emulsifier for use in many food and pharmaceutical formulations.

\subsection{Toxicity of Microbactan}

Based solely on the Artemia salina toxicity test, microbactan proved innocuous, as expected for a biologically derived surface-active agent; this class of compound is generally biodegradable and non-toxic [2]. Although synthetic surfactants exhibited the highest emulsifying activity in this study, Triton ${ }^{\circledR}$ X-100 (also a non-ionic surface-active), at least, proved to be toxic in our Artemia bioassay (Table 3). Polyoxyethylene octyl phenols (the Triton X series) are known to be highly cytotoxic, solubilizing the membrane lipid bilayer [28]. In fact, these synthetic surfactants can actually inhibit aromatic hydrocarbon biodegradation via toxic interactions, making them less suitable for bioremediation purposes [27,29]. The Artemia salina toxicity bioassay is a reliable primary screen, given the sensitivity of this crustacean to a wide range of biologically active compounds of diverse chemistries, including pesticide residues, mycotoxins, stream pollutants, anaesthetics, dinoflagellate toxins, 
morphine-like compounds and oil dispersants [30]. In addition, this bioassay has demonstrated good correlation with other cell-based tests such as tumor cell lines (e.g., KB, P-388, 388, L5178Y and L1210) and mammalian systems [31,32]. Reinforcing this finding, an experimental study on marine biofilm colonization on surfaces coated with microbactan showed that this biopolymer did not affect biofilm formation (unpublished results).

Table 3. Anti-crustacean activity of surfactants against Artemia salina nauplii.

\begin{tabular}{cc}
\hline Surfactant & LC $_{\mathbf{5 0}}(\boldsymbol{\mu g} / \mathbf{m L})$ \\
\hline Microbactan & $>1000$ \\
Triton X-100 & $100.3 \pm 3.8$ \\
Tween 80 & $>1000$ \\
\hline
\end{tabular}

\subsection{Phylogenetic Reassessment of Microbacterium sp. MC3B-10}

The reassessment of the phylogenetic position of Microbacterium sp. MC3B-10 based on its $16 \mathrm{~S}$ rDNA gene, using a more robust bioinformatics approach, confirmed that its closest relative was Microbacterium trichothecenolyticum, with a similarity of 99.2\% (underline, Figure 4). Stackebrandt and Ebers [33] established that a cutoff of 98.7\% $16 \mathrm{~S} r D N A$ gene homology is appropriate for species differentiation within a genus. Following this criterion and given the fact that Microbacterium is a very tight genus with respect to $16 S$ rDNA gene homology between valid species [34], Microbacterium sp. MC3B-10 could be classified as $M$. trichothecenolyticum. However, definitive identification of this bacterial isolate requires a polyphasic approach including biochemical, physiological, chemotaxonomic, and nucleic acid-based methods, along with a range of microscopies, as previously shown for newly described Microbacterium species [35].

The in-silica analysis revealed novel strains of the genus Microbacterium (MC24 and MC60) that had been isolated from an intertidal environment in Brazil and were capable of synthesizing bioemulsifiers [36]. These isolates were also related to Microbacterium sp. MC3B-10, but at lower similarity levels (97\%). It should be noted that, except for M. resistens, M. hominis, and M. paraoxydans, all microbacteria are considered environmental bacteria [34]. Certain Microbacterium species, such as M. thalassium, M. halophilum, and M. phyllosphaerae, occur in coastal habitats [35,37]. However, the biotechnological potential of this genus as a marine bioemulsifier producer has only been reported recently $[8,36]$. The occurrence of bioemulsifier-producing Microbacterium species in intertidal environments is not surprising, given the metabolic versatility exhibited by this genus; some of them can metabolize hydrocarbons, presumably through bioemulsifier synthesis [38,39]. In addition, the availability of hydrophobic substrates in coastal marine environments may select for bacteria capable of synthesizing surface-active molecules to enhance nutrient uptake [1]. 
Figure 4. Neighbor-joining phylogenetic tree, based on $16 \mathrm{~S} r D N A$ gene sequences, showing the positions of strain MC3B-10 (AY833570) relative to all known Microbacterium species. Accession numbers of $16 S$ rDNA gene sequences of reference organisms are shown in parentheses. Bootstrap values (1000 replicates, $>50 \%)$ are shown above the nodes. The bar indicates the relative sequence divergence ( 0.01 nucleotide substitutions per site). Curtobacterium luteum and C. michiganense were used as outgroups.

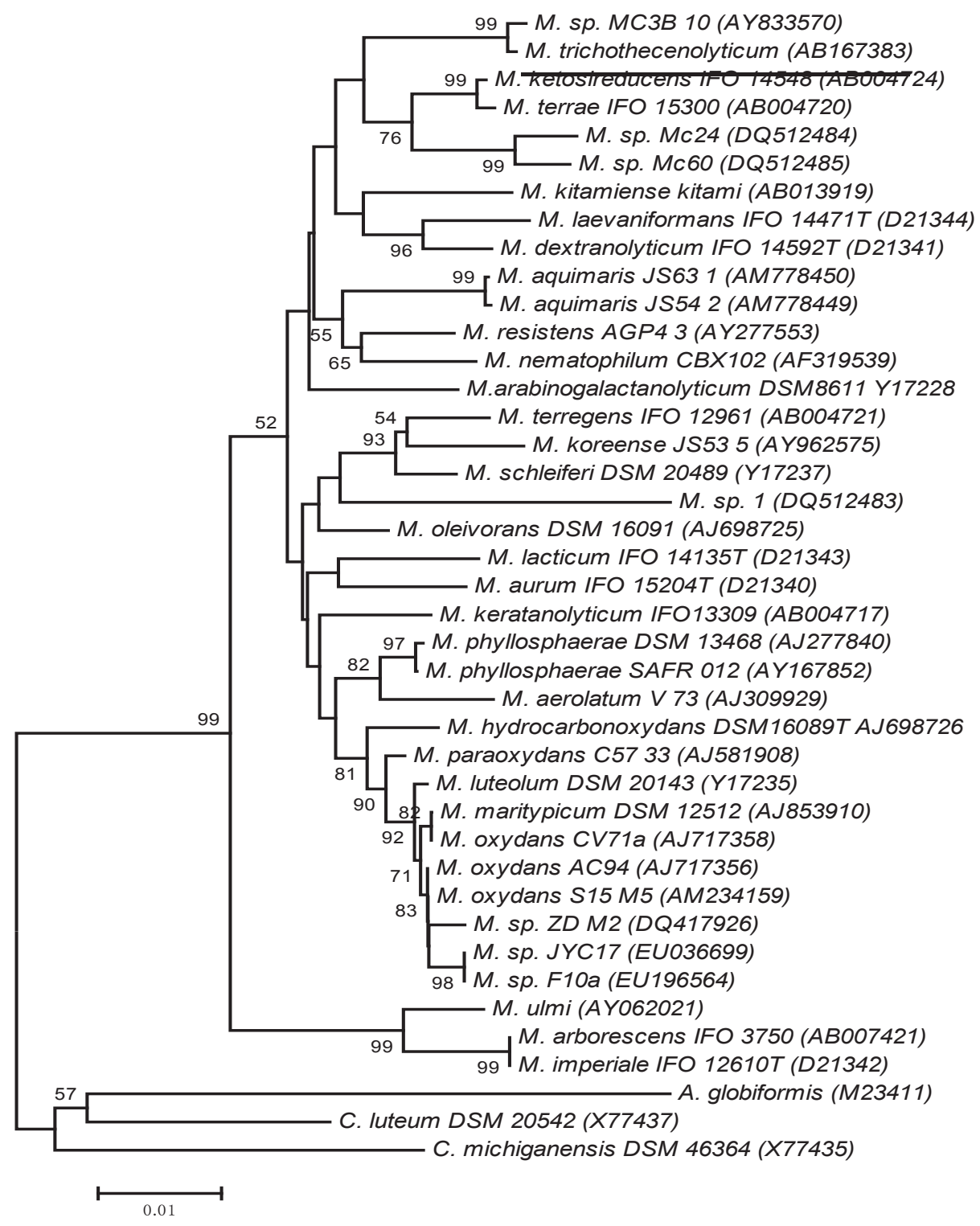




\section{Experimental Section}

\subsection{Production of Microbactan}

Microbacterium sp. MC3B-10 was originally isolated from pristine rocky intertidal shores in the state of Campeche, southern Gulf of Mexico, Mexico. Microbactan was produced following a batch shake flask fermentation of an overnight culture $(50 \mathrm{~mL})$ of Microbacterium sp. MC3B-10 as previously reported [8]. The exopolymeric material was extracted from the fermented broth, redissolved in a small volume of distilled water and then dialyzed (molecular weight cutoff 12,000-14,000 Da, Spectrum ${ }^{\circledR}$, CA, USA) for $72 \mathrm{~h}$. The resulting material was lyophilized and kept in the dark before analysis.

\subsection{Lipid Analysis and Fatty Acid Composition}

Lipids were determined using Fourier-transform infrared spectroscopy (FT-IR) [8] and spectrophotometry, using triolein as standard lipid [40]. Fatty acid composition was investigated as follows. After mild acid hydrolysis of the exopolymer $(0.7064 \mathrm{~g})$ at $80{ }^{\circ} \mathrm{C}$ for $30 \mathrm{~min}$, the hydrolysate was extracted with $\mathrm{CHCl}_{3}: \mathrm{CH}_{3} \mathrm{OH}: \mathrm{H}_{2} \mathrm{O}(3: 2: 1)$ and the aqueous phase extracted two more times with $\mathrm{CHCl}_{3}(1: 1)$. The $\mathrm{CHCl}_{3}$ fractions were combined and evaporated under reduced pressure [41]. Before GC-MS analysis, the sample was pre-treated as described previously [42]. The methylation of fatty acids was carried out with $5 \mathrm{~mL}$ of $\mathrm{HCl}$-methanol at $80{ }^{\circ} \mathrm{C}$ for $30 \mathrm{~min}$. The fatty acid methyl ethers were extracted with hexane and subjected to analysis. GC-MS was performed using helium as carrier gas on a Perkin Elmer Clarus 580 GC equipped with a Clarus SQ 8S mass spectrometer, equipped with an Elite- 5 capillary column $(30 \mathrm{~m} \times 0.32 \mathrm{~mm}$ i.d., $0.25 \mu \mathrm{m}$ film thickness).

\subsection{High Performance Size Exclusion Chromatography}

The molecular weight of microbactan was determined using an HPLC system Prominence Shimadzu ${ }^{\mathrm{TM}}$, a PL aquagel-OH mixed, $8 \mu \mathrm{m}$ (Varian) guard column (U $7.5 \mathrm{~mm} \times \mathrm{L} 50 \mathrm{~mm}$ ), and a PL aquagel-OH mixed (Varian, Palo Alto, CA, USA) separation column (U $7.5 \times 300 \mathrm{~mm}$, operating range $10^{2}-10^{7} \mathrm{~g} / \mathrm{mol}$ ). Elution was performed at $1 \mathrm{~mL} / \mathrm{min}$ with $0.1 \mathrm{M}$ ammonium acetate containing $0.03 \% \mathrm{NaN}_{3}$, and the eluate filtered through a $0.1 \mu \mathrm{m}$ membrane (Durapore Membrane, PVDF, Hydrophilic type VVLP, Millipore ${ }^{\circledR}$, Saint Quentin en Yvelines, France). A differential refractive index (RI) detector (L2490, VWR Hitachi, Fontenay sous bois, France) and a multi-angle light scattering detector (Dawn Heleos ${ }^{\mathrm{TM}}$, Wyatt, Toulouse, France) were coupled on-line and data computed with Astra software for absolute molar mass determination.

\subsection{Ionic Charge}

The ionic charge of microbactan was assessed using a modified double diffusion technique [43]. Briefly, two $12 \mathrm{~mm}$-diameter plugs were taken from Petri dishes containing 1\% agar. One of the 
resulting wells was filled with $200 \mu \mathrm{L}$ of microbactan solution at $1 \mathrm{mg} / \mathrm{mL}$ and the other with commercial anionic (sodium dodecyl sulphate SDS and Teepol ${ }^{\circledR}$ 610S Sigma-Aldrich Química, S. de R.L. de C.V., Toluca, Mexico State, Mexico) or cationic (barium chloride and cetyltrimethylammonium bromide) surfactants supplied by Sigma-Aldrich. These surfactants were used at $20 \mathrm{mmol}$, except for barium chloride $(50 \mathrm{mmol})$. The appearance of precipitation lines between the wells was indicative of the ionic character of microbactan. Plates were incubated at $28{ }^{\circ} \mathrm{C}$ and monitored daily.

\subsection{Emulsifying Activity}

The emulsifying activity of microbactan was assessed against aromatic hydrocarbons (benzene and xylene), vegetable oils (corn, olive and sunflower) and mineral, motor and crude oils, all at 1\%. Oils were acquired from local commercial suppliers and the hydrocarbons were of analytical grade (J.T. Baker, Center Valley, PA, USA; E.M. Sciences, Hatfield, PA, USA). The emulsifying activity was measured by combining equal volumes of microbactan solution $(1 \% w / v)$ and the target hydrophobic substrates in 12-mm-diameter glass tubes, as previously described [8]. Controls included Triton $^{\circledR}$ X-100 and Tween ${ }^{\circledR} 80$ (Research Organics, Cleveland, OH, USA), a plant-derived polysaccharide (gum arabic from Spectrum $^{\circledR}$ ) and xanthan gum, a bacterial polysaccharide (ICN Biomedicals, Inc, Irvine, CA, USA). All evaluations were performed in triplicate.

\subsection{Effects of Temperature, Salinity and pH on Emulsifying Activity}

The effect of temperature, $\mathrm{NaCl}$ content and $\mathrm{pH}$ on emulsifying activity of microbactan was tested using motor oil because this substrate yielded the highest levels of emulsification ( $\sim 96 \%)$. The influence of temperature was determined by pretreating at desired temperatures $\left(5,50\right.$ and $\left.100{ }^{\circ} \mathrm{C}\right)$ microbactan solutions that were either heated for $15 \mathrm{~min}$ in a water bath or cooled for $10 \mathrm{~min}$ in a freezer, before being assayed [23]. The effect of $\mathrm{NaCl}$ was investigated at three concentrations $(3.5,5$ and $10 \% \mathrm{w} / \mathrm{v}$ ) and $\mathrm{pH}$ values of 4,7 and 10 were studied. Emulsification with motor oil was carried out at room temperature as in Item $3.5[22,24]$.

\subsection{Toxicity Test}

Brine shrimp eggs (Salt Creek ${ }^{\mathrm{TM}}$, Salt Lake City, UT, USA) were hatched at $27{ }^{\circ} \mathrm{C}$ under continuous aeration and illumination in seawater prepared with sea salts (Coralife ${ }^{\circledR}$, Rhinelander, WI, USA) at $38 \mathrm{~g} / \mathrm{L}$ and supplemented with $6 \mathrm{mg} / \mathrm{L}$ of dried yeast [44]. Solutions of Triton ${ }^{\circledR} \mathrm{X}-100$ and Tween ${ }^{\circledR} 80$ (Research Organics, Cleveland, OH, USA) and microbactan were dissolved in seawater at concentrations of 1000, 500, 100, 50 and $10 \mu \mathrm{g} / \mathrm{mL}$ [45]. The 50\% Lethal Concentration (LC50) was determined by counting the dead nauplii after an incubation period of $24 \mathrm{~h}$. Data were analyzed with the Finney computer program as described previously [27]. 


\subsection{Statistical Analysis}

All the experiments were run in triplicate. For the emulsification assays, a two-way analysis of variance (ANOVA) was used to assess the effect of biopolymer and controls on the hydrophobic substrates. When there was a significant difference $(p \leq 0.05)$ between microemulsion and controls, we applied the Tukey test aposteriori. These tests were performed with Sigma Stat software version 2.0 (1997).

\subsection{Phylogenetic Reassessment}

The purpose of this analysis was twofold: first, to corroborate the identification of the species of Microbacterium MC3B-10 based on its 16S rDNA gene (AY833570) using a more robust bioinformatics approach (see details below) with the sequences reported in [8], and second to prove if recently reported species of Microbacterium displaying bioemulsifying activity or originally isolated from polluted environments were phylogenetically close to Microbacterium sp. MC3B-10. The following additional sequences were obtained from the GenBank database, Microbacterium sp. Mc1 DQ512483, Mc24 DQ512484, Mc60 DQ512485, M. aquimaris JS54-2 AM778449, M. aquimaris JS63-1 AM778450, Microbacterium sp. F10a EU196564, M. oleivorans DSM 16091 AJ698726 and $M$. sp. ZD-M2 DQ417926. In total, 41 sequences (1418 bp) were aligned using the CLUSTALW algorithm implemented in MEGA 4.3 software [46]. Phylogenetic analyses were performed using the Neighbor Joining (NJ) algorithm: phylogenetic analysis using parsimony V4.0 beta 10, 2002. For NJ analyses, the evolutionary model selected was the GTR + I + G (General Time Reversible Model + Invariable sites + Gamma distribution) inferred from the program Modeltest V.3.06 [47]. Support for nodes of the NJ tree was determined by calculating bootstrap proportion values [48] based on 1000 resamplings of neighbor-joining searches. The 16S rDNA sequences of Curtobacterium luteum and C. michiganense were used as outgroup.

\section{Conclusions}

This study demonstrated that the novel Microbacterium sp. MC3B-10, probably indigenous to the marine intertidal zone, synthesizes an environmentally-friendly exopolymeric non-ionic glycolipoprotein capable of emulsifying aromatic hydrocarbons and oils. The functional stability of this bioemulsifier was retained for long periods of time and at a range of temperature, $\mathrm{NaCl}$ concentration and $\mathrm{pH}$. The chemistry, activity and stability of microbactan make it useful for environmental and personal care applications. Overall, our results suggest that bioemulsifier-producing bacteria warrant intensified bioprospection in the intertidal zones. Additionally, this study corroborates the still untapped resource represented by marine microorganisms for new biosurfactants, bioemulsifiers and biopolymers. This work thus strengthens the notion that marine microbial diversity is a non-exhausted source of novel biomolecules and particularly emphasizes the biotechnological significance of Microbacterium species derived from the intertidal environment. 


\section{Acknowledgments}

This research was supported by a grant Marine biofilm inhibition by bacterial exopolymeric substance-based coatings and characterization of producing isolates (F/3617-2F) 2008-2011, from the International Foundation for Science (IFS) F/3617-1, Stockholm, Sweden; Organization for the Prohibition of Chemical Weapons, The Hague, The Netherlands.

\section{Conflicts of Interest}

The authors declare no conflict of interest.

\section{References}

1. Ron, E.; Rosenberg, E. Natural roles of biosurfactants. Environ. Microbiol. 2001, 3, 229-236.

2. Banat, I.M.; Franzetti, A.; Gandolfi, I.; Bestetti, G.; Martinotti, M.; Fracchia, L.; Smyth, T.; Marchant, R. Microbial biosurfactants, production, applications and future potential. Appl. Microbiol. Biotechnol. 2010, 87, 427-444.

3. Freitas, F.; Alves, V.; Reis, M. Advances in bacterial exopolysaccharides: From production to biotechnological applications. Trends Biotechnol. 2011, 29, 388-398.

4. Freitas, F.; Alves, V.; Carvalheira, M.; Costa, N.; Oliveira, R.; Reis, M. Emulsifying behaviour and rheological properties of the extracellular polysaccharide produced by Pseudomonas oleovorans grown on glycerol byproduct. Carbohyd. Polym. 2009, 78, 549-556.

5. Satpute, S.; Banat, I.; Dhakephalkar, P.; Banpurkar, A.; Chopade, B. Biosurfactants, bioemulsifiers and exopolysaccharides from marine microorganisms. Biotechnol. Adv. 2010, 28, 436-450.

6. Gutiérrez, T.; Leo, V.; Walker, G.; Green, D. Emulsifying properties of a glycoprotein extract produced by a marine Flexibacter species strain TG382. Enzyme Microb. Technol. 2009, 45, 53-57.

7. Ortega-Morales, B.O.; Chan-Bacab, M.J.; de la Rosa-García, S.C.; Camacho-Chab, J.C. Valuable processes and products from marine intertidal microbial communities. Curr. Opin. Biotechnol. 2010, 21, 346-352.

8. Ortega-Morales, B.O.; Santiago, J.; Chan-Bacab, M.J.; Miranda, E.; Fardeau, M.; Carrero, J.; Bartolo, P.; Valadéz, A.; Guezennec, J. Characterization of extracellular polymers synthesized by tropical intertidal biofilm bacteria. J. Appl. Microbiol. 2007, 102, 254-264.

9. Beech, I.; Hanjagsit, L.; Kalaji, M.; Neal, A.L.; Zinkevich, V. Chemical and structural characterization of exopolymers produced by Pseudomonas sp. NCIMB 2021 in continuous culture. Microbiology 1999, 145, 1491-1497.

10. Amaral, P.; Silva, J.; Lehocky, M.; Barros-Timmons, A.; Coelho, M.; Marrucho, I.; Coutinho, J.A.P. Production and characterization of a bioemulsiftier from Yarrowia lipolytica. Process Biochem. 2006, 41, 1894-1898. 
11. Luna-Velasco, M.A.; Esparza-García, F.; Cansares-Villanueva, R.O.; Rodríguez-Vázquez, R. Production and properties of a bioemulsifier synthesized by phenanthrene-degrading Penicillum sp. Process Biochem. 2007, 42, 310-314.

12. Maier, R.M. Biosurfactants: Evolution and diversity in bacteria. Adv. Appl. Microbiol. 2003, 52, $101-121$.

13. Navon-Venezia, S.; Zosim, Z.; Gottlieb, A.; Legmann, R.; Carmeli, S.; Ron, E.Z.; Rosenberg, E. Alasan, a new bioemulsifier from Acinetobacter radioresistens. Appl. Environ. Microb. 1995, 61, $3240-3244$.

14. Thavasi, R.; Jayalakshmi, S.; Balasubramanian, T.; Banat, I. Biosurfactant production by Corynebacterium kutscheri from waste motor lubricant oil and peanut oil cake. Lett. Appl. Microbiol. 2007, 45, 686-691.

15. Thavasi, R.; Jayalakshmi, S.; Balasubramanian, T.; Banat, I. Production and characterization of a glycolipid biosurfactant from Bacillus megaterium using economically cheaper sources. World J. Microbiol. Biotechnol. 2007, 24, 917-925.

16. Whitman, W. Food Emulsifiers: Chemistry, Technology, Functional Properties and Applications; Ten Alps Publishing: London, UK, 1990.

17. Kim, S.; Ravichandran, D.; Khan, S.; Kim, Y. Prospective of the cosmeceuticals derived from marine organisms. Biotechnol. Bioprocess Eng. 2008, 13, 511-523.

18. Kumar, A.; Mody, K.; Jha, B. Evaluation of biosurfactant/bioemulsifier production by a marine bacterium. Bull. Environ. Contam. Toxicol. 2007, 79, 617-621.

19. Willumsen, P.A.; Karlson, U. Screening of bacteria, isolated from PAH-contaminated soils, for production of biosurfactants and bioemulsifiers. Biodegradation 1997, 7, 415-423.

20. Gutiérrez, T.; Mulloy, B.; Bavington. C.; Black, K.; Green, D. Partial purification and chemical characterization of a glycoprotein (putative hydrocolloid) emulsifier produced by a marine bacterium Antarctobacter. Appl. Microbiol. Biotechnol. 2007, 76, 1017-1026.

21. Perfumo, A.; Smyth, T.J.; Marchant, R.; Banat, I.M. Production and Roles of Biosurfactants and Bioemulsifiers in Accessing Hydrophobic Substrates. In Handbook of Hydrocarbon and Lipid Microbiology; Timmis, K.N., Ed.; Springer-Verlag: Berlin, Germany, 2010; pp. 1502-1510.

22. Sarubbo, L.; Moura, J.; Campos-Takaki, G. Production and stability studies of the bioemulsifier obtained from a new strain of Candida glabrata UCP 1002. Electron. J. Biotechnol. 2006, 9, 400-406.

23. Rufino, R.; Sarubbo, A.; Campos, G. Enhancement of stability of biosurfactant produced by Candida lipolytica using industrial residue as substrate. World J. Microb. Biotechnol. 2007, 23, 729-734.

24. Ilori, M.O.; Amobi, C.; Odocha, A. Factors affecting biosurfactant production by oil degrading Aeromonas spp. isolated from a tropical environment. Chemosphere 2005, 61, 985-992.

25. Sarubbo, L.; Farias, C.; Campos-Takaki, G. Co-utilization of canola oil and glucose on the production of a surfactant by Candida lipolytica. Curr. Microbiol. 2007, 54, 68-73. 
26. Rosenberg, E.; Rubinovitz, C.; Gottlieb, A.; Rosenhak, S.; Ron, E.Z. Production of biodispersan by Acinetobacter calcoaceticus A2. Appl. Environ. Microb. 1988, 54, 317-322.

27. Pelletier, E.; Delille, D.; Delille, B. Crude oil bioremediation in sub-Antarctic intertidal sediments: Chemistry and toxicity of oiled residues. Mar. Environ. Res. 2004, 57, 311-327.

28. Weyermann, J.; Lochmann, D.; Zimmer, A. A practical note on the use of cytotoxicity assays. Int. J. Pharm. 2005, 288, 369-376.

29. Meyer, B.N.; Ferrigni, N.R.; Putnam, J.E.; Jacobsen, L.B.; Nichols, D.E.; McLauglin, J.L. Brine shrimp: A convenient general bioassay for active plant constituents. Planta. Med. 1982, 45, 31-34.

30. McLaughlin, J.L. Crown-gall Tumors in Potato Discs and Brine Shrimp Lethality: Two Simple Bioassays for Higher Plant Screening and Fractionation. In Methods in Plant Biochemistry; Hostettmann, K., Ed.; Academic Press: London, UK, 1991; Volume 6, pp. 1-32.

31. Birndorf, H.C.; D’Alossio, J.; Bagshaw, J.C. DNA-dependant RNA-polymerases from Artemia, embryos. Characterization of polymerases I and II from nauplius larvae. Dev. Biol. 1975, 45, 34-43.

32. Perfeito, J.P.; Santos, M.L.; López, K.S.; Paula, J.E.; Silveira, D. Characterization and biological properties of Pouteria torta extracts. Rev. Bras. Farmacogn. 2005, 15, 183-186.

33. Stackebrandt, E.; Ebers, J. Taxonomic parameters revisited: Tarnished gold standards. Microbiol. Today 2006, 33, 152-155.

34. Gneiding, K.; Frodl, R.; Funke, G. Identities of Microbacterium spp. encountered in human clinical specimens. J. Clin. Microbiol. 2008, 46, 3646-3652.

35. Takeuchi, M.; Hatano, K. Proposal of six new species in the genus Microbacterium and transfer of Flavobacterium marinotypicum ZoBell and Upham to the genus Microbacterium as Microbacterium maritypicum comb. nov. Int. J. Syst. Bacteriol. 1998, 48, 973-982.

36. Aniszewski, E.; Silva, R.; Faria, F.; Gomes, S.; Soares, A. Bioemulsifier production by Microbacterium sp. strains isolated from mangrove and their application to remove cadmiun and zinc from hazardous industrial residue. Braz. J. Microbiol. 2010, 41, 235-245.

37. Burmølle, M.; Webb, J.; Rao, D.; Hansen, L.; Sørensen, S.; Kjelleberg, S. Enhanced biofilm formation and increased resistance to antimicrobial agents and bacterial invasion are caused by synergistic interactions in multispecies biofilms. Appl. Environ. Microb. 2006, 72, 3916-3925.

38. Schippers, A.; Bosecker, K.; Sproer, C.; Schumann, P. Microbacterium oleivorans sp. nov. and Microbacterium hydrocarbonoxydans sp. nov., novel crude-oil-degrading Gram-positive bacteria. Int. J. Syst. Evol. Microbiol. 2005, 55, 655-660.

39. Franzetti, A.; Gandolfi, I.; Bertolini, V.; Raimondi, C.; Piscitello, M.; Papacchini, M.; Bestetti, G. Phylogenetic characterization of bioemulsifier-producing bacteria. Int. Biodeterior. Biodegrad. 2011, 65, 1095-1099.

40. Izard, J.; Limberger, R. Rapid screening method for quantification of bacterial cell lipids from whole cells. J. Microbiol. Meth. 2003, 55, 411-418. 
41. Ganfield, M.C.; Pieringer, R.A. Phosphatidylkojibiosyl diglyceride. The covalently linked lipid constituent of the membrane lipoteichoic acid from Streptococcus faecalis (faecium) ATCC 9790. J. Biol. Chem. 1975, 250, 702-709.

42. Rezanka T.; Vokoun, J.; Slavicek, J.; Podojil, M. Determination of fatty acids in algae by capillary gas chromatography-mass spectrometry. J. Chromatogr. 1983, 268, 71-78.

43. Van Oss, C.J. Specifically impermeable precipitate membranes formed through double diffusion in gels: Behavior with complex forming and with simple systems. J. Colloid Interf. Sci. 1968, 27, 684-690.

44. Ortega-Morales, B.O.; Chan-Bacab, M.J.; Miranda-Tello, E.; Fardeau M.L.; Carrero J.C.; Stein, T. Antifouling activity of sessile bacilli derived from marine surface. J. Ind. Microbiol. Biotechnol. 2008, 35, 9-15.

45. Solís, P.; Wright, C.; Anderson, M.; Gupta, M.; Phillipson, D.A. A Microwell cytotoxic using Artemia salina (brine shrimp). Planta Med. 1993, 59, 250-252.

46. Tamura, K.; Dudley, J.; Nei, M.; Kumar, S. MEGA4: Molecular Evolutionary Genetics Analysis (MEGA) software version 4.0. Mol. Biol. Evol. 2007, 24, 1596-1599.

47. Posada, D.; Crandall, K.A. Modeltest: Testing the model of DNA substitution. Bioinformatics 1998, 14, 817-818.

48. Felsenstein, J. Confidence limits on phylogenies: An approach using the bootstrap. Evolution 1985, 39, 783-791. 


\title{
Archaeal Diversity in Biofilm Technologies Applied to Treat Urban and Industrial Wastewater: Recent Advances and Future Prospects
}

\author{
Kadiya Calderón, Alejandro González-Martínez, Cinta Gómez-Silván, Francisco Osorio, \\ Belén Rodelas and Jesús González-López
}

\begin{abstract}
Biological wastewater treatment (WWT) frequently relies on biofilms for the removal of anthropogenic contaminants. The use of inert carrier materials to support biofilm development is often required, although under certain operating conditions microorganisms yield structures called granules, dense aggregates of self-immobilized cells with the characteristics of biofilms maintained in suspension. Molecular techniques have been successfully applied in recent years to identify the prokaryotic communities inhabiting biofilms in WWT plants. Although methanogenic Archaea are widely acknowledged as key players for the degradation of organic matter in anaerobic bioreactors, other biotechnological functions fulfilled by Archaea are less explored, and research on their significance and potential for WWT is largely needed. In addition, the occurrence of biofilms in WWT plants can sometimes be a source of operational problems. This is the case for membrane bioreactors (MBR), an advanced technology that combines conventional biological treatment with membrane filtration, which is strongly limited by biofouling, defined as the undesirable accumulation of microbial biofilms and other materials on membrane surfaces. The prevalence and spatial distribution of archaeal communities in biofilm-based WWT as well as their role in biofouling are reviewed here, in order to illustrate the significance of this prokaryotic cellular lineage in engineered environments devoted to WWT.
\end{abstract}

Reprinted from Int. J. Mol. Sci. Cite as: Calderón, K.; González-Martínez, A.; Gómez-Silván, C.; Osorio, F.; Rodelas, B.; González-López, J. Archaeal Diversity in Biofilm Technologies Applied to Treat Urban and Industrial Wastewater: Recent Advances and Future Prospects. Int. J. Mol. Sci.

2013, 14, 18572-18598.

\section{Archaea and Biofilms: An Introduction}

Archaea is one of the three domains of life distinguished by Carl Woese by phylogenetic analysis based on 16S rRNA genes [1]. They are abundant and metabolically-diverse microorganisms which coexist with Bacteria and Eukarya in most Earth environments; however, they remain the least well known of the branches of the phylogenetic tree of life, despite the many efforts made to investigate their role in natural and engineered systems [2]. Their diversity remains rather unexplored, although it has been estimated to be comparable to that observed for Bacteria [2]. The physiological functions of the Archaea identified in mixed microbial communities suggest their significant role in the biogeochemical cycles of the planet, maintaining the flow and recycling of the nutrients in many environments [3]. In particular, the recent discovery of ammonia-oxidizing Archaea (AOA) changed the classical view of 
the nitrogen $(\mathrm{N})$ cycle, as AOA are currently regarded as the main ammonia-oxidizing organisms in oceans and geothermal habitats [4].

Biofilms are complex, spatially-structured multicellular communities, formed on the surfaces or interfaces of materials of both organic and inorganic nature [5]. Biofilms are known to have existed since the discovery of microorganisms, as they were first visualized by van Leewenhoeck in the XVII century [6], and have become accepted as the dominant microbial life style in nature. Cell aggregation and surface adhesion provide a protected mode of growth, enabling survival in hostile environments. The nature of biofilm structure is dynamic, as the cells anchored to the surface eventually disperse and revert into the planktonic mode of living, which then enables the colonization of new niches [7].

The steps that lead to the formation of microbial biofilms have been extensively described by different authors $[5,8,9]$. It is generally accepted that the process starts when microbes associated with a surface change from a reversible to an irreversible mode of attachment to it, followed by the aggregation of cells and their subsequent proliferation. The cells in the biofilm are encased in a matrix of self-produced polymers of heterogeneous nature (lipids, polysaccharides, extracellular nucleic acids or proteins), referred to as the EPS (extracellular polymeric substances), which fulfill important functions [5]. The extraordinary tolerance of biofilms to antimicrobial compounds, heavy metals and other damaging agents derives from a complex mixture of physical, chemical and physiological factors: the metabolic heterogeneity of the community, the particular physiological state of the microorganisms in the different biofilm layers, the support of syntrophic and other mutualistic interactions, and the development of specialized subpopulations of resistant phenotypes and persister cells [10]. The relative contribution of each of these mechanisms (and possibly others) varies with the type of biofilm and the nature of the environment where they develop [3].

Since biofilms have been recorded in fossils more three billion years old, this lifestyle is acknowledged as an ancient feature of prokaryotes [7]. In past decades, the focus of researchers was centered mainly on bacterial biofilms; however, thanks to recent advances in monospecies cultures, it has been possible to demonstrate that Archaea are also capable of attaching to biotic and abiotic surfaces and developing biofilms [3]. Biofilm formation in the environment by members of the archaeal Phyla Euryarchaeaota, Crenarchaeota, Korarchaeota and Thaumarchaeota is well documented, particularly in extreme habitats [11-14]. It is also well known that Archaea are present in biofilms of engineered habitats, such as acid-mine drainages, aquarium biofilters, or wastewater treatment (WWT) plants based on different technologies [14-19]. This review aims to summarize the current knowledge on the characteristics of Archaea and the roles they play under the biofilm lifestyle in WWT systems, with particular emphasis on their occurrence, diversity and attributed functions.

\section{Biofilm Systems Associated to WWT}

Biological WWT technologies based on the use of biofilms are broadly applied for the removal of organic matter, nitrogen and other anthropogenic contaminants occurring in wastewater. Mixed-population biofilms develop in these systems, normally requiring the addition of carrier inert materials to provide 
a supporting surface. Although many configurations of biofilm-based WWT plants have been devised, they can be classified into two broad types: fixed-bed reactors, which regard all systems in which the biofilms develop on a static media; and expanded-bed reactors, which include carrier media subjected to continuous motion driven by stirring or an air flux [20]. Amongst other advantages compared to the more generally applied conventional activated sludge (CAS) technology, biofilm-based systems are simple to control and maintain, reduce space needs, lower cost, and minimize unwanted odors and noise [21].

Different WWT systems use granular sludge (GS), based on the aggregation of microbial biomass in structures named granules, which are regarded as suspended biofilm systems and dissimilar to flocs in their shape, structure and substrate diffusion properties [22,23]. Their typical morphology and inner structure is shown in Figure 1 [23]. Granules develop in the absence of a supporting surface by the auto-immobilization of the microorganisms, and are functionally described as concentric layers of densely-packed, near-spherical biofilms, each of which is inhabited by different microbial trophic groups $[24,25]$. Each granule is a functional unit in itself, comprising all the different microorganisms necessary for the degradation of wastewater, producing biomass and EPS [26].

GS has advantages over the conventional floc aggregates and biofilms developed on supporting media, with the main one being the wider surface area provided for the biofilm [27]. GS can develop in both aerobic and anaerobic systems, provided that certain conditions are given in bioreactor design [28]. The granulation process and granule stability are affected by many operating and external factors such as temperature, hydraulic retention time (HRT), organic loading rate (OLR), nutrient availability, and the presence of divalent cations and heavy metals $[25,26,28,29]$. In this review, only factors known to have an influence on archaeal diversity will be discussed.

Figure 1. Scanning electron micrographs of anaerobic granular sludge cultivated in an Expanded Granular Sludge Bed (EGSB) reactor. (A) Morphology of anaerobic granules used (40× magnification); (B,C,D) Inner structure of anaerobic granules (6000× magnification). Reprinted from [23], Process Biochemistry, Vol. 40, Wang, J. and Kang, J., The characteristics of anaerobic ammonium oxidation (ANAMMOX) by granular sludge from an EGSB reactor, Pages 1973-1978, Copyright (2005), with permission from Elsevier.
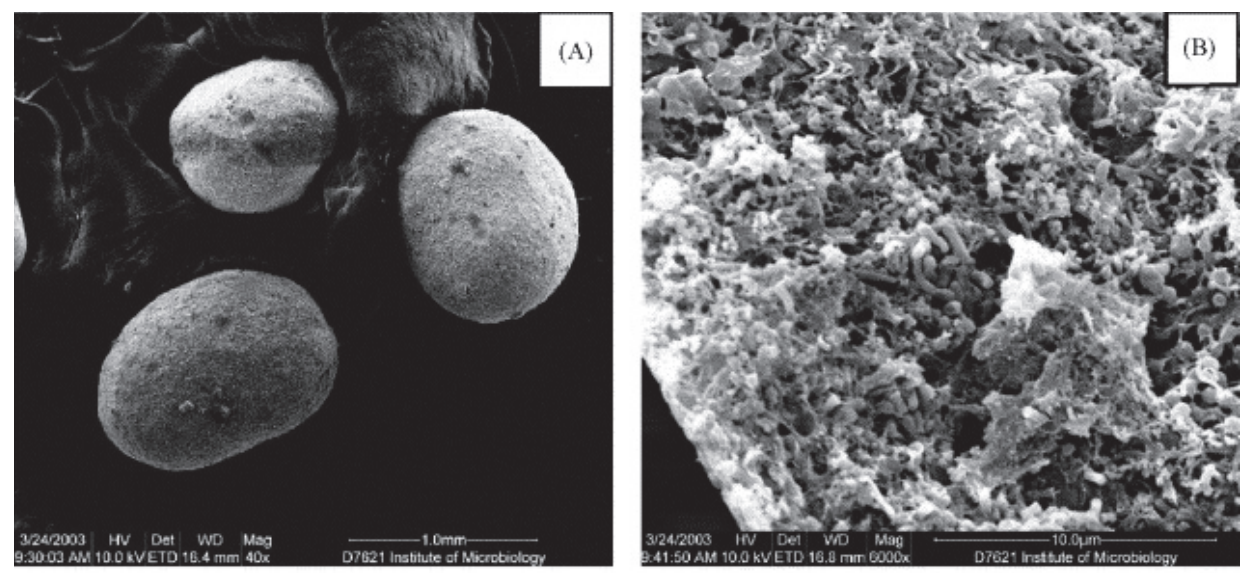
Figure 1. Cont.
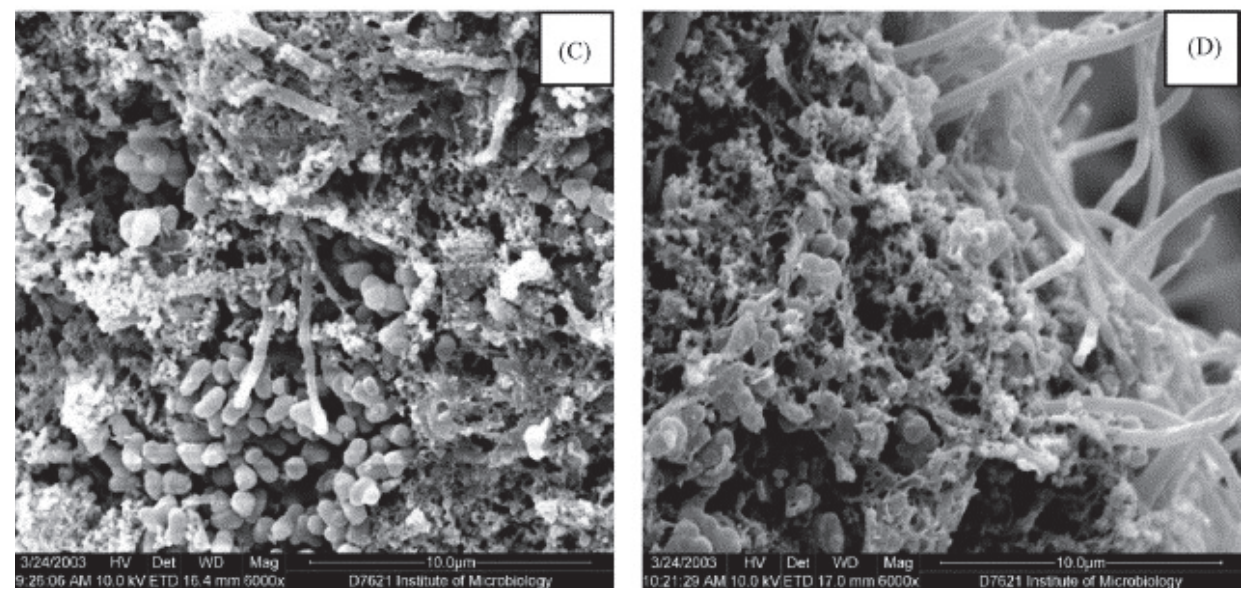

\section{Archaeal Communities in Anaerobic Bioreactors}

Anaerobic bioreactors are used for the degradation of organic matter, generating methane as a value-added by-product [30]. The methanogenic metabolism is an exclusive feature of a group of prokaryotes classified in the Phylum Euryarchaeota, which is currently divided into six orders: Methanobacteriales, Methanococcales, Methanomicrobiales, Methanosarcinales, Methanopyrales and Methanocellales [31,32]. There are also a number of 16S rRNA gene types that are often retrieved from WWT which presumably belong to as yet uncultivated archaeal taxa with metabolic functions close to those of known methanogens [33]. This is the case of sequences assigned to the WSA2 (or ArcI) group, which is considered to be an archaeal taxon at the class level [34].

Despite their ample phylogenetic, morphological and physiological diversity, methanogens only use a limited number of substrates to obtain energy. Most methanogens are restricted to using $\mathrm{H}_{2}+\mathrm{CO}_{2}$ or formate [31]. Some members of the Methanomicrobiales use secondary alcohols, and Methanosarcinales are the more metabolically versatile, being often able to use methyl group-containing compounds and also comprising the only acetoclastic methanogens, Methanosarcina spp. and Methanosaeta spp. [30,31].

Studies on the microbial diversity of anaerobic bioreactors have increased in the last 20 years, fuelled by the introduction of molecular cultivation independent methods. A wide array of primers and probes targeting phylogenetic markers of methanogens are currently available [34]. The archaeal diversity in this type of systems is limited when compared with bacterial diversity. The sequences retrieved from anaerobic reactors belong mostly to members of the Euryarchaeota phylum, although the occurrence of crenarchaeotal sequences has also been reported [33,35-37]. Despite the many differences in wastewater nature, bioreactor design and operating conditions, an overall conclusion is that the dominant Archaea are the methanogens, which usually belong to the Methanobacteriaceae, Methanosarcinaceae and Methanosaetaceae [35,37-43]. In most of the systems studied, both acetoclastic and hydrogenotrophic $\mathrm{CO}_{2}$-utilizing methanogenic Archaea coexist. It has been suggested that this configures the minimal archaeal microbiota required for stable anaerobic digestion [35]. 
Granular biomass formation by archaeal populations has been widely studied in anaerobic digestion processes [22,35,37-41,44-49]. From the technological point of view, these systems comprise mainly the UASB and expanded granular sludge bed (EGSB) reactors [28]. In 2003, McHugh et al. [50] proposed a layered structure for the anaerobic granules in which a central core of acetoclastic methanogens is surrounded by a layer of hydrogen- or formate-producing acetogens and hydrogen- or formateconsuming methanogens. The proposed granule structure provides an outside layer of microorganisms that hydrolyze and acidify complex organic matter [51] (Figure 2). Once the reactors have been seeded with anaerobic sludge and wastewater, the wastewater flows in the upward direction through the sludge and granule formation slowly occurs spontaneously under appropriate conditions of substrate and nutrient availability, $\mathrm{pH}$, alkalinity, and upflow velocity [26].

Figure 2. Anaerobic granule formation, according to the model of McHugh et al. [50].

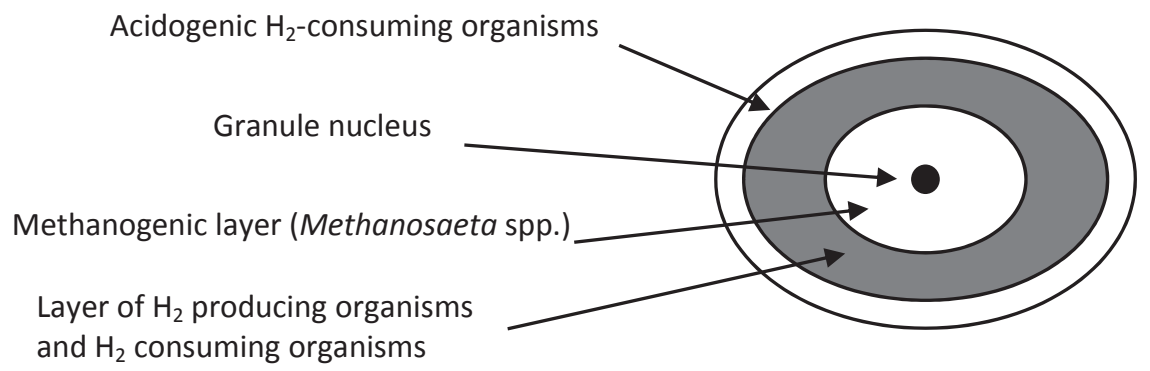

Several other types of anaerobic reactors have been successfully designed and applied to a lesser extent for the treatment of a wide range of organic-rich wastewaters (reviewed by Tabatabaei et al. [41]). Anaerobic reactors comprising a fixed-bed or an expanded-bed phase for biofilm development have been widely evaluated for the treatment of urban and industrial wastewaters [35]. The bioreactors can be entirely designed as biofilm-based, or include a biofilm phase associated to a granular phase as part of an UASB or an anaerobic baffled reactor (ABR). Methanogenic Archaea adhere preferentially to packing support materials [52]; thus, the performance of methanogenesis is higher in bioreactors when such a surface is provided for biofilm development [42]. Besides, a biofilm phase helps to improve and maintain granulation in the associated granular phase [53]. Several packing materials, such as charcoal, gravel, brick pieces, pumice stones, coconut coir, carbon fiber, nylon fiber and plastic pieces have been tested [54,55].

Some efforts have been made to describe the core prokaryotic microorganisms essential for the anaerobic degradation of organic matter, providing evidence that the archaeal communities are indeed composed of a restricted number of operational taxonomic units (OTUs). Leclerc et al. [35] used molecular methods (16S rRNA-based single-strand conformation polymorphism fingerprints and clone libraries) to analyze and compare the diversity of Archaea in 44 anaerobic bioreactors based on different technologies and treating diverse types of wastes. Most frequently, a combination of sequences phylogenetically close to Methanobacterium spp. and Methanosaeta concilii was found. The authors 
also concluded that the distribution of the archaeal species was not strongly influenced by the nature of the wastewater, but depended in part on the type of bioreactor technology. The stirred-tank digesters were able to support a community of a higher diversity compared to the biofilm-based technologies. Some archaeal populations were often found to exclude each other, showing preference for a particular type of bioreactor design. For instance, Methanosarcina frisus was prevalent in stirred-tank and fixed-film digesters, but occurred in low levels in upflow anaerobic sludge bed (UASB) reactors, which in contrast favored the presence of Methanosaeta spp. Rivière et al. [33] compared seven mesophilic $\left(29-37{ }^{\circ} \mathrm{C}\right)$ digesters used for sludge reduction in urban WWT plants across France, Germany and Chile, by analyzing large clone libraries of archaeal 16S rRNA gene fragments. In total, 69 different archaeal OTUs were found, with the majority of the sequences $(62.4 \%)$ being affiliated to three OTUs shared among 4-7 of the analyzed digesters, and 24 other OTUs (34\%) shared by 2-4 digesters. The last 42 OTUs were specific for one digester (3.6\% of the sequences). In agreement with the study by Leclerc et al. [35], most of the recognized OTUs were affiliated to methanogenic Archaea (Methanosarcinales, Methanomicrobiales, Methanobacteriales and ArcI group) with Methanosaeta spp. as the main acetoclastic methanogen. Interestingly, the most represented OTU belonged to the ArcI lineage, and members of ArcI were the dominant archaeal populations $(41 \%-69 \%$ of the sequences) in four of the analyzed anaerobic digesters.

The structure of archaeal communities in fixed-bed or expanded-bed biofilm systems has been scarcely investigated. In the study by Leclerc et al. [35], one fixed-bed reactor and seven fluidized-bed reactors treating diverse types of industrial wastewaters (brewery, winery, dairy) were evaluated, finding Methanobacterium, Methanosaeta and Methanosarcina as the prevalent genera. Comparing the results with those of GS systems, the authors concluded that all the fixed-bed and fluidized-bed reactors exhibited similar and distinctive archaeal diversity patterns, suggesting that the required attachment of cells to the supporting media strongly conditioned community structure. More recent studies indicate that Methanobacteriales and Methanomicrobiales coexist in fixed-film anaerobic reactors. Zhang et al. [42] explored the community dynamics in different compartments of two mesophilic fixed-bed anaerobic baffled reactors (FABRs) by the generation of archaeal clone libraries of the 16S rRNA gene and quantitative real-time PCR (qPCR). Although Methanobacteriales and Methanosaeta dominated the seed sludge used to inoculate the FABRs, Methanomicrobiales increased 30- to 42-fold after 32 days of operation. Methanolinea and Methanospirillum showed a preference to colonize the carbon fiber support during the start-up period, particularly in the last compartment of the system, where methanogenesis took place at the highest rate. Rademacher et al. [43] characterized the community structure of microbial biofilms developed in a thermophilic biogas system, by means of massive parallel sequencing (454-pyrosequencing). The bioreactor was a two-phase leach-bed process, with separate compartments for cellulolysis and methanogenesis on fixed-films supported by plastic carriers (Bioflow-40 media). 16S rRNA gene sequences and analysis of Pfam protein families were used to describe the structure of both the cellulolytic and methanogenic communities. Archaea represented 2\% of the $16 \mathrm{~S}$ rRNA sequences retrieved from the cellulolytic biofilm and a $12 \%$ of the methanogenic 
biofilm. Methanomicrobia dominated in the cellulolytic biofilm (2\%), while both Methanomicrobia (7\%) and Methanobacteria (4\%) prevailed in the methanogenic biofilm, where the two most abundant genera detected were Methanosarcina and Methanobacterium (both 4\%). The functional analysis supported the evidence of a clear spatial distribution of Archaea between both compartments. Four percent of the environmental genes belonged to Archaea in the cellulolytic biofilm, while the methanogenic biofilm revealed a higher contribution (22\%).

The influence of operation conditions on the diversity of archaeal communities in GS, fixed-bed and expanded-bed reactors has been widely investigated in recent years. Two factors often regarded relevant are OLR and HRT. Several studies have been conducted under varying ORL and HRT in reactors treating municipal and industrial wastewaters of diverse nature and operated at different temperatures $[37,39,40,44,56,57]$. Analyzing the diversity of the prokaryotic communities by means of different molecular approaches, most of these studies concluded that Archaea were less sensitive than bacteria to changes in ORL and HRT $[37,39,44,56]$. The archaeal community in GS remained rather stable throughout operation, being mainly composed of members of Methanobacteriaceae, Methanosaetaceae and Methanosarcinaceae (Table 1). In contrast, in the packed-bed biofilm reactors the community was dominated by Methanobacteriaceae, Methanomicrobiaceae and Methanosarcinaceae, whose prevalence shifted along the experiments depending on the changes of both ORL and HRT [56,57].

Temperature is one factor that can affect the structure and dynamics of microbial communities in WWT plants; Archaea are not an exception. Several studies have evaluated the effect of temperature on the methanogenic communities in anaerobic bioreactors, comparing their diversity under thermophilic, mesophilic, or psycrophilic conditions. A pioneering work by Visser et al. [38] using immunochemical methods revealed differences in the composition of the methanogenic community after a temperature change from 38 to $55^{\circ} \mathrm{C}$, showing that diversity decreased at higher temperatures and that quantitative changes of the size of several subpopulations took place, including Methanobrevibacter smithii, Methanobrevibacter arboriphilus, Methanosarcina thermophila, Methanospirillum hungatei, Methanobacterium thermoautotrophicum, and Methanogenium cariaci. In contrast, Sekiguchi et al. [58] analyzed a clone library representing the archaeal community in granules of two UASB reactors fed synthetic wastewater and operated at 35 and $55{ }^{\circ} \mathrm{C}$, and detected a similar composition of the methanogenic communities, composed mainly of Methanosaeta concilii, Methanosaeta thermophila and populations closely related to the Methanobacteriales. Using more sensitive molecular fingerprinting methods, Khemkhao et al. [47] evaluated the adaptation of microbial diversity from mesophilic to thermophilic conditions in five consecutive phases $(37,42,47$, 52 and $57^{\circ} \mathrm{C}$ ) in a UASB granular reactor treating palm oil mill effluent. The results of their study showed that in all cases the acetoclastic methanogens (Methanosaeta and Methanosarcina) were the dominant Archaea detected in the granules. Also, these authors reported that the dynamics of the archaeal populations were low at temperatures below $52{ }^{\circ} \mathrm{C}$, while important microbial community shifts, particularly of the Methanosaeta species, occurred when temperature rose from 52 to $57^{\circ} \mathrm{C}$ [47]. 
Table 1. Effect of Organic Loading Rate (OLR) and Hydraulic Retention Time (HRT) on the diversity of methanogenic Archaea in anaerobic bioreactors.

\begin{tabular}{|c|c|c|c|c|c|}
\hline Reference & [37] & [39] & [44] & [56] & [57] \\
\hline Type of bioreactor & EGSB & UASB & EGSB & \multicolumn{2}{|c|}{ Packed-bed biofilm } \\
\hline $\begin{array}{c}\text { Nature of } \\
\text { wastewater }\end{array}$ & $\begin{array}{c}\text { Leachate from municipal } \\
\text { sewage sludge } \\
\text { incineration plant }\end{array}$ & $\begin{array}{l}\text { Unbleached } \\
\text { cellulose pulp }\end{array}$ & Oleic acid & \multicolumn{2}{|c|}{$\begin{array}{l}\text { Short-chain fatty } \\
\text { acids }\end{array}$} \\
\hline Temperature $\left({ }^{\circ} \mathrm{C}\right)$ & $33 \pm 1$ & $30 \pm 3$ & 37 & \multicolumn{2}{|c|}{55} \\
\hline $\begin{array}{c}\text { ORL } \\
\left(\mathrm{kg} \mathrm{COD} / \mathrm{m}^{3} / \text { day }\right)\end{array}$ & 3.0 to 18.4 & 0.53 to 1.40 & 2 to 8 & 10 to 129 & 2.9 to 12.2 \\
\hline HRT (h) & 2.5 to 4.0 & 36 to 24 & 24 & 24 to 1.4 & 15 to 3.6 \\
\hline $\begin{array}{c}\text { Method of study } \\
\text { of prokaryotic } \\
\text { diversity }\end{array}$ & DGGE, qPCR & SEM, DGGE & DGGE, FISH & $\begin{array}{l}\text { Clone } \\
\text { library }\end{array}$ & DGGE \\
\hline $\begin{array}{c}\text { Prevalent } \\
\text { Archaea detected }\end{array}$ & $\begin{array}{c}\text { Methanosaeta }(68.4 \%) \\
\text { shifting to } \\
\text { Methanosarcina }(62.3 \%) \\
\text { at the end of the } \\
\text { experiment }\end{array}$ & $\begin{array}{c}\text { Methanosarcina } \\
\text { Methanosaeta }\end{array}$ & $\begin{array}{c}\text { Methanobacterium } \\
\text { Methanosaeta }\end{array}$ & \multicolumn{2}{|c|}{$\begin{array}{c}\text { Methanoculleus } \\
\text { Methanothermobacter } \\
\text { Methanosarcina }\end{array}$} \\
\hline
\end{tabular}

COD: chemical oxygen demand; SEM: scanning electron microscopy; DGGE: denaturing gradient gel electrophoresis; FISH: fluorescence in situ hybridization; qPCR: quantitative real-time PCR.

Many efforts have been focused to investigate the effect of low temperatures on archaeal diversity in GS anaerobic bioreactors, since the development of a well-functioning psychrophilic microbial consortium is a key factor to keep their operational stability. The results of several studies comparing parallel experiments in bioreactors operated at both psycrophilic and mesophilic conditions are summarized in Table 2, demonstrating temperature-dependent changes of the methanogenic community structure. A general conclusion is that the relative abundance of Methanosaeta spp. decreased at $15{ }^{\circ} \mathrm{C}$, favoring the proliferation of Methanosarcina spp., and the dominance of the hydrogenotrophic methanogens, particularly the Methanomicrobiales. Other available studies reached similar conclusions regarding the diversity of methanogens in anaerobic GS operated at low temperature [59-61]. Besides, O'Reilly et al. [45] concluded that the structure of the archaeal communities was drastically changed from that of the seed sludge under mesophilic conditions, while it remained considerably more stable under psychrophilic conditions.

In contrast, few studies have been directed to unravel how low temperatures influence methanogenic populations in anaerobic fixed-bed biofilm systems. 16S rRNA clone libraries and qPCR analyses demonstrated that Methanomicrobiales became enriched and displaced the Methanobacteriales in a packed-bed biofilm anaerobic reactor when temperature dropped from 18 to $5{ }^{\circ} \mathrm{C}$, while the Methanosaetaceae remained at similar levels of abundance throughout the experiment [62]. Members of the Methanomicrobiales and Methanosaetaceae were able to proliferate and become 
stably adhered to the carbon fiber carrier; hence, the authors concluded that these archaeal groups had an important role for the efficiency of methanogenesis at low temperatures in this type of system.

Table 2. Effect of temperature on the diversity of methanogenic Archaea in anaerobic bioreactors operated under psycrophilic or mesophilic conditions. See Table 1 footnote for abbreviations.

\begin{tabular}{|c|c|c|c|}
\hline Reference & [45] & [49] & [63] \\
\hline Type of bioreactor & EGSB & EGSB & EGSB \\
\hline Nature of wastewater & Synthetic glucose wastewater & $\begin{array}{l}\text { Synthetic brewery } \\
\text { wastewater }\end{array}$ & \begin{tabular}{c|c} 
& $\begin{array}{c}\text { Synthetic } \\
\text { wastewater } \\
\text { Synthetic }\end{array}$ \\
wastewater & $\begin{array}{c}\text { added with } \\
\text { trichloroethylene } \\
(10-60 \mathrm{mg} / \mathrm{L})\end{array}$ \\
\end{tabular} \\
\hline Temperature $\left({ }^{\circ} \mathrm{C}\right)$ & 15 and 37 & 15 and 20 & 15 and 37 \\
\hline $\begin{array}{l}\text { ORL (kg COD } \\
\left./ \mathrm{m}^{3} / \text { day }\right)\end{array}$ & 5.8 & - & 3 \\
\hline $\operatorname{HRT}(\mathrm{h})$ & 12 & 18 & 24 \\
\hline $\begin{array}{l}\text { Method of study of } \\
\text { prokaryotic diversity }\end{array}$ & DGGE, qPCR & Clone library, DGGE & qPCR \\
\hline $\begin{array}{l}\text { Archaea detected at } \\
\text { both temperatures }\end{array}$ & $\begin{array}{c}\text { Methanobacterium beijingense } \\
\text { Methanosaeta concilii }\end{array}$ & $\begin{array}{c}\text { Methanobacterium } \\
\text { Methanosaeta }\end{array}$ & $\begin{array}{c}\text { Methanobacteriales } \\
\text { Methanosaetaceae }\end{array}$ \\
\hline $\begin{array}{l}\text { Archaea favored by } \\
\text { psycrophilic conditions }\end{array}$ & $\begin{array}{l}\text { Methanocorpusculum } \\
\text { Methanosarcinaceae }\end{array}$ & $\begin{array}{c}\text { Methanospirillum } \\
\text { Methanosphaerula } \\
\text { Methanometylovorans } \\
\text { Methanosarcina }\end{array}$ & Methanomicrobiales \\
\hline $\begin{array}{l}\text { Archaea favored by } \\
\text { mesophilic conditions }\end{array}$ & Methanospirillum hungatei & - & - \\
\hline $\begin{array}{l}\text { Relevant effects of } \\
\text { temperature }\end{array}$ & $\begin{array}{l}\text { qPCR demonstrated important } \\
\text { shifts of Methanosaeta } \\
\text { abundance at } 15^{\circ} \mathrm{C} \\
\text { Hydrogenotrophic methanogens } \\
\text { prevailed at } 15^{\circ} \mathrm{C} \text {, particularly } \\
\text { Methanomicrobiales }\end{array}$ & $\begin{array}{l}\text { Lower temperature } \\
\text { decreased the abundance } \\
\text { of Methanosaeta and led } \\
\text { to a higher diversity of } \\
\text { methanogens }\end{array}$ & $\begin{array}{l}\text { Start up was slower at } 15^{\circ} \mathrm{C} \\
\text { Methanomicrobiales emerged } \\
\text { earlier at } 15^{\circ} \mathrm{C} \\
\text { Methanosaetaceae response } \\
\text { to trichloroethylene toxicity } \\
\text { differed with temperature }\end{array}$ \\
\hline
\end{tabular}

The effect of the dissolved oxygen concentration (DO) on the archaeal populations in GS has been also evaluated. Hirisawa et al. [64] demonstrated that oxygen concentration did not affect significantly the performance or microbial diversity of UASB granular reactors when operated at different chemical oxygen demand (COD) to sulphate ratios (COD: $\mathrm{SO}_{4}{ }^{2-}$ ). Archaea were the dominant domain inside the UASB reactor $(68 \%$ of the cells) with a DO of $3.0 \pm 0.7 \mathrm{mg} / \mathrm{L}$. Under these operational conditions, Methanosaeta-like cells were the main methanogens detected by FISH and DGGE fingerprinting. The authors postulated the formation of consortia by the methanogens and facultative bacteria which 
were able to fast uptake the available $\mathrm{O}_{2}$, providing a mechanism of aerotolerance to the methanogens. Additionally, these results were obtained in granular sludge with a large size (2-3 mm diameter), which was found to be the majority of granular biomass inside the reactor (76\%). The thickness of the granules and their concentric layered structure acted as a physical barrier to oxygen diffusion, and segregated niches of low-oxygen concentration were generated in their inner zones. Granular sludge of smaller diameter may thus yield different results. The tolerance of methanogenesis to oxygen in GS is of great interest, as this study demonstrated that the application of limited oxygen quantities did not inhibit methanogenesis or sulphate reduction in the UASB, while it allowed a low production of hydrogen sulphide, which is a toxic compound for the hydrogenotrophic methanogens.

The chemical composition of the treated water also affects the characteristics of the microbial communities in GS. Kobayashi et al. [65] reported that granulation was enhanced by the addition of certain concentrations of starch-containing waste to an UASB bioreactor treating methanol wastes, increasing the size of the granules formed in the bioreactor. Moreover, the addition of starch led to drastic changes of the structure of the archaeal populations, as revealed by DGGE and FISH. The authors observed that in the absence of starch the main archaeal species in the granular bioreactor were Methanomethylovorans hollandica, Methanobacterium aarhusense, Methanobacterium subterraneum and Methanolinea tarda. When starch was added to the UASB, methylotrophic Methanomethylovorans hollandica were still the most abundant methanogens, but an important shift of the rest of populations occurred, and Methanosaeta spp. (M. concilii and M. barkeri) became prevalent in the community. The authors pointed to the generation of acetate due to the degradation of the starch by fermentative bacteria as a possible factor influencing the proliferation of the acetoclastic Methanosaeta species.

Besides the metabolic role of methanogenic Archaea in anaerobic digestion, their contribution to the stability of GS has been widely reported. Many of the above-mentioned studies highlight that Methanosaeta spp. populations are abundant in stable, big-size granules, concluding that these organisms are required for the good performance of anaerobic bioreactors. Due to their filamentous-like morphology, these methanogens have been suggested to act as a backbone for granule initiation, becoming the basis for gathering other granule-forming microorganisms [66,67]. In particular, Methanosaeta concilii is believed to play a key role in setting up granulation [68-70]. The initiation of granules by filamentous cells is followed by the subsequent colonization of acetogenic bacteria and hydrogenotrophic methanogens, leading to the layered granular biofilm structure [26].

The diversity or possible roles of Archaea in aerobic granular formation are completely unknown. Recent studies based on molecular tools have thoroughly analyzed the roles of bacteria, ciliated protozoa and fungi on the structuration of granules and their stability; however, the archaeal division was not explored [22,71]. Methanogenic Archaea seem not to be restricted to colonize and form biofilms in engineered systems operated under anaerobic conditions. Goméz-Silván et al. [16] analyzed the structure of the archaeal communities in samples of different pilot-scale bioreactors treating wastewater under aerobic conditions, including biofilm samples from submerged fixed-biofilters 
consisting of one aerated and one anoxic column, and using clayey schists as the biofilm support media. Temperature gradient gel electrophoresis (TGGE) of 16S rRNA gene fragments and phylogenetic analysis of the reamplified TGGE bands demonstrated that populations affiliated to the methanogenic Archaea (Methanosarcinales, Methanobacteriales and Methanomicrobiales) were present in all of the analyzed samples regardless of the aeration conditions, although the composition of the community varied depending of the characteristics of the treated water and the type of technology used. These authors also suggested that the methanogens found in the aerated WWT plants investigated in their study may simply survive under oxygen exposure and be restricted in their activity to the anoxic areas of the plants, or just play structural roles in cell-aggregate development as they are proposed to do in GS. Archaea have also been detected in other aerated WWT systems [72-76].

\section{Ammonia-Oxidizing Archaea (AOA) in WWT Plants: Occurrence and Significance}

Since the first description of an aerobic Crenarchaeota group as potential ammonia-oxidizing organisms [77], the global $N$-cycle has been reconsidered. After isolation of the first AOA, Nitrosopumilus maritimus [78], only one other isolate-Candidatus Nitrososphaera viennensis - has been obtained so far [79], although many other AOA have been enriched from different environments (Table 3). In recent years, a vast number of studies based on molecular tools were performed in natural ecosystems such as soils, oceans or geothermal habitats and allowed the evaluation of the contribution of AOA to ammonia oxidation. In many cases, AOA were found to be dominant over ammonia-oxidizing bacteria (AOB), which were, until then, the only known organisms responsible for the limiting step of nitrification: ammonia oxidation [4,80]. However, with few exceptions [11] the vast majority of studies performed to date have been based on the detection of the archaeal amoA gene without demonstrating active ammonia oxidation by AOA, and the presence or high abundance of a functional gene does not mean that its associated function is actually operating. For this reason, some authors proposed the term amoA-encoding archaeon (AEA) to refer to these prokaryotic organisms [81-83]. Recently, phylogenetic studies lead to the reclassification of the AOA and AEA as members of a new archaeal Phylum, the Thaumarchaeota $[4,84,85]$, and highlighted this group as the potential ancestor of Archaea [85]. 
Table 3. Current status of proposed classification of ammonia-oxidizing Thaumarchaeota. Please note that not all the taxonomic names are published validly.

\begin{tabular}{|c|c|c|c|c|}
\hline Orders & Genera & Species & Origin & Reference \\
\hline \multirow{6}{*}{$\begin{array}{l}\text { Nitrosopumilales } \\
\text { (Group I.1a, marine) }\end{array}$} & \multirow{4}{*}{ Nitrosopumilus } & N. maritimus & Aquarium in Seattle (USA) & {$[78]$} \\
\hline & & $\begin{array}{l}\text { Candidatus } \\
\text { N. koreensis }\end{array}$ & $\begin{array}{c}\text { 78-m-deep marine sediment off } \\
\text { Svalbard (Arctic Circle) }\end{array}$ & {$[86]$} \\
\hline & & $\begin{array}{l}\text { Candidatus } \\
\text { N. salaria }\end{array}$ & $\begin{array}{c}\text { Sediments in the San Francisco } \\
\text { Bay estuary (USA) }\end{array}$ & {$[87]$} \\
\hline & & $\begin{array}{l}\text { Candidatus } \\
\text { N. sediminis }\end{array}$ & $\begin{array}{c}\text { Marine sediment off Svalbard } \\
\text { (Arctic Circle) }\end{array}$ & {$[88]$} \\
\hline & \multirow{2}{*}{$\begin{array}{c}\text { Candidatus } \\
\text { Nitrosoarchaeum }\end{array}$} & $\begin{array}{l}\text { Candidatus } \\
\text { N. koreensis }\end{array}$ & $\begin{array}{l}\text { Soil sample from the rhizosphere } \\
\text { of Caragana sinica }\end{array}$ & [89] \\
\hline & & $\begin{array}{l}\text { Candidatus } \\
\text { N. limnia } \\
\end{array}$ & $\begin{array}{l}\text { Low-salinity sediments in San } \\
\text { Francisco Bay (USA) }\end{array}$ & {$[90]$} \\
\hline \multirow{2}{*}{$\begin{array}{c}\text { Cenarchaeales } \\
\text { (Group I.1a associated) }\end{array}$} & Cenarchaeum & C. symbiosum & Marine sponge & [91] \\
\hline & $\begin{array}{l}\text { Candidatus } \\
\text { Nitrosotalea }\end{array}$ & $\begin{array}{c}\text { Candidatus } \\
\text { N. devanaterra }\end{array}$ & Acidic soil ( $\mathrm{pH} 4.5)$ & {$[92]$} \\
\hline \multirow{2}{*}{$\begin{array}{l}\text { Nitrososphaerales } \\
\text { (Group I.1b, soil) }\end{array}$} & \multirow{2}{*}{$\begin{array}{c}\text { Candidatus } \\
\text { Nitrososphaera }\end{array}$} & $\begin{array}{c}\text { Candidatus } \\
\text { N. viennensis }\end{array}$ & Garden soil in Vienna (Austria) & {$[79]$} \\
\hline & & $\begin{array}{c}\text { Candidatus } \\
\text { N. gargensis }\end{array}$ & $\begin{array}{l}\text { Microbial mats of the Siberian } \\
\text { Garga hot spring }\end{array}$ & {$[93]$} \\
\hline $\begin{array}{c}\text { Unclassified } \\
\text { Thaumarchaeota } \\
\text { (Group ThAOA) }\end{array}$ & $\begin{array}{l}\text { Candidatus } \\
\text { Nitrosocaldus }\end{array}$ & $\begin{array}{c}\text { Candidatus } \\
\text { N. yellowstoni }\end{array}$ & $\begin{array}{l}\text { Sediment from hydrothermal } \\
\text { spring in Yellowstone (USA) }\end{array}$ & {$[94]$} \\
\hline
\end{tabular}

Considering that ammonia is the main $\mathrm{N}$-species in urban wastewaters, its average concentration, and the fact that the application of the CAS technology under aerated conditions is the most widespread WWT, an important role of AOA in the $N$-removal from the water bodies in engineered systems was initially expected. Using clone libraries, Park et al. [95] detected for the first time the presence of AEA in five out of nine different CAS-based WWT plants. However, since then, few studies have proven the presence of AEA in WWT based on different kind of technologies. Many of the available studies also compared the abundance of AEA with that of AOB (Table 4). The results obtained have led to controversial conclusions, reporting either the complete absence of AEA [96], a minimal contribution of AEA to the ammonia-oxidizing community [97-100], an equal contribution [101], or even AEA outcompeting AOB under certain conditions [96,102-104]. 
Table 4. Occurrence and abundance of amoA-encoding archaeon (AEA) and ammonia-oxidizing bacteria (AOB) in wastewater treatment (WWT) plants.

\begin{tabular}{|c|c|c|c|c|c|c|c|c|c|}
\hline Reference & \multicolumn{2}{|c|}{ [95] } & [99] & \multicolumn{2}{|c|}{$[105]$} & [98] & [106] & \multicolumn{2}{|c|}{ [102] } \\
\hline Method of study & \multicolumn{2}{|c|}{ Clone library } & qPCR & \multicolumn{2}{|c|}{ qPCR } & qPCR & Clone & \multicolumn{2}{|c|}{ qPCR } \\
\hline $\begin{array}{l}\text { No. and type of } \\
\text { WWT plants }\end{array}$ & $5 \mathrm{AS}$ & $4 \mathrm{AS}$ & $1 \mathrm{AS}$ & $\begin{array}{c}4 \text { urban } \\
\text { AS }\end{array}$ & $\begin{array}{c}3 \text { industrial } \\
\text { AS }\end{array}$ & MBR & MBR & 3 urban & 3 industrial \\
\hline SRT (days) & 17.4 & 11 & & 17.75 & 12 & $\begin{array}{l}\text { Complete } \\
\text { retention }\end{array}$ & $15-20$ & & \\
\hline HRT (h) & 40 & 22.5 & 6.2 & 4.5 & 54.3 & & 8 & & \\
\hline COD & 540 & 177 & 179 & & & 465 & 596 & 266.3 & 1334.67 \\
\hline BOD & 271.5 & 254 & & 39.69 & 984.83 & 249 & 333 & & \\
\hline $\begin{array}{c}\text { Average } \\
\text { influent } \mathrm{NH}_{4}^{+} \\
(\mathrm{mg} / \mathrm{L})\end{array}$ & 28.54 & 24.47 & 18.9 & 8.23 & 180.8 & 4.8 & & 34.23 & 121.53 \\
\hline $\begin{array}{c}\text { Average } \\
\text { effluent } \mathrm{NH}_{4}^{+} \\
(\mathrm{mg} / \mathrm{L})\end{array}$ & 0.16 & 0.38 & 0.86 & 1.2 & 17.05 & 0.3 & 1 & & \\
\hline $\begin{array}{l}\% \mathrm{NH}_{4}^{+} \\
\text {removal }\end{array}$ & 99.30 & 97.90 & 95.45 & 79.60 & 83.50 & 72.00 & & & \\
\hline DO (mg/L) & 3.38 & 3.80 & 3.87 & & & & & & \\
\hline $\begin{array}{l}\text { TSS sludge } \\
(\mathrm{mg} / \mathrm{L})\end{array}$ & & & 3335 & 2815 & 4177 & 1,1710 & 4600 & & \\
\hline $\mathrm{AEA} *$ & + & - & $10^{4}-10^{6}$ & $10^{8}-10^{11}$ & $\mathrm{ND}\left(<10^{2}\right)$ & $10^{3}-10^{4}$ & + & $10^{5}-10^{6}$ & $10^{3}-10^{4}$ \\
\hline $\mathrm{AOB} *$ & $+($ except 1$)$ & + & $10^{8}-10^{9}$ & $10^{8}-10^{10}$ & $10^{9}-10^{10}$ & $10^{5}-10^{6}$ & + & $10^{3}-10^{5}$ & $10^{7}-10^{9}$ \\
\hline
\end{tabular}

AS: activated sludge; MBR: membrane bioreactor; SRT: solids retention time; HRT: hydraulic retention time; COD: chemical oxygen demand; BOD: biological oxygen demand at 5 days; DO: dissolved oxygen; TSS: total suspended solids; ND: not detected. * clone library: positive $(+)$ or negative $(-)$ detection; qPCR: number of amoA gene copies/l activated sludge.

$\mathrm{AOB}$ and AOA are phylogenetically distant, displaying significant differences in cell physiology and structure, and also demonstrating a significant level of ecological differentiation, as they are present in diverse niches [107,108]. For example, AEA appear to be more sensitive to drought, lysis, temperature and $\mathrm{pH}$ changes compared to AOB [107,108]. In the early studies conducted in WWT plants, Park et al. [95] pointed out that the AEA occurred in systems with alternation of aeration conditions, with low DO and long retention times (solids retention time, SRT $>15$ days, and HRT $>24 \mathrm{~h}$ ), outcompeting AOB in a system with very low DO $(<0.2 \mathrm{mg} / \mathrm{L})$. The kinetic parameter $\left(\mathrm{K}_{\mathrm{s}}\right)$ for oxygen described for AOA is slightly lower than the values described for AOB [83], but studies in other WWT systems also detected a high abundance of AEA at higher DO, suggesting that AEA tolerate a wide range of oxygen concentrations [105]. 
The effect of operational parameters like SRT and HRT is also not clarified. It is well known that longer retention times favor the development of slow-growth microorganisms, as it is the case for both $\mathrm{AOB}$ and AOA. In this sense, the membrane bioreactor (MBR) technologies intensify this effect, due to the separation of solids by a filtration process [109]. However, the few studies conducted in WWT plants using this kind of technology did not clarify the positive effect of SRT over the abundance of the AEA community $[98,106]$.

Recent studies described that the most important factor affecting AEA abundance in WWT plants is the available concentration of ammonia. Strong negative correlations are reported among ammonia levels in influent or effluent water and the abundance of archaeal amo $A$ copies $[104,105,110]$. The $K_{\mathrm{s}}$ for ammonia of AOA is much lower than the values measured for AOB in WWT plants, but the growth rates of AOA are in range with those of the Nitrosospira/Nitrosomonas oligotropha cluster, with the AOB displaying the higher affinity for ammonia. These data suggest that the AOA are dominant under ammonia-limiting concentrations, whereas these AOB are not able to grow [83]. With ammonia levels closer to their $K_{\mathrm{s}}$, Nitrosospira/Nitrosomonas oligotropha cluster and AEA co-dominate, while at higher ammonia concentrations, the AEA seem to be inhibited $[83,105]$. In general, $\mathrm{AOB}$ tend to dominate in systems receiving high direct additions of inorganic ammonia, whereas systems sustained by the mineralization of organic material (ammonification) select for AEA [4]. However, AEA have been recently detected in a CAS system with high influent ammonia concentration [100]. The flocs' stratification could explain the detection of a sensitive microorganism under suboptimal conditions, but further analyses are required [83].

\section{Archaea in Biofilms Formed in Membrane Bioreactors (MBR) and their Roles in Biofouling}

MBR are an advanced technology that combines the classical biological treatment of wastewater with the use of micro- or ultrafiltration membranes to perform the liquid-solid separation, avoiding the use of the secondary clarifiers [111]. After some decades of existence, membrane bioreactors (MBR) are currently well established as WWT systems which directly compete with the CAS processes due to their many advantages, mostly the generation of pathogen-free treated water that can be directly reused [112]. Compared to CAS, MBR are characterized by a high SRT, which influences the biology of the system, lowering the microbial metabolic activity and growth rates due to the limitation of substrates [113], and favoring the development of slow-growing microorganisms [109]. In both CAS- and MBR-based WWT systems, different populations of microorganism grow together in cell aggregates (flocs), which are stratified structures that are less dense than granules but also hold different microhabitats along their depth $[74,75,114]$.

Anaerobic Membrane Bioreactors (AnMBR) combine an anaerobic bioreactor with a membrane technology for advanced wastewater treatment. There are two main biological focuses of interest in terms of biofilms: the sludge bed of the bioreactor (typically an UASB) where the microbiota is attached to the sludge granules and treats the wastewater, and the biofilm formation on the coupled-membrane 
surfaces. Hence, the quality of the biofilms supported by the sludge particles and the intimacy of the sludge-wastewater contact are the factors which determine the success of treatment.

The bacterial diversity of MBR is well described; however, the archaeal community remains less explored, with most of the studies being focused on the methanogenic community in AnMBR and, most recently, to AEA in aerobic systems $[98,102,110]$. Despite their strictly anaerobic metabolism, it has been found that methanogenic Archaea are often part of the microbiota of aerated WWT systems [72-76], and a few studies have also reported their presence in aerated MBR [16,102]. The presence of anaerobic Archaea under aerated conditions is explained by the anoxic microenvironments created by the flocs' stratification, located in the core of the aggregates. In early studies [75], methanogenic Archaea were detected in activated sludge flocs, but it was not until a few years later that their ability to grow in aerated WWT plants was confirmed [74]. These studies also demonstrated the inactivation of the methanogenesis when the Archaea came into contact with oxygen, but showed that Archaea remained viable and rapidly became active when the anoxic conditions returned. In this sense, the methanogenic Archaea have been described as highly persistent under unfavorable nutritional conditions and tolerant to $\mathrm{O}_{2}[74,115]$.

\subsection{Biofouling in MBR Systems}

During the last decades, the interest for the application of the membrane technologies has emerged in WWT. However, one of the drawbacks limiting the use of these systems is biofouling, or the progressive accumulation of pore-blocking materials on the surface of the membranes, due to the growth of microbial biofilms and the subsequent gathering of different types of organic and inorganic materials [112]. The reduction of the permeate efflux and an increase in transmembrane pressure are the major signs of biofouling [116,117]. Consequently, higher energy use and an increase of the frequency of the required chemical cleaning operations of the membranes are needed, which means shorter membrane lifespans and membrane-replacement costs [9]. Hence, better understanding of membrane fouling is not only the key to solving the problem, but is also one of the main factors driving membrane technology forward.

Biofouling starts with the accumulation of microorganisms at the liquid-solid phase transition, occurring by the deposition, growth and metabolism of bacterial cells or flocs on the membranes [118]. Biofilms may or may not uniformly cover the substratum and minimally consist of one or more usually multiple layers of living and dead microorganisms and their associated extracellular products $[17,118]$.

In MBR systems assisted by microfiltration (MF) or ultrafiltration (UF), membrane fouling is a major issue. Although there are various factors that affect membrane fouling on MBR, such as membrane and biomass properties, feed water characteristics and operating conditions, membrane biofouling via microbial products plays a critical role in determining the feasibility of utilizing MBR when compared with other biological processes. Organic colloids and soluble polysaccharides (a part of the bacterial EPS) were found to be the main contributors to membrane fouling and influence the membrane performance in wastewater filtration applications. Studies by Rosenberger et al. [119] 
demonstrated the involvement of fouling in the soluble and colloidal substances in effluents and in the water phase of activated sludge of MBR systems. Bound EPS has been noticed as a key foulant in these systems. Ramesh et al. [120,121] fractionated bound EPS into tightly-bound EPS and loosely-bound EPS. They stated that the tightly-bound EPS have the highest fouling potential, while the loosely-bound EPS contribute most of the filtration resistance of the sludge in the MBR.

Recent research has been dedicated to the study of biofouling under a multidisciplinary approach, although these efforts have been mostly focused on membrane technologies applied in aerobic WWT. Many of the available studies aimed for the characterization of the microbial populations responsible for biofouling in MBR and other membrane-based systems, but these have been mainly centered on Bacteria [122-124], and little work is available which has analyzed the relevance of Archaea in biofouling. A recent study by Calderón et al. [17] examined the biodiversity of prokaryotic organisms in the fouling biofilms of an AnMBR, based on the UASB technology and coupled to UF membrane modules. They showed that chemical cleaning $(\mathrm{NaClO})$ did not completely remove membrane biofouling, and the populations which remained attached after this operation supported the re-growth of the biofilm, leading to the regeneration of a community of similar structure. 16S rRNA-gene TGGE fingerprints targeting Archaea and sequencing of isolated TGGE bands revealed that the prevalent populations in the foulant layers were closely related to the Methanospirillaceae (63\% of identified sequences), followed by populations related to Methanosaeta spp. Together with methanogenic Archaea, some bacterial populations phylogenetically close to the genus Sphingomonas spp. were detected as persistent components of the biofouling. Other authors have also pointed out the involvement of Sphingomonas spp. on biofilm formation in membrane systems. Miura et al. [122] analyzed for over three months the adhesion and formation of biofilms on the hollow-fiber MF membrane surfaces of a full-scale submerged MBR using real municipal wastewater delivered from the primary sedimentation basin of a municipal WWT facility. The characteristics of the fouling layers were monitored using scanning electron microscopy (SEM), and the composition of planktonic and biofilm microbial communities in the MBR were analyzed using culture-independent molecular-based methods (FISH, 16S rRNA gene clone libraries and phylogenetic analysis), concluding that sphingomonads had an important role in biofouling. These findings are consistent with the well-known ability of sphingomonads to colonize solid surfaces favored by their swarming and twitching motility, where they usually adhere strongly regardless of the surface nature, aided by the production of abundant exopolymers.

As the efficiency of backflushing and $\mathrm{NaClO}$ treatment as routine antifouling methods was proven to be limited, the use of alternative strategies was suggested, particularly those specifically directed towards microbial groups shown to be resistant to standard chemical cleaning methods (i.e., Sphingomonadaceae bacteria and methanogenic Archaea). Overall, the development of more appropriate strategies to control membrane biofouling requires a more thorough understanding of biofilm properties and behavior, especially the early steps in biofilm formation [9]. Currently, control measures for membrane biofouling include applying intermittent suction, improving module 
configurations, improving aeration, reducing the concentration of suspended solids in the bioreactor, applying a tangential surface shear force, backwashing the membrane module, and adding exogenous antibacterial agents $[120,125]$. In biological terms, quorum quenching has been developed as a new and prosperous strategy in antifouling [126].

\section{Future Prospects}

The knowledge of archaeal diversity, abundance and functions has considerably increased in the last decades. In particular, their unique role as methanogenic organisms has been a central subject of investigation, and their significance in many ecological niches is currently well understood. Regarding the importance of these organisms in WWT, the structure and dynamics of archaeal communities in granular systems are thoroughly investigated, and the information on the influence of operating conditions on their diversity and performance is extensive. However, analogous research focused on fixed-film and expanded-bed reactors is limited in comparison, even though the benefits of providing a support material for biofilm formation are well acknowledged to improve methanogenesis and the general performance of anaerobic bioreactors. The reasons for the widespread presence of methanogenic Archaea in aerobic WWT, the understanding of their survival strategies in a theoretically hostile environment, the roles they may fulfill in organic matter degradation under aerobic conditions, or their suggested contribution to structural stability of suspended cell aggregates and biofilms, are also challenges for future research on the subject.

The wide distribution of AEA in the environment is well recognized at present. There is ample confirmation of their prevalence over AOB in habitats such as oceans, sprigs, soils or estuarine sediments [11,107,127-129]. However, the abundance of AEA in engineered habitats is reported to be highly variable, and the reasons determining this random distribution remain obscure. In particular, the influence of geography on AEA occurrence is striking. To the best of the authors' knowledge, there are still no reports of AEA detection in urban WWT plants based in Europe [96], while their presence in WWT systems examined in America and Asia is frequently reported [83]. The adaptation of AOA to low-ammonia levels is suggested by several studies, but other factors such as low carbon substrate availability, low pH, low DO concentration and sulphide content characterize niches where AEA are reported abundant [129]. The survey of AEA occurrence in WWT is still fairly limited, and the information gathered to date is often contradictory; thus, the factors determining the occurrence and abundance of AEA need to be further addressed.

The real contribution of AEA to ammonia oxidation in engineered habitats also needs to be assessed. Mußmann et al. [96] found that AEA outnumbered AOB up to 10-fold in a WWT plant treating refinery wastewater, but the application of a nitrification mathematical model, the detection of poor archaeal assimilation of labeled ${ }^{13} \mathrm{CO}_{2}$, and FISH-microautoradiography (FISH-MAR) studies performed with ${ }^{14} \mathrm{C}$-inorganic carbon strongly evidenced that $\mathrm{AEA}$ were not acting as true chemolithoautotrophic ammonia-oxidizing microbes despite carrying and transcribing the amoA gene. The authors failed to find the possible source of carbon used by the AEA, even though they made 
a great effort applying FISH-MAR using a variety of radiolabeled substrates (amino acids, pyruvate, acetate, benzoate, and phenol). Further research is thus required to reveal the roles and importance of these organisms when expressing a heterotrophic mode of living in WWT, as well as the nature of the substrates that support their growth.

The use of MBR in wastewater treatment is steadily growing due to their many advantages over the CAS process; however, biofouling is a major issue restraining the broad application of this technology. Consequently, control of biofouling has become the main topic in MBR research. Conventional methods applied to minimize or eliminate biofouling often fail, because particular members of the biofilm community are intrinsically resistant to such chemical and physical treatments [17,130]. Alternative antifouling strategies are thus welcomed to efficiently eliminate the persistent components of the fouling biofilms. Methanogenic Archaea have been detected as recalcitrant components of the biofilms fouling membranes in MBR systems [17]. Studies analyzing de novo biofilm development inside an UASB reactor conclude that Archaea are absent during the initial phases of biofilm formation, but proliferate during the consolidation stage [131]. The reasons why Archaea are particularly persistent to antifouling strategies remain to be clarified. The unique characteristics of the archaeal cell envelope [132] may contribute to the persistence of these organisms on membrane surfaces.

Information about the mechanisms which control biofilm formation by Archaea is scattered. An endopolysaccharidase (disaggregatase) was isolated from a strain of Methanosarcina mazei, which efficiently dispersed the aggregates of $M$. mazei cells and was only secreted at certain stages of their life cycle [133]. The gene encoding the enzyme has been isolated and characterized [134]; however, the regulation of its expression and the possible role of disaggregatase under the biofilm life style have not been yet clarified. The roles of transcriptional regulators of the Lrs14 family in surface attachment and biofilm development have been just recently described in the Crenarchaeota [135]. Future studies should bring forth new insights into the regulation of biofilm formation and dispersal in Archaea.

In recent years, several authors have proposed advanced antifouling methods, focused to the particular biological characteristics of the microorganisms that made them able to develop very persistent biofilms. Enzymatic disruption of EPS, addition of chemical uncouplers, quorum-quenchers, or bacterial polysaccharides with antibiofilm activity are some of the methods which have proven effective for the dispersal of bacterial biofilms [136,137]. However, there is virtually no information available on the effectiveness of these approaches on biofilm-forming Archaea, although these prokaryotic organisms have been commonly identified in mixed-population biofilms in both aerated and anaerobic WWT plants.

Inhibition of quorum sensing (QS) by quorum quenchers is one of the more promising biological tools recently introduced to control microbial attachment and membrane fouling [126,137]. QS mechanisms in Archaea are still poorly known. However, the implication of acyl-homoserine lactones (AHLs) as QS signals in methanogenic Archaea has been recently revealed [62]. The luxI and luxR homologues, fill and filR, were located in the genome of a Methanosaeta harundinacea strain and were confirmed as the determinants of the production of long-chain $\left(\mathrm{C}_{10}-\mathrm{C}_{14}\right)$ AHLs. The fillR genes actively regulate cell assembly by determining the morphology change of $M$. harundinacea from short 
cells to long filaments, hence controlling the role of these organisms in cell aggregation. The production of AHL-like compounds has been observed in pure cultures of Methanosarcina mazei and Methanothermobacter thermoautotrophicus, and orthologues of the fill-filR genes were also detected in the genomes of several methanogens (Methanosaeta concilii, Methanosaeta thermophila, M. mazei and Methanospirillum hungatei). These data suggest that QS mediated by AHLs is widespread in this archaeal clade. Consequently, methanogenic AHLs are promising tools for the promotion of granulation of sludge; at the same time, knowledge of the QS mechanism of these organisms provides new targets for the control of archaeal-related biofouling by means of quorum-quenching.

\section{Acknowledgements}

This research was supported by the Spanish Ministerio de Economía y Competitividad (MINECO) in collaboration with Fondo Europeo de Desarrollo Regional (FEDER) (project reference CTM2010-17609/TECNO), and by Junta de Andalucía (project reference P09-RNM-5412). MINECO (FPI program) and Universidad de Granada (Plan Propio) are also acknowledged for personal grants to C.G.S.

\section{Conflicts of Interest}

The authors declare no conflict of interest.

\section{References}

1. Woese, C.R.; Fox, G.E. Phylogenetic structure of the prokaryotic domain: The primary kingdoms. Proc. Natl. Acad. Sci. USA 1977, 74, 5088-5090.

2. Gribaldo, S.; Brochier-Armanet, C. The origin and evolution of Archaea: A state of the art. Philos. Trans. R. Soc. Lond. Ser. B 2006, 361, 1007-1022.

3. Fröls, S. Archaeal biofilms: Widespread and complex. Biochem. Soc. Trans. 2013, 41, 393-398.

4. Stahl, D.A.; de la Torre, J.R. Physiology and diversity of ammonia-oxidizing archaea. Annu. Rev. Microbiol. 2012, 66, 83-101.

5. Stoodley, P.; Sauer, K.; Davies, D.G.; Costerton, J.W. Biofilms as complex differentiated communities. Annu. Rev. Microbiol. 2002, 56, 187-209.

6. Van Leewenhoeck, A. An abstract of a letter from Mr. Anthony Leewenhoeck at Delft, Dated Sep. 17. 1683. Containing some microscopical observations, about animals in the scurf of the teeth, the substance call'd worms in the nose, the cuticula consisting of scales. Philos. Trans. $R$ Soc. Lond. Ser. B 1683, 166, 568-574.

7. Hall-Stoodley, L.; Costerton, J.W.; Stoodley, P. Bacterial biofilms: From the natural environment to infectious diseases. Nat. Rev. Microbiol. 2004, 2, 95-108.

8. Watnick, P.; Kolter, R. Biofilm, city of microbes. J. Bacteriol. 2000, 182, 2675-2679. 
9. Guo, W.; Ngo, H.-H.; Li, J. A mini-review on membrane fouling. Bioresour. Technol. 2012, 122, 27-34.

10. Harrison, J.J.; Ceri, H.; Turner, R.J. Multimetal resistance and tolerance in microbial biofilms. Nat. Rev. Microbiol. 2007, 5, 928-938.

11. Weidler, G.W.; Gerbl, F.W.; Stan-Lotter, H. Crenarchaeota and their role in the nitrogen cycle in a subsurface radioactive thermal spring in the Austrian Central Alps. Appl. Environ. Microbiol. 2008, 74, 5934-5942.

12. Reysenbach, A.L.; Ehringer, M.; Hershberger, K. Microbial diversity at 83 degrees C in Calcite Springs, Yellowstone National Park: Another environment where the Aquificales and "Korarchaeota" coexist. Extremophiles 2000, 4, 61-67.

13. Jones, D.S.; Albrecht, H.L.; Dawson, K.S.; Schaperdoth, I.; Freeman, K.H.; Pi, Y.; Pearson, A.; Macalady, J.L. Community genomic analysis of an extremely acidophilic sulfur-oxidizing biofilm. ISME J. 2012, 6, 158-170.

14. Sauder, L.A.; Engel, K.; Stearns, J.C.; Masella, A.P.; Pawliszyn, R.; Neufeld, J.D. Aquarium nitrification revisited: Thaumarchaeota are the dominant ammonia oxidizers in freshwater aquarium biofilters. PLoS One 2011, 6, e23281.

15. Edwards, K.J.; Bond, P.L.; Gihring, T.M.; Banfield, J.F. An archaeal iron-oxidizing extreme acidophile important in acid mine drainage. Science 2000, 287, 1796-1799.

16. Gómez-Silván, C.; Molina-Munoz, M.; Poyatos, J.M.; Ramos, A.; Hontoria, E.; Rodelas, B.; González-López, J. Structure of archaeal communities in membrane-bioreactor and submerged-biofilter wastewater treatment plants. Bioresour. Technol. 2010, 101, 2096-2105.

17. Calderon, K.; Rodelas, B.; Cabirol, N.; Gonzalez-Lopez, J.; Noyola, A. Analysis of microbial communities developed on the fouling layers of a membrane-coupled anaerobic bioreactor applied to wastewater treatment. Bioresour. Technol. 2011, 102, 4618-4627.

18. Morales, M.; Arancibia, J.; Lemus, M.; Silva, J.; Gentina, J.; Aroca, G. Bio-oxidation of $\mathrm{H}_{2} \mathrm{~S}$ by Sulfolobus metallicus. Biotechnol. Lett. 2011, 33, 2141-2145.

19. Justice, N.B.; Pan, C.; Mueller, R.; Spaulding, S.E.; Shah, V.; Sun, C.L.; Yelton, A.P.; Miller, C.S.; Thomas, B.C.; Shah, M.; et al. Heterotrophic archaea contribute to carbon cycling in low-pH, suboxic biofilm communities. Appl. Environ. Microbiol. 2012, 78, 8321-8330.

20. Cheng, K.-C.; Demirci, A.; Catchmark, J. Advances in biofilm reactors for production of value-added products. Appl. Microbiol. Biotechnol. 2010, 87, 445-456.

21. Gómez-Villalba, B.; Calvo, C.; Vilchez, R.; González-López, J.; Rodelas, B. TGGE analysis of the diversity of ammonia-oxidizing and denitrifying bacteria in submerged filter biofilms for the treatment of urban wastewater. Appl. Microbiol. Biotechnol. 2006, 72, 393-400.

22. Winkler, M.K.; Kleerebezem, R.; de Bruin, L.M.; Verheijen, P.J.; Abbas, B.; Habermacher, J.; Van Loosdrecht, M.C. Microbial diversity differences within aerobic granular sludge and activated sludge flocs. Appl. Microbiol. Biotechnol. 2013, 97, 7447-7458. 
23. Wang, J.; Kang, J. The characteristics of anaerobic ammonium oxidation (ANAMMOX) by granular sludge from an EGSB reactor. Process Biochem. 2005, 40, 1973-1978.

24. Lettinga, G. Anaerobic digestion and wastewater treatment systems. Antonie Leeuwenhoek 1995, 67, 3-28.

25. Tiwari, M.K.; Guha, S.; Harendranath, C.S.; Tripathi, S. Influence of extrinsic factors on granulation in UASB reactor. Appl. Microbiol. Biotechnol. 2006, 71, 145-154.

26. Abbasi, T.; Abbasi, S.A. Formation and impact of granules in fostering clean energy production and wastewater treatment in upflow anaerobic sludge blanket (UASB) reactors. Renew. Sustain. Energy Rev. 2012, 16, 1696-1708.

27. Van der Star, W.R.L.; Abma, W.R.; Blommers, D.; Mulder, J.-W.; Tokutomi, T.; Strous, M.; Picioreanu, C.; Van Loosdrecht, M.C.M. Startup of reactors for anoxic ammonium oxidation: Experiences from the first full-scale anammox reactor in Rotterdam. Water Res. 2007, 41, 4149-4163.

28. Skiadas, I.V.; Gavala, H.N.; Schmidt, J.E.; Ahring, B.K. Anaerobic granular sludge and biofilm reactors. Adv. Biochem. Eng. Biotechnol. 2003, 82, 35-67.

29. Adav, S.S.; Lee, D.-J.; Show, K.-Y.; Tay, J.-H. Aerobic granular sludge: Recent advances. Biotechnol. Adv. 2008, 26, 411-423.

30. Angelidaki, I.; Karakashev, D.; Batstone, D.J.; Plugge, C.M.; Stams, A.J.M. Biomethanation and its potential. Methods Enzymol. 2011, 494, 327-351.

31. Liu, Y.; Whitman, W.B. Metabolic, phylogenetic, and ecological diversity of the methanogenic archaea. Ann. N. Y. Acad. Sci. 2008, 1125, 171-189.

32. Sakai, S.; Imachi, H.; Hanada, S.; Ohashi, A.; Harada, H.; Kamagata, Y. Methanocella paludicola gen. nov., sp. nov., a methane-producing archaeon, the first isolate of the lineage "Rice Cluster I", and proposal of the new archaeal order Methanocellales ord. nov. Int. J. Syst. Evol. Microbiol. 2008, 58, 929-936.

33. Rivière, D.; Desvignes, V.; Pelletier, E.; Chaussonnerie, S.; Guermazi, S.; Weissenbach, J.; Li, T.; Camacho, P.; Sghir, A. Towards the definition of a core of microorganisms involved in anaerobic digestion of sludge. ISME J. 2009, 3, 700-714.

34. Narihiro, T.; Sekiguchi, Y. Oligonucleotide primers, probes and molecular methods for the environmental monitoring of methanogenic archaea. Microb. Biotechnol. 2011, 4, 585-602.

35. Leclerc, M.; Delgènes, J.-P.; Godon, J.-J. Diversity of the archaeal community in 44 anaerobic digesters as determined by single strand conformation polymorphism analysis and 16S rDNA sequencing. Environ. Microbiol. 2004, 6, 809-819.

36. Collins, G.; Kavanagh, S.; McHugh, S.; Connaughton, S.; Kearney, A.; Rice, O.; Carrigg, C.; Scully, C.; Bhreathnach, N.; Mahony, T.; et al. Accessing the black box of microbial diversity and ecophysiology: Recent advances through polyphasic experiments. J. Environ. Sci. Health Part A 2006, 41, 897-922. 
37. Dang, Y.; Ye, J.; Mu, Y.; Qiu, B.; Sun, D. Effective anaerobic treatment of fresh leachate from MSW incineration plant and dynamic characteristics of microbial community in granular sludge. Appl. Microbiol. Biotechnol. 2013, 1-12.

38. Visser, F.A.; Van Lier, J.B.; Macario, A.J.; Conway de Macario, E. Diversity and population dynamics of methanogenic bacteria in a granular consortium. Appl. Environ. Microbiol. 1991, 57, 1728-1734.

39. Buzzini, A.P.; Sakamoto, I.K.; Varesche, M.B.; Pires, E.C. Evaluation of the microbial diversity in an UASB reactor treating wastewater from an unbleached pulp plant. Process Biochem. 2006, 41, 168-176.

40. Del Nery, V.; Pozzi, E.; Damianovic, M.H.R.Z.; Domingues, M.R.; Zaiat, M. Granules characteristics in the vertical profile of a full-scale upflow anaerobic sludge blanket reactor treating poultry slaughterhouse wastewater. Bioresour. Technol. 2008, 99, 2018-2024.

41. Tabatabaei, M.; Rahim, R.A.; Abdullah, N.; Wright, A.-D.G.; Shirai, Y.; Sakai, K.; Sulaiman, A.; Hassan, M.A. Importance of the methanogenic archaea populations in anaerobic wastewater treatments. Process Biochem. 2010, 45, 1214-1225.

42. Zhang, D.; Li, J.; Guo, P.; Li, P.; Suo, Y.; Wang, X.; Cui, Z. Dynamic transition of microbial communities in response to acidification in fixed-bed anaerobic baffled reactors (FABR) of two different flow directions. Bioresour. Technol. 2011, 102, 4703-4711.

43. Rademacher, A.; Zakrzewski, M.; Schluter, A.; Schonberg, M.; Szczepanowski, R.; Goesmann, A.; Puhler, A.; Klocke, M. Characterization of microbial biofilms in a thermophilic biogas system by high-throughput metagenome sequencing. FEMS Microbiol. Ecol. 2012, 79, 785-799.

44. Pereira, M.A.; Roest, K.; Stams, A.J.; Mota, M.; Alves, M.; Akkermans, A.D. Molecular monitoring of microbial diversity in expanded granular sludge bed (EGSB) reactors treating oleic acid. FEMS Microbiol. Ecol. 2002, 41, 95-103.

45. O’Reilly, J.; Lee, C.; Collins, G.; Chinalia, F.; Mahony, T.; O'Flaherty, V. Quantitative and qualitative analysis of methanogenic communities in mesophilically and psychrophilically cultivated anaerobic granular biofilims. Water Res. 2009, 43, 3365-3374.

46. Li, J.; Wang, J.; Luan, Z.; Deng, Y.; Chen, L. Evaluation of performance and microbial community in a two-stage UASB reactor pretreating acrylic fiber manufacturing wastewater. Bioresour. Technol. 2011, 102, 5709-5716.

47. Khemkhao, M.; Nuntakumjorn, B.; Techkarnjanaruk, S.; Phalakornkule, C. UASB performance and microbial adaptation during a transition from mesophilic to thermophilic treatment of palm oil mill effluent. J. Environ. Manag. 2012, 103, 74-82.

48. Nelson, M.C.; Morrison, M.; Schanbacher, F.; Yu, Z. Shifts in microbial community structure of granular and liquid biomass in response to changes to infeed and digester design in anaerobic digesters receiving food-processing wastes. Bioresour. Technol. 2012, 107, 135-143.

49. Xing, W.; Zuo, J.E.; Dai, N.; Cheng, J.; Li, J. Reactor performance and microbial community of an EGSB reactor operated at 20 and $15^{\circ} \mathrm{C}$. J. Appl. Microbiol. 2009, 107, 848-857. 
50. McHugh, S.; Carton, M.; Mahony, T.; O'Flaherty, V. Methanogenic population structure in a variety of anaerobic bioreactors. FEMS Microbiol. Lett. 2003, 219, 297-304.

51. Liu, Y.; Xu, H.-L.; Yang, S.-F.; Tay, J.-H. Mechanisms and models for anaerobic granulation in upflow anaerobic sludge blanket reactor. Water Res. 2003, 37, 661-673.

52. Sasaki, K.; Morita, M.; Hirano, S.; Ohmura, N.; Igarashi, Y. Effect of adding carbon fiber textiles to methanogenic bioreactors used to treat an artificial garbage slurry. J. Biosci. Bioeng. 2009, 108, 130-135.

53. Najafpour, G.D.; Zinatizadeh, A.A.L.; Mohamed, A.R.; Hasnain Isa, M.; Nasrollahzadeh, H. High-rate anaerobic digestion of palm oil mill effluent in an upflow anaerobic sludge-fixed film bioreactor. Process Biochem. 2006, 41, 370-379.

54. Patel, P.; Patel, C.; Madamwar, D. Anaerobic upflow fixed-film bioreactor for biomethanation of salty cheese whey. Appl. Biochem. Biotechnol. 1999, 76, 193-201.

55. Acharya, B.K.; Mohana, S.; Madamwar, D. Anaerobic treatment of distillery spent wash-A study on upflow anaerobic fixed film bioreactor. Bioresour. Technol. 2008, 99, 4621-4626.

56. Sasaki, K.; Haruta, S.; Tatara, M.; Yamazawa, A.; Ueno, Y.; Ishii, M.; Igarashi, Y. Microbial community in methanogenic packed-bed reactor successfully operating at short hydraulic retention time. J. Biosci. Bioeng. 2006, 101, 271-273.

57. Sasaki, K.; Haruta, S.; Ueno, Y.; Ishii, M.; Igarashi, Y. Archaeal population on supporting material in methanogenic packed-bed reactor. J. Biosci. Bioeng. 2006, 102, 244-246.

58. Sekiguchi, Y.; Kamagata, Y.; Syutsubo, K.; Ohashi, A.; Harada, H.; Nakamura, K. Phylogenetic diversity of mesophilic and thermophilic granular sludges determined by $16 \mathrm{~S}$ rRNA gene analysis. J. Microbiol. 1998, 144, 2655-2665.

59. McHugh, S.; Carton, M.; Collins, G.; O'Flaherty, V. Reactor performance and microbial community dynamics during anaerobic biological treatment of wastewaters at 16-37 degrees $\mathrm{C}$. FEMS Microbiol. Ecol. 2004, 48, 369-378.

60. Connaughton, S.; Collins, G.; O'Flaherty, V. Development of microbial community structure and actvity in a high-rate anaerobic bioreactor at $18^{\circ} \mathrm{C}$. Water Res. 2006, 40, 1009-1017.

61. Bandara, W.M.K.R.T.W.; Kindaichi, T.; Satoh, H.; Sasakawa, M.; Nakahara, Y.; Takahashi, M.; Okabe, S. Anaerobic treatment of municipal wastewater at ambient temperature: Analysis of archaeal community structure and recovery of dissolved methane. Water Res. 2012, 46, 5756-5764.

62. Zhang, G.; Zhang, F.; Ding, G.; Li, J.; Guo, X.; Zhu, J.; Zhou, L.; Cai, S.; Liu, X.; Luo, Y.; et al. Acyl homoserine lactone-based quorum sensing in a methanogenic archaeon. ISME J. 2012, 6, 1336-1344.

63. Siggins, A.; Enright, A.M.; O'Flaherty, V. Methanogenic community development in anaerobic granular bioreactors treating trichloroethylene (TCE)-contaminated wastewater at 37 degrees $\mathrm{C}$ and 15 degrees C. Water Res. 2011, 45, 2452-2462. 
64. Hirasawa, J.S.; Sarti, A.; Del Aguila, N.K.; Varesche, M.B. Application of molecular techniques to evaluate the methanogenic archaea and anaerobic bacteria in the presence of oxygen with different COD: Sulfate ratios in a UASB reactor. Anaerobe 2008, 14, 209-218.

65. Kobayashi, T.; Yan, F.; Takahashi, S.; Li, Y.Y. Effect of starch addition on the biological conversion and microbial community in a methanol-fed UASB reactor during long-term continuous operation. Bioresour. Technol. 2011, 102, 7713-7719.

66. Sallis, P.J.; Uyanik, S. Granule development in a split-feed anaerobic baffled reactor. Bioresour. Technol. 2003, 89, 255-265.

67. Song, M.; Shin, S.G.; Hwang, S. Methanogenic population dynamics assessed by real-time quantitative PCR in sludge granule in upflow anaerobic sludge blanket treating swine wastewater. Bioresour. Technol. 2010, 101, S23-S28.

68. Angenent, L.T.; Sung, S.; Raskin, L. Formation of granules and Methanosaeta fibres in an anaerobic migrating blanket reactor (AMBR). Environ. Microbiol. 2004, 6, 315-322.

69. Fernandez, N.; Sierra-Alvarez, R.; Amils, R.; Field, J.A.; Sanz, J.L. Compared microbiology of granular sludge under autotrophic, mixotrophic and heterotrophic denitrification conditions. Water Sci. Technol. 2009, 59, 1227-1236.

70. Zheng, D.; Angenent, L.T.; Raskin, L. Monitoring granule formation in anaerobic upflow bioreactors using oligonucleotide hybridization probes. Biotechnol. Bioeng. 2006, 94, 458-472.

71. Weber, S.D.; Ludwig, W.; Schleifer, K.H.; Fried, J. Microbial composition and structure of aerobic granular sewage biofilms. Appl. Environ. Microbiol. 2007, 73, 6233-6240.

72. Czepiel, P.M.; Crill, P.M.; Harriss, R.C. Methane emissions from municipal wastewater treatment processes. Environ. Sci. Technol. 1993, 27, 2472-2477.

73. Daelman, M.R.J.; Van Voorthuizen, E.M.; Van Dongen, U.G.J.M.; Volcke, E.I.P.; Van Loosdrecht, M.C.M. Methane emission during municipal wastewater treatment. Water Res. 2012, 46, 3657-3670.

74. Gray, N.D.; Miskin, I.P.; Kornilova, O.; Curtis, T.P.; Head, I.M. Occurrence and activity of Archaea in aerated activated sludge wastewater treatment plants. Environ. Microbiol. 2002, 4, $158-168$.

75. Lens, P.N.; De Poorter, M.P.; Cronenberg, C.C.; Verstraete, W.H. Sulfate reducing and methane producing bacteria in aerobic wastewater treatment systems. Water Res. 1995, 29, 871-880.

76. Ren, Y.; Wang, J.; Li, H.; Zhang, J.; Qi, P.; Hu, Z. Nitrous oxide and methane emissions from different treatment processes in full-scale municipal wastewater treatment plants. Environ. Technol. 2012, doi:10.1080/09593330.2012.696717.

77. Treusch, A.H.; Leininger, S.; Kletzin, A.; Schuster, S.C.; Klenk, H.P.; Schleper, C. Novel genes for nitrite reductase and Amo-related proteins indicate a role of uncultivated mesophilic crenarchaeota in nitrogen cycling. Environ. Microbiol. 2005, 7, 1985-1995.

78. Könneke, M.; Bernhard, A.E.; De La Torre, J.R.; Walker, C.B.; Waterbury, J.B.; Stahl, D.A. Isolation of an autotrophic ammonia-oxidizing marine archaeon. Nature 2005, 437, 543-546. 
79. Tourna, M.; Stieglmeier, M.; Spang, A.; Konneke, M.; Schintlmeister, A.; Urich, T.; Engel, M.; Schloter, M.; Wagner, M.; Richter, A.; et al. Nitrososphaera viennensis, an ammonia oxidizing archaeon from soil. Proc. Natl. Acad. Sci. USA 2011, 108, 8420-8425.

80. Beman, J.M.; Francis, C.A. Diversity of ammonia-oxidizing archaea and bacteria in the sediments of a hypernutrified subtropical estuary: Bahia del Tobari, Mexico. Appl. Environ. Microbiol. 2006, 72, 7767-7777.

81. Dang, H.; Li, J.; Zhang, X.; Li, T.; Tian, F.; Jin, W. Diversity and spatial distribution of amoA-encoding archaea in the deep-sea sediments of the tropical West Pacific Continental Margin. J. Appl. Microbiol. 2009, 106, 1482-1493.

82. Hatzenpichler, R. Diversity, physiology, and niche differentiation of ammonia-oxidizing Archaea. Appl. Environ. Microbiol. 2012, 78, 7501-7510.

83. Limpiyakorn, T.; Fürhacker, M.; Haberl, R.; Chodanon, T.; Srithep, P.; Sonthiphand, P. amoA-encoding archaea in wastewater treatment plants: A review. Appl. Microbiol. Biotechnol. 2013, 97, 1425-1439.

84. Brochier-Armanet, C.; Boussau, B.; Gribaldo, S.; Forterre, P. Mesophilic crenarchaeota: Proposal for a third archaeal phylum, the Thaumarchaeota. Nat. Rev. Microbiol. 2008, 6, 245-252.

85. Spang, A.; Hatzenpichler, R.; Brochier-Armanet, C.; Rattei, T.; Tischler, P.; Spieck, E.; Streit, W.; Stahl, D.A.; Wagner, M.; Schleper, C. Distinct gene set in two different lineages of ammonia-oxidizing archaea supports the phylum Thaumarchaeota. Trends Microbiol. 2010, 18, 331-340.

86. Park, S.J.; Kim, J.G.; Jung, M.Y.; Kim, S.J.; Cha, I.T.; Kwon, K.; Lee, J.H.; Rhee, S.K. Draft genome sequence of an ammonia-oxidizing archaeon, "Candidatus Nitrosopumilus koreensis" AR1, from marine sediment. J. Bacteriol. 2012, 194, 6940-6941.

87. Mosier, A.C.; Allen, E.E.; Kim, M.; Ferriera, S.; Francis, C.A. Genome sequence of "Candidatus Nitrosopumilus salaria" BD31, an ammonia-oxidizing archaeon from the San Francisco Bay estuary. J. Bacteriol. 2012, 194, 2121-2122.

88. Park, S.J.; Kim, J.G.; Jung, M.Y.; Kim, S.J.; Cha, I.T.; Ghai, R.; Martin-Cuadrado, A.B.; Rodriguez-Valera, F.; Rhee, S.K. Draft genome sequence of an ammonia-oxidizing archaeon, "Candidatus Nitrosopumilus sediminis" AR2, from Svalbard in the Arctic Circle. J. Bacteriol. 2012, 194, 6948-6949.

89. Kim, B.K.; Jung, M.Y.; Yu, D.S.; Park, S.J.; Oh, T.K.; Rhee, S.K.; Kim, J.F. Genome sequence of an ammonia-oxidizing soil archaeon, "Candidatus Nitrosoarchaeum koreensis" MY1. J. Bacteriol. 2011, 193, 5539-5540.

90. Blainey, P.C.; Mosier, A.C.; Potanina, A.; Francis, C.A.; Quake, S.R. Genome of a low-salinity ammonia-oxidizing archaeon determined by single-cell and metagenomic analysis. PLoS One 2011, 6, e16626. 
91. Preston, C.M.; Wu, K.Y.; Molinski, T.F.; DeLong, E.F. A psychrophilic crenarchaeon inhabits a marine sponge: Cenarchaeum symbiosum gen. nov., sp. nov. Proc. Natl. Acad. Sci. USA 1996, 93, 6241-6246.

92. Lehtovirta-Morley, L.E.; Stoecker, K.; Vilcinskas, A.; Prosser, J.I.; Nicol, G.W. Cultivation of an obligate acidophilic ammonia oxidizer from a nitrifying acid soil. Proc. Natl. Acad. Sci. USA 2011, 108, 15892-15897.

93. Hatzenpichler, R.; Lebedeva, E.V.; Spieck, E.; Stoecker, K.; Richter, A.; Daims, H.; Wagner, M. A moderately thermophilic ammonia-oxidizing crenarchaeote from a hot spring. Proc. Natl. Acad. Sci. USA 2008, 105, 2134-2139.

94. De La Torre, J.R.; Walker, C.B.; Ingalls, A.E.; Könneke, M.; Stahl, D.A. Cultivation of a thermophilic ammonia oxidizing archaeon synthesizing crenarchaeol. Environ. Microbiol. 2008, 10, 810-818.

95. Park, H.D.; Wells, G.F.; Bae, H.; Criddle, C.S.; Francis, C.A. Occurrence of ammonia-oxidizing archaea in wastewater treatment plant bioreactors. Appl. Environ. Microbiol. 2006, 72, 5643-5647.

96. Mußmann, M.; Brito, I.; Pitcher, A.; Sinninghe Damsté, J.S.; Hatzenpichler, R.; Richter, A.; Nielsen, J.L.; Nielsen, P.H.; Müller, A.; Daims, H.; et al. Thaumarchaeotes abundant in refinery nitrifying sludges express amoA but are not obligate autotrophic ammonia oxidizers. Proc. Natl. Acad. Sci. USA 2011, 108, 16771-16776.

97. Jin, T.; Zhang, T.; Yan, Q. Characterization and quantification of ammonia-oxidizing archaea (AOA) and bacteria (AOB) in a nitrogen-removing reactor using T-RFLP and qPCR. Appl. Microbiol. Biotechnol. 2010, 87, 1167-1176.

98. Ozdemir, B.; Mertoglu, B.; Yapsakli, K.; Aliyazicioglu, C.; Saatci, A.; Yenigun, O. Investigation of nitrogen converters in membrane bioreactor. J. Environ. Sci. Health Part A 2011, 46, 500-508.

99. Wells, G.F.; Park, H.D.; Yeung, C.H.; Eggleston, B.; Francis, C.A.; Criddle, C.S. Ammonia-oxidizing communities in a highly aerated full-scale activated sludge bioreactor: Betaproteobacterial dynamics and low relative abundance of Crenarchaea. Environ. Microbiol. 2009, 11, 2310-2328.

100. Yapsakli, K.; Aliyazicioglu, C.; Mertoglu, B. Identification and quantitative evaluation of nitrogen-converting organisms in a full-scale leachate treatment plant. J. Environ. Manag. 2011, 92, 714-723.

101. Sonthiphand, P.; Limpiyakorn, T. Change in ammonia-oxidizing microorganisms in enriched nitrifying activated sludge. Appl. Microbiol. Biotechnol. 2011, 89, 843-853.

102. Bai, Y.; Sun, Q.; Wen, D.; Tang, X. Abundance of ammonia-oxidizing bacteria and archaea in industrial and domestic wastewater treatment systems. FEMS Microbiol. Ecol. 2012, 80, 323-330.

103. Kayee, P.; Sonthiphand, P.; Rongsayamanont, C.; Limpiyakorn, T. Archaeal amoA genes outnumber bacterial amoA genes in municipal wastewater treatment plants in Bangkok. Microb. Ecol. 2011, 62, 776-788. 
104. Sauder, L.A.; Peterse, F.; Schouten, S.; Neufeld, J.D. Low-ammonia niche of ammonia-oxidizing archaea in rotating biological contactors of a municipal wastewater treatment plant. Environ. Microbiol. 2012, 14, 2589-2600.

105. Limpiyakorn, T.; Sonthiphand, P.; Rongsayamanont, C.; Polprasert, C. Abundance of amoA genes of ammonia-oxidizing archaea and bacteria in activated sludge of full-scale wastewater treatment plants. Bioresour. Technol. 2011, 102, 3694-3701.

106. Yu, T.; Li, D.; Qi, R.; Li, S.T.; Xu, S.W.; Yang, M. Structure and dynamics of nitrifier populations in a full-scale submerged membrane bioreactor during start-up. Appl. Microbiol. Biotechnol. 2011, 90, 369-376.

107. Adair, K.; Schwartz, E. Evidence that ammonia-oxidizing archaea are more abundant than ammonia-oxidizing bacteria in semiarid soils of northern Arizona, USA. Microb. Ecol. 2008, 56, 420-426.

108. Prosser, J.I.; Nicol, G.W. Relative contributions of archaea and bacteria to aerobic ammonia oxidation in the environment. Environ. Microbiol. 2008, 10, 2931-2941.

109. Witzig, R.; Manz, W.; Rosenbergerb, S.; Krugerb, U.; Kraumeb, M.; Szewzyk, U. Microbiological aspects of a bioreactor with submerged membranes for aerobic treatment of municipal wastewater. Water Res. 2002, 36, 394-402.

110. Ye, L.; Zhang, T. Bacterial communities in different sections of a municipal wastewater treatment plant revealed by $16 \mathrm{~S}$ rDNA 454 pyrosequencing. Appl. Microbiol. Biotechnol. 2013, 97, 2681-2690.

111. Judd, S. The status of membrane bioreactor technology. Trends Biotechnol. 2008, 26, 109-116.

112. Le-Clech, P. Membrane bioreactors and their uses in wastewater treatments. Appl. Microbiol. Biotechnol. 2010, 88, 1253-1260.

113. LaPara, T.M.; Klatt, C.G.; Chen, R. Adaptations in bacterial catabolic enzyme activity and community structure in membrane-coupled bioreactors fed simple synthetic wastewater. J. Biotechnol. 2006, 121, 368-380.

114. He, S.B.; Xue, G.; Wang, B.Z. Factors affecting simultaneous nitrification and de-nitrification (SND) and its kinetics model in membrane bioreactor. J. Hazard Mater. 2009, 168, 704-710.

115. Santegoeds, C.M.; Damgaard, L.R.; Hesselink, G.; Zopfi, J.; Lens, P.; Muyzer, G.; De Beer, D. Distribution of sulfate-reducing and methanogenic bacteria in anaerobic aggregates determined by microsensor and molecular analyses. Appl. Environ. Microbiol. 1999, 65, 4618-4629.

116. Ridgway, H.F.; Flemming, H.-C. Biofouling of Membranes. In Water Treatment Membrane Processes, 1st ed.; Mallevialle, J., Odendaal, P.E., Eds.; McGraw-Hill: New York, NY, USA, 1996; pp. 6.1-6.62.

117. Herrera-Robledo, M.; Morgan-Sagastume, J.M.; Noyola, A. Biofouling and pollutant removal during long-term operation of an anaerobic membrane bioreactor treating municipal wastewater. Biofouling 2010, 26, 23-30. 
118. Ivnitsky, H.; Katz, I.; Minz, D.; Volvovic, G.; Shimoni, E.; Kesselman, E.; Semiat, R.; Dosoretz, C.G. Bacterial community composition and structure of biofilms developing on nanofiltration membranes applied to wastewater treatment. Water Res. 2007, 41, 3924-3935.

119. Rosenberger, S.; Evenblij, H.; Te Poele, S.; Wintgens, T.; Laabs, C. The importance of liquid phase analyses to understand fouling in membrane assisted activated sludge processes - Six case studies of different European research groups. J. Membr. Sci. 2005, 263, 113-126.

120. Ramesh, A.; Lee, D.J.; Wang, M.L.; Hsu, J.P.; Juang, R.S.; Hwang, K.J.; Liu, J.C.; Tseng, S.J. Biofouling in membrane bioreactor. Sep. Sci. Technol. 2006, 41, 1345-1370.

121. Ramesh, A.; Lee, D.J.; Lai, J.Y. Membrane biofouling by extracellular polymeric substances or soluble microbial products from membrane bioreactor sludge. Appl. Microbiol. Biotechnol. 2007, 74, 699-707.

122. Miura, Y.; Watanabe, Y.; Okabe, S. Membrane biofouling in pilot-scale membrane bioreactors (MBRs) treating municipal wastewater: Impact of biofilm formation. Environ. Sci. Technol. 2007, 41, 632-638.

123. Gao, D.-W.; Zhang, T.; Tang, C.-Y.Y.; Wu, W.-M.; Wong, C.-Y.; Lee, Y.H.; Yeh, D.H.; Criddle, C.S. Membrane fouling in an anaerobic membrane bioreactor: Differences in relative abundance of bacterial species in the membrane foulant layer and in suspension. J. Membr. Sci. 2010, 364, 331-338.

124. Lin, H.; Liao, B.-Q.; Chen, J.; Gao, W.; Wang, L.; Wang, F.; Lu, X. New insights into membrane fouling in a submerged anaerobic membrane bioreactor based on characterization of cake sludge and bulk sludge. Bioresour. Technol. 2011, 102, 2373-2379.

125. Chang, I.; Le Clech, P.; Jefferson, B.; Judd, S. Membrane fouling in membrane bioreactors for wastewater treatment. J. Environ. Eng. 2002, 128, 1018-1029.

126. Yeon, K.M.; Cheong, W.S.; Oh, H.S.; Lee, W.N.; Hwang, B.K.; Lee, C.H.; Beyenal, H.; Lewandowski, Z. Quorum sensing: A new biofouling control paradigm in a membrane bioreactor for advanced wastewater treatment. Environ. Sci. Technol. 2009, 43, 380-385.

127. Leininger, S.; Urich, T.; Schloter, M.; Schwark, L.; Qi, J.; Nicol, G.W.; Prosser, J.I.; Schuster, S.C.; Schleper, C. Archaea predominate among ammonia-oxidizing prokaryotes in soils. Nature 2006, 442, 806-809.

128. Wuchter, C.; Abbas, B.; Coolen, M.J.; Herfort, L.; Van Bleijswijk, J.; Timmers, P.; Strous, M.; Teira, E.; Herndl, G.J.; Middelburg, J.J. Archaeal nitrification in the ocean. Proc. Natl. Acad. Sci. USA 2006, 103, 12317-12322.

129. Erguder, T.H.; Boon, N.; Wittebolle, L.; Marzorati, M.; Verstraete, W. Environmental factors shaping the ecological niches of ammonia-oxidizing archaea. FEMS Microbiol. Rev. 2009, 33, 855-869.

130. Lequette, Y.; Boels, G.; Clarisse, M.; Faille, C. Using enzymes to remove biofilms of bacterial isolates sampled in the food-industry. Biofouling 2010, 26, 421-431. 
131. Fernandez, N.; Diaz, E.E.; Amils, R.; Sanz, J.L. Analysis of microbial community during biofilm development in an anaerobic wastewater treatment reactor. Microb. Ecol. 2008, 56, 121-132.

132. Mathai, J.C.; Sprott, G.D.; Zeidel, M.L. Molecular mechanisms of water and solute transport across archaebacterial lipid membranes. J. Biol. Chem. 2001, 276, 27266-27271.

133. Xun, L.Y.; Mah, R.A.; Boone, D.R. Isolation and characterization of disaggregatase from Methanosarcina mazei LYC. Appl. Environ. Microbiol. 1990, 56, 3693-3698.

134. Osumi, N.; Kakehashi, Y.; Matsumoto, S.; Nagaoka, K.; Sakai, J.; Miyashita, K.; Kimura, M.; Asakawa, S. Identification of the gene for disaggregatase from Methanosarcina mazei. Archaea 2008, 2, 185-191.

135. Orell, A.; Peeters, E.; Vassen, V.; Jachlewski, S.; Schalles, S.; Siebers, B.; Albers, S.V. Lrs14 transcriptional regulators influence biofilm formation and cell motility of Crenarchaea. ISME J. 2013, doi:10.1038/ismej.2013.68.

136. Bernal, P.; Llamas, M.A. Promising biotechnological applications of antibiofilm exopolysaccharides. Microb. Biotechnol. 2012, 5, 670-673.

137. Xiong, Y.; Liu, Y. Biological control of microbial attachment: A promising alternative for mitigating membrane biofouling. Appl. Microbiol. Biotechnol. 2010, 86, 825-837. 


\title{
The Interaction of CuS and Halothiobacillus HT1 Biofilm in Microscale Using Synchrotron Radiation-Based Techniques
}

\author{
Huirong Lin, Guangcun Chen, Shenhai Zhu, Yingxu Chen, Dongliang Chen, Wei Xu, \\ Xiaohan Yu and Jiyan Shi
}

\begin{abstract}
In order to investigate the microbe-mineral interaction in the micro scale, spatial distribution and speciation of $\mathrm{Cu}$ and $\mathrm{S}$ in Halothiobacillus HT1 biofilm formed on a CuS surface was examined using synchrotron-based X-ray techniques. Confocal laser scanning microscope (CLSM) results indicated that Halothiobacillus HT1 biofilm formation gave rise to distinct chemical and redox gradients, leading to diverse niches in the biofilm. Live cells were distributed at the air-biofilm and membrane-biofilm interface. CuS was oxidized by Halothiobacillus HT1 biofilm, and copper penetrated into the biofilm. Sulfide was oxidized to cysteine (77.3\%), sulfite (3.8\%) and sulfonate (18.9\%). $\mathrm{Cu}$-cysteine-like species were involved in the copper homeostasis. These results significantly improve our understanding of the interfacial properties of the biofilm-mineral interface.
\end{abstract}

Reprinted from Int. J. Mol. Sci. Cite as: Lin, H.; Chen, G.; Zhu, S.; Chen, Y.; Chen, D.; Xu, W.; Yu, X.; Shi, J. The Interaction of CuS and Halothiobacillus HT1 Biofilm in Microscale Using Synchrotron Radiation-Based Techniques. Int. J. Mol. Sci. 2013, 14, 11113-11124.

\section{Introduction}

Microbes cycle metals through biogeochemical processes, including accumulation, transformation and biomineralization, thus leading to changes in toxicity and bioavailability [1,2]. Sulfide oxidation by microbes is used for the biological production of metals, such as copper, gold and zinc. Sulfur oxidizing bacteria contribute strongly to the biological oxidation of metal sulfide $[3,4]$. However, contrary to their significant role in the global sulfur cycle and the biotechnological importance, the microbial fundamentals of sulfur oxidation are incompletely understood, due to the complexity of this reaction.

The microbe-mineral interface serves as a solid phase source of electrons, and biogeochemistry of the microbe-mineral interactions have been paid great attention to during the past few decades [5-7]. Many of the critical processes occur at the biofilm-mineral interface on the molecular scale. Therefore, attention should be focused on microenvironments, where chemical transformations occur. A better understanding of the interfacial properties of the biofilms-mineral interface, especially the interfacial chemical processes at the micron and nanometer levels, is needed [6,8].

Microbes usually operate as consortia of organisms rather than as single cells. Biofilms are physiologically distinct from bacteria growing in a free-swimming planktonic state and present genetic and physiological heterogeneity [9-11]. Growth of biofilm can enhance resistance to metal toxicity. Previous report showed that the ability of biofilms to survive heavy metals stress is better than planktonic microbes [12]. The metabolic activity, microenvironment characteristics and microbial 
community composition of biofilm are involved in resistance to metal toxicity. Biofilms can sorb metals and retard metal diffusion, leading to protection in the interior of the biofilms [13]. The genetic basis for metal resistance in sulfur oxidizing bacteria has been studied by several investigators [14]. Basic understanding of environmental materials and processes at the molecular scale is essential for risk assessment and management and reduction of environmental pollutants. Therefore, the description of the speciation and distribution of metals in biofilms is critically important for modeling and understanding the detoxification mechanism.

The aim of this study was to investigate the interaction in sulfur oxidizing bacteria biofilm-metal sulfide at the micro scale. A heavy-metals-tolerant Halothiobacillus HT1 was chosen [15]. The interaction in the $\mathrm{CuS}$ and biofilm of the Halothiobacillus interface was studied. The spatial distribution and speciation of copper in Halothiobacillus HT1 biofilm formed on CuS was determined using synchrotron-based X-ray fluorescence microscopy (XRF) and micro-X-ray absorption near edge structure (micro-XANES) analysis. Cell viability was detected using live-dead staining. Sulfur speciation was measured using sulfur K-edge XANES.

\section{Results}

\subsection{Spatial Distribution of Live and Dead Halothiobacillus HT1 Cells in the Biofilms}

Halothiobacillus HT1 is a heavy-metals-tolerant sulfur oxidizing bacterium, which belongs to Gammaproteobacteria, Halothiobacillus (GenBank accession number GU013549). In order to analyze the interaction of Halothiobacillus HT1 biofilm and $\mathrm{CuS}$, the spatial distribution of live and dead cells in Halothiobacillus HT1 biofilm sections was studied using Live/Dead staining combined with CLSM imaging. As shown in Figure 1, after $72 \mathrm{~h}$ cultivation, the HT1 cells presented different distributions in the biofilm formed on CuS. At the air-biofilm interface and membrane-biofilm interface, the CLSM imaging results showed green, while in the middle, the results showed red. These results indicated that there were more live cells at the air-biofilm interface and membrane-biofilm interface than in the middle.

Figure 1. Spatial distribution of live and dead cells in Halothiobacillus HT1 biofilm reacted with $\mathrm{CuS}$ after dyeing and CLSM. (A) Light microscope images of Halothiobacillus HT1 biofilm; (B) a composite of live and dead cells; (C) live cells; (D) dead cells. Bars $=250 \mu \mathrm{m}$.

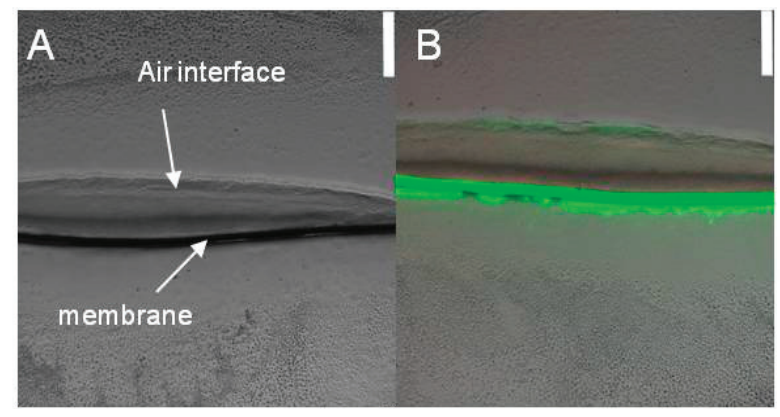


Figure 1. Cont.

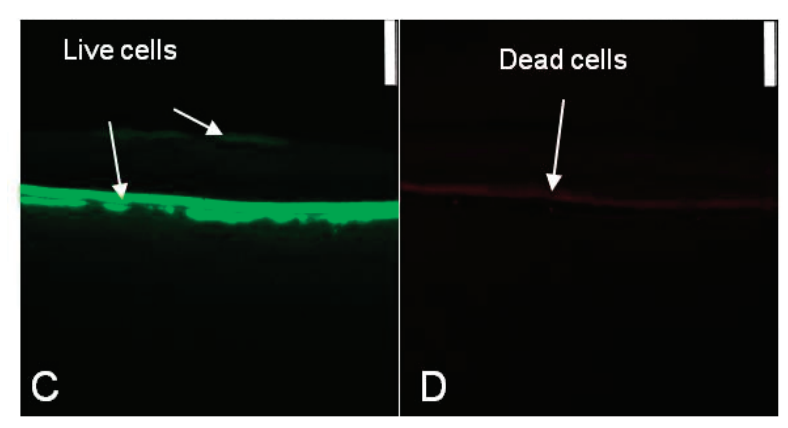

\subsection{Spatial Distributions of Cu in Biofilm and Cu Speciation}

$\mathrm{XRF}$ is considered to be a powerful tool for quantitative mapping of trace element distributions [16]. It can visualize the metal ion distribution in tissues or cells. The colony biofilms were thicker in the center and thinner at the edges. The thickness of the biofilm grown on CuS was about $150 \mu \mathrm{m}$, while the control was about $100 \mu \mathrm{m}$. Figure 2 showed the Halothiobacillus HT1 biofilms section, the scanning area of XRF and the distribution characters of the elements in the scanning area. The elements were not evenly distributed in the biofilms. There was a $\mathrm{Cu}$ accumulation layer in the middle of the Halothiobacillus HT1 biofilm in the presence of $\mathrm{CuS}$, suggesting $\mathrm{Cu}$ penetrated about $100-150 \mu \mathrm{m}$ from the membrane interface.

Compared with bulk XAFS, micro-XAFS could analyze the speciation of elements in small ozone. The $\mathrm{Cu}$ K-edge micro-XANES spectra were conducted to determine the speciation of $\mathrm{Cu}$ in the center and at the edge of the biofilm formed on CuS. Linear combination arithmetic was used to determine the probable $\mathrm{Cu}$ speciation in the sample as analyzed by the LSFitXAFS program. There were some differences in the XANES spectra of the center and the edge, as shown in Figure 3. As shown in Table 1, species resembling $\mathrm{Cu}$-cysteine was the major species both in the center (67.8\%) and at the edge (48.4\%). In the center of the biofilm reacted with $\mathrm{CuS}, \mathrm{Cu}$-alginate- and $\mathrm{Cu}$-citrate-like species accounted for $21.4 \%$ and $10.8 \%$, respectively. While at the edge, $\mathrm{Cu}$-histidine- $(22.3 \%)$ and $\mathrm{CuS}$ (19.3\%)-like species accounted for minor proportions, with $\mathrm{Cu}$-alginate- and $\mathrm{Cu}$-citrate-like species in smaller proportions $(2.9 \%$ and $7.1 \%$, respectively). 
Figure 2. X-ray fluorescence microscopy (XRF) maps of qualitative spatial distributions and concentration gradients of elements in the sections of Halothiobacillus HT1 biofilms grown on LB medium. (Left) Halothiobacillus HT1 biofilm reacted with CuS; (Right) Halothiobacillus HT1 biofilm.

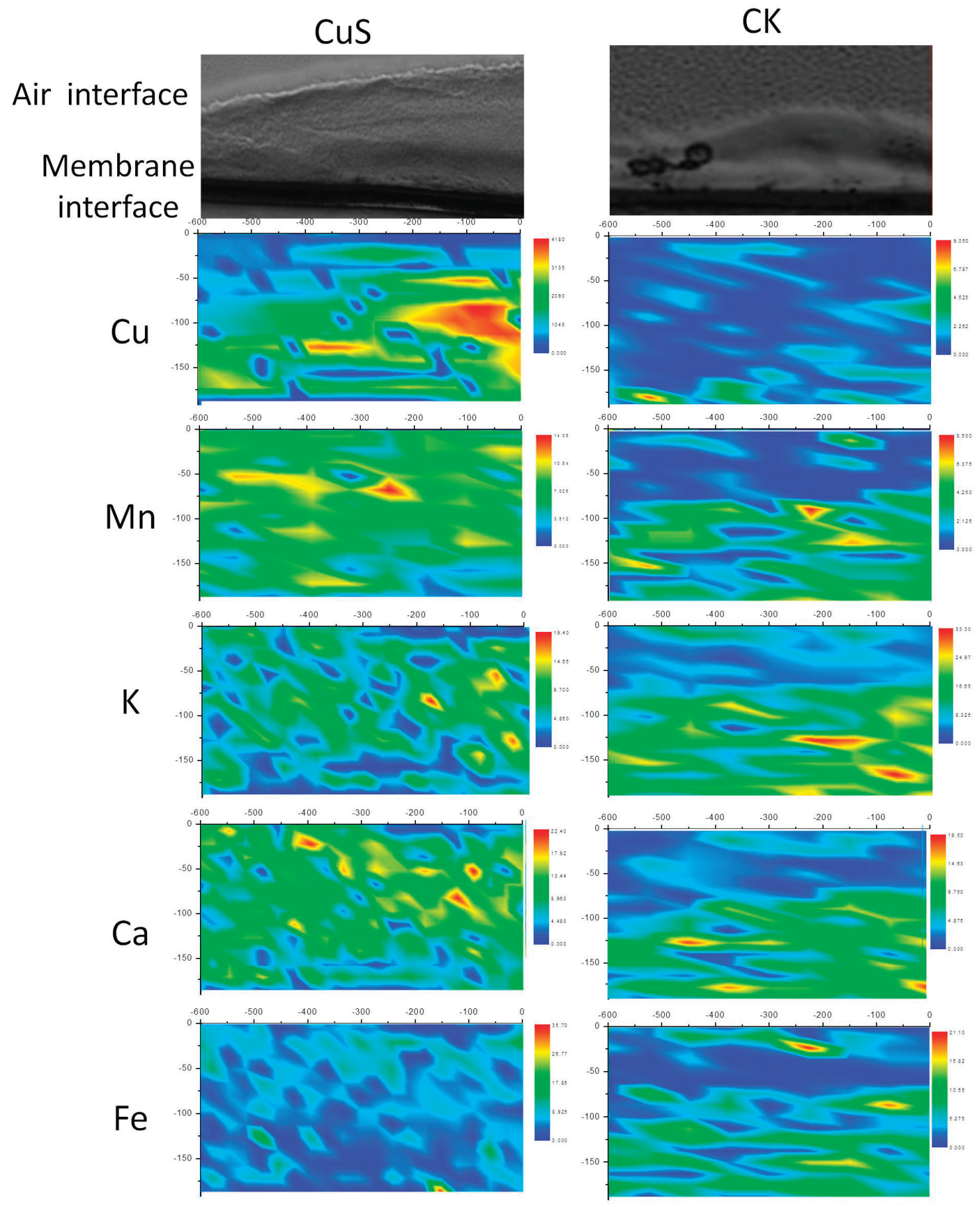


Figure 3. Comparison of copper K-edge XANES spectra of reference compounds and Halothiobacillus HT1 biofilm after being reacted with CuS. Black solid lines: data. Dashed lines: fits with data sets of reference compounds.

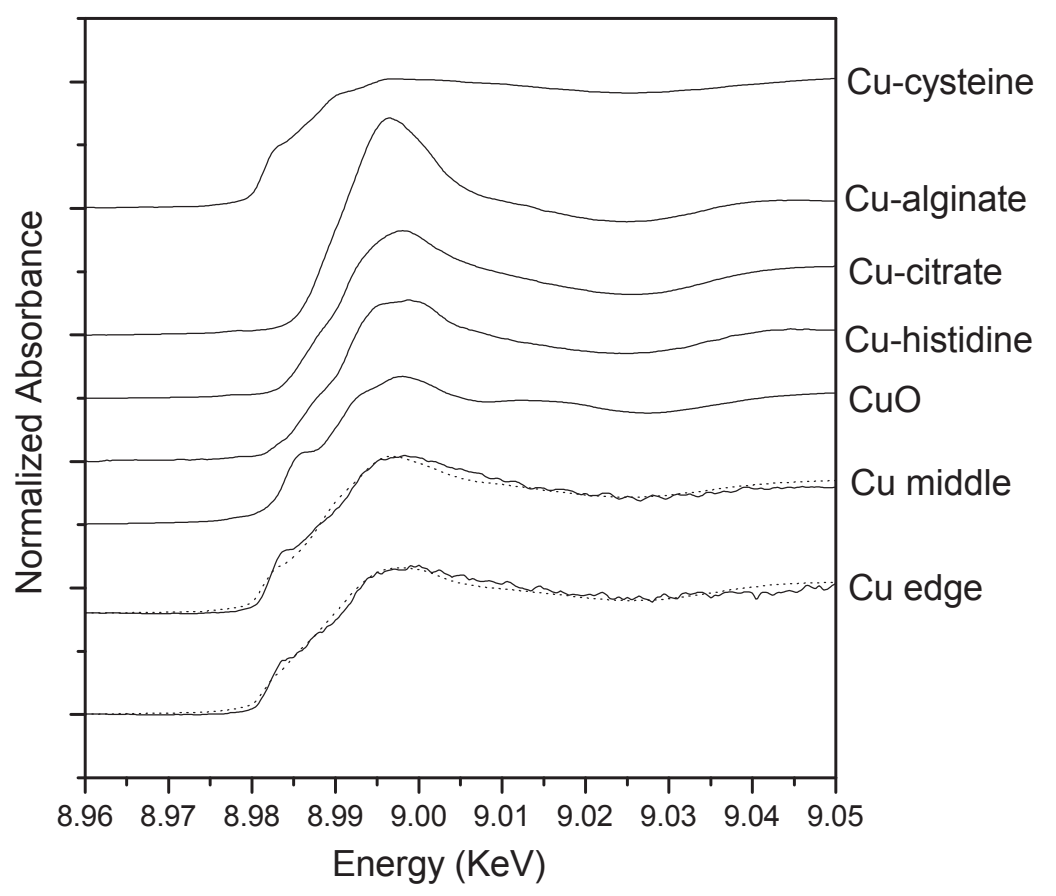

Table 1. The results of fitting the micro-XANES spectra with a linear combination of the measured data sets of representative model compounds. Copper oxidation states were assigned according to the similarity of the absorption edge energies of reference compounds. Rss: residual sum of squares.

\begin{tabular}{ccccccc}
\hline Samples & Cu-cysteine (\%) & Cu-alginate (\%) & Cu-citrate (\%) & Cu-histidine (\%) & CuO (\%) & Rss \\
\hline Center & 67.8 & 21.4 & 10.8 & - & - & 0.51 \\
Edge & 48.4 & 2.9 & 7.1 & 22.3 & 19.3 & 0.51 \\
\hline
\end{tabular}

\subsection{Sulfur Speciation in the Biofilms}

As an essential macronutrient for microorganisms, plants and animals, sulfur (S) exists in a variety of organic and inorganic species, with oxidation states ranging from -2 to +6 . The spectra of reference compounds and the samples are shown in Figure 4. Different reference compounds presented different structures of S. For example, cysteine, reduced glutathione presented R-SH, while cystine, oxidized glutathione presented $\mathrm{R}-\mathrm{S}-\mathrm{S}-\mathrm{R}$. There were multiple oxidations of sulfur in biofilm formed on $\mathrm{CuS}$. As shown in Table 2, species resembling cysteine ( $\mathrm{R}-\mathrm{SH})$ were the major sulfur species in the biofilm (77.3\%), with species resembling sulfite $\left(\mathrm{SO}_{3}{ }^{2-}\right)$ and sulfonate $\left(\mathrm{R}-\mathrm{SO}_{2}-\mathrm{O}-\mathrm{X}\right)$ in minor proportions. While in the absence of $\mathrm{CuS}$ (the control sample), no oxidized sulfur was detected. 
Figure 4. Comparison of sulfur K-edge XANES in Halothiobacillus HT1 biofilm (CK), Halothiobacillus HT1 biofilm reacted with $\mathrm{CuS}$ and reference compounds.

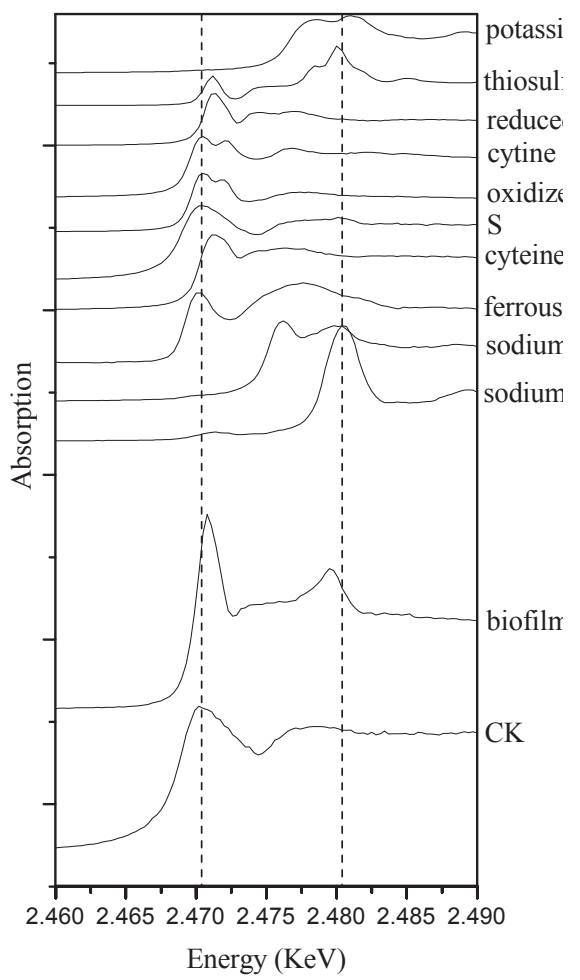

Table 2. Percentage of different $\mathrm{S}$ species in the biofilms as assessed by $\mathrm{S}$ K-edge XANES (atom $\% \mathrm{~S}$ ).

\begin{tabular}{ccccc}
\hline Treatments & Sulfur & Cysteine & Sulfite & Sulfonate \\
\hline $\mathrm{CK}$ & 100 & 0 & 0 & 0 \\
$\mathrm{CuS}$ & 0 & 77.3 & 3.8 & 18.9 \\
\hline
\end{tabular}

\section{Discussion}

\subsection{The Relationship of Cu Distribution and Live/Dead Cells in Biofilms}

Using CLSM, two active zones were found in the biofilm of HT1: the air-biofilm interface and the membrane-biofilm interface. Biofilm formation seemed to give rise to distinct chemical and redox gradients. The different distributions of the cells indicated that oxygen played an important role in the distribution of live cells [17]. At the air-biofilm interface, oxygen was enough for the growth of aerobes. As a result, Halothiobacillus HT1 cells in this area were active, leading to the larger quantities of live cells than in the middle. While at the membrane-biofilm interface, where the oxygen density was relatively low, more live cells were detected than in the middle. The reason might be attributed to the fact that this area played an important role in the transport of nutrition. Therefore, the 
cells were activated at the medium-biofilm interface. Biofilm growth of pathogenic bacteria might influence the rate of carbon and inorganic nutrient cycling [18]. The XRF results showed nonuniform distributions of the elements (Figure 4). Our results supported the previous reports that there were diverse niches in biofilms, and biofilms were physiologically distinct from bacteria in planktonic form [19-21]. The presence of gradients of dissolved gases, nutrients and solute concentrations might be responsible for the distribution of live and dead cells of Halothiobacillus HT1.

In addition, a better understanding of the distribution and mass transfer process within the biofilm is important for understanding their influences on biogeochemical transformation of metals. Metal might deposit as metallic oxide, phosphate, sulfate or carbonate at certain area, due to the heterogeneous distribution of $\mathrm{pH}$, Eh and $\mathrm{O}_{2}$. As a micro-analytical technique for the quantitative mapping of elemental distributions, XRF is compatible with fully hydrated biological samples [22,23]. In this study, XRF is used to detect the distribution of $\mathrm{Cu}$ in biofilm of Halothiobacillus HT1 formed on CuS. Our results indicated that $\mathrm{CuS}$ can be oxidized by Halothiobacillus HT1, as oxidized sulfur (sulfite and sulfonate) was detected using sulfur K-edge XANES analysis (Table 2). As a result, ionic copper was obtained and penetrated into the Halothiobacillus HT1 biofilm. As shown in Figure 2, copper accumulated in the layer near the membrane-biofilm interface. This result indicated that the $\mathrm{CuS}$ and Halothiobacillus HT1 biofilm reacted actively. This might be another reason for the larger quantity of live cells in membrane-biofilm interface than in the middle. The heterogeneous distribution of $\mathrm{Cu}$ found in this study was similar with the result of Templeton conducted on the distribution of $\mathrm{Pb}$ at biofilm-metal oxide interfaces [8]. Another study also showed that Zn equally distributed in the $12 \mu \mathrm{m}$ surface layer of the $35 \mu \mathrm{m} \mathrm{E}$. coli biofilm [24]. All these results confirmed the heterogeneous distribution of metal in microbe biofilms. Synchrotron-based XRF and micro-XANES spectra were successfully applied to investigate the spatial distribution of elements within HT1 biofilms and the speciation of $\mathrm{Cu}$. Our results indicated that there was spatial heterogeneity vertically (Figure 2) and horizontally (Figure 3 and Table 1) within the biofilms

\subsection{Effects of Halothiobacillus HT1 Biofilms on CuS Transformation}

Some specific properties of biofilms can be related to the heterogeneity of their structure and composition. In this study, biofilms formed on $\mathrm{CuS}$ were about $150 \mu \mathrm{m}$ thick, while the control was only about $100 \mu \mathrm{m}$, indicating that HT1 might react with the $\mathrm{CuS}$, since CuS provided substrate for it. To further analyze how microbes influence the fate of metal sulfide, speciation of $\mathrm{Cu}$ and $\mathrm{S}$ was studied. Using sulfur K-edge XANES, sulfur transformation in the biofilms was found. As shown in Figure 4, sulfur was oxidized to cysteine, sulfite and sulfonate in the biofilms formed on $\mathrm{CuS}$. This might be attributed to the reaction of $\mathrm{CuS}$ and Halothiobacillus HT1. Sulfur oxidizing bacteria are considered to be capable of oxidizing mineral sulfide to sulfate. In this study, oxidized sulfur detected in the biofilm indicated that $\mathrm{CuS}$ was oxidized biologically in the presence of Halothiobacillus HT1 biofilms. However, S was found to exist as diverse molecular species (cysteine, sulfite and sulfonate), which might be the intermediate products of sulfide oxidization, but not the end 
product (sulfate). The presence of cysteine, sulfite and sulfonate in the biofilm indicated heterogeneity in the redox state and implied that intermediate sulfur compounds were available for metabolism by Halothiobacillus HT1.

Intimate organic-mineral associations are often the result of bacterial activity. Attached bacteria and adsorbed organic matter may interact with sorption processes on metal sulfide surface by changing the characteristics of the electrical double layer at the solid-solution interface, blocking surface sites or providing a variety of new sites for metal binding. Extracellular polymeric substances (EPS) were considered to enclose biofilms and contain many active groups. Micro-XANES is an element-specific spectroscopic tool to identify the local environment of a target atom within a sample. Therefore, we also studied the speciation of copper in the biofilm formed on $\mathrm{CuS}$ by using micro-XANES. There were several active groups, such as hydroxyl $(-\mathrm{OH})$, sulfhydryl $(-\mathrm{SH})$ and amino $\left(-\mathrm{NH}_{2}\right)$, in the biofilms. The $\mathrm{Cu}$-cysteine analog was the major $\mathrm{Cu}$ species. In correspondence, sulfur K-edge XANES results also confirmed that cysteine was the main sulfur species.

In order to survive heavy metals stress, microbes usually apply different mechanisms, such as biosorption, precipitation and complexation with sulfides, phosphates or carbonates. Active efflux or detoxification of metal ions by different transformations was found to be involved in many metal resistance systems [25]. For some bacteria, it was believed that inorganic polyphosphates and transport of metal phosphate complexes were involved in heavy metal tolerance [26-28]. $\mathrm{Cu}$ homeostasis proteins were also found in previous study [29]. In this study, cysteine analogs likely played an important role in the penetration of copper into the biofilm. The high percentage of Cu-cysteine-like species in the biofilm confirmed that the $\mathrm{Cu}$ bond to cysteine groups could be defenses against toxic copper. Complexation with - $\mathrm{SH}$ groups might contribute to the detoxification of $\mathrm{Cu}$ since - $\mathrm{SH}$-containing groups were considered to be bioactive molecules, which can maintain $\mathrm{Cu}$ homeostasis through cation binding. These results were consistent with some previous reports concerning other bacteria, which showed that cellular proteins rich in thiol groups participated in the copper homeostasis [30].

At the biofilm-mineral interface, many critical processes occur. Our study attempted to study the interaction of $\mathrm{CuS}$ and Halothiobacillus HT1 biofilm at the micro scale. More work about the interfacial properties of the biofilm-mineral interface are needed in the future. For example, scanning transmission X-ray microscopy (STXM), which uses near-edge X-ray absorption spectroscopy (NEXAFS) as its contrast mechanism, can be further used to fully hydrate biological materials at a smaller scale (nanoscale).

\section{Experimental Section}

\subsection{Biofilms Cultivation}

Halothiobacillus $\mathrm{HT} 1$ was retrieved from $-70{ }^{\circ} \mathrm{C}$ stock cultures by incubating on the LB agar plate at $28{ }^{\circ} \mathrm{C}$ for $48 \mathrm{~h}$. Then, a single colony was suspended into $1 \mathrm{~mL}$ of sterile $0.9 \% \mathrm{NaCl}$. Zero-point-one grams of $\mathrm{CuS}$ (pretreated with $0.25 \mathrm{M}$ EDTA, $\mathrm{pH} 8.0$ for antioxidation and acetone for sulfide 
remover) and $1 \mathrm{~mL}$ sterile water were added in an EP tube to prepare the suspension. Then, $300 \mu \mathrm{L}$ of this suspension was added on LB solid medium. Nuclepore ${ }^{\circledR}$ polyester membranes (13 mm diameter, $0.1 \mu \mathrm{m}$ pore, $6 \mu \mathrm{m}$ thick, Whatman) were sterilized by immersion in $70 \%$ ethanol for $2 \mathrm{~min}$ individually, air dried and transferred with sterile forceps to the LB solid media surface. Three membranes were spaced in an equilateral triangular pattern and $3 \mu \mathrm{L}$ of the Halothiobacillus HT1 suspension were transferred to the center of each membrane and then inoculated at $28{ }^{\circ} \mathrm{C}$ for $72 \mathrm{~h}$. Control treatments without adding $\mathrm{CuS}$ were also prepared. Each treatment was prepared in four groups for staining, XRF analysis, sulfur XANES and Cu micro-XANES analysis, respectively.

\subsection{Live/Dead Cells Distribution Using CLSM Image}

Biofilms were stained with the Live/Dead BacLight Kit (Molecular Probes) to determine the distribution of Live/Dead cells. Three microliters of Syto-9 and $3 \mu \mathrm{L}$ propidium iodide were suspended in $1 \mathrm{~mL} 0.9 \%$ saline to prepare the staining agents. The biofilms were placed on the staining agent for $30 \mathrm{~min}$ in the dark. Live cells of Halothiobacillus HT1 stain green, and dead cells train orange-red.

Then, the stained biofilms were cryoembeded and cryosected as follows: biofilms were placed on the chuck. Cuts perpendicular to the plane of biofilms were made using a low profile microtome blade (Paracu $^{\mathrm{TM}}$, McCormick ${ }^{\mathrm{TM}}$ Scientific). Fifty micrometer-thick cross sections from the middle of each biofilms were placed on glass coverslips and examined using microscopy to confirm the thickness and structure of biofilms sections and then stored at $-20{ }^{\circ} \mathrm{C}$ for analysis. The samples were examined using a Leica TCS SP5 confocal laser scanning microscope (CLSM) to detect the distribution of live/dead cells of Halothiobacillus HT1.

\subsection{Distribution of Cu in the Biofilm by Using Synchrotron-Based X-Ray Fluorescence}

Biofilms were sectioned as described above and placed on 3M adhesive tapes (Scotch, 810, 3M Company, St. Paul, MN, USA). X-ray fluorescence (XRF) analysis of the biofilms was performed at the XRF microprobe station (beam line 4W1B) of Beijing Synchrotron Radiation Facility (BSRF), Institute of High Energy Physics of China. The electron energy in the storage ring was $2.2 \mathrm{GeV}$, with a current range from 78 to $120 \mathrm{~mA}$. The size of the exciting X-ray beam was $10 \mu \mathrm{m} \times 20 \mu \mathrm{m}$. XRF spectra were collected by a PGY Si (Li) solid detector, positioned at $90^{\circ}$ to the beam line. The scanning points of the samples were selected and observed by a microscope. Spectra data were processed by the AXIL program to integrate the area of the element excited peak. Relative contents of elements were calculated by calibrating the peak area with electron current and normalized with Compton scattering intensity. PyMca [31] and origin 8.0 was used to analyze the distribution of the elements in the biofilms. 


\subsection{Copper Speciation Analysis Using Cu K-Edge Micro-XANES}

Two points located in the edge and center regions of the Halothiobacillus HT1 biofilm grown on $\mathrm{CuS}$ (the size of exciting X-ray beam was $40 \mu \mathrm{m} \times 70 \mu \mathrm{m}$ ) were selected for $\mathrm{Cu}$ micro-XANES analysis. A $50 \mu \mathrm{m}$ thick cross section was obtained using cryosectioning methods described above and placed on $3 \mathrm{M}$ adhesive tape and then stored at $-20{ }^{\circ} \mathrm{C}$ until analysis. The $\mathrm{Cu} \mathrm{K}$-edge micro-XANES spectra were measured at beam line $15 \mathrm{U}$ of Shanghai Synchrotron Radiation Facility (SSRF). It was operated at $3.5 \mathrm{GeV}$ with a current of $210-150 \mathrm{~mA}$ in the fluorescence mode for the energy range from 8.95 to $9.06 \mathrm{keV}$. The fluorescence XANES spectra were collected for $5 \mathrm{~s}$ dwell times and analyzed as described by the previous description [32].

\subsection{Sulfur Speciation Analysis Using Sulfur K-Edge XANES}

Each of the biofilms were freeze dried, mixed and ground for XANES analysis. Sulfur speciation in the biofilms was analyzed by X-ray Absorption Spectroscopy at Beijing Synchrotron Radiation Facility (BSRF). The biofilms samples were laid on $3 \mathrm{M}$ tape for analysis. The storage ring was operated at the energy of $2.5 \mathrm{GeV}$ with $\mathrm{Si}$ (111) double crystals. Spectra were recorded at 4B7A beamline (medium $\mathrm{X}$-ray beamline, $2100-6000 \mathrm{eV}$ ) and scanned at step widths of $0.3 \mathrm{eV}$ in the region between 2420 and $2520 \mathrm{eV}$. Reference compounds were ferrous sulfide, elemental sulfur, potassium persulfate, sodium thiosulfate, reduced glutathione, cystine, oxidized glutathione, cysteine, dimethyl sulfone, sodium diphenylamine sulfonate, sodium dodecyl sulfate (SDS), sodium sulfite and sodium sulfate. The X-ray energy was calibrated with reference to the spectrum of the highest resonance energy peak of $\mathrm{Na}_{2} \mathrm{SO}_{4}$ at $2,480.4 \mathrm{eV}$. The data were analyzed as described by the previous description [33].

\section{Conclusions}

Our results indicated that biofilm formation of Halothiobacillus HT1 gave rise to distinct chemical and redox gradients, leading to diverse niches in biofilms. There were two active zones in the biofilm of HT1: the air-biofilm interface and the membrane-biofilm interface. Copper was mainly distributed near the membrane-biofilm interface. Halothiobacillus HT1 biofilm oxidized CuS. Cysteine was synthesized for tolerance against $\mathrm{Cu}$. The $\mathrm{Cu}$-cysteine analog was involved in chelation within strain HT1 when it interacted with $\mathrm{Cu}$ to survive heavy metals stress.

\section{Acknowledgments}

This work was supported by the National Natural Science Foundation of China (11179025, 21177109, 41071302) and the Zhejiang Provincial Natural Science Foundation of China (R5110031). We gratefully thank the staff at the Beijing Synchrotron Radiation Facility (BSRF) and Shanghai Synchrotron Radiation Facility (SSRF) for their generous help. 


\section{Conflict of Interest}

The authors declare no conflict of interest.

\section{References}

1. Dynes, J.J.; Tyliszczak, T.; Araki, T.; Lawrence, J.R.; Swerhone, G.D.W.; Leppard, G.G.; Hitchcock, A.P. Speciation and quantitative mapping of metal species in microbial biofilms using scanning transmission X-ray Microscopy. Environ. Sci. Technol. 2006, 40, 1556-1565.

2. Geoffrey, M.G. Microbial influence on metal mobility and application for bioremediation. Geoderma 2004, 122, 109-119.

3. Ito, T.; Sugita, K.; Okabe, S. Isolation, characterization, and in situ detection of a novel chemolithoautotrophic sulfur-oxidizing bacterium in wastewater biofilms growing under microaerophilic conditions. Appl. Environ. Microbiol. 2004, 70, 3122-3129.

4. Ma, S.; Banfield, J.F. Micron-scale $\mathrm{Fe}^{2+} / \mathrm{Fe}^{3+}$, intermediate sulfur species and $\mathrm{O}_{2}$ gradients across the biofilm-solution-sediment interface control biofilm organization. Geochim. Cosmochim. Ac. 2011, 75, 3568-3580.

5. Edwards, K.J.; Bond, P.L.; Druschel, G.K.; McGuire, M.M.; Hamers, R.J.; Banfield, J.F. Geochemical and biological aspects of sulfide mineral dissolution: Lessons from Iron Mountain, California. Chem. Geol. 2000, 169, 383-397.

6. Templeton, A.; Knowles, E. Microbial transformations of minerals and metals: Recent advances in geomicrobiology derived from synchrotron-based X-ray spectroscopy and X-ray microscopy. Ann. Rev. Earth. Pl. Sc. 2009, 37, 367-391.

7. Zachara, J.M.; Fredrickson, J.K.; Smith, S.C.; Gassman, P.L. Solubilization of Fe(III) oxide-bound trace metals by a dissimilatory Fe(III) reducing bacterium. Geochim. Cosmochim. Ac. 2001, 65, 75-93.

8. Templeton, A.S.; Trainor, T.P.; Traina, S.J.; Spormann, A.M.; Brown, G.E. Pb(II) distributions at biofilm-metal oxide interfaces. Proc. Natl. Acad. Sci. USA 2001, 98, 11897-11902.

9. Drenkard, E.; Ausubel, F.M. Pseudomonas biofilm formation and antibiotic resistance are linked to phenotypic variation. Nature 2002, 416, 740-743.

10. Fux, C.A.; Costerton, J.W.; Stewart, P.S.; Stoodley, P. Survival strategies of infectious biofilms. Trends Microbiol. 2005, 13, 34-40.

11. Sandt, C.; Smith-Palmer, T.; Pink, J.; Brennan, L. Pink, D. Confocal Raman microspectroscopy as a tool for studying the chemical heterogeneities of biofilms in situ. J. Appl. Microbiol. 2007, 103, $1808-1820$.

12. Harrison, J.J.; Ceri, H.; Turner, R.J. Multimetal resistance and tolerance in microbial biofilms. Nat. Rev. Microbiol. 2007, 5, 928-938.

13. Harrison, J.J.; Ceri, H.; Stremick, C.A.; Turner, R.J. Biofilm susceptibility to metal toxicity. Environ. Microbiol. 2004, 6, 1220-1227. 
14. Butcher, B.G.; Deane, S.M.; Rawlings, D.E. The chromosomal arsenic resistance genes of Thiobacillus ferrooxidans have an unusual arrangement and confer increased arsenic and antimony resistance to Escherichia coli. Appl. Environ. Microbiol. 2000, 66, 1826-1833.

15. Shi, J.Y.; Lin, H.R.; Yuan, X.F.; Zhao, Y.D. Isolation and characterization of a novel sulfur-oxidizing chemolithoautotroph Halothiobacillus from $\mathrm{Pb}$ polluted paddy soil. Afr. J. Biotechnol. 2011, 10, 4121-4126.

16. Ortega, R. Chemical elements distribution in cells. Nucl. Instr. Meth. Phys. Res. 2005, 231, 218-223.

17. Rani, S.A.; Pitts, B.; Beyenal, H.; Veluchamy, R.A.; Lewandowski, Z.; Davison, W.M.; Buckingham-Meyer, K.; Stewart, P.S. Spatial patterns of DNA replication, protein synthesis, and oxygen concentration within bacterial biofilms reveal diverse physiological states. J. Bacteriol. 2007, 189, 4223-4233.

18. Hall-Stoodley, L.; Costerton, J.W.; Stoodley, P. Bacterial biofilms: From the natural environment to infectious diseases. Nat. Rev. Microbiol. 2004, 2, 95-108.

19. Battin, T.J.; Sloan, W.T.; Kjelleberg, S.; Daims, H.; Head, I.M.; Curtis, T.P.; Eberl, L. Microbial landscapes: New paths to biofilm research. Appl. Environ. Microbiol. 2007, 5, 76-81.

20. Sauer, K.; Camper, A.K.; Ehrlich, G.D.; Costerton, J.W.; Davies, D.G. Pseudomonas aeruginosa displays multiple phenotypes during development as a biofilm. J. Bacteriol. 2002, 184, 1140-1154.

21. Stewart, P.S.; Franklin, M.J. Physiological heterogeneity in biofilms. Nat. Rev. Microbiol. 2008, 6, 199-210.

22. Chen, G.C.; Chen, X.C.; Yang, Y.Q.; Hay, A.G.; Yu, X.H.; Chen, Y.X. Sorption and distribution of copper in unsaturated Pseudomonas putida CZ1 biofilms as determined by X-ray fluorescence microscopy. Appl. Environ. Microbiol. 2011, 77, 4719-4727.

23. Fahrni, C.J. Biological applications of X-ray fluorescence microscopy: Exploring the subcellular topography and speciation of transition metals. Curr. Opin. Chem. Biol. 2007, 11, 121-127.

24. Hu, Z.Q.; Hidalgo, G.; Houston, P.L.; Hay, A.G.; Shuler, M.L.; Abruna, H.D.; Ghiorse, W.C.; Lion, L.W. Determination of spatial distributions of zinc and active biomass in microbial biofilms by two-photon laser scanning microscopy. Appl. Environ. Microbiol. 2005, 71, 4014-4021.

25. Silver, S.; Phung, L.T. Bacterial heavy metal resistance: New surprises. Ann. Rev. Microbiol. 1996, 50, 753-789.

26. Alvarez, S.; Jerez, C.A. Copper ions stimulate polyphosphate degradation and phosphate efflux in Acidithiobacillus ferrooxidans. Appl. Environ. Microbiol. 2004, 70, 5177-5182.

27. Kornberg, A.; Rao, N.N.; Ault-Richer, D. Inorganic polyphosphate: A molecule of many functions. Ann. Rev. Biochem. 1999, 68, 89-125.

28. Remonsellez, F.; Orell, A.; Jerez, C.A. Copper tolerance of the thermoacidophilic archaeon Sulfolobus metallicus: Possible role of polyphosphate metabolism. Microbiology 2006, 152, 59-66.

29. Kim, B.E.; Nevitt, T.; Thiele, D.J. Mechanisms for copper acquisition, distribution and regulation. Nat. Chem. Biol. 2008, 4, 176-185. 
30. Quaranta, D.; McCarty, R.; Bandarian, V.; Rensing, C. The copper-inducible cin operon encodes an unusual methionine-rich azurin-like protein and a pre-Q0 reductase in Pseudomonas putida KT2440. J. Bacteriol. 2007, 189, 5361-5371.

31. PyMca. Available online: http://pymca.sourceforge.net (accessed on 15 July 2011).

32. Shi, J.Y.; Wu, B.; Yuan, X.F.; Cao, Y.Y.; Chen, X.C.; Chen, Y.X.; Hu, T.D. An X-ray absorption spectroscopy investigation of speciation and biotransformation of copper in Elsholtzia splendens. Plant Soil 2008, 302, 163-174.

33. Lin, H.R.; Shi, J.Y.; Chen, X.C.; Yang, J.J.; Chen, Y.X.; Zhao, Y.D.; Hu, T.D. Effects of lead upon the actions of sulfate-reducing bacteria in the rice rhizosphere. Soil Biol. Biochem. 2010, 42, $1038-1044$. 


\title{
Enhancing Metagenomics Investigations of Microbial Interactions with Biofilm Technology
}

\section{Robert J. C. McLean and Kavita S. Kakirde}

\begin{abstract}
Investigations of microbial ecology and diversity have been greatly enhanced by the application of culture-independent techniques. One such approach, metagenomics, involves sample collections from soil, water, and other environments. Extracted nucleic acids from bulk environmental samples are sequenced and analyzed, which allows microbial interactions to be inferred on the basis of bioinformatics calculations. In most environments, microbial interactions occur predominately in surface-adherent, biofilm communities. In this review, we address metagenomics sampling and biofilm biology, and propose an experimental strategy whereby the resolving power of metagenomics can be enhanced by incorporating a biofilm-enrichment step during sample acquisition.
\end{abstract}

Reprinted from Int. J. Mol. Sci. Cite as: McLean, R.J.C.; Kakirde, K.S. Enhancing Metagenomics Investigations of Microbial Interactions with Biofilm Technology. Int. J. Mol. Sci. 2013, 14,

$22246-22257$.

\section{Introduction}

The global distribution of microorganisms is impressive, ranging from the deep subsurface in terrestrial [1] and marine environments [2], to the upper atmosphere [3]. Although culturing techniques are improving, the vast majority of microorganisms in natural environments including soil are as yet uncultured. Estimates of microbial composition, diversity, and even ecological interactions are performed using a variety of culture-independent approaches including metagenomics [4]. One highly notable early achievement from molecular investigations was the identification of three domains of life, Archaea, Bacteria, and Eukarya [5]. The advances of sequencing technology from the traditional Sanger protocol to higher throughput, more economical approaches such as pyrosequencing and Illumina-based sequencing [6] have resulted in the generation of considerable data, and as a result these systems biology approaches require considerable bioinformatics analysis and genome sequence construction [7]. A number of highly significant results have arisen from metagenomics studies including the discovery of "Candidatus Pelagibacter ubique" strain HTCC1062, originally identified as clade SAR11, which is considered the most abundant microorganism in the pelagic ocean [8]. Based on genome analysis, unusual nutrient requirements for "Ca. P. ubique" were identified and this extreme oligotroph can now be cultured on defined media [9].

\section{Experimental Strategies for Extraction of Metagenomic DNA from Soil Biofilms}

Surface-adherent microbial communities (biofilms) are a common feature of microbial growth in many environments [10] including soils. In the investigation of a soil biofilm it may be of particular 
interest to look at specific sections that may indicate a multitude of interactions between microbial populations in the biofilm. Visualization and imaging using microscopy techniques can be used to target this subset of the entire microbial population from the sample biofilm. There are two methods for the extraction and processing of metagenomic DNA from a microbial population, direct and indirect extraction. In the direct extraction method pioneered by Ogram et al. [11], any extracellular DNA is first separated from the environmental sample by treating it with an alkaline buffer. The cells in the matrix are then subjected to direct mechanical (e.g., bead beating) lysis followed by extraction of DNA released from these cells. DNA recovered by centrifugation is then concentrated and purified before cloning. In contrast, the indirect method involves recovery of microbial cells from the sample. The recovered cells are subjected to cell lysis (chemical and enzymatic) followed by DNA extraction and purification [12]. Although time-consuming the indirect extraction method prevents the contamination from non-bacterial DNA [13] that may be present in the sample. Direct extraction methods provide high yield of lower size DNA fragments whereas indirect methods provide low yield of higher size DNA fragments. Both methods have distinct advantages and limitations, and the choice should be based on the intended downstream application and the objective of the study. Irrespective of the DNA extraction method, care must be taken to avoid co-isolation of organic compounds that may be present in the sample and can inhibit downstream processes. Various factors to be considered pertaining to soil metagenomics and the use of specific strategies based on the ultimate goal of the study are discussed by Kakirde et al. [14] and this provides a good guideline for designing a metagenomics project. Since there are multiple approaches that can be adopted at each stage of a metagenomic analysis it is important to select appropriate DNA extraction and purification methods and consider if cloning is necessary.

Direct sequencing of metagenomic DNA can be performed followed by sequence analysis. The vastly growing field of next generation sequencing technology offers a plethora of options for sequencing such as 454 Pyrosequencing and Illumina among others. Every platform offers different coverage and read length and the cost per base of sequencing is likely to become more affordable with the rapid advances in this field. The massive amount of sequence data generated by next-generation sequencers requires the use of specialized bioinformatics tools to mine and analyze the output. The sequence-only method is comparatively less time-consuming than the alternative, which is construction of metagenomic libraries and subsequent function and or sequence-based screening to identify gene products encoded by the target microbial partners. An appropriate cloning vector and a host organism should be used in capturing and cloning these genes. Depending on the desired insert size and purity, the DNA for cloning in many instances can be obtained by using commercially available kits (such as Qiagen and MoBio). Some of the methods commonly used for purification of extracted DNA are the standard phenol-chloroform extraction, cesium chloride density gradient centrifugation and chromatography. Often a combination of methods can lead to greater purity but this is also accompanied by increased DNA loss. Hence the purification protocol(s) should be selected according to the requirements of the concentration and purity of the DNA that is to be cloned. Prior to 
cloning DNA can be sheared using physical shearing or partial restriction digestion, size-selected by electrophoresis [15] and then electroeluted [16]. Cosmid and fosmid vectors have been used for cloning DNA from environmental samples with an insert size between 30 and $50 \mathrm{~kb}$ [14]. Fosmids are based on the bacterial F-factor and are stably maintained in the host due to their low copy number (1-2 copies per cell), which is tightly regulated in a host such as E. coli. Fosmid vectors have a higher cloning efficiency as compared to bacterial artificial chromosome (BAC) vectors. A limitation of fosmid vectors is the limited insert size. Larger inserts can be cloned by using a BAC vector, which can easily maintain fragments greater than $100 \mathrm{~kb}$ [17]. BAC vectors can be induced to a high copy number for increased expression and DNA yield from metagenomic clones, and can also be stably maintained at single copy [18]. In investigating specific interactions within the biofilm such as syntrophy, competition or the transfer of antibiotic resistance elements cloning would be preferable to the sequence only approach especially when looking for novel mechanisms. E. coli is one of the commonly used heterologous hosts in construction of metagenomic libraries since it has a high cloning efficiency and is easy to culture and work with in vitro [19-22]. Other heterologous hosts such as Streptomyces species have been used for heterologous expression of cloned metagenomic DNA in multiple studies [23,24]. The use of Archaea, specifically extreme halophiles as a host for expression of cloned DNA has been done in previous studies. The percent $\mathrm{G}+\mathrm{C}$ content of the cloned genes, predominant partners (Gram positive or Gram negative) in the biofilm samples are some factors that can be considered in selecting a suitable host. Vectors systems used in the process should also be compatible with the selected host organism.

Construction of metagenomic libraries followed by a function-based screening is an excellent strategy to actually detect the gene products of the cloned inserts and could be used to identify various metabolic products, including both growth enhancing as well as antimicrobial compounds produced by microbial partners in the biofilm. The effect of these compounds on various tester microorganisms can be determined by using a bioassay method in the functional screen. Similarly the presence of specific antimicrobial resistance elements can be detected by incorporating the particular antibiotic in the bioassay during screening of the metagenomic clones. Although cost-intensive, if feasible a combined sequence and function based analysis can be very effective in determining the chemistry and basic charcteristics of the microbial partners in the biofilm interaction. The preliminary information obtained from the sequence data can be used for designing a specifically targeted function based metagenomics screen. Figure 1 summarizes the general steps of a metagenomics strategy to investigate microbial communities in environmental samples. 
Figure 1. General steps in a metagenomics strategy to investigate microbial communities in environmental samples.

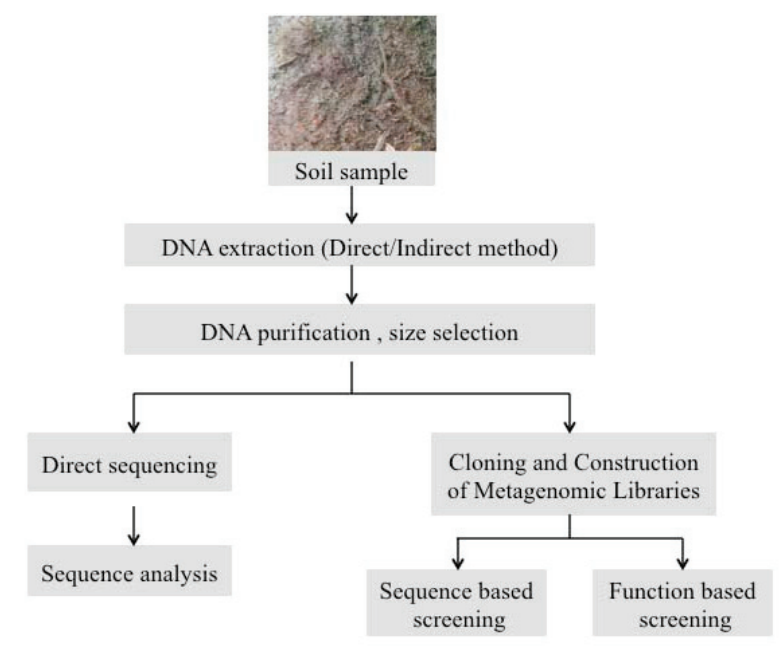

In addition to identifying genes of interest, a sequence based screening of the metagenomic libraries can be used in identification of regulatory elements that have been shown to control the formation and structure of biofilms [25]. A sequence only approach utilizing the power of the 454 sequencing technology is a good strategy for this purpose and yields good quality metagenomic sequences. These sequences can be deposited in GenBank and then referenced against available environmental databases and metagenomic datasets. The metagenomics RAST (MG-RAST) server is an excellent and free public resource that compares both protein and nucleotide databases to generate phylogenetic and functional summaries of the metagenomic sequence data [26]. MEGAN (Metagenome Analyzer), a computer program is another bioinformatics tool for analysis of high-throughput metagenomic sequence data and gene prediction that compares DNA reads against databases using comparative tools such as BLAST [27]. Metagenomic sequence analysis of microbial communities in a biofilm using the tools mentioned here can be used to identify and predict gene functions and can provide a different perspective to investigate the dynamic interactions between microbial partners within the biofilm environment.

\section{Bacterial Adhesion and Biofilm Ecology}

Bacterial adhesion to surfaces has been known for some time [28] but has only been recognized as a dominant mode of bacterial growth in nature in the past 20-30 years [10,29]. Surface-adherent microbial communities, now referred to as biofilms [10] are common in most environments. The prominence of biofilms is easily explained in flowing systems such as rivers [30] or pipelines [31], wherein surface adhesion enables microorganisms to persevere in spite of shear forces. Nutrients adsorb onto surfaces and microorganisms would therefore be attracted to sources of nutrition - a phenomenon sometimes referred to as the bottle effect [32]. Metabolic and genetic interactions are facilitated when 
organisms grow in close proximity within biofilms. Wolfaardt et al. [33] studied the ability of soil bacteria to grow on a commercial herbicide, diclophop methyl and found that bacteria could survive on this compound as a sole carbon source only if present as a biofilm consortium. Pure cultures of the soil isolates were unable to grow on this herbicide regardless of whether they were grown as planktonic or biofilm cultures. Similarly, mixed planktonic cultures were unable to grow on this herbicide [33]. Nitrification is another well-known biological phenomenon consisting of a two step process involving ammonia oxidation to nitrite, followed by nitrite oxidation to nitrate [34]. Ammonia oxidizing microorganisms are found in close proximity to nitrite oxidizers within nitrifying biofilms [35,36]. Syntrophic metabolism within microbial aggregates has also been reported in interspecies hydrogen transfer during anaerobic digestion of cellulose [37,38]. Biofilm growth has also been shown to promote genetic exchange through transformation [39] and conjugation [40,41] due to the close proximity of the donor and recipient organisms.

Biofilm studies with pure cultures have shown that these communities go through a developmental process [42] involving initial adhesion of microorganisms to a surface, aggregation into clumps (microcolonies), a maturation process and finally a dispersion process. In some organisms, notably Pseudomonas aeruginosa, Staphylococcus aureus and Vibrio cholerae, genes and mechanisms for biofilm development have been identified (reviewed in [42-44]). At the morphological level, there is evidence that similar processes occurs within mixed community biofilms, with the added complication of ecological interactions between species. In the dental field, there has been considerable work showing the population development of biofilms on teeth (dental plaque). When a hydroxyapatite tooth surface is cleaned, it becomes rapidly coated by adsorbed salivary proteins, which form a conditioning film [45]. Primary colonizing bacteria including Streptococcus gordonii, Streptococcus oralis and Actinomyces naislundii then attach to the conditioning film [46] and are in turn colonized by other organisms such as the cariogenic gram positive Streptococcus mutans [47]. Cell surface features including surface carbohydrates and carbohydrate-binding proteins (lectins), permitting the binding (coaggregation) of individual species to each other, is a major feature of population development in dental biofilms [47]. Microbial succession certainly occurs in other environments [48-50], and in biofilms associated with higher organisms, the host may play an active role in biofilm development. In the rhizosphere, plant exudates function as bacterial nutrients and play an important role in bacterial recruitment, and associated biofilm development and bacterial succession [50]. Cell signal interactions [51-53] are also important, during microbial colonization, biofilm formation and population succession. Other factors that are also important during biofilm population development include antimicrobial vesicle formation [54], antimicrobial chemicals [55] and bacteriocins [56]. At least two studies have shown that polymicrobial biofilms are more resistant to antibacterial agents and stress, than single species biofilms [57,58].

Another feature of biofilms is an indication of cell specialization. This is particularly prominent and well-described in biofilms formed by the social bacterium, Myxococcus xanthus in which some cells are involved in reproduction, others in nutrient acquisition, and others have structural roles [59]. 
Similar analogies have been shown in other organisms [43]. Certainly chemical gradients including nutrient levels, $\mathrm{pH}$, and oxygen levels (in aerobic biofilms) result in a physiological gradient [60]. The structure and specialization seen within biofilms has been likened to a city [61] (Figure 2), with different physiological functions and even component species being present in clusters (microcolonies). Using the city metaphor for biofilms [60], an individual microcolony may function as one apartment building and will have ecological interactions (synergy, antagonism, synthrophic metabolism, genetic exchange, etc.) with neighboring microcolonies ("apartment buildings"). While biofilm structure and function is certainly complex, it largely reflects the situation in which bacteria naturally exist. As a result, broad based molecular microbial ecology studies would benefit by focusing on biofilms.

Figure 2. Biofilm enrichment strategy for metagenomics investigation. Confocal microscopy examination of a mixed population biofilm of E. coli and P. aeruginosa stained with the Live/Dead ${ }^{\mathrm{TM}}$ stain (Life Technologies, Grand Island, NY, USA) reveals microcolonies with viable (A) and non-viable (B) cells. Sampling and metagenomics analyses from these two microcolonies could suggest mechanisms underlying the loss of viability or other cellular interactions. While conventional genetic analyses can be performed for a mixed population biofilm containing known, genetically tractable organisms such as E. coli and P. aeruginosa [62], it is not practical for many naturally occurring biofilms with potentially unculturable organisms. This combination biofilm-enrichment strategy for metagenomics would be particularly useful in natural biofilms wherein the component populations may not be known.

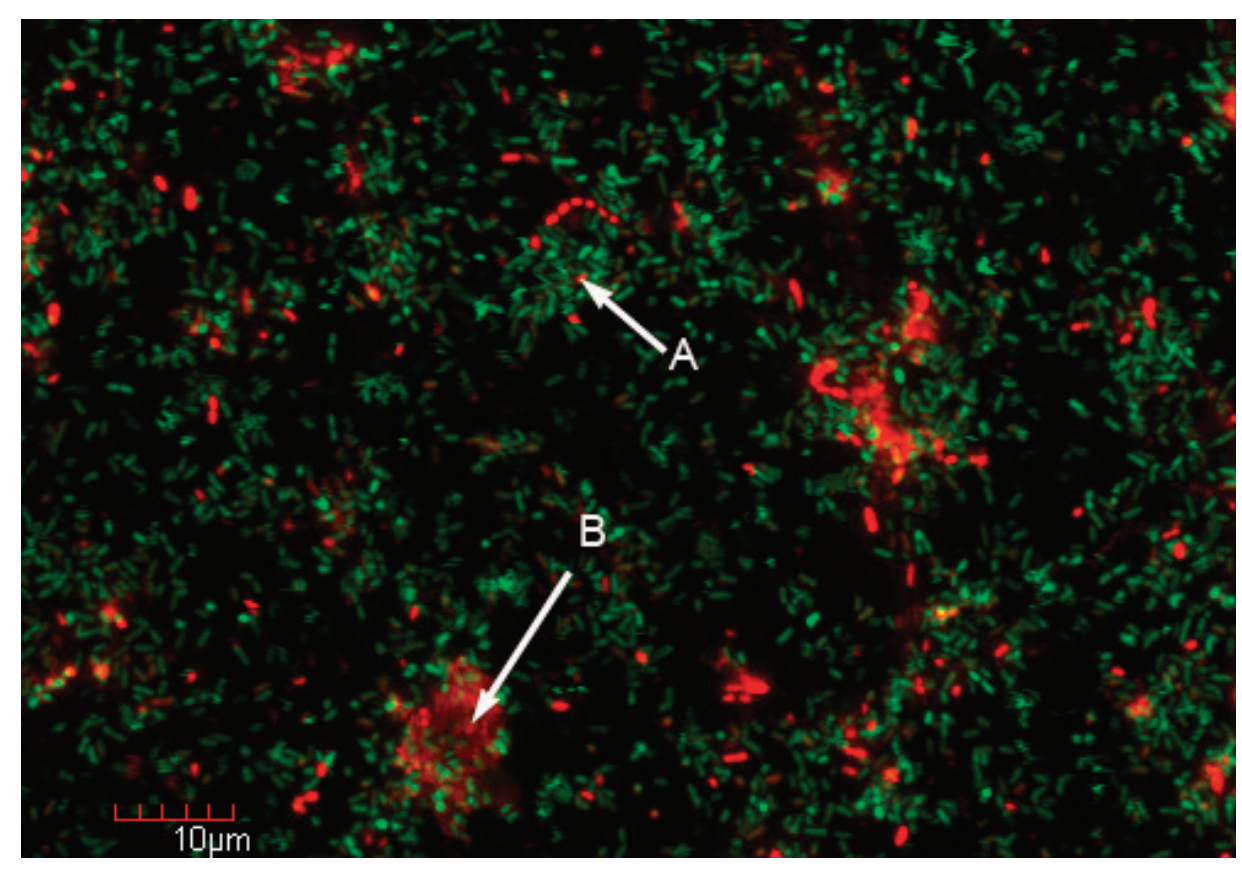




\section{Biofilm Technology and Its Potential Application to Molecular Microbial Ecology}

In most environments, microorganisms live as surface-adherent biofilm communities [10]. Within biofilms, many and possibly most microbial interactions and processes occur. Included in naturally occurring biofilm communities are cultivable and non-cultivable microorganisms [4]. While broad-based molecular approaches, such as metagenomics offer an invaluable insight to identifying new organisms and potential interactions, the methods commonly used to obtain the genetic material obtain samples from relatively large samples and as a result data and interpretations are based on sample averaging, which would include biofilm and planktonic populations, and likely cellular fragments and extracellular DNA. As shown in Figure 2, we propose the incorporation of biofilm technology as an experimental strategy to obtain higher resolution and more accurate investigations of microbial activities and interactions as they occur in nature.

The ideal strategy to study biofilms would be to examine samples in situ or alternatively those obtained directly from the field (or host if associated with a higher organism). Except for the molecular approaches used, this strategy mimics the direct morphological examinations of biofilms performed by Zobell [28], Costerton [10] and others. In the case of easily obtained and accessible biofilms such as those associated with rock surfaces in streams ([63] or urinary catheter infections [64], access to biofilms is not an issue. Problems arise with inaccessible biofilms, particularly if these biofilms occur in the deep subsurface [2,65], or alternatively with water circulating systems in nuclear facilities [66]. While practical aspects of biofilm accessibility and data reproducibility are certainly considerations in natural samples, experimental manipulation may not be feasible. To circumvent this, a number of sampling protocols have been developed for the study of biofilms. At the simplest level, glass microscope slides or other suitable substrata may be inserted into water or soil and will be readily colonized by resident bacteria [67]. Alternatively, liquid from a pipeline or cooling system can be diverted through a biofilm sampling device [31]. An excellent three volume set of Methods in Enzymology [68-70] was published in 1999 and 2001, which summarizes many commonly used techniques used for biofilm research. As well, standardized biofilm growth and testing protocols for antimicrobial agent susceptibility have been developed [71-73].

As stated earlier, biofilm structure is complex and many physiological activities may change from one small population of cells (consortia) to another. Ideally, broad-based metagenomics processes to identify organisms and genes, as well as other complementary approaches such as RNA-seq [74], metabolomics [75] and proteomics [76] approaches to identify gene expression and microbial activity, could be mapped at the single cell level or within small consortia. The biofilm enrichment process for metagenomics is shown in Figure 2. Given the low (typically sub fmole) concentration of molecules in bacteria [77], analytical methods and detection limits need to be refined. As an alternative approach, broad based approaches could be used on whole biofilms and then reporter genes and chemically sensitive probes could be used to map activity using confocal microscopy [60,78]. Several fundamentally important biological issues could be addressed by this biofilm-enrichment metagenomics strategy 
including the mechanisms whereby microbial interactions occur in nature, do novel unrecognized interactions occur, do previously unknown organisms participate, and finally where do these interactions occur.

\section{Conclusions}

Direct observations of most natural environments reveal that microorganisms frequently exist within surface-adherent biofilm communities $[10,43,47]$. Similarly, the majority of organisms in many environments cannot be cultured but are identified through culture-independent techniques including metagenomics $[3,4,6,19]$. Aside from the identification of community members, culture-independent techniques are used to infer microbial interactions [58]. A number of studies using reporter gene technology and confocal microscopy reveal microbial interactions including genetic exchange, signaling, and metabolite exchange to occur between adjacent microorganisms within biofilm communities [34,36,78]. Here, we propose the use of biofilm-enrichment as an experimental strategy to enhance the resolving power of metagenomics and other culture-independent techniques to identify novel microbial interaction mechanisms.

\section{Acknowledgments}

Work in RJCM's laboratory is sponsored by a Research Enhancement Grant from Texas State University and an endowment from the Homer Prince Foundation. We would like to dedicate this manuscript to our mentors, J.W. Costerton, T.J. Beveridge, and M.R. Liles who instilled in us a love of high quality science.

\section{Conflicts of Interest}

The authors declare no conflict of interest.

\section{Reference}

1. Balkwill, D.L.; Ghiorse, W.C. Characterization of subsurface bacteria associated with two shallow aquifers in Oklahoma. Appl. Environ. Microbiol. 1985, 50, 580-588.

2. Mason, O.U.; di Meo-Savoie, C.A.; van Nostrand, J.D.; Zhou, J.; Fisk, M.R.; Giovannoni, S.J. Prokaryotic diversity, distribution, and insights into their role in biogeochemical cycling in marine basalts. ISME J. 2009, 3, 231-242.

3. DeLeon-Rodriguez, N.; Lathem, T.L.; Rodrigues, L.M.; Barazesh, J.M.; Anderson, B.E.; Beyersdorf, A.J.; Ziemba, L.D.; Bergin, M.; Nenes, A.; Konstantinidis, K.T. Microbiome of the upper troposphere: Species composition and prevalence, effects of tropical storms, and atmospheric implications. Proc. Natl. Acad. Sci. USA 2013, 110, 2575-2580.

4. Temperton, B.; Giovannoni, S.J. Metagenomics: Microbial diversity through a scratched lens. Curr. Opin. Microbiol. 2012, 15, 605-612. 
5. Woese, C.R.; Fox, G.E. Phylogenetic structure of the prokaryotic domain: The primary kingdoms. Proc. Natl. Acad. Sci. USA 1977, 74, 5088-5090.

6. Shade, A.; Gregory Caporaso, J.; Handelsman, J.; Knight, R.; Fierer, N. A meta-analysis of changes in bacterial and archaeal communities with time. ISME J. 2013, 7, 1493-1506.

7. Nagarajan, N.; Pop, M. Sequence assembly demystified. Nat. Rev. Genet. 2013, 14, 157-167.

8. Francois, P.; Tu Quoc, P.; Bisognano, C.; Kelley, W.L.; Lew, D.P.; Schrenzel, J.; Cramton, S.E.; Götz, F.; Vaudaux, P. Lack of biofilm contribution to bacterial colonisation in an experimental model of foreign body infection by Staphylococcus aureus and Staphylococcus epidermidis. FEMS Immunol. Med. Microbiol. 2003, 35, 135-140.

9. Carini, P.; Steindler, L.; Beszteri, S.; Giovannoni, S.J. Nutrient requirements for growth of the extreme oligotroph 'Candidatus Pelagibacter. ubique' HTCC1062 on a defined medium. ISME J. 2013, 7, 592-602.

10. Costerton, J.W.; Cheng, K.J.; Geesey, G.G.; Ladd, T.I.; Nickel, J.C.; Dasgupta, M.; Marrie, T.J. Bacterial biofilms in nature and disease. Annu. Rev. Microbiol. 1987, 41, 435-464.

11. Ogram, A.; Sayler, G.S.; Barkay, T. DNA extraction and purification from sediments. J. Microbiol. Methods 1987, 7, 57-66.

12. Holben, W.E.; Jansson, J.K.; Chelm, B.K.; Tiedje, J.M. DNA probe method for the detection of specific microorganisms in the soil bacterial community. Appl. Environ. Microbiol. 1988, 54, 703-711.

13. Osborn, A.M.; Smith, C.J. Molecular Microbial Ecology; Taylor and Francis: New York, NY, USA, 2005.

14. Kakirde, K.S.; Parsley, L.C.; Liles, M.R. Size does matter: Application-driven approaches for soil metagenomics. Soil Biol. Biochem. 2010, 42, 1911-1923.

15. Quaiser, A.; Ochsenreiter, T.; Klenk, H.P.; Kletzin, A.; Treusch, A.H.; Meurer, G.; Eck, J.; Sensen, C.W.; Schleper, C. First insight into the genome of an uncultivated crenarchaeote from soil. Environ. Microbiol. 2002, 4, 603-611.

16. Osoegawa, K.; Woon, P.Y.; Zhao, B. Frengen, E.; Tateno, M.; Catanese, J.J.; De Jong, P.J. An improved approach for construction of bacterial artificial chromosome libraries. Genomics 1998, 52, 1-8.

17. Shizuya, H.; Birren, B.; Kim, U.J.; Mancino, V.; Slepak, T.; Tachiiri, Y.; Simon, M. Cloning and stable maintenance of 300-kilobase-pair fragments of human DNA in Escherichia coli using an F-factor-based vector. Proc. Natl. Acad. Sci. USA 1992, 89, 8794-8797.

18. Wild, J.; Hradecna, Z.; Szybalski, W. Conditionally amplifiable BACs: Switching from single-copy to high-copy vectors and genomic clones. Genome Res. 2002, 12, 1434-1444.

19. Handelsman, J.; Rondon, M.R.; Brady, S.F.; Clardy, J.; Goodman, R.M. Molecular biological access to the chemistry of unknown soil microbes: A new frontier for natural products. Chem. Biol. 1998, 5, R245-R249. 
20. Heath, C.; Hu, X.P.; Cary, S.C.; Cowan, D. Identification of a novel alkaliphilic esterase active at low temperatures by screening a metagenomic library from Antarctic desert soil. Appl. Environ. Microbiol. 2009, 75, 4657-4659.

21. Rondon, M.R.; August, P.R.; Bettermann, A.D.; Brady, S.F.; Grossman, T.H.; Liles, M.R.; Loiacono, K.A.; Lynch, B.A.; MacNeil, I.A.; Minor, C.; et al. Cloning the soil metagenome: A strategy for accessing the genetic and functional diversity of uncultured microorganisms. Appl. Environ. Microbiol. 2000, 66, 2541-2547.

22. Liles, M.R.; Williamson, L.L.; Goodman, R.M.; Handelsman, J. Isolation of High Molecular Weight Genomic DNA from Soil Bacteria for Genomic Library Construction. In Molecular Microbial Ecology Manual; Kowalchuk, G.A., Bruijn, F.J., Head, I.M., Akkermans, A.D.L., van Elsas, J.D., Eds.; Kluwer Academic Publishing: Dordrecht, The Netherlands, 2004; pp. 839-852.

23. Martinez, A.; Kolvek, S.J.; Hopke, J.; Yip, M.S.; Osburne, M.S. Environmental DNA fragment conferring early and increased sporulation and antibiotic production in Streptomyces. species. Appl. Environ. Microbiol. 2005, 71, 1638-1641.

24. King, R.W.; Bauer, J.D.; Brady, S.F. An environmental DNA-derived type II polyketide biosynthetic pathway encodes the biosynthesis of the pentacyclic polyketide erdacin. Angew. Chem. Int. Ed. 2009, 48, 6257-6261.

25. Davies, D.G.; Parsek, M.R.; Pearson, J.P.; Iglewski, B.H.; Costerton, J.W.; Greenberg, E.P. The involvement of cell-to-cell signals in the development of a bacterial biofilm. Science 1998, 280, 295-298.

26. Meyer, F.; Paarmann, D.; D’Souza, M.; Olson, R.; Glass, E.M.; Kubal, M.; Paczian, T.; Rodriguez, A.; Stevens, R.; Wilke, A.; et al. The metagenomics RAST server-A public resource for the automatic phylogenetic and functional analysis of metagenomes. BMC Bioinf. 2008, 9, 386.

27. Huson, D.H.; Auch, A.F.; Qi, J.; Schuster, S.C. MEGAN analysis of metagenomic data. Genome Res. 2007, 17, 377-386.

28. Zobell, C.E.; Allen, E.C. The significance of marine bacteria in the fouling of submerged surfaces. J. Bacteriol. 1935, 29, 239-251.

29. McLean, R.J.C.; Lam, J.S.; Graham, L.L. Training the biofilm generation-A tribute to JW Costerton. J. Bacteriol. 2012, 194, 6711.

30. Costerton, J.W.; Geesey, G.G.; Cheng, K.J. How bacteria stick. Sci. Am. 1978, 238, 86-95.

31. McCoy, W.F.; Bryers, J.D.; Robbins, J.; Costerton, J.W. Observations of fouling biofilm formation. Can. J. Microbiol. 1981, 27, 910-917.

32. Schmitt, J.; Nivens, D.; White, D.C.; Flemming, H.C. Changes of biofilm properties in response to sorbed substances: An FTIR-ATR study. Water Sci. Technol. 1995, 32, 149-155.

33. Wolfaardt, G.M.; Lawrence, J.R.; Robarts, R.D.; Caldwell, S.J.; Caldwell, D.E. Multicellular organization in a degradative biofilm community. Appl. Environ. Microbiol. 1994, 60, 434-446. 
34. Gieseke, A.; Bjerrum, L.; Wagner, M.; Amann, R. Structure and activity of multiple nitrifying bacterial populations co-existing in a biofilm. Environ. Microbiol. 2003, 5, 355-369.

35. Egli, K.; Fanger, U.; Alvarez, P.J.; Siegrist, H.; van der Meer, J.R.; Zehnder, A.J.B. Enrichment and characterization of an anammox bacterium from a rotating biological contactor treating ammonium-rich leachate. Arch. Microbiol. 2001, 175, 198-207.

36. Schramm, A.; de Beer, D.; van den Heuvel, J.C.; Ottengraf, S.; Amann, R. Microscale distribution of populations and activities of Nitrosospira. and Nitrospira. spp. along a macroscale gradient in a nitrifying bioreactor: Quantification by in situ hybridization and the use of microsensors. Appl. Environ. Microbiol. 1999, 65, 3690-3696.

37. Schink, B. Synergistic interactions in the microbial world. Antonie van Leeuwenhoek 2002, 81, 257-261.

38. Thiele, J.H.; Chartrain, M.; Zeikus, J.G. Control of interspecies electron flow during anaerobic digestion: Role of floc formation in syntrophic methanogenesis. Appl. Environ. Microbiol. 1988, 54, 10-19.

39. Li, Y.H.; Lau, P.C.Y.; Lee, J.H.; Ellen, R.P.; Cvitkovitch, D.G. Natural genetic transformation of Streptococcus mutans growing in biofilms. J. Bacteriol. 2001, 183, 897-908.

40. Hausner, M.; Wuertz, S. High rates of conjugation in bacterial biofilms as determined by quantitative in situ analysis. Appl. Environ. Microbiol. 1999, 65, 3710-3713.

41. Christensen, B.B.; Sternberg, C.; Andersen, J.B.; Eberl, L.; Møller, S.; Givskov, M.; Molin, S. Establishment of new genetic traits in a microbial biofilm community. Appl. Environ. Microbiol. 1998, 64, 2247-2255.

42. Petrova, O.E.; Sauer, K. Sticky situations: Key components that control bacterial surface attachment. J. Bacteriol. 2012, 194, 2413-2425.

43. O’Toole, G.A.; Kaplan, H.B.; Kolter, R. Biofilm formation as microbial development. Annu. Rev. Microbiol. 2000, 54, 49-79.

44. Karatan, E.; Watnick, P. Signals, regulatory networks, and materials that build and break bacterial biofilms. Microbiol. Mol. Biol. Rev. 2009, 73, 310-347.

45. Marsh, P.D.; Bradshaw, D.J. Dental plaque as a biofilm. J. Ind. Microbiol. 1995, 15, 169-175.

46. Palmer, R.J., Jr.; Kazmerzak, K.; Hansen, M.C.; Kolenbrander, P.E. Mutualism versus independence: Strategies of mixed-species oral biofilms in vitro using saliva as the sole nutrient source. Infect. Immun. 2001, 69, 5794-5804.

47. Kolenbrander, P.E.; Andersen, R.N.; Kazmerzak, K.; Wu, R.; Palmer, R.J., Jr. Spatial organization of oral bacteria in biofilms. Methods Enzymol. 1999, 310, 322-332.

48. Shade, A.; McManus, P.S.; Handelsman, J. Unexpected diversity during community succession in the apple flower microbiome. mBio 2013, 4, e00602-e00612.

49. Nicol, G.W.; Tscherko, D.; Embley, T.M.; Prosser, J.I. Primary succession of soil Crenarchaeota across a receding glacier foreland. Environ. Microbiol. 2005, 7, 337-347. 
50. Chaparro, J.M.; Badri, D.V.; Bakker, M.G.; Sugiyama, A.; Manter, D.K.; Vivanco, J.M. Root exudation of phytochemicals in Arabidopsis follows specific patterns that are developmentally programmed and correlate with soil microbial functions. PLoS One 2013, 8, e55731.

51. Steidle, A.; Sigl, K.; Schuhegger, R. Ihring, A.; Schmid, M.; Gantner, S.; Stoffels, M.; Riedel, K.; Givskov, M.; Hartmann, A.; et al. Visualization of $N$-acylhomoserine lactone-mediated cell-cell communication between bacteria colonizing the tomato rhizosphere. Appl. Environ. Microbiol. 2001, 67, 5761-5770.

52. McLean, R.J.C.; Barnes, M.B.; Windham, M.K.; Merchant, M.M.; Forstner, M.R.J.; Fuqua, C. Cell-cell influences on bacterial community development in aquatic biofilms. Appl. Environ. Microbiol. 2005, 71, 8987-8990.

53. Pacheco, A.R.; Sperandio, V. Inter-kingdom signaling: Chemical language between bacteria and host. Curr. Opin. Microbiol. 2009, 12, 192-198.

54. Mashburn, L.M.; Whiteley, M. Membrane vesicles traffic signals and facilitate group activities in a prokaryote. Nature 2005, 437, 422-425.

55. Egan, S.; James, S.; Holmstrom, C.; Kjelleberg, S. Correlation between pigmentation and antifouling compounds produced by Pseudoalteromonas tunicata. Environ. Microbiol. 2002, 4, 433-442.

56. Drider, D.; Fimland, G.; Héchard, Y.; McMullen, L.M.; Prévost, H. The continuing story of class IIa bacteriocins. Microbiol. Mol. Biol. Rev. 2006, 70, 564-582.

57. Whiteley, M.; Ott, J.R.; Weaver, E.A.; McLean, R.J.C. Effects of community composition and growth rate on aquifer biofilm bacteria and their susceptibility to betadine disinfection. Environ. Microbiol. 2001, 3, 43-52.

58. Burmølle, M.; Webb, J.S.; Rao, D.; Hansen, L.H.; Sørensen, S.J.; Kjelleberg, S. Enhanced biofilm formation and increased resistance to antimicrobial agents and bacterial invasion are caused by synergistic interactions in multispecies biofilms. Appl. Environ. Microbiol. 2006, 72, 3916-3923.

59. Kaplan, H.B. Multicellular development and gliding motility in Myxococcus xanthus. Curr. Opin. Microbiol. 2003, 6, 572-577.

60. Rani, S.A.; Pitts, B.; Beyenal, H.; Veluchamy, R.A.; Lewandowski, Z.; Davison, V.M.; Buckingham-Meyer, K.; Stewart, P.S. Spatial patterns of DNA replication, protein synthesis, and oxygen concentration within bacterial biofilms reveal diverse physiological states. J. Bacteriol. 2007, 189, 4223-4233.

61. Watnick, P.; Kolter, R. Biofilm, city of microbes. J. Bacteriol. 2000, 182, 2675-2679.

62. Chu, W.; Zere, T.R.; Weber, M.M.; Wood, T.K.; Whiteley, M.; Hidalgo-Romano, B.; Valenzuela, E., Jr.; McLean, R.J.C. Indole production promotes Escherichia coli mixed culture growth with Pseudomonas aeruginosa by inhibiting quorum signaling. Appl. Environ. Microbiol. 2012, 78, 411-419.

63. Geesey, G.G.; Richardson, W.T.; Yeomans, H.G.; Irvin, R.T.; Costerton, J.W. Microscopic examination of natural sessile bacterial populations from an alpine stream. Can. J. Microbiol. 1977, 23, 1733-1736. 
64. Nickel, J.C.; Gristina, A.G.; Costerton, J.W. Electron microscopic study of an infected Foley catheter. Can. J. Surg. 1985, 28, 50-54.

65. Cusack, F.; Brown, D.R.; Costerton, J.W.; Clementz, D.M. Field and laboratory studies of microbial/fines plugging of water injection wells: Mechanism, diagnosis and removal. J. Pet Sci. Eng. 1987, 1, 39-50.

66. Santo Domingo, J.W.; Berry, C.J.; Summer, M.; Fliermans, C.B. Microbiology of spent nuclear fuel storage basins. Curr. Microbiol. 1998, 37, 387-394.

67. Marshall, K.C.; Stout, R.; Mitchell, R. Mechanisms of the initial events in the sorption of marine bacteria to solid surfaces. J. Gen. Microbiol. 1971, 68, 337-348.

68. Doyle, R.J. Biofilms. In Methods in Enzymology; Academic Press: San Diego, CA, USA, 1999; Volume 310, pp. 1-720.

69. Doyle, R.J. Microbial Growth in Biofilms. Part A: Developmental and Molecular Biological Aspects. In Methods in Enzymology; Academic Press: San Diego, CA, USA, 2001; Volume 336, pp. $1-469$.

70. Doyle, R.J. Microbial Growth in Biofilms, Part B: Special Environments and Physicochemical Aspects. In Methods in Enzymology; Academic Press, San Diego, CA, USA, 2001; Volume 337, pp. 1-469.

71. Goeres, D.M.; Loetterle, L.R.; Hamilton, M.A.; Murga, R.; Kirby, D.W.; Donlan, R.M. Statistical assessment of a laboratory method for growing biofilms. Microbiology 2005, 151, 757-762.

72. ASTM. E2562-12: Standard Test Method for Quantification of Pseudomonas aeruginosa Biofilm Grown with High Shear and Continuous Flow Using CDC Biofilm Reactor. In Annual Book of ASTM Standards; ASTM International: West Conshohocken, PA, USA, 2012.

73. ASTM. E2871-12: Standard Test Method for Evaluating Disinfectant Efficacy against Pseudomonas aeruginosa Biofilm Grown in CDC Biofilm Reactor Using Single Tube Method. In Annual Book of ASTM Standards; ASTM International: West Conshohocken, PA, USA, 2012.

74. Westermann, A.J.; Gorski, S.A.; Vogel, J. Dual RNA-seq of pathogen and host. Nat. Rev. Microbiol. 2012, 10, 618-630.

75. Yanes, O.; Tautenhahm, R.; Patti, G.J.; Siuzdak, G. Expanding coverage of the metabolome for global metabolite profiling. Anal. Chem. 2011, 83, 2152-2161.

76. Sauer, K.; Cullen, M.C.; Rickard, A.H.; Zeef, L.A.H.; Davies, D.G.; Gilbert, P. Characterization of nutrient-induced dispersion in Pseudomonas aeruginosa PAO1 biofilm. J. Bacteriol. 2004, 186, 7312-7326.

77. Song, L.; Shan, D.; Zhao, M.; Pink, B.A.; Minnehan, K.A.; York, L.; Gardel, M.; Sullivan, S.; Phillips, A.F.; Hayman, R.B.; et al.-Direct detection of bacterial genomic DNA at sub-femtomolar concentrations using single molecule arrays. Anal. Chem. 2013, 85, 1932-1939.

78. Andersen, J.B.; Heydorn, A.; Hentzer, M.; Eberl, L.; Geisenberger, O.; Christensen, B.B.; Molin, S.; Givskov, M. gfp-based $N$-acyl homoserine lactone sensor systems for detection of bacterial communication. Appl. Environ. Microbiol. 2001, 67, 575-585. 


\begin{abstract}
MDPI AG
Klybeckstrasse 64

4057 Basel, Switzerland

Tel. +41616837734

Fax +41613028918

http://www.mdpi.com/
\end{abstract}

IJMS Editorial Office

E-mail: ijms@mdpi.com

http://www.mdpi.com/journal/ijms 

